Universidade de São Paulo

Instituto de Astronomia, Geofísica e Ciências Atmosféricas

Departamento de Astronomia

Luciene da Silva Coelho

\title{
Formação de Moléculas Orgânicas em Ambientes Interestelares
}

São Paulo 

Luciene da Silva Coelho

\section{Formação de Moléculas Orgânicas em Ambientes Interestelares}

Dissertação apresentada ao Departamento de Astronomia do Instituto de Astronomia, Geofísica e Ciências Atmosféricas da Universidade de São Paulo como requisito parcial para a obtenção do título de Mestre em Ciências.

Versão Corrigida.

A versão original encontra-se na unidade.

Área de Concentração: Astronomia

Orientador: Prof. Dr. Amâncio César Santos Friaça

São Paulo 

Àqueles que estiveram comigo durante esta jornada! 



\section{Agradecimentos}

À minha mãe Cléa, e aos meus irmãos Alexandre e Allan por me ajudarem, me estimularem e me darem suporte para chegar aqui. Devo tudo a vocês;

Ao Professor Doutor Amâncio César S. Friaça por me orientar neste projeto e em outros que ainda estão por vir;

À Ana Cecília Soja e ao Rafael Santucci por tudo, sem vocês eu não conseguiria chegar aqui e conto com vocês na qualificação!!!

À Fernanda, Maria Clara e Pedro Caetano por tornarem minha vida mais feliz;

Ao Professor Doutor Jacques Le Bourlet e ao Professor Doutor Franck Le Petit pela gentileza em me assessorar na utilização do Código Meudon PDR;

À Professora Doutora Ruth pelos conselhos sempre úteis, principalmente nos relatórios;

Ao Professor Rama pelos conselhos e por me ajudar a crescer pessoal e profissionalmente;

À Professora Sílvia Rossi pelo colo e pelas broncas;

À Professora Vera Jatenco pelo semestre que trabalhamos juntas;

Aos amigos Cris Forcioni, Fábio Rodrigues, Felipe A. Augusto, por toda a ajuda e disponibilidade em me atender e tirar minhas dúvidas, principalmente em química!!!;

Aos amigos James, Rodrigo Costa, César, Artur, Lilian, Andressa, Isis, Elisa, Aiara, Thaíse, Giovanni, Denise, Tatiane, Alexandra, Mariana Tanaka, Mariane Marins, alguns por simplismente estarem lá e os outros por entenderem porque eu não podia estar lá.

Aos colegas Marcus, Vinicius e Oscar por disponibilizarem esta versão super amigável do latex facilitando muito minha dissertação;

Ao Marco, Luis e Ulisses da informática, e também, é claro, as meninas queridas Marina, Regina, Conceição e Cida da secretaria, sem vocês o IAG não funcionaria; 
À CAPES pelo apoio financeiro;

Ao Instituto de Astronomia, Geofísica e Ciências Atmosféricas - IAG/USP

Esta tese/dissertação foi escrita em IATEX com a classe IAGTESE, para teses e dissertações do IAG. 
"And in the end the love you take is equal the love you make" Lennon and McCartney

"Não importa o que eu já sei, eu ainda erro demais"

Herbert Vianna 



\section{Resumo}

Este trabalho apresenta o estudo de algumas moléculas do meio interestelar úteis para o levantamento do conteúdo de matéria orgânica do universo e para as condições prébióticas na Terra e em outros ambientes no universo. Utilizamos como objeto-teste a Nebulosa Cabeça de Cavalo, devido à sua geometria simples, à sua distância moderada até nós, ao seu campo de radiação ultravioleta bem conhecido resultante da iluminação por uma estrela próxima, $\sigma$ Orionis, e por ter sido extensivamente estudada por diversos trabalhos. Desse modo, podemos investigar com segurança diversos processos físicos e químicos no meio interestelar.

O principal instrumento utilizado neste trabalho foi o código PDR Meudon devido ao fato de que é amplamente utilizado por ser um dos programas de análise de dados de projetos recentes de astronomia, como o projeto Herschel, e por ser público. O código pode ser utilizado para modelizar com confiabilidade a Nebulosa Cabeça de Cavalo, visto que ela mesma é uma PDR (região de fotodissociação) prototípica. Atualizamos o setor de química do código para testar diversos cenários de formação de moléculas.

Consideramos o impacto nas abundâncias derivadas das moléculas de várias suposições em relação ao estado do gás (modelos isocórico, isotérmico e isobárico), decidindo em favor de um modelo isobárico. Verificou-se o papel dos raios cósmicos e de vários conjuntos de dados das reações químicas.

Obtivemos as abundâncias de várias moléculas, incluindo algumas de potencial importância pré-biótica: CN e seus íons, HCN, HNC, nitrilas e seus íons, hidretos de nitrogênio, benzeno. Investigamos o papel dos ânions e dos PAHs. Finalmente, exploramos canais de produção para heterocíclicos nitrogenados com relevância em astrobiologia: pirrol e piridina. 
As presentes simulações apresentaram como a exploração de uma pequena gama de possíveis canais de produção de heterocíclicos já resultou em abundâncias significativas para ao menos uma espécie de heterocíclicos nitrogenados, a piridina. Dessa forma, excursões sistemáticas pelos diversos canais de produção deverão revelar mais espécies para serem alvos de buscas. 


\section{Abstract}

This work presents the study of some molecules of the interstellar medium that are useful for the bookkeeping of the molecular content of the universe and for prebiotic conditions on Earth and in other environments in the universe. The Horsehead Nebula was chosen as test object, due to its simple geometry, its moderate distance to us, its wellknown ultraviolet radiation field resulting from the star $\sigma$ Orionis, and due the fact that it has been extensively studied in several works. In this way, we can safely investigate several physical and chemical processes on the interstellar medium.

The main tool used in the present work was the Meudon PDR code due the fact that it is widely used as one of the legacy data analysis programs of current astronomy projects, e.g. the Herschel project, and it is public. The code can reliably model the Horsehead Nebula, since this nebula is a prototypic PDR (photodissociation region). We updated the chemical sector of the code in order to test several scenarios for molecule production.

We considered the impact on the derived molecule abundances of several assumptions relative to the gas state (isochoric, isothermal and isobaric models), and the isobaric model was found to be the most plausible. We checked the role of cosmic rays and several datasets of chemical reactions.

We derived the abundances of several molecules, including some of potential prebiotic importance: $\mathrm{CN}$ and their ions, $\mathrm{HCN}, \mathrm{HNC}$, nitriles and their ions, nitrogen hydrides, and benzene. We investigated the role of anions and PAHs. Finally, we explored production channels for astrobiologically relevant nitrogenated heterocycles: pyrrole and pyridine.

This presents simulations show us how the exploration of a small quantities of possibles path of prodution of heterocycles resulted already in significants abundances at least one n-heterocycle specie, the pyridine. Thereby, systemact tours for the many productions 
paths should show more species to be targe of searches. 


\section{Lista de Abreviações}

$\boldsymbol{\Delta}_{\mathbf{f}} \mathbf{H}^{\mathbf{0}}$ Variação da entalpia de formação.

AIBs Bandas Aromáticas no Infravermelho

Akari Satélite astronômico no infravermelho desenvolvido pela Agência de Exploração Espacial Japonesa.

ALMA Da sigla em inglês para The Atacama Large Millimeter/submillimeter Array Radiotelescópio desenvolvido em parceria entre Europa, América do Norte, leste da Ásia e Chile.

$\mathbf{A}_{\mathbf{V}}$ Extinção na faixa espectral do visível.

CHO Elementos carbono, hidrogênio e oxigênio.

CHON Elementos carbono, hidrogênio, oxigênio e nitrogênio.

CHONPS Elementos essenciais para a vida, ou seja, carbono, hidrogênio, oxigênio, nitrogênio, fósforo e enxofre.

CoRoT Da sigla para Convection Rotation et Transits Planétaires - Missão espacial liderada pela Agência Espacial Francesa em conjunto com com a Agência Espacial Européia com objetivo de buscar exoplanetas e realizar astrosismologia.

DFT Teoria da densidade funcional.

DIBs Da sigla em inglês para Diffuse Interstellar band - bandas interestelares difusas.

DNA Da sigla em inglês para deoxyribonucleic acid - ácido desoxirribonucleico. 
ESO Da sigla em inglês para European Southern Observatory - Observatório Europeu do Sul.

FIR Da sigla em inglês para far infrared - infravermelho distante

FUV Da sigla em inglês para far ultraviolet - ultravioleta distante

HARPS Da sigla em inglês para High Accuracy Radial velocity Planetary Search project - espectrometro dedicado a busca por exoplanetas, instalado no telescópio de 3.6 metros em La Silla.

Herschel Observatório espacial desenvolvido pela Agência Espacial Européia.

HHN Da sigla em inglês para Horsehead Nebula - Nebulosa Cabeça de Cavalo.

Kepler Telescópio espacial da NASA que visa a busca por planetas habitáveis.

LLAMA Da sigla em inglês para Long Latin American Millimeter Array - Radiotelescópios para comprimentos de onda milimétricos e submilimétricos.

$\mathbf{M}_{\odot}$ Massa solar.

Mag Magnitude.

NASA Da sigla em inglês para National Aeronautics and Space Administration - Administração Nacional de Aeronáutica e Espacial dos Estados Unidos da América.

$\mathbf{n}_{\mathbf{H}}$ Densidade total de núcleos de hidrogênio.

Odin Mini-satélite desenvolvido pela Suécia em cooperação com França, Canadá e Finlândia com proposta de estudar a atmosfera terrestre além de objetos astronômicos.

PACS Da sigla em inglês para Photo-conductor Array Camera and Spectrometer - Espectrômetro e câmera fotocondutora instalados no observatório espacial Herschel.

PAHs Da sigla em inglês para policiclic aromatic hidrocarbon- hidrocarbonetos aromáticos policíclicos.

PANHs Da sigla em inglês para policiclic aromatic nitrogen-hidrocarbon- hidrocarbonetos nitrogenados aromáticos policíclicos. 
PDR Da sigla em inglês para photon-dominated region - região fotodominada ou de fotodissociação.

RNA Da sigla em inglês para ribonucleic acid-ácido ribonucleico.

Sophie Da sigla em francês para Spectrographe pour l'Observation des Phénomènes des Intériuers stellaires et des Exoplanètes - espetrógrafo instalado no telescópio de 1.93 metros do Haute-Provence Observatory no sudoeste da França.

SPICA Da sigla em inglês para Space Infrared Telescope for Cosmology and Astrophysics - observatório espacial proposto pela Agência de Exploração Espacial Japonesa para ser lançado em 2018.

Spitzer Telescópio espacial da NASA que opera na região do infravermelho do espectro eletromagnético.

SWAS Da sigla em inglês para Submillimeter Wave Astronomy Satellite - telescópio espacial da NASA designado a estudar a composição química de nuvens de gás interestelares.

$\mathbf{T}_{\mathbf{c}}$ Temperatura cinética.

$\mathbf{T}_{\mathbf{e}}$ Temperatura eletrônica.

$\mathbf{T}_{\text {ef }}$ Temperatura efetiva.

UV Ultravioleta.

VISIR Da sigla em inglês para The VLT spectrometer and imager for the mid-infraredespectrometro para o infravermelho médio usado pelo ESO.

VLT Da sigla em inglês para Very Large Telescope - Constituido por quatro telescópios principais de 8.2 metros de diâmetro e outros quatro telescópios auxiliares de 1.8 metros que juntos operam como um "interferômetro gigante". 



\section{Lista de Figuras}

1.1 Mapa das Áreas de estudos da Astrobiologia (Briggs, 2009) . . . . . . . 28

1.2 Carboidratos formados por cadeias de carbono. (Gilmour e Sephton, 2004) 36

1.3 Membranas lipídicas de células. (Gilmour e Sephton, 2004) _. . . . . . . 36

1.4 Produção de proteínas a partir de aminoácidos. (Gilmour e Sephton, 2004) 37

1.5 Bases encontradas no DNA. (Gilmour e Sephton, 2004). . . . . . . . . . . . 37

2.1 Ilustração de uma PDR com seus principais elementos. (Le Petit, 2012) . . 45

2.2 Ilustração de nuvem molecular com suas regiões típicas. (Le Petit, 2012)] . 46

2.3 Nebulosa Cabeça de Cavalo (HHN) e circunvizinhança. (NASA, 2010) . . . 56

2.4 Características geométricas do código em uma nuvem. (Le Petit, 2012) . . 58

3.1 Variacão dos principais parâmetros no modelo com $n_{H}$ constante. . . . . . 67

3.2 Teste de Convergência do código para a HHN . . . . . . . . . . . . . . . . 68

3.3 Teste de Convergência do código para a HHN . . . . . . . . . . . . . . . . 68

3.4 Teste da influência da taxa de ionizacão por raios cósmicos na HHN. . . . . 69

3.5 Teste da influência da taxa de ionizacão por raios cósmicos na HHN. . . . . 70

3.6 Teste da influência da variacão da entalpia de formação na HHN. . . . . . 72

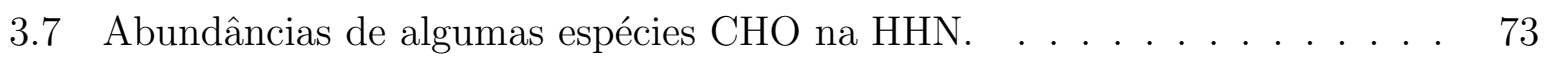

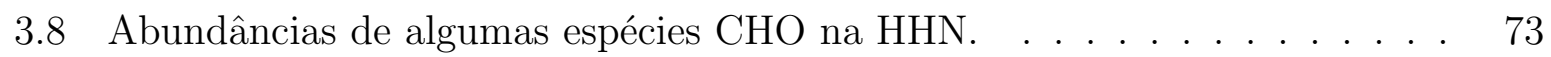

3.9 Abundância de algumas espécies CHO na HHN. . . . . . . . . . . . . . 74

3.10 Abundâncias do $\mathrm{CN} . C N^{+} . C N^{-}$. $\mathrm{HCN}$ e $\mathrm{HNC}$ em relacão ao $\mathrm{CN}$. . . . . 75

3.11 Variacão dos principais parâmetros no modelo isobárico. . . . . . . . . . 76

3.12 Abundâncias de CHO para o modelo isobárico ao longo da HHN. . . . . . 77

3.13 Abundância CN, HCN e HNC para o modelo isobárico ao longo da HHN. . 78 

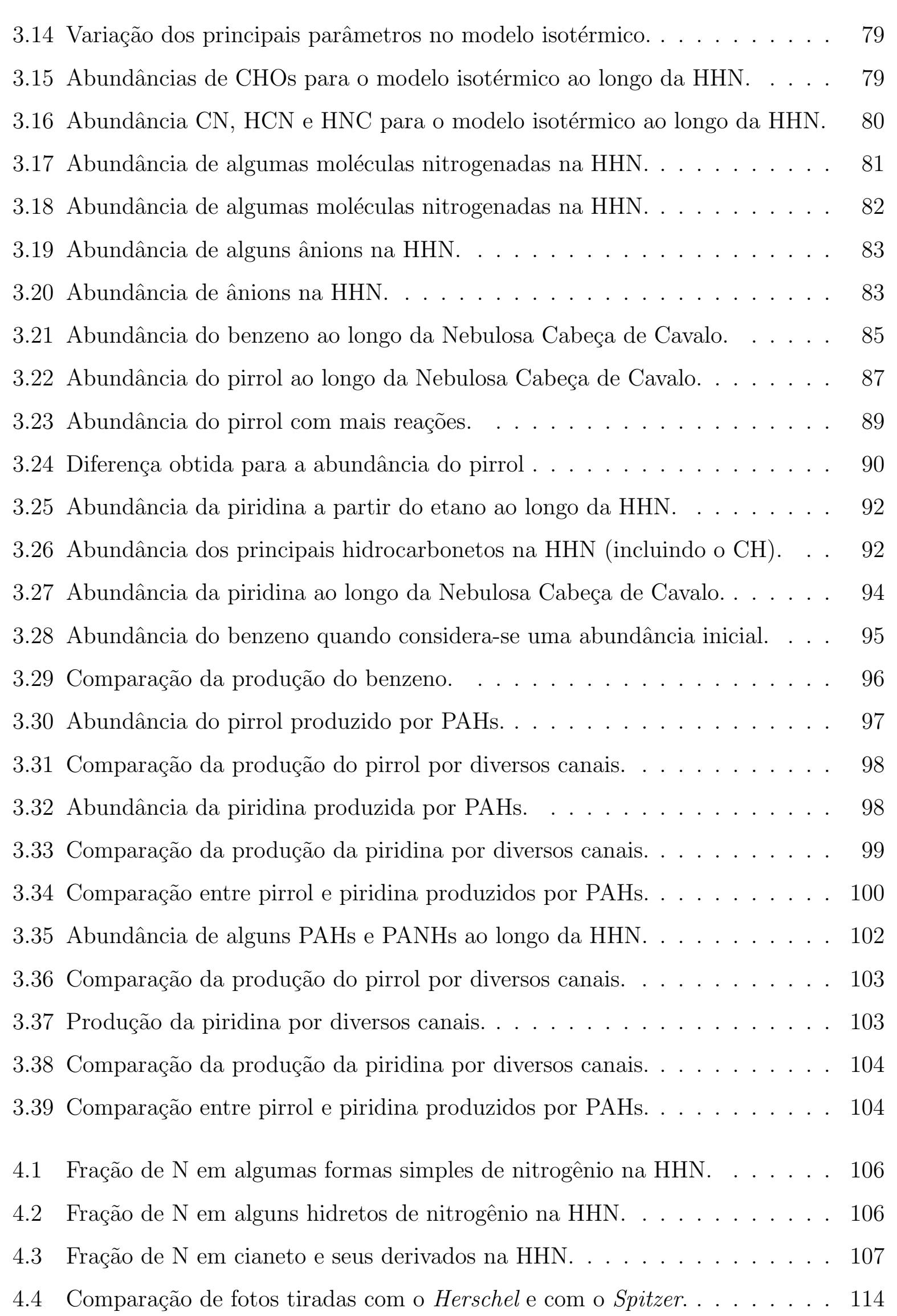
5.1 Moléculas e exoplanetas detectados ao longo dos anos . . . . . . . . . . . 119 



\section{Lista de Tabelas}

1.1 Os dez elementos mais abundantes . . . . . . . . . . . . . . . . . . . . . . 35

2.1 Comprimentos de onda de transições de níveis de energia. . . . . . . . . . . 48

2.2 Valores médios para taxas de reação.(Maciel, 2002) . . . . . . . . . . . . . 56

2.3 Características físicas da HHN.(Gerin et al., 2009) . . . . . . . . . . . . . . 57

3.1 Parâmetros iniciais do modelo padrão para a Nebulosa Cabeça de Cavalo. . 66

3.2 Valores usados na variacão da entalpia de formacão $\left(\Delta_{f} H^{\circ}\right) \ldots \ldots$. . . 71

3.3 Reacões químicas. parâmetros e tipos de reacão usados para a acrilonitrila 81

3.4 Reacões químicas, parâmetros e tipos de reacão usados para o benzeno . . 84

3.5 Reacões químicas, parâmetros e tipos de reacão usados para o pirrol . . . . 88

3.6 Mais reacões químicas. parâmetros e tipos de reação para estimar o pirrol . 89

3.7 Formacão da piridina a partir do $C_{2} H_{6} \ldots \ldots \ldots \ldots \ldots \ldots$

3.8 Reacões químicas, parâmetros e tipos de reacão para estimar a piridina . . 93

3.9 Reacões químicas e parâmetros para pirrol e piridina produzidos por PAHs. 97

3.10 Reações químicas e parâmetros para pirrol e piridina produzidos por PAHs. 101

4.1 Razões de densidade de Coluna em relacão ao CN . . . . . . . . . . . . . . 107

4.2 Razões de densidade de Coluna dos hidretos . . . . . . . . . . . . . . . . . . 108

4.3 Razões de densidade de Coluna em relacão ao CN. . . . . . . . . . . . . . . 108

4.4 Densidade de Coluna das principais moléculas na HHN . . . . . . . . . . . 109

5.1 Transicões de moléculas observáveis com o ALMA. . . . . . . . . . . . . . 123

A.1 Moléculas encontradas em ambientes interestelares . . . . . . . . . . . . 137 
B.1 Elementos usados no modelo da HHN e seus parâmetros. . . . . . . . . . 139

B.2 Reações químicas, parâmetros e tipos de reação usados no código . . . . . 144 


\section{Sumário}

1. Introducãd . . . . . . . . . . . . . . . . . . . . . . . . . 27

1.1 Matéria Orgânica no Universo . . . . . . . . . . . . . . . . . . . . . 27

1.2 Astrobiologia . . . . . . . . . . . . . . . . . . . . . 30

1.3 Origem e Busca pela Vida . . . . . . . . . . . . . . . . . . . . . . . . . 31

1.3 .1 o que é vida? . . . . . . . . . . . . . . . . . . 31

1.4 Água . . . . . . . . . . . . . . . . . . . . . . . . . . . . . 33

1.5 Carbono . . . . . . . . . . . . . . . . . . . . . . 34

1.6 Nitrogênio . . . . . . . . . . . . . . . . . . . . . . . . . . . . . . . . . . . . . 35

1.6 .1 Ácidos Nucleicos (DNA/RNA) . . . . . . . . . . . . . . . 37

1.6.2 Espécies Nitrogenadas de Interesse Astrobiológico . . . . . . . . . . 37

1.7 O Mundo Aromático . . . . . . . . . . . . . . . . . . . . . . . . . 38

1.8 Organização da Dissertação $\ldots \ldots$. . . . . . . . . . . . . . . 41

2. Base de Dados ... . . . . . . . . . . . . . . . . . . . . 43

2.1 Meio Interestelar $\ldots \ldots \ldots$. . . . . . . . . . . . . . . . . . . 43

2.1.1 Regiões de Fotodissociacão . . . . . . . . . . . . . . . . . . 45

2.2 Deteccão de Moléculas no Meio Interestelar . . . . . . . . . . . . . . . . . 47

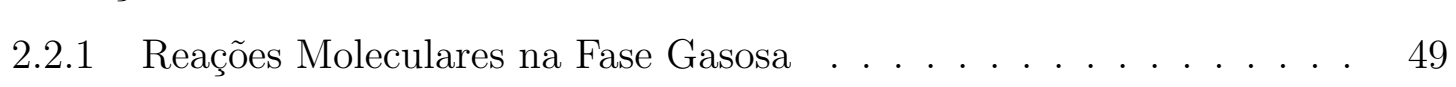

2.2.1.1 Reacões Íon-Molécula _ . . . . . . . . . . . . . . . . . 49

2.2.1.2 Reacões Neutro-Neutro . . . . . . . . . . . . . . . . . 52

2.2.1.3 Associacão Radiativa . . . . . . . . . . . . . 52

2.2.1.4 Recombinação Radiativa . . . . . . . . . . . . . . . . 53 
2.2.1.5 Recombinacão Dissociativa . . . . . . . . . . . 53

2.2.1.6 Reacões de Troca de Carga . . . . . . . . . . . . 53

2.2 .2 Destruicão de Moléculas . . . . . . . . . . . . . . . . . 53

2.2.2.1 Fotodissociacão . . . . . . . . . . . . . . 54

2.2.2.2 Dissociação Colisional . . . . . . . . . . . . . 54

2.3 Cinética de Reacão . . . . . . . . . . . . . . . . . . . . . 54

2.3 .1 Taxas de Reacão . . . . . . . . . . . . . . . . . 55

2.4 Nebulosa Cabeca de Cavalo . . . . . . . . . . . . . . . . . . 56

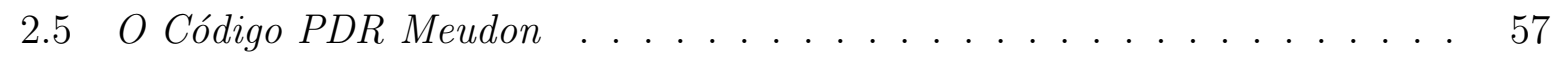

2.5.1 Características do Código . . . . . . . . . . . . . 58

2.5.1.1 Reações Químicas . . . . . . . . . . . . . . 60

3. Simulacões e Modelagens . . . . . . . . . . . . . . . . . . . 65

3.1 Condicões Iniciais da Nebulosa Cabeca de Cavalo $\ldots . . \quad \ldots$

3.2 Modelo para uma Densidade de Gás Constante $\ldots . . . . . .66$

3.2 .1 Convergência nas Iteracões . . . . . . . . . . . . . . . 67

3.2.2 O Papel dos Raios Cósmicos . . . . . . . . . . . . . . . . 69

3.2.3 Efeitos das Incertezas da Entalpia de Formação . . . . . . . . . . . 70

3.2.4 Escolha da Base de Dados de Química . . . . . . . . . . . . . . 72

3.2.5 Moléculas Nitrogenadas Simples: CN, HCN e HNC . . . . . . . . 74

3.3 Modelo Isobárico $\ldots \ldots \ldots$. . . . . . . . . . . . . . . . . . 76

3.4 Modelo Isotérmico $\ldots \ldots \ldots \ldots$. . . . . . . . . . . . . . . . 78

3.5 Nitrilas . . . . . . . . . . . . . . . . . . . . . . . . . 80

3.6 Íns . . . . . . . . . . . . . . . . . . . . . . . . . . . . . . . 82

3.7 Benzeno . . . . . . . . . . . . . . . . . . . . . 84

3.8 Pirrol $\ldots \ldots \ldots \ldots \ldots \ldots$

3.9 Piridina $\ldots \ldots \ldots \ldots \ldots$

3.10 O Papel dos $\mathrm{PAHs}$. . . . . . . . . . . . . . . . . . . . . 94

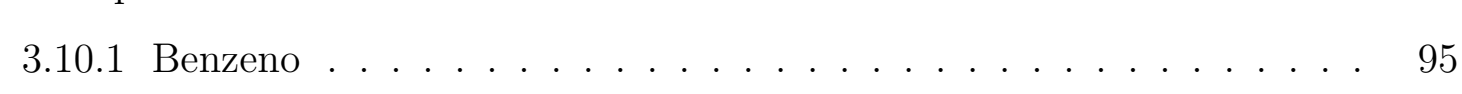

3.10.2 PAHs, PANHs e Heterocíclicos Nitrogenados (Pirrol e Piridina) . . 96 


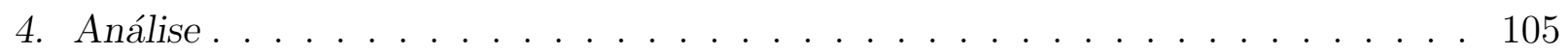

4.1 Inventário do Nitrogênio no Meio Interestelar . . . . . . . . . . . . . . . . 105

4.2 Rotas para a Producão de Heterocíclicos . . . . . . . . . . . . . . . . 109

4.3 Busca por Moléculas em Ambientes Interestelares e Circum-estelares . . . . 112

5. Conclusões e Perspectivas . . . . . . . . . . . . . . . . . . 117

5.1 Precisamos de uma Revolucão Molecular . . . . . . . . . . . . . . . . . . . 118

5.2 Próximos Passos em Simulações . . . . . . . . . . . . . . . . . . . . . . 121

5.3 Perspectivas Observacionais . . . . . . . . . . . . . . . . 123

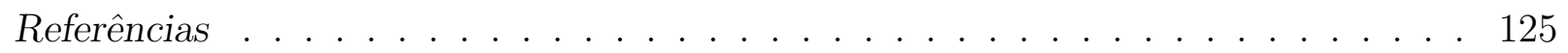

$\begin{array}{ll}\text { Apêndice } & 135\end{array}$

A. Moléculas Encontradas em Ambientes Interestelares e Circum-estelares . . . . . 137

B. Moléculas e reações químicas usadas na modelagem da Nebulosa Cabeça de Cavalo139 

Capítulo 1

\section{Introdução}

O estudo do universo orgânico tornou-se uma das áreas de fronteira em astrofísica. O enorme crescimento que esta área apresentou nos últimos anos deve-se ao aumento da disponibilidade de bases de dados em laboratório e de cálculos quânticos fundamentais com respeito às taxas de reações e espectros de moléculas. Grande parte das moléculas observadas no espaço são orgânicas e, de fato, houve uma mudança paradigmática muito recente, motivada pelo florescimento da astrobiologia, ou seja, o estudo multidisciplinar da origem, evolução, distribuição e destino da vida no Universo, considerando em especial a vida em outros lugares além da Terra (Lafleur, 1941). Além disso, diversos observatórios tanto espaciais como em solo têm explorado partes do espectro eletromagnético rico em linhas moleculares, desde o infravermelho próximo ao rádio, incluindo o infravermelho médio e distante e o submilimétrico/milimétrico. Uma das principais frentes exploradas pela astrobiologia é o estudo da biologia terrestre, já que a busca pela vida em qualquer lugar do Universo é condicionada por nosso conhecimento da vida na Terra. Além disso, a origem e a evolução da vida terrestre, é condicionada pelas condições que possui nosso planeta no Sistema Solar e na nossa Galáxia (Friaça, 2012). O surgimento da vida no Universo passou a ser visto como uma etapa da evolução cosmológica da complexidade, da qual a formação das moléculas orgânicas representam uma importante fase.

\subsection{Matéria Orgânica no Universo}

A primeira molécula descoberta no meio interestelar foi o radical metilidina $(\mathrm{CH})$, identificada em 1937 pelo astrônomo P. Swings e pelo físico L. Rosenfeld com base em espectros obtidos por Durham e Adams (1937) para uma amostra de estrelas de tipo 


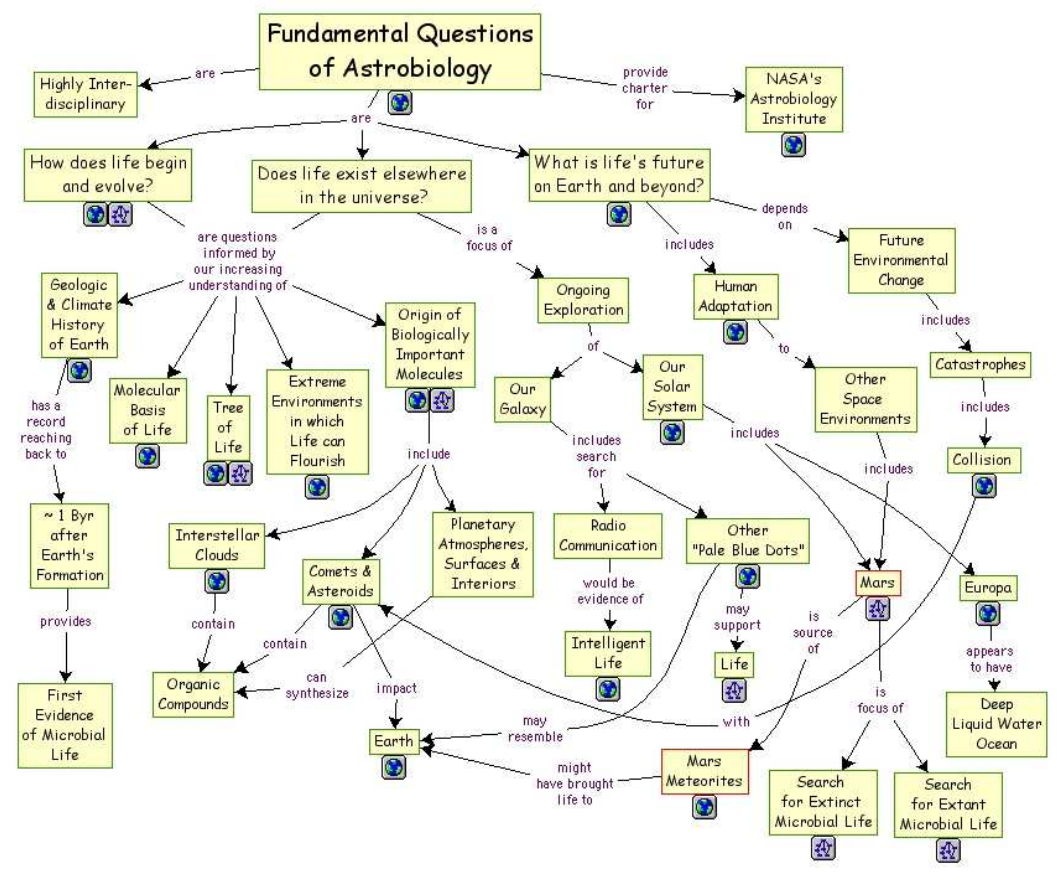

Figura 1.1: Mapa das Áreas de estudos da Astrobiologia (Briggs, 2009)

"early", usando o recém-completado espectrógrafo Coudé do observatório de Monte Wilson. No seu trabalho de 1937, Durham e Adams identificaram facilmente nos espectros estelares linhas do $\mathrm{Ti}^{+}$de origem interestelar, mas restavam algumas linhas de origem desconhecida. No mesmo ano, Swings e Rosenfeld reconheceram o comprimento de onda de uma das linhas não identificadas a $4300.3 \AA$ como um dos componentes da banda $4315 \AA$ do CH (Herzberg, 1988). Nesse momento, começou a era do universo molecular em astrofísica.

Pode-se dizer que também que em 1937 começou a era do universo orgânico em astrofísica. A definição de química orgânica tem alguma variação, mas um modo de definila seria o campo da química que estuda compostos onde comparece a ligação CH. Esta definição exclui o $\mathrm{CO}$ e $C N^{-}$assim como compostos mais complexos onde não comparece o $\mathrm{H}$, como os fulerenos $-C_{60}$ e $C_{70}$, por exemplo - de serem orgânicos. O radical $\mathrm{CH}$ normalmente não é considerado um composto orgânico, mas temos que levar em conta que a química de ambientes astrofísicos difere daquela dos laboratórios usuais, pelo papel importante dos radicais livres e dos íons, além de mecanismos de fornecimento de energia normalmente não considerados em condições terrestres, como fótons ultravioleta (UV) de curto comprimento de onda e raios cósmicos. 
Também para o HCN é crítico na definição de química orgânica, visto que normalmente não é considerado orgânico. Mas, segundo o ponto de vista astrofísico, ele seria orgânico porque apresenta a ligação H-C. Ademais é o precursor da importante classe de nitrilas, que apresentam abundâncias significativas no meio interstelar. Também é importante ao se considerar os compostos heterocíclicos nitrogenados, de grande significado na biologia terrestre.

Além do meio interestelar, representado tanto por nuvens difusas interestelares como por nebulosas, os envelopes circum-estelares e, principalmente, arredores de gigantes vermelhas, são regiões ricas em carbono, onde se encontra grande quantidade de matéria orgânica. Verificou-se que as reações químicas que formam moléculas orgânicas nestas regiões (Cherchneff et al., 1992) fazem delas as fontes dominantes de uma importante classe de compostos orgânicos, os hidrocarbonetos aromáticos policíclicos (PAHs, na sigla em inglês). Tais moléculas, consistindo de vários anéis aromáticos fundidos, representam um reservatório importante de carbono no meio interstelar, chegando a aprisionarem 30-50\% de todo carbono desse meio (Puget e Leger, 1989). Essa alta proporção de PAHs reflete suas abundâncias elevadas nos sítios de produção e a sua resistência às condições do meio interestelar. De fato, modelos dos envelopes carbonados frios mostram que mais carbono está contido em PAHs do que em $\mathrm{CO}$ a temperaturas de cerca de $850 \mathrm{~K}$, quando $C / O>5$ (Helling et al., 1996). Os ventos estelares expelem estas moléculas para o meio interestelar e, a partir daí, elas podem ser encontradas em outros ambientes.

Inúmeras moléculas diferentes foram identificadas no meio interestelar e em envelopes circum-estelares (Tabela A.1 vista no anexo), e essa lista se expande diariamente. A tabela A.1 no anexo mostra, por uma atualização de agosto de 2012, que já foram encontradas no meio interestelar e em envelopes circum-estelares cerca de 170 moléculas. As moléculas nitrogenadas são de especial interesse para considerações bióticas e pré-bióticas, e pela Tabela A.1 podemos ver que cerca de um terço delas são nitrogenadas. Como foi dito acima, os compostos heterocíclicos nitrogenados, e em especial os heterocíclicos aromáticos nitrogenados são de grande interesse pela sua presença na bioquímica terrestre. As classes das purinas e pirimidinas, que contêm as bases nitrogenadas dos ácidos nucleicos ilustram esse ponto. Desse modo, neste trabalho daremos especial atenção aos compostos heterocíclicos nitrogenados. 
A matéria orgânica é componente fundamental de sistemas vivos e, portanto, os estudos sobre a origem da vida e a evolução da biosfera procuram elucidar como se deu a passagem de compostos orgânicos abióticos para a primeiras formas de vida e como as substâncias orgânicas permanecem disponíveis para os seres vivos na biosfera por períodos de tempo de vários bilhões de anos. Além disso, é inevitável que a distribuição da matéria orgânica no Universo tenha um impacto direto na origem da vida na Terra e em outras partes do Cosmos além do nosso planeta. Por esse motivo, o estudo do conteúdo molecular do universo é um dos eixos da pesquisa em astrobiologia.

\subsection{Astrobiologia}

Existe vida fora da Terra? Se existir, é um tipo de vida similar às formas de vida que se conhece na Terra? Como detectá-la? Estas são algumas das mais fascinantes perguntas que defrontam as ciências hoje, sendo a astrobiologia a área que se dedica particularmente ao estudo da origem, da evolução e da distribuição da vida no Universo.

Três estratégias clássicas foram seguidas na busca por vida extraterrestre: o estudo celular de organismos exóticos terrestres, a busca por matéria orgânica, como o estudo realizado neste trabalho, e microorganismos vivos fora da Terra e o uso de radiotelescópios para detectar sinais de vida inteligente no Universo (Chela-Flores, 2001).

A primeira estratégia tem por objetivo entender como a vida na Terra começou. Pesquisas revelaram organismos exóticos, os chamados extremófilos, vivendo em ambientes inóspitos, tais como o fundo de oceanos, lençóis glaciais antárticos e fluxos de lava vulcânicos, que apresentam temperatura e pressão que podem até ser semelhantes às encontradas durante a formação da Terra há cerca de 4,5 bilhões de anos atrás (Chela-Flores, 2001). Descobertas recentes indicam que há ecossistemas inteiros que não dependem da luz solar, estendendo nosso conceito de limites de zona de habitabilidade no Sistema Solar. Pesquisar nossas próprias origens não somente amplia nossa avaliação da enorme diversidade da vida aqui na Terra, mas também pode ajudar-nos a entender as situações extremas que organismos simples podem tolerar, tais como ambientes encontrados em outros corpos celestes, tornando mais provável que exista vida em outro lugar.

A segunda estratégia é a busca por formas simples de matéria orgânica - aminoácidos ou proteínas, por exemplo - que podem encontrar-se incrustadas em rochas antigas de 
planetas, cometas ou meteoritos, ou, ainda, em nuvens interestelares. Hoje já há evidências de fluxos de água líquida num passado geológico recente, ou até atual, em Marte. A Missão Espacial Galileu forneceu ampla evidência de um oceano embaixo da superfície congelada de Europa (Chela-Flores, 2001). Um dos objetivos primários da astrobiologia é determinar onde a vida pode existir além da Terra e, se isto é possível, quais as condições ambientais limitantes.

A terceira estratégia usada na busca por indícios de vida fora da Terra utiliza os radiotelescópios que, além de pesquisarem os comprimentos de onda invisíveis ao olho humano, permitem a detecção de anomalias nas ondas de rádio, que podem representar sinais de vida no cosmos. Os astrônomos têm vasculhado o espectro em rádio há cinco décadas, aproximadamente, sem nenhum sinal de civilização extraterrestre (Chela-Flores, 2001).

A busca de vida extraterrestre, combinada com grandes avanços em astronomia espacial e de solo levou a encontrar seguidamente novos planetas extrassolares e mesmo novos sistemas planetários, e mantém a esperança de encontrar vida inteligente "em algum lugar lá fora".

Estas três estratégias fornecem um mapa para uma grande jornada de descobertas, incluindo a possibilidade de encontrar um lugar real no Universo que seja como o planeta Terra e, ao mesmo tempo, elucidar como a vida se desenvolveu no nosso planeta.

\subsection{Origem e Busca pela Vida}

A procura por vida dentro e fora do Sistema Solar está intrinsecamente relacionada à compreensão dos sistemas vivos na ciência moderna. Porém, definir o que é vida não é uma tarefa tão simples como parece; é preciso examinar a química e a função dos elementos que constituem um sistema vivo. Outro passo é estudar os lugares no Universo e na Terra onde a matéria-prima para a vida poderia ter se formado antes da vida ter começado de fato. Finalmente, temos que entender os mecanismos através dos quais a matéria-prima não biológica pode ter se combinado resultando nos primeiros organismos vivos.

\subsubsection{O que é vida?}

Durante toda a história, muitas questões têm sido levantadas sobre como e quando a vida surgiu. Inicialmente, muitos consideraram que a vida surgiu espontânea e repentina- 
mente na Terra. Estas suposições eram apoiadas pelas evidências observacionais da época sobre a geração espontânea de moscas e larvas de insetos a partir de carne podre, piolhos a partir de suor, enguias e peixes a partir da lama do mar e sapos e ratos a partir do solo úmido. Ocasionalmente, a idéia da geração espontânea era questionada. Por exemplo, em 1668, o médico Francesco Redi (1627-1697) demonstrou que as larvas de insetos eram postas por moscas e se a carne fosse deixada em um recipiente fechado, então, as moscas adultas eram impedidas de entrar e depositar seus ovos e as larvas não apareciam. De qualquer modo, quando o microscópio holandês feito por Anthony van Leeuwenhoek (1632-1723) detectou microorganismos em 1676, a geração espontânea era a explicação que melhor dava conta de tais criaturas. O problema foi finalmente resolvido em 1862, quando em uma tentativa de ganhar um prêmio oferecido pela Academia Francesa de Ciência, Louis Paster (1822-1895) realizou uma série de experimentos convincentes demonstrando a inexistência da geração espontânea. Pasteur mostrou que se um caldo ou solução estiver devidamente esterilizado e excluído de contatos com microorganismos, ele poderá permanecer estéril indefinidamente (Gilmour e Sephton, 2004).

Pasteur respondeu uma questão importante ao provar que a geração espontânea não era a origem da vida, mas inevitavelmente fez surgir questões novas e mais difíceis. Se toda a vida vem de vida existente, de onde veio a primeira vida? Ironicamente, em contraste ao banimento da velha e arraigada ideia que a vida surge espontaneamente de matéria inanimada, veio a inevitável e lógica conclusão que a primeira vida pode ter aparecido exatamente assim - surgida de materiais não-vivos presentes no Universo.

Se vamos estabelecer quando e como a vida se originou, devemos primeiro definir o que é vida.

Em geral, muitos biólogos costumam identificar duas características chave que indicam vida (Gilmour e Sephton, 2004):

- a capacidade de se auto-replicar;

- a capacidade de evoluir de acordo com a teoria Darwiniana.

Para um organismo se auto-replicar é preciso que ele seja capaz de produzir cópias dele mesmo. Para a evolução Darwiniana acontecer, imperfeições ou mutações devem acontecer ocasionalmente, durante o processo de copiamento, e estas novas características devem 
estar sujeitas à seleção natural. A natureza favorece algumas características particulares sob dadas condições ambientais e aqueles indivíduos que melhor se adaptarem às condições existentes sobreviverão mais facilmente. Por este processo, uma mudança evolutiva com qualquer característica vantajosa por qualquer tipo de mutação deve ser passada para as gerações futuras (Gilmour e Sephton, 2004).

Uma pequena lista de apenas duas características pode não ser uma definição muito confiável de vida. Por isso, a NASA propôs a seguinte definição: "vida é um sistema químico auto-sustentável capaz de permitir a evolução Darwiniana" (Joyce, 1994). De qualquer forma, qualquer definição de vida será igualmente falha sob certas circunstâncias. Por exemplo, a mula é a descendência de jumento com égua, que são espécies distintas, por isso a mula é estéril. Uma mula não pode se multiplicar e, sendo assim, é incapaz de satisfazer os critérios de auto-replicação e de evolução Darwiniana, mas apesar disso, não se pode negar que ela esteja viva. Entretanto, para a maioria dos casos, essa definição de vida será uma definição satisfatória.

Para que a vida seja auto-sustentável e capaz de evoluir conforme a Teoria de Darwin, energia e materiais básicos precisam ser extraídos do ambiente ao redor para permitir crescimento e replicação. Além disso, alguns tipos de sistemas vivos devem estar presentes para governar a química da vida. Para um primeiro passo na procura por vida no Universo podemos nos basear na compreensão dos sistemas vivos na Terra, o que significa vida baseada em água líquida, um conjunto de elementos biogênicos, como o carbono e o nitrogênio, além de uma fonte de energia livre. Nesse estágio, a busca pela vida conduz à busca de água, carbono, nitrogênio e energia livre para sustentar a vida.

\section{4 Água}

À primeira vista, a àgua líquida parece ser essencial para a vida. Sistemas vivos precisam de um meio no qual uma grande variedade de moléculas possam se dissolver e onde as reações químicas possam ocorrer rapidamente. O fato da água preencher estes requisitos justifica que ela possa ser chamada de solvente universal. Poucos outros solventes poderiam ter a mesma capacidade da água para facilitar a existência da vida. A água existe como líquida em uma faixa de temperatura que não é nem tão fria, que pode freiar a velocidade das reações químicas, nem tão quente que impeça a formação de cadeias orgânicas. 
Uma alternativa ocasionalmente proposta, a amônia, poderia ser líquida em outros mundos muito mais frios que o nosso, mas a tais baixas temperaturas as reações químicas que levariam à vida operariam lentamente e os sistemas vivos teriam que experimentar lapsos de tempo excessivamente longos para alcançarem a estabilidade.

Ademais, os elementos que formam a água, o hidrogênio e o oxigênio, são os elementos mais abundantes não só dos seres vivos terrestres, mas também do Universo, seguidos pelo carbono e pelo nitrogênio.

\subsection{Carbono}

O carbono é o único elemento que pode formar moléculas suficientemente grandes para realizar algumas funções necessárias para a vida como conhecemos. Pode formar cadeias químicas com diversos outros átomos, permitindo uma grande diversidade química. A importância do carbono para a bioquímica terrestre é ilustrada pela posição que ocupa na frente da sigla CHONPS, que designa os elementos essenciais para a vida, ou seja, carbono, hidrogênio, oxigênio, nitrogênio, fósforo e enxofre, aos quais se acrescentam os macroelementos cloro, sódio, potássio e cálcio e cerca de uma dúzia de microelementos, tais como ferro, magnésio e zinco.

Uma das principais características do carbono é a capacidade de vários de seus compostos de se dissolverem facilmente na água. Tal capacidade de interação mútua faz dos compostos de carbono e da água as mais importantes substâncias para o desenvolvimento de organismos vivos. Atualmente, todas as formas de vida conhecidas são baseadas em carbono.

A abundância relativa dos elementos mais comuns no Universo indica uma grande disponibilidade dos elementos necessários para construir os compostos biogênicos (Tabela 1.1). Os quatro elementos mais abundantes utilizados para a vida na Terra (hidrogênio, oxigênio, carbono e nitrogênio, ou CHONs) são também os quatro elementos quimicamente ativos (excetuando os gases nobres), com maiores abundâncias cósmicas. 
Tabela 1.1 - Os dez elementos mais abundantes no Universo, na Terra e nos organismos vivos [átomos de elementos por 100.000 átomos no total] (Gilmour e Sephton, 2004)

\begin{tabular}{lc|cc|cc|cc|cc}
\hline \hline \multicolumn{2}{c|}{ Universo } & Toda a Terra & Crosta terrestre & Oceanos terrestres & Humanos \\
\hline $\mathrm{H}$ & 92.714 & $\mathrm{O}$ & 48.880 & $\mathrm{O}$ & 60.425 & $\mathrm{H}$ & 66.200 & $\mathrm{H}$ & 60.563 \\
$\mathrm{He}$ & 7.185 & $\mathrm{Fe}$ & 18.870 & $\mathrm{Si}$ & 20.475 & $\mathrm{O}$ & 33.100 & $\mathrm{O}$ & 25.670 \\
$\mathrm{O}$ & 50 & $\mathrm{Si}$ & 14.000 & $\mathrm{Al}$ & 6.251 & $\mathrm{Cl}$ & 340 & $\mathrm{C}$ & 10.680 \\
$\mathrm{Ne}$ & 20 & $\mathrm{Mg}$ & 12.500 & $\mathrm{H}$ & 2.882 & $\mathrm{Na}$ & 290 & $\mathrm{~N}$ & 2.440 \\
$\mathrm{C}$ & 15 & $\mathrm{~S}$ & 11.400 & $\mathrm{Na}$ & 2.155 & $\mathrm{Mg}$ & 34 & $\mathrm{Ca}$ & 230 \\
$\mathrm{~N}$ & 8 & $\mathrm{Ni}$ & 1.400 & $\mathrm{Ca}$ & 1.878 & $\mathrm{~S}$ & 17 & $\mathrm{P}$ & 130 \\
$\mathrm{Si}$ & 2,3 & $\mathrm{Al}$ & 1300 & $\mathrm{Fe}$ & 1.858 & $\mathrm{Ca}$ & 6 & $\mathrm{~S}$ & 130 \\
$\mathrm{Mg}$ & 2,1 & $\mathrm{Na}$ & 640 & $\mathrm{Mg}$ & 1.784 & $\mathrm{~K}$ & 6 & $\mathrm{Na}$ & 75 \\
$\mathrm{Fe}$ & 1,4 & $\mathrm{Ca}$ & 460 & $\mathrm{~K}$ & 1.374 & $\mathrm{C}$ & 1,4 & $\mathrm{~K}$ & 37 \\
$\mathrm{~S}$ & 0,9 & $\mathrm{P}$ & 140 & $\mathrm{Ti}$ & 191 & $\mathrm{Si}$ & - & $\mathrm{Cl}$ & 33 \\
\end{tabular}

Depois da água, as moléculas mais abundantes em sistemas vivos são as macromoléculas biológicas: carboidratos, lipídios, proteínas e ácidos nucleicos, todas formadas por cadeias de carbono.

Os carboidratos são importantes como fontes de energia para a vida (Figura 1.2) e os lipídios, para a formação da membrana celular (Figura 1.3). Já as proteínas, longas cadeias de aminoácidos, são responsáveis pela catálise e pela produção das enzimas, constituindo uma das principais classes de macromoléculas biológicas (Figura 1.4).

\subsection{Nitrogênio}

O nitrogênio é o quarto elemento quimicamente ativo mais abundante no Universo. Este elemento é de extrema importância, pois juntamente com o carbono, oxigênio e fósforo é um dos elementos que compõe o portador de informação biológica na Terra - o DNA. Além disso, o nitrogênio permite a montagem de uma série de heterocíclicos complexos e de compostos assimétricos. Outrossim, a valência ímpar do nitrogênio introduz assimetrias e heterogeneidades, que são uma condição necessária para o armazenamento da informação. 


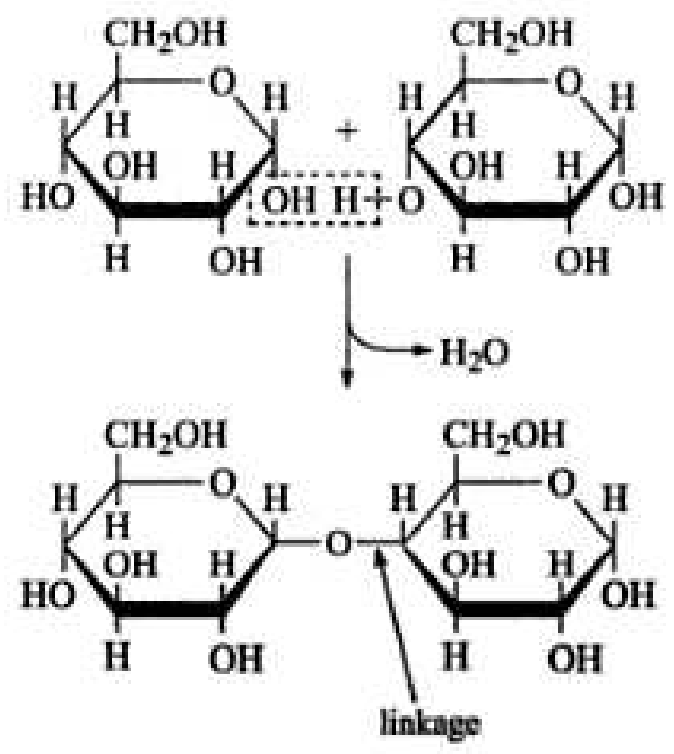

Figura 1.2: Carboidratos formados por cadeias de carbono - transformação de energia para organismos vivos. (Gilmour e Sephton, 2004)

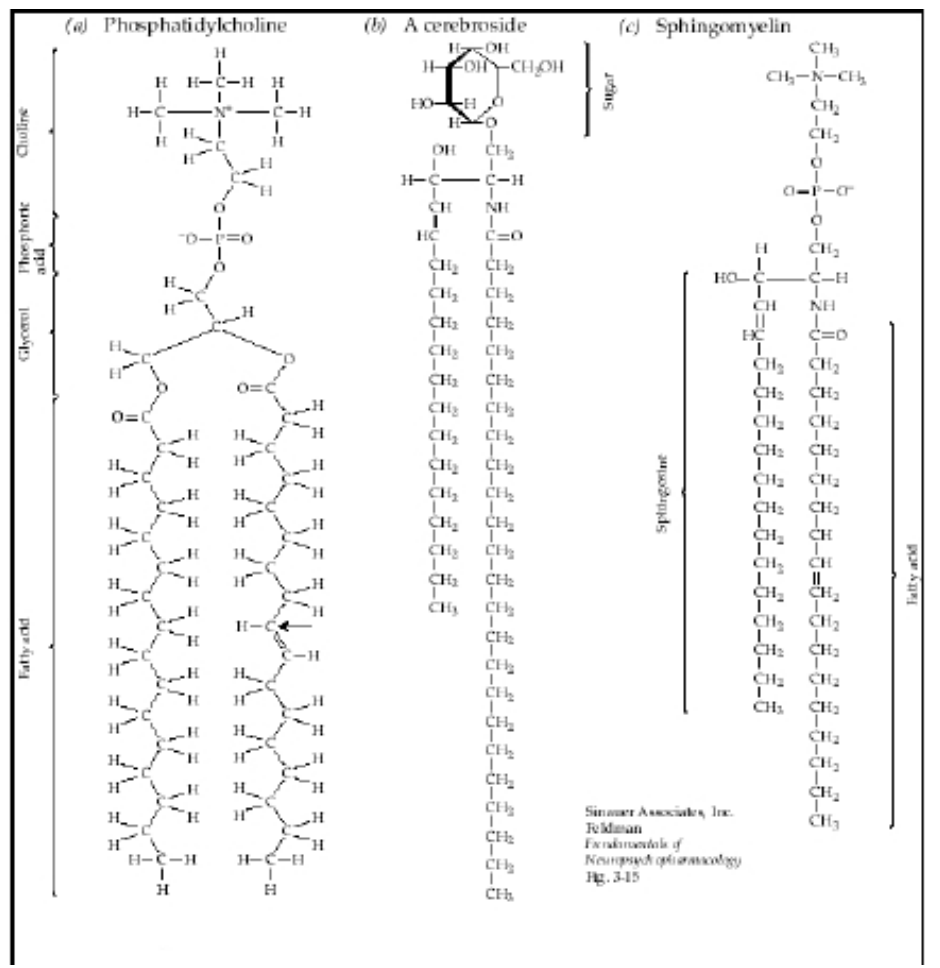

Figura 1.3: Membranas lipídicas de células. (Gilmour e Sephton, 2004) 


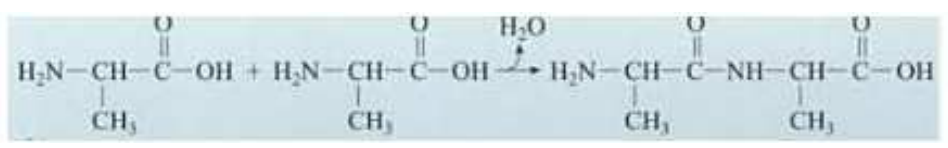

Figura 1.4: Produção de proteínas a partir de aminoácidos. (Gilmour e Sephton, 2004)

\subsection{1 Ácidos Nucleicos (DNA/RNA)}

Ácidos Nucleicos podem ser as maiores macromoléculas biológicas conhecidas. Elas consistem em uma coleção de nucleotídios individuais ligados em longas cadeias lineares de polímeros. Assim como açúcares e aminoácidos, nucleotídios podem ser ligados por simples reações que envolvem a perda de água. Cada nucleotídio é composto por uma pentose (açúcar com cinco átomos de carbono), um ou mais grupos de fosfato e por uma base nitrogenada, para as quais há cinco possibilidades: adenina, citosina, timina e guanina (Figura 1.5), além da uracila.

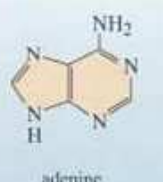

adenine

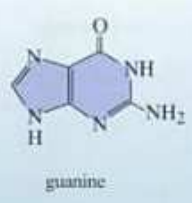

guanine
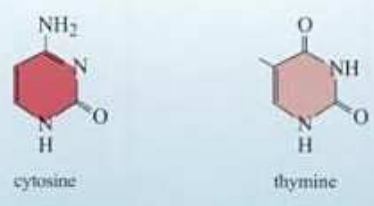

Figura 1.5: Bases encontradas no DNA. (Gilmour e Sephton, 2004).

Os organismos vivos contêm dois tipos de ácidos nucleicos: DNA e RNA, sendo o DNA o ácido nucleico que contém as instruções genéticas usadas no desenvolvimento e funcionamento de todos os organismos vivos.

\subsubsection{Espécies Nitrogenadas de Interesse Astrobiológico}

O espectro no infravermelho para as bases nitrogenadas ainda não é bem conhecido para a fase gasosa, o que dificulta sua detecção no meio interestelar. Há poucos trabalhos como o de Plützer et al. (2001), que apresenta um espectro para a nucleobase adenina produzido em jatos supersônicos com linhas de absorção na faixa de números de onda entre 36050 e $36700 \mathrm{~cm}^{-1}$. Porém, outros compostos contendo a função nitrila, tais como $\mathrm{CH}_{3} \mathrm{CN}$-acetonitrila, $\mathrm{CH}_{3} \mathrm{CH}_{2} \mathrm{CN}$-propanonitrila, $\mathrm{CH}_{2} \mathrm{CHCN}$-acrilonitrila, $\mathrm{HCCCN}$ 
-cianoacetileno, $H C C N$-cianometileno, $H C N$ e o $O C N^{-}$, foram detectados recentemente na atmosfera de Titã, em comas cometárias e no meio interestelar (Hudson e Moore, 2004). De fato, esta é uma das áreas que está em desenvolvimento e que possibilitará grandes descobertas observacionais num futuro próximo.

Dentro do Sistema Solar, a química da nitrila é particularmente relevante em Titã, já que sua atmosfera oferece condições de temperatura e pressão para a formação de tais compostos, além das reações estimuladas por radiação cósmica, fótons ultravioleta (UV) e pela magnetosfera de Saturno. As nitrilas também são relevantes no contexto de estudo de cometas.

Os cometas são essenciais para entender as nebulosas solares e sua evolução, já que as moléculas são mais facilmente detectáveis nestes objetos devido à sua trajetória cruzando a órbita terrestre e servem de comparativo para o que se pode encontrar nas regiões de formação estelar e, também, para pesquisas dos processos químicos que ocorrem no meio interestelar.

Nesse contexto, cabe salientar a teoria da Panspermia, que sugere que a vida não necessariamente tenha se originado na Terra mas em cometas (Napier et al., 2007), ou ao menos transportada para cá por estes; mais especificamente, Wickramasinghe et al. (2012) refere-se aos planetas primordiais, nos quais teria havido o início da vida, ou pelo menos a formação dos primeiros blocos construtores, alguns milhões de anos após o Big Bang, desde a primeira condensação do $H_{2}$, seria possível mapear essa história evolucionária pelo processo de colisão de cometas e outros astros que expeliram gás e poeira na nuvem zoodiacal, quando da passagem dos primeiros corpos planetários pelo sistema solar (Wickramasinghe et al., 2012). Outra teoria, mais aceita, é de que os cometas possam ter fornecido compostos orgânicos chaves para o inicio da vida na Terra. Dentre estes, os compostos heterocíclicos nitrogenados têm especial importância.

\subsection{O Mundo Aromático}

Apesar do crescente avanço das pesquisas, ainda não há um resultado conclusivo que explique o surgimento da vida no nosso planeta. Embora haja muitas hipóteses para a origem da vida, ainda não há provas convincentes de que um cenário é mais provável do que o outro. Na verdade, ao olhar para os sistemas químicos, não existe sequer uma 
definição sem ambiguidade que separe "vida" de "não-vida". Todos concordam, porém, que a vida tenha que, de alguma forma, passar sua informação genética ao longo do tempo para se perpetuar.

Existem aproximadamente 170 moléculas detectadas no meio interestelar (ver tabela A.1 no anexo) e várias delas são importantes para compreender a origem da vida. Cabe salientar os hidrocarbonetos aromáticos policíclicos (PAHs), que são moléculas orgânicas encontradas em todo espaço e podem ter desempenhado um papel fundamental na origem da vida. De fato, os PAHs devem ter sido as primeiras grandes moléculas produzidas logo após a primeira geração de estrelas massivas do Universo jovem (Chela-Flores, 2001).

Estas moléculas de carbono e hidrogênio são chamadas "policíclicas" devido as suas múltiplos anéis de átomos de carbono, e "aromáticas" devido às fortes ligações químicas do anel conjugado, pares isolados ou orbitais vazios que mostram uma estabilidade mais forte do que se poderia esperar da estabilidade de um conjugado sozinho. Os PAHs podem ser encontrados na Terra quando ocorre a combustão incompleta de materiais à base de carbono. Constituem uma família de compostos caracterizada por possuírem dois ou mais anéis aromáticos condensados. Essas substâncias, bem como os seus derivados nitrogenados e oxigenados, são encontrados como constituintes de misturas complexas em todos os ambientes.

Segundo a bioquímica moderna, os três principais requisitos dos sistemas celulares são ácidos nucleicos, proteinas e membranas. A maior parte destes blocos de construção da vida, no espaço, é encontrado em meteoritos carbonáceos, mas há indícios de algumas moléculas complexas na fase gasosa no meio interestelar(Chela-Flores, 2001).

Os PAHs podem ter sido material importante para a estabilidade da vida em sua origem, pois possuem uma estrutura muito robusta contra diversos tipos de degradação, incluindo por radiação. Eles podem ser modificados, mas não serão totalmente destruídos. Mesmo se forem divididos, os fragmentos ainda estarão disponíveis para futuras moléculas. Em contrapartida, outras moléculas mais imediatamente ligadas à vida, como os aminoácidos, não têm grande probabilidade de serem observadas no meio interestelar, uma vez que fótons ultravioleta (UV) as destruiriam (Chela-Flores, 2001).

Os meteoritos contêm cerca de três por cento de carbono, no máximo. Destes, $80 \%$ são incorporados a redes aromáticas. Trata-se de um material abundante, estável ao calor 
e parcialmente insolúvel, e bastante resistente a radiação. Logo, por resistir mesmo sob condições muito hostis, como durante o possível início da Terra, esse material pode ter sido mais importante do que inicialmente se suspeitava. Os PAHs são as moléculas orgânicas livres mais abundantes no espaço, ambiente certamente menos propício à formação molecular em geral do que a Terra, uma vez que não existe uma atmosfera protetora (Lunine, 2005).

Os três requisitos para um sistema vivo são a existência de sistemas informacionais, redes metabólicas e compartimentalização. Os PAHs podem desempenhar o papel de polímeros informacionais ao constituir de um modo direto templates com blocos de PAHs complementares. Em relação à compartimentalização os PAHs são capazes de se organizarem em bicamadas para constituir estruturas primitivas de membrana (Ehrenfreund et al., 2006).

Um ponto importante é que os PAHs também podem ser fotossensibilizados, porque podem realizar transferência de carga entre cátions e ânions. Assim, eles podem desempenhar um papel metabólico como transdutores energia. Além disso, Nicolas Platts, do Laboratório de Geofísica do Carnegie Institution of Washington propôs que, pela junção de PAHs, eles podem formar um polímero informacional semelhante a um ácido nucleico (Platts, 1992). Portanto, o material aromático pode ser utilizado como "recipiente" para os três requisitos à vida de uma só vez.

A recente detecção de $C_{4} H^{-}, C_{6} H^{-}$e $C_{8} H^{-}$levou à investigação dos ânions de hidrocarbonetos no meio interestelar e no ambiente circum-estelar. A razão encontrada entre a abundância de ânions e moléculas neutras é de, pelo menos, uma pequena porcentagem, uma vez que essas últimas têm mais de cinco átomos de carbono. Esses cálculos predizem, ainda, ânions de $n$ átomos de carbono (Cordiner et al., 2007a).

Acredita-se que a captura eletrônica por hidrocarbonetos é muito eficiente para as espécies que contêm mais de cinco átomos de carbono. Os ânions são criados de forma eficaz e podem ser abundantes mesmo em regiões onde eles são rapidamente destruídos por fótons. Em particular, acredita-se que os ânions como $C_{6} H^{-}, C_{8} H^{-}$e $C_{10} H^{-}$possam ter, em relação à sua abundância com as espécies neutras, uma pequena porcentagem superior à unidade, enquanto $\mathrm{C}_{4} \mathrm{H}^{-}$, embora desenvolvida de forma relativamente ineficiente, pode ser observada em objetos astronômicos com grandes abundâncias de $C_{4} H$ (Cordiner et al., 
$2007 \mathrm{a})$.

Considerando o papel da carga dos PAHs quanto à extinção ultravioleta, uma combinação de PAHs marjoritariamente neutros e com carga negativa reproduz satisfatoriamente curvas de extinção interestelar observadas (Cecchi-Pestellini et al., 2008).

Além disso, as assim chamadas Bandas Aromáticas no Infravermelho (AIBs, na sigla em inglês) são atribuídas à emissão infravermelha de PAHs aquecidos, excitados por fótons UV. Também se acredita que algumas das Bandas Difusas Interestelares (DIBs, na sigla em inglês), um conjunto de linhas de absorção no visível e no infravermelho próximo, teriam sua origem nos PAHs (ver seções 3.10 e 4.2 desta dissertação).

Assim, os PAHs são excelentes moléculas alvo para a busca de matéria orgânica que foi produzida em outras partes do Sistema Solar ou mesmo em outros locais da Galáxia e entregue posteriormente quase intacta em planetas como Marte e a Terra.

\subsection{Organização da Dissertação}

Esta dissertação está organizada como segue: no segundo capítulo, encontram-se as informações sobre o meio interestelar e as principais reações de formação e de destruição de compostos, uma breve descrição da Nebulosa Cabeça de Cavalo como modelo padrão para regiões de fotodissociação e da estrutura do código PDR Meudon que foi usado para modelizar esta região. No capítulo três estão apresentados os testes realizados com o código, os resultados das simulações com os respectivos modelos utilizados. O capítulo quatro faz uma análise dos resultados obtidos. Conclusões e perspectivas são apresentados no capítulo cinco. 


\section{Capítulo 2}

\section{Base de Dados}

O principal instrumento utilizado neste estudo foi um modelo computacional para regiões de fotodissociação (PDRs), o código PDR Meudon, podendo ser usado no estudo de propriedades físicas e químicas de nuvens difusas, nuvens moleculares densas e regiões circum-estelares, além das regiões de fotodissociação (Le Petit et al., 2006). Dessa forma, é possível analisar a região estudada de acordo com seus principais parâmetros, como a incidência de um campo de radiação, a densidade, a temperatura e a pressão da região, bem como as propriedades químicas de compostos que podem ser formados e/ou destruídos e suas reações químicas.

\subsection{Meio Interestelar}

O componente mais óbvio do meio interestelar é constituído pelos fótons, dos quais os produzidos por estrelas quentes, especialmente de tipo $\mathrm{O}$ e $\mathrm{B}$, fótons $\mathrm{UV}$, têm especial importância ao constituir um campo de radiação associado ao meio interestelar geral, que pode aquecer e ionizar o gás, interagindo também com os demais componentes do meio.

A idéia de um gás interestelar é relativamente recente, as primeiras evidências remontam às observações da binária espectroscópica $\delta$ Orionis em 1904, feitas por Johannes Franz Hartmann (1865-1936), que revelaram a presença de linhas de absorção de CaII que não participavam do movimento orbital do par. Hartmann concluiu pela existência de uma nuvem de gás na linha de visada de $\delta$ Orionis, afastando-se com velocidade radial de $16 \mathrm{~km} / \mathrm{s}$.

O gás interestelar está geralmente associado a grãos interestelares. Caso uma nuvem contendo gás e grãos não esteja associada a estrelas brilhantes, os grãos absorverão a 
radiação do campo, apresentando-se no céu como nebulosas escuras. É o caso do Saco de Carvão e da Nebulosa Cabeça de Cavalo, na constelação de Órion.

Caso a nuvem de grãos esteja associada a estrelas moderadamente quentes, com temperaturas efetivas até $T_{e f} \simeq 25000 K$, os grãos podem espalhar a radiação estelar, formando uma nebulosa de reflexão. Essas nebulosas são importantes para a determinação das propriedades físicas dos grãos. Um exemplo é a nebulosa de reflexão ao redor das Plêiades.

Quando a nebulosa está associada a estrelas muito quentes, com $T_{e f} \geq 25000 K$, o gás ao redor encontra-se fotoionizado, e a nebulosa é uma nebulosa difusa ou região HII. O gás ionizado ocupa uma região bem definida no espaço, com uma separação nítida entre a região HII ionizada e quente, com temperatura eletrônica $T_{e} \simeq 10^{4} K$, e a região HI neutra e fria, com temperatura cinética de $T_{c} \simeq 10^{2} K$. As regiões HII apresentam intensa emissão nas linhas UV e ópticas do H, He e elementos pesados e, além disso, emissão em rádio e no infravermelho. Essas regiões são associadas com as regiões de formação estelar e têm um papel importante no estudo da evolução química da Galáxia e na definição dos braços espirais, dos quais são os principais traçadores (Maciel, 2002).

Outros tipos de nebulosas são formadas no processo de evolução estelar. Estrelas com massa da ordem de $1 M_{\odot}$ terminam suas vidas ejetando suas camadas externas, tornase uma anã branca e, posteriormente, uma anã negra. Expulsas, suas camadas externas formam uma nebulosa planetária. Este tipo de nebulosa possui propriedades análogas às região HII, pois suas estrelas centrais são objetos muito quentes com $T_{\text {ef }} \geq 30000 \mathrm{~K}$ e fotoioniza essas regiões. Estrelas com massas maiores do que $9 M_{\odot}$ terminam suas vidas ejetando toda ou parte de sua massa de um modo explosivo, constituindo as supernovas. Forma-se uma nebulosa gasosa brilhante a partir do material estelar espalhado pelo espaço interestelar, chamada resto de supernova. Através das colisões entre o material ejetado e o meio interestelar o gás nesta região é ionizado. Os processos não-térmicos, como a emissão síncrotron, são os principais responsáveis pela emissão da radiação.

Até o século XIX, as nebulosas brilhantes se confundiam com objetos como a "Nebulosa" de Andrômeda, que é uma galáxia. Huggins (1824-1911), obteve e analisou os primeiros espectros, entre 1864 e 1868, e mostrou que as galáxias tinham espectros contínuos característicos das estrelas que as compõem, enquanto as nebulosas possuem espectros de linhas brilhantes típicos de gás aquecido, tornando evidentes as distinções entre as regiões. 
Os grãos interestelares são os principais responsáveis pela polarização da radiação das estrelas e, assim, fornecem evidências da existência de um campo magnético fraco no meio interestelar - com intensidade $B \simeq 10^{-6}$ Gauss - pois este tipo de campo pode causar uma anisotropia, como a apresentada na polarização, segundo uma direção preferencial.

O espaço interestelar contém também raios cósmicos, partículas de alta energia como prótons, elétrons e núcleos de elementos pesados, que atravessam a região com velocidades próximas à da luz. A detecção e análise dos raios cósmicos permite estudar as condições físicas de seus locais de origem através dos possíveis processos de aceleração que tenham sofrido.

\subsubsection{Regiões de Fotodissociação}

Quando somente fótons, em sua grande maioria menos energéticos do que a energia de ionização do hidrogênio, chegam à camada superficial de uma grande nuvem molecular, dissociando e ionizando suas moléculas, deixando o resto da nuvem predominantemente neutra, ou seja, molecular, a camada superficial da nuvem é chamada de região fotodominada ou de fotodissociação, PDR (photon-dominated region, na sigla em inglês). A distinção entre PDRs e regiões HII torna-se clara se a definição de PDR aplicada não for a de região fotodominada, já que as regiões HII também são dominadas por fótons, mas a de regiões de fotodissociação, pois moléculas dissociadas são dificilmente encontradas em regiões HII.

Uma PDR é definida abrangentemente como uma região onde as propriedades físicas e químicas do gás são determinadas por fótons penetrantes do ultravioleta distante (FUV, $6<h \nu<13.6 \mathrm{eV})$.

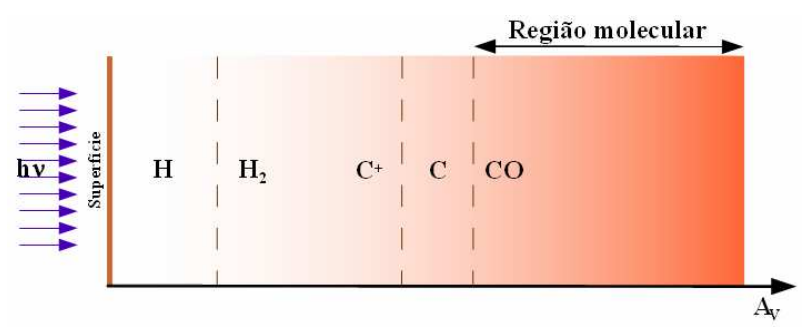

Figura 2.1: Ilustração esquemática de uma PDR com as regiões de aparecimento das principais espécies atômicas e moleculares. (Le Petit, 2012)

Próximo à superfície da nuvem, o campo de radiação FUV é forte, mas vai per- 
dendo intensidade ao penetrar a nuvem e, assim, as espécies mais importantes passam de íons para moléculas; a complexidade química aumenta, pois as espécies moleculares podem ser formadas sem serem imediatamente destruídas pela radiação de alta energia (ver Le Petit et al., 2006; Gerin et al., 2009).

O aquecimento da nuvem se dá principalmente pelo campo de radiação incidente, mas outras fontes também são importantes: a desexcitação colisional de moléculas de $H_{2}$ vibracionalmente excitadas, emitindo fótons no processo; colisões poeira-gás quando a temperatura do grão é maior que a do gás; raios cósmicos, que podem penetrar fundo na nuvem; efeito fotoelétrico na superfície dos grãos e dos PAHs pelos fótons FUV; a formação e dissociação de $H_{2}$; a turbulência do gás; e reações químicas no interior da nuvem (Le Petit et al., 2006).

O resfriamento se dá principalmente pela emissão por moléculas excitadas, pela emissão no contínuo pelos grãos e pelas colisões poeira-gás quando a temperatura do grão é menor do que a do gás.

A densidade da nuvem e a intensidade do campo de radiação FUV basicamente determinam o tamanho e a estrutura química - a distribuição de abundância de cada constituinte químico - da PDR da nuvem.

Os grãos na nuvem molecular têm grande importância física, pois determinam grande parte da curva de extinção da nuvem, catalisam algumas reações químicas e são responsáveis por toda formação de hidrogênio molecular em condições padrão galácticas, além de participarem do balanço térmico da nuvem por aquecimento fotoelétrico e colisão poeiragás (Le Petit et al., 2006).

Quanto mais adentramos a nuvem, ou seja, maior a extinção $\left(A_{V}\right)$, mais energética deve ser a radiação para conseguir penetrá-la. Passando da região da PDR (região I na figura 2.2) dominada por fótons FUV, vem uma região ainda dominada por fótons FUV, mas somente parcialmente, pois o campo de radiação externo é fortemente atenuado. Nessa região (II na figura 2.2) há o acúmulo de capas de gelo na superfície dos grãos na nuvem molecular. A fotodissociação é devido ao atenuado campo FUV que, ainda assim, consegue fazer espécies em estado sólido na superfície dos grãos passarem para o estado gasoso.

Em regiões ainda mais profundas das nuvens moleculares, no núcleo frio, o campo de radiação FUV foi praticamente todo atenuado e somente raios cósmicos têm papel 


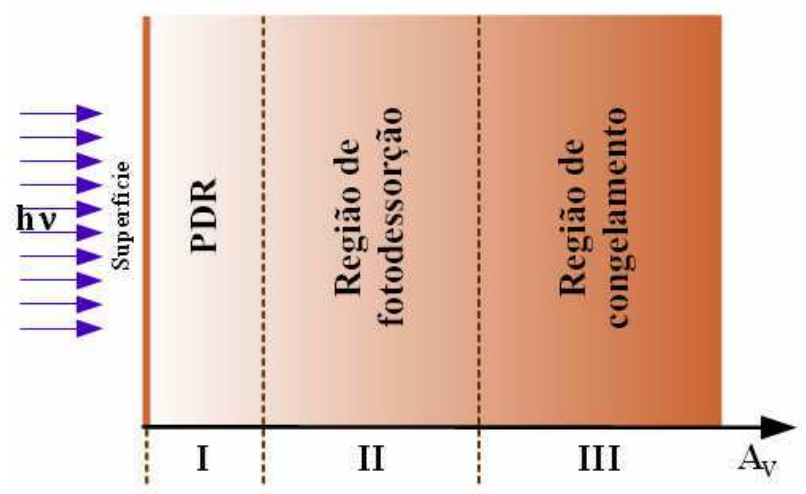

Figura 2.2: Ilustração esquemática de uma nuvem molecular com suas três regiões típicas. (Le Petit, 2012)

importante como agentes externos (Hollenbach et al., 2009).

\subsection{Detecção de Moléculas no Meio Interestelar}

Moléculas apresentam linhas de emissão e absorção assim como os átomos, porém o número de linhas do espectro molecular é muito maior, já que elas podem estar excitadas tanto eletronicamente como também vibracional e rotacionalmente, na fase de gás.

A mecânica quântica prevê que, assim como no caso das transições eletrônicas, somente algumas transições vibracionais e rotacionais são permitidas. As energias destes estados de vibração e rotação podem ser entendidas, respectivamente, como modos de vibração ao redor das posições de equilíbrio dos átomos da estrutura molecular, uns em relação aos outros e como rotação das moléculas como um todo ao redor dos eixos, a partir do centro de massa (Karplus e Porter, 1970).

Um espectro molecular a baixa resolução $(>0.1 \AA$ ) apresentará linhas finas e muitas bandas (linhas grossas). Numa resolução mais alta, as bandas são resolvidas em um complexo sistema de linhas finas decorrentes das transições entre estados vibracionais e rotacionais. Essas transições emitem e absorvem radiação numa ampla gama de comprimentos de onda, indo do infravermelho a microondas (Karplus e Porter, 1970), conforme mostra a tabela 2.1 . 
Tabela 2.1 - Comprimentos de onda de diversas emissões provenientes de transições entre diversos tipos de átomos, núcleos atômicos e moléculas. As denominações FUV, NIR e FIR são, respectivamente, ultravioleta distante, infravermelho próximo e infravermelho distante. (Karplus e Porter, 1970)

\begin{tabular}{lcc}
\hline \hline Comprimento de onda & Origem & Radiação \\
\hline $10^{-1}-10^{3} \AA$ & Transições eletrônicas internas de átomos e moléculas & Raios-X e FUV \\
$10^{3}-10^{4} \AA$ & Transições eletrônicas externas & UV $\left(10^{3}-4 \times 10^{3} \AA\right)$ \\
& de átomos e moléculas & Visível $\left(4 \times 10^{3}-7 \times 10^{3} \AA\right)$ \\
$10^{4}-10^{6} \AA$ & Vibrações moleculares & NIR $\left(>7 \times 10^{3} \AA\right)$ \\
$1-10^{2} \mu m$ & Vibrações moleculares & Infravermelho (IR) \\
$10^{2}-10^{5} \mu m$ & Rotações moleculares & Infravermelho (IR) \\
$0.1-10^{2} \mathrm{~mm}$ & Rotações moleculares & FIR $\left(10^{2}-10^{3} \mu m\right)$ \\
$10-30 \mathrm{~cm}$ & Rotações moleculares e ressonância elétron-spin & Microondas $\left(10^{3} \mu m-0.1 \mathrm{~mm}\right)$ \\
$0.3-300 \mathrm{~m}$ & Ressonância nuclear-magnética & Microondas \\
& & Ondas de rádio \\
\hline
\end{tabular}

A presença de moléculas no meio interestelar é inferida por suas linhas de emissão ou absorção, pois essas são características das ligações químicas entre seus átomos constituintes. Mas para moléculas mais complexas a quantidade de linhas pode ser imensa, tornando difícil distinguir entre linhas de diferentes moléculas ou entre linhas de diferentes átomos. No caso de PAHs e de outras moléculas grandes, as linhas de diferentes ligações químicas podem até ser observadas, mas a estrutura espacial das ligações entre seus átomos constituintes não pode ser inferida diretamente do espectro observado. Isso dificulta a detecção de moléculas complexas, fato percebido na redução da quantidade de moléculas detectadas com grande número de átomos. (ver tabela A.1)

As observações são feitas tanto por observatórios em solo como em órbita. Os telescópios em solo operam no infravermelho próximo, no rádio e, mais recentemente, na faixa de microondas e milimétrico/submilimétrico. Os instrumentos espaciais incluem o ISO, o Spitzer, o Akari e o Herschel operando do infravermelho próximo ao distante, e instrumentos menos sensíveis como o SWAS e o Odin operando com microondas. 


\subsubsection{Reações Moleculares na Fase Gasosa}

Os processos de formação e destruição de moléculas no meio interestelar apresentam quatro diferenças básicas com relação aos processos conhecidos na atmosfera terrestre (Maciel, 2002): i) os principais processos que levam à formação e fixação de uma população estável de moléculas interestelares são, basicamente, processos na fase gasosa, já que as espécies atômicas e moleculares nas nuvens interestelares estão essencialmente na fase gasosa, com exceção dos grãos sólidos; ii) ocorrência de reações envolvendo três ou mais partículas são praticamente impedidas devido às baixas densidades das nuvens interestelares, mesmo as mais densas - da ordem de $10^{4}$ por $\mathrm{cm}^{-3}$. Em compensação, devido à sua destruição mais lenta e sua maior estabilidade nessas nuvens, radicais e moléculas muito reativos em laboratório, como $\mathrm{OH}$ e $\mathrm{N}_{2} \mathrm{H}^{+}$, podem ser estudados mais detalhadamente nas nuvens interestelares. Além disso, algumas espécies somente foram identificadas no meio interestelar, como $\mathrm{HC}_{7} \mathrm{~N}$ e $\mathrm{HC}_{9} \mathrm{~N}$; iii) a energia cinética dos átomos e das moléculas é baixa, pois as temperaturas das nuvens interestelares são muito baixas e somente reações exotérmicas têm, geralmente, importância. Algumas reações ocorrem quando processos dinâmicos injetam no gás uma energia superior à energia térmica média dos átomos nas nuvens. As nuvens têm movimentos aleatórios com velocidade $\left(\simeq 10 \mathrm{kms}^{-1}\right)$ superiores à velocidade do som em nuvens interestelares típicas $\left(\simeq 1 \mathrm{kms}^{-1}\right)$, de modo que a colisão de duas nuvens pode produzir ondas de choque com energia suficiente para elevar sua temperatura localmente por um fator da ordem de cem; iv) no meio interestelar, as reações de oxigênio são muito menos importantes nas nuvens interestelares do que nas condições de laboratório, em que a alta reatividade do oxigênio tem um papel preponderante nos processos químicos, já que a abundância de oxigênio é muito mais baixa que a do hidrogênio. Por exemplo a molécula de $\mathrm{CO}$, que em condições terrestres transforma-se facilmente em $\mathrm{CO}_{2}$, é a segunda mais abundante no meio interestelar. Isso se deve à grande estabilidade do CO nas nuvens interestelares e mesmo nas atmosferas das estrelas mais fria e, assim, ela é utilizada para determinar a abundância da espécie mais importante, o $\mathrm{H}_{2}$.

\subsubsection{Reações Íon-Molécula}

Provavelmente, as reações mais importantes da fase gasosa no meio interestelar são as reações íon-molécula. A presença de íons dentro das nuvens moleculares é assegurada pela 
radiação UV ou pela propagação de partículas energéticas - os raios cósmicos, e a carga elétrica de um dos reagentes resulta em uma força de atração, que favorece a reação.

Exemplos dos principais processos são (Maciel, 2002):

$$
\begin{gathered}
C+h \nu \rightarrow C^{+}+e^{-} \\
H_{2}+\text { r.c. } \rightarrow H_{2}^{+}+e^{-}+\text {r.c. }
\end{gathered}
$$

onde r.c. significa raios cósmicos.

Nas nuvens interestelares as reações íon-moléculas frequentemente envolvem o $H_{2}$. Por exemplo, o íon $H_{2}^{+}$produzido pela reação 2.2 pode desencadear as seguintes reações em nuvens densas (Maciel, 2002):

$$
\begin{gathered}
\mathrm{H}_{2}^{+}+\mathrm{H}_{2} \rightarrow \mathrm{H}_{3}^{+}+\mathrm{H} \\
\mathrm{H}_{3}^{+}+\mathrm{O} \rightarrow \mathrm{OH}^{+}+\mathrm{H}_{2} \\
\mathrm{OH}^{+}+\mathrm{H}_{2} \rightarrow \mathrm{H}_{2} \mathrm{O}^{+}+H \\
\mathrm{H}_{2} \mathrm{O}^{+}+\mathrm{H}_{2} \rightarrow \mathrm{H}_{3} \mathrm{O}^{+}+H \\
\mathrm{H}_{3} \mathrm{O}^{+}+e^{-} \rightarrow \mathrm{H}_{2} \mathrm{O}+\mathrm{H}
\end{gathered}
$$

com a produção de $\mathrm{H}_{2} \mathrm{O}$ na reação de recombinação dissociativa 2.7. Essa reação pode ser substituída pela formação de $\mathrm{OH}$, como por exemplo

$$
\mathrm{H}_{3} \mathrm{O}^{+}+e^{-} \rightarrow \mathrm{OH}+\mathrm{H}_{2}
$$

O mesmo resultado, isto é, a formação de $\mathrm{H}_{2} \mathrm{O}$ e $\mathrm{OH}$, pode resultar da reação

$$
\mathrm{O}^{+}+\mathrm{H}_{2} \rightarrow \mathrm{OH}^{+}+\mathrm{H}
$$

seguindo-se, então, as reações 2.5$]$ a 2.8 . 
A química do carbono nas nuvens interestelares densas é também baseada nas reações íon-molécula, em especial a formação de CO. A partir do íon $H_{3}^{+}$formado em 2.3 e de maneira semelhante às reações 2.4 a 2.6, temos (Maciel, 2002):

$$
\begin{gathered}
\mathrm{H}_{3}^{+}+\mathrm{C} \rightarrow \mathrm{CH}^{+}+\mathrm{H}_{2} \\
\mathrm{CH}^{+}+\mathrm{H}_{2} \rightarrow \mathrm{CH}_{2}^{+}+\mathrm{H} \\
\mathrm{CH}_{2}^{+}+\mathrm{H}_{2} \rightarrow \mathrm{CH}_{3}^{+}+\mathrm{H}
\end{gathered}
$$

A formação do CO é feita, então, pelas reações

$$
\begin{gathered}
\mathrm{CH}_{3}^{+}+\mathrm{O} \rightarrow \mathrm{HCO}^{+}+\mathrm{H}_{2} \\
\mathrm{HCO}^{+}+e^{-} \rightarrow \mathrm{CO}+\mathrm{H}
\end{gathered}
$$

Em nuvens difusas a penetração da radiação produz íons reativos como o $C^{+}$, que se associa radiativamente com $H_{2}$ (Maciel, 2002):

$$
\mathrm{C}^{+}+\mathrm{H}_{2} \rightarrow \mathrm{CH}_{2}^{+}+h \nu
$$

O produto $\left(\mathrm{CH}_{2}^{+}\right)$pode sofrer reações como 2.12 a 2.14 ou formar $\mathrm{CH}$ ou $\mathrm{CH}_{2}$ pelas reações

$$
\begin{aligned}
& \mathrm{CH}_{3}^{+}+e^{-} \rightarrow \mathrm{CH}+\mathrm{H}_{2} \\
& \mathrm{CH}_{3}^{+}+e^{-} \rightarrow \mathrm{CH}_{2}+\mathrm{H}
\end{aligned}
$$

As reações íon-molécula estão em geral envolvidas na formação das moléculas mais abundantes que são observadas no meio interestelar, e têm também um papel importante na síntese de moléculas longas, como os cianopoliacetilenos $H C_{9} N$ e $H C_{11} N$. De fato, acredita-se que reações íon-molécula envolvendo $\mathrm{NH}_{3}$ ou $\mathrm{NH}_{2}$ levem à produção de HCN, a partir do qual são formadas as moléculas mais complexas por incremento de pares de átomos de carbono. 


\subsubsection{Reações Neutro-Neutro}

Embora menos eficientes que as reações íon-molécula, as colisões de átomos neutros, ou de um átomo com uma molécula, podem levar à formação de uma nova molécula. Neste caso, a interação é mais fraca, podendo eventualmente haver uma barreira de energia que dificulta a reação. Esta poderá ocorrer se a partícula incidente tiver energia suficiente ou puder atravessar a barreira de potencial por tunelamento. Alguns exemplos são:

$$
\begin{aligned}
& \mathrm{O}+\mathrm{OH} \rightarrow \mathrm{O}_{2}+\mathrm{H} \\
& \mathrm{N}+\mathrm{NO} \rightarrow \mathrm{N}_{2}+\mathrm{O}
\end{aligned}
$$

No caso da primeira reação, a barreira é desprezível, mas a segunda é lenta para $T \simeq$ $10 K$ e mais rápida para $T \simeq 300 K$, havendo uma barreira importante (Maciel, 2002).

A molécula de $\mathrm{H}_{2} \mathrm{O}$ pode ser produzida em nuvens interestelares a partir do $\mathrm{O}$ neutro - mais abundante que o íon $O^{+}$envolvido na reação 2.9] - pela reação

$$
\mathrm{O}+\mathrm{H}_{2} \rightarrow \mathrm{H}_{2} \mathrm{O}+\mathrm{h \nu}
$$

Essa reação é exotérmica, mas possui uma barreira de energia de ativação correspondente a cerca de $100 K$ (Maciel, 2002). Essa temperatura pode ser alcançada por meio de ondas de choque. Reações endotérmicas, como a reação envolvendo $\mathrm{C}$ e $\mathrm{H}_{2}$ para produzir hidrocarbonetos ou $\mathrm{N}$ e $\mathrm{H}_{2}$ produzindo amônia $\left(\mathrm{NH}_{3}\right)$ podem também ocorrer pela mesma razão.

\subsubsection{Associação Radiativa}

Reações do tipo

$$
A+B \rightarrow A B+h \nu
$$

são chamadas reações de associação radiativa e podem ocorrer no meio interestelar, sendo o excesso de energia dos átomos A e B transportado pela radiação, deixando-os com energia insuficiente para se separarem. Este tipo de reação não ocorre frequentemente entre os átomos neutros, mas pode ser importante para interações íon-átomo ou íon-molécula, 
como 2.15 ou em

$$
C^{+}+H \rightarrow C H^{+}+h \nu
$$

\subsubsection{Recombinação Radiativa}

Em uma recombinação radiativa, um íon recombina-se com um elétron, havendo emissão de um fóton. Por exemplo, além de 2.9, o íon $O^{+}$pode ser destruído por

$$
\mathrm{O}^{+}+e^{-} \rightarrow \mathrm{O}+\mathrm{h \nu}
$$

\subsubsection{Recombinação Dissociativa}

Esta é uma reação em que um íon molecular recombina-se com um elétron, com a formação de dois produtos neutros, como em

$$
\begin{gathered}
\mathrm{OH}_{2}^{+}+e^{-} \rightarrow \mathrm{OH}+\mathrm{H} \\
\mathrm{OH}_{3}^{+}+e^{-} \rightarrow \mathrm{OH}+\mathrm{H}_{2}
\end{gathered}
$$

Geralmente, essas recombinações são mais rápidas que as recombinações radiativas. Outros exemplos são as reações 2.7, 2.16 e 2.17.

\subsubsection{Reações de Troca de Carga}

Em nuvens difusas, a radiação não é suficientemente energética para ionizar o $O$, mas o íon $\mathrm{O}^{+}$pode ser obtido por uma reação de troca de carga do tipo

$$
\mathrm{O}+\mathrm{H}^{+} \rightarrow \mathrm{O}^{+}+\mathrm{H}
$$

Os íons $\mathrm{H}^{+}$são produzidos pela ionização do $\mathrm{H}$ pelos ráios cósmicos. O íon $\mathrm{O}^{+}$produzido pode, então, ser usado para as reações iniciadas com 2.9 até a formação de $\mathrm{H}_{2} \mathrm{O}$ ou $\mathrm{OH}$.

\subsubsection{Destruição de Moléculas}

As reações consideradas nos processos acima podem também destruir algumas moléculas já formadas, as quais serão, então, reagentes de outras reações. Os principais processos de destruição de moléculas interestelares são a fotodissociação e a dissociação colisional. 


\subsubsection{Fotodissociação}

Possivelmente o principal meio de destruição das moléculas nas nuvens interestelares difusas é a fotodissociação como, por exemplo, na reação

$$
\mathrm{OH}+\mathrm{h \nu} \rightarrow \mathrm{O}+\mathrm{H}
$$

As moléculas em nuvens interestelares não protegidas pelos grãos de poeira podem ser destruídas pela radiação UV em escalas de tempo relativamente curtas, da ordem de algumas centenas de anos. As escalas de tempo para a fotodissociação tornam-se apreciavelmente mais longas à medida que aumenta-se a extinção da nuvem interestelar, o que tende a bloquear os fótons do campo de radiação.

\subsubsection{Dissociação Colisional}

No interior de nuvens densas o processo dominante de dissociação molecular é colisional, pois os fótons UV não conseguem penetrar devido à absorção pelos grãos nas regiões periféricas. De fato, a maior densidade nessas regiões favorece a ocorrência de reações na fase gasosa, com a eventual dissociação de espécies moleculares. Além disso, processos dinâmicos como ondas de choque podem favorecer a formação de moléculas, fornecendo a energia necessária para superar a barreira de energia de ativação. Entretanto, se o choque for suficientemente intenso, com velocidade de algumas dezenas de $\mathrm{km} / \mathrm{s}$, as colisões poderão dissociar moléculas como o $H_{2}$, produzindo átomos de $\mathrm{H}$ que, por sua vez, podem dissociar colisionalmente outras moléculas como $\mathrm{NH}$ ou $\mathrm{NH}_{3}$.

\subsection{Cinética de Reação}

Nas nuvens moleculares densas ocorrem os principais processos moleculares. As abundâncias moleculares não são, em geral, aquelas obtidas admitindo equilíbrio químico, essencialmente devido à dependência de muitas das reações químicas com a temperatura do gás. Portanto, a química interestelar é controlada basicamente pela cinética das reações, de modo que as reações devem ser consideradas individualmente. 


\subsubsection{Taxas de Reação}

Considere uma reação do tipo

$$
A+B \rightarrow M+X
$$

Chamando $\sigma$ a seção de choque da reação, pode-se definir a constante de reação ou coeficiente de reação $\kappa$ pela relação

$$
\kappa=\langle\sigma v\rangle
$$

onde $v$ é a velocidade relativa dos reagentes. Admitindo, por exemplo, uma distribuição maxwelliana de velocidades para os átomos reagentes, a constante de reação pode depender, portanto, da temperatura do gás.

A taxa de reação $r$ mede a taxa de variação dos reagentes e produtos envolvidos na reação no decorrer do tempo. A taxa $r$ é uma quantidade positiva e é, geralmente, proporcional à constante de reação e às densidades dos reagentes, podendo ser escrita como

$$
r=\kappa n_{A} n_{B}
$$

onde $n_{A}$ e $n_{B}$ são as densidades numéricas dos reagentes $\mathrm{A}$ e $\mathrm{B}$. Se $\sigma$ for medido em $\mathrm{cm}^{2}$ e $v$ em $\mathrm{cm} / \mathrm{s}$, a constante $\kappa$ será medida $\mathrm{em}_{\mathrm{cm}^{3}} / \mathrm{s}$ e, medindo as densidades em $\mathrm{cm}^{-3}$, a taxa $r$ tem unidades de $\mathrm{cm}^{-3} \mathrm{~s}^{-1}$.

As constantes de reação podem depender fortemente da temperatura, em particular quando há barreira de energia de ativação. Essa dependência, da constante de reação $\kappa$ com a temperatura é frequentemente escrita utilizando-se a clássica equação de Arrhenius,

$$
\kappa(T)=A e^{-E_{a} / \kappa T}
$$

onde A é o fator de Arrhenius e $E_{a}$ é a energia de ativação. Desta relação, temos:

$$
\ln \kappa=\ln A-\frac{E_{a}}{\kappa T}
$$

De modo geral, as constantes de reação variam bastante de uma reação para outra e, frequentemente, com a temperatura. A tabela 2.2 mostra alguns valores médios para os principais tipos de reação na fase gasosa e pode ser considerada como uma primeira aproximação quando não houver dados disponíveis para a reação (Maciel, 2002). 
Tabela 2.2 - Valores médios para os principais tipos de reação na fase gasosa. (Maciel, 2002)

\begin{tabular}{lc}
\hline \hline \multicolumn{1}{c}{ Tipo de Reação } & $\kappa\left(\mathrm{cm}^{3} / \mathrm{s}\right)$ \\
\hline Reações íon-molécula & $10^{-9}$ \\
Reações neutro-neutro & $10^{-11}$ \\
Associação radiativa - diatômica & $10^{-17}$ \\
Associação radiativa - poliatômica & $10^{-9}$ \\
Recombinação radiativa & $10^{-12}$ \\
Recombinação dissociativa & $10^{-6}$ \\
Reações de troca de carga & $10^{-9}$ \\
& \\
\hline
\end{tabular}

\subsection{Nebulosa Cabeça de Cavalo}

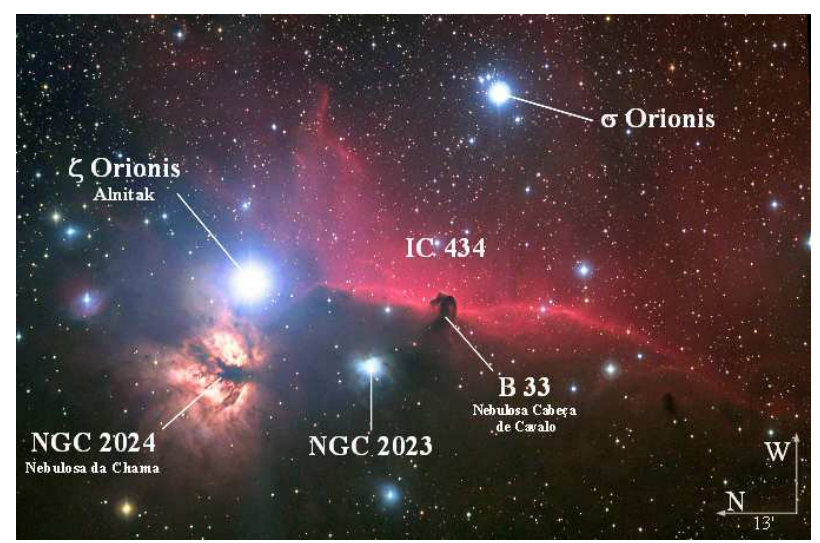

Figura 2.3: Nebulosa Cabeça de Cavalo (HHN) e circunvizinhança. (NASA, 2010)

Um importante objeto, usado como objeto-modelo, é a Nebulosa Cabeça de Cavalo, do inglês Horsehead Nebula (HHN). Ela aparece como uma mancha escura contra a luminosa região HII IC434, em luz visível. A HHN foi escolhida como objeto-modelo por ser exemplo representativo de PDR e de nuvem molecular, tendo sido extensivamente observada e parametrizada devido à sua distância moderada $(d \simeq 400 p c)$, geometria simples e um campo de radiação FUV bem conhecido, onde a estrela $\sigma$ Orionis ioniza a região, conforme parametrizado por Gerin et al. (2009). Além disso, a modelagem clássica de Cordiner et al. (2007b) para este objeto e o seu espectro rico em linhas moleculares, como as de $C_{4} H$ e de $C_{6} H$, fazem dessa nebulosa um alvo ideal para testar qualquer modelo 
para a formação de linhas moleculares. Outrossim, é possível ampliar os estudos sobre a região, tendo como base os resultados obtidos por Goicoechea et al. (2009) e Gerin et al. (2009), considerando essa região como arquétipo de nuvens moleculares. As características físicas mais importantes da HHN estão sintetizadas na tabela 2.3 .

Tabela 2.3 - Características físicas da Nebulosa Cabeça de Cavalo. (Gerin et al., 2009)

Nome
Localização
Distância da Terra
Estrela iluminadora
Campo de radiação FUV
Profundidade ao longo da linha de visada
Inclinação da linha de visada
Perfil de densidade
Temperatura cinética
Pressão térmica

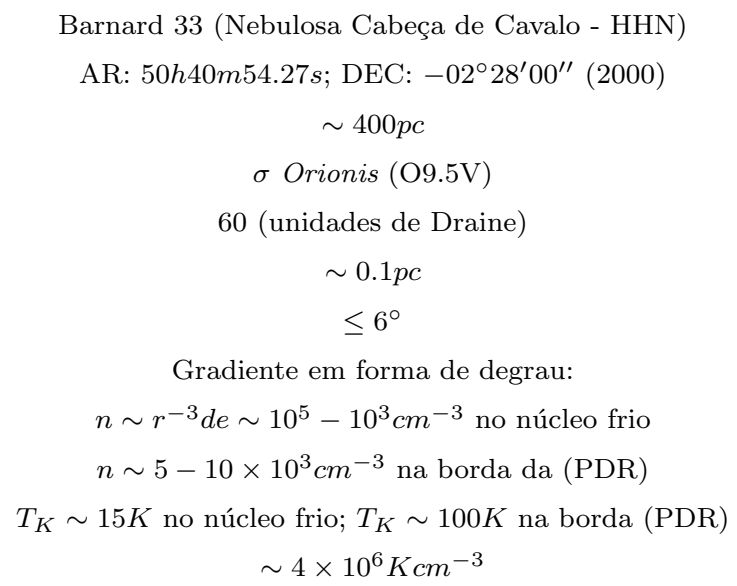

$\sigma$ Orionis é na verdade um sistema quíntuplo (Kaler, 2012), na borda de um pequeno aglomerado estelar, a 1150 anos-luz da Terra. O sistema de cinco estrelas é dominado por um par de estrelas: a mais luminosa do par tem tipo espectral $09.5 \mathrm{~V}$ e, a menos luminosa do par tem tipo espectral B0.5V.

\subsection{O Código PDR Meudon}

Modelos teóricos sobre a estrutura das PDRs vêm sendo feitos há cerca de 30 anos, evoluindo para complexos códigos computacionais e passando a considerar um número crescente de efeitos físicos, provendo resultados cada vez mais acurados (Röllig et al., 2007). O código PDR Meudon é um desses modelos computacionais, podendo ser usado no estudo físico e químico de nuvens difusas, PDRs, nuvens moleculares densas e regiões circumestelares.

Há uma variedade de códigos para o cálculo de condições químicas e físicas em PDRs, sendo o código PDR Meudon um código amplamente utilizado, pelo fato de estar disponível 
publicamente (http://pdr.obspm.fr/PDRcode.html) e de ser um dos programas usados como recurso dos trabalhos a serem conduzidos com o observatório Herschel. Ele é descrito em Le Petit et al. (2006), Röllig et al. (2007). Deve ser mencionado também um importante trabalho (Röllig et al., 2007) que compara os resultados de diversos códigos PDR, entre eles o código PDR Meudon.

\subsubsection{Características do Código}

O modelo considera uma nuvem unidimensional, com bordas paralelas e bem definidas (Figura 2.4), podendo ter extensão finita ou semi-finita. O observador sempre se encontra no lado negativo. O modelo considera, ainda, uma geometria plano-paralela estacionária para o gás e poeira, iluminado por um campo de radiação UV, caracterizado pela equação 2.35 e ajustado por um fator $\chi$, que representa a intensidade do campo de radiação FUV incidente em unidades do campo de radiação interestelar médio definido por Draine (1978), proveniente de um ou de ambos os lados da nuvem (as duas intensidades podem ser diferentes $-\chi^{+}$para o lado positivo e $\chi^{-}$para o lado negativo).

Uma estrela de dado tipo espectral também pode ser introduzida a uma distância $d$ (em parsecs) para criar um campo de radiação adicional. O código resolve a equação de transferência radiativa (no UV) de uma forma iterativa, em cada ponto da nuvem, considerando também as absorções causadas por transições de $\mathrm{H}$ e $H_{2}$, além do contínuo devido à poeira. O modelo também calcula o equilíbrio térmico, tendo em vista processos de aquecimento (tais como o efeito fotoelétrico), a química, raios cósmicos e outros parâmetros, além do resfriamento resultante da emissão no infravermelho e milimétrico, abundante em íons, átomos e/ou moléculas. A abundância de cada espécie é calculada em cada ponto. O estado de excitação de algumas espécies importantes é então calculado e, assim, o programa é capaz de calcular a densidade de coluna e emissividade/intensidade.

O campo de radiação padrão é o campo de Draine (Draine, 1978), adotado no código como

$$
I(\lambda)=\frac{1}{4 \pi}\left(\frac{6.300 \times 10^{7}}{\lambda^{4}}-\frac{1.0237 \times 10^{11}}{\lambda^{5}}+\frac{4.0812 \times 10^{13}}{\lambda^{6}}\right)
$$

onde $\lambda$ é dado em $\stackrel{\AA}{A}$ e $I(\lambda)$ está em $\mathrm{erg} \cdot \mathrm{cm}^{-2} s r^{-1} \AA^{-1}$, sendo usada no intervalo de comprimentos de onda entre $912 \leq \lambda \leq 2400 \AA$. Para outros comprimentos de onda, o perfil usado é dado pela equação 2.34 . 


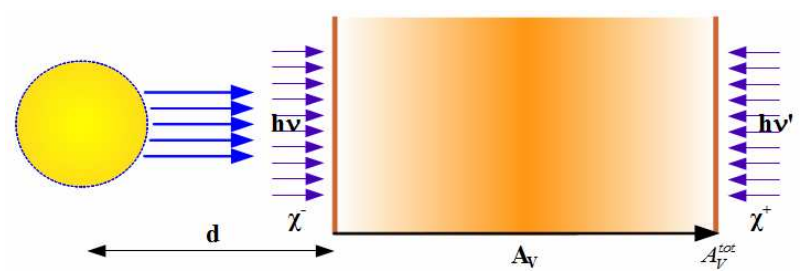

Figura 2.4: Ilustração de algumas características geométricas do código Meudon PDR em uma nuvem. O $A_{V}^{t o t}$ é o tamanho da nuvem, no caso $\chi^{+}$de uma nuvem finita. (Le Petit, 2012)

$$
I(\lambda)=1.38243 \times 10^{-5} \lambda^{-0.3}
$$

É comum medir a intensidade do campo de radiação usando o parâmetro $G$ devido a Habing (1968), que é expresso, no modelo, pela equação 2.35.

$$
G=\frac{1}{5.6 \times 10^{-14}} \int_{912}^{2400} u(\lambda) d \lambda
$$

O campo de radiação adicional devido à estrela é oriundo da criação de um espectro de corpo negro a partir da temperatura efetiva $T_{e f}$ e do raio $r^{*}$ do tipo espectral da estrela.

As distâncias na nuvem são medidas em extinção $A_{V}$, dada pela equação 2.36

$$
A_{V}=2.5 \log _{10}(e) \tau
$$

com $A_{V}$ dado em magnitudes e $\tau$ sendo a profundidade óptica em determinado ponto da nuvem (Rybicki e Lightman, 1979).

A relação entre a profundidade óptica e uma distância real $l$, entre $l$ e $A_{V}$, é dada pela equação 2.37 (Karplus e Porter, 1970).

$$
l=2.5 \log _{10}(e) \frac{C_{D}}{R_{V}} \int_{0}^{\tau_{\max }} \frac{d t \tau}{n_{H}\left(\tau_{V}\right)}
$$

onde, $C_{D}=\frac{N_{H}}{E_{B-V}}$, sendo $N_{H}\left[\mathrm{~cm}^{-2}\right]=N(H)+2 N\left(H_{2}\right)$ a densidade de coluna total do hidrogênio não ionizado, $E_{B-V}$ o excesso de cor, $R_{V}=\frac{A_{V}}{E_{B-V}}$, e $n_{H}\left(\tau_{V}\right)\left[\mathrm{cm}^{-3}\right]=n\left(H^{+}\right)+$ $n(H)+2 n\left(H_{2}\right)$ a densidade total de núcleos de hidrogênio a uma profundidade óptica visível $\tau_{V}$. O limite superior de integração $\tau_{\max }$ é a profundidade óptica máxima da nuvem. Valores galácticos típicos para estes parâmetros são de estados estacionários $C_{D}=5.8 \times 10^{21}$ $\mathrm{cm}^{-2} \mathrm{mag}^{-1}$ e $R_{V}=3.1$. 
Uma das grandes restrições do modelo é a aproximação de estado estacionário, de modo que os resultados não podem ser comparados diretamente às observações de regiões com evolução rápida. No entanto, o tempo em escalas de fotoprocessos é modesto comparado ao de extinção e/ou alta radiação de campos. O período de tempo dado pela fotodissociação do $H_{2}$ é tipicamente $1000 / \chi$ anos na beira de uma nuvem (com radiação UV). O estado estacionário é então uma aproximação satisfatória (Le Petit et al., 2006).

Podem-se definir os parâmetros que descrevem o sistema e que podem ser ajustado como melhor convém. A primeira hipótese é de que cada célula de gás é pequena o suficiente para que todas as quantidades físicas possam ser constantes, mas suficientemente grande para a média estatística ser significante. Podemos, assim, falar da quantidade "temperatura cinética" $\left(T_{K}\right)$ como uma função da posição. Esta única hipótese exclui alguns problemas interessantes, como a presença de choques. As duas quantidades físicas mais importantes consideradas são densidade e temperatura. Para a temperatura variável, as equações são resolvidas para equilíbrio térmico, e a densidade em si torna-se uma variável se algum tipo de equação de estado for utilizada. Os casos mais usuais a serem resolvidos são aqueles de equilíbrio térmico com densidade ou pressão constantes.

Outra restrição é o grupo de propriedades ou constantes que têm valores bem definidos, mas incertezas a cerca desses valores podem existir, em alguns casos por serem determinadas experimentalmente, além de poderem variar conforme a fonte na literatura.

\subsubsection{Reações Químicas}

Os resultados do modelo são altamente dependentes da química e da micro-física (as constantes ou propriedades) existentes nas PDRs. Neste caso, o modelo só tem uso se a descrição da micro-física em que ele se sustenta for acurada. Assim, os processos físicos e químicos medidos em laboratório e observações precisas são requisitos fundamentais na construção dos modelos.

No caso das reações químicas, são diversos os parâmetros necessários para que estas tenham precisão suficiente para estimar a realidade nas PDRs. Estes parâmetros são estabelecidos através, principalmente, de modelos quânticos que calculam as taxas das reações baseados na densidade dos reagentes e produtos formados na região.

Para inserir uma nova molécula no arquivo de entrada de química do código é necessário 
inicialmente adicionar alguns parâmetros básicos dessa nova espécie na lista de moléculas propriamente dita, como a abundância inicial (dada normamente como nula) e sua entalpia de formação, usada para o balanço térmico.

Após o término da lista de espécies, o código lê as reações listadas, sendo possível acrescentar reações com até dois reagentes e quatro produtos. Todas as espécies da reação devem estar declaradas na listagem inicial. Para as reações ocorrerem é preciso, ainda, declarar o tipo de reação e as três variáveis reais, obtidas a partir de cálculos quânticos fundamentais ou experimentos de laboratório, descrevendo a magnitude e a dependência com a temperatura da constante de reação, dadas como $\alpha, \beta$ e $\gamma$ (ver as tabelas B.1 e B.2).

As constantes de reação são calculadas de diferentes modos, dependendo do tipo de ocorrência. Os tipos de 1 a 10 correspondem a reações de fase gasosa; os tipos de 11 a 18 são reações que envolvem grãos. Os tipos acima de 100 são referentes a casos especiais. Os principais tipos encontram-se mais detalhados abaixo.

As reações de tipo 1 referem-se a destruição da espécie por raios cósmicos. Sua taxa de reação é dada pela equação 2.38, Neste tipo de reações alpha e beta não são usados.

$$
\kappa_{1}=\gamma \zeta \mathrm{s}^{-1}
$$

Reações do tipo 2 são de destruição por fótons secundários e sua taxa de reação é dada pela equação 2.39 .

$$
\kappa_{2}=\gamma \zeta\left(\frac{T_{\mathrm{K}}}{300}\right)^{\alpha} \frac{n\left(\mathrm{H}_{2}\right)}{n(\mathrm{H})+\mathrm{n}\left(\mathrm{H}_{2}\right)} \mathrm{s}^{-1}
$$

Na equação 2.39, além da fração de hidrogênio em $H_{2}$, aparece $\zeta$, a fração de $H$ ionizado por raios cósmicos. Neste cálculo, $\beta$ não é usado.

As de tipo 3 referem-se à associação radiativa e a constante de reação é calculada pela equação 2.40;

$$
\kappa_{3}=\gamma\left(\frac{T}{300}\right)^{\alpha} \exp (-\beta / T) \mathrm{cm}^{3} \mathrm{~s}^{-1} .
$$

As reações do tipo 4 são reações "ordinárias" de fase gasosa. Suas constantes de reação também são dadas pela equação 2.40. As reações de tipo 6 são reações endotérmicas de fase gasosa com $H_{2}$, com suas constantes de reação dadas pela equação 2.41, onde $E_{i}$ é a 
energia interna de cada nível do $H_{2}$ usada para diminuir a barreira exponencial, somando todos os níveis.

$$
\kappa_{6}=\gamma\left(\frac{T}{300.0}\right)^{\alpha} \exp \left(\frac{-\beta-E_{i}}{T}\right) \mathrm{cm}^{3} \mathrm{~s}^{-1} .
$$

As reações do tipo 5 são fotoreações, cujas constantes de reação são dadas por 2.42, que só é usada quando a taxa de fotodestruição não for computada explicitamente no código por integração direta da seção de choque do campo de radiação.

$$
\kappa_{5}=0.5 \gamma \chi \exp \left(-\beta A_{V}\right) \mathrm{s}^{-1}
$$

onde $\chi$ é o fator de escala do campo de radiação incidente em relação ao campo de Draine.

A primeira exceção, representada pelo tipo 101, é a reação 2.43, que usa a energia interna do $\mathrm{H}_{2}$ antes das reações do tipo 6 serem introduzidas.

$$
N^{+}+H_{2}
$$

A segunda exceção é dada pela reação 2.44 que é do tipo 102:

$$
H_{3}^{+}+H D
$$

Outras exceções são as reações 2.45 e 2.46, dos tipos 103 e 104, respectivamente.

$$
\begin{aligned}
& \mathrm{O}^{+}+H \\
& H^{+}+O
\end{aligned}
$$

As reações do tipo 11 são reações que ocorrem na superfície dos grãos e sua constante de reação é dada pela equação 2.47, onde X: e Y: são as espécies adsorvidas na superfícies do grão e $x k h y d r$ depende das características dos grãos.

$$
\begin{aligned}
& \mathrm{X}:+\mathrm{Y}: \rightarrow \text { produtos } \\
& \kappa_{11}=\frac{\gamma}{x k h y d r} \mathrm{~cm}^{3} \mathrm{~s}^{-1} .
\end{aligned}
$$


As reações do tipo 12 são fotorreações nas superfícies dos grãos e sua constante de reação é calculada pela equação [2.42. Já as de tipo 13 são de adsorção nos grãos, com taxas de reação dadas pela equação 2.48, onde coef é calculado internamente:

$$
\kappa_{13}=\gamma \operatorname{coef} \mathrm{s}^{-1}
$$

Os demais tipos de reação têm cálculos das constantes de reação muito mais complexos e possuem rotinas para realizá-los. Essas reações referem-se às de neutralização por colisão de íons nos grãos (tipo 14), as de tipo 15 à desorção explosiva, as de tipo 16 à desorção induzida por raios cósmicos, as de tipo 17 são de fotodissociação, enquanto as de tipo 18 são de evaporação térmica.

As reações de tipo 113, 123, 118 e 128 são parcialmente artificiais, construidas especificamente para considerar a adsorção e desorção do $H_{2}$ nos grãos. De fato é possível ter uma diminuição na temperatura do grão de acordo com o tamanho deste. O processo pode afetar fortemente o gás na razão de $H_{2}$.

O grau de complexidade da química dos grãos cresce proporcionalmente ao conhecimento que se acumula sobre eles, no entanto, esse conhecimento é muito pequeno quando comparado àquele já acumulado para a química da fase gasosa. Tais implementações vem sendo realizadas nos códigos, porém este tipo de química não é frequentemente utilizada.

As tabelas apresentadas no apêndice, ou seja, as B.1 e B.2 foram usadas como arquivo de química inicial no programa Meudon para regiões PDR. Estas tabelas foram construídas tendo por base o banco de dados do próprio código, usando duas versões diferentes (2006 e 2008) combinadas, já que o arquivo mais atual não apresentava moléculas e suas respectivas reações de formação e de destruição que estavam inclusas no anterior. Estas moléculas listadas no próprio código equivalem às espécies numeradas até 120 na tabela B.1.

Todas as demais moléculas foram inseridas uma a uma, assim como qualquer reação de formação e destruição na qual elas estivessem presentes. As espécies numeradas de 150 a 201 referem-se às moléculas neutras inseridas, enquanto as com número superior a 300 são íons inclusos.

A inclusão de moléculas no arquivo de química é realizada como descrito a seguir. Primeiro, verifica-se se tal espécie possui reações de formação e destruição, bem como seus parâmetros para o cálculo da taxa de reação, conhecidas para ambientes interestelares. 
Isto se dá a partir de consulta a bancos de dados de astroquímica, como o UDFA (2012), o Astrochemistry (2012), o Herbst (2012), o ChemSpider (2012) e posterior consulta ao banco de dados NIST (2012), Chemeo (2012) ou Goos et al. (2012) para aquisição da entalpia de formação de tal molécula e inserção da molécula na listagem inicial e sua rede de reações no arquivo usado como input do programa.

Para obter os dados de algumas espécies que não são cadastradas em tais bancos de dados ou nunca tiveram publicações com tais dados, estes foram então estimados a partir de uma reação encontrada em laboratórios terrestres, preferencialmente reações que não envolvessem água ou algum diluente líquido como catalisador. Para isso foi usado o banco de dados Reaxys (2012). Inferindo que estas reações apliquem-se ao meio interestelar, podese estimar as taxas de reação destas moléculas, assim como algumas reações de destruição. 
Capítulo 3

\section{Simulações e Modelagens}

As simulações usando o código PDR Meudon foram divididas, basicamente, em três etapas, de maneira a otimizar o estudo das condições físicas e químicas mais relevantes na formação e destruição de moléculas que, de alguma forma, estejam relacionadas à origem de vida tal como conhecemos. O objeto teste utilizado foi a Nebulosa Cabeça de Cavalo $(H H N)$, juntamente com um campo de radiação adicional proveniente de uma estrela, a qual simulava a estrela mais luminosa (tipo O9,5V) de $\sigma$ Orionis, conforme parametrizado por Gerin et al. (2009), e abundâncias iniciais de várias espécies dadas se-

gundo Goicoechea et al. (2009). Nas primeiras simulações, mantivemos a densidade de núcleos de hidrogênio constante, em uma tentativa de representar a situação real, permitindo o uso da temperatura cinética $T_{K}$ do modelo, compatível com dados obtidos na literatura. Nessa etapa, realizamos uma série de testes do código. Numa segunda etapa, as simulações foram repetidas e consideramos o impacto nas abundâncias derivadas das moléculas de várias suposições em relação ao estado do gás (modelos isocórico, isotérmico e isobárico), decidindo em favor de um modelo isobárico. Na terceira etapa, obtivemos as abundâncias de várias moléculas, incluindo algumas de potencial importância pré-biótica: CN e seus íons, HCN, HNC, nitrilas e seus íons, hidretos de nitrogênio, benzeno. Investigamos o papel dos ânions e dos PAHs. Finalmente, exploramos canais de produção para dois heterocíclicos nitrogenados com relevância em astrobiologia, o pirrol e a piridina.

\subsection{Condições Iniciais da Nebulosa Cabeça de Cavalo}

A tabela 3.1 apresenta um sumário das condições iniciais.

As abundâncias dos metais relativas ao hidrogênio, que constam na tabela 3.1. foram 
obtidas como um valor médio das simulações e estimativas de Goicoechea et al. (2009). Da mesma forma, a densidade padrão $n_{H}$ foi escolhida por ser um valor intermediário entre as estimativas dos limites máximo e mínimo dadas por Gerin et al. (2009) para o núcleo frio da nebulosa.

Tabela 3.1 - Parâmetros iniciais do modelo padrão para a Nebulosa Cabeça de Cavalo. As abundâncias que não constam na tabela foram mantidas como no padrão do código Meudon, normalmente $\sim 10^{-20}$.

\begin{tabular}{lccc}
\hline \multicolumn{1}{c}{ Parâmetro } & Valor & Unidade & Comentário \\
\hline Campo de radiação FUV - $\chi$ & 60 & "Draine" & Draine (1978) \\
Temperatura cinética $T_{\text {inicial }}$ & 15 & $\mathrm{~K}$ & Goicoechea et al. (2009) \\
Pressão térmica & $4 \times 10^{6}$ & $\mathrm{Kcm}^{-3}$ & \\
Tipo espectral da estrela iluminadora & O9.5 & & Kaler (2012) \\
Distância $d$ da estrela à HHN & 3.5 & $\mathrm{pc}$ & Kaler (2012) \\
Taxa de ionização por raios cósmicos & $5 \times 10^{-17}$ & $\mathrm{~s}^{-1}$ & \\
Densidade de núcleos de hidrogênio - $n_{H}$ & $10^{4}$ & $\mathrm{~cm}^{-3}$ & \\
{$[\mathrm{He}]$} & $1.00 \times 10^{-1}$ & & \\
{$[\mathrm{O}]$} & $3.02 \times 10^{-4}$ & & \\
{$[\mathrm{C}]$} & $1.38 \times 10^{-4}$ & & \\
{$[\mathrm{~N}]$} & $7.95 \times 10^{-5}$ & & em relação ao hidrogênio: \\
{$[\mathrm{D}]$} & $1.60 \times 10^{-5}$ & & \\
{$[\mathrm{~S}]$} & $3.50 \times 10^{-6}$ & & \\
{$[\mathrm{Fe}]$} & $10^{-8}$ & & \\
{$[\mathrm{Si}]$} & $10^{-8}$ & & \\
& & & \\
\hline
\end{tabular}

Na tabela 3.1, as abundâncias dos elementos referem-se à fase gasosa. As abundâncias de O, C e S têm depleções moderadas devido aos grãos, N não tem depleção e Fe e Si têm fortes depleções. Para facilitar possíveis comparações com os resultados de Goicoechea et al. (2009), usamos as abundâncias solares de Anders e Grevesse (1989), as mesmas empregadas por Goicoechea et al. (2009).

\subsection{Modelo para uma Densidade de Gás Constante}

O primeiro passo foi considerar o modelo com uma densidade de gás constante, com $n_{H} \simeq 10^{4} \mathrm{~cm}^{-3}$, onde $n_{H}$ é a densidade total de núcleos de hidrogênio $n_{H}=n(H)+$ 
$2 n\left(H_{2}\right)+n\left(H^{+}\right)$, adotando os parâmetros de Gerin et al. (2009) para a HHN.

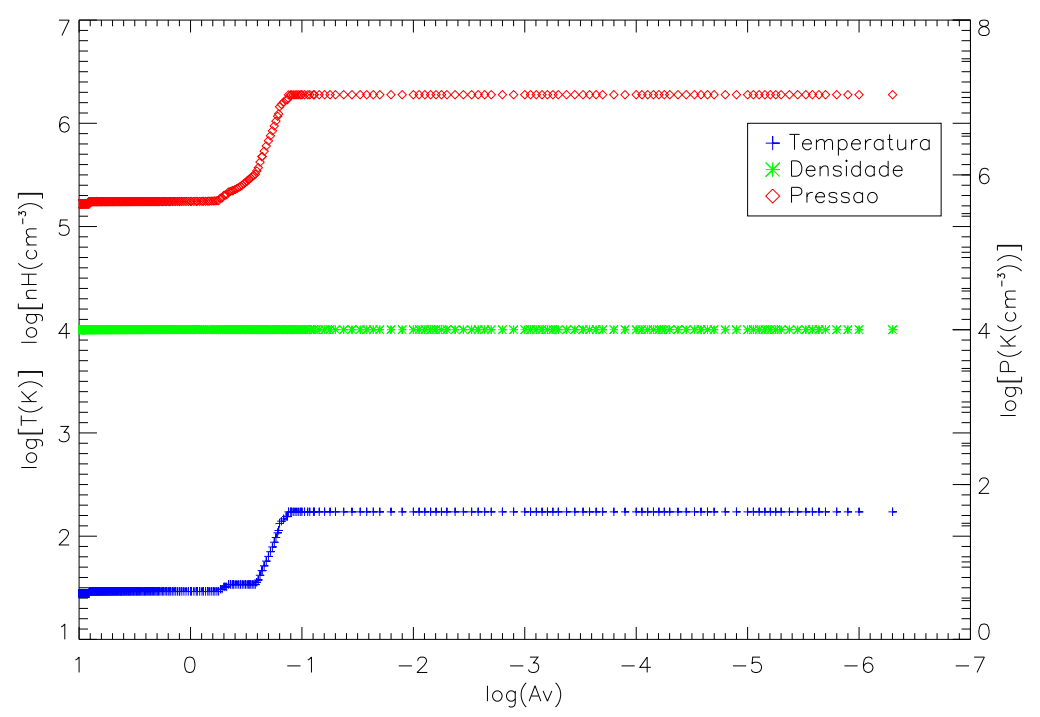

Figura 3.1: Variação dos parâmetros densidade do gás, temperatura e pressão para o modelo com densidade do gás constante.

A figura 3.1 mostra predições para a temperatura, densidade do gás e pressão como função da profundidade da PDR para o modelo com densidade constante. A temperatura é mais baixa na região interna até $A_{V} \sim-1$, indicando a dependência do aquecimento fotoelétrico com a intensidade do campo de radiação FUV.

\subsubsection{Convergência nas Iterações}

Para garantir que fosse escolhido o número adequado de iterações, ou seja, aquele que fosse suficiente para a convergência dos resultados, foram feitos testes de maneira a determinar a influência do número de iterações nos resultados. O programa foi rodado com 20, 30 e 50 iterações para as moléculas $\mathrm{C}, \mathrm{CH}_{4}, \mathrm{CN}$ e $\mathrm{HCN}$, escolhidas por serem espécies simples típicas das nuvens. O resultado é mostrado na figura 3.2. Mesmo quando se usam entre 5 e 10 iterações podemos ver que a convergência é alcançada rapidamente (figura 3.3).

Pelas figuras 3.2 e 3.3 observamos que a convergência dos dados se dá já para a menor quantidade de iterações e que a diferença dos valores obtidos para um número maior de iterações não é significativa em nenhum dos casos observados. Esses resultados permitem 


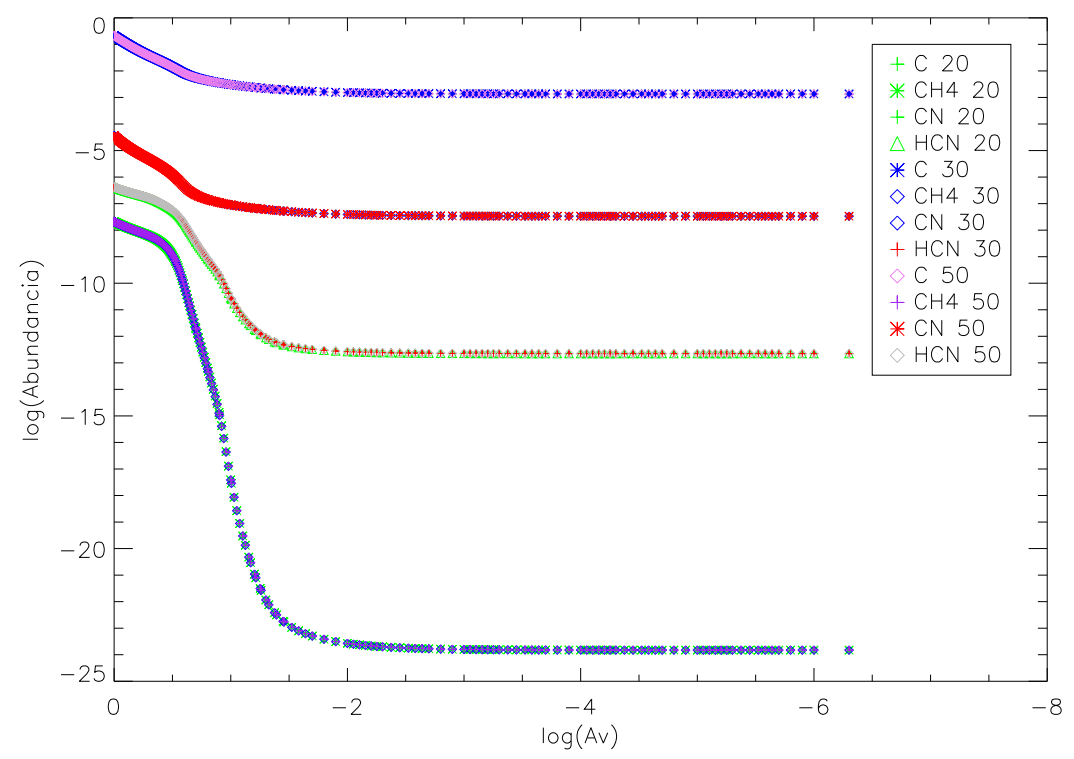

Figura 3.2: Teste de convergência para a Nebulosa Cabeça de Cavalo usando as espécies C, $\mathrm{CH}_{4}, \mathrm{CN}$ e HCN para 20, 30 e 50 iterações do código Meudon PDR

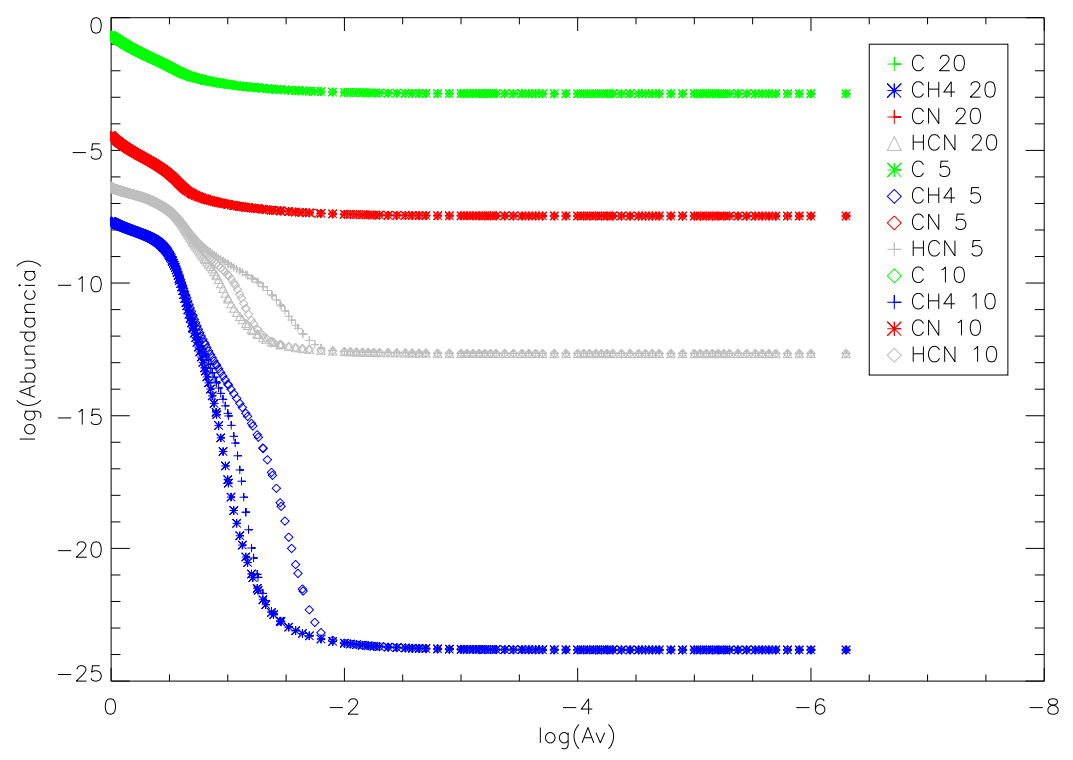

Figura 3.3: Teste de convergência para a Nebulosa Cabeça de Cavalo usando as espécies C, $\mathrm{CH}_{4}, \mathrm{CN}$ e HCN para 5, 10 e 20 iterações do código Meudon PDR

considerar que não há necessidade de simular a região com um número muito grande de iterações. Porém, Le Petit et al. (2006) adverte para flutuações nos dados que podem ocorrer nas primeiras dez iterações. Portanto, optou-se por usar vinte iterações em nossas 
simulações, diminuindo, assim, as incertezas nos resultados. A profundidade da nuvem também determinará o número de iterações adequado. Para nuvens difusas típicas $\left(A_{V}=\right.$ $0.5-1$ e $n_{H}=100 \mathrm{~cm}^{-3}$ ) são suficientes dez iterações para alcançarmos a convergência, enquanto que para nuvens escuras, modeladas como nuvens semi-infinitas, bastam 5-8 iterações. Já nuvens muito difusas $\left(A_{V}<0.5\right)$ podem exigir 20 iterações.

\subsubsection{O Papel dos Raios Cósmicos}

Os raios cósmicos afetam o estado de ionização e a física das nuvens moleculares, sendo a principal fonte de aquecimento e ionização do gás nas regiões mais espessas da nuvem, blindadas contra o campo de radiação interestelar. Um outro efeito dos raios cósmicos é a produção de fótons UV secundários no interior das nuvens por cascatas eletrônicas do $H_{2}$ em seguida à excitação do $H_{2}$ por colisões com raios cósmicos (Prasad e Tarafdar, 1983). Portanto, os raios cósmicos mantêm um certo grau de ionização no gás blindado contra a radiação UV e podem desempenhar um papel fundamental na química íon-neutro ao determinar as abundâncias de íons chave (Herbst e Klemperer, 1973).
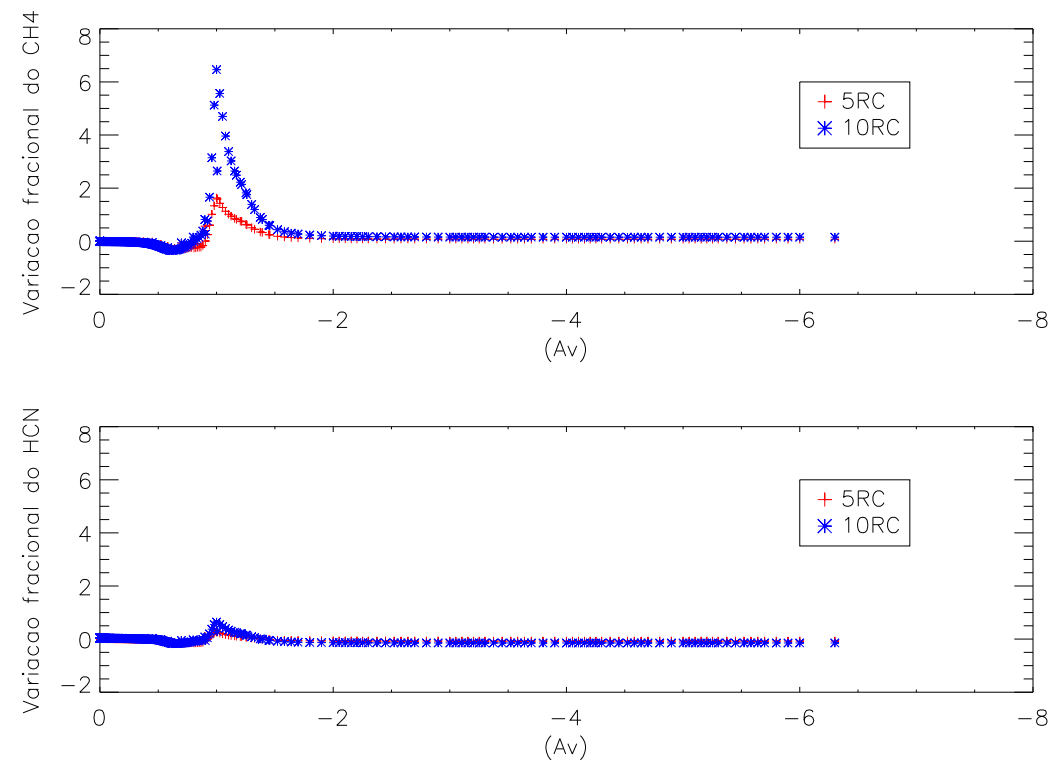

Figura 3.4: Variação das abundâncias de $\mathrm{CH}_{4}$ e HCN na Nebulosa Cabeça de Cavalo, simulada para a taxa de ionização por raios cósmicos aumentada em 5 e 10 vezes.

Como podemos ver nas figuras 3.4 e 3.5, no caso de maior taxa de ionização por raios cósmicos, há alterações das densidades de algumas espécies mais abundantes para uma 

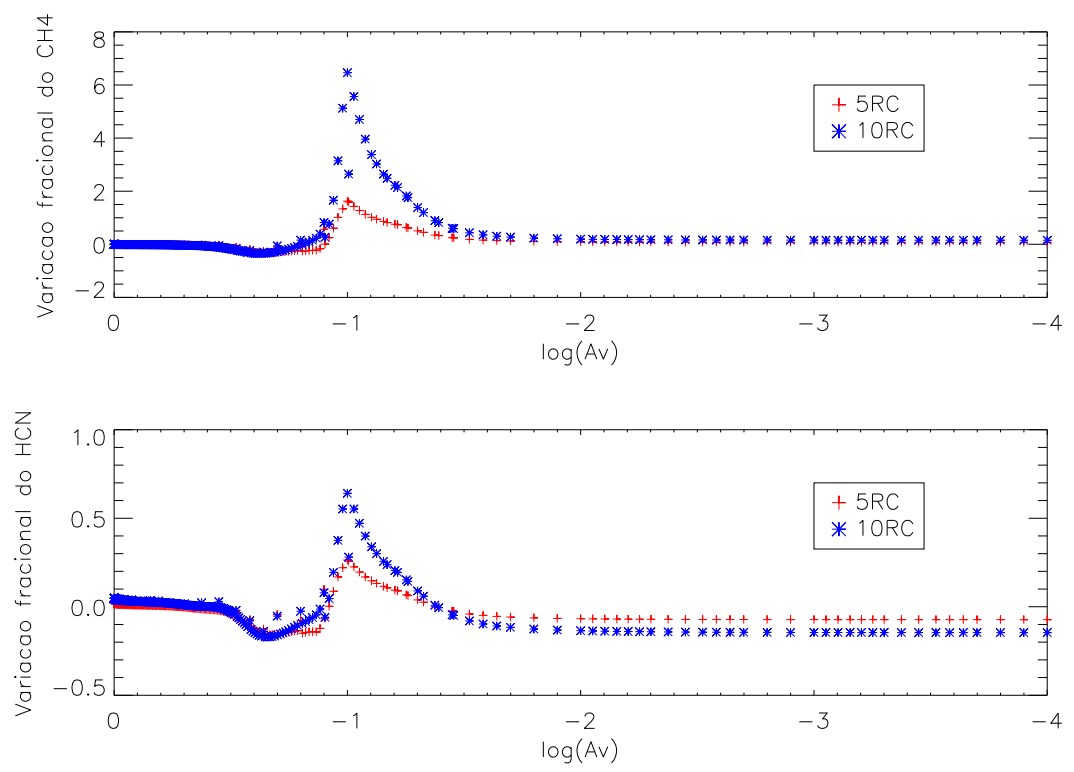

Figura 3.5: Variação das abundâncias de $\mathrm{CH}_{4}$ e HCN na Nebulosa Cabeça de Cavalo, simulada para a taxa de ionização por raios cósmicos padrão e esta aumentada em 5 e 10 vezes, ampliando a região onde há diferença causada por esta taxa.

taxa de ionização diferente daquela padrão usada no modelo para a HHN. Concluímos que este parâmetro pode ter relevância na modelagem física da região, como seria de se esperar do fato que ele é responsável por diversas reações de destruição das moléculas, como pode ser visto na tabela B.2, no apêndice. Ademais, a ionização por raios cósmicos pode ter um impacto maior na produção de espécies menos abundantes, formadas a partir dos produtos das reações de raios cósmicos com as espécies mais abundantes. Deve-se notar que a grandes profundidades ópticas, onde a radiação UV não penetra, a única fonte de ionização e dissociação de certas moléculas são os raios cósmicos.

\subsubsection{Efeitos das Incertezas da Entalpia de Formação}

A entalpia de formação $\left(\Delta_{f} H^{\circ}\right)$ de um composto químico refere-se à variação da energia da reação de formação deste composto a partir das espécies elementares que o compõem. Trata-se da energia liberada ou absorvida pela reação de formação de compostos.

Este foi o parâmetro físico de maior incerteza do modelo, pois ainda não existem resultados definitivos na literatura, não havendo concesso entre os autores. Em alguns casos foi usada a entalpia medida a $298 \mathrm{~K}$, enquanto a maioria dos compostos foram medidos a 
zero Kelvin. As principais referências para se obter os valores de $\Delta_{f} H^{\circ}$ usados nas simulações foram Goos et al. (2012), NIST (2012), Le Teuff et al. (2000), Lide et al. (2008) e o próprio banco de dados do código PDR Meudon.

Os valores das entalpias de formação de cada composto usado na modelagem da HHN, encontram-se no apêndice, na tabela B.1, onde $\left(^{*}\right)$ indica $\Delta_{f} H^{\circ}$ medida a $298 \mathrm{~K}$ e $(* *)$ representa os isomeros mais estáveis.

Para estudar as variações causadas pela entalpia de formação, a figura 3.6 apresenta os efeitos da variação deste parâmetro entre limites inferiores e superiores para alguns compostos. Para isto, seguiu-se os seguintes critérios analisados a partir dos valores que já constavam no banco de dados do próprio código PDR Meudon:

1. $\Delta_{f} H^{\circ}$ dos cátions é sempre maior que $\Delta_{f} H^{\circ}$ dos compostos neutros.

2. $\Delta_{f} H^{\circ}$ dos compostos neutros é sempre maior que $\Delta_{f} H^{\circ}$ dos ânions.

3. Os cadeias maiores possuem maiores $\Delta_{f} H^{\circ}$ do que os de cadeia menor da mesma "família", por exemplo, $\Delta_{f} H^{\circ}\left(C_{3} N\right)>\Delta_{f} H^{\circ}\left(C_{2} N\right)$.

Seguindo estes critérios, foram escolhidas algumas moléculas para que se realizassem as comparações tanto por possuírem os limites de maiores e menores entalpia de formação, caso do $\mathrm{C}_{5} \mathrm{~N}^{+}$e do $\mathrm{H}_{2} \mathrm{O}$ respectivamente, como também o $\mathrm{CN}$ com seu cátion e ânion. Os valores usados para este estudo podem ser encontrados na tabela 3.2 .

Tabela 3.2 - Valores máximos e mínimos usados no teste de variação da entalpia de formação $\left(\Delta_{f} H^{\circ}\right) \mathrm{em} \mathrm{kJ} / \mathrm{mol}$.

\begin{tabular}{lccc}
\hline \hline Espécie & $\Delta_{f} H^{\circ}$ & $\Delta_{f} H^{\circ}$ limite - inferior & $\Delta_{f} H^{\circ}$ limite - superior \\
\hline $\mathrm{CN}$ & 103.200 & 63.975 & 429.300 \\
$\mathrm{CN}^{+}$ & 429.300 & 103.200 & 2000.000 \\
$\mathrm{CN}^{-}$ & 63.975 & -93.965 & 103.200 \\
$\mathrm{C}_{5} N^{+}$ & 1800.000 & -93.965 & 2000.000 \\
$\mathrm{H}_{2} \mathrm{O}$ & -57.100 & -93.965 & 2000.000 \\
& & & \\
\hline
\end{tabular}

A partir da figura 3.6, percebe-se que a variação deste parâmetro tem pouca relevância na abundância dos compostos ao longo da HHN. Este é um parâmetro a ser considerado em análise mais fina, já que este resultado só é representativo para as reações em fase 


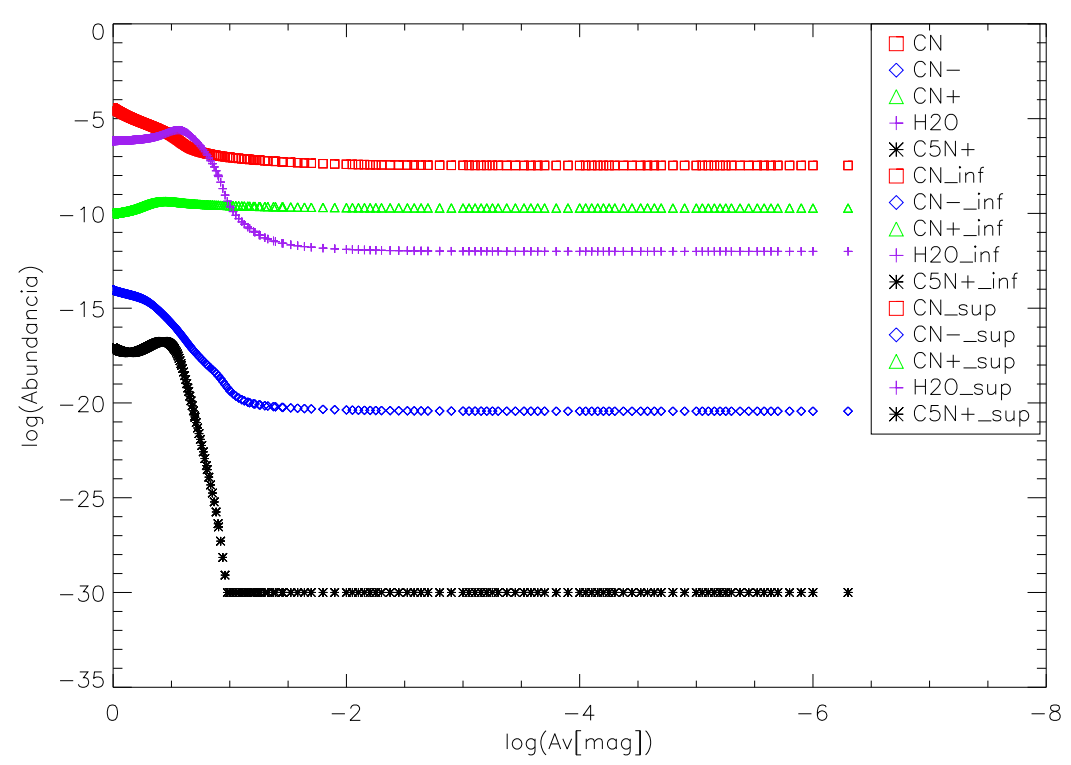

Figura 3.6: Teste da influência da variação da entalpia de formação, ao longo da Nebulosa Cabeça de Cavalo, usando-se valores máximos e mínimos possíveis.

gasosa, desconsiderando as reações nos grãos, como acontece neste formato do modelo.

A influência da entalpia de formação na abundância das espécies tem que ser melhor estudada em um modelo que considere as reações nos grãos dentro da nuvem.

\subsubsection{Escolha da Base de Dados de Química}

A fim de verificar se nossas simulações geravam resultados compatíveis com os obtidos por trabalhos anteriores Gerin et al. (2009) e Goicoechea et al. (2009), obtivemos as abundâncias de algumas moléculas simples, estudadas nos trabalhos citados, como CO, $\mathrm{CO}^{+}, \mathrm{HCO}, \mathrm{HCO}^{+}, \mathrm{C}_{2} \mathrm{H}$ e $\mathrm{C}_{3} \mathrm{H}$ em função da profundidade da nuvem. O comportamento das abundâncias pode ser analisado a partir da figura 3.7.

Pela figura (3.7), o comportamento para as curvas de abundância das espécies CHO reproduz bem os resultados de Gerin et al. (2009) e Goicoechea et al. (2009), para $\log \left(A_{V}\right)<$ 0.8. Ao compararmos nossos valores, obtidos com densidade constante, aos dos artigos citados, levamos em conta que Gerin et al. (2009) e Goicoechea et al. (2009) consideram um perfil de densidade $n_{H}(r) \propto r^{-p}$, onde r é a distância do centro à borda da nuvem, sendo mais plano na região central $(p=0.5)$ e mais acentuado na região mais externa $(p=0.3)$. O raio de transição $(r \approx 0.04) p c$ corresponde a $n_{H} \simeq 2 \times 10^{5} \mathrm{~cm}^{-3}$. Desse modo, é 


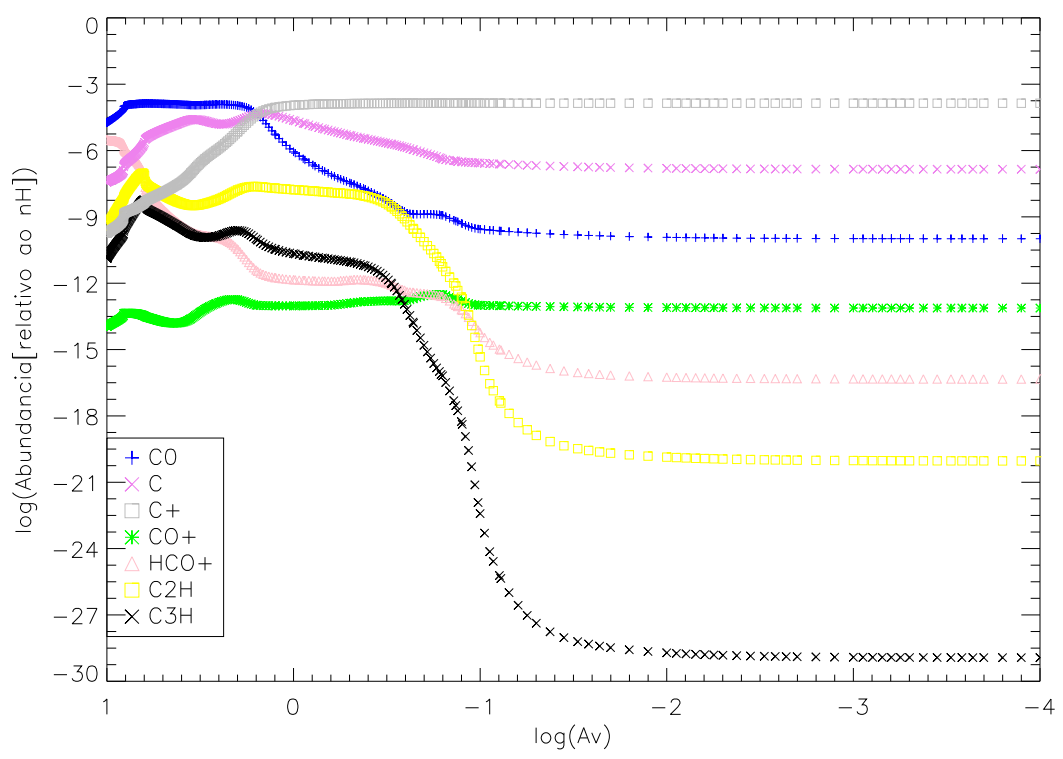

Figura 3.7: Abundâncias de algumas espécies CHO, ao longo da Nebulosa Cabeça de Cavalo, para o modelo com densidade do gás constante, usando o banco de dados de química atualizado neste trabalho.

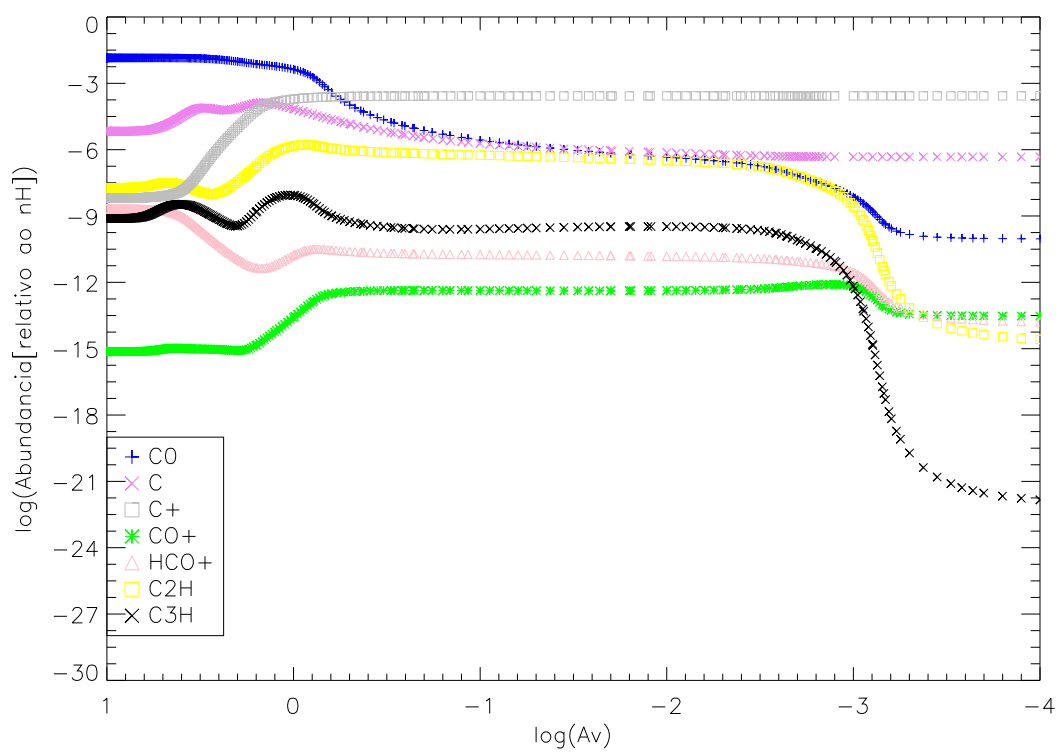

Figura 3.8: Abundâncias de algumas espécies CHO ao longo da Nebulosa Cabeça de Cavalo, usando apenas o arquivo de química, de 2006, do próprio banco de dados do código PDR Meudon. 


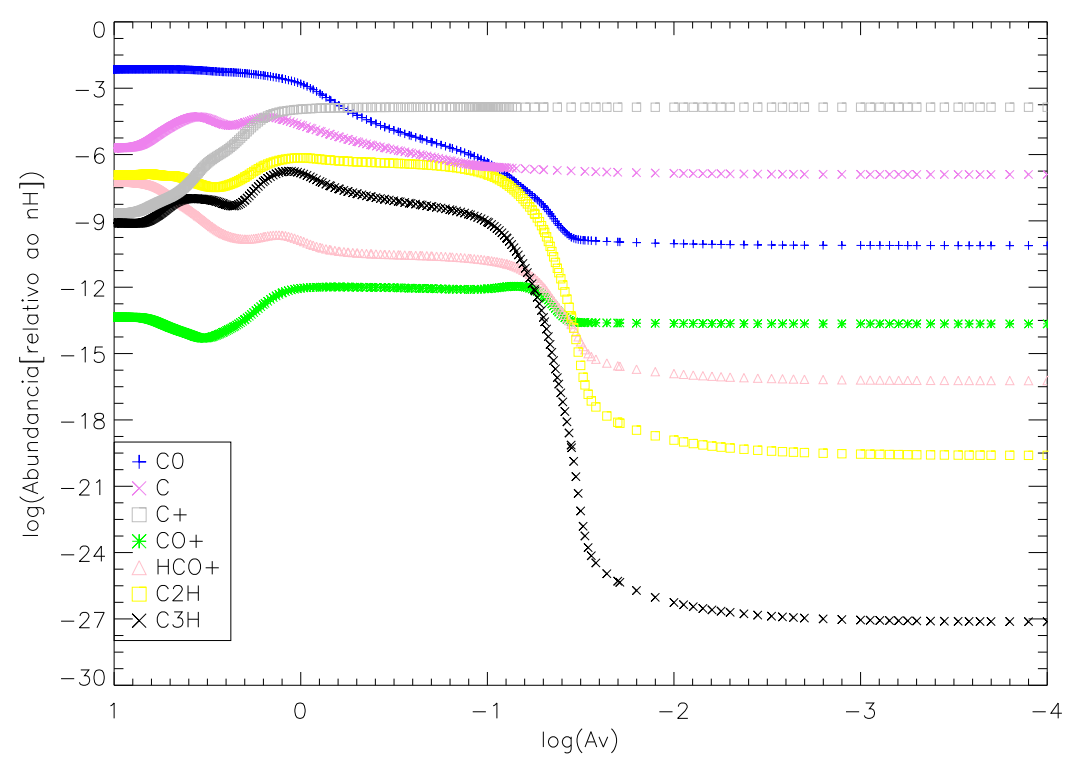

Figura 3.9: Abundância de algumas espécies CHO ao longo da Nebulosa Cabeça de Cavalo, usando o arquivo de química do próprio banco de dados do código PDR Meudon, atualizado em 2008.

esperada a discrepância encontrada na região central onde ocorre a mudança do regime de densidade.

Deve-se observar, ademais, o efeito da base de dados da química adotada. Os resultados da figura 3.7 incluem nossas atualizações da química. Já em uma simulação usando o arquivo de química datado de 2006, conforme mostra a figura 3.8, vemos que as moléculas se mantém com maior abundância até $A_{V} \simeq 10^{-3} \mathrm{mag}$, o que não ocorre quando se usa um arquivo de química com uma rede de reações mais ampla.

A figura 3.9 mostra a abundância das mesmas moléculas para um arquivo de química mais recente, obtido em 2008. Percebe-se que a queda da abundância das moléculas acontece muito mais próximo ao centro da nuvem, em $\log \left(A_{V}\right)=0.8-0.9$ mag. Este resultado é obtido mesmo sem usar o arquivo de química mais complexo e com reações de formação e destruição de moléculas mais complexas, como mostrado na figura 3.7.

Na próxima seção, será investigado o que os modelos com um perfil de gradiente de densidade de gás predizem e se os resultados seriam mais compatíveis com aqueles encontrados na literatura. 


\subsubsection{Moléculas Nitrogenadas Simples: CN, HCN e HNC}

Após o teste de algumas propriedades físicas características da região da HHN, pode-se, enfim, começar a análise do comportamento de algumas moléculas chaves para a química prebiótica. Para isso, o estudo inicial envolveu as moléculas $\mathrm{CN}, \mathrm{CN}^{+}, \mathrm{CN}^{-}, \mathrm{HCN}$ e HNC, dada a relevância destas para a formação de moléculas orgânicas nitrogenadas de importância biológica. As abundâncias obtidas, em relação ao CN, estão representadas no gráfico 3.10 .

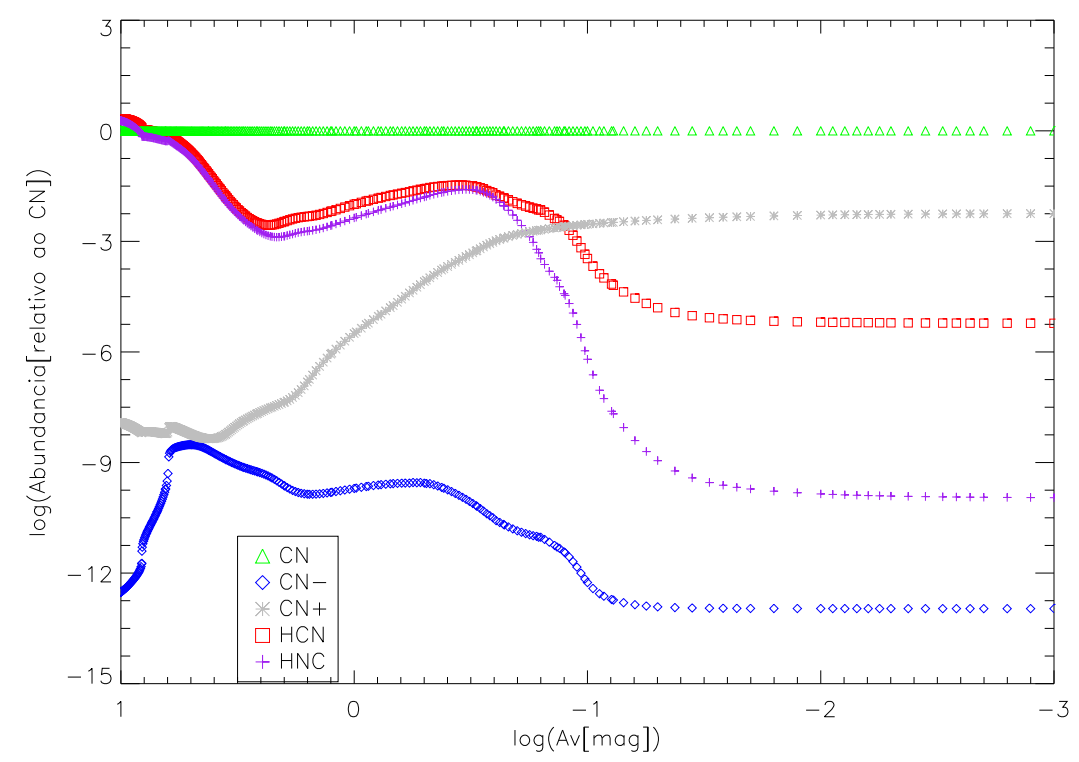

Figura 3.10: Abundâncias do $\mathrm{CN}, C N^{+}, C N^{-}$, $\mathrm{HCN}$ e $\mathrm{HNC}$ em relação ao $\mathrm{CN}$ ao longo da Nebulosa Cabeça de Cavalo, para o modelo com densidade do gás constante.

Estes primeiros resultados são importantes, pois representam o primeiro passo em direção ao cálculo das abundâncias dos heterocíclicos nitrogenados. A partir deles podese prever e comparar as abundâncias de moléculas de relevância biológica, já que as abundâncias das moléculas orgânicas fundamentais estão diretamente relacionadas com os processos de formação e destruição destas três moléculas: CN, HCN e HNC.

É notável a diferença da abundância entre as moléculas HCN e HNC, mas este fato é compatível com o esperado já que estas moléculas possuem diferentes processos de formação e o HCN é mais facilmente formado, pois a razão entre o número de vezes em que o HCN aparece em reações de formação sobre o número de vezes em que é destruído é $\frac{f}{d}=0.88$, enquanto a do HNC é de apenas $\frac{f}{d}=0.32$, como pode ser observado no apêndice B.2. 
Há de se considerar ainda que a baixa abundância do $C N^{-}$pode ser devida às poucas reações de formação e destruição conhecidas e estudadas para este ânion no meio interestelar. Já o $C N^{+}$tem uma rede de reações mais completa, o que implica em uma abundância mais condizente com a realidade.

\subsection{Modelo Isobárico}

No modelo isobárico, o programa calcula o balanço térmico a partir da temperatura inicial. A pressão é definida como $P=n_{H} \times T \mathrm{~cm}^{-3} \mathrm{~K}$.

A figura 3.11 mostra predições para a temperatura, densidade do gás e pressão para o modelo com pressão constante como função da profundidade da PDR. A queda na temperatura no centro da nuvem provoca um aumento na densidade, como pode ser visto na figura 3.11. Além disso, o perfil do gradiente de densidade é proporcional a $r^{-3}$, até $n_{H} \simeq 10^{5}$.

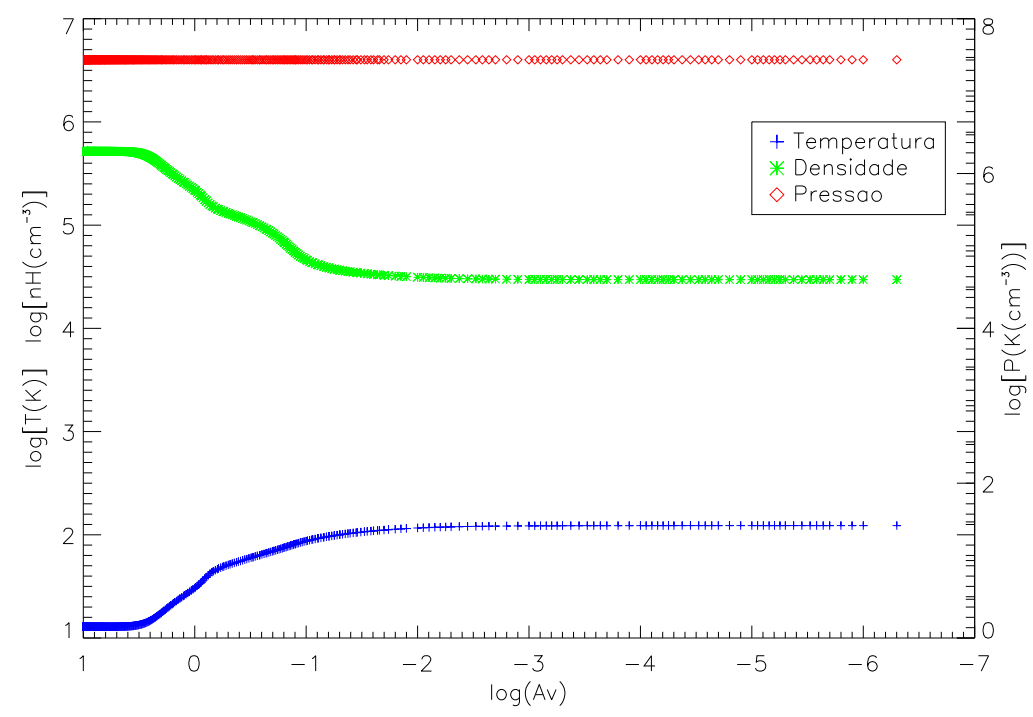

Figura 3.11: Variação dos parâmetros densidade do gás, temperatura e pressão para o modelo isobárico.

Segundo Le Petit (2009), os modelos isobáricos podem apresentar algumas instabilidades numéricas devido à variação tanto da densidade como também da temperatura. Realmente pode-se observar uma instabilidade nos parâmetros da figura 3.11 no intervalo 
entre $\log \left(A_{V}\right)=-0.5$ e $\log \left(A_{V}\right)=-1.5 \mathrm{mag}$.

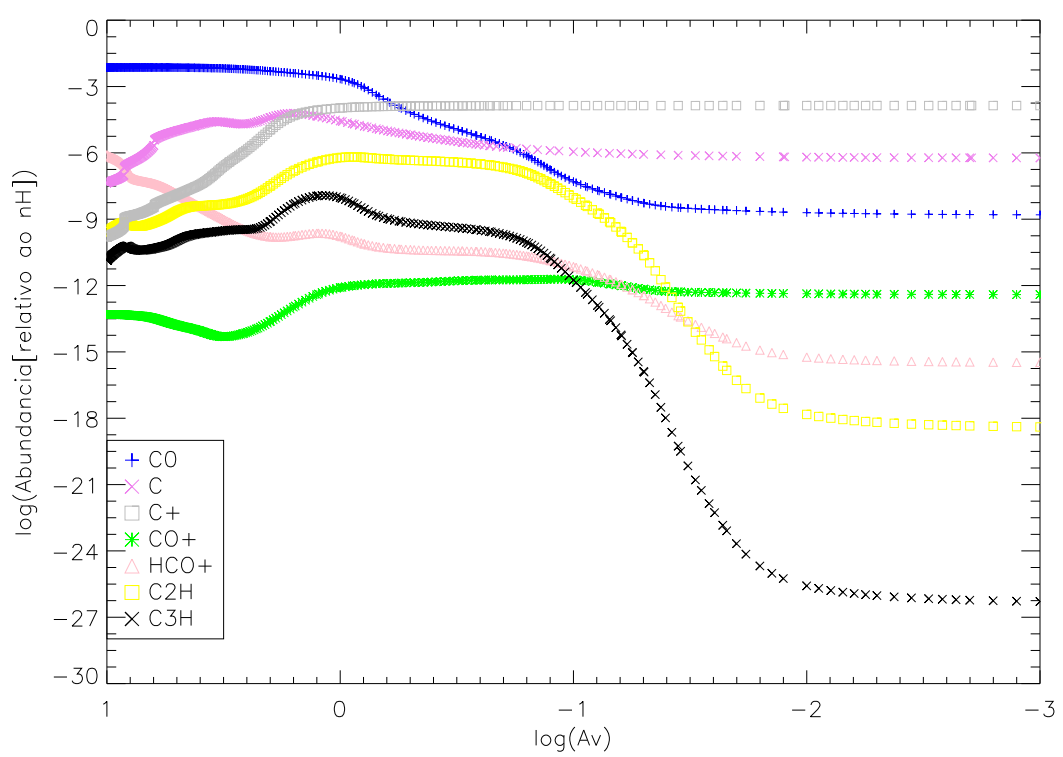

Figura 3.12: Abundâncias de algumas espécies CHO ao longo da Nebulosa Cabeça de Cavalo para o modelo isobárico.

Para este modelo, as abundâncias das espécies CHO mostradas na figura 3.12 quando se compara com os dados gerados por Gerin et al. (2009) e Goicoechea et al. (2009), é compatível com estes trabalhos, apresentando o mesmo comportamento da curva de densidade e valores semelhantes, principalmente próximo ao núcleo da nebulosa.

De fato, Habart et al. (2005) , em seu trabalho usando o código Meudon também para a HHN, comparando seus dados a emissões observadas por algumas espécies, também chega a conclusão que o modelo isobárico representa melhor os dados observados. Porém, como neste trabalho foram usadas apenas reações em fase gasosa, desconsiderando as que envolvem grãos, ambos modelos geram resultados semelhantes de abundâncias, como prevê Le Petit (2009).

O gráfico 3.13, referente ao modelo isobárico, possui o mesmo perfil de abundância para as espécies $\mathrm{CN}, C N^{+}, C N^{-}, \mathrm{HCN}$ e HNC que o gráfico 3.10 obtido para o modelo de densidade de gás constante. Os valores das abundâncias são bastante compatíveis entre si. Há, neste caso, um comportamento com oscilações no perfil da abundância nas reações mais internas da nebulosa, entre $A_{V}=0.5$ e $A_{V}=10$ magnitude, que se trata, praticamente da mesma região de instabilidade apresentada para os próprios parâmetros físicos do modelo, 


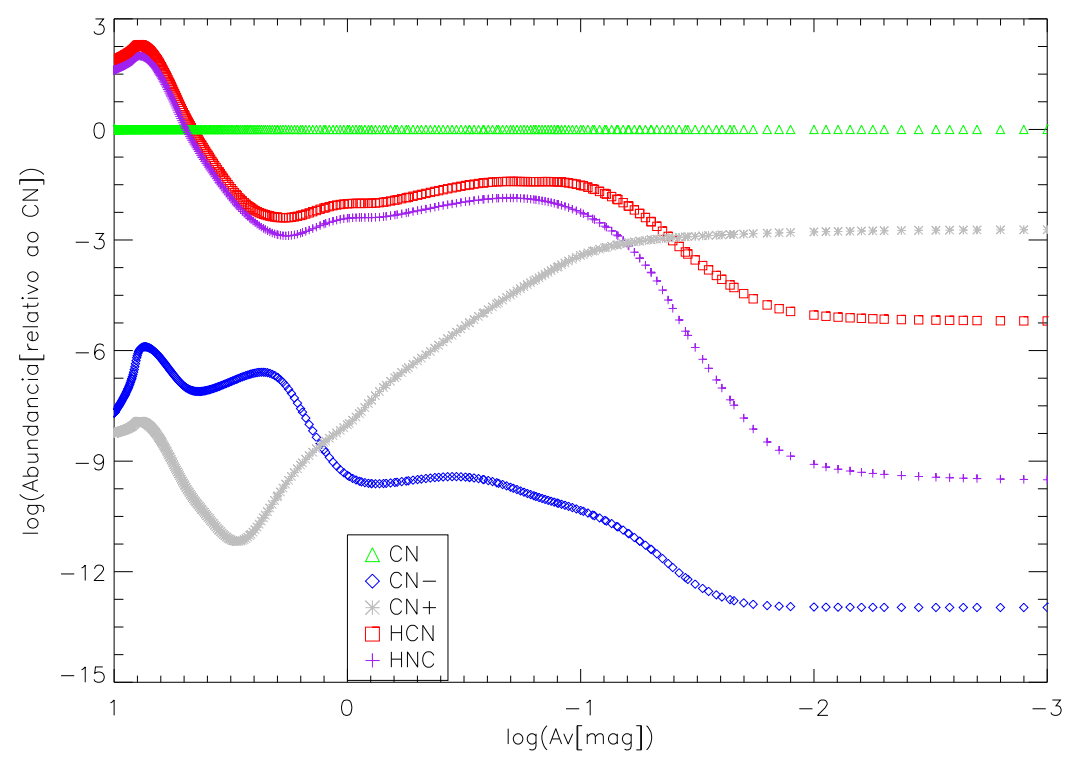

Figura 3.13: Abundância do CN, HCN e HNC para o modelo isobárico ao longo da Nebulosa Cabeça de Cavalo.

como visto na figura 3.11 .

\subsection{Modelo Isotérmico}

No caso do modelo isotérmico, o programa calcula o balanço térmico, porém, a densidade do gás também permanece constante. A figura 3.14 mostra predições para a temperatura, densidade do gás e pressão para o modelo com temperatura constante como função da profundidade da PDR.

A figura 3.14 mostra uma queda da pressão próximo ao centro da nuvem. Esta queda deve-se, principalmente, à transição entre hidrogênio neutro e ionizado, já que a densidade é definida aqui como a densidade total de prótons $n_{H}=n(H)+2 n\left(H_{2}\right)+n\left(H^{+}\right)$(Le Petit, 2009). O modelo isotérmico foi obtido apenas para comparação com os outros modelos, já que a física usada aqui é bastante simples, considerando apenas a pressão como variável, ainda assim, considerando apenas o hidrogênio para o cálculo de $n_{H}$. Este modelo é pouco plausível, o que justifica o fato dele ter sido pouco utilizado para PDRs (uma excessão é Cordiner et al. (2007b)).

Para o caso do modelo isotérmico, a abundância destas moléculas apresenta a mesma 


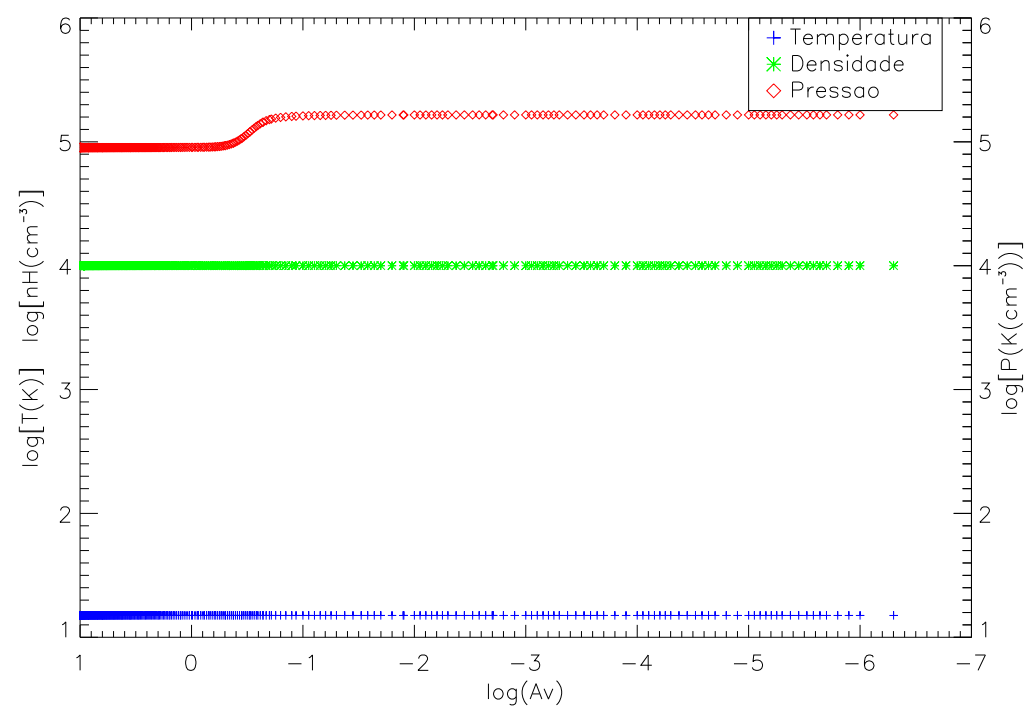

Figura 3.14: Variação dos parâmetros densidade do gás, temperatura e pressão para o modelo isotérmico.

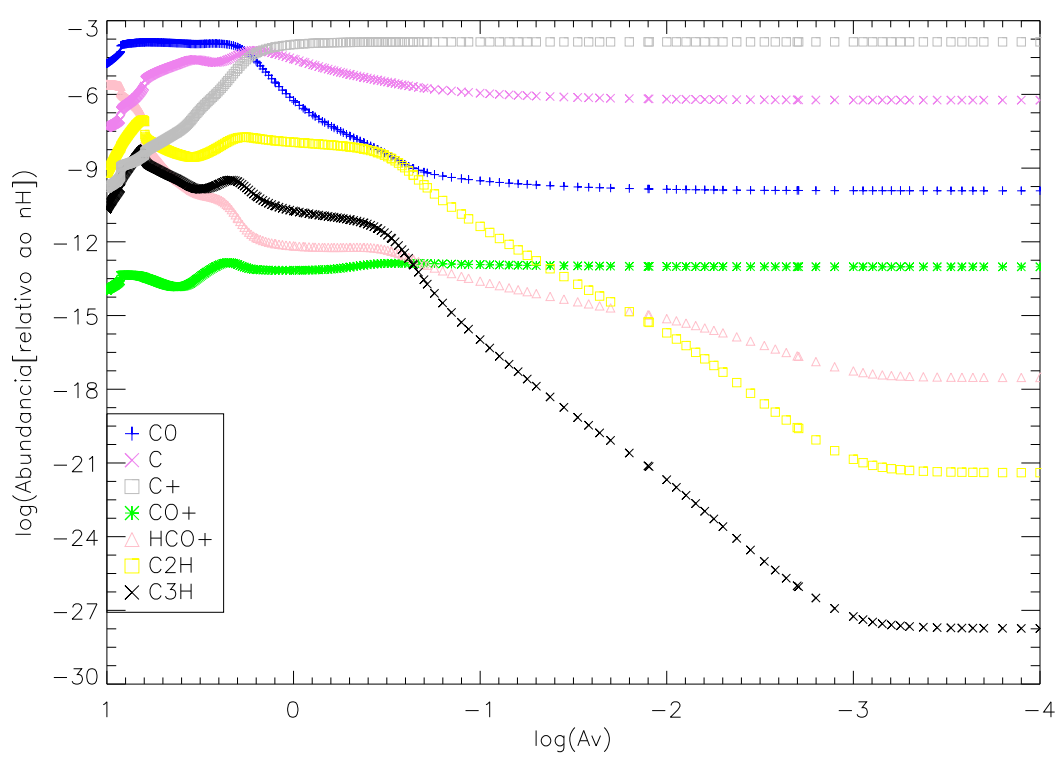

Figura 3.15: Abundâncias de algumas espécies CHO, realtivo à densidade, para o modelo isotérmico ao longo da Nebulosa Cabeça de Cavalo.

discrepância de até duas ordens de grandeza quando comparadas aos trabalhos de Gerin et al. (2009) e Goicoechea et al. (2009), mas a física envolvida neste modelo é mais simples que a usada nos demais. Dessa forma, já era esperado alguma diferença com outros dados. 
Mesmo assim, as abundâncias encontradas são bastante semelhantes ao modelo com densidade constante.

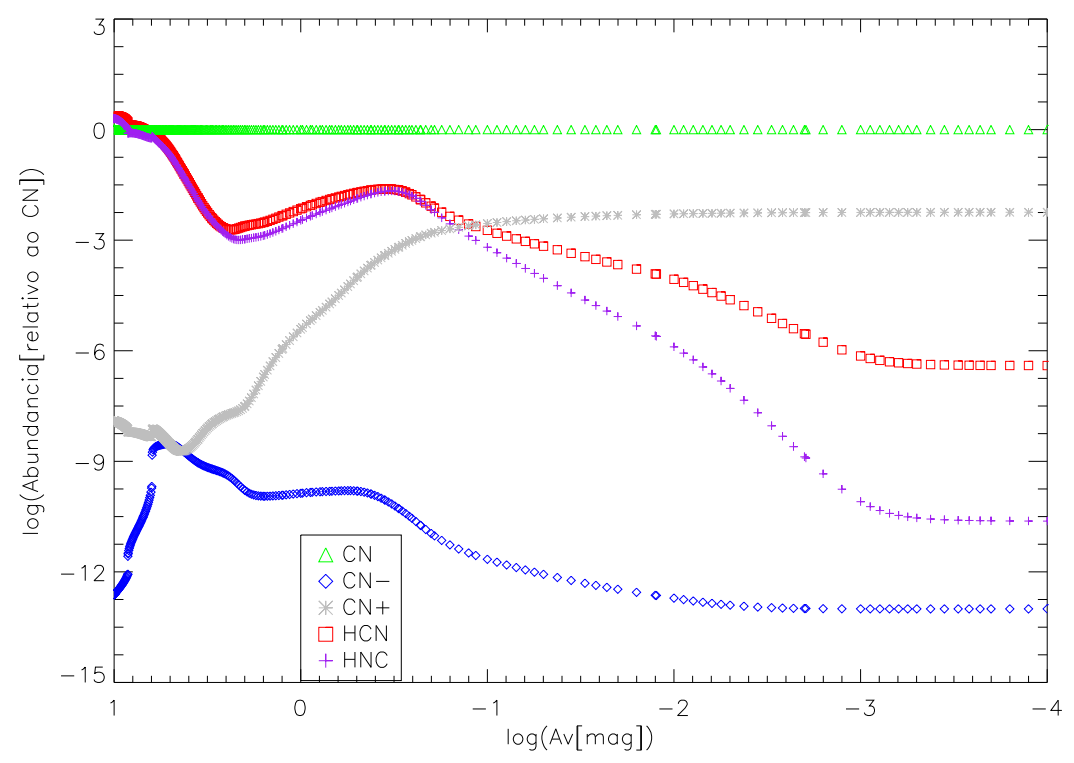

Figura 3.16: Abundância de CN, HCN e HNC para o modelo isotérmico ao longo da Nebulosa Cabeça de Cavalo.

Embora o modelo isotérmico seja bastante simples, a figura 3.16 apresentou resultados bastante similares aos outros dois modelos, se bem que haja uma evidente instabilidade para as moléculas HCN e HNC próximo à $\log \left(A_{V}\right)=-1$ mag e o pico do HCN seja menor, chegando a coincidir com o pico do HNC, fato que não ocorre para os demais modelos.

Em todos os cálculos a seguir utilizamos o modelo isobárico, por ser o mais plausível do ponto de vista físico.

\subsection{Nitrilas}

Algumas moléculas simples contendo nitrogênio foram analisadas, pois através da reação destas é que o nitrogênio se torna disponível para a formação de moléculas mais complexas e que são fundamentais para a vida como a conhecemos. Desta forma, foram escolhidas para análise as moléculas $C_{2} N, C_{3} N, C_{5} N, C_{2} N_{2}, H C_{3} N$-cianoacetileno, $H_{5} N$ -cianodiacetileno e $\mathrm{H}_{3} \mathrm{C}_{3} \mathrm{~N}$-acrilonitrila, bem como seus cátions, exceto para a acrilonitrila. Conduzimos uma atualização para os arquivos de química do código Meudon para 
incluir uma série de nitrilas. Como ilustração, a tabela 3.3 apresenta as reações químicas e seus respectivos parâmetros para a inclusão da acrilonitrila $\left(H_{3} C_{3} N\right)$. As abundâncias destas moléculas são apresentadas nas figuras 3.17 e 3.18 ,

Tabela 3.3 - Reações químicas, parâmetros e tipos de reação usados na modelagem da Nebulosa Cabeça de Cavalo para a acrilonitrila $\left(\mathrm{C}_{3} \mathrm{H}_{3} \mathrm{~N}\right)$.

\begin{tabular}{|c|c|c|c|c|c|c|}
\hline \multicolumn{2}{|c|}{ Reagentes } & \multicolumn{2}{|c|}{ Produtos } & \multirow{2}{*}{$\begin{array}{c}\gamma \\
4.00 \mathrm{e}-12\end{array}$} & \multirow{2}{*}{$\begin{array}{c}\alpha \\
0.00\end{array}$} & \multirow{2}{*}{$\frac{\beta}{1.8}$} \\
\hline $\mathrm{c} 5 \mathrm{~h} 5 \mathrm{n}$ & photon & $\mathrm{c} 2 \mathrm{~h} 2$ & c3h3n & & & \\
\hline $\mathrm{c}+$ & c3h3n & c $3 h 2+$ & hen & $9.84 \mathrm{e}-10$ & 0.00 & 0.0 \\
\hline $\mathrm{c}+$ & c3h3n & c3h3+ & $\mathrm{cn}$ & $1.80 \mathrm{e}-09$ & 0.00 & 0.0 \\
\hline c3h3n & phosec & $\mathrm{c} 2 \mathrm{~h} 3$ & $\mathrm{cn}$ & $1.30 \mathrm{e}-17$ & 0.00 & 375.0 \\
\hline c3h3n & photon & $\mathrm{c} 2 \mathrm{~h} 3$ & $\mathrm{cn}$ & $1.00 \mathrm{e}-10$ & 0.00 & 1.7 \\
\hline $\mathrm{cn}$ & $\mathrm{c} 2 \mathrm{~h} 4$ & c3h3n & $\mathrm{h}$ & $1.25 \mathrm{e}-10$ & 0.70 & 30.0 \\
\hline
\end{tabular}

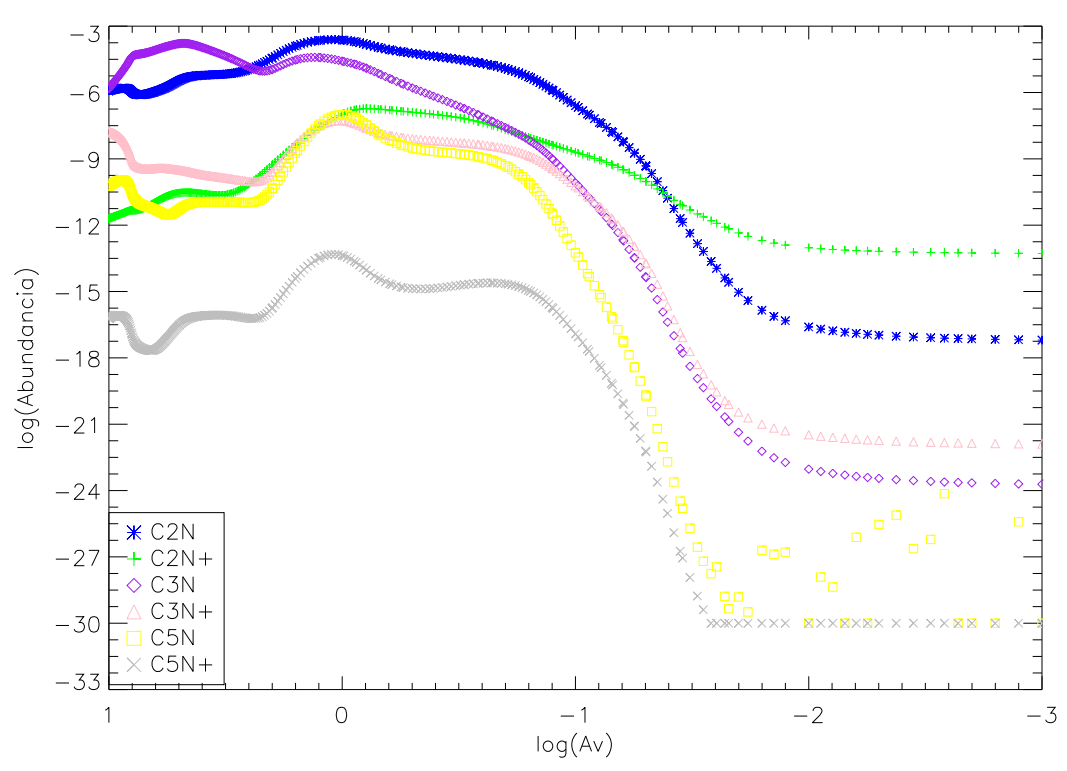

Figura 3.17: Abundância de algumas moléculas nitrogenadas ao longo da Nebulosa Cabeça de Cavalo.

Algumas dessas moléculas nitrogenadas apresentam um comportamento singular. As abundâncias $\operatorname{dos} C_{5} N, C_{5} N^{+}, H C_{3} N, H C_{5} N$ e do $H C_{5} N^{+}$apresentam um platô em sua abundância em $10^{-30}$ (formalmente zero em nossas simulações), indicando que suas 


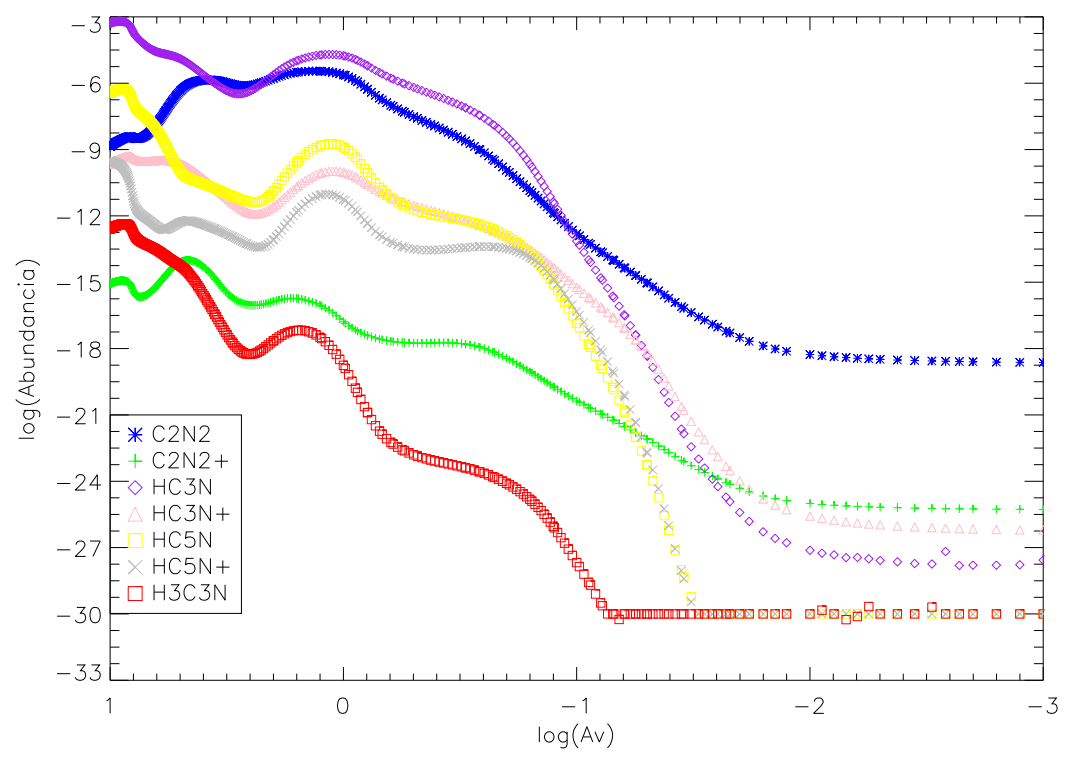

Figura 3.18: Abundância de algumas moléculas nitrogenadas na extensão da Nebulosa Cabeça de Cavalo.

abundâncias caem rapidamente em direção à borda da nebulosa, concentrando-se ao redor da sua região central.

Tanto o $C_{5} N$ como o $H C_{3} N$ apresentam ainda uma flutuação no limite do zero em suas abundâncias, assinalando alguma instabilidade na dinâmica das reações. Essa instabilidade deve ser corrigida quando suas reações químicas de formação e destruição nos ambientes interestelares e circum-estelares forem estudadas mais profundamente.

Um resultado significativo é observado para as moléculas $C_{2} N, C_{3} N$ e $H C_{3} N$, pois suas espécies neutras começam mais abundantes, porém, ainda no começo da nuvem as espécies iônicas se tornam mais abundantes. Este comportamento é esperado devido à diminuição da radiação ultravioleta distante que ocorre dentro da nuvem, mantendo os cátions mais estáveis e abundantes depois de serem formados.

\section{6 Íns}

Alguns poucos ânions já possuem algumas reações de formação e de destruição conhecidas, assim como seus parâmetros quânticos usados nos cálculos de taxa de reação. Essas poucas moléculas também foram estudadas e são mostradas nas figuras 3.19 e 3.20 . 

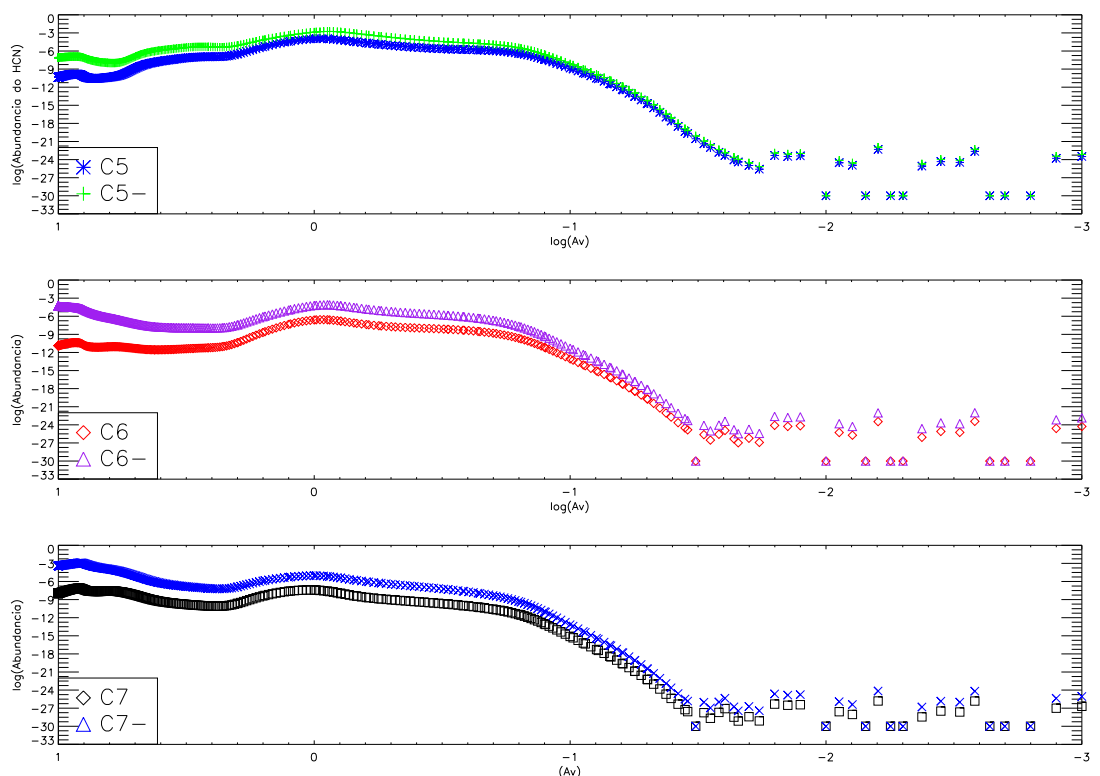

Figura 3.19: Abundância de alguns ânions ao longo da Nebulosa Cabeça de Cavalo.
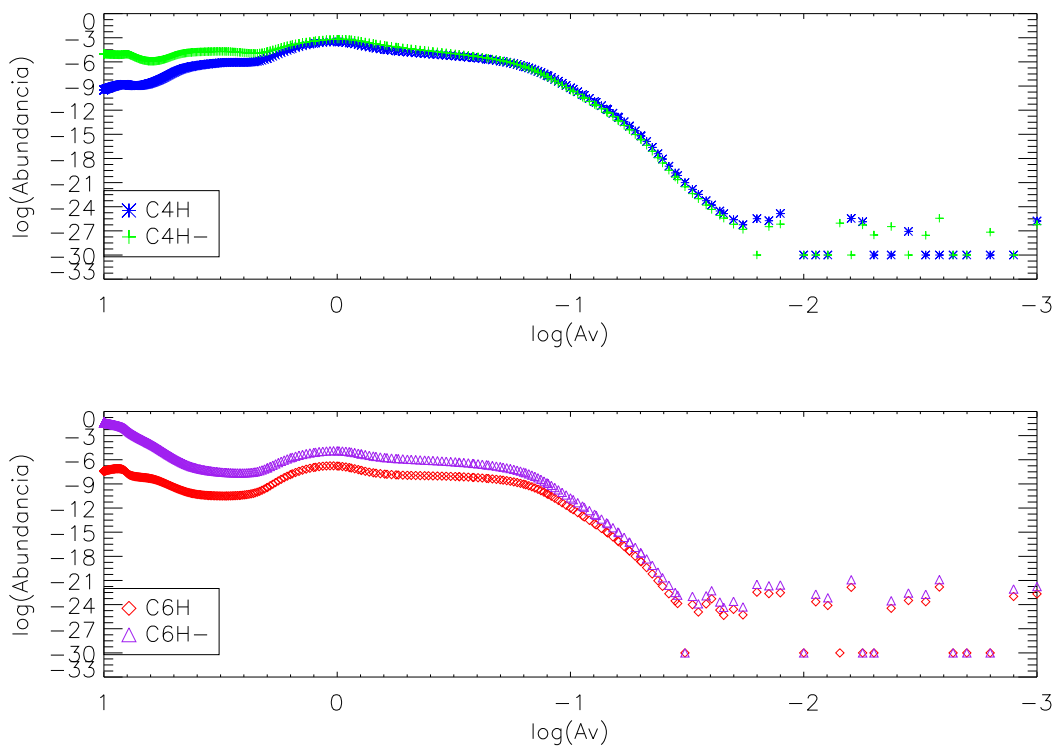

Figura 3.20: Abundância de ânions ao longo da Nebulosa Cabeça de Cavalo.

Todas as espécies estudadas mostraram flutuações em suas abundâncias mínimas e todos eles chegam a praticamente zero de abundância rapidamente. Isto mostra que suas reações ainda não estão bem definidas e que existe um problema dinâmico que tem que ser melhor estudado, afetando a borda, como também aconteceu no caso das nitrilas. 
Os ânions das nitrilas não foram abordados, pois nenhum deles, com exceção do $C N^{-}$, teve as reações de formação e destruição estudadas. Portanto, esperam-se estudos destas reações para um melhor conhecimento daquelas importantes moléculas.

\subsection{Benzeno}

Muitas moléculas cíclicas têm importantes funções pré-bióticas. O benzeno $\left(C_{6} H_{6}\right)$ é uma delas, já que este composto é uma das moléculas mais simples com anel capazes de formar algumas espécies maiores e com maior importância biótica. A substituição de dois átomos de carbono no anel do benzeno por dois nitrogênios produz pirimidinas. A pirimidina $\left(c-C_{4} H_{4} N_{2}\right)$ é o análogo do anel não substituído para as três bases do DNA e do RNA: timina, citosina e uracila, que é, portanto, uma molécula de importância extrema para a Astrobiologia (Kuan et al., 2004).

O resultado obtido no estudo do benzeno é mostrado na figura 3.21. Para chegarmos a este resultado foi usada a rede de reações químicas de formação e destruição do benzeno que é exibida na tabela 3.4 .

Tabela 3.4 - Reações químicas, parâmetros e tipos de reação usados na modelagem da Nebulosa Cabeça de Cavalo para o benzeno.

\begin{tabular}{|c|c|c|c|c|c|c|c|}
\hline \multicolumn{2}{|c|}{ Reagentes } & \multicolumn{3}{|c|}{ Produtos } & \multirow{2}{*}{$\begin{array}{c}\gamma \\
5.00 \mathrm{e}-07\end{array}$} & \multirow{2}{*}{$\frac{\alpha}{-0.50}$} & \multirow{2}{*}{$\begin{array}{c}\beta \\
0.0\end{array}$} \\
\hline $\mathrm{c} 6 \mathrm{~h} 7+$ & electr & c6h6 & $\mathrm{h}$ & & & & \\
\hline $\mathrm{c}+$ & c6h6 & c3h3+ & $\mathrm{c} 4 \mathrm{~h} 3$ & & $1.44 \mathrm{e}-10$ & 0.00 & 0.0 \\
\hline c2h3+ & c6h6 & $\mathrm{c} 6 \mathrm{~h} 7+$ & $\mathrm{c} 2 \mathrm{~h} 2$ & & $1.60 \mathrm{e}-09$ & 0.00 & 0.0 \\
\hline c3h5+ & c6h6 & c6h7+ & c3h4 & & $1.15 \mathrm{e}-10$ & 0.00 & 0.0 \\
\hline $\operatorname{ch} 5+$ & c6h6 & c6h7+ & $\operatorname{ch} 4$ & & $2.00 \mathrm{e}-09$ & 0.00 & 0.0 \\
\hline $\mathrm{h} 3+$ & c6h6 & $\mathrm{c} 6 \mathrm{~h} 7+$ & h2 & & $3.90 \mathrm{e}-09$ & 0.00 & 0.0 \\
\hline h3o+ & c6h6 & $\mathrm{c} 6 \mathrm{~h} 7+$ & h2o & & $1.30 \mathrm{e}-09$ & 0.00 & 0.0 \\
\hline hco+ & c6h6 & $\mathrm{c} 6 \mathrm{~h} 7+$ & co & & $1.60 \mathrm{e}-09$ & 0.00 & 0.0 \\
\hline he+ & c6h6 & c6h5+ & he & $\mathrm{h}$ & $7.00 \mathrm{e}-10$ & 0.00 & 0.0 \\
\hline he+ & c6h6 & c5h5+ & $\mathrm{ch}$ & he & $7.00 \mathrm{e}-10$ & 0.00 & 0.0 \\
\hline
\end{tabular}

Claramente, a abundância do benzeno cai a zero na borda da nuvem muito rapidamente e sua abundância é desde o início bastante pequena. Este é um fato esperado e facilmente 


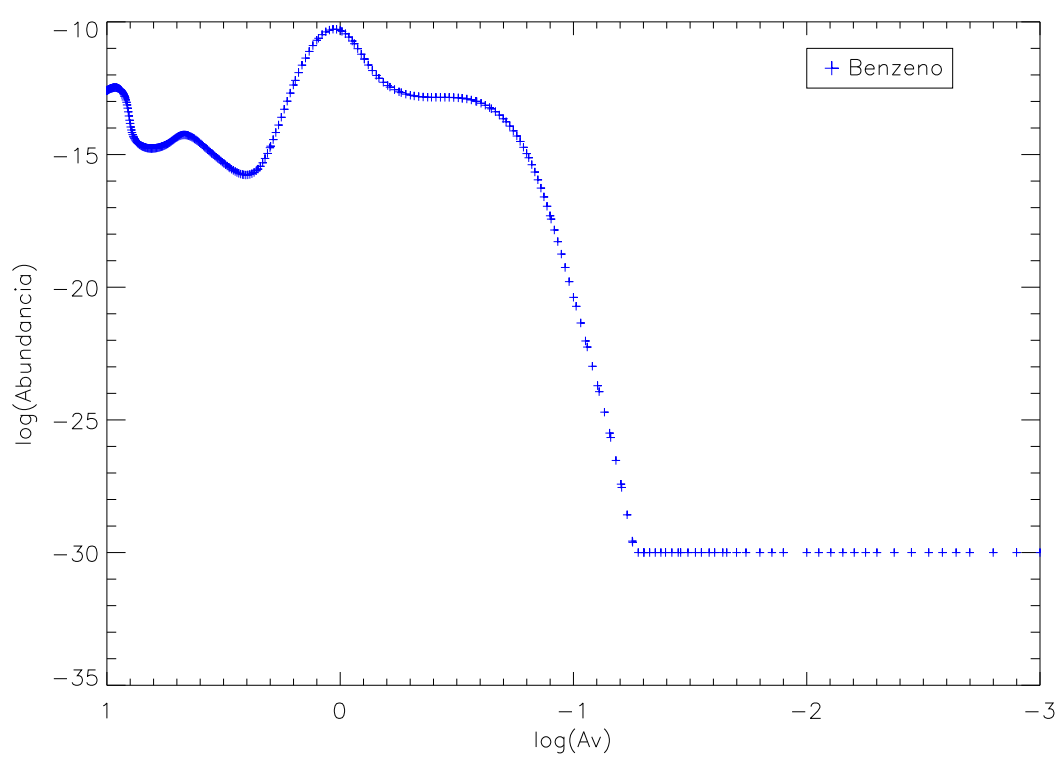

Figura 3.21: Abundância do benzeno ao longo da Nebulosa Cabeça de Cavalo.

explicado, pois esta molécula possui apenas uma reação de formação na sua rede de reações conhecidas, enquanto ela é destruída por diversas reações que produzem outras moléculas. Por ser uma molécula prebiótica tão importante, sua rede de reações deverá ser estendida para um estudo mais detalhado.

Porém, não é apenas o fato de não ter suas reações para o meio interestelar explicitadas que torna este composto tão pouco abundante, mas o fato deste modelo não estar considerando as reações em grãos na formação de moléculas complexas. Moléculas complexas detectadas na atualidade não podem ser contabilizadas em reação de fase gasosa, já que elas sofrem depleção nas superfícies dos grãos. As rotas de formação deste tipo de moléculas complexas têm sido recentemente propostas usando reações no corpo de grãos de gelo reguladas pela fotoquímica de fótons ultravioletas (D’Hendecourt, 2011). Além disso, os modelos de Woods et al. (2002) indicam que quando a extinção cai para 10 mag a uma distância de $\sim 10^{16} \mathrm{~cm}$ da estrela central, a abundância de moléculas como o benzeno cai rapidamente, indicando destruição por fótons UV interestelares. 


\subsection{Pirrol}

O pirrol $\left(C_{4} H_{5} N\right)$ é uma molécula heterocíclica fundamental. Ela é um importante bloco construtor biomolecular. Esta molécula e suas derivadas são essenciais para as funções biológicas vitais, como a hemoglobina e a clorofila. Em astrobiologia, acreditase compostos orgânicos com anéis, incluindo N-heterocíclicos, podem ter desempenhado um importante papel na evolução da vida terrestre e na química prebiótica de ambientes planetários. Com isso em mente, Titã, com uma atmosfera substancial composta principalmente por nitrogênio e metano, é um objeto cativante para a comunidade científica. De fato, estes orgânicos (tanto hidrocarbonetos como nitrilas), estão presentes na atmosfera de baixa temperatura e gás fotoativo, permitindo analogias com a Terra primitiva. Na tentativa de simular Titã e a química prebiótica em experimentos de laboratório, pirrol e piridina foram identificados como moléculas chave adicionadas a outras espécies moleculares, incluindo compostos policíclicos aromáticos contendo N (Soorkia et al., 2010).

Todavia, as respectivas funções (bio)químicas do pirrol e da piridina podem ser profundamente diferentes devido às suas diferenças estruturais intrínsecas. Tanto o pirrol como a piridina seguem a regra de Hückel's (a qual estima se uma molécula em anel planar terá propriedades aromáticas; uma molécula em anel segue a regra de Hückel quando o número dos seus elétrons é igual a $4 n+2$ ), portanto têm propriedades aromáticas. Mas, a principal diferença é que o par solitário de elétrons no átomo de nitrogênio na piridina não está localizada no anel aromático, como está no pirrol (Soorkia et al., 2010).

Pirrol e piridina fornecem exemplos arquetípicos de como as propriedades físicas e químicas fundamentais poderiam ser significativamente diferentes para duas moléculas cíclicas que se diferem por apenas um átomo de carbono. Espécies N-herocíclicas pequenas como o pirrol e a piridina estão entre aquelas que provavelmente são as mais importantes do ponto de vista astrobiológico. As reações dessas moléculas com radicais e/ou espécies iônicas subsequentemente podem fornecer espécies carbonadas maiores contendo nitrogênio. A inclusão do N em PAHs poderia promover a formação de anéis hidrocarbonetos adicionais (Soorkia et al., 2010) e, assim, essas moléculas poderiam contribuir para a formação de PANHs muito grandes, que se acredita desempenhar um importante papel na química interestelar. Infelizmente, a procura no meio interestelar por pirrol e piridina, entre outros compostos, não tem obtido êxito. 
Utilizaremos, nesta seção e na próxima, os resultados de Soorkia et al. (2010), assim como aqueles do modelo fotoquímico de Krasnopolsky (2009) para a atmosfera de Titã. Os resultados para o pirrol estão mostrados nas figuras 3.22 e 3.23 .

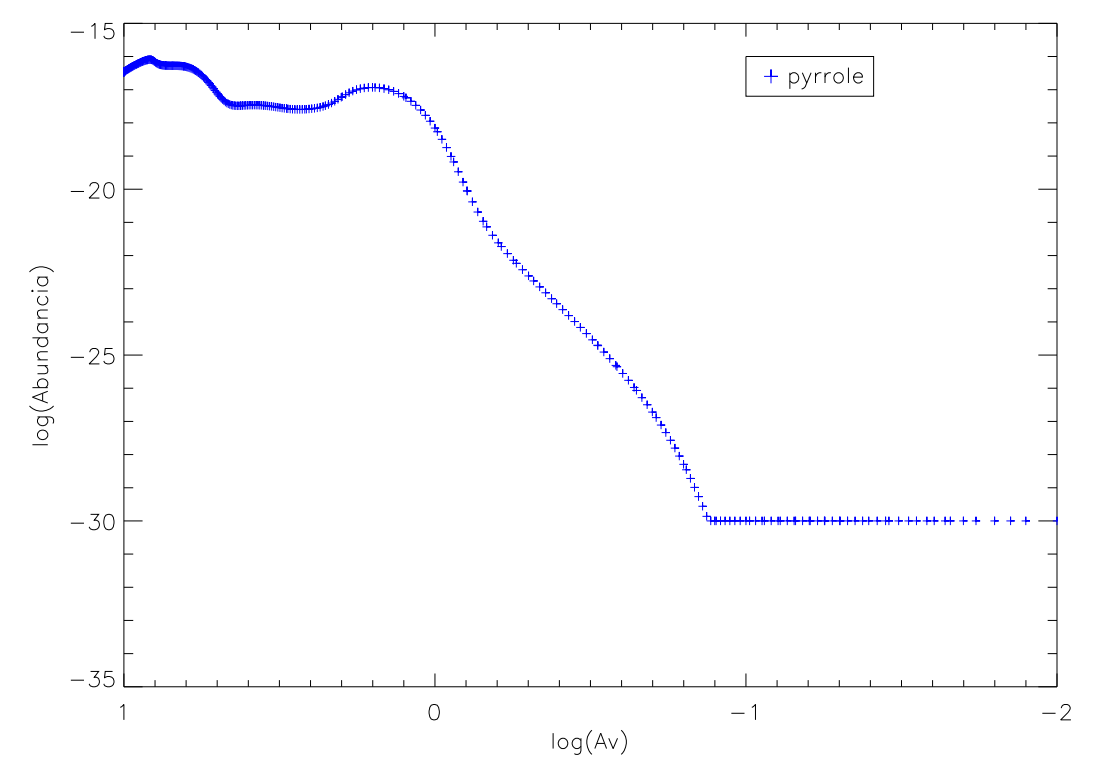

Figura 3.22: Abundância do pirrol ao longo da Nebulosa Cabeça de Cavalo.

Como o pirrol é uma molécula de extrema importância prebiótica, é altamente relevante tentar estimar sua abundância na HHN, porém os resultados obtidos para este composto constituem apenas estimativas, já que ele ainda não teve estudada suas reações em condições análogas às do meio interestelar.

O único canal para a produção de pirrol no modelo de Krasnopolsky (2009) para a atmosfera de Titã é a reação $N^{*}+C_{4} H_{6} \rightarrow C_{4} H_{5} N+H \mathrm{n}$ onde $N^{*}$ é o nitrogênio atômico no estado metaestável ${ }^{2} D, N\left({ }^{2} D\right)$. $N^{*}$ é produzido por fotodissociação ou dissociação por fótons, elétrons e raios cósmicos do $N_{2}$. De acordo com Nicolas et al. (2003), a fotodissociação radiativa do $N_{2}$ produz principalmente $N^{+}+N^{*}$. Como o $N^{*}$ decai para o estado fundamental com uma taxa de $1.06 \times 10^{-5} \mathrm{~s}^{-1}$, sendo muito rápido para os processos em uma nuvem interestelar, esse canal de produção de pirrol pode não relevante para a Nebulosa Cabeça de Cavalo.

Um possível progenitor para o pirrol é o butenal (Jacques Le Bourlout, comunicação privada), visto que o propenal e o propanal já foram observados no meio interestelar 
(Hollis et al., 2004). Assim, resultados foram obtidos a partir de uma reação de formação conhecida em laboratório, estimando-se os parâmetros de sua taxa de destruição no meio interestelar levando-se em consideração que este tipo de reação tem, conforme a tabela 2.2, valor médio para a constante de reação $\kappa \simeq 10^{-11}\left(\mathrm{~cm}^{3} / \mathrm{s}\right)$ e a partir de reações de destruição estimadas causadas por fótons UV e por raios cósmicos, sendo os produtos da fotodissociação distribuídos entre cinco canais, como pode ser visto na tabela 3.5 .

Tabela 3.5 - Reações químicas, parâmetros e tipos de reação para a produção do pirrol a partir do butenal para a HHN.

\begin{tabular}{|c|c|c|c|c|c|c|c|}
\hline \multicolumn{2}{|c|}{ Reagentes } & \multicolumn{3}{|c|}{ Produtos } & \multirow{2}{*}{$\begin{array}{c}\gamma \\
5.00 \mathrm{e}-07\end{array}$} & \multirow{2}{*}{$\frac{\alpha}{0.5}$} & \multirow{2}{*}{$\frac{\beta}{0.0}$} \\
\hline c4h6o & nh3 & c4h5n & $\mathrm{h} 2 \mathrm{o}$ & $\mathrm{h} 2$ & & & \\
\hline $\mathrm{c} 4 \mathrm{~h} 5 \mathrm{n}$ & phosec & $\mathrm{c} 2 \mathrm{~h} 5$ & $\mathrm{c} 2 \mathrm{n}$ & & $2.00 \mathrm{e}-18$ & 0 & 1000.0 \\
\hline c4h5n & phosec & $\mathrm{h} 2 \mathrm{cn}$ & c3h3 & & $2.00 \mathrm{e}-18$ & 0 & 1000.0 \\
\hline c4h5n & phosec & hc3n & $\operatorname{ch} 4$ & & $2.00 \mathrm{e}-18$ & 0 & 1000.0 \\
\hline $\mathrm{c} 4 \mathrm{~h} 5 \mathrm{n}$ & phosec & $\mathrm{h} 3 \mathrm{c} 2 \mathrm{n}$ & $\mathrm{c} 2 \mathrm{~h} 2$ & & $2.00 \mathrm{e}-18$ & 0 & 1000.0 \\
\hline c4h5n & phosec & $\mathrm{c} 3 \mathrm{~h} 4$ & $\mathrm{hcn}$ & & $2.00 \mathrm{e}-18$ & 0 & 1000.0 \\
\hline $\mathrm{c} 4 \mathrm{~h} 5 \mathrm{n}$ & photon & $\mathrm{c} 2 \mathrm{~h} 5$ & $\mathrm{c} 2 \mathrm{n}$ & & $2.00 \mathrm{e}-12$ & 0 & 1.8 \\
\hline c4h5n & photon & $\mathrm{h} 2 \mathrm{cn}$ & c3h3 & & $2.00 \mathrm{e}-12$ & 0 & 1.8 \\
\hline c4h5n & photon & hc3n & $\operatorname{ch} 4$ & & $2.00 \mathrm{e}-12$ & 0 & 1.8 \\
\hline $\mathrm{c} 4 \mathrm{~h} 5 \mathrm{n}$ & photon & $\mathrm{h} 3 \mathrm{c} 2 \mathrm{n}$ & $\mathrm{c} 2 \mathrm{~h} 2$ & & $2.00 \mathrm{e}-12$ & 0 & 1.8 \\
\hline c4h5n & photon & $\mathrm{c} 3 \mathrm{~h} 4$ & hen & & $2.00 \mathrm{e}-12$ & 0 & 1.8 \\
\hline
\end{tabular}

Tendo em vista a pouca quantidade da molécula progenitora butenal, $\left(\mathrm{C}_{4} \mathrm{H}_{6} \mathrm{O}\right)$, a pequena abundância encontrada para o pirrol é esperada. Há de se considerar, ainda, que também para o pirrol, assim como discutido para o caso do benzeno, é uma molécula complexa que deve ter suas rotas de formação ligadas à poeira e aos grãos de gelo, que ainda deverão ser estudadas.

Devido à importância do pirrol, a necessidade de estudar mais amplamente as reações de formação desta molécula se tornou evidente. Desta forma, baseando-se no trabalho de Peeters et al. (2005) sobre a piridina e o pirrol, onde comparece a s-triazina, exploramos um outro canal de formação do pirrol tendo a s-triazina como reagente. Para isto, foi necessário ainda considerar que as moléculas reajam efetivamente com o $\mathrm{CH}$ para a formação de compostos mais estáveis, conforme Soorkia et al. (2010). 
Desta forma, precisou-se incluir alguns compostos que não possuem suas reações e taxas de reações conhecidas para condições do meio interestelar, como por exemplo, a própria s-triazina e, assim como para o canal de produção a partir do $\mathrm{C}_{4} \mathrm{H}_{6} \mathrm{O}$ fomos obrigados a fazer estimativas das taxas de reação e de reações de destruição causadas por fótons UV e por raios cósmicos. As reações usadas neste modelo são vistas na tabela 3.6, O resultado obtido, acrescentando as reações da tabela 3.5 às da tabela 3.6, é mostrado na figura 3.23 .

Tabela 3.6 - Reações químicas, parâmetros e tipos de reação usados na estimativa do pirrol a partir da s-triazina para a $\mathrm{HNN}$.

\begin{tabular}{|c|c|c|c|c|c|c|c|}
\hline \multicolumn{2}{|c|}{ Reagentes } & \multicolumn{3}{|c|}{ Produtos } & \multirow{2}{*}{$\begin{array}{c}\gamma \\
5.00 \mathrm{e}-07\end{array}$} & \multirow{2}{*}{$\begin{array}{c}\alpha \\
0.50\end{array}$} & \multirow{2}{*}{$\begin{array}{c}\beta \\
0.0\end{array}$} \\
\hline $\mathrm{c} 2 \mathrm{n} 2$ & $\operatorname{ch} 3 n$ & $\mathrm{c} 3 \mathrm{~h} 3 \mathrm{n} 3$ & photon & & & & \\
\hline c3h3n3 & phosec & hen & hen & hen & $1.00 \mathrm{e}-17$ & 0.00 & 0.0 \\
\hline c3h3n3 & photon & hen & hen & hen & $9.00 \mathrm{e}-11$ & 0.00 & 1.8 \\
\hline $\mathrm{ch}$ & c3h3n3 & $\mathrm{c} 4 \mathrm{~h} 4 \mathrm{n}$ & $\mathrm{n} 2$ & & $5.00 \mathrm{e}-07$ & 0.50 & 0.0 \\
\hline c4h4n & phosec & $\mathrm{c} 2 \mathrm{~h} 2$ & $\mathrm{c} 2 \mathrm{~h} 2$ & $\mathrm{n}$ & $3.30 \mathrm{e}-18$ & 0.00 & 1000.0 \\
\hline c4h4n & phosec & c3h3 & hen & & $3.30 \mathrm{e}-18$ & 0.00 & 1000.0 \\
\hline c4h4n & phosec & c3h3 & hnc & & $3.30 \mathrm{e}-18$ & 0.00 & 1000.0 \\
\hline c4h4n & photon & $\mathrm{c} 2 \mathrm{~h} 2$ & $\mathrm{c} 2 \mathrm{~h} 2$ & $\mathrm{n}$ & $3.30 \mathrm{e}-12$ & 0.00 & 1.8 \\
\hline $\mathrm{c} 4 \mathrm{~h} 4 \mathrm{n}$ & photon & c3h3 & hen & & $3.30 \mathrm{e}-12$ & 0.00 & 1.8 \\
\hline c4h4n & photon & c3h3 & hnc & & $3.30 \mathrm{e}-12$ & 0.00 & 1.8 \\
\hline $\mathrm{ch}$ & $\mathrm{c} 4 \mathrm{~h} 4 \mathrm{n}$ & c4h5n & c & & $5.00 \mathrm{e}-07$ & 0.50 & 0.0 \\
\hline
\end{tabular}

O novo resultado obtido aumenta em até quatro ordens de grandeza a abundância do pirrol no estado gasoso, como mostra a figura 3.24. Este fato é significativo, pois ainda que não conheçamos todas as reações de formação e destruição deste composto, podemos ver que adicionando apenas mais uma reação de formação temos uma abundância muito maior e que, assim, seria mais facilmente detectada.

Porém, em regiões de gás e poeira em envelopes de estrelas velhas, a polimerização do acetileno pode produzir benzeno, PAHs e grandes cadeias de carbono em partículas de poeira (Cherchneff et al., 1992). N-heterocíclicos podem ser formados como produtos da polimerização do acetileno. A substituição do intermediário $C_{2} H_{2}$ pelo $\mathrm{HCN}$ pode levar a incorporação direta de um átomo de nitrogênio dentro de um anel aromático (Ricca et al., 2001), formando piridinas. Devido à pequena fração $H C N / C_{2} H_{2}$ encontrada nestes en- 


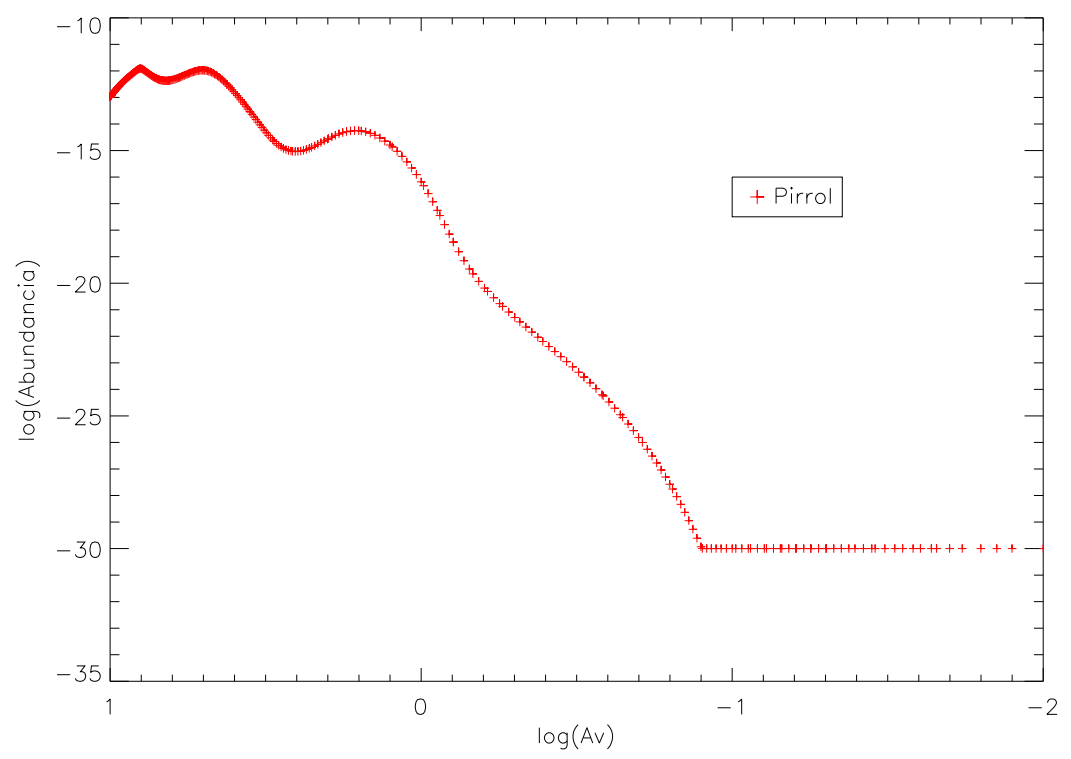

Figura 3.23: Abundância do pirrol, acrescentando a produção a partir da s-triazina, ao longo da Nebulosa Cabeça de Cavalo.

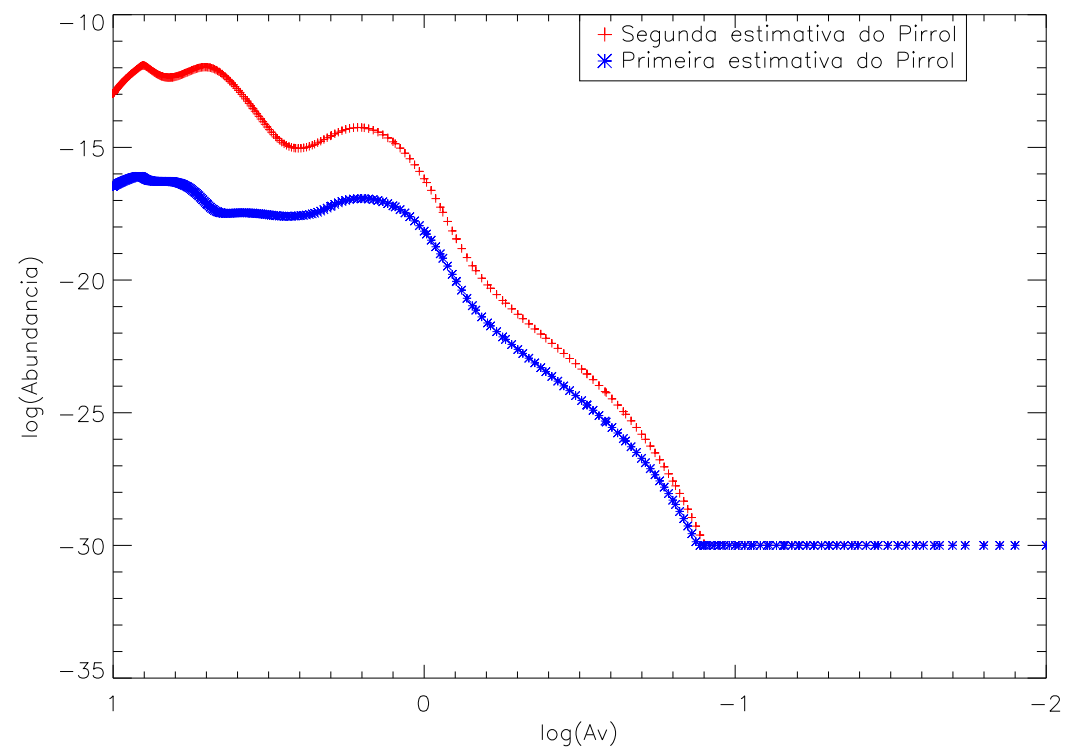

Figura 3.24: Diferença entre a abundância do pirrol quando estimado apenas pelas reações vistas na tabela 3.5 e quando estimado incluindo as reações da tabela 3.6 .

velopes, este cenário prediz menores abundâncias de moléculas aromáticas contendo mais de um átomo de nitrogênio por anel, como a pirimidina (dois nitrogênios) e a s-triazina (três nitrogênios) (Peeters et al., 2005). Tendo isto em vista, embora o cenário que contém 
a formação do pirrol incluindo as reações da tabela 3.6 produza maior abundância desta moléculas, ele ainda é limitado, já que ele envolve reações com a s-triazina.

Contudo, este resultado é bastante expressivo, pois mostra a possibilidade de fazermos inferências para a química interestelar a partir de atmosferas planetárias, em particular de Titã, que possui uma atmosfera densa e fria, na qual Soorkia et al. (2010) estudou os processos de reação do $\mathrm{CH}$ na fase gasosa que podem levar a formação de piridina a partir do pirrol.

\subsection{Piridina}

A piridina $\left(\mathrm{C}_{5} \mathrm{H}_{5} \mathrm{~N}\right)$ é percursora de importantes nucleobases. Como o pirrol $\left(\mathrm{C}_{4} \mathrm{H}_{5} \mathrm{~N}\right)$ e a piridina são as moléculas aromáticas heterocíclicas mais simples de 5 e 6 membros, a sua investigação é fundamental para a compreensão da síntese de espécies cíclicas mais complexas do meio interestelar. São compostos bastante semelhantes ao benzeno, porém a inclusão do nitrogênio em seu anel aromático induz um momento de dipolo permanente, que permite que esta molécula seja observada com um espectro puramente rotacional (Peeters et al., 2005).

Para esta importante molécula, no modelo fotoquímico de Krasnopolsky (2009) há uma única fonte dada pela reação do etano com o radical $C_{3} N$, conforme mostrado na tabela 3.7. Dessa forma, foi acrescentada tal reação no modelo para a Nebulosa Cabeça de Cavalo e obteve-se o resultado apresentado na figura 3.25 .

Tabela 3.7 - Formação da piridina a partir do etano para Nebulosa Cabeça de Cavalo.

\begin{tabular}{lllllll}
\hline \hline Reagentes & \multicolumn{2}{c}{ Produtos } & $\gamma$ & $\alpha$ & $\beta$ \\
\hline c3n & $\mathrm{c} 2 \mathrm{~h} 6$ & $\mathrm{c} 5 \mathrm{~h} 5 \mathrm{n}$ & $\mathrm{h}$ & $4.00 \mathrm{e}-10$ & 0.00 & 0.0 \\
& & & & & \\
\hline
\end{tabular}

Como podemos ver da figura 3.25 as abundâncias derivadas para a piridina são praticamente nulas, o que decorre do fato da abundância do etano na Nebulosa Cabeça de Cavalo ser bastante baixa, como podemos ver na figura [3.26, que permite verificar a importância dos principais hidrocarbonetos na Nebulosa Cabeça de Cavalo. 


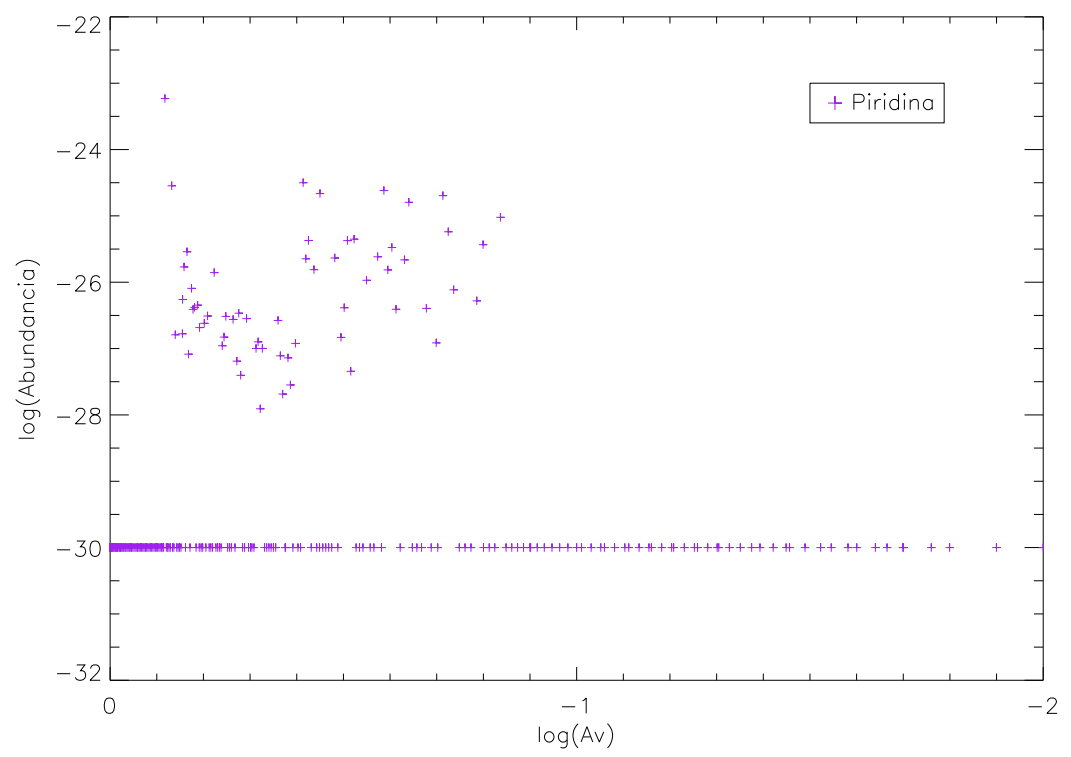

Figura 3.25: Abundância da piridina a partir do etano ao longo da Nebulosa Cabeça de Cavalo.

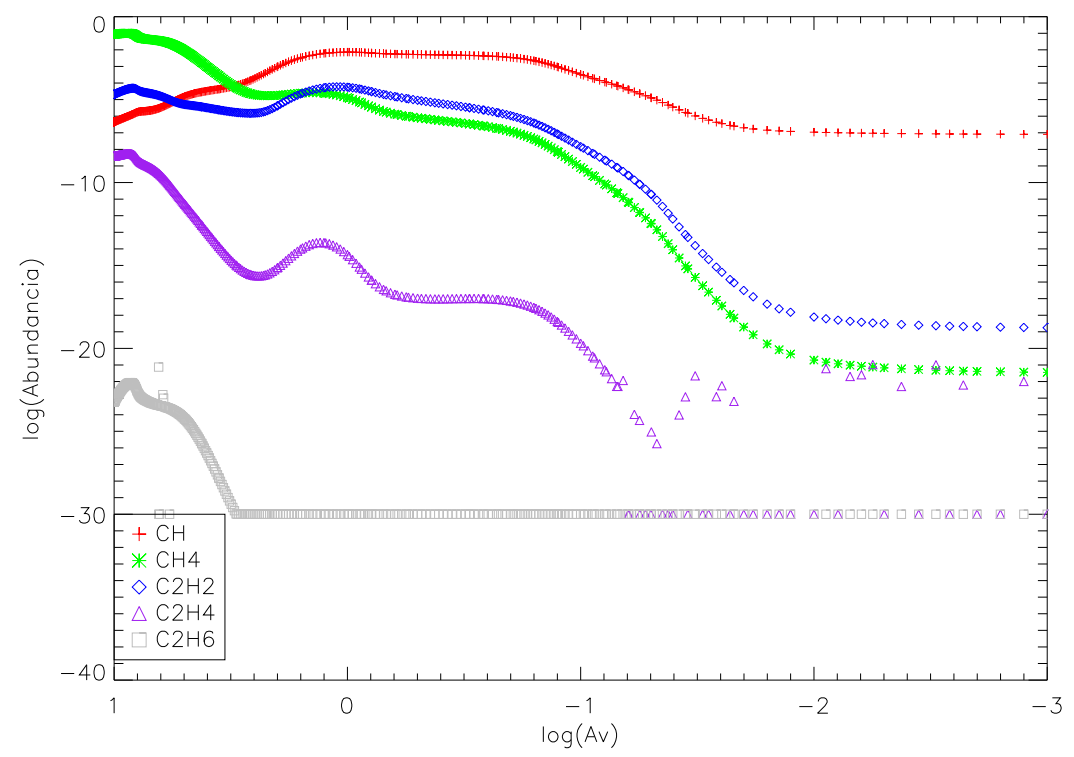

Figura 3.26: Abundância dos principais hidrocarbonetos na Nebulosa Cabeça de Cavalo (incluindo o $\mathrm{CH}$ ).

Os resultados obtidos para o etano, mostram que realmente a abundância deste para a Nebulosa Cabeça de Cavalo é a menor abundância dentre os hidrocarbonetos comuns com dois carbonos, e de fato, sua abundância não seria capaz de produzir uma quantidade 
significativa de piridina na região. No caso dos estudos realizados por Krasnopolsky (2009), estes se referem à atmosfera de Titã, onde a abundância desta espécie é muito maior devido à atmosfera desta lua ser rica em hidrocarbonetos.

Contudo, uma importante reação de formação da piridina, através da reação do $\mathrm{CH}$ com o pirrol, foi estudada por Soorkia et al. (2010), que derivou uma constante de reação $\kappa=4 \times 10^{-11} \mathrm{~cm}^{3} \mathrm{~s}^{-1}$. Embora as reações de formação e destruição envolvendo estas moléculas não sejam bem conhecidas no meio interestelar, há alguns experimentos de laboratório com a piridina que foram realizados com vista às condições do meio interestelar ou podem ser aplicados nessas condições.

A seção de choque para a dissociação da piridina foi calculada por Peeters et al. (2005) como $1.2 \times 10^{-17} \mathrm{~cm}^{2}$ em cerca de $1800 \AA$ para a lâmpada de fluxo de hidrogênio utilizada em seus experimentos (Cottin et al., 2003). Contudo o trabalho não distingue os fragmentos e nem a faixa de comprimentos de onda $\Delta \lambda$ em que ocorre a fotodissociação. Essas propriedades, contudo, podem ser derivadas de outros trabalhos (Lin et al. (2005), Ni et al. (2007) e Vall-llosera et al. (2008)). Assim, podemos adotar $\Delta \lambda=500 \AA$, o que implica uma taxa de fotodissociação total de $1.2 \times 10^{-11} \mathrm{~s}^{-1}$. Há também vários canais para a fotodestruição. Lin et al. (2005) identificou, em termos de massa dos fragmentos, seis canais, mas nem todos com os produtos univocamente determinados em virtude da dificuldade em se discernir entre isomeros de mesma massa. Consideramos neste trabalho os três canais principais, com produção de $\mathrm{CH}_{2} \mathrm{CN}, \mathrm{HC}_{3} \mathrm{~N}$ e $\mathrm{CH}_{2} \mathrm{CHCN}$.

Em uma primeira aproximação, supomos a produção igual para esses três canais, assim, $\kappa=4 \times 10^{-12} s^{-1}$ para cada um deles. A tabela 3.8 mostra um sumário para as reações usadas e as taxas de reações para a estimativa da piridina. E os resultados obtidos são mostrados na figura 3.27 .

Tabela 3.8 - Reações químicas, parâmetros e tipos de reação usados na produção da piridina a partir do pirrol, para a HNN.

\begin{tabular}{|c|c|c|c|c|c|c|}
\hline \multicolumn{2}{|c|}{ Reagentes } & \multicolumn{2}{|c|}{ Produtos } & \multirow{2}{*}{$\begin{array}{c}\gamma \\
4.00 \mathrm{e}-10\end{array}$} & \multirow{2}{*}{$\begin{array}{c}\alpha \\
0.00\end{array}$} & \multirow{2}{*}{$\begin{array}{l}\beta \\
0.0\end{array}$} \\
\hline $\mathrm{ch}$ & $\mathrm{c} 4 \mathrm{~h} 5 \mathrm{n}$ & c5h5n & $\mathrm{h}$ & & & \\
\hline $\mathrm{c} 5 \mathrm{~h} 5 \mathrm{n}$ & photon & $\mathrm{c} 3 \mathrm{~h} 3$ & $\mathrm{c} 2 \mathrm{~h} 2 \mathrm{n}$ & $4.00 \mathrm{e}-12$ & 0.00 & 1.8 \\
\hline c5h5n & photon & $\mathrm{c} 2 \mathrm{~h} 4$ & hc3n & $4.00 \mathrm{e}-12$ & 0.00 & 1.8 \\
\hline $\mathrm{c} 5 \mathrm{~h} 5 \mathrm{n}$ & photon & $\mathrm{c} 2 \mathrm{~h} 2$ & c3h3n & $4.00 \mathrm{e}-12$ & 0.00 & 1.8 \\
\hline
\end{tabular}


Tabela 3.8 - Continuação

\begin{tabular}{cccccc}
\hline \hline Reagentes & Produtos & $\gamma$ & $\alpha$ & $\beta$ \\
\hline
\end{tabular}

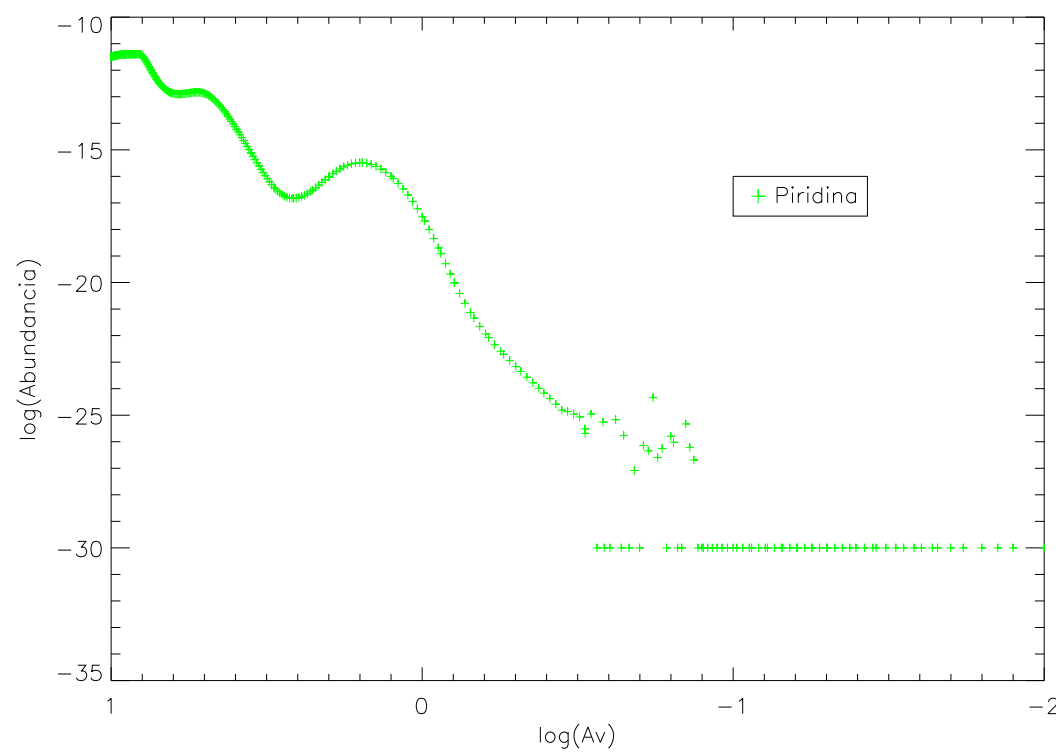

Figura 3.27: Abundância da piridina ao longo da Nebulosa Cabeça de Cavalo.

Assim como no caso do pirrol e do benzeno, a baixa abundância da piridina é justificada por haver apenas uma reação de formação para algumas reações de destruição deste composto. Além disso, como nos casos anteriores deve-se levar em consideração a limitação do modelo em usar apenas reações na fase gasosa, não considerando a fase de grãos, que constituiriam o sítio de formação privilegiada para uma molécula tão complexa como esta.

A instabilidade apresentada no gráfico 3.27 para abundância abaixo de $10^{-25}$ é característica de espécies com abundância próxima de zero, para as quais a rede de reações acaba por fornecer incrementos e decréscimos discretos associados aos processos de formação e destruição envolvendo pequenas quantidades que se anulam de um passo de cálculo para outro e que a seguir voltam a ser não-nulas.

Apesar das baixas abundâncias obtidas, este resultado já é um bom ponto de partida para futuros modelos e para buscas observacionais que possam ser realizadas, haja vista a importância pré-biótica destas espécies. 


\subsection{O Papel dos PAHs}

Os PAHs podem conter uma grande fração do carbono presente no meio interestelar, tipicamente da ordem de $20 \%$ (Joblin et al., 1992). Acredita-se que sejam os responsáveis pelas assim chamadas "Bandas Aromáticas no Infravermelho"(AIBs, na sigla em inglês), um conjunto de linhas de emissão estreitas que dominam o espectro infra-vermelho de muitos objetos galácticos e extragalácticos. Cerca de $20 \%$ da luminosidade emitida pela poeira é devida a estas linhas (Li et al., 2004). As AIBs mais fortes estão a $3.3 \mu m, 6.2$ $\mu m, 7.7 \mu m, 8.6 \mu m, 11.3 \mu m$ e $12.7 \mu m$. A característica em $3.3 \mu m$ é associada com os modos de estiramento do $\mathrm{CH}$, enquanto que o modo estiramento do $\mathrm{CC}$ é associado com as bandas em $6.2 \mu \mathrm{m}$ e $7.7 \mu \mathrm{m}$, sendo que as outras AIBs são associadas com vários modos de deformação angular da ligação CH, tanto no plano como fora do plano (Allamandola et al., 1989).

A emissão interestelar por PAHs em $6.2 \mathrm{~mm}$ é provavelmente dominada por espécies com dimensões entre 60 e 90 átomos de carbono (Hudgins et al., 2005). Portanto, neste trabalho, seguindo Flower e Pineau des Forêts (2003), adotamos o circum-coroneno, $\mathrm{C}_{54} \mathrm{H}_{18}$, como representativo do PAH interestelar. Este PAH pertence à família dos PAHs mais compactos, os pericondensados de simetria $D_{6 h}$ (fórmula $C_{6 n^{2}} H_{6 n}$ ), que minimizam o número de átomos de hidrogênio por átomo de carbono (Puget e Leger, 1989).

Consideramos a abundância inicial de PAH como $10^{-6}$ partículas de $C_{54} H_{18}$ em relação ao hidrogênio, o que corresponde a uma fração de carbono em PAHs no meio interestelar de $15 \%$.

\subsubsection{Benzeno}

Também consideramos uma abundância inicial para o benzeno de $10^{-6}$ partículas em relação ao hidrogênio, extrapolando para pequenos valores de $N_{C}$ (o número de carbonos em um PAH) uma lei de densidade $n\left(N_{C}\right) \propto N_{C}^{-2.25}$ (Silva et al., 1998), válida desde $N_{C}=6$ até $N_{C}=486$ (o pericondensado $C_{486} H_{54}$ ou $n=9$ na sequencia $C_{6 n^{2}} H_{6 n}$ ).

A suposição de alta densidade inicial para o benzeno leva a uma descontinuidade em $A_{V} \sim 3$, provavelmente ligada à mudança do regime de opacidade, como visto na figura 3.28. Comparando com as densidades anteriormente calculadas para o benzeno há um incremento de densidade na borda da nuvem que depois cai, a medida que penetra na 


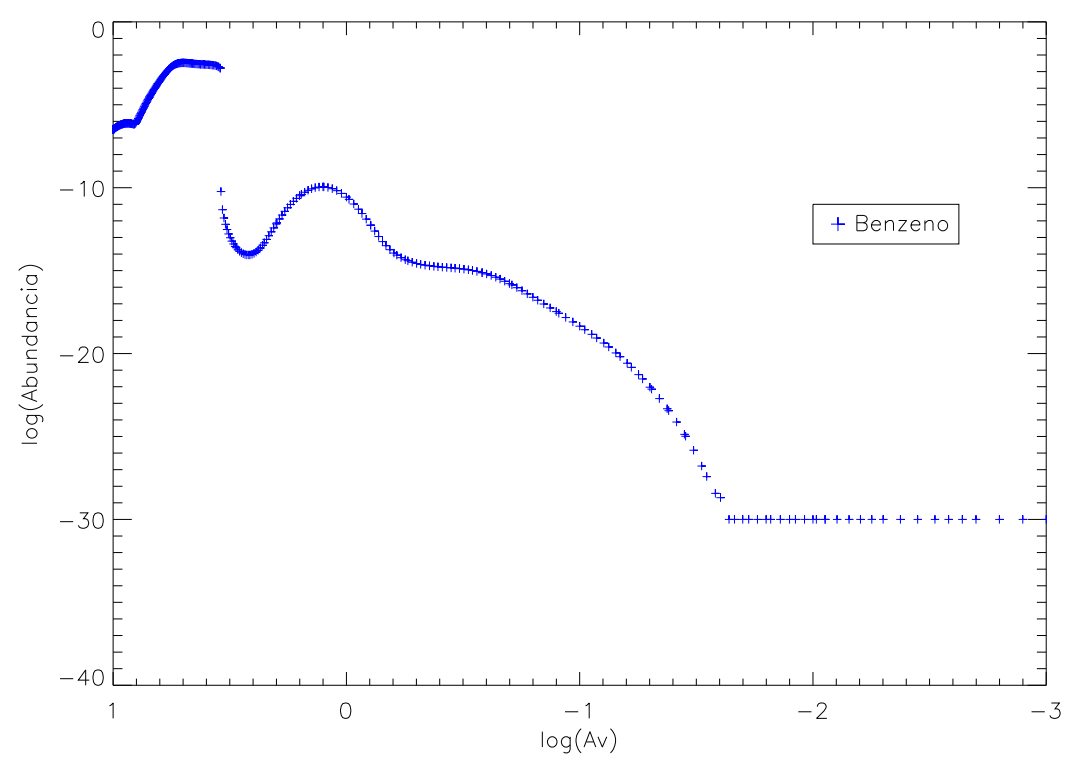

Figura 3.28: Abundância do benzeno quando considera-se uma abundância inicial de $10^{-6}$ para o mesmo.

nuvem a valores abaixo dos iniciais para o benzeno, em $A_{V} \simeq-0.1$. Após, a nova densidade cresce e em $A_{V} \simeq 1$, torna-se maior do que a anterior. Finalmente, em $A_{V} \sim 3$ há uma descontinuidade marcando uma mudança de regime e o novo valor sempre se coloca acima de 5 ordens de magnitude (as vezes 8 ordens de magnitude) mais abundante do que o inicial. Nas regiões mais internas, a abundância do benzeno fica bastante alta, ainda como reflexo das condições iniciais.

\subsubsection{PAHs, PANHs e Heterocíclicos Nitrogenados (Pirrol e Piridina)}

Além de PAHs, o meio interestelar deve conter também heterocíclicos nitrogenados aromáticas policíclicos (PANHs, na sigla em inglês). Hudgins et al. (2005) interpreta a variação do perfil da AIB a $6.2 \mu m$ (devida a uma ligação CC) em relação ao esperado de um PAH simples, como indicando a substituição de um carbono por um nitrogênio. No artigo, testa-se hipóteses alternativas sem êxito: substituição por O ou Si; complexos PAHíon metálico; e grandes PAHs assimétricos. Conclui-se que ao menos 1-2\% do nitrogênio cósmico foi sequestrado em PAHs. Ademais, se o N substituído for localizado na periferia do PAH, o PANH resultante é significativamente reativo, o que pode levar à produção posterior de outros heterocíclicos nitrogenados. Assim testamos um canal de produção de 


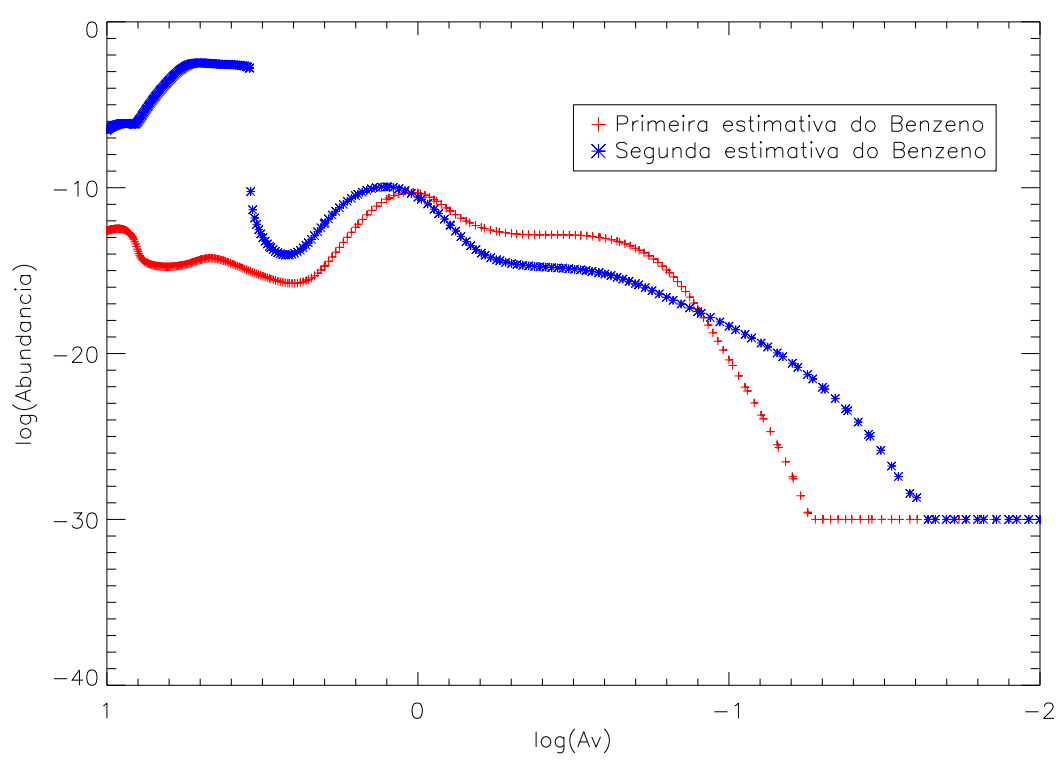

Figura 3.29: Comparação entre a abundância do benzeno quando considera-se uma abundância inicial de $10^{-6}$ ou de zero para o mesmo.

pirrol e piridina via PANHs derivados de PAHs.

Em conformidade a sequência de passos para a incorporação de um átomo de nitrogênio em policíclicos aromáticos proposta por Ricca et al. (2001), adotamos o conjunto de reações da tabela 3.9 para obtermos canais adicionais para a produção de piridina.

Tabela 3.9 - Reações químicas, parâmetros e tipos de reação para a produção de pirrol e piridina com a participação de PAHs.

\begin{tabular}{|c|c|c|c|c|c|c|}
\hline Reagentes & & Produtos & & $\gamma$ & $\alpha$ & $\beta$ \\
\hline c54h18 & $\mathrm{h}$ & c54h17 & h2 & $5.00 \mathrm{e}-08$ & 0.50 & 0.0 \\
\hline c54h18 & $\mathrm{c} 2 \mathrm{~h}$ & c54h17 & $\mathrm{c} 2 \mathrm{~h} 2$ & $5.00 \mathrm{e}-08$ & 0.50 & 0.0 \\
\hline c54h17 & hen & c55h18n & photon & $5.00 \mathrm{e}-07$ & 0.50 & 0.0 \\
\hline c55h18n & $\mathrm{c} 2 \mathrm{~h} 2$ & c57h19n & $\mathrm{h}$ & $5.00 \mathrm{e}-07$ & 0.50 & 0.0 \\
\hline c57h19n & $\operatorname{ch} 4$ & c54h18 & c4h5n & $5.00 \mathrm{e}-07$ & 0.50 & 0.0 \\
\hline c57h19n & $\mathrm{c} 2 \mathrm{~h} 4$ & c54h18 & $\mathrm{c} 5 \mathrm{~h} 5 \mathrm{n}$ & $5.00 \mathrm{e}-07$ & 0.50 & 0.0 \\
\hline
\end{tabular}

No caso dos heterocíclicos nitrogenados também ocorre uma descontinuidade para altos valores da densidade do pirrol e da piridina, como podemos ver nas figuras $3.30,3.31,3.32$ e 3.33. O mesmo comportamento descontínuo da densidade que era apresentado para o benzeno é repetido para estas espécies. 


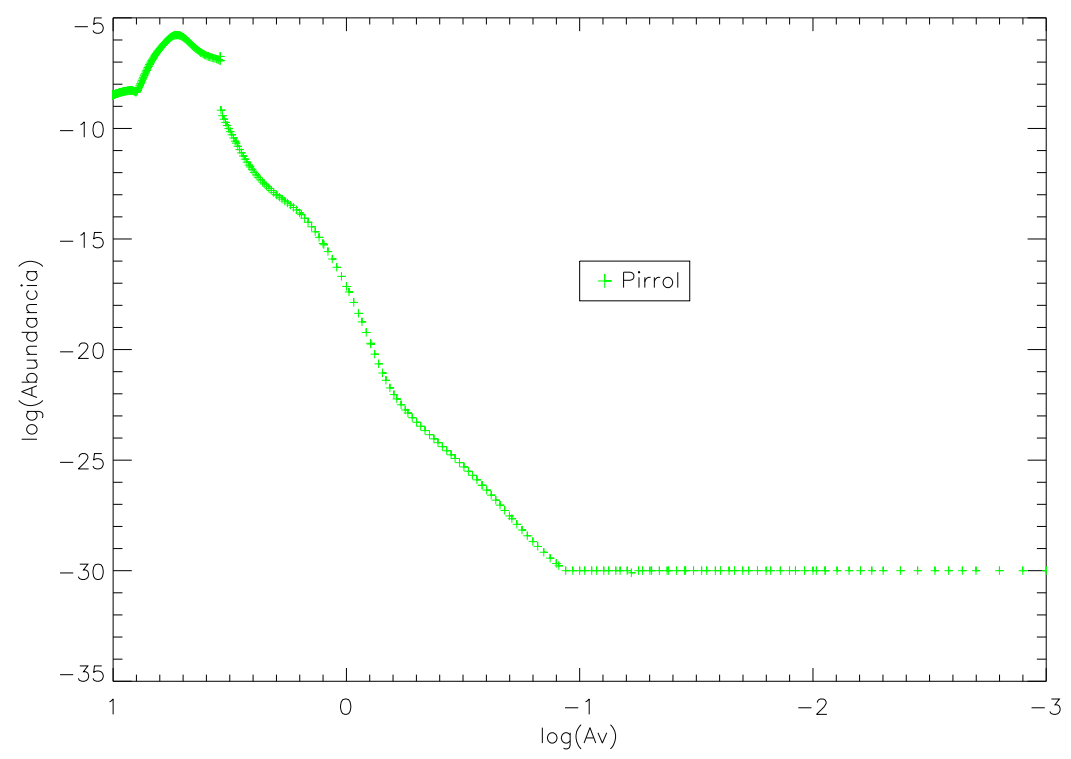

Figura 3.30: Abundância do pirrol quando se introduz um PAH com uma dada abundância inicial e formação a partir de PANHs.

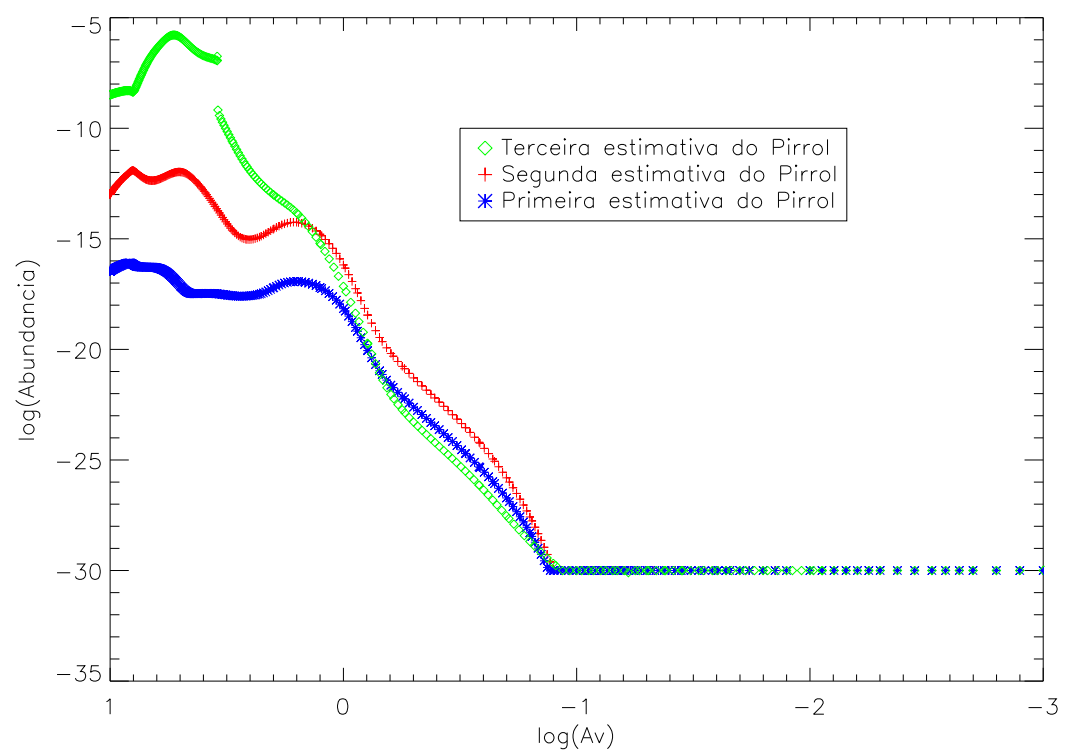

Figura 3.31: Comparação entre as abundâncias do pirrol quando se introduz um PAH com uma dada abundância inicial e formação através de PANHs.

Um ponto importante é que o PAH $\left(C_{54} H_{18}\right)$ atua como um catalizador que promove a reunião de espécies comuns como o HCN e hidrocarbonetos para gerar os heterocíclicos nitrogenados. O comportamento do pirrol e da piridina se distingue daquele do benzeno 


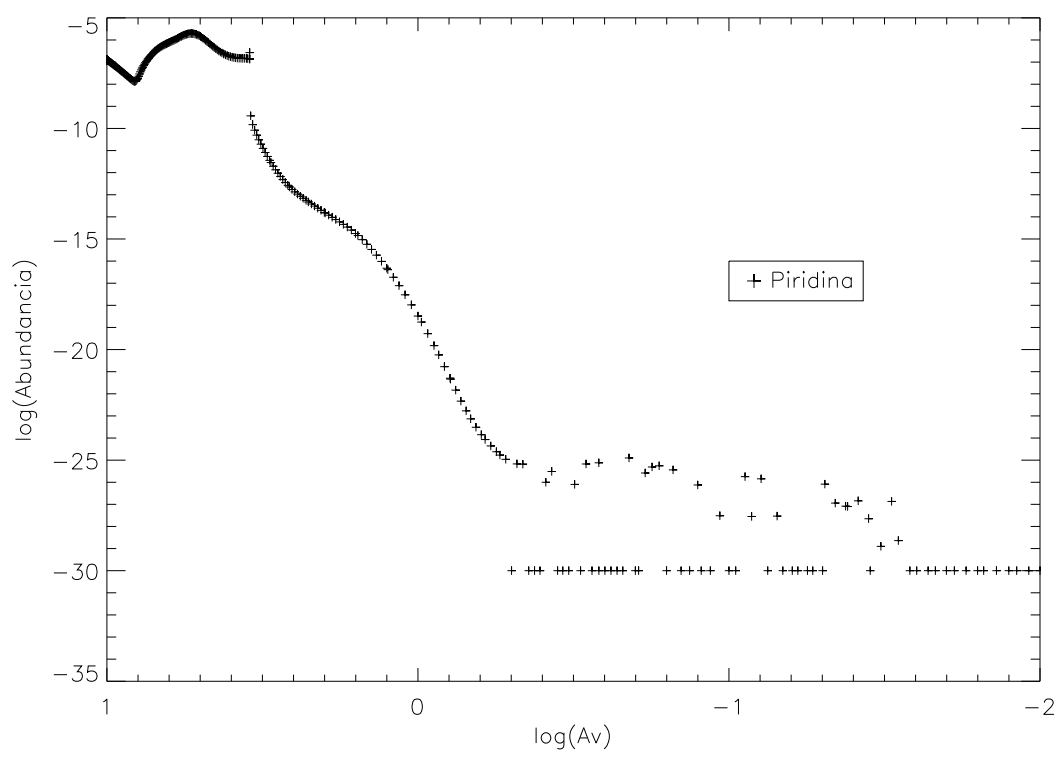

Figura 3.32: Abundância da piridina quando se introduz um PAH com uma dada abundância inicial e formação de PANHs.

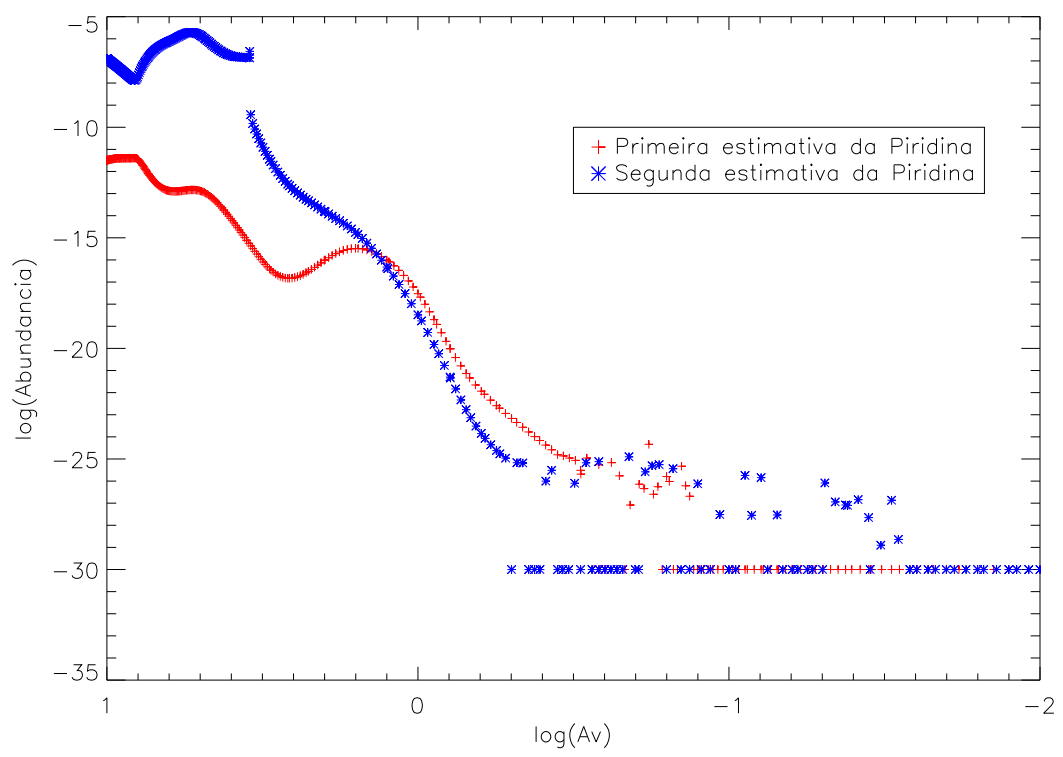

Figura 3.33: Comparação entre as abundâncias da piriridina quando introduz-se um PAH com uma dada abundância inicial e formação de PANHs.

pelo fato de que, após um ligeiro rebaixamento em relação às densidades dessas espécies geradas sem o PAH, nas bordas da nebulosa $\left(A_{V}<1\right)$, o crescimento da densidade é acentuado em direção ao centro e depois ocorre a descontinuidade. Incluindo-se a produção 
através de PAHs (as espécies $C_{55} H_{18} N$ e $C_{57} H_{19} N$ da tabela 3.9), as abundâncias da piridina e do pirrol aumentam ordens de magnitude, ilustrando o poder deste canal de produção.

É interessante observar que na região mais interna $\left(A_{V}>3\right)$, a abundância da piridina é maior do que a do pirrol (figura 3.34). Maiores abundâncias da piridina em relação ao pirrol já haviam sido obtidas no modelo fotoquímico de Krasnopolsky (2009) para a atmosfera de Titã.

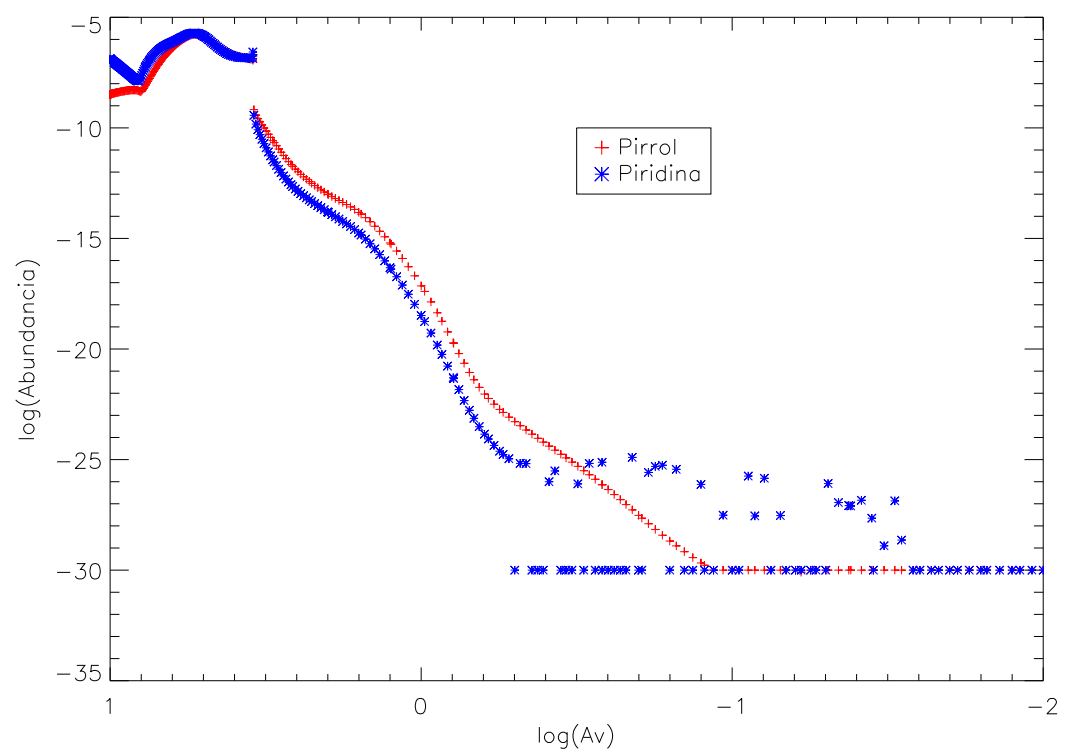

Figura 3.34: Comparação entre as abundância do pirrol e da piridina quando se introduz um PAH com uma dada abundância inicial e formação a partir de PANHs.

Os modelos incluindo PAH anteriores, com abundância inicial dada $[P A H]=10^{-6}$ representam apenas um primeira exploração das possibilidades da produção de heterocíclicos nitrogenados via PAHs, inclusive com uma superestimativa das taxas de produção dos heterocíclicos nitrogenados dadas pelos valores da Tabela 3.9. Também não foram incluídas reações de destruição dos PAHs e dos PANHs. Agora consideraremos uma situação mais realística envolvendo os PAHs. Um grande problema encontrado é que para as espécies consideradas não há cálculos ou dados experimentais, obrigando-nos a recorrer a estimativas.

Os PAHs são extremamente resistentes ao campo de radiação interestelar, devido ao fato de que a energia de ligação dos átomos de carbono é $8 \mathrm{eV}$, e que a energia de um 
fóton UV incidente é distribuída sobre a rede de átomos de carbono do PAH em diversos modos de vibração (Leger et al., 1989). Assim, um PAH com 50 átomos de carbono pode sobreviver 1,1 Ganos no campo de radiação Galáctico (Allain et al., 1996b). Isto é muito mais longo que o tempo de vida de uma nebulosa típica, como é a HNN. O comportamento de um PAH é práticamente o mesmo de um elemento cuja abundância é constante. Assim, consideraremos nos próximos modelos a abundância dos PAH como fixa (em relação ao hidrogênio).

Contudo, embora o PAH possa ser considerado uma "unidade indivisível", ele pode perder ou ganhar hidrogênios, pois a energia necessária para a perda de um átomo de hidrogênio é 4,5 eV (Leger et al., 1989). Assim, um parâmetro adicional que descreve um PAH é o seu grau de hidrogenação, $\alpha_{H / C}$.

O número de átomos de hidrogênio ligados na periferia de um PAH depende de sua história e do ambiente. Campos de radiação mais duros e intensos resultam em uma desidrogenação do PAH e em uma redução de $\alpha_{H / C}$. O grau de hidrogenação irá afetar a razão entre as bandas vibracionais devidas ao $\mathrm{CH}$ e CC. Assim, a razão de fluxos nas linhas $F(8.6 \mu m) / F(7.7 \mu m)$ pode ser usada como um diagnóstico de desidrogenação, já que que a linha $7.7 \mu m$ é devida a ligações CC enquanto que a linha $8.6 \mu m$ é devida a ligações CH. Os valores observados dessa razão excluem uma desidrogenação maior que 50\% para a maioria das fontes (Schutte et al., 1993).

Em grandes PAHs, a desidrogenação torna-se ineficaz por causa de sua alta densidade de modos vibracionais nos quais a energia do fóton absorvido é rapidamente dissipada. A taxa de fotodissociação do PAH decresce fortemente com o seu tamanho. Assim, para o campo de Draine, (Allain et al., 1996a), encontram que a fotodissociação do coroneno $\left(C_{24} H_{12}\right)$ pela perda de um $\mathrm{H}$ tem uma taxa de $2.56 \times 10^{-9} s^{-1}$, enquanto que a taxa de fotodissociação de um PAH com 50 átomos de carbono é $2.27 \times 10^{-16} \mathrm{~s}^{-1}$. Como o nosso PAH $\left(\mathrm{C}_{54} H_{18}\right)$ é apenas representativo da população de PAHs podemos escolher o coeficiente da reação para a fotodissociação do $C_{54} H_{18}$ no $C_{54} H_{17}$ como qualquer valor nesse intervalo. Adotamos, como pode ser visto na Tabela $3.10,10^{-11} s^{-1}$. Este também foi o valor adotado para o coeficiente de fotodissociação dos PANHs.

Um outro ponto a ser considerado é que a fotodissociação torna-se mais fácil para 
Tabela 3.10 - Reações químicas, parâmetros e tipos de reação para a produção de pirrol e piridina com a participação de PAHs.

\begin{tabular}{|c|c|c|c|c|c|c|}
\hline Reagentes & & Produtos & & $\gamma$ & $\alpha$ & $\beta$ \\
\hline c54h18 & $\mathrm{h}$ & c54h17 & h2 & $1.00 \mathrm{e}-10$ & 0.00 & 0.0 \\
\hline c54h18 & $\mathrm{c} 2 \mathrm{~h}$ & c54h17 & $\mathrm{c} 2 \mathrm{~h} 2$ & $1.00 \mathrm{e}-10$ & 0.00 & 0.0 \\
\hline c54h17 & hen & $\mathrm{c} 55 \mathrm{~h} 18 \mathrm{n}$ & photon & $1.00 \mathrm{e}-10$ & 0.00 & 0.0 \\
\hline $\mathrm{c} 55 \mathrm{~h} 18 \mathrm{n}$ & $\mathrm{c} 2 \mathrm{~h} 2$ & c57h19n & $\mathrm{h}$ & $1.00 \mathrm{e}-10$ & 0.00 & 0.0 \\
\hline c57h19n & $\mathrm{c} 2 \mathrm{~h} 4$ & c54h18 & $\mathrm{c} 5 \mathrm{~h} 5 \mathrm{n}$ & $1.00 \mathrm{e}-10$ & 0.00 & 0.0 \\
\hline c54h18 & photon & c54h17 & $\mathrm{h}$ & $1.00 \mathrm{e}-11$ & 0.00 & 1.5 \\
\hline c57h19n & photon & $\mathrm{c} 54 \mathrm{~h} 18$ & hc3n & $1.00 \mathrm{e}-11$ & 0.00 & 1.5 \\
\hline $\mathrm{c} 55 \mathrm{~h} 18 \mathrm{n}$ & photon & $\mathrm{c} 54 \mathrm{~h} 17$ & hen & $1.00 \mathrm{e}-11$ & 0.00 & 1.5 \\
\hline
\end{tabular}

PAHs previamente desidrogenados (Allain et al., 1996b). Assim, toda uma hierarquia de graus de hidrogenação deveria ser considerada em um trabalho completo. Neste trabalho, estamos considerando apenas o PAH totalmente hidrogenado $\left(C_{54} H_{18}\right)$ e o desidrogenado uma única vez $\left(C_{54} H_{17}\right)$.

Como respeito às taxas das reações binárias, adotamos um coeficiente de reação de $10^{-10} \mathrm{~cm}^{-3} \mathrm{~s}^{-1}$, em conformidade com os valores típicos para reações íon-neutro de $10^{-9}$ $\mathrm{cm}^{-3} \mathrm{~s}^{-1}$, para reações neutro-neutro de $10^{-11} \mathrm{~cm}^{-3} \mathrm{~s}^{-1}$, e radical-neutro de $10^{-10} \mathrm{~cm}^{-3} \mathrm{~s}^{-1}$ (Le Page et al. (2001); Vuong e Foing (2000)). Finalmente excluimos o canal de produção do pirrol envolvendo a reação $C_{57} H_{19} N+\mathrm{CH}_{4}$, já que a baixa entalpia de formação do $\mathrm{CH}_{4}(-15.97 \mathrm{kcal} / \mathrm{mol})$ torna essa reação termodinamicamente desfavorável.

Os resultados obtidos estão apresentados nas figuras 3.35, 3.36, 3.37, 3.38 e 3.39,

Como podemos ver da Figura 3.35, os PAHs são dehidrogenados ao longo da maior parte da HHN, exceto na região mais interna $\left(A_{V} \geq 5\right)$, onde a forma inteiramente hidrogenada do PAH predomina. As formas nitrogenadas (PANHs) têm abundâncias nulas nas bordas da nuvem e depois crescem em direção ao centro. O PANH mais abundante é o $C_{57} H_{19} N$, o precursor imediato da piridina. Sua abundância chega a superar a dos PAHs no centro da nuvem, onde $A_{V}$ é próximo de 10.

Na rede de reações da Tabela 3.10, não é produzido pirrol a partir dos PANHs, e assim a sua abundância é reduzida aos valores anteriores à introdução dos PAHs. A figura 3.36 mostra esse retorno das abundâncias do pirrol àqueles resultados dos canais de produção das tabelas 3.5 e 3.6 .

Já a introdução dos PAHs representa um canal de produção de piridina bastante efi- 


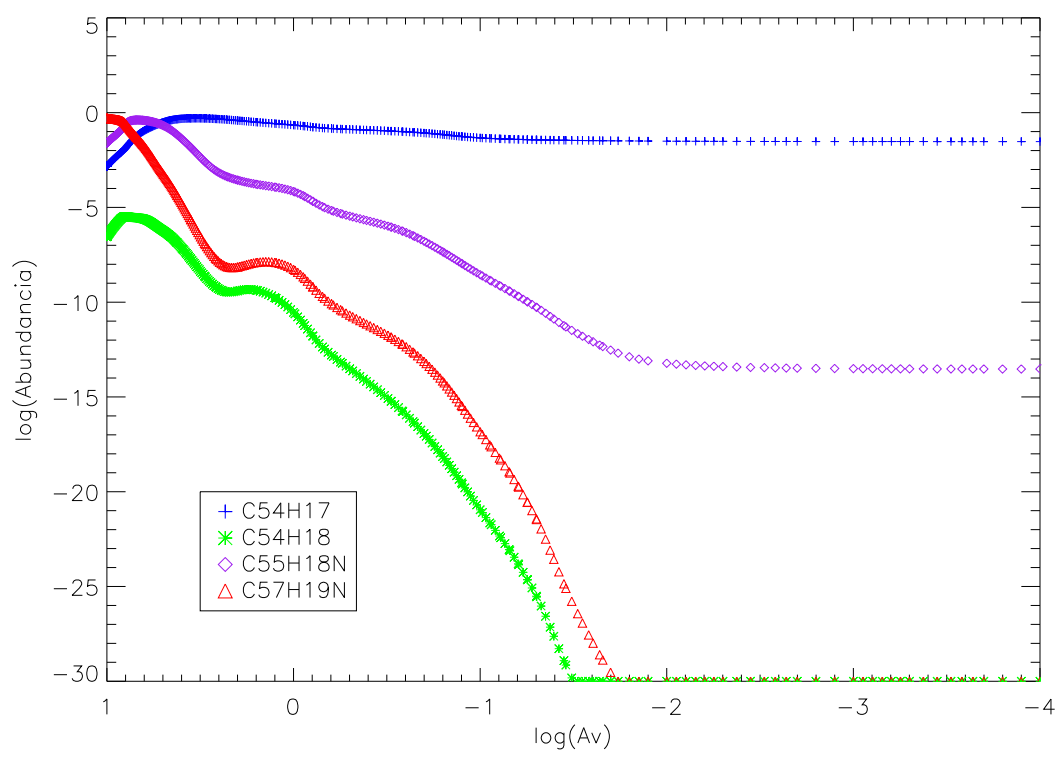

Figura 3.35: Abundância dos PAHs e PANHs ao longo da Nebulosa Cabeça de Cavalo, para uma abundância fixa do PAH e a rede de reações da Tabela 3.10.

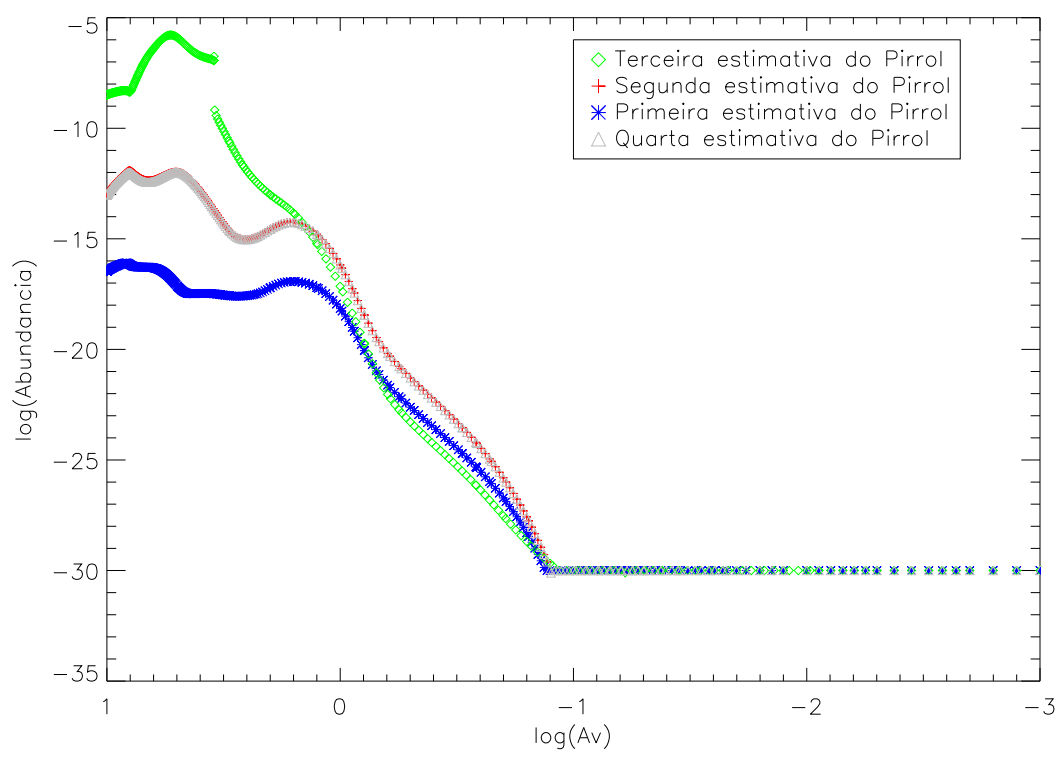

Figura 3.36: Comparação entre as abundâncias do pirrol para uma abundância fixa do PAH e a rede de reações da Tabela 3.10 .

ciente (figuras 3.37 e 3.38). Esse canal de produção é mais relevante do que a produção a partir do pirrol (Tabela 3.8) para as regiões mais internas da nuvem, $A_{V}>5$, onde ele acarreta um aumento de mais de sete ordens de magnitude das abundâncias da piridina. 


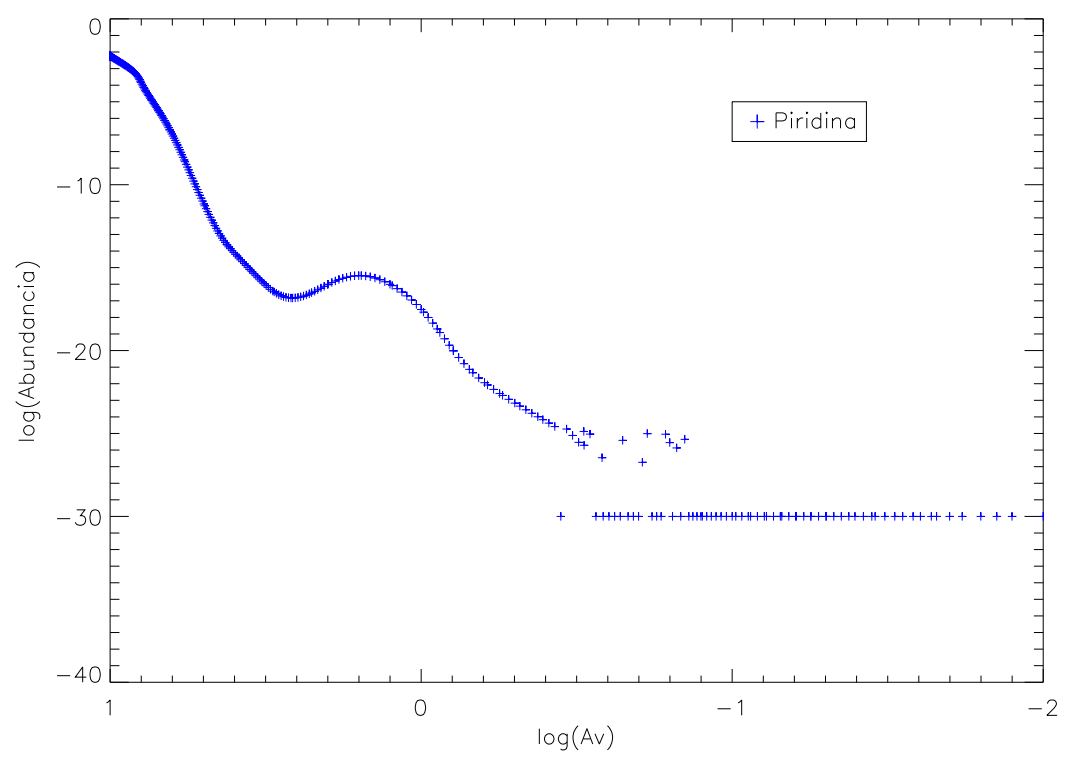

Figura 3.37: Abundância da piridina para uma abundância fixa do PAH e a rede de reações da Tabela 3.10,

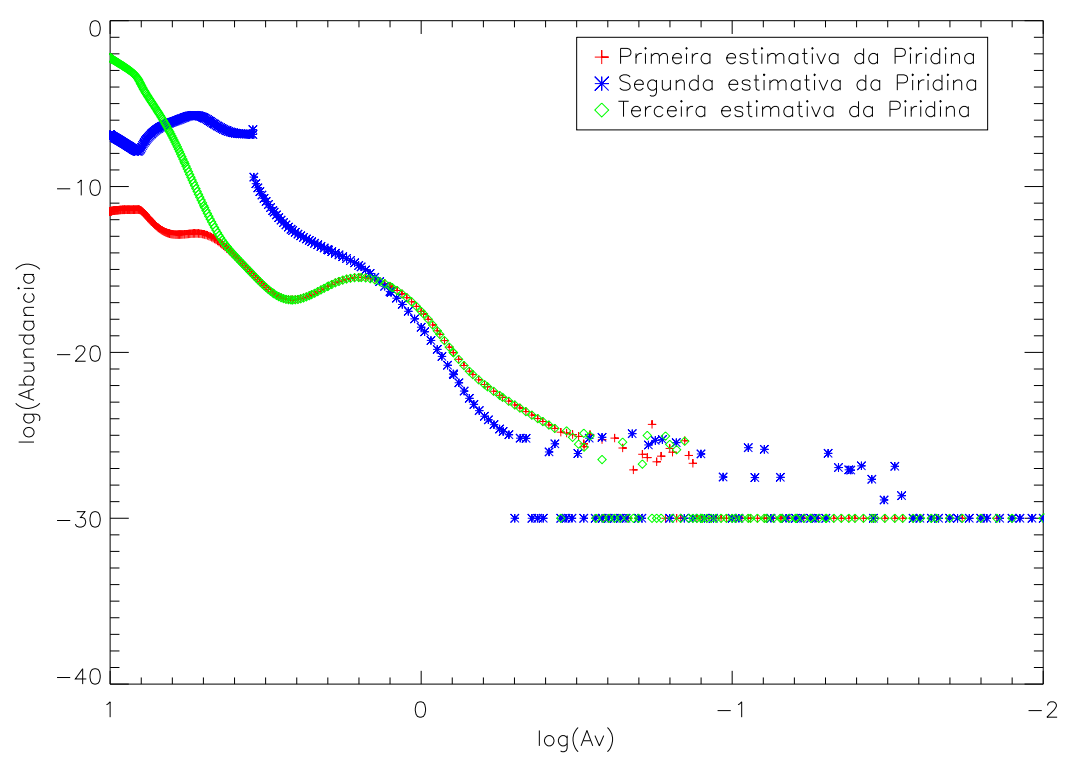

Figura 3.38: Comparação entre as abundâncias da piridina para uma abundância fixa do PAH e a rede de reações da Tabela 3.10.

A abundância resultante da piridina é maior nas regiões centrais da HHN (Figura 3.37). A inclusão do canal adicional da produção de piridina via PAH leva à abundâncias significativas dessa espécie em $A_{V}=10$ enquanto que as abundâncias do pirrol permanecem 
muito baixas.

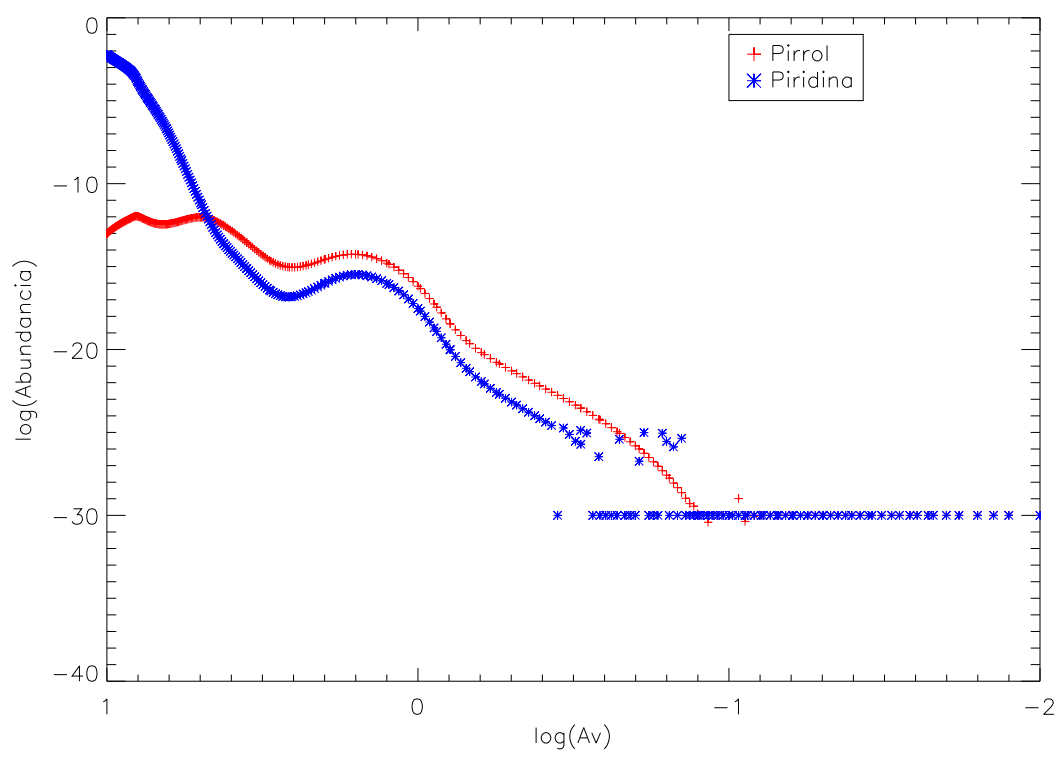

Figura 3.39: Comparação entre as abundâncias do pirrol e da piridina para uma abundância fixa do PAH e a rede de reações da Tabela 3.10 . 
Capítulo 4

\section{Análise}

O nitrogênio é um dos mais abundantes elementos do Universo e um ingrediente fundamental da vida. Desse modo, é necessário fazer um inventário das várias formas de nitrogênio presentes no Universo para se mapear as possíveis químicas alternativas para a vida. Durante a formação de um anel aromático, um átomo de carbono pode ser substituido por um de nitrogênio em reações de fase gasosa com moléculas nitrogenadas, tais como o HCN, produzindo uma molécula heterocíclica nitrogenada. Um levantamento dos heterocíclicos interestelares pode fornecer um quadro mais abrangente de sua história química e de possíveis papéis pré-bióticos dos heterocíclicos no surgimento da vida na Terra. O presente capítulo pretende fornecer algumas contribuições nesse sentido.

\subsection{Inventário do Nitrogênio no Meio Interestelar}

As figuras 4.1, 4.2 e 4.3 mostram que dentre as moléculas, o CN é o maior reservatório de nitrogênio na Nebulosa Cabeça de Cavalo. Fora da região central da Nebulosa notase, porém, que este elemento apresenta-se em sua maior parte na forma de nitrogênio atômico. A figura 4.3 indica, ainda, que no centro da nuvem o nitrogênio apresenta-se em maior quantidade no $\mathrm{HCN}, \mathrm{HNC}$ e $H C_{3} N$, supondo a concentração do $\mathrm{CN}$. A maior concentração de N no centro da HHN em moléculas maiores decorre destas estarem mais blindadas contra a radiação UV nesta região.

As tabelas 4.1, 4.2 e 4.3 apresentam as razões de densidade de coluna, relativas ao $\mathrm{CN}$, para algumas espécies nitrogenadas simples, hidretos de nitrogênio e para o cianeto e seus derivados.

Nitrogênio é o terceiro elemento quimicamente ativo mais abundante no Universo. Nas 


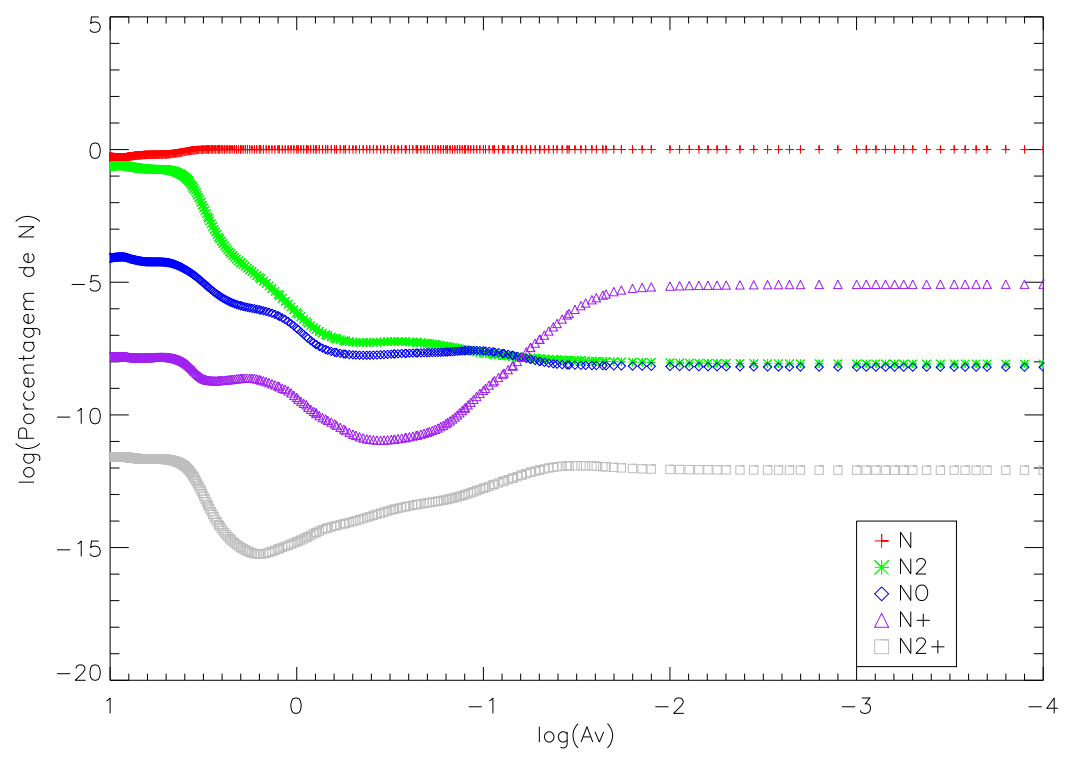

Figura 4.1: Fração de N em algumas formas simples de nitrogênio ao longo da Nebulosa Cabeça de Cavalo.

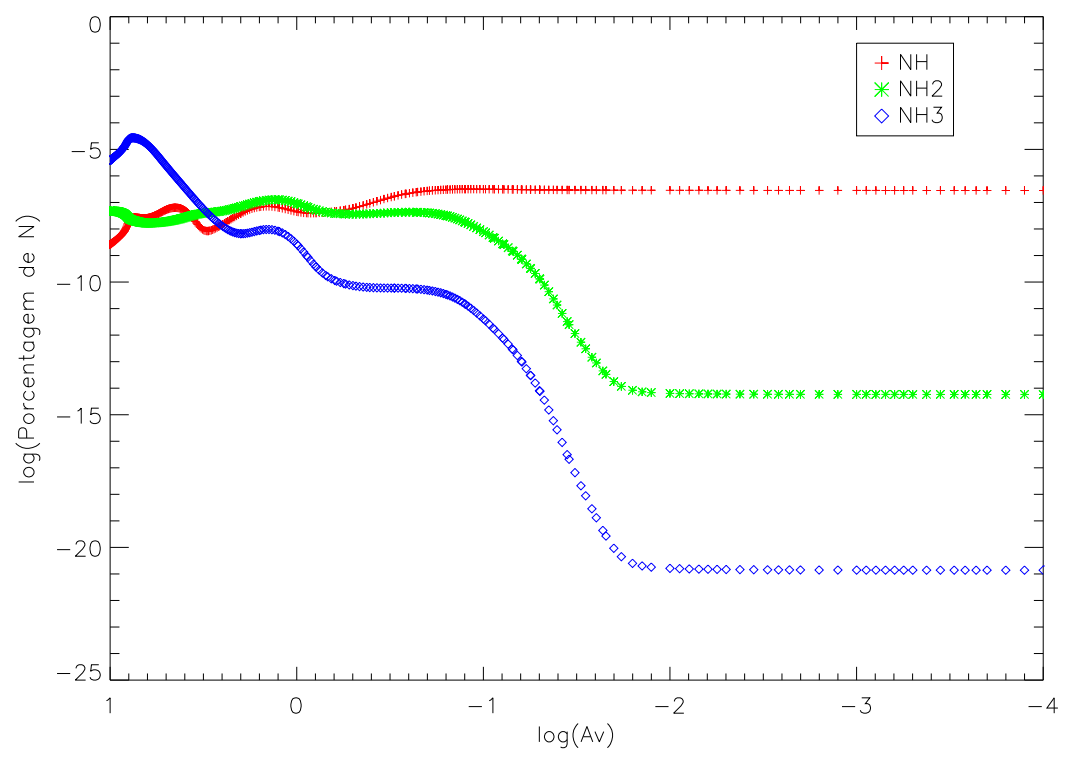

Figura 4.2: Fração de $\mathrm{N}$ em alguns hidretos de nitrogênio ao longo da Nebulosa Cabeça de Cavalo.

atmosferas planetárias, como na Terra e Titã, o nitrogênio molecular é a molécula dominante. Também no meio interestelar, espera-se que o $N_{2}$ seja uma espécie nitrogenada abundante. Como se vê da Tabela 4.1 e da figura 4.1 isso é o que ocorre, pois o $N_{2}$, depois 


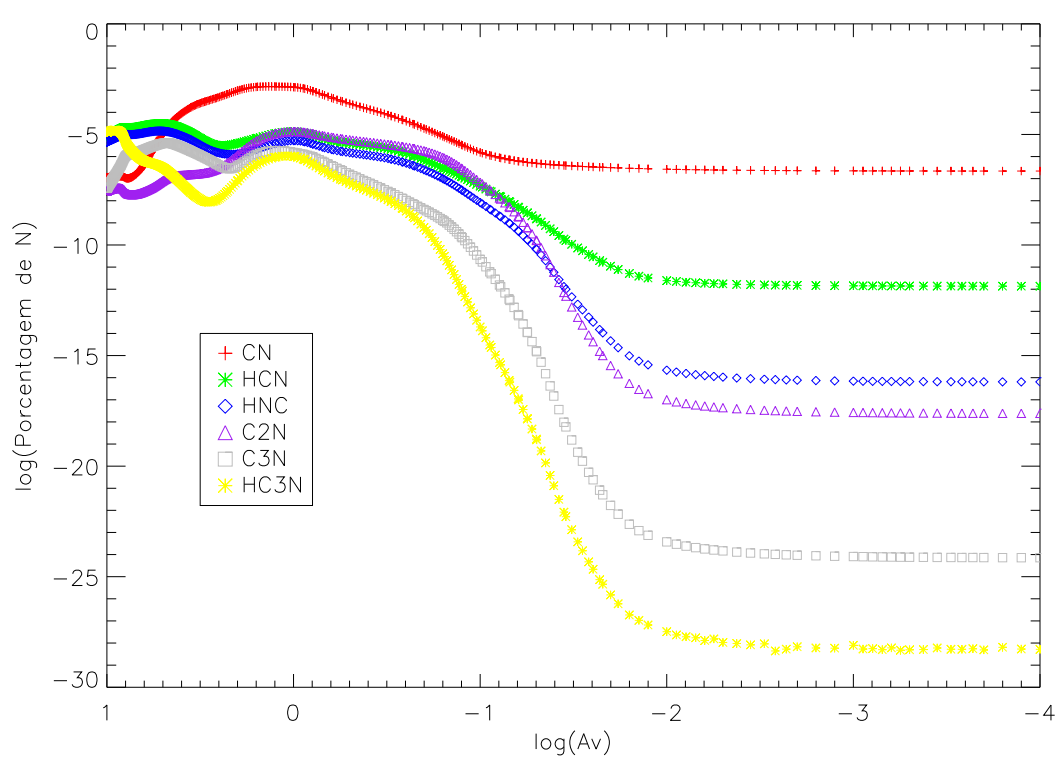

Figura 4.3: Fração de N em cianeto e seus derivados ao longo da Nebulosa Cabeça de Cavalo.

do nitrogênio atômico, torna-se a forma nitrogenada dominante em $A_{V}>1$. Contudo, o $N_{2}$ não possui transições vibracionais ou rotacionais visíveis no IR e, assim, sua abundância no meio interestelar é pouco conhecida. No entanto, a sua abundância pode ser inferida do $\mathrm{N}_{2} H^{+}$. Maret et al. (2006), a partir de observações de nuvens moleculares escuras, encontraram que a abundância do nitrogênio atômico é maior do que aquela do nitrogênio molecular, em conformidade com os nossos resultados.

Tabela 4.1 - Razões de densidade de coluna $\left(\mathrm{cm}^{-2}\right)$, em relação ao $\mathrm{CN}$, do $\mathrm{N}_{2}$ e $\mathrm{NO}$ e dos íns $N^{+}$e $N_{2}^{+}$.

\begin{tabular}{cccc}
\hline Molécula & $A_{V}=1 \mathrm{mag}$ & $A_{V}=3 \mathrm{mag}$ & $A_{V}=10 \mathrm{mag}$ \\
\hline $\mathrm{N}(\mathrm{CN})$ & $6.44 \times 10^{13}$ & $3.42 \times 10^{14}$ & $3.75 \times 10^{14}$ \\
$N\left(N_{2}\right) / \mathrm{N}(\mathrm{CN})$ & $2.94 \times 10^{-4}$ & 0.29 & 496 \\
$\mathrm{~N}(\mathrm{NO}) / \mathrm{N}(\mathrm{CN})$ & $8.84 \times 10^{-5}$ & $1.69 \times 10^{-3}$ & 0.17 \\
$N\left(N^{+}\right) / \mathrm{N}(\mathrm{CN})$ & $4.02 \times 10^{-4}$ & $7.72 \times 10^{-5}$ & $1.08 \times 10^{-4}$ \\
$N\left(N_{2}^{+}\right) / \mathrm{N}(\mathrm{CN})$ & $2.05 \times 10^{-10}$ & $4.30 \times 10^{-11}$ & $5.6 \times 10^{-9}$ \\
\hline
\end{tabular}

Os hidretos de nitrogênio são importantes moléculas para compreender a química do nitrogênio porque eles estão entre as primeiras moléculas neutras formadas em um gás com 
a composição inicial dominada por hidrogênio e hélio. Amônia foi a primeira molécula interestelar detectada em direção ao centro da Galáxia (Cheung et al., 1968) e espera-se que domine os hidretos de nitrogênio em nuvens escuras. Essa tendência é bem reproduzida pelos nossos resultados, como podemos ver da figura 4.2 e da tabela 4.2, para $A_{V}=10$. Existe, contudo, um problema em relação à razão $N H: N H_{2}$ que persiste para vários modelos em relação à comparação de dados observacionais com precisão de modelos, pois a razão $N H: N H_{2}$ prevista pelas simulações é muito baixa. Observações da protoestrela IRAS 16293-2422, indicam $\mathrm{NH}: \mathrm{NH}_{2}: \mathrm{NH}_{3} \sim 5: 1: 300$, enquanto que o modelo prevê 1:1:200 para $A_{V}=10$. Essa discrepância entre observações e modelos para estas razões já havia sido assinalada por Hily-Blant et al. (2010). Aparentemente alguma química hidrogênio-nitrogênio adicional é necessária.

Tabela 4.2 - Razões de densidade de coluna $\left(\mathrm{cm}^{-2}\right)$, em relação ao $\mathrm{CN}$, para hidretos de nitrogênio.

\begin{tabular}{cccc}
\hline \hline Molécula & $A_{V}=1 \mathrm{mag}$ & $A_{V}=3 \mathrm{mag}$ & $A_{V}=10 \mathrm{mag}$ \\
\hline $\mathrm{N}(\mathrm{CN})$ & $6.44 \times 10^{13}$ & $3.42 \times 10^{14}$ & $3.75 \times 10^{14}$ \\
$\mathrm{~N}(\mathrm{NH}) / \mathrm{N}(\mathrm{CN})$ & $2.87 \times 10^{-4}$ & $8.71 \times 10^{-5}$ & $1.52 \times 10^{-4}$ \\
$N\left(\mathrm{NH}_{2}\right) / \mathrm{N}(\mathrm{CN})$ & $9.58 \times 10^{-5}$ & $8.53 \times 10^{-5}$ & $1.55 \times 10^{-4}$ \\
$N\left(\mathrm{NH}_{3}\right) / \mathrm{N}(\mathrm{CN})$ & $7.45 \times 10^{-7}$ & $1.04 \times 10^{-5}$ & $3.25 \times 10^{-2}$ \\
\hline
\end{tabular}

Tabela 4.3 - Razões de densidade de coluna $\left(\mathrm{cm}^{-2}\right)$, em relação ao CN, para cianetos e seus derivados.

\begin{tabular}{cccc}
\hline \hline Molécula & $A_{V}=1 \mathrm{mag}$ & $A_{V}=3 \mathrm{mag}$ & $A_{V}=10 \mathrm{mag}$ \\
\hline $\mathrm{N}(\mathrm{CN})$ & $6.44 \times 10^{13}$ & $3.42 \times 10^{14}$ & $3.75 \times 10^{14}$ \\
$\mathrm{~N}(\mathrm{HCN}) / \mathrm{N}(\mathrm{CN})$ & $1.14 \times 10^{-2}$ & $7.16 \times 10^{-3}$ & $6.11 \times 10^{-2}$ \\
$N(H N C) / \mathrm{N}(\mathrm{CN})$ & $4.56 \times 10^{-3}$ & $2.81 \times 10^{-3}$ & $2.93 \times 10^{-2}$ \\
$N\left(C_{2} N\right) / \mathrm{N}(\mathrm{CN})$ & $1.45 \times 10^{-2}$ & $5.91 \times 10^{-3}$ & $5.57 \times 10^{-3}$ \\
$N\left(C_{3} N\right) / \mathrm{N}(\mathrm{CN})$ & $9.64 \times 10^{-4}$ & $9.33 \times 10^{-4}$ & $5.71 \times 10^{-3}$ \\
$N\left(H C_{3} N\right) / \mathrm{N}(\mathrm{CN})$ & $5.22 \times 10^{-4}$ & $3.54 \times 10^{-4}$ & $1.24 \times 10^{-2}$ \\
& & &
\end{tabular}




\subsection{Rotas para a Produção de Heterocíclicos}

A tabela 4.4 lista a densidade de coluna $\left(\mathrm{cm}^{-2}\right)$ do pirrol e da piridina para distintos canais de produção em diversos pontos da HHN. Pirrol* refere-se aos cálculos de produção deste somente com as reações da tabela 3.5 e Piridina* refere-se à quantidade de piridina produzida apenas a partir do etano (reações da tabela 3.7). A densidade de coluna do CN é tomada como referência. Também foram incluidos o $C N^{+}, C N^{-}, \mathrm{HCN}$ e o HNC. Pirrol $^{\dagger}$ e Piridina ${ }^{\dagger}$ referem-se à densidade de coluna destes quando inclui-se um PAH com uma dada abundância inicial no arquivo de química. Pirrol ${ }^{\S}$ e Piridina ${ }^{\S}$ referem-se aos resultados com a abundância do PAH fixa e as reações da Tabela 3.10.

Tabela 4.4 - Densidade de Coluna $\left(\mathrm{cm}^{-2}\right)$ do pirrol e da piridina para distintos canais de produção em diversos pontos da HHN. Pirrol* refere-se aos cálculos de produção deste somente com as reações da tabela 3.5 e Piridina* refere-se à quantidade de piridina produzida apenas a partir do etano (reações da tabela 3.7). Pirrol $^{\dagger}$ e Piridina ${ }^{\dagger}$ referem-se à densidade de coluna destes quando inclui-se um PAH com uma dada abundância inicial no arquivo de química. A densidade de coluna do CN é tomada como referência.Pirrol ${ }^{\S}$ e Piridina ${ }^{\S}$ referem-se aos resultados com a abundância do PAH fixa e as reações da Tabela 3.10.

\begin{tabular}{cccc}
\hline \hline Molécula & $A_{V}=1 \mathrm{mag}$ & $A_{V}=3 \mathrm{mag}$ & $A_{V}=10 \mathrm{mag}$ \\
\hline $\mathrm{CN}$ & $6.44 \times 10^{13}$ & $3.42 \times 10^{14}$ & $3.75 \times 10^{14}$ \\
$C N^{+}$ & $3.45 \times 10^{7}$ & $3.50 \times 10^{7}$ & $3.50 \times 10^{7}$ \\
$C N^{-}$ & $1.89 \times 10^{4}$ & $2.56 \times 10^{7}$ & $2.96 \times 10^{7}$ \\
$\mathrm{HCN}$ & $7.37 \times 10^{11}$ & $2.45 \times 10^{12}$ & $2.29 \times 10^{13}$ \\
$\mathrm{HNC}$ & $2.94 \times 10^{11}$ & $9.60 \times 10^{11}$ & $1.10 \times 10^{13}$ \\
Pirrol $^{*}$ & $3.71 \times 10^{-4}$ & $6.17 \times 10^{-2}$ & $9.88 \times 10^{-1}$ \\
Pirrol $^{\dagger}$ & $2.85 \times 10^{-2}$ & 25.30 & $1.37 \times 10^{4}$ \\
Pirrol $^{\dagger}$ & $2.71 \times 10^{-3}$ & $1.58 \times 10^{4}$ & $8.52 \times 10^{9}$ \\
Pirrol $^{\S}$ & $2.85 \times 10^{-2}$ & 25.30 & $1.37 \times 10^{4}$ \\
Pridina $^{*}$ & $2.14 \times 10^{-10}$ & $2.51 \times 10^{-9}$ & $3.29 \times 10^{-5}$ \\
Piridina & $1.19 \times 10^{-3}$ & 1.20 & $3.40 \times 10^{4}$ \\
Piridina $^{\dagger}$ & $1.15 \times 10^{-4}$ & $2.01 \times 10^{3}$ & $1.14 \times 10^{10}$ \\
Piridina $^{\S}$ & $1.19 \times 10^{-3}$ & 1.20 & $1.50 \times 10^{13}$ \\
& & & \\
\hline
\end{tabular}

A abundância de $C N^{+}$já é baixa nas regiões centrais da nuvem, como é de se esperar, o que justifica o fato de sua densidade de coluna não crescer quando se vai a profundidades 
maiores (de $A_{V}=1$ para $10 \mathrm{mag}$ ). Por outro lado, a abundância do $C N^{-}$é muito baixa em relação às observações. Agúndez et al. (2010) encontraram $C N^{-} / C N=2.5 \times$ $10^{-3}$ para o envelope da estrela IRC+10216, um valor muito acima da razão prevista de $10^{-7}$. Além do fato do código Meudon não se prestar a modelizar envelopes circumestelares, essa subestimativa indica que a química do CN está muito incompleta, pois mesmo modelos projetados para envelopes estelares preveem razões ordens de magnitude abaixo das observadas (Agúndez et al., 2010).

A grande maioria dos trabalhos relacionados à heterocíclicos no meio interestelar têm se focado na destruição dessas espécies pela radiação UV ou raios cósmicos (Peeters et al. (2005), Ruiterkamp et al. (2005) e Cottin et al. (2003)). Uns poucos trabalhos se dedicaram à sintese de heterocíclicos, em geral, em gelos irradiados por radiação ultravioleta que destrói algum heterocíclico complexo já presente (ver Nuevo et al. (2012) em relação à piridina). Assim, a investigação de novas rotas para a produção de heterocíclicos, como resumida na tabela 4.4, é fundamental. Vimos que os grandes PAHs podem exercer o papel de catalisador na formação de outros PAHs. O processo de incorporação de um átomo de nitrogênio em um PAH, seguindo os passos sugeridos por Ricca et al. (2001) permitiu definir uma nova rota para a produção dos heterocíclicos nitrogenados pirrol e piridina.

Tendo em vista a presença constante de PAHs e de PANHs em ambientes interestelares e circum-estelares, essas espécies podem catalizar a formação não só de heterocíclicos com um átomo de nitrogênio incorporado, mas com dois átomos, como a pirimidina, a pirimidona e a uracila. Nesse caso, contudo, a abundância esperada deve ser menor.

Como vemos da tabela 4.4, a densidade de coluna da piridina é cerca de $10^{13} \mathrm{~cm}^{-2}$ para a rota de produção via PAHs. As entradas Pirrol ${ }^{\dagger}$ e Piridina ${ }^{\dagger}$ fornecem densidades de coluna que não pretendem ser realísticas, mas apenas servem para verificar a plausibilidade do mecanismo de produção de heterocíclicos nitrogenados via PAHs. Já as densidades de coluna do Pirrol ${ }^{\S}$ e Piridina ${ }^{\S}$ foram calculadas em condições mais realísticas. Se escalonarmos a densidade de coluna do CN da HHN, para Sgr B2, que apresenta fontes com $N(C N) \sim 3 \times 10^{15} \mathrm{~cm}^{-2}$ (Adande e Ziurys, 2012), obteremos densidades de coluna da ordem de $10^{14} \mathrm{~cm}^{-2}$, para a piridina. Esse valor é elevado em relação aos limites superiores das observações visando detectar esta molécula, indicando que houve uma superestimativa no cálculo da sua taxa de produção. Por outro lado, a alta abundância obtida para essa 
molécula torna-se um alvo para futuras observações, mesmo após correções da sua química. Nesse sentido, a investigação de Titã e dos corpos gelados do Sistema Solar poderá fornecer um laboratório local para testar a química e a física do meio interestelar. É interessante que no caso de Titã (Krasnopolsky, 2009) a piridina apresente maiores abundâncias do que o pirrol, exatamente como o modelo prevê para a HHN. Deve-se, porém, notar que, dentro dos canais examinados aqui, não se encontrou a produção de pirrols via PAHs.

Ao se considerar PAHs de abundância fixa, a abundância da piridina aumentou acentuadamente, atingindo uma densidade de coluna acima dos limites superiores determinados por observações (Simon e Simon, 1973). Isso sugere que a constante de reação para sua formação a partir do $C_{54} H_{19} N$ (Tabela 3.10) tenha sido superestimada. Por outro lado, não houve um canal adicional para a produção do pirrol via PAHs e sua abundância permaneceu baixa, em conformidade com as observações (Myers et al., 1980). Contudo, deve-se observar que poucos canais de produção foram investigados. Pode surgir, em uma exploração mais ampla de possibilidades, por exemplo, um canal adicional para o pirrol. Também a consideração de canais adicionais deverá elevar a abundância da piridina.

Algo que não foi levado em consideração na rede de reações envolvendo os PAHs são os cátions. A introdução de espécies $P A H^{+}$deverá elevar a taxa de produção de várias espécies, pois as taxas de reação cátion-neutros tem coeficientes tipicamente da ordem de $10^{-9} \mathrm{~s}^{-1} \mathrm{~cm}^{-3}$ (Vuong e Foing, 2000), em vez do valor $10^{-10} \mathrm{~s}^{-1} \mathrm{~cm}^{-3}$ adotado aqui como típico para reações radical-neutro (Le Page et al., 2001).

Outro fator que poderia aumentar a produção de heterocíclicos nitrogenados seria um maior número de sítios desidrogenados no PAH. De fato, aqui somente consideramos a ejeção de apenas um átomo de $\mathrm{H}$, enquanto pode haver mais de um. Uma hierarquia de PAHs com mútiplos graus de desidrogenação deveria comparecer em um modelo completo. Em nossos cálculos para a espécie representativa, o $C_{54} H_{18}$, ele aparece essencialmente como a forma desidrogenada uma vez $C_{54} H_{17}$. Isso corresponde a um grau de hidrogenação $x_{H}=17 / 18=94 \%$, ou seja, em média, o PAH não está desidrogenado.

Infelizmente, as observações das linhas de emissão no infravermelho atribuidas aos PAHs, as AIBs, não permitem decidir esta questão. Não se distingue $x_{H}=100 \%, 95 \%$, $90 \%$ ou $75 \%$. No máximo, pode-se dizer que a maior parte das observações é compatível com $x_{H}>50 \%$ (Schutte et al., 1993) . As AIBs não fornecem uma assinatura de quando os 
PAHs responsáveis pela emissão em infravermelho estão totalmente hidrogenados, mas apenas de quando estão quase totalmente desidrogenados. Esta última situação ocorre para campos de radiação muito intensos como, por exemplo, de um núcleo ativo de galáxia. Neste caso, pode-se encontrar $x_{H}<0.1$ (Siebenmorgen e Kruegel, 1992). Outra possível assinatura dos PAHs seriam as Bandas Interestelares Difusas (DIBs, na sigla em inglês), um conjunto de linhas de absorção largas $(F W M M \geq 1 \AA)$ observadas no visível e infravermelho próximo (Leger e D'Hendecourt (1985), Herbig (1995), Draine (2003)). O fato das bandas serem muito largas exclui moléculas com menos de 5 átomos na fase gasosa e, portanto é mais provável que as DIBs sejam associadas com as populações de grãos e poeira. Entre estas populações, a de PAHs foi sugerida por vários estudos. Em particular, a DIB mais forte, a $4430 \AA$, foi atribuída ao cátion do coroneno duplamente desidrogenado $C_{24} H_{10}^{+}$(Duley, 2006). Esta identificação permitiria o conhecimento de pelo menos um estado de desidrogenação de um PAH. Infelizmente, experimentos de laboratório com o $C_{24} H_{10}^{+}$(Useli-Bacchitta et al., 2010) revelaram, além de uma transição eletrônica a 442 nm que seria identificada com a DIB a $4430 \AA$, uma mais forte a $458 \mathrm{~nm}$, o que exclui o $C_{24} H_{10}^{+}$como portador da DIB a $4430 \AA$. Portanto, até o momento, a distribuição detalhada dos estados de desidrogenação dos PAHs é desconhecida, o que nos dá uma maior liberdade para explorar uma faixa maior de PAHs desidrogenados.

Um outro resultado das nossas simulações é que essencialmente todo PAH está na forma de PANHs no centro da nuvem. Isso é compatível com as previsões de Hudgins et al. (2005) de que mais de 1-2\% de todo nitrogênio cósmico está sequestrado na população de PAHs interestelares. De fato, dada a abundância $[P A H]=10^{-6}$ e a abundância do nitrogênio no meio interestelar $[N]=7.95 \times 10^{-5}$, obtemos que $1.3 \%$ do nitrogênio está na população de PAH - PANHs. Como Hudgins et al. (2005) estabelece apenas um limite inferior para o total de nitrogênio presentes em PAHs, podemos a princípio, ter dois ou mais sítios dopados do nitrogênio no nosso PAH típico $\mathrm{C}_{54} H_{18}$, um limite consistente com o conhecimento sobre o grau de desidrogenação de PAHs e que permitiria multiplicar pelo número de sítios desidrogenados-nitrogenados a taxa de produção de heterocíclicos nitrogenados. 


\subsection{Busca por Moléculas em Ambientes Interestelares e Circum-estelares}

Há cada vez mais sugestões de que várias moléculas que constituem as unidades básicas da vida são mais facilmente sintetizadas no meio interestelar do que na Terra, e que o nosso planeta foi posteriormente enriquecido por essas moléculas que vieram bombardeadas por cometas. Os cometas são reservatórios de moléculas que contém poeira da nuvem primitiva que originou o Sistema Solar e, além disso, podem ser considerados como intermediários entre o meio interestelar e o Sistema Solar. Buscas por grandes moléculas de relevância biológica no meio interestelar têm sido conduzidas por décadas e resultou na identificação de aproximadamente 170 moléculas no meio interestelar e circum-estelar - lista que pode ser aumentada em cerca de $10 \%$ se incluir as detecção não confirmadas - desde moléculas diatômicas a fulerenos. Outras moléculas importantes que foram detectadas nesta árdua busca foram aldeídos, como o propenal $\left(\mathrm{CH}_{2} \mathrm{CHCHO}\right)$ e o propanal $\left(\mathrm{CH}_{3} \mathrm{CH}_{2} \mathrm{CHO}\right)$ (Hollis et al., 2004), como também um açúcar simples, o glicoaldeído $\left(\mathrm{CH}_{2} \mathrm{OHCHO}\right)$ (Hollis et al. (2000); Hollis et al. (2004)), e mesmo um precursor do açúcar ribose, presente na estrutura dos acídos nucleicos, a molécula cíclica óxido de etileno $\left(c-\mathrm{C}_{2} \mathrm{H}_{4} \mathrm{O}\right)$ (Dickens et al., 1997). Além do conhecimento de moléculas nitrogenadas, aquelas das espécies oxigenadas-aldeídos, alcoois, açúcares etc. - é também fundamental para o entedimento da química pré-biótica. Nesse sentido, observações de regiões ricas destas moléculas, como o Centro Galáctico (Requena-Torres et al., 2008) são de grande importância astrobiológica.

Com a expectativa de aumentar o nosso conhecimento do conteúdo molecular do Universo, o Telescópio Herschel, lançado em 14 de maio de 2009, já demonstra seus primeiros resultados. Com alta resolução no Infravermelho, em três cores, foi realizada uma foto de M51, a 'Whirlpool galaxy', como mostra a figura 4.4. Vermelho, verde e azul corresponde a $160 \mu \mathrm{m}, 100 \mu \mathrm{m}$ e $70 \mu \mathrm{m}$, respectivamente. O aparelho utilizado foi o Herschel's Photoconductor Array Camera and Spectrometer, PACS. É possível analisar, ainda, a resolução deste equipamento, quando comparamos a imagem de M51 com uma do Spitzer Telescope. A imagem do Herschel tem uma definição muito maior e mais nítida, como mostra a figura 4.4.

Os PAHs devem constituir o maior reservatório de moléculas orgânicas no meio interestelar, além de desempenharem um papel essencial na formação de moléculas mais com- 


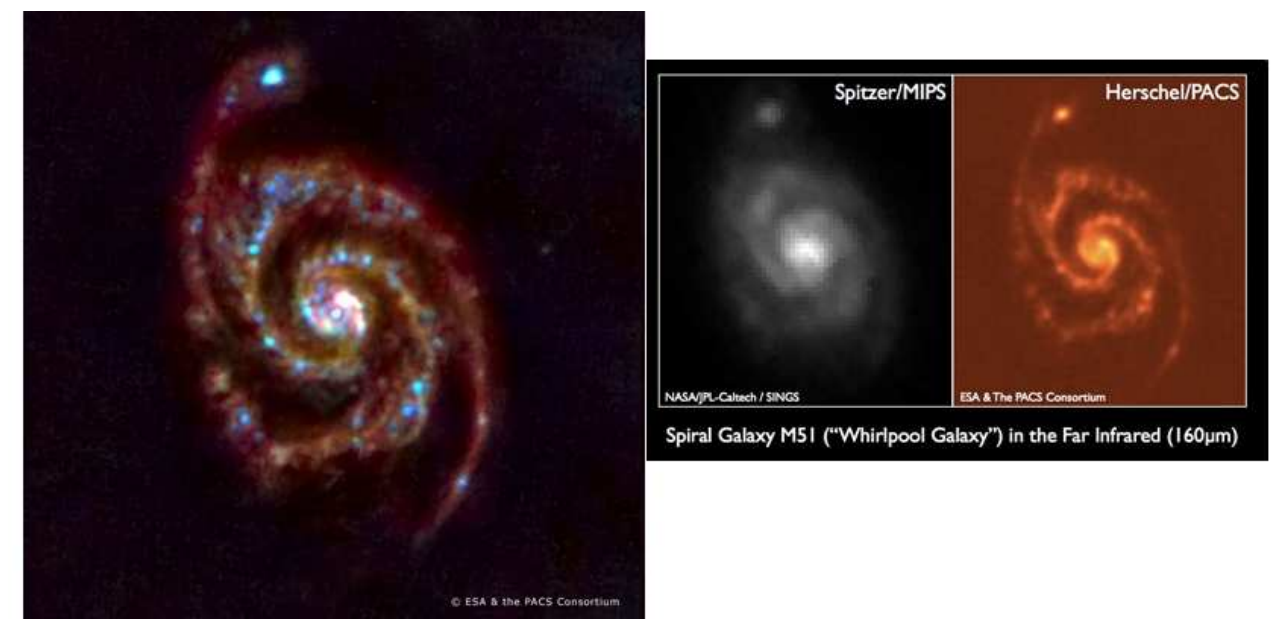

Figura 4.4: Foto de M51 tirada pelo Herschel (direita) e a mesma galáxia comparando as imagens do Herschel e do Spitzer Telescope (esquerda) (Science e Technology, 2011).

plexas, mas a busca por bandas de PAHs no Infravermelho-distante (FIR) é um projeto difícil, já que se prevê que as bandas fracas e nossa habilidade para observá-las dependerá de quão diversas são as misturas dos PAHs interestelares. O Herschel oferece a possibilidade de investigar esta questão graças a características e a faixa espectral que seus instrumentos cobrem. SOFIA e ALMA, que estão agora entrando em cena, podem também trazer novos insights dentro deste tópico. A próxima missão espacial no FIR/sulmilimétrico será o SPICA (com data de lançamento prevista para 2018). Mas, nenhuma destas missões permitirá cobrir toda a faixa espectral do Herschel e, então, nós poderíamos tentar uma busca árdua por estas bandas de PAH com o Herschel. Como demonstramos no capítulo 3, PAHs desidrogenados podem ser cruciais para a formação de compostos heterocíclicos e, portanto, o grau de desidrogenação dos PAHs deve ser investigado pela comparação entre linhas produzidas por ligações $\mathrm{CH}$ e as produzidas por ligações CC.

A previsão das bandas e perfis de bandas dos PAHs é uma tarefa teórica fundamental, e vários modelos têm buscado esse objetivo como, por exemplo, o de Ceccarelli et al. (2001), que inclui resfriamento por cascata e detalha propriedades moleculares (anarmocidade, rotação etc.). Neste cômputo, há ainda muito trabalho de laboratório a ser feito e isto não é tarefa fácil para experimentos ou cálculos teóricos. Do ponto de vista experimental, há a necessidade de espectroscopia no infravermelho-distante para as moléculas de PAH. Os cálculos da matriz de parâmetros anarmônicos com cálculos da química quântica usando 
a teoria da densidade funcional (DFT) são muito complicados. Para altas temperaturas, alternativas têm sido encontradas, tais como dinâmicas moleculares com esquema de aproximação DFT (Porezag et al., 1995), mas necessita cálculos para baixas temperaturas. Um grande esforço ainda é necessário em relação a este assunto, tanto observacional como do ponto de vista de laboratório.

Uma classe de moléculas astrobiologicamente interessantes é a constituída pelos compostos heterocíclicos. Foi isto que motivou as simulações no capítulo 3 com essas espécies. $\mathrm{Na}$ bioquímica terrestre, os heterocíclicos das classes das pirimidinas (citosina, timina e uracila) e das purinas (adenina e guanina) são as nucleobases usadas no maquinário informacional do DNA e RNA. Moléculas heterocíclicas simples poderiam ser buscadas através de observações desde a faixa do rádio até o infravermelho de ambientes interestelares e circustelares. Compostos heterocíclicos simples, similarmente aos PAHs, devem ser abundantes, pois ambos os tipos de moléculas são resistentes à radiação UV (Peeters et al. 2005). Algumas dessas espécies poderiam ser alvos de futuras jornadas observacionais: oxazol $\left(\mathrm{C}_{3} \mathrm{H}_{3} \mathrm{NO}\right)$, furano $\left(\mathrm{C}_{4} \mathrm{H}_{4} \mathrm{O}\right)$, também o pirrol $\left(\mathrm{C}_{4} \mathrm{H}_{4} \mathrm{NH}\right)$ e a piridina $\left(\mathrm{C}_{5} \mathrm{H}_{5} \mathrm{~N}\right)$. O Oxazol é de especial interesse porque, além de ser uma molécula relativamente pequena (com 8 átomos), o seu derivado, amino-oxazol $\left(\mathrm{C}_{3} \mathrm{H}_{2} \mathrm{NH}_{2} \mathrm{NO}\right)$, foi proposto como o precusor dos ribonucleotídeos de pirimidinas, no cenário do "Mundo do RNA"para a origem da vida na Terra (Powner et al., 2009). Além disso, o amino-oxazol pode ser montado a partir de moléculas detectadas no meio interestelar: a cianamida e do glicoaldeído $\left(\mathrm{CH}_{2} \mathrm{OHCHO}\right.$ ) (Hollis et al., 2000), (Hollis et al., 2004), (Halfen et al., 2006). Neste trabalho, a seção 4.2 demonstrou que a piridina pode ter abundâncias suficientemente altas para serem alvos de missões observacionais futuras.

Com a disponibilidade de dados observacionais para transições de moléculas desde o infravermelho até o rádio proporcionadas tanto por instrumentos espaciais (Spitzer e Herschel) como de solo (o VIZIR e o MIDI, instalados no VLT, e o ALMA), o estudo de moléculas complexas no meio interestelar tanto da Galáxia como de outras galáxias deverá experimetar uma grande expansão. A faixa do milimétrico é bastante promissora, haja vista a recente detecção no milimétrico da uréia $\left(\left(\mathrm{NH}_{2}\right)_{2} \mathrm{CO}\right)$, que desempenha um importante papel na química pré-biótica (Kuo et al., 2010). Finalmente, a participação brasileira no VLT e no ALMA (em especial, atravé do projeto LLAMA) tornará exequíveis 
projetos nacionais voltados para a detecção de moléculas em vários contextos astrofísicos.

As presentes simulações apresentaram como a exploração de uma pequena gama de possíveis canais de produção de heterocíclicos já resultou em abundâncias significativas para ao menos uma espécie de heterocíclicos nitrogenados, a piridina. Excursões sistemáticas pelos diversos canais de produção deverão revelar mais espécies para serem alvos destas buscas. 
Capítulo 5

\section{Conclusões e Perspectivas}

O objetivo deste estudo foi investigar a abundância de algumas moléculas de relevância pré-biótica que podem ser formadas no meio interestelar, o que deverá trazer contribuições para elucidar os cenários de origem da vida na Terra e outros lugares do Universo.

Para tanto, optou-se por estudar uma região fotodominada (PDR - do inglês photondominated region) por ser uma região de formação molecular. Modelos para PDRs foram usados para computar os parâmetros físicos e químicos de nuvens interestelares geometricamente simples, expostas à radiação ultravioleta distante (FUV). Devido à sua geometria e campo de radiação FUV serem bem conhecidos, a Nebulosa Cabeça de Cavalo (HHN do inglês Horsehead Nebula) representa um arquétipo de PDRs e fornece bons modelos numéricos para formação de moléculas na região. Por isso a HHN foi escolhida como objeto teste neste trabalho.

Para tais modelos foi usado o código PDR Meudon, pois é um código disponível publicamente e é um dos recursos dos programas a serem conduzidos com o observatório Herschel (Le Petit et al., 2006). Além disso, este código é amplamente usado porque permite definir e ajustar os parâmetros que descrevem o sistema como melhor convir. Porém, como todo modelo numérico, este apresenta uma série de aproximações que restrigem o programa. Entre essas restrições, neste trabalho, considerou-se no modelo apenas reações de formação e destruição de moléculas na fase gasosa, desprezando aquelas em grãos. Outras duas importantes restrições que devem ser consideradas são os valores das constantes definidas que podem ter incertezas e, a suposição de estado estacionário que impede que o modelo seja aplicado a regiões que não estejam em equilíbrio.

Procuramos comparar nossos modelos para a HHN com as simulações de Gerin et al. 
(2009) e Goicoechea et al. (2009), já conhecidos na literatura, de modo a termos segurança em relação às previsões sobre as abundâncias de moléculas prebióticas relevantes. Foram considerados os casos de densidade do gás constante, de pressão constante e isotérmico.

O modelo isobárico revelou-se o mais plausível e com previsões comparáveis aos resultados de Gerin et al. (2009) e Goicoechea et al. (2009).

Ao fazer comparações com observações, deve-se levar em conta que o modelo considera apenas reações de formação e destruição de moléculas na fase gasosa, sem incluir reações que envolvam grãos de poeira e gelo.

Estabelecido o modelo a ser usado, foram simuladas as abundâncias de moléculas que tenham potencial importância astrobiológica, como o $\mathrm{CN}$ e seus íons, o $\mathrm{HCN}$ e o $\mathrm{HNC}$, que estão na base de reações de formação de moléculas de importância biológica como as pirimidinas, que entram na composição dos ácidos nucleicos. As moléculas contendo nitrogênio são essenciais para a produção de bases nitrogenadas, que são responsáveis pela transferência da informação nos seres vivos da Terra. Investigamos a formação e a abundância do benzeno, a molécula aromática arquetípica, capaz de produzir pirimidinas, e dos heterocíclicos nitrogenados pirrol e piridina.

O pirrol e a piridina são as primeiras moléculas heterocíclicas aromáticas com anéis de cinco e seis membros, respectivamente. Devido à sua simplicidade e robustez são as mais prováveis de serem descobertas em buscas por moléculas pré-bióticas no espaço. Investigamos vários canais para a produção destas moléculas, e uma rota de síntese bastante promissora foi aquela onde estão presentes os PAHs, que atuam como catalisadores no processo de produção dos N-heterocíclicos.

\subsection{Precisamos de uma Revolução Molecular}

A lista de moléculas detectadas que é dada na tabela A.1 tem crescido de ano para ano, mas apenas incrementalmente e graças, principalmente, ao desenvolvimento de novos instrumentos. Porém, a taxa de crescimento do número de detecções de novas moléculas está longe de ser elevada. A investigação sobre as espécies moleculares no espaço é um esforço meticuloso, e o número de regiões astronômicas com espectros de alto sinal-ruído é pequeno. Novas espécies são descobertas por pesquisas metódicas e a detecção de novas moléculas é, muitas vezes, demorada, uma vez que é necessária a confirmação de várias 
transições da mesma molécula em bandas de diferentes frequências. Frequentemente apenas linhas fracas são identificadas, misturadas com transições muito próximas.

Uma coisa é certa: o inventário atual de moléculas está longe de ser abrangente. O avanço no campo da astroquímica precisa de um salto para atender as demandas da astrobiologia.

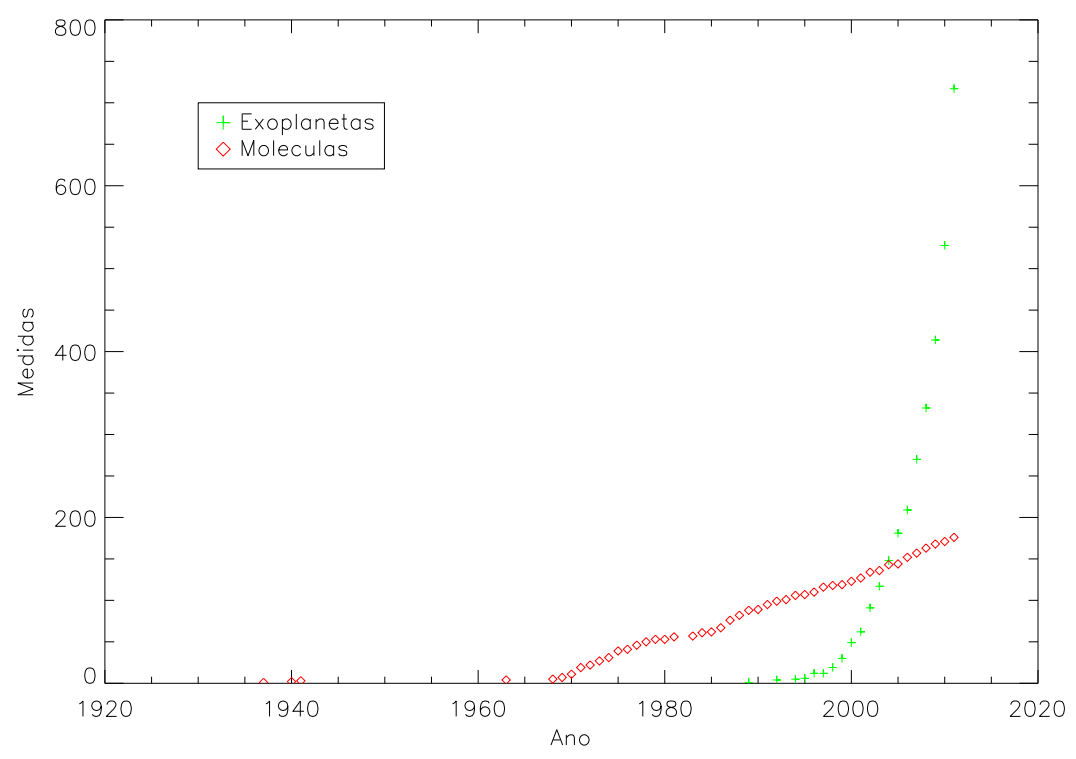

Figura 5.1: Moléculas e exoplanetas detectados ao longo dos anos.

A figura 5.1 mostra uma comparação entre o número cumulativo de moléculas detectadas no espaço e do número de exoplanetas descobertos em função do tempo. Uma característica impressionante destes dados é que a taxa de detecção de exoplanetas foi se acelerando com o tempo, enquanto a taxa de detecção das moléculas se manteve mais ou menos constante. No final de 2011 havia um total de 170 moléculas detectadas e confirmadas e 717 exoplanetas já descobertos (Physikalisches, 2012), (Cologne, 2012), (NRAO, 2012) e (Encyclopaedia, 2012).

O crescimento exponencial do número de exoplanetas se assemelha à lei de Moore, segundo a qual a densidade de transistores no interior de um microchip dobra, aproximadamente, a cada dois anos (Moore, 1965). A aceleração do número de planetas descobertos é devido aos novos avanços tecnológicos - os satélites CoRoT e Kepler, espectrógrafos como o HARPS e o Sophie, metodologias de tratamento de dados mais sofisticadas e um es- 
forço concentrado da comunidade científica internacional na busca de exoplanetas. Este comportamento exponencial é característico de vários desenvolvimentos tecnológicos da humanidade, por exemplo emissões de dióxido de carbono, e não poderá ser sustentado para sempre devido aos recursos finitos disponíveis para a pesquisa ou em virtude do tamanho finito da população objeto. Mais cedo ou mais tarde, a taxa de detecção de exoplanetas vai chegar a um estágio de aumento apenas discreto. Mas o que acontece com a pesquisa de espécies moleculares no espaço é que ela nunca experimentou fase exponencial e mantém um ritmo linear, uma vez que a primeira molécula interestelar $(\mathrm{CH})$ foi identificada em 1937 (Swings e Rosenfeld, 1937).

Como provocar uma revolução exponencial na busca de moléculas no espaço?

As revoluções são inflamadas pela frustração, e temos a grande frustração na realização a tarefa básica de identificação de uma substância dentro da floresta de linhas interestelares, que se estende de UV para o rádio. As características não identificadas em espectros interestelares têm sido observadas quase que desde os primórdios da astroquímica. Recentemente, o número de tais linhas tem aumentado rapidamente em paralelo com a maior sensibilidade e ampla faixa de frequência de novos instrumentos de observação. Muitas vezes, as linhas têm sua origem em moléculas grandes com espectros densos. Assim, não houve um aumento no número de moléculas "detectadas". No entanto, a explosão no número de recursos é muito mais rápida do que o número de identificações. É extremamente difícil distinguir uma molécula nova no espectro complexo que envolve muitas vezes iterações com estados vibracionais das moléculas. Questões ainda permanecem sem resposta. Por exemplo, as Bandas Aromáticas no Infravermelho (AIBs) são atribuídas a PAHs do meio interestelar com uma certeza razoável. No entanto, não sabemos a distribuição nem os tamanhos dos PAHs que lhes deu origem. Nós temos uma identificação positiva de apenas um primeiro $\mathrm{PAH}$, o benzeno $\left(C_{6} H_{6}\right)$, e ainda não foram amplamente aceitas as detecções do naftaleno $\left(C_{10} H_{8}\right)$ e do antraceno $\left(C_{14} H_{10}\right)$ (Iglesias-Groth et al., 2008), (Iglesias-Groth et al., 2010). Não há pistas observacionais dos próximos membros da série, os PAHs de quatro anéis, tais como pireno $\left(C_{16} H_{10}\right)$, criseno $\left(C_{18} H_{12}\right)$, ou tetraceno $\left(\mathrm{C}_{18} \mathrm{H}_{12}\right)$. E o desafio é ainda maior quando se tenta identificar os complexos compostos heterocíclicos da bioquímica.

O problema fundamental é que o aumento dos resultados observacionais está longe de 
acelerar o crescimento dos bancos de dados em um ritmo rápido. Extrair as assinaturas de novas espécies moleculares do abundante material observacional envolve vários aspectos: i) observações; ii) cálculos quânticos teóricos de química básica e dos processos físicos, iii) experimentos de laboratório (com ambas as fases, gasosa e sólida); iv) e simulações dos ambientes que dão origem às linhas. Este esforço representa um projeto de longo prazo. Um reforço adicional de observação nos ajudará a melhor compreender a complexidade do universo molecular. Os novos sistemas de observação, tanto no espaço como no solo Spitzer, Herschel, SOFIA, ALMA, JWST, Spica - abrirão novas janelas no infravermelho e no milimétrico/submilimetrico, para bases de frequência mais completas que permitirão identificações mais confiáveis de novas espécies moleculares. Neste caso, os mesmos instrumentos que são usados para examinar as origens do universo hoje também poderão nos ajudar a desvendar as origens da vida.

\subsection{Próximos Passos em Simulações}

O presente trabalho representa os passos iniciais no estudo da astroquímica pré-biótica. Dados experimentais assim como evidências observacionais devem ser levados em conta para o avanço desta pesquisa. Para tanto, a continuação deste trabalho deve envolver um avanço nas simulações, considerando principalmente as reações de formação e destruição de moléculas em grãos de poeira e gelo e a inclusão menos aproximada de PAHs.

Além disso, nessa fase do projeto é essencial um trabalho em laboratório que permita reproduzir a formação destas importantes moléculas em ambientes interestelares. Uma opção seria utilizar o Laboratório de AstroBiologia (AstroLab) do Observatório Abrahão de Moraes para simular a produção de compostos orgânicos em gelos e grãos interestelares. Em particular, é preciso investigar os processos de química de estado sólido e de superfície em grãos, com determinações mais precisas das escalas de tempo dos saltos das moléculas adsorvidas entre sítios na superfície dos grãos. Também é preciso um melhor conhecimento da evaporação de voláteis de mantos de gelo de grãos interestelares, principalmente na presença de radiação ultravioleta e de raios cósmicos, assim como dos fatores de aderência de alcatrões nos gelos. Irradiação por radiação ultravioleta com comprimentos de onda bem definidos será possível graças ao Laboratório Nacional de Luz Síncrotron. Canhões de elétrons e de prótons permitirão simular os raios cósmicos. Experimentos com gelos têm 
sido bastante comuns, mas há uma carência muito grande de experimentos envolvendo a fase gasosa, que exigirão montagens experimentais engenhosas. Os experimentos de laboratório são um passo importante para definir estratégias observacionais com instrumentos capacitados para encontrar estes tipos de molécula, como o ALMA e o Herschel, de forma a aumentar a quantidade de dados para construir um modelo padrão confiável de estimativas de abundâncias de espécies químicas.

Em todo caso, o avanço deste trabalho torna evidente a necessidade do aumento nos bancos de dados, no que diz respeito ao cálculo dos parâmetros quânticos das taxas de reações para a formação e destruição de moléculas importantes no meio interestelar, principalmente para moléculas maiores e mais complexas, assim como também ampliar os estudos sobre quais são estas reações. Em particular são necessários os parâmetros fundamentais - seções de choque, constantes de reação, entalpias e comprimentos de onda de transições - para grandes moléculas, com mais de 10 átomos ou até mais de 20 átomos. Isso já pode estar sendo necessário para realizar o garimpo de espécies químicas dentro da floresta de linhas que está emergindo das observações por detectores com maior sensibilidade.

Um ponto importante é estender a faixa de temperatura das bases de dados que frequentemente se restringe à temperatura ambiente terrestre, enquanto é necessário ter dados a temperaturas muito baixas para se determinar com segurança a dependência com a temperatura dos coeficientes de reação. Outro tópico crítico é que teoricamente se sabe que a química em grãos de tamanho finito pode ser diferente daquela em superfícies infinitas. Como investigar esse comportamento em laboratório? Poderia se utilizar algum dispositivo que levitasse um grão individual por um longo período de tempo?

Além dos cálculos quânticos e dos experimentos de laboratório, muito insight referente à química do meio interestelar pode ser obtido utilizando ambientes próximos de nós, no próprio Sistema Solar, como padrões para aferir processos a baixas temperaturas no meio interestelar. Isso já foi feito parcialmente neste trabalho ao recorrermos a modelos fotoquímicos de Titã. Os fenômenos em corpos gelados do Sistema Solar constituem referências para a compreensão dos gelos em nebulosas, regiões circum-estelares e no meio interestelar difuso. Em particular, os cometas são laboratórios cósmicos nos quais muitos dos processos relevantes à astroquímica e astrobiologia estão ocorrendo suficientemente 
perto de nós para serem observados em detalhe e mesmo visitados in situ.

Sem estes estudos mais aprofundados, as simulações das abundâncias de importantes moléculas que poderiam ter originado a vida irão pouco além de estimativas cruas, limitando nosso conhecimento sobre a origem da vida na Terra e sua distribuição no Universo.

\subsection{Perspectivas Observacionais}

Devido aos parâmetros físicos e as abundâncias químicas nas PDRs, tais como a HHN, uma comparação acurada de observações com os modelos não pode ser realizada sem a informação das intensidades das linhas moleculares. Em virtude das pequenas escalas espaciais envolvidas, a interferometria (sub)milimétrica parece ser o melhor método para obter a informação espacial necessária para a resolução das quantidades físicas e químicas. De qualquer modo, muitas espécies interessantes mostram linhas relativamente fracas, mas que podem ser detectadas numa fonte forte e próxima como a HHN. Para acessar uma amostra mais completa de linhas moleculares, instrumentos mais sensíveis são necessários, como os fornecidos pelo ALMA, que é capaz de detectar algumas das moléculas mais relevantes em astrobiologia, como mostrado na tabela 5.1, onde assinalamos as bandas do ALMA que podem ser utilizadas para a observação dessas espécies.

Tabela 5.1 - Transições de moléculas observáveis com o ALMA.

\begin{tabular}{lccc}
\hline \hline \multicolumn{1}{c}{ Molécula (Transição) } & Frequência $(\mathrm{GHz})$ & Banda do ALMA & Frequência $(\mathrm{GHz})$ \\
\hline $\mathrm{CN}(N=1-0 / N=2-1)$ & $113.5 / 226.8$ & $3 / 6$ & $84-119 / 211-275$ \\
HCN $(J=3-2)$ & $265-267$ & 6 & $211-27$ \\
HNC $(J=1-0)$ & 87.32 & 3 & $84-119$ \\
Piridina $(J=45-44)$ & 269.247 & 6 & $211-27$ \\
Pirrol $\left(9_{09}-8_{08}\right)$ & 86.109 & 3 & $84-119$ \\
& & & \\
\hline
\end{tabular}

Além da moléculas usualmente observadas em nuvens moleculares, como o CN, HCN e HNC (Krips et al., 2011), a piridina tem uma transição rotacional característica ( $J=$ 45 - 44) a 269,247 GHz (Ye et al., 2005), dentro da banda 6 do ALMA e o pirrol outra característica $\left(9_{09}-8_{08}\right)$, a 86,109 GHz (Mvers et al., 1980), que cai na banda 3 do ALMA. 
Já se suspeita há tempos que anéis sejam menos abundantes do que cadeias de moléculas (Mvers et al., 1980), o que tem frustrado as buscas por heterocíclicos no meio interestelar (Huang et al., 2005), mas a nova geração de instrumentos como o ALMA e o Herschel deverá permitir em breve converter a frustração em excitação pela busca. 


\section{Referências Bibliográficas}

Adande G. R., Ziurys L. M., Millimeter-wave Observations of $\mathrm{CN}$ and $\mathrm{HNC}$ and Their ${ }^{15} \mathrm{~N}$ Isotopologues: A New Evaluation of the ${ }^{14} \mathrm{~N} /{ }^{15} \mathrm{~N}$ Ratio across the Galaxy, ApJ, 2012, vol. 744 , p. 194

Agúndez M., Cernicharo J., Guélin M., Kahane C., Roueff E., Kłos J., Aoiz F. J., Lique F., Marcelino N., Goicoechea J. R., González García M., Gottlieb C. A., McCarthy M. C., Thaddeus P., Astronomical identification of $\mathrm{CN}^{-}$, the smallest observed molecular anion, A\&A, 2010, vol. 517, p. L2

Allain T., Leach S., Sedlmayr E., Photodestruction of PAHs in the interstellar medium. I. Photodissociation rates for the loss of an acetylenic group., A\&A, 1996a, vol. 305, p. 602

Allain T., Leach S., Sedlmayr E., Photodestruction of PAHs in the interstellar medium. II. Influence of the states of ionization and hydrogenation., A\&A, 1996b, vol. 305, p. 616

Allamandola L. J., Tielens A. G. G. M., Barker J. R., Interstellar polycyclic aromatic hydrocarbons - The infrared emission bands, the excitation/emission mechanism, and the astrophysical implications, ApJS, 1989, vol. 71, p. 733

Anders E., Grevesse N., Abundances of the elements - Meteoritic and solar, Geochim. Cosmochim. Acta, 1989, vol. 53, p. 197

Astrochemistry K. D., KIDA. http://kida.obs.u-bordeaux1.fr, 2012

Briggs G., Center for Mars Exploration (CMEX Mars) - NASA. http://cmex.ihmc.us/cmex/Astrobiology 
Ceccarelli C., Baudry A., Caux E., Tielens A. G. G. M., Joblin C. e. a., HIFI Survey of Water Lines from Protostars. In The Promise of the Herschel Space Observatory, vol. 460 of ESA Special Publication, 2001, p. 219

Cecchi-Pestellini C., Malloci G., Mulas G., Joblin C., Williams D. A., The role of the charge state of PAHs in ultraviolet extinction, A\&A, 2008, vol. 486, p. L25

Chela-Flores J., The New Science of Astrobiology - From Genesis of the Living Cell to Evolution of Intelligent Behavior in the Universe. Kluwer Academic Publishers, 2001, $251 \mathrm{p}$.

Chemeo High Quality Chemical Properties. http://www.chemeo.com/38-987-5, 2012

ChemSpider The free chemical database. http://www.chemispider.com/Search.aspx, 2012

Cherchneff I., Barker J. R., Tielens A. G. G. M., Polycyclic aromatic hydrocarbon formation in carbon-rich stellar envelopes, ApJ, 1992, vol. 401, p. 269

Cheung A. C., Rank D. M., Townes C. H., Thornton D. D., Welch W. J., Detection of $\mathrm{NH}_{3}$ Molecules in the Interstellar Medium by Their Microwave Emission, Physical Review Letters, 1968, vol. 21, p. 1701

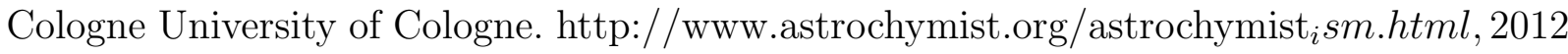

Cordiner M. A., Millar T. J., Herbst E., Chuimin R. N., Walsh C., Molecular anion chemistry in interstellar and circumstellar environments, 2007a

Cordiner M. A., Millar T. J., Herbst E., Chuimin R. N., Walsh C., Molecular anion chemistry in interstellar and circumstellar environments. In Molecules in Space and Laboratory , $2007 \mathrm{~b}$

Cottin H., Moore M. H., Bénilan Y., Photodestruction of Relevant Interstellar Molecules in Ice Mixtures, ApJ, 2003, vol. 590, p. 874

D'Hendecourt L. S., Molecular complexity in astrophisical environments: From astrochemistry to astrobiology?, 2011 
Dickens J. E., Irvine W. M., Ohishi M., Ikeda M., Ishikawa S., Nummelin A., Hjalmarson A., Detection of Interstellar Ethylene Oxide (c-C 2H 4O), ApJ, 1997, vol. 489, p. 753

Draine B. T., Photoelectric heating of interstellar gas, ApJS, 1978, vol. 36, p. 595

Draine B. T., Interstellar Dust Grains, ARA\&A, 2003, vol. 41, p. 241

Duley W. W., Dehydrogenated Cations of Coronene, $\mathrm{C}_{24} \mathrm{H}^{+}{ }_{x}$ : The Source of Many Diffuse Interstellar Bands, ApJ, 2006, vol. 643, p. L21

Ehrenfreund P., Rasmussen S., Cleaves J., Chen L., Experimentally Tracing the Key Steps in the Origin of Life: The Aromatic World, Astrobiology, 2006, vol. 6, p. 490

Encyclopaedia T. E. P., The Extrasolar Planets Encyclopaedia. http://http://exoplanet.eu/catalog-all.php, 2012

Flower D. R., Pineau des Forêts G., The influence of grains on the propagation and structure of C-type shock waves in interstellar molecular clouds, MNRAS, 2003, vol. 343, p. 390

Friaça A., A vida num Contexto Cósmico. Notas de Aula, 2012

Gerin M., Pety J., Goicoechea J. R., The Horsehead Nebula, a Template Source for Interstellar Physics and Chemistry. In Submillimeter Astrophysics and Technology: a Symposium Honoring Thomas G. Phillips, vol. 417 of Astronomical Society of the Pacific Conference Series, 2009, p. 165

Gilmour I., Sephton M. A., An introduction to Astrobiology. Cambridge, 2004, 364 p.

Goicoechea J. R., Pety J., Gerin e. a., The ionization fraction gradient across the Horsehead edge: an archetype for molecular clouds, A\&A, 2009, vol. 498, p. 771

Goos E., Burcat A., Ruscic B., Extended Third Millenium Ideal Gas and Condensed Phase Termochemical Database for Combustion with Updates from Active Thermochemical Tables, 2012, vol. 1, p. 133

Habart E., Abergel A., Walmsley C. M., Teyssier D., Pety J., Density structure of the Horsehead nebula photo-dissociation region, A\&A, 2005, vol. 437, p. 177 
Habing H. J., The interstellar radiation density between 912 A and 2400 A, Bull. Astron. Inst. Netherlands, 1968, vol. 19, p. 421

Halfen D. T., Apponi A. J., Woolf N., Polt R., Ziurys L. M., A Systematic Study of Glycolaldehyde in Sagittarius B2(N) at 2 and $3 \mathrm{~mm}$ : Criteria for Detecting Large Interstellar Molecules, ApJ, 2006, vol. 639, p. 237

Helling C., Jorgensen U. G., Plez B., Johnson H. R., Formation of PAHs, polyynes, and other macromolecules in the photosphere of carbon stars., A\&A, 1996, vol. 315, p. 194

Herbig G. H., The Diffuse Interstellar Bands, ARA\&A, 1995, vol. 33, p. 19

Herbst E., Interstellar Chemistry Gas-phase Model. http://www.physics.ohio-

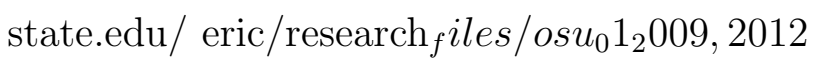

Herbst E., Klemperer W., The Formation and Depletion of Molecules in Dense Interstellar Clouds, ApJ, 1973, vol. 185, p. 505

Herzberg G., Historical Remarks on the Discovery of Interstellar Molecules, JRASC, 1988, vol. 82 , p. 115

Hily-Blant P., Maret S., Bacmann A. e. a., Nitrogen hydrides in the cold envelope of IRAS 16293-2422, A\&A, 2010, vol. 521, p. L52

Hollenbach D., Kaufman M. J., Bergin E. A., Melnick G. J., Water, $\mathrm{O}_{2}$, and Ice in Molecular Clouds, ApJ, 2009, vol. 690, p. 1497

Hollis J. M., Jewell P. R., Lovas F. J., Remijan A., Green Bank Telescope Observations of Interstellar Glycolaldehyde: Low-Temperature Sugar, ApJ, 2004, vol. 613, p. L45

Hollis J. M., Jewell P. R., Lovas F. J., Remijan A., Møllendal H., Green Bank Telescope Detection of New Interstellar Aldehydes: Propenal and Propanal, ApJ, 2004, vol. 610, p. L21

Hollis J. M., Lovas F. J., Jewell P. R., Interstellar Glycolaldehyde: The First Sugar, ApJ, 2000, vol. 540, p. L107 
Huang H.-C., Kuan Y.-J., Charnley S. B., Hirano N., Takakuwa S., Bourke T. L., Organic molecules in the hot corinos and circumstellar disks of IRAS 16293-2422, Advances in Space Research, 2005, vol. 36, p. 146

Hudgins D. M., Bauschlicher Jr. C. W., Allamandola L. J., Variations in the Peak Position of the $6.2 \mu \mathrm{m}$ Interstellar Emission Feature: A Tracer of $\mathrm{N}$ in the Interstellar Polycyclic Aromatic Hydrocarbon Population, ApJ, 2005, vol. 632, p. 316

Hudson R. L., Moore M. H., Reactions of nitriles in ices relevant to Titan, comets, and the interstellar medium: formation of cyanate ion, ketenimines, and isonitriles, Icarus, 2004, vol. 172, p. 466

Iglesias-Groth S., Manchado A., García-Hernández D. A., González Hernández J. I., Lambert D. L., Evidence for the Naphthalene Cation in a Region of the Interstellar Medium with Anomalous Microwave Emission, ApJ, 2008, vol. 685, p. L55

Iglesias-Groth S., Manchado A., Rebolo R., González Hernández J. I., García-Hernández D. A., Lambert D. L., A search for interstellar anthracene towards the Perseus anomalous microwave emission region, MNRAS, 2010, vol. 407, p. 2157

Joblin C., Leger A., Martin P., Contribution of polycyclic aromatic hydrocarbon molecules to the interstellar extinction curve, ApJ, 1992, vol. 393, p. L79

Joyce G. F., "Foreward"In Origins of Life: The Central Concepts, D.W. Deamer \& G.R. Fleischacker (eds.), Jones and Bartlett Publishers, Boston, pp. xi-xii, 1994

Kaler University of Illinois. http://stars.astro.illinois.edu/sow/sigmaori.html, 2012

Karplus M., Porter R. N., Atoms and molecules; an introduction for students of physical chemistry, 1970

Krasnopolsky V. A., A photochemical model of Titan's atmosphere and ionosphere, Icarus, 2009, vol. 201, p. 226

Krips M., Martin S., Eckart A., Neri R. e. a., Submillimeter arrey plateu de bure interferometer multiple line observations of the nearby Seyfert 2 Galaxy NGC 1068: shock-related gas kinematics and heating in the central 100 pc?, Ap\&SS, 2011, p. 27 
Kuan Y.-J., Charnley S. B., Huang H.-C., Kisiel Z., Ehrenfreund P., Tseng W.-L., Yan C.H., Searches for interstellar molecules of potential prebiotic importance, Advances in Space Research, 2004, vol. 33, p. 31

Kuo H.-L., Remijan A. J., Snyder L. E., Looney L. W., Friedel D. N., Lovas F. J., McCall B. J., Hollis J. M., Detection of Interstellar Urea. In "Midwest Astrochemistry Meeting 2010, held 5-6 November at the University of Illinois at Urbana-Champaign. ¡A href="http://midwest.astrochemistry.us/MWAM10/" ¿http://midwest.astrochemistry.usi/A¿, article \#P09" , 2010, p. 9

Lafleur L. J., Astrobiology, Leaflet of the Astronomical Society of the Pacific, 1941, vol. 3, p. 333

Le Page V., Snow T. P., Bierbaum V. M., Hydrogenation and Charge States of PAHS in Diffuse Clouds. I. Development of a Model, ApJS, 2001, vol. 132, p. 233

Le Petit F., Ducumentation Run PDR models. The Meudon PDR Code, 2009

Le Petit F., The Meudon PDR Code. http://pdr.obspm.fr/PDRcode.html, 2012

Le Petit F., Nehmé C., Le Bourlot J., Roueff E., A Model for Atomic and Molecular Interstellar Gas: The Meudon PDR Code, ApJS, 2006, vol. 164, p. 506

Le Teuff Y. H., Millar T. J., Markwick A. J., The UMIST database for astrochemistry 1999. In IAU Joint Discussion, vol. 1 of IAU Joint Discussion, 2000

Leger A., D'Hendecourt L., Are polycyclic aromatic hydrocarbons the carriers of the diffuse interstellar bands in the visible?, A\&A, 1985, vol. 146, p. 81

Leger A., D'Hendecourt L., Boissel P., Desert F. X., Photo-thermo-dissociation. I - A general mechanism for destroying molecules, A\&A, 1989, vol. 213, p. 351

Li A., Witt A. N., Clayton G. C., T. D. B., Astrophysics of Dust, ASP Conferrence Series, 2004, vol. 309

Lide D., Baysinger G., Berger L., Goldberg R., Haynes W., CRC Handbook of Chemistry and Physics. National Institute of Standards and Technology, 2008, 2692 p. 
Lin M. F., Dyakov A. Y., Tseng C. M., Mebel M. A., et al. L. H. S., Photodissociation dynamics of pyridine, The Journal of Chemical Physics, 2005, vol. 123

Lunine J., Astrobiology a multidisciplinary approach. Pearson Addison Wesley, 2005, 586 p.

Maciel W., Astrofísica do Meio Interestelar. São Paulo; Edusp, 2002, 368 p.

Maret S., Bergin E. A., Lada C. J., A low fraction of nitrogen in molecular form in a dark cloud, Nature, 2006, vol. 442, p. 425

Moore G. E., Cramming more components onto integrated circuits, 1965, vol. 38

Myers P. C., Thaddeus P., Linke R. A., A search for interstellar pyrrole - Evidence that rings are less abundant than chains, ApJ, 1980, vol. 241, p. 155

Napier W. M., Wickramasinghe J. T., Wickramasinghe N. C., The origin of life in comets, International Journal of Astrobiology, 2007, vol. 6, p. 321

NASA APOD - NASA. http://apod.nasa.gov/apod/ap050321.html, 2010

Ni K. C., Lin M. F., Tseng C. M., Dyakov A. Y., Photodissociation Dynamics of Small Aromatic Molecules Studied by Multimass Ions Imaging, The Journal of Physics and Chemistry B, 2007, vol. 111, p. 12631

Nicolas C., Alcaraz C., Thissen R., Vervloet M., Dutuit O., Dissociative photoionization of $\mathrm{N}_{2}$ in the $2432 \mathrm{eV}$ photon energy range, Journal of Physics B Atomic Molecular Physics, 2003, vol. 36, p. 2239

NIST N. I. o. S. . T., NIST - National Institute of Standards and Technology. http://webbook.nist.gov/chemistry, 2012

NRAO National Radio Astronomy Observatory. http://www.cv.nrao.edu/ awootten/allmols.html, 2012

Nuevo M., Milam S. N., Sandford S. A., Nucleobases and Prebiotic Molecules in Organic Residues Produced from the Ultraviolet Photo-Irradiation of Pyrimidine in NH3and H2O+NH3Ices, Astrobiology, 2012, vol. 12, p. 295 
Peeters Z., Botta O., Charnley S. B., Kisiel Z., Kuan Y.-J., Ehrenfreund P., Formation and photostability of N-heterocycles in space. I. The effect of nitrogen on the photostability of small aromatic molecules, A\&A, 2005, vol. 433, p. 583

Physikalisches I., Universitat zu Koln. http://www.astro.uni-koeln.de/cdms/molecules, 2012

Platts N., Astrobiology Magazine. Astrobiology Magazine, 1992 http://www.astrobio.net/index.phpoption.com/interviewtask/detailid/1992

Plützer C., Nir E., de Vries M. S., Kleinermanns K., IR UV double-resonance spectroscopy of the nucleobase adenine, Physical Chemistry Chemical Physics (Incorporating Faraday Transactions), 2001, vol. 3, p. 5466

Porezag D., Frauenheim T., Köhler T., Seifert G., Kaschner R., Construction of tight-bindinglike potentials on the basis of density-functional theory, Physical Review B, 1995, vol. 1, p. 12947

Powner M. W., Gerland B., Sutherland J. D., Synthesis of activated pyrimidine ribonucleotides in prebiotically plausible conditions, Nature International weekly journal of science, 2009, vol. 1, p. 239

Prasad S. S., Tarafdar S. P., UV radiation field inside dense clouds - Its possible existence and chemical implications, ApJ, 1983, vol. 267, p. 603

Puget J. L., Leger A., A new component of the interstellar matter - Small grains and large aromatic molecules, ARA\&A, 1989, vol. 27, p. 161

Röllig M., Abel N. P., Bell e. a., A photon dominated region code comparison study, A\&A, 2007, vol. 467, p. 187

Röllig M., Abel N. P., Bell T., et al. B., A photon dominated region code comparison study, A\&A, 2007, vol. 467, p. 187

Reaxys reaxys.com. http://www.reaxys.com/reaxys/secured/start.do, 2012

Requena-Torres M. A., Martín-Pintado J., Martín S., Morris M. R., The Galactic Center: The Largest Oxygen-bearing Organic Molecule Repository, ApJ, 2008, vol. 672, p. 352 
Ricca A., Bauschlicher C. W., Bakes E. L. O., A Computational Study of the Mechanisms for the Incorporation of a Nitrogen Atom into Polycyclic Aromatic Hydrocarbons in the Titan Haze, Icarus, 2001, vol. 154, p. 516

Ruiterkamp R., Peeters Z., Moore M. H., Hudson R. L., Ehrenfreund P., A quantitative study of proton irradiation and UV photolysis of benzene in interstellar environments, A\&A, 2005, vol. 440, p. 391

Rybicki G. B., Lightman A. P., Radiative process in Astrophysics. IAG-USP, 1979, 382 p.

Schutte W. A., Tielens A. G. G. M., Allamandola L. J., Theoretical modeling of the infrared fluorescence from interstellar polycyclic aromatic hydrocarbons, ApJ, 1993, vol. 415, p. 397

Science Technology http://sci.esa.int/science-e/www/object/index.cfm?fobjectid=45075. Science Programme European Space Agency, 2011

Siebenmorgen R., Kruegel E., Dust model containing polycyclic aromatic hydrocarbons in various environments, A\&A, 1992, vol. 259, p. 614

Silva L., Granato G. L., Bressan A., Danese L., Modeling the Effects of Dust on Galactic Spectral Energy Distributions from the Ultraviolet to the Millimeter Band, ApJ, 1998, vol. 509, p. 103

Simon M. N., Simon M., Search for Interstellar Acrylonitrile, Pyrimidine, and Pyridine, ApJ, 1973, vol. 184, p. 757

Soorkia S., Taatjes C. A., Osborn D.-L., Selby T. M., Trevitt A. J., Wilson K.-R., Leone S.-R., Direct detection od pyridine formation by the reaction of $\mathrm{CH}(\mathrm{CD})$ with pyrrole: a ring expansion reaction, Physical Chemistry Chemical Physics, 2010, vol. 12, p. 8649

Swings P., Rosenfeld L., Considerations Regarding Interstellar Molecules, ApJ, 1937, vol. 86, p. 483

UDFA The UMIST Database for Astrochemistry. http://www.udfa.net, 2012 
Useli-Bacchitta F., Bonnamy A., Mulas G., Malloci G., Toublanc D., Joblin C., Visible photodissociation spectroscopy of PAH cations and derivatives in the PIRENEA experiment, Chemical Physics, 2010, vol. 371, p. 16

Vall-llosera G., Coreno M., Erman P., Huels M. A., Jakubowska K. e. a., VUV photoinisation of free azabezenes: Pyridine, pyrazine, pyrimidine, pyridazine and s-triazine, International Journal of Mass Spectrometry, 2008, vol. 275, p. 55

Vuong M. H., Foing B. H., Dehydrogenation of polycyclic aromatic hydrocarbons in the diffuse interstellar medium, A\&A, 2000, vol. 363, p. L5

Wickramasinghe N. C., Wallis J., Wallis D. H., Schild R. E., Gibson C. H., Life-bearing primordial planets in the solar vicinity, Ap\&SS, 2012, p. 191

Woods P. M., Millar T. J., Zijlstra A. A., Herbst E., The Synthesis of Benzene in the Protoplanetary Nebula CRL 618, ApJ, 2002, vol. 574, p. L167

Ye E., Bettens R.-P., De Luciea F. C., Petkie T. D., Albert S., Millimeter and submillimeter wave rotational spectrum of pyridine in the ground and excited vibrational states, Journal of Molecular Spectroscopy, 2005, vol. 232, p. 61 
Apêndice 

Apêndice A

\section{Moléculas Encontradas em Ambientes Interestelares e}

\section{Circum-estelares}

Tabela A.1 - Moléculas encontradas em ambientes interestelares e circunestelares.

\begin{tabular}{|c|c|c|c|c|c|c|}
\hline \multirow{7}{*}{2 atoms } & $H_{2}$ & $\mathrm{AlF}$ & $\mathrm{AlCl}$ & $C_{2}$ & $\mathrm{CH}$ & $\mathrm{CH}^{+}$ \\
\hline & $\mathrm{CN}$ & $\mathrm{CO}$ & $\mathrm{CO}^{+}$ & $\mathrm{CP}$ & $\mathrm{SiC}$ & $\mathrm{HCl}$ \\
\hline & $\mathrm{KCl}$ & NH & $\mathrm{NO}$ & NS & $\mathrm{NaCl}$ & $\mathrm{OH}$ \\
\hline & $\mathrm{PN}$ & $\mathrm{SO}$ & $\mathrm{SO}^{+}$ & $\mathrm{SiN}$ & $\mathrm{SiO}$ & $\mathrm{SiS}$ \\
\hline & CS & $\mathrm{HF}$ & HD & $\mathrm{FeO}(?)$ & $\mathrm{O}_{2}$ & $C F^{+}$ \\
\hline & $\mathrm{SiH}(?)$ & $\mathrm{PO}$ & $\mathrm{AlO}$ & $\mathrm{OH}^{+}$ & $C N^{-}$ & $\mathrm{SH}^{+}$ \\
\hline & $\mathrm{LiH}$ & $\mathrm{SH}$ & $N_{2}$ & $S_{2} \dagger$ & $N_{2}^{+} \dagger$ & $\mathrm{CN}^{+} \dagger$ \\
\hline \multirow[t]{8}{*}{3 atoms } & $C_{3}$ & $\mathrm{C}_{2} \mathrm{H}$ & $\mathrm{C}_{2} \mathrm{O}$ & $C_{2} S$ & $\mathrm{CH}_{2}$ & $\mathrm{HCN}$ \\
\hline & $\mathrm{HCO}$ & $\mathrm{HCO}^{+}$ & $\mathrm{HCS}^{+}$ & $\mathrm{HOC}^{+}$ & $\mathrm{H}_{2} \mathrm{O}$ & $\mathrm{H}_{2} \mathrm{~S}$ \\
\hline & $\mathrm{HNC}$ & HNO & $\mathrm{MgCN}$ & $\mathrm{MgNC}$ & $\mathrm{N}_{2} H^{+}$ & $\mathrm{N}_{2} \mathrm{O}$ \\
\hline & $\mathrm{NaCN}$ & OCS & $\mathrm{SO}_{2}$ & $c-S i C_{2}$ & $\mathrm{CO}_{2}$ & $\mathrm{NH}_{2}$ \\
\hline & $H_{3}^{+}$ & $H_{2} D^{+}$ & $H D_{2}^{+}$ & $\mathrm{SiCN}$ & $\mathrm{AlNC}$ & $\mathrm{SiNC}$ \\
\hline & $\mathrm{HCP}$ & $\mathrm{CCP}$ & $\mathrm{AlOH}$ & $\mathrm{H}_{2} \mathrm{O}^{+}$ & $\mathrm{H}_{2} \mathrm{Cl}^{+}$ & $\mathrm{KCN}$ \\
\hline & $\mathrm{FeCN}$ & $O C N^{-}$ & $\mathrm{CO}_{2}^{+}$ & $H_{2} S^{+}$ & $\mathrm{CN}_{2}$ & HDO \\
\hline & $C S_{2} \dagger$ & & & & & \\
\hline \multirow[t]{5}{*}{4 atoms } & $c-C_{3} H$ & $l-C_{3} H$ & $C_{3} N$ & $\mathrm{C}_{3} \mathrm{O}$ & $C_{3} S$ & $\mathrm{C}_{2} \mathrm{H}_{2}$ \\
\hline & $\mathrm{NH}_{3}$ & $\mathrm{HCCN}$ & $\mathrm{HCNH}^{+}$ & $\mathrm{HNCO}$ & HNCS & $\mathrm{HOCO}^{+}$ \\
\hline & $\mathrm{H}_{2} \mathrm{CO}$ & $\mathrm{H}_{2} \mathrm{CN}$ & $\mathrm{H}_{2} \mathrm{CS}$ & $\mathrm{H}_{3} \mathrm{O}^{+}$ & $c-S_{i C}$ & $\mathrm{CH}_{3}$ \\
\hline & $C_{3} N^{-}$ & $\mathrm{PH}_{3}(?)$ & HCNO & $\mathrm{HOCN}$ & $\mathrm{HSCN}$ & $\mathrm{H}_{2} \mathrm{O}_{2}$ \\
\hline & $C_{4}(? ?)$ & & & & & \\
\hline \multirow[t]{3}{*}{5 atoms } & $C_{5}$ & $\mathrm{C}_{4} \mathrm{H}$ & $\mathrm{C}_{4} \mathrm{Si}$ & $l-C_{3} H_{2}$ & $c-C_{3} H_{2}$ & $\mathrm{H}_{2} \mathrm{CCN}$ \\
\hline & $\mathrm{CH}_{4}$ & $H C_{3} N$ & $\mathrm{HC}_{2} \mathrm{NC}$ & $\mathrm{HCOOH}$ & $\mathrm{H}_{2} \mathrm{CNH}$ & $\mathrm{H}_{2} \mathrm{C}_{2} \mathrm{O}$ \\
\hline & $\mathrm{H}_{2} \mathrm{NCN}$ & $\mathrm{HNC}_{3}$ & $\mathrm{SiH}_{4}$ & $\mathrm{H}_{2} \mathrm{COH}^{+}$ & $\mathrm{C}_{4} H^{-}$ & $\mathrm{HC}(\mathrm{O}) \mathrm{CN}$ \\
\hline \multirow[t]{3}{*}{6 atoms } & $\mathrm{C}_{5} \mathrm{H}$ & $l-H_{2} C_{4}$ & $\mathrm{C}_{2} \mathrm{H}_{4}$ & $\mathrm{CH}_{3} \mathrm{CN}$ & $\mathrm{CH}_{3} \mathrm{NC}$ & $\mathrm{CH}_{3} \mathrm{OH}$ \\
\hline & $\mathrm{CH}_{3} \mathrm{SH}$ & $\mathrm{HC}_{3} \mathrm{NH}^{+}$ & $\mathrm{HC}_{2} \mathrm{CHO}$ & $\mathrm{NH}_{2} \mathrm{CHO}$ & $C_{5} N$ & $l-H C_{4} H$ \\
\hline & $l-H C_{4} N$ & $c-\mathrm{H}_{2} \mathrm{C}_{3} \mathrm{O}$ & $\mathrm{H}_{2} \mathrm{CCNH}(?)$ & $C_{5} N^{-}$ & & \\
\hline
\end{tabular}

Continua na próxima página... 
Tabela A.1 - Continuação

\begin{tabular}{|c|c|c|c|c|c|c|}
\hline 7 atoms & $\begin{array}{c}\mathrm{C}_{6} \mathrm{H} \\
c-\mathrm{C}_{2} \mathrm{H}_{4} \mathrm{O}\end{array}$ & $\begin{array}{l}\mathrm{CH}_{2} \mathrm{CHCN} \\
\mathrm{H}_{2} \mathrm{CCHOH}\end{array}$ & $\begin{array}{c}\mathrm{CH}_{3} \mathrm{C}_{2} \mathrm{H} \\
\mathrm{C}_{6} \mathrm{H}^{-}\end{array}$ & $\mathrm{HC}_{5} \mathrm{~N}$ & $\mathrm{CH}_{3} \mathrm{CHO}$ & $\mathrm{CH}_{3} \mathrm{NH}_{2}$ \\
\hline \multirow[t]{2}{*}{8 atoms } & $\mathrm{CH}_{3} \mathrm{C}_{3} \mathrm{~N}$ & $\mathrm{HC}(\mathrm{O}) \mathrm{OCH}_{3}$ & $\mathrm{CH}_{3} \mathrm{COOH}$ & $\mathrm{C}_{7} \mathrm{H}$ & $H_{2} C_{6}$ & $\mathrm{CH}_{2} \mathrm{OHCHO}$ \\
\hline & $l-H C_{6} H$ & $\mathrm{CH}_{2} \mathrm{CHCHO}(?)$ & $\mathrm{CH}_{2} \mathrm{CCHCN}$ & $\mathrm{H}_{2} \mathrm{NCH}_{2} \mathrm{CN}$ & $\mathrm{C}_{2} \mathrm{H}_{6} \dagger$ & $\left(\mathrm{NH}_{2}\right)_{2} \mathrm{CO}(? ?)$ \\
\hline \multirow[t]{2}{*}{9 atoms } & $\mathrm{CH}_{3} \mathrm{C}_{4} \mathrm{H}$ & $\mathrm{CH}_{3} \mathrm{CH}_{2} \mathrm{CN}$ & $\left(\mathrm{CH}_{3}\right)_{2} \mathrm{O}$ & $\mathrm{CH}_{3} \mathrm{CH}_{2} \mathrm{OH}$ & $\mathrm{HC}_{7} \mathrm{~N}$ & $\mathrm{C}_{8} \mathrm{H}$ \\
\hline & $\mathrm{CH}_{3} \mathrm{C}(\mathrm{O}) \mathrm{NH}_{2}$ & $\mathrm{C}_{8} \mathrm{H}^{-}$ & $\mathrm{C}_{3} \mathrm{H}_{6}$ & & & \\
\hline 10 atoms & $\mathrm{CH}_{3} \mathrm{C}_{5} \mathrm{~N}$ & $\left(\mathrm{CH}_{3}\right)_{2} \mathrm{CO}$ & $\left(\mathrm{CH}_{2} \mathrm{OH}\right)_{2}$ & $\mathrm{CH}_{3} \mathrm{CH}_{2} \mathrm{CHO}$ & $\mathrm{NH}_{2} \mathrm{CH}_{2} \mathrm{COOH}(? ?) \dagger$ & \\
\hline 11 atoms & $\mathrm{HC}_{9} \mathrm{~N}$ & $\mathrm{CH}_{3} \mathrm{C}_{6} \mathrm{H}$ & $\mathrm{C}_{2} \mathrm{H}_{5} \mathrm{OCHO}$ & & & \\
\hline 12 atoms & $\mathrm{C}_{6} \mathrm{H}_{6}$ & $\mathrm{C}_{2} \mathrm{H}_{5} \mathrm{OCH}_{3} ?$ & $n-C_{3} H_{7} C N$ & $\mathrm{CO}\left(\mathrm{CH}_{2} \mathrm{OH}\right)_{2}(? ?)$ & & \\
\hline$>12$ atoms & $H C_{11} N$ & $\mathrm{C}_{10} \mathrm{H}_{8}^{+}$ & $C_{14} H_{10}^{+}(? ?)$ & $C_{24}(? ?)$ & $C_{60}$ & $C_{70}$ \\
\hline
\end{tabular}

? Detecção incerta, mas provável.

?? Detecção não confirmada.

$\dagger$ Detectada em cometas. 
Apêndice B

\section{Moléculas e reações químicas usadas na modelagem da}

\section{Nebulosa Cabeça de Cavalo}

Tabela B.1 - Elementos usados no modelo da Nebulosa Cabeça de Cavalo e seus parâmetros.

\begin{tabular}{|c|c|c|c|c|c|c|c|c|c|}
\hline \multirow{2}{*}{$\begin{array}{c}\text { Número } \\
1\end{array}$} & \multirow{2}{*}{$\begin{array}{c}\text { Espécie } \\
\mathrm{h}\end{array}$} & \multicolumn{6}{|c|}{ Codificação da Composição Atômica } & \multirow{2}{*}{$\begin{array}{c}\text { Abundância Inicial } \\
9.900 \mathrm{e}-01\end{array}$} & \multirow{2}{*}{$\begin{array}{c}\text { Entalpia de Formação - kJ/mol } \\
51.634\end{array}$} \\
\hline & & 1 & 0000 & 0000 & 00000 & 000000 & 0 & & \\
\hline 2 & $\mathrm{~h} 2$ & 2 & 0000 & 0000 & 00000 & 000000 & 0 & $5.000 \mathrm{e}-03$ & 0.000 \\
\hline 3 & he & 0 & 0001 & 0000 & 00000 & 000000 & 0 & $1.000 \mathrm{e}-01$ & 0.000 \\
\hline 4 & $\mathrm{c}$ & 0 & 1000 & 0000 & 00000 & 000000 & 0 & $0.060 \mathrm{e}-04$ & 169.980 \\
\hline 5 & ch & 1 & 1000 & 0000 & 00000 & 000000 & 0 & $0.0 \mathrm{e}-00$ & 141.600 \\
\hline 6 & $\operatorname{ch} 2$ & 2 & 1000 & 0000 & 00000 & 000000 & 0 & $0.0 \mathrm{e}-00$ & 93.900 \\
\hline 7 & $\operatorname{ch} 3$ & 3 & 1000 & 0000 & 00000 & 000000 & 0 & $0.0 \mathrm{e}-00$ & 34.800 \\
\hline 8 & $\operatorname{ch} 4$ & 4 & 1000 & 0000 & 00000 & 000000 & 0 & $0.0 \mathrm{e}-00$ & -15.970 \\
\hline 9 & o & 0 & 0010 & 0000 & 00000 & 000000 & 0 & $3.020 \mathrm{e}-04$ & 58.980 \\
\hline 10 & o2 & 0 & 0020 & 0000 & 00000 & 000000 & 0 & $0.0 \mathrm{e}-00$ & 0.000 \\
\hline 11 & $\mathrm{oh}$ & 1 & 0010 & 0000 & 00000 & 000000 & 0 & $0.0 \mathrm{e}-00$ & 9.250 \\
\hline 12 & $\mathrm{~h} 2 \mathrm{o}$ & 2 & 0010 & 0000 & 00000 & 000000 & 0 & $0.0 \mathrm{e}-00$ & -57.100 \\
\hline 13 & co & 0 & 1010 & 0000 & 00000 & 000000 & 0 & $0.0 \mathrm{e}-00$ & -27.200 \\
\hline 14 & hco & 1 & 1010 & 0000 & 00000 & 000000 & 0 & $0.0 \mathrm{e}-00$ & 10.700 \\
\hline 15 & $\mathrm{~h} 2 \mathrm{co}$ & 2 & 1010 & 0000 & 00000 & 000000 & 0 & $0.0 \mathrm{e}-00$ & -25.000 \\
\hline 16 & $\mathrm{co} 2$ & 0 & 1020 & 0000 & 00000 & 000000 & 0 & $0.0 \mathrm{e}-00$ & -93.965 \\
\hline 17 & $\mathrm{c} 2$ & 0 & 2000 & 0000 & 00000 & 000000 & 0 & $0.0 \mathrm{e}-00$ & 198.200 \\
\hline 18 & $\mathrm{c} 2 \mathrm{~h}$ & 1 & 2000 & 0000 & 00000 & 000000 & 0 & $0.0 \mathrm{e}-00$ & 113.300 \\
\hline 19 & $\mathrm{c} 2 \mathrm{~h} 2$ & 2 & 2000 & 0000 & 00000 & 000000 & 0 & $0.0 \mathrm{e}-00$ & 54.320 \\
\hline 20 & c3 & 0 & 3000 & 0000 & 00000 & 000000 & 0 & $0.0 \mathrm{e}-00$ & 194.000 \\
\hline 21 & $\mathrm{c} 3 \mathrm{~h}$ & 1 & 3000 & 0000 & 00000 & 000000 & 0 & $0.0 \mathrm{e}-00$ & $170.000^{*}$ \\
\hline 22 & $\mathrm{c} 3 \mathrm{~h} 2$ & 2 & 3000 & 0000 & 00000 & 000000 & 0 & $0.0 \mathrm{e}-00$ & $119.000^{*}$ \\
\hline 23 & $\mathrm{n}$ & 0 & 0100 & 0000 & 00000 & 000000 & 0 & $7.950 \mathrm{e}-05$ & 112.530 \\
\hline 24 & $\mathrm{nh}$ & 1 & 0100 & 0000 & 00000 & 000000 & 0 & $0.0 \mathrm{e}-00$ & 90.000 \\
\hline 25 & $\mathrm{nh} 2$ & 2 & 0100 & 0000 & 00000 & 000000 & 0 & $0.0 \mathrm{e}-00$ & 46.200 \\
\hline 26 & nh3 & 3 & 0100 & 0000 & 00000 & 000000 & 0 & $0.0 \mathrm{e}-00$ & -9.299 \\
\hline
\end{tabular}

Continua na próxima página... 
Tabela B.1 - Continuação

\begin{tabular}{|c|c|c|c|c|c|c|c|c|c|}
\hline \multirow{2}{*}{$\begin{array}{c}\text { Número } \\
27\end{array}$} & \multirow{2}{*}{$\begin{array}{c}\text { Espécie } \\
\text { cn }\end{array}$} & \multicolumn{6}{|c|}{ Codificação da Composição Atômica } & \multirow{2}{*}{$\begin{array}{c}\text { Abundância Inicial } \\
0.0 \mathrm{e}-00\end{array}$} & \multirow{2}{*}{$\begin{array}{c}\text { Entalpia de Formação }-\mathrm{kJ} / \mathrm{mol} \\
103.200\end{array}$} \\
\hline & & 0 & 1100 & 0000 & 00000 & 000000 & 0 & & \\
\hline 28 & hen & 1 & 1100 & 0000 & 00000 & 000000 & 0 & $0.0 \mathrm{e}-00$ & 32.390 \\
\hline 29 & hnc & 1 & 1100 & 0000 & 00000 & 000000 & 0 & $0.0 \mathrm{e}-00$ & 48.000 \\
\hline 30 & $\mathrm{n} 2$ & 0 & 0200 & 0000 & 00000 & 000000 & 0 & $0.0 \mathrm{e}-00$ & 0.000 \\
\hline 31 & no & 0 & 0110 & 0000 & 00000 & 000000 & 0 & $0.0 \mathrm{e}-00$ & 21.460 \\
\hline 32 & $\mathrm{~s}$ & 0 & 0000 & 0000 & 00000 & 001000 & 0 & $1.64 \mathrm{e}-06$ & 65.600 \\
\hline 33 & $\mathrm{sh}$ & 1 & 0000 & 0000 & 00000 & 001000 & 0 & $0.0 \mathrm{e}-00$ & 32.600 \\
\hline 34 & $\mathrm{~h} 2 \mathrm{~s}$ & 2 & 0000 & 0000 & 00000 & 001000 & 0 & $0.0 \mathrm{e}-00$ & -4.230 \\
\hline 35 & cs & 0 & 1000 & 0000 & 00000 & 001000 & 0 & $0.0 \mathrm{e}-00$ & 63.000 \\
\hline 36 & $\mathrm{~h} 2 \mathrm{cs}$ & 2 & 1000 & 0000 & 00000 & 001000 & 0 & $0.0 \mathrm{e}-00$ & 25.000 \\
\hline 37 & so & 0 & 0010 & 0000 & 00000 & 001000 & 0 & $0.0 \mathrm{e}-00$ & 1.200 \\
\hline 38 & so2 & 0 & 0020 & 0000 & 00000 & 001000 & 0 & $0.0 \mathrm{e}-00$ & -70.300 \\
\hline 39 & ocs & 0 & 1010 & 0000 & 00000 & 001000 & 0 & $0.0 \mathrm{e}-00$ & -34.000 \\
\hline 40 & fe & 0 & 0000 & 0000 & 00000 & 000001 & 0 & $0.0 \mathrm{e}-00$ & 98.700 \\
\hline 79 & $\mathrm{~h}+$ & 1 & 0000 & 0000 & 00000 & 000000 & 1 & $0.0 \mathrm{e}-00$ & 365.200 \\
\hline 41 & $\mathrm{~h} 2+$ & 2 & 0000 & 0000 & 00000 & 000000 & 1 & $0.0 \mathrm{e}-00$ & 355.700 \\
\hline 42 & h3+ & 3 & 0000 & 0000 & 00000 & 000000 & 1 & $0.0 \mathrm{e}-00$ & 265.000 \\
\hline 43 & he+ & 0 & 0001 & 0000 & 00000 & 000000 & 1 & $0.0 \mathrm{e}-00$ & 567.000 \\
\hline 44 & $c+$ & 0 & 1000 & 0000 & 00000 & 000000 & 1 & $1.320 \mathrm{e}-04$ & 429.700 \\
\hline 45 & $\operatorname{ch}+$ & 1 & 1000 & 0000 & 00000 & 000000 & 1 & $0.0 \mathrm{e}-00$ & 387.000 \\
\hline 46 & $\operatorname{ch} 2+$ & 2 & 1000 & 0000 & 00000 & 000000 & 1 & $0.0 \mathrm{e}-00$ & 331.000 \\
\hline 47 & $\operatorname{ch} 3+$ & 3 & 1000 & 0000 & 00000 & 000000 & 1 & $0.0 \mathrm{e}-00$ & 262.000 \\
\hline 48 & $\operatorname{ch} 4+$ & 4 & 1000 & 0000 & 00000 & 000000 & 1 & $0.0 \mathrm{e}-00$ & 272.000 \\
\hline 49 & $\operatorname{ch} 5+$ & 5 & 1000 & 0000 & 00000 & 000000 & 1 & $0.0 \mathrm{e}-00$ & $216.000^{*}$ \\
\hline 50 & $\mathrm{o}+$ & 0 & 0010 & 0000 & 00000 & 000000 & 1 & $0.0 \mathrm{e}-00$ & 373.000 \\
\hline 51 & $\mathrm{o} 2+$ & 0 & 0020 & 0000 & 00000 & 000000 & 1 & $0.0 \mathrm{e}-00$ & 278.400 \\
\hline 52 & $\mathrm{oh}+$ & 1 & 0010 & 0000 & 00000 & 000000 & 1 & $0.0 \mathrm{e}-00$ & 309.000 \\
\hline 53 & h2o+ & 2 & 0010 & 0000 & 00000 & 000000 & 1 & $0.0 \mathrm{e}-00$ & 233.700 \\
\hline 54 & h3o+ & 3 & 0010 & 0000 & 00000 & 000000 & 1 & $0.0 \mathrm{e}-00$ & 143.000 \\
\hline 55 & $\mathrm{co}+$ & 0 & 1010 & 0000 & 00000 & 000000 & 1 & $0.0 \mathrm{e}-00$ & 295.970 \\
\hline 56 & hco+ & 1 & 1010 & 0000 & 00000 & 000000 & 1 & $0.0 \mathrm{e}-00$ & $197.300^{*}$ \\
\hline 56 & hoct & 1 & 1010 & 0000 & 00000 & 000000 & 1 & $0.0 \mathrm{e}-00$ & $230.000^{*}$ \\
\hline 57 & hco $2+$ & 1 & 1020 & 0000 & 00000 & 000000 & 1 & $0.0 \mathrm{e}-00$ & $141.000^{*}$ \\
\hline 58 & $\mathrm{c} 2+$ & 0 & 2000 & 0000 & 00000 & 000000 & 1 & $0.0 \mathrm{e}-00$ & 476.000 \\
\hline 59 & $\mathrm{c} 2 \mathrm{~h}+$ & 1 & 2000 & 0000 & 00000 & 000000 & 1 & $0.0 \mathrm{e}-00$ & 404.000 \\
\hline 60 & $\mathrm{c} 2 \mathrm{~h} 2+$ & 2 & 2000 & 0000 & 00000 & 000000 & 1 & $0.0 \mathrm{e}-00$ & 317.500 \\
\hline 61 & $\mathrm{c} 2 \mathrm{~h} 3+$ & 3 & 2000 & 0000 & 00000 & 000000 & 1 & $0.0 \mathrm{e}-00$ & 267.900 \\
\hline 62 & $\mathrm{c} 2 \mathrm{~h} 4+$ & 4 & 2000 & 0000 & 00000 & 000000 & 1 & $0.0 \mathrm{e}-00$ & 256.800 \\
\hline 63 & $\mathrm{c} 3+$ & 0 & 3000 & 0000 & 00000 & 000000 & 1 & $0.0 \mathrm{e}-00$ & $479.000^{*}$ \\
\hline 64 & $\mathrm{c} 3 \mathrm{~h}+$ & 1 & 3000 & 0000 & 00000 & 000000 & 1 & $0.0 \mathrm{e}-00$ & $381.000 *$ \\
\hline 65 & c3h2+ & 2 & 3000 & 0000 & 00000 & 000000 & 1 & $0.0 \mathrm{e}-00$ & $330.000 *$ \\
\hline 66 & c3h3+ & 3 & 3000 & 0000 & 00000 & 000000 & 1 & $0.0 \mathrm{e}-00$ & $282.000^{*}$ \\
\hline 67 & $\mathrm{n}+$ & 0 & 0100 & 0000 & 00000 & 000000 & 1 & $0.0 \mathrm{e}-00$ & 447.690 \\
\hline
\end{tabular}

Continua na próxima página... 
Tabela B.1 - Continuação

\begin{tabular}{|c|c|c|c|c|c|c|c|c|c|}
\hline \multirow{2}{*}{$\begin{array}{c}\text { Número } \\
68\end{array}$} & \multirow{2}{*}{$\begin{array}{c}\text { Espécie } \\
\mathrm{nh}+\end{array}$} & \multicolumn{3}{|c|}{ Codificação da } & \multicolumn{3}{|c|}{ Composição Atômica } & \multirow{2}{*}{$\begin{array}{c}\text { Abundância Inicial } \\
0.0 \mathrm{e}-00\end{array}$} & \multirow{2}{*}{$\begin{array}{c}\text { Entalpia de Formação }-\mathrm{kJ} / \mathrm{mol} \\
401.100\end{array}$} \\
\hline & & 1 & 0100 & 0000 & 00000 & 000000 & 1 & & \\
\hline 69 & $\operatorname{nh} 2+$ & 2 & 0100 & 0000 & 00000 & 000000 & 1 & $0.0 \mathrm{e}-00$ & 302.700 \\
\hline 70 & $\operatorname{nh} 3+$ & 3 & 0100 & 0000 & 00000 & 000000 & 1 & $0.0 \mathrm{e}-00$ & 224.900 \\
\hline 71 & $\operatorname{nh} 4+$ & 4 & 0100 & 0000 & 00000 & 000000 & 1 & $0.0 \mathrm{e}-00$ & $151.000^{*}$ \\
\hline 72 & $\mathrm{cn}+$ & 0 & 1100 & 0000 & 00000 & 000000 & 1 & $0.0 \mathrm{e}-00$ & 429.300 \\
\hline 73 & $\mathrm{c} 2 \mathrm{n}+$ & 0 & 2100 & 0000 & 00000 & 000000 & 1 & $0.0 \mathrm{e}-00$ & $387.000^{*}$ \\
\hline 74 & hen + & 1 & 1100 & 0000 & 00000 & 000000 & 1 & $0.0 \mathrm{e}-00$ & 346.000 \\
\hline 75 & hnct & 1 & 1100 & 0000 & 00000 & 000000 & 1 & $0.0 \mathrm{e}-00$ & 336.000 \\
\hline 76 & henh + & 2 & 1100 & 0000 & 00000 & 000000 & 1 & $0.0 \mathrm{e}-00$ & $226.000 * * *$ \\
\hline 77 & h2nc+ & 2 & 1100 & 0000 & 00000 & 000000 & 1 & $0.0 \mathrm{e}-00$ & $265.000 *$ \\
\hline 78 & $\mathrm{n} 2+$ & 0 & 0200 & 0000 & 00000 & 000000 & 1 & $0.0 \mathrm{e}-00$ & 359.298 \\
\hline 79 & $\mathrm{n} 2 \mathrm{~h}+$ & 1 & 0200 & 0000 & 00000 & 000000 & 1 & $0.0 \mathrm{e}-00$ & $247.500^{*}$ \\
\hline 80 & no+ & 0 & 0110 & 0000 & 00000 & 000000 & 1 & $0.0 \mathrm{e}-00$ & 235.330 \\
\hline 81 & hno+ & 1 & 0110 & 0000 & 00000 & 000000 & 1 & $0.0 \mathrm{e}-00$ & $256.800^{* *}$ \\
\hline 82 & $\mathrm{~s}+$ & 0 & 0000 & 0000 & 00000 & 001000 & 1 & $1.860 \mathrm{e}-06$ & $304.000 *$ \\
\hline 83 & $\mathrm{sh}+$ & 1 & 0000 & 0000 & 00000 & 001000 & 1 & $0.0 \mathrm{e}-00$ & $271.800^{*}$ \\
\hline 84 & $\mathrm{~h} 2 \mathrm{~s}+$ & 2 & 0000 & 0000 & 00000 & 001000 & 1 & $0.0 \mathrm{e}-00$ & $237.000 *$ \\
\hline 85 & h3s+ & 3 & 0000 & 0000 & 00000 & 001000 & 1 & $0.0 \mathrm{e}-00$ & $190.000^{*}$ \\
\hline 86 & $\operatorname{cs}+$ & 0 & 1000 & 0000 & 00000 & 001000 & 1 & $0.0 \mathrm{e}-00$ & $324.000^{*}$ \\
\hline 87 & hcs + & 1 & 1000 & 0000 & 00000 & 001000 & 1 & $0.0 \mathrm{e}-00$ & $243.000 *$ \\
\hline 88 & so+ & 0 & 0010 & 0000 & 00000 & 001000 & 1 & $0.0 \mathrm{e}-00$ & $239.200^{*}$ \\
\hline 89 & hso+ & 1 & 0010 & 0000 & 00000 & 001000 & 1 & $0.0 \mathrm{e}-00$ & $150.000^{* * *}$ \\
\hline 90 & hso2+ & 1 & 0020 & 0000 & 00000 & 001000 & 1 & $0.0 \mathrm{e}-00$ & $143.000^{*}$ \\
\hline 91 & hocs + & 1 & 1010 & 0000 & 00000 & 001000 & 1 & $0.0 \mathrm{e}-00$ & $181.000^{*}$ \\
\hline 92 & $\mathrm{~h} 2 \mathrm{co}+$ & 2 & 1010 & 0000 & 00000 & 000000 & 1 & $0.000 \mathrm{e}+00$ & 225.800 \\
\hline 93 & $\mathrm{~h} 3 \mathrm{co}+$ & 3 & 1010 & 0000 & 00000 & 000000 & 1 & $0.000 \mathrm{e}+00$ & 168.800 \\
\hline 94 & $\mathrm{~h} 2 \mathrm{cs}+$ & 2 & 1000 & 0000 & 00000 & 001000 & 1 & $0.000 \mathrm{e}+00$ & 240.000 \\
\hline 95 & h3cs + & 3 & 1000 & 0000 & 00000 & 001000 & 1 & $0.000 \mathrm{e}+00$ & 208.000 \\
\hline 97 & fe+ & 0 & 0000 & 0000 & 00000 & 000001 & 1 & $1.500 \mathrm{e}-08$ & 280.240 \\
\hline 120 & h: & 1 & 0000 & 0000 & 00000 & 000000 & 0 & $1.000 \mathrm{e}-20$ & 51.634 \\
\hline 121 & h2: & 2 & 0000 & 0000 & 00000 & 000000 & 0 & $1.000 \mathrm{e}-20$ & 0.000 \\
\hline 150 & $\mathrm{c} 2 \mathrm{~h} 4$ & 4 & 2000 & 0000 & 00000 & 000000 & 0 & $0.0 \mathrm{e}-00$ & 52.470 \\
\hline 151 & $\mathrm{c} 2 \mathrm{~h} 3$ & 3 & 2000 & 0000 & 00000 & 000000 & 0 & $0.0 \mathrm{e}-00$ & 299.000 \\
\hline 152 & hc3 & 1 & 3000 & 0000 & 00000 & 000000 & 0 & $0.0 \mathrm{e}-00$ & $172.300^{*}$ \\
\hline 153 & $\mathrm{~h} 2 \mathrm{c} 3$ & 2 & 3000 & 0000 & 00000 & 000000 & 0 & $0.0 \mathrm{e}-00$ & $130.000^{* * *}$ \\
\hline 154 & c4 & 0 & 4000 & 0000 & 00000 & 000000 & 0 & $0.0 \mathrm{e}-00$ & 232.000 \\
\hline 155 & $\mathrm{c} 4 \mathrm{~h}$ & 1 & 4000 & 0000 & 00000 & 000000 & 0 & $0.0 \mathrm{e}-00$ & $290.000^{* * *}$ \\
\hline 156 & $\mathrm{c} 4 \mathrm{~h} 2$ & 2 & 4000 & 0000 & 00000 & 000000 & 0 & $0.0 \mathrm{e}-00$ & $105.000^{*}$ \\
\hline 157 & c3h3 & 3 & 3000 & 0000 & 00000 & 000000 & 0 & $0.0 \mathrm{e}-00$ & 339.000 \\
\hline 158 & $\mathrm{c} 3 \mathrm{~h} 4$ & 4 & 3000 & 0000 & 00000 & 000000 & 0 & $0.0 \mathrm{e}-00$ & 185.400 \\
\hline 159 & $\mathrm{c} 5 \mathrm{~h} 2$ & 2 & 5000 & 0000 & 00000 & 000000 & 0 & $0.0 \mathrm{e}-00$ & 690.360 \\
\hline 160 & $\mathrm{c} 4 \mathrm{~h} 3$ & 3 & 4000 & 0000 & 00000 & 000000 & 0 & $0.0 \mathrm{e}-00$ & $501.829 *$ \\
\hline 161 & $\mathrm{c} 6 \mathrm{~h}$ & 1 & 6000 & 0000 & 00000 & 000000 & 0 & $0.0 \mathrm{e}-00$ & 991.800 \\
\hline
\end{tabular}

Continua na próxima página... 
Tabela B.1 - Continuação

\begin{tabular}{|c|c|c|c|c|c|c|c|c|c|}
\hline \multirow{2}{*}{$\begin{array}{c}\text { Número } \\
162\end{array}$} & \multirow{2}{*}{$\begin{array}{l}\text { Espécie } \\
\text { c6h2 }\end{array}$} & \multicolumn{3}{|c|}{ Codificação da } & \multicolumn{3}{|c|}{ Composição Atômica } & \multirow{2}{*}{$\begin{array}{c}\text { Abundância Inicial } \\
0.0 \mathrm{e}-00\end{array}$} & \multirow{2}{*}{$\begin{array}{c}\text { Entalpia de Formação }-\mathrm{kJ} / \mathrm{mol} \\
696.000\end{array}$} \\
\hline & & 2 & 6000 & 0000 & 00000 & 000000 & 0 & & \\
\hline 163 & $\mathrm{c} 5 \mathrm{~h}$ & 1 & 5000 & 0000 & 00000 & 000000 & 0 & $0.0 \mathrm{e}-00$ & 853.430 \\
\hline 164 & $\mathrm{c} 5 \mathrm{~h} 4$ & 4 & 5000 & 0000 & 00000 & 000000 & 0 & $0.0 \mathrm{e}-00$ & 557.214 \\
\hline 165 & c5 & 0 & 5000 & 0000 & 00000 & 000000 & 0 & $0.0 \mathrm{e}-00$ & 1061.18 \\
\hline 166 & c6 & 0 & 6000 & 0000 & 00000 & 000000 & 0 & $0.0 \mathrm{e}-00$ & 1216.08 \\
\hline 167 & $\mathrm{c} 7$ & 0 & 7000 & 0000 & 00000 & 000000 & 0 & $0.0 \mathrm{e}-00$ & 1309.34 \\
\hline 168 & $\mathrm{c} 7 \mathrm{~h}$ & 1 & 7000 & 0000 & 00000 & 000000 & 0 & $0.0 \mathrm{e}-00$ & 1080.1 \\
\hline 169 & $\mathrm{c} 8$ & 0 & 8000 & 0000 & 00000 & 000000 & 0 & $0.0 \mathrm{e}-00$ & 1487 \\
\hline 170 & $\mathrm{c} 8 \mathrm{~h}$ & 1 & 8000 & 0000 & 00000 & 000000 & 0 & $0.0 \mathrm{e}-00$ & 1218.5 \\
\hline 171 & c9 & 0 & 9000 & 0000 & 00000 & 000000 & 0 & $0.0 \mathrm{e}-00$ & 1554 \\
\hline 172 & $\mathrm{c} 8 \mathrm{~h} 2$ & 2 & 8000 & 0000 & 00000 & 000000 & 0 & $0.0 \mathrm{e}-00$ & 891.800 \\
\hline 173 & c6h6 & 6 & 6000 & 0000 & 00000 & 000000 & 0 & $0.0 \mathrm{e}-00$ & 100.410 \\
\hline 174 & hno & 1 & 0110 & 0000 & 00000 & 000000 & 0 & $0.0 \mathrm{e}-00$ & 109.809 \\
\hline 175 & $\mathrm{c} 2 \mathrm{~h} 5$ & 5 & 2000 & 0000 & 00000 & 000000 & 0 & $0.0 \mathrm{e}-00$ & 130.773 \\
\hline 176 & $\mathrm{c} 2 \mathrm{n}$ & 0 & 2100 & 0000 & 00000 & 000000 & 0 & $0.0 \mathrm{e}-00$ & 674.474 \\
\hline 177 & $\mathrm{~h} 2 \mathrm{cn}$ & 2 & 1100 & 0000 & 00000 & 000000 & 0 & $0.0 \mathrm{e}-00$ & 242.229 \\
\hline 178 & c3n & 0 & 3100 & 0000 & 00000 & 000000 & 0 & $0.0 \mathrm{e}-00$ & 629.000 \\
\hline 179 & hc3n & 1 & 3100 & 0000 & 00000 & 000000 & 0 & $0.0 \mathrm{e}-00$ & 351.000 \\
\hline 180 & $\mathrm{~h} 3 \mathrm{c} 2 \mathrm{n}$ & 3 & 2100 & 0000 & 00000 & 000000 & 0 & $0.0 \mathrm{e}-00$ & 169.982 \\
\hline 181 & $\mathrm{c} 4 \mathrm{n}$ & 0 & 4100 & 0000 & 00000 & 000000 & 0 & $0.0 \mathrm{e}-00$ & 754.800 \\
\hline 182 & $\mathrm{c} 2 \mathrm{~h} 4 \mathrm{o}$ & 4 & 2010 & 0000 & 00000 & 000000 & 0 & $0.0 \mathrm{e}-00$ & -155.7 \\
\hline 183 & $\operatorname{ch} 40$ & 4 & 1010 & 0000 & 00000 & 000000 & 0 & $0.0 \mathrm{e}-00$ & -190.11 \\
\hline 184 & $\mathrm{c} 2 \mathrm{~h} 4 \mathrm{o} 2$ & 4 & 2020 & 0000 & 00000 & 000000 & 0 & $0.0 \mathrm{e}-00$ & -344.396 \\
\hline 185 & c4h6o2 & 6 & 4020 & 0000 & 00000 & 000000 & 0 & $0.0 \mathrm{e}-00$ & -308.273 \\
\hline 186 & c4h5n & 5 & 4100 & 0000 & 00000 & 000000 & 0 & $0.0 \mathrm{e}-00$ & 124.857 \\
\hline 187 & $\mathrm{c} 7 \mathrm{n}$ & 0 & 7100 & 0000 & 00000 & 000000 & 0 & $0.0 \mathrm{e}-00$ & 1000 \\
\hline 188 & $\mathrm{c} 5 \mathrm{n}$ & 0 & 5100 & 0000 & 00000 & 000000 & 0 & $0.0 \mathrm{e}-00$ & 850.000 \\
\hline 189 & $\mathrm{c} 2 \mathrm{n} 2$ & 0 & 2200 & 0000 & 00000 & 000000 & 0 & $0.0 \mathrm{e}-00$ & 307.342 \\
\hline 191 & $\mathrm{c} 2 \mathrm{~h} 2 \mathrm{n}$ & 2 & 2100 & 0000 & 00000 & 000000 & 0 & $0.0 \mathrm{e}-00$ & 260.540 \\
\hline 192 & hc5n & 1 & 5100 & 0000 & 00000 & 000000 & 0 & $0.0 \mathrm{e}-00$ & 600.000 \\
\hline 193 & hc7n & 1 & 7100 & 0000 & 00000 & 000000 & 0 & $0.0 \mathrm{e}-00$ & 1000 \\
\hline 194 & $\operatorname{ch} 2 \mathrm{o} 2$ & 2 & 1020 & 0000 & 00000 & 000000 & 0 & $0.0 \mathrm{e}-00$ & -378.6 \\
\hline 195 & ch3no & 3 & 1110 & 0000 & 00000 & 000000 & 0 & $0.0 \mathrm{e}-00$ & -178.241 \\
\hline 196 & ch3ns & 3 & 1100 & 0000 & 00000 & 100000 & 0 & $0.0 \mathrm{e}-00$ & -100 \\
\hline 197 & c3h3ns & 3 & 3100 & 0000 & 00000 & 100000 & 0 & $0.0 \mathrm{e}-00$ & -170 \\
\hline 198 & $\operatorname{ch} 3 n$ & 3 & 1100 & 0000 & 00000 & 000000 & 0 & $0.0 \mathrm{e}-00$ & 96.616 \\
\hline 199 & c3h3n3 & 3 & 3300 & 0000 & 00000 & 000000 & 0 & $0.0 \mathrm{e}-00$ & 100 \\
\hline 200 & $\mathrm{c} 4 \mathrm{~h} 4 \mathrm{n}$ & 4 & 4100 & 0000 & 00000 & 000000 & 0 & $0.0 \mathrm{e}-00$ & 195 \\
\hline 201 & c5h5n & 5 & 5100 & 0000 & 00000 & 000000 & 0 & $0.0 \mathrm{e}-00$ & 156.922 \\
\hline 202 & $\mathrm{c} 2 \mathrm{~h} 6$ & 6 & 2000 & 0000 & 00000 & 000000 & 0 & $0.0 \mathrm{e}-00$ & -68.232 \\
\hline 203 & c3h3n & 3 & 3100 & 0000 & 00000 & 000000 & 0 & $0.0 \mathrm{e}-00$ & 190.874 \\
\hline 300 & $\mathrm{o} 2 \mathrm{~h}+$ & 1 & 0020 & 0000 & 00000 & 000000 & 1 & $0.0 \mathrm{e}-00$ & 264.900 \\
\hline 301 & h2c3+ & 2 & 3000 & 0000 & 00000 & 000000 & 1 & $0.0 \mathrm{e}-00$ & $330.000^{*}$ \\
\hline
\end{tabular}

Continua na próxima página... 
Tabela B.1 - Continuação

\begin{tabular}{|c|c|c|c|c|c|c|c|c|c|}
\hline \multirow{2}{*}{$\begin{array}{c}\text { Número } \\
302\end{array}$} & \multirow{2}{*}{$\begin{array}{c}\text { Espécie } \\
\text { c4+ }\end{array}$} & \multicolumn{3}{|c|}{ Codificação da } & \multicolumn{3}{|c|}{ Composição Atômica } & \multirow{2}{*}{$\begin{array}{c}\text { Abundância Inicial } \\
0.0 \mathrm{e}-00\end{array}$} & \multirow{2}{*}{$\begin{array}{c}\text { Entalpia de Formação }-\mathrm{kJ} / \mathrm{mol} \\
522.000\end{array}$} \\
\hline & & 0 & 4000 & 0000 & 00000 & 000000 & 1 & & \\
\hline 303 & $\mathrm{c} 4 \mathrm{~h}+$ & 1 & 4000 & 0000 & 00000 & 000000 & 1 & $0.0 \mathrm{e}-00$ & $381.000^{* * *}$ \\
\hline 304 & c4h2+ & 2 & 4000 & 0000 & 00000 & 000000 & 1 & $0.0 \mathrm{e}-00$ & $340.000 *$ \\
\hline 305 & $\mathrm{c} 4 \mathrm{~h} 3+$ & 3 & 4000 & 0000 & 00000 & 000000 & 1 & $0.0 \mathrm{e}-00$ & $291.000 *$ \\
\hline 306 & h3c3+ & 3 & 3000 & 0000 & 00000 & 000000 & 1 & $0.0 \mathrm{e}-00$ & $282.000 *$ \\
\hline 307 & c4h5+ & 5 & 4000 & 0000 & 00000 & 000000 & 1 & $0.0 \mathrm{e}-00$ & 1085.3 \\
\hline 308 & c3h5+ & 5 & 3000 & 0000 & 00000 & 000000 & 1 & $0.0 \mathrm{e}-00$ & 945.000 \\
\hline 309 & c6h3+ & 3 & 6000 & 0000 & 00000 & 000000 & 1 & $0.0 \mathrm{e}-00$ & 1188 \\
\hline 310 & c6h4+ & 4 & 6000 & 0000 & 00000 & 000000 & 1 & $0.0 \mathrm{e}-00$ & 1271.8 \\
\hline 311 & $\mathrm{c} 6 \mathrm{~h} 5+$ & 5 & 6000 & 0000 & 00000 & 000000 & 1 & $0.0 \mathrm{e}-00$ & 1148.98 \\
\hline 312 & c5h5+ & 5 & 5000 & 0000 & 00000 & 000000 & 1 & $0.0 \mathrm{e}-00$ & 1116.8 \\
\hline 313 & c5h4+ & 4 & 5000 & 0000 & 00000 & 000000 & 1 & $0.0 \mathrm{e}-00$ & 1332 \\
\hline 314 & c6h2+ & 2 & 6000 & 0000 & 00000 & 000000 & 1 & $0.0 \mathrm{e}-00$ & 159.000 \\
\hline 315 & c4h4+ & 4 & 4000 & 0000 & 00000 & 000000 & 1 & $0.0 \mathrm{e}-00$ & 126.000 \\
\hline 316 & $\mathrm{c} 6 \mathrm{~h}+$ & 1 & 6000 & 0000 & 00000 & 000000 & 1 & $0.0 \mathrm{e}-00$ & $1000^{*}$ \\
\hline 317 & $\mathrm{c} 8 \mathrm{~h} 2+$ & 2 & 8000 & 0000 & 00000 & 000000 & 1 & $0.0 \mathrm{e}-00$ & 1741 \\
\hline 318 & $\mathrm{c} 9 \mathrm{~h}+$ & 1 & 9000 & 0000 & 00000 & 000000 & 1 & $0.0 \mathrm{e}-00$ & $1390^{*}$ \\
\hline 319 & c9+ & 0 & 9000 & 0000 & 00000 & 000000 & 1 & $0.0 \mathrm{e}-00$ & 2451 \\
\hline 320 & c3h4+ & 4 & 3000 & 0000 & 00000 & 000000 & 1 & $0.0 \mathrm{e}-00$ & 1194.5 \\
\hline 321 & c6h7+ & 7 & 6000 & 0000 & 00000 & 000000 & 1 & $0.0 \mathrm{e}-00$ & 892.200 \\
\hline 322 & $\mathrm{c}-$ & 0 & 1000 & 0000 & 00000 & 000000 & -1 & $0.0 \mathrm{e}-00$ & 589.785 \\
\hline 323 & h- & 1 & 0000 & 0000 & 00000 & 000000 & -1 & $0.0 \mathrm{e}-00$ & 143.200 \\
\hline 324 & o- & 0 & 0010 & 0000 & 00000 & 000000 & -1 & $0.0 \mathrm{e}-00$ & 105.400 \\
\hline 325 & oh- & 1 & 0010 & 0000 & 00000 & 000000 & -1 & $0.0 \mathrm{e}-00$ & -137.7 \\
\hline 326 & cn- & 0 & 1100 & 0000 & 00000 & 000000 & -1 & $0.0 \mathrm{e}-00$ & 63.975 \\
\hline 327 & c4h- & 1 & 4000 & 0000 & 00000 & 000000 & -1 & $0.0 \mathrm{e}-00$ & 206.000 \\
\hline 328 & c5- & 0 & 5000 & 0000 & 00000 & 000000 & -1 & $0.0 \mathrm{e}-00$ & 821.000 \\
\hline 329 & c6- & 0 & 6000 & 0000 & 00000 & 000000 & -1 & $0.0 \mathrm{e}-00$ & 776.000 \\
\hline 330 & c7- & 0 & 7000 & 0000 & 00000 & 000000 & -1 & $0.0 \mathrm{e}-00$ & 1015 \\
\hline 331 & c6h- & 1 & 6000 & 0000 & 00000 & 000000 & -1 & $0.0 \mathrm{e}-00$ & 820.000 \\
\hline 332 & $\mathrm{c} 4 \mathrm{n}+$ & 0 & 4100 & 0000 & 00000 & 000000 & 1 & $0.0 \mathrm{e}-00$ & 1878.616 \\
\hline 333 & $\operatorname{ch} 50+$ & 5 & 1010 & 0000 & 00000 & 000000 & 1 & $0.0 \mathrm{e}-00$ & 585.970 \\
\hline 334 & $\mathrm{c} 2 \mathrm{~h} 5 \mathrm{o} 2+$ & 5 & 2020 & 0000 & 00000 & 000000 & 1 & $0.0 \mathrm{e}-00$ & -190.11 \\
\hline 335 & $\mathrm{c} 2 \mathrm{~h} 4 \mathrm{o} 2+$ & 4 & 2020 & 0000 & 00000 & 000000 & 1 & $0.0 \mathrm{e}-00$ & 895.815 \\
\hline 338 & $\mathrm{c} 5 \mathrm{n}+$ & 0 & 5100 & 0000 & 00000 & 000000 & 1 & $0.0 \mathrm{e}-00$ & 1800 \\
\hline 339 & $\mathrm{c} 7 \mathrm{n}+$ & 0 & 7100 & 0000 & 00000 & 000000 & 1 & $0.0 \mathrm{e}-00$ & 2000 \\
\hline 340 & $\mathrm{c} 2 \mathrm{nh}+$ & 1 & 2100 & 0000 & 00000 & 000000 & 1 & $0.0 \mathrm{e}-00$ & 526.552 \\
\hline 341 & hc3n+ & 1 & 3100 & 0000 & 00000 & 000000 & 1 & $0.0 \mathrm{e}-00$ & 1474 \\
\hline 342 & $\mathrm{c} 2 \mathrm{n} 2+$ & 0 & 2200 & 0000 & 00000 & 000000 & 1 & $0.0 \mathrm{e}-00$ & 1594.8 \\
\hline 343 & $\mathrm{c} 2 \mathrm{~h} 2 \mathrm{n}+$ & 2 & 2100 & 0000 & 00000 & 000000 & 1 & $0.0 \mathrm{e}-00$ & 360.590 \\
\hline 344 & hc5n+ & 1 & 5100 & 0000 & 00000 & 000000 & 1 & $0.0 \mathrm{e}-00$ & 1800 \\
\hline 345 & $\mathrm{c} 5 \mathrm{~h}+$ & 1 & 5000 & 0000 & 00000 & 000000 & 1 & $0.0 \mathrm{e}-00$ & 620.000 \\
\hline 346 & $\mathrm{c} 7 \mathrm{~h}+$ & 1 & 7000 & 0000 & 00000 & 000000 & 1 & $0.0 \mathrm{e}-00$ & 800.000 \\
\hline
\end{tabular}

Continua na próxima página... 
Tabela B.1 - Continuação

\begin{tabular}{cccccccccc}
\hline \hline \multirow{2}{*}{ Número } & Espécie & & \multicolumn{2}{c}{ Codificação da Composição Atômica } & Abundância Inicial & Entalpia de Formação - kJ/mol \\
\hline 337 & $\mathrm{c} 3 \mathrm{n}+$ & 0 & 3100 & 0000 & 00000 & 000000 & 1 & $0.0 \mathrm{e}-00$ & 1400 \\
338 & $\mathrm{c} 2 \mathrm{~h} 6+$ & 6 & 2000 & 0000 & 00000 & 000000 & 1 & $0.0 \mathrm{e}-00$ & $1036.130^{*}$ \\
\hline
\end{tabular}

(*) Medida a 298K.

${ }^{(* *)}$ Isomeros mais estáveis.

$(* * *)$ Entalpia incomum.

Tabela B.2 - Reações químicas, parâmetros e tipos de reação usados na modelagem da HNN.

\begin{tabular}{|c|c|c|c|c|c|c|c|c|}
\hline \multicolumn{2}{|c|}{ Reagentes } & \multicolumn{3}{|c|}{ Produtos } & \multirow{2}{*}{$\frac{\gamma}{1.00 \mathrm{e}+00}$} & \multirow{2}{*}{$\begin{array}{c}\alpha \\
0\end{array}$} & \multirow{2}{*}{$\frac{\beta}{0.00}$} & \multirow{2}{*}{$\begin{array}{c}\text { Tipo de Reação } \\
11\end{array}$} \\
\hline $\mathrm{h}:$ & $\mathrm{h}:$ & $\mathrm{h} 2$ & & & & & & \\
\hline $\mathrm{h}$ & grain & $\mathrm{h}:$ & & & $1.00 \mathrm{e}+00$ & 0 & 0.00 & 13 \\
\hline $\mathrm{h}:$ & grain & $\mathrm{h}$ & & & $1.00 \mathrm{e}-00$ & 0 & 350.00 & 18 \\
\hline $\mathrm{h} 2$ & grain & h2: & & & $1.00 \mathrm{e}+00$ & 0 & 0.00 & 113 \\
\hline h2: & photon & $\mathrm{h} 2$ & & & $1.00 \mathrm{e}-00$ & 0 & 0.00 & 117 \\
\hline h2: & grain & $\mathrm{h} 2$ & & & $1.00 \mathrm{e}-00$ & 0 & 450.00 & 118 \\
\hline $\mathrm{h}$ & crp & $\mathrm{h}+$ & electr & & $4.60 \mathrm{e}-01$ & 0 & 0.0 & 1 \\
\hline he & crp & he+ & electr & & $5.00 \mathrm{e}-01$ & 0 & 0.0 & 1 \\
\hline $\mathrm{h} 2$ & crp & $\mathrm{h}+$ & $\mathrm{h}$ & electr & $4.00 \mathrm{e}-02$ & 0 & 0.0 & 1 \\
\hline $\mathrm{h} 2$ & crp & $\mathrm{h}$ & $\mathrm{h}$ & & $1.50 \mathrm{e}-00$ & 0 & 0.0 & 1 \\
\hline $\mathrm{h} 2$ & crp & $\mathrm{h} 2+$ & electr & & $9.60 \mathrm{e}-01$ & 0 & 0.0 & 1 \\
\hline c & crp & $\mathrm{c}+$ & electr & & $1.80 \mathrm{e}+00$ & 0 & 0.0 & 1 \\
\hline o & crp & $\mathrm{o}+$ & electr & & $2.80 \mathrm{e}+00$ & 0 & 0.0 & 1 \\
\hline c & phosec & $\mathrm{c}+$ & electr & & $5.10 \mathrm{e}+02$ & 0 & 0.0 & 2 \\
\hline $\mathrm{ch}$ & phosec & c & $\mathrm{h}$ & & $7.56 \mathrm{e}+02$ & 0 & 0.0 & 2 \\
\hline $\operatorname{ch} 2$ & phosec & $\operatorname{ch} 2+$ & electr & & $5.00 \mathrm{e}+02$ & 0 & 0.0 & 2 \\
\hline ch3 & phosec & $\operatorname{ch} 2$ & $\mathrm{~h}$ & & $5.00 \mathrm{e}+02$ & 0 & 0.0 & 2 \\
\hline $\operatorname{ch} 3$ & phosec & $\operatorname{ch} 3+$ & electr & & $5.00 \mathrm{e}+02$ & 0 & 0.0 & 2 \\
\hline $\operatorname{ch} 4$ & phosec & $\operatorname{ch} 2$ & $\mathrm{~h} 2$ & & $2.34 \mathrm{e}+03$ & 0 & 0.0 & 2 \\
\hline $\operatorname{ch}+$ & phosec & c & $\mathrm{h}+$ & & $1.76 \mathrm{e}+02$ & 0 & 0.0 & 2 \\
\hline oh & phosec & o & $\mathrm{h}$ & & $0.51 \mathrm{e}+03$ & 0 & 0.0 & 2 \\
\hline h2o & phosec & oh & $\mathrm{h}$ & & $0.97 \mathrm{e}+03$ & 0 & 0.0 & 2 \\
\hline o2 & phosec & $\mathrm{o} 2+$ & electr & & $1.17 \mathrm{e}+02$ & 0 & 0.0 & 2 \\
\hline o2 & phosec & o & o & & $0.75 \mathrm{e}+03$ & 0 & 0.0 & 2 \\
\hline $\mathrm{co} 2$ & phosec & co & o & & $1.71 \mathrm{e}+03$ & 0 & 0.0 & 2 \\
\hline $\mathrm{c} 2$ & phosec & c & c & & $2.37 \mathrm{e}+02$ & 0 & 0.0 & 2 \\
\hline $\mathrm{c} 2 \mathrm{~h}$ & phosec & $\mathrm{c} 2$ & $\mathrm{~h}$ & & $5.00 \mathrm{e}+03$ & 0 & 0.0 & 2 \\
\hline
\end{tabular}

Continua na próxima página... 
Tabela B.2 - Continuação

\begin{tabular}{|c|c|c|c|c|c|c|c|c|}
\hline \multicolumn{2}{|c|}{ Reagentes } & \multicolumn{3}{|c|}{ Produtos } & \multirow{2}{*}{$\frac{\gamma}{5.15 \mathrm{e}+03}$} & \multirow{2}{*}{$\begin{array}{c}\alpha \\
0\end{array}$} & \multirow{2}{*}{$\begin{array}{l}\beta \\
0.0\end{array}$} & \multirow{2}{*}{$\begin{array}{c}\text { Tipo de Reação } \\
2\end{array}$} \\
\hline $\mathrm{c} 2 \mathrm{~h} 2$ & phosec & $\mathrm{c} 2 \mathrm{~h}$ & $\mathrm{~h}$ & & & & & \\
\hline $\mathrm{c} 2 \mathrm{~h} 2$ & phosec & $\mathrm{c} 2 \mathrm{~h} 2+$ & electr & & $1.31 \mathrm{e}+03$ & 0 & 0.0 & 2 \\
\hline c3 & phosec & $\mathrm{c} 2$ & $\mathrm{c}$ & & $1.12 \mathrm{e}+03$ & 0 & 0.0 & 2 \\
\hline $\mathrm{c} 3 \mathrm{~h}$ & phosec & c3 & $\mathrm{h}$ & & $5.00 \mathrm{e}+03$ & 0 & 0.0 & 2 \\
\hline c3h2 & phosec & $\mathrm{c} 3 \mathrm{~h}$ & $\mathrm{~h}$ & & $5.00 \mathrm{e}+03$ & 0 & 0.0 & 2 \\
\hline $\mathrm{co}$ & phosec & $\mathrm{c}$ & o & & $6.80 \mathrm{e}+02$ & 1.2 & 0.0 & 2 \\
\hline $\mathrm{co}$ & phosec & $\mathrm{co}+$ & electr & & $3.00 \mathrm{e}+00$ & 0 & 0.0 & 2 \\
\hline hco & phosec & $\mathrm{co}$ & $\mathrm{h}$ & & $4.21 \mathrm{e}+02$ & 0 & 0.0 & 2 \\
\hline hco & phosec & hcot & electr & & $1.17 \mathrm{e}+03$ & 0 & 0.0 & 2 \\
\hline h2co & phosec & $\mathrm{co}$ & h2 & & $2.66 \mathrm{e}+03$ & 0 & 0.0 & 2 \\
\hline o & $\mathrm{h} 2$ & oh & $\mathrm{h}$ & & $1.55 \mathrm{e}-13$ & 2.8 & 2980.0 & 4 \\
\hline o2 & $\mathrm{h}$ & oh & o & & $1.63 \mathrm{e}-09$ & -0.9 & 8750.0 & 4 \\
\hline oh & $\mathrm{h}$ & $\mathrm{o}$ & h2 & & $7.00 \mathrm{e}-14$ & 2.8 & 1950.0 & 4 \\
\hline oh & h2 & h2o & $\mathrm{h}$ & & $9.54 \mathrm{e}-13$ & 2 & 1490.0 & 4 \\
\hline h2o & $\mathrm{h}$ & oh & $\mathrm{h} 2$ & & $5.24 \mathrm{e}-12$ & 1.9 & 9265.0 & 4 \\
\hline $\mathrm{c}$ & h2 & $\mathrm{ch}$ & $\mathrm{h}$ & & $1.16 \mathrm{e}-09$ & 0.5 & 14100.0 & 4 \\
\hline $\mathrm{ch}$ & $\mathrm{h} 2$ & $\operatorname{ch} 2$ & $\mathrm{~h}$ & & $2.38 \mathrm{e}-10$ & 0 & 1760.0 & 4 \\
\hline $\operatorname{ch} 2$ & h2 & $\operatorname{ch} 3$ & $\mathrm{~h}$ & & $5.18 \mathrm{e}-11$ & 0.17 & 6400.0 & 4 \\
\hline $\operatorname{ch} 3$ & h2 & $\operatorname{ch} 4$ & $\mathrm{~h}$ & & $3.00 \mathrm{e}-10$ & 0 & 5460.0 & 4 \\
\hline $\mathrm{c} 2$ & h2 & $\mathrm{c} 2 \mathrm{~h}$ & $\mathrm{~h}$ & & $1.60 \mathrm{e}-10$ & 0 & 1419.0 & 4 \\
\hline $\mathrm{c} 2 \mathrm{~h}$ & h2 & $\mathrm{c} 2 \mathrm{~h} 2$ & $\mathrm{~h}$ & & $1.14 \mathrm{e}-11$ & 0 & 950.0 & 4 \\
\hline $\mathrm{ch}$ & $\mathrm{h}$ & $\mathrm{c}$ & h2 & & $1.16 \mathrm{e}-09$ & 0.5 & 2200.0 & 4 \\
\hline $\operatorname{ch} 2$ & $\mathrm{~h}$ & $\mathrm{ch}$ & $\mathrm{h} 2$ & & $4.70 \mathrm{e}-10$ & 0 & 370.0 & 4 \\
\hline ch3 & $\mathrm{h}$ & $\operatorname{ch} 2$ & h2 & & $5.18 \mathrm{e}-11$ & 0.17 & 5600.0 & 4 \\
\hline $\operatorname{ch} 4$ & $\mathrm{~h}$ & $\operatorname{ch} 3$ & h2 & & $3.00 \mathrm{e}-10$ & 0 & 6560.0 & 4 \\
\hline o2 & $\mathrm{c}$ & $\mathrm{co}$ & $\mathrm{o}$ & & $3.30 \mathrm{e}-11$ & 0.5 & 0.0 & 4 \\
\hline oh & $\mathrm{co}$ & $\operatorname{co} 2$ & $\mathrm{~h}$ & & $4.40 \mathrm{e}-13$ & -1.15 & 390.0 & 4 \\
\hline oh & $\mathrm{c}$ & $\mathrm{co}$ & $\mathrm{h}$ & & $3.10 \mathrm{e}-11$ & -0.36 & 0.0 & 4 \\
\hline oh & $\mathrm{o}$ & o2 & $\mathrm{h}$ & & $3.10 \mathrm{e}-11$ & -0.36 & 0.0 & 4 \\
\hline $\mathrm{ch}$ & o & hco+ & electr & & $2.40 \mathrm{e}-14$ & 0.5 & 0.0 & 4 \\
\hline $\mathrm{ch}$ & o & $\mathrm{co}$ & $\mathrm{h}$ & & $9.50 \mathrm{e}-11$ & 0.5 & 0.0 & 4 \\
\hline $\operatorname{ch} 2$ & $\mathrm{o}$ & $\mathrm{co}$ & $\mathrm{h}$ & $\mathrm{h}$ & $2.00 \mathrm{e}-11$ & 0.5 & 0.0 & 4 \\
\hline $\operatorname{ch} 3$ & o & $\mathrm{co}$ & h2 & $\mathrm{h}$ & $1.80 \mathrm{e}-20$ & 0.5 & 0.0 & 4 \\
\hline $\operatorname{ch} 3$ & o & h2co & $\mathrm{h}$ & & $1.40 \mathrm{e}-10$ & 0 & 0.0 & 4 \\
\hline $\mathrm{c} 2$ & o & $\mathrm{co}$ & $\mathrm{c}$ & & $5.00 \mathrm{e}-11$ & 0.5 & 0.0 & 4 \\
\hline $\mathrm{c} 2 \mathrm{~h}$ & o & $\mathrm{co}$ & $\mathrm{ch}$ & & $1.00 \mathrm{e}-10$ & 0 & 250.0 & 4 \\
\hline $\mathrm{c} 2 \mathrm{~h}$ & o2 & $\operatorname{co} 2$ & $\mathrm{ch}$ & & $1.00 \mathrm{e}-10$ & 0 & 2000.0 & 4 \\
\hline c3 & o & $\mathrm{co}$ & $\mathrm{c} 2$ & & $5.00 \mathrm{e}-12$ & 0 & 900.0 & 4 \\
\hline $\mathrm{c} 3 \mathrm{~h}$ & o & $\mathrm{c} 2 \mathrm{~h}$ & $\mathrm{CO}$ & & $1.70 \mathrm{e}-11$ & 0 & 0.0 & 4 \\
\hline c3h2 & o & $\mathrm{c} 2 \mathrm{~h} 2$ & $\mathrm{CO}$ & & $5.00 \mathrm{e}-11$ & 0.5 & 0.0 & 4 \\
\hline $\mathrm{c}$ & $\operatorname{ch} 2$ & $\mathrm{c} 2 \mathrm{~h}$ & $\mathrm{~h}$ & & $1.00 \mathrm{e}-10$ & 0 & 0.0 & 4 \\
\hline $\mathrm{c}$ & $\operatorname{ch} 3$ & $\mathrm{c} 2 \mathrm{~h} 2$ & $\mathrm{~h}$ & & $1.00 \mathrm{e}-10$ & 0 & 0.0 & 4 \\
\hline $\mathrm{c}$ & $\mathrm{c} 2 \mathrm{~h}$ & c3 & $\mathrm{h}$ & & $1.00 \mathrm{e}-10$ & 0 & 0.0 & 4 \\
\hline
\end{tabular}

Continua na próxima página... 
Tabela B.2 - Continuação

\begin{tabular}{|c|c|c|c|c|c|c|c|}
\hline \multicolumn{2}{|c|}{ Reagentes } & & \multirow{2}{*}{$\frac{\text { Produtos }}{\mathrm{h}}$} & \multirow{2}{*}{$\frac{\gamma}{2.90 \mathrm{e}-10}$} & \multirow{2}{*}{$\frac{\alpha}{-0.12}$} & \multirow{2}{*}{$\begin{array}{l}\beta \\
0.0\end{array}$} & \multirow{2}{*}{$\begin{array}{c}\text { Tipo de Reação } \\
4\end{array}$} \\
\hline $\mathrm{c}$ & $\mathrm{c} 2 \mathrm{~h} 2$ & $\mathrm{c} 3 \mathrm{~h}$ & & & & & \\
\hline $\mathrm{c}$ & $\mathrm{c} 2 \mathrm{~h} 2$ & c3 & $\mathrm{h} 2$ & $1.45 \mathrm{e}-10$ & -0.12 & 0.0 & 4 \\
\hline $\mathrm{c}+$ & $\mathrm{h} 2$ & $\operatorname{ch}+$ & $\mathrm{h}$ & $1.50 \mathrm{e}-10$ & 0 & 4640.0 & 4 \\
\hline $\operatorname{ch}+$ & $\mathrm{h}$ & $\mathrm{c}+$ & h2 & $1.50 \mathrm{e}-10$ & 0 & 0.0 & 4 \\
\hline $\mathrm{ch}+$ & $\mathrm{h} 2$ & $\operatorname{ch} 2+$ & $\mathrm{h}$ & $1.20 \mathrm{e}-09$ & 0 & 0.0 & 4 \\
\hline $\operatorname{ch} 2+$ & $\mathrm{h}$ & $\operatorname{ch}+$ & h2 & $1.20 \mathrm{e}-09$ & 0 & 2700.0 & 4 \\
\hline $\operatorname{ch} 2+$ & h2 & $\operatorname{ch} 3+$ & $\mathrm{h}$ & $7.00 \mathrm{e}-10$ & 0 & 0.0 & 4 \\
\hline $\operatorname{ch} 3+$ & $\mathrm{h}$ & $\operatorname{ch} 2+$ & $\mathrm{h} 2$ & $7.00 \mathrm{e}-10$ & 0 & 10560.0 & 4 \\
\hline $\operatorname{ch} 3+$ & h2 & $\operatorname{ch} 4+$ & $\mathrm{h}$ & $2.00 \mathrm{e}-10$ & 0 & 32500.0 & 4 \\
\hline $\operatorname{ch} 4+$ & $\mathrm{h}$ & $\operatorname{ch} 3+$ & $\mathrm{h} 2$ & $2.00 \mathrm{e}-10$ & 0 & 0.0 & 4 \\
\hline $\operatorname{ch} 4+$ & h2 & $\operatorname{ch} 5+$ & $\mathrm{h}$ & $3.30 \mathrm{e}-11$ & -1.35 & 23.0 & 4 \\
\hline $\operatorname{ch} 5+$ & $\mathrm{h}$ & $\operatorname{ch} 4+$ & $\mathrm{h} 2$ & $4.00 \mathrm{e}-11$ & 0 & 2200.0 & 4 \\
\hline $\mathrm{h}+$ & $\mathrm{h} 2$ & $\mathrm{~h} 2+$ & $\mathrm{h}$ & $6.40 \mathrm{e}-10$ & 0 & 21300.0 & 4 \\
\hline $\mathrm{h} 2+$ & $\mathrm{h}$ & $\mathrm{h}+$ & $\mathrm{h} 2$ & $6.40 \mathrm{e}-10$ & 0 & 0.0 & 4 \\
\hline $\mathrm{h} 2+$ & $\mathrm{h} 2$ & h3+ & $\mathrm{h}$ & $2.10 \mathrm{e}-09$ & 0 & 0.0 & 4 \\
\hline h3+ & $\mathrm{h}$ & $\mathrm{h} 2+$ & $\mathrm{h} 2$ & $2.10 \mathrm{e}-09$ & 0 & 20000.0 & 4 \\
\hline $\mathrm{h}+$ & o & $\mathrm{o}+$ & $\mathrm{h}$ & $1.66 \mathrm{e}-10$ & 0.139 & 227.0 & 4 \\
\hline $\mathrm{h}+$ & $\mathrm{o} 2$ & $\mathrm{o} 2+$ & $\mathrm{h}$ & $1.20 \mathrm{e}-09$ & 0 & 0.0 & 4 \\
\hline $\mathrm{h}+$ & oh & $\mathrm{oh}+$ & $\mathrm{h}$ & $1.60 \mathrm{e}-08$ & -0.5 & 0.0 & 4 \\
\hline $\mathrm{h}+$ & h2o & $\mathrm{h} 2 \mathrm{o}+$ & $\mathrm{h}$ & $7.30 \mathrm{e}-09$ & -0.5 & 0.0 & 4 \\
\hline $\mathrm{h}+$ & hco & $\mathrm{co}+$ & $\mathrm{h} 2$ & $1.30 \mathrm{e}-09$ & -0.5 & 0.0 & 4 \\
\hline $\mathrm{h}+$ & hco & $\mathrm{h} 2+$ & $\mathrm{co}$ & $1.30 \mathrm{e}-09$ & -0.5 & 0.0 & 4 \\
\hline $\mathrm{h}+$ & hco & hco+ & $\mathrm{h}$ & $1.30 \mathrm{e}-09$ & -0.5 & 0.0 & 4 \\
\hline $\mathrm{h}+$ & $\mathrm{ch}$ & $\mathrm{ch}+$ & $\mathrm{h}$ & $1.40 \mathrm{e}-08$ & -0.5 & 0.0 & 4 \\
\hline $\mathrm{h}+$ & $\operatorname{ch} 2$ & $\mathrm{ch}+$ & $\mathrm{h} 2$ & $1.14 \mathrm{e}-09$ & -0.5 & 0.0 & 4 \\
\hline $\mathrm{h}+$ & $\operatorname{ch} 2$ & $\operatorname{ch} 2+$ & $\mathrm{h}$ & $1.14 \mathrm{e}-09$ & -0.5 & 0.0 & 4 \\
\hline $\mathrm{h}+$ & $\operatorname{ch} 3$ & $\operatorname{ch} 3+$ & $\mathrm{h}$ & $3.40 \mathrm{e}-09$ & 0 & 0.0 & 4 \\
\hline $\mathrm{h}+$ & $\operatorname{ch} 4$ & $\operatorname{ch} 3+$ & $\mathrm{h} 2$ & $2.28 \mathrm{e}-09$ & 0 & 0.0 & 4 \\
\hline $\mathrm{h}+$ & $\operatorname{ch} 4$ & $\operatorname{ch} 4+$ & $\mathrm{h}$ & $1.52 \mathrm{e}-09$ & 0 & 0.0 & 4 \\
\hline $\mathrm{h}+$ & $\operatorname{co} 2$ & hco+ & o & $4.20 \mathrm{e}-09$ & 0 & 0.0 & 4 \\
\hline $\mathrm{h}+$ & h2co & hco+ & $\mathrm{h} 2$ & $4.60 \mathrm{e}-09$ & -0.5 & 0.0 & 4 \\
\hline $\mathrm{h}+$ & $\mathrm{h} 2 \mathrm{co}$ & $\mathrm{h} 2 \mathrm{co}+$ & $\mathrm{h}$ & $4.60 \mathrm{e}-09$ & -0.5 & 0.0 & 4 \\
\hline $\mathrm{h} 2+$ & $\mathrm{c}$ & $\operatorname{ch}+$ & $\mathrm{h}$ & $2.40 \mathrm{e}-09$ & 0 & 0.0 & 4 \\
\hline $\mathrm{h} 2+$ & o & $\mathrm{oh}+$ & $\mathrm{h}$ & $1.50 \mathrm{e}-09$ & 0 & 0.0 & 4 \\
\hline $\mathrm{h} 2+$ & $\mathrm{CO}$ & hco+ & $\mathrm{h}$ & $2.16 \mathrm{e}-09$ & 0 & 0.0 & 4 \\
\hline $\mathrm{h} 2+$ & $\mathrm{CO}$ & $\mathrm{co}+$ & $\mathrm{h} 2$ & $6.44 \mathrm{e}-10$ & 0 & 0.0 & 4 \\
\hline $\mathrm{h} 2+$ & $\operatorname{co} 2$ & $\mathrm{co}+$ & h2o & $1.40 \mathrm{e}-09$ & 0 & 0.0 & 4 \\
\hline $\mathrm{h} 2+$ & $\operatorname{co} 2$ & hco2+ & $\mathrm{h}$ & $2.35 \mathrm{e}-09$ & 0 & 0.0 & 4 \\
\hline $\mathrm{h} 2+$ & oh & $\mathrm{oh}+$ & $\mathrm{h} 2$ & $7.60 \mathrm{e}-10$ & 0 & 0.0 & 4 \\
\hline $\mathrm{h} 2+$ & oh & $\mathrm{h} 2 \mathrm{o}+$ & $\mathrm{h}$ & $7.60 \mathrm{e}-10$ & 0 & 0.0 & 4 \\
\hline $\mathrm{h} 2+$ & h2o & h2o+ & h2 & $3.90 \mathrm{e}-09$ & 0 & 0.0 & 4 \\
\hline $\mathrm{h} 2+$ & h2o & h3o+ & $\mathrm{h}$ & $3.40 \mathrm{e}-09$ & 0 & 0.0 & 4 \\
\hline $\mathrm{h} 2+$ & $\mathrm{ch}$ & $\operatorname{ch}+$ & h2 & $7.10 \mathrm{e}-10$ & 0 & 0.0 & 4 \\
\hline
\end{tabular}

Continua na próxima página... 
Tabela B.2 - Continuação

\begin{tabular}{|c|c|c|c|c|c|c|c|c|c|}
\hline \multicolumn{2}{|c|}{ Reagentes } & \multicolumn{4}{|c|}{ Produtos } & \multirow{2}{*}{$\frac{\gamma}{7.10 \mathrm{e}-10}$} & \multirow{2}{*}{$\begin{array}{l}\alpha \\
0\end{array}$} & \multirow{2}{*}{$\begin{array}{l}\beta \\
0.0\end{array}$} & \multirow{2}{*}{$\begin{array}{c}\text { Tipo de Reação } \\
4\end{array}$} \\
\hline h2+ & $\mathrm{ch}$ & $\operatorname{ch} 2+$ & $\mathrm{h}$ & & & & & & \\
\hline h $2+$ & $\operatorname{ch} 2$ & $\operatorname{ch} 3+$ & $\mathrm{h}$ & & & $1.00 \mathrm{e}-09$ & 0 & 0.0 & 4 \\
\hline h2+ & $\operatorname{ch} 2$ & $\operatorname{ch} 2+$ & h2 & & & $1.00 \mathrm{e}-09$ & 0 & 0.0 & 4 \\
\hline h2+ & $\operatorname{ch} 4$ & $\operatorname{ch} 3+$ & $\mathrm{h}$ & $\mathrm{h} 2$ & & $2.30 \mathrm{e}-09$ & 0 & 0.0 & 4 \\
\hline h2+ & $\operatorname{ch} 4$ & $\operatorname{ch} 4+$ & h2 & & & $1.40 \mathrm{e}-09$ & 0 & 0.0 & 4 \\
\hline $\mathrm{h} 2+$ & $\operatorname{ch} 4$ & $\operatorname{ch} 5+$ & $\mathrm{h}$ & & & $1.10 \mathrm{e}-10$ & 0 & 0.0 & 4 \\
\hline h3+ & o & $\mathrm{oh}+$ & h2 & & & $8.00 \mathrm{e}-10$ & 0 & 0.0 & 4 \\
\hline h3+ & oh & h2o+ & h2 & & & $9.50 \mathrm{e}-09$ & -0.5 & 0.0 & 4 \\
\hline h3+ & h2o & h3o+ & h2 & & & $4.50 \mathrm{e}-09$ & -0.5 & 0.0 & 4 \\
\hline h3+ & $\mathrm{co}$ & hco+ & $\mathrm{h} 2$ & & & $1.70 \mathrm{e}-09$ & 0 & 0.0 & 4 \\
\hline h3+ & $\mathrm{CO}$ & hoct & h2 & & & $9.44 \mathrm{e}-11$ & 0 & 0.0 & 4 \\
\hline h3+ & $\mathrm{co} 2$ & hco $2+$ & $\mathrm{h} 2$ & & & $2.00 \mathrm{e}-09$ & 0 & 0.0 & 4 \\
\hline h3+ & $\mathrm{c}$ & $\mathrm{ch}+$ & $\mathrm{h} 2$ & & & $2.00 \mathrm{e}-09$ & 0 & 0.0 & 4 \\
\hline h3+ & $\mathrm{ch}$ & $\operatorname{ch} 2+$ & $\mathrm{h} 2$ & & & $8.50 \mathrm{e}-09$ & -0.5 & 0.0 & 4 \\
\hline h3+ & $\operatorname{ch} 2$ & $\operatorname{ch} 3+$ & h2 & & & $1.40 \mathrm{e}-09$ & -0.5 & 0.0 & 4 \\
\hline h3+ & $\operatorname{ch} 3$ & $\operatorname{ch} 4+$ & h2 & & & $2.10 \mathrm{e}-09$ & 0 & 0.0 & 4 \\
\hline h3+ & $\operatorname{ch} 4$ & $\operatorname{ch} 5+$ & $\mathrm{h} 2$ & & & $1.90 \mathrm{e}-09$ & 0 & 0.0 & 4 \\
\hline h3+ & h2co & h3co+ & $\mathrm{h} 2$ & & & $6.30 \mathrm{e}-09$ & -0 & 0.0 & 4 \\
\hline he+ & $\mathrm{h}$ & $\mathrm{h}+$ & he & & & $1.90 \mathrm{e}-15$ & 0 & 0.0 & 4 \\
\hline he+ & h2 & $\mathrm{h}+$ & $\mathrm{h}$ & he & & $1.10 \mathrm{e}-13$ & -0.24 & 0.0 & 4 \\
\hline he+ & $\mathrm{h} 2$ & $\mathrm{~h} 2+$ & he & & & $9.60 \mathrm{e}-15$ & 0 & 0.0 & 4 \\
\hline he+ & oh & $\mathrm{oh}+$ & he & & & $5.50 \mathrm{e}-10$ & 0 & 0.0 & 4 \\
\hline he+ & oh & $\mathrm{o}+$ & $\mathrm{h}$ & he & & $5.50 \mathrm{e}-10$ & 0 & 0.0 & 4 \\
\hline he+ & h2o & $\mathrm{oh}+$ & $\mathrm{h}$ & he & & $2.30 \mathrm{e}-10$ & -0.94 & 0.0 & 4 \\
\hline he+ & h2o & h2o+ & he & & & $4.86 \mathrm{e}-11$ & -0.94 & 0.0 & 4 \\
\hline he+ & h2o & $\mathrm{h}+$ & oh & he & & $1.64 \mathrm{e}-10$ & -0.94 & 0.0 & 4 \\
\hline he+ & hco & $\operatorname{ch}+$ & o & he & & $6.90 \mathrm{e}-10$ & -0.5 & 0.0 & 4 \\
\hline he+ & hco & $\mathrm{co}+$ & $\mathrm{h}$ & he & & $6.90 \mathrm{e}-10$ & -0.5 & 0.0 & 4 \\
\hline he+ & $\mathrm{co}$ & $\mathrm{c}+$ & o & he & & $1.50 \mathrm{e}-09$ & 0 & 0.0 & 4 \\
\hline he+ & o2 & $\mathrm{o}+$ & o & he & & $1.00 \mathrm{e}-09$ & 0 & 0.0 & 4 \\
\hline he+ & $\operatorname{co} 2$ & $\mathrm{co}+$ & o & he & & $7.70 \mathrm{e}-10$ & 0 & 0.0 & 4 \\
\hline he+ & $\operatorname{co} 2$ & $\mathrm{o}+$ & $\mathrm{co}$ & he & & $1.80 \mathrm{e}-10$ & 0 & 0.0 & 4 \\
\hline he+ & $\operatorname{co} 2$ & $\mathrm{c}+$ & o2 & he & & $4.00 \mathrm{e}-11$ & 0 & 0.0 & 4 \\
\hline he+ & $\mathrm{ch}$ & $\mathrm{c}+$ & $\mathrm{h}$ & he & & $1.10 \mathrm{e}-09$ & 0 & 0.0 & 4 \\
\hline he+ & $\mathrm{ch}$ & $\mathrm{ch}+$ & he & & & $3.83 \mathrm{e}-09$ & -0.5 & 0.0 & 4 \\
\hline he+ & $\operatorname{ch} 2$ & $\mathrm{c}+$ & h2 & he & & $7.50 \mathrm{e}-10$ & 0 & 0.0 & 4 \\
\hline he+ & $\operatorname{ch} 2$ & $\operatorname{ch}+$ & $\mathrm{h}$ & he & & $7.50 \mathrm{e}-10$ & 0 & 0.0 & 4 \\
\hline he+ & ch3 & $\mathrm{ch}+$ & $\mathrm{h} 2$ & he & & $9.00 \mathrm{e}-10$ & 0 & 0.0 & 4 \\
\hline he+ & ch3 & $\operatorname{ch} 2+$ & $\mathrm{h}$ & he & & $9.00 \mathrm{e}-10$ & 0 & 0.0 & 4 \\
\hline he+ & $\operatorname{ch} 4$ & $\mathrm{~h}+$ & $\operatorname{ch} 3$ & he & & $4.00 \mathrm{e}-10$ & 0 & 0.0 & 4 \\
\hline he+ & $\operatorname{ch} 4$ & $\mathrm{ch}+$ & $\mathrm{h} 2$ & $\mathrm{~h}$ & he & $2.56 \mathrm{e}-10$ & 0 & 0.0 & 4 \\
\hline he+ & $\operatorname{ch} 4$ & $\operatorname{ch} 2+$ & $\mathrm{h} 2$ & he & & $8.48 \mathrm{e}-10$ & 0 & 0.0 & 4 \\
\hline he+ & $\operatorname{ch} 4$ & $\operatorname{ch} 3+$ & $\mathrm{h}$ & he & & $8.00 \mathrm{e}-11$ & 0 & 0.0 & 4 \\
\hline
\end{tabular}

Continua na próxima página... 
Tabela B.2 - Continuação

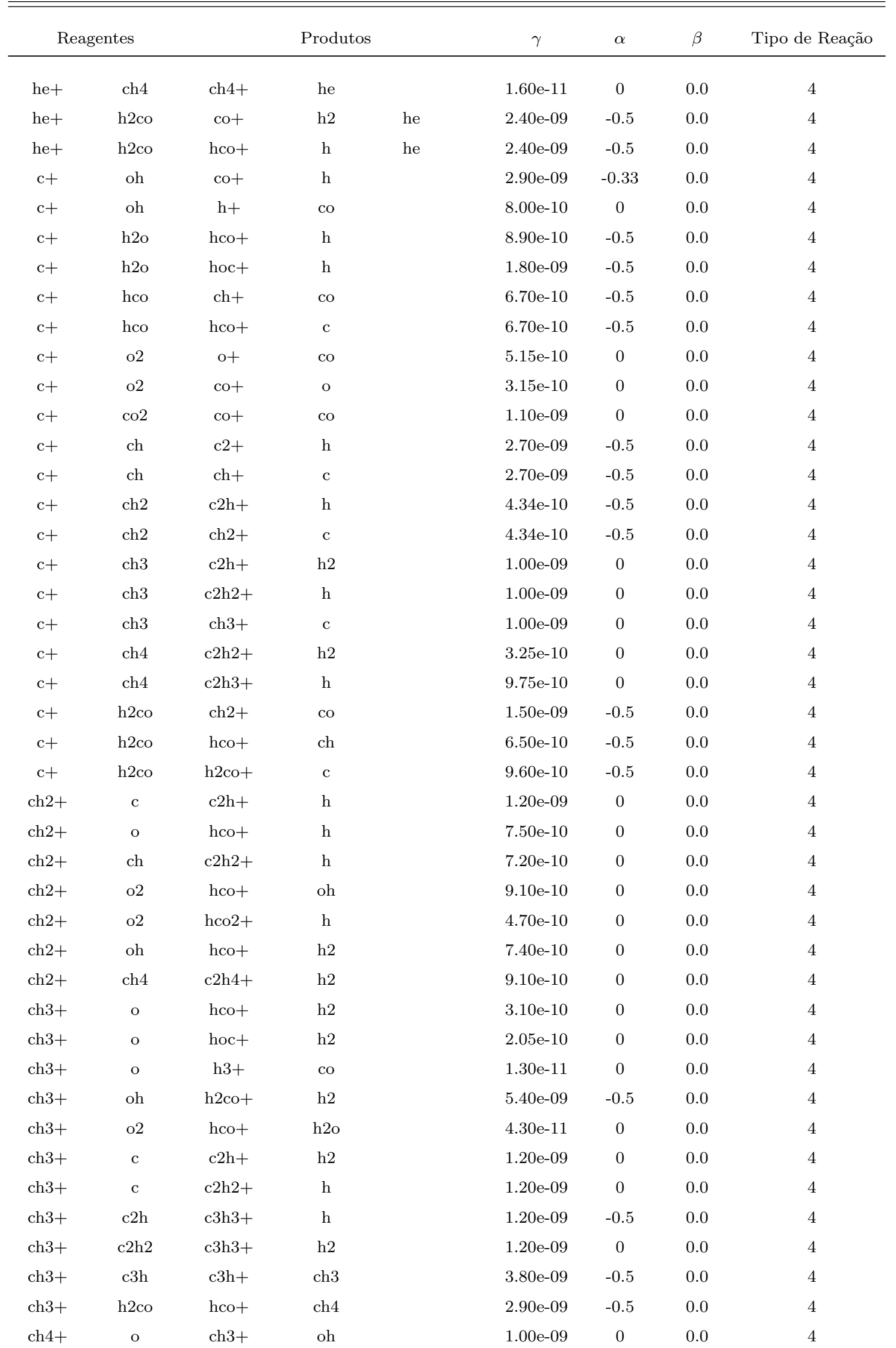

Continua na próxima página... 
Tabela B.2 - Continuação

\begin{tabular}{|c|c|c|c|c|c|c|c|c|}
\hline \multicolumn{2}{|c|}{ Reagentes } & \multicolumn{3}{|c|}{ Produtos } & \multirow{2}{*}{$\begin{array}{c}\gamma \\
1.40 \mathrm{e}-09\end{array}$} & \multirow{2}{*}{$\begin{array}{l}\alpha \\
0\end{array}$} & \multirow{2}{*}{$\begin{array}{l}\beta \\
0.0\end{array}$} & \multirow{2}{*}{$\begin{array}{c}\text { Tipo de Reação } \\
4\end{array}$} \\
\hline $\operatorname{ch} 4+$ & $\mathrm{co}$ & hco+ & $\operatorname{ch} 3$ & & & & & \\
\hline $\operatorname{ch} 4+$ & o2 & $\mathrm{o} 2+$ & $\operatorname{ch} 4$ & & $4.00 \mathrm{e}-10$ & 0 & 0.0 & 4 \\
\hline $\operatorname{ch} 4+$ & $\operatorname{co} 2$ & hco $2+$ & $\operatorname{ch} 3$ & & $1.20 \mathrm{e}-09$ & 0 & 0.0 & 4 \\
\hline $\operatorname{ch} 4+$ & h2o & h3o+ & $\operatorname{ch} 3$ & & $2.50 \mathrm{e}-09$ & 0 & 0.0 & 4 \\
\hline $\operatorname{ch} 4+$ & h2co & h2co+ & $\operatorname{ch} 4$ & & $1.62 \mathrm{e}-09$ & 0 & 0.0 & 4 \\
\hline $\operatorname{ch} 4+$ & $\mathrm{h} 2 \mathrm{co}$ & h3co+ & $\operatorname{ch} 3$ & & $1.98 \mathrm{e}-09$ & 0 & 0.0 & 4 \\
\hline $\operatorname{ch} 5+$ & c & $\operatorname{ch}+$ & $\operatorname{ch} 4$ & & $1.00 \mathrm{e}-09$ & 0 & 0.0 & 4 \\
\hline $\operatorname{ch} 5+$ & $\mathrm{c}$ & $\mathrm{c} 2 \mathrm{~h} 3+$ & h2 & & $1.00 \mathrm{e}-09$ & 0 & 0.0 & 4 \\
\hline $\operatorname{ch} 5+$ & $\mathrm{c}$ & $\mathrm{c} 2 \mathrm{~h} 4+$ & $\mathrm{h}$ & & $1.00 \mathrm{e}-09$ & 0 & 0.0 & 4 \\
\hline $\operatorname{ch} 5+$ & o & h3o+ & $\operatorname{ch} 2$ & & $2.16 \mathrm{e}-10$ & 0 & 0.0 & 4 \\
\hline $\operatorname{ch} 5+$ & $\mathrm{CO}$ & hco+ & $\operatorname{ch} 4$ & & $9.90 \mathrm{e}-10$ & 0 & 0.0 & 4 \\
\hline $\operatorname{ch} 5+$ & h2o & h3o+ & $\operatorname{ch} 4$ & & $3.70 \mathrm{e}-09$ & 0 & 0.0 & 4 \\
\hline $\operatorname{ch} 5+$ & $\mathrm{h} 2 \mathrm{co}$ & h3co+ & $\operatorname{ch} 4$ & & $2.70 \mathrm{e}-09$ & -0.5 & 0.0 & 4 \\
\hline $\mathrm{o}+$ & $\mathrm{h}$ & $\mathrm{h}+$ & o & & $1.04 \mathrm{e}-10$ & 0.39 & 0.0 & 4 \\
\hline $\mathrm{o}+$ & $\mathrm{h} 2$ & $\mathrm{oh}+$ & $\mathrm{h}$ & & $1.20 \mathrm{e}-09$ & 0 & 0.0 & 4 \\
\hline $\mathrm{o}+$ & $\mathrm{ch}$ & $\operatorname{ch}+$ & o & & $3.50 \mathrm{e}-10$ & 0 & 0.0 & 4 \\
\hline $\mathrm{o}+$ & $\mathrm{ch}$ & $\mathrm{co}+$ & $\mathrm{h}$ & & $3.50 \mathrm{e}-10$ & 0 & 0.0 & 4 \\
\hline $\mathrm{o}+$ & $\operatorname{ch} 4$ & $\operatorname{ch} 3+$ & oh & & $1.10 \mathrm{e}-10$ & 0 & 0.0 & 4 \\
\hline $\mathrm{o}+$ & $\operatorname{ch} 4$ & $\operatorname{ch} 4+$ & o & & $8.90 \mathrm{e}-10$ & 0 & 0.0 & 4 \\
\hline $\mathrm{o}+$ & o2 & $\mathrm{o} 2+$ & o & & $3.00 \mathrm{e}-11$ & 0 & 0.0 & 4 \\
\hline $\mathrm{o}+$ & oh & $\mathrm{o} 2+$ & $\mathrm{h}$ & & $3.60 \mathrm{e}-10$ & 0 & 0.0 & 4 \\
\hline $\mathrm{o}+$ & oh & $\mathrm{oh}+$ & o & & $3.60 \mathrm{e}-10$ & 0 & 0.0 & 4 \\
\hline $\mathrm{o}+$ & h2o & h2o+ & o & & $3.20 \mathrm{e}-09$ & 0 & 0.0 & 4 \\
\hline $\mathrm{o}+$ & $\operatorname{co} 2$ & $\mathrm{o} 2+$ & $\mathrm{CO}$ & & $1.10 \mathrm{e}-09$ & 0 & 0.0 & 4 \\
\hline $\mathrm{o} 2+$ & c & $\mathrm{co}+$ & o & & $5.20 \mathrm{e}-11$ & 0 & 0.0 & 4 \\
\hline $\mathrm{o} 2+$ & c & $\mathrm{c}+$ & o2 & & $5.20 \mathrm{e}-11$ & 0 & 0.0 & 4 \\
\hline $\mathrm{o} 2+$ & $\mathrm{c} 2$ & $\mathrm{co}+$ & $\mathrm{co}$ & & $4.10 \mathrm{e}-10$ & 0 & 0.0 & 4 \\
\hline $\mathrm{o} 2+$ & $\mathrm{ch}$ & $\operatorname{ch}+$ & o2 & & $3.10 \mathrm{e}-10$ & 0 & 0.0 & 4 \\
\hline $\mathrm{o} 2+$ & $\mathrm{ch}$ & hco+ & o & & $3.10 \mathrm{e}-10$ & 0 & 0.0 & 4 \\
\hline $\mathrm{o} 2+$ & $\operatorname{ch} 2$ & $\operatorname{ch} 2+$ & o2 & & $4.30 \mathrm{e}-10$ & 0 & 0.0 & 4 \\
\hline $\mathrm{o} 2+$ & $\operatorname{ch} 2$ & $\mathrm{~h} 2 \mathrm{co}+$ & o & & $4.30 \mathrm{e}-10$ & 0 & 0.0 & 4 \\
\hline $\mathrm{o} 2+$ & hco & hco + & o2 & & $3.60 \mathrm{e}-10$ & 0 & 0.0 & 4 \\
\hline $\mathrm{o} 2+$ & $\mathrm{h} 2 \mathrm{co}$ & hco + & o2 & $\mathrm{h}$ & $2.30 \mathrm{e}-10$ & 0 & 0.0 & 4 \\
\hline $\mathrm{o} 2+$ & $\mathrm{h} 2 \mathrm{co}$ & $\mathrm{h} 2 \mathrm{co}+$ & o2 & & $9.90 \mathrm{e}-10$ & 0 & 0.0 & 4 \\
\hline $\mathrm{oh}+$ & h2 & $\mathrm{h} 2 \mathrm{o}+$ & $\mathrm{h}$ & & $1.01 \mathrm{e}-09$ & 0 & 0.0 & 4 \\
\hline $\mathrm{oh}+$ & c & $\operatorname{ch}+$ & o & & $1.20 \mathrm{e}-09$ & 0 & 0.0 & 4 \\
\hline $\mathrm{oh}+$ & $\mathrm{O}$ & $\mathrm{o} 2+$ & $\mathrm{h}$ & & $7.10 \mathrm{e}-10$ & 0 & 0.0 & 4 \\
\hline $\mathrm{oh}+$ & $\mathrm{ch}$ & $\operatorname{ch}+$ & oh & & $3.50 \mathrm{e}-10$ & 0 & 0.0 & 4 \\
\hline $\mathrm{oh}+$ & $\mathrm{ch}$ & $\operatorname{ch} 2+$ & o & & $3.50 \mathrm{e}-10$ & 0 & 0.0 & 4 \\
\hline $\mathrm{oh}+$ & $\mathrm{CO}$ & hco + & o & & $1.00 \mathrm{e}-09$ & 0 & 0.0 & 4 \\
\hline $\mathrm{oh}+$ & $\mathrm{o} 2$ & $\mathrm{o} 2+$ & oh & & $5.90 \mathrm{e}-10$ & 0 & 0.0 & 4 \\
\hline $\mathrm{oh}+$ & oh & h2o+ & o & & $7.00 \mathrm{e}-10$ & 0 & 0.0 & 4 \\
\hline $\mathrm{oh}+$ & $\operatorname{ch} 2$ & $\operatorname{ch} 2+$ & oh & & $4.80 \mathrm{e}-10$ & 0 & 0.0 & 4 \\
\hline
\end{tabular}

Continua na próxima página... 
Tabela B.2 - Continuação

\begin{tabular}{|c|c|c|c|c|c|c|c|}
\hline \multicolumn{2}{|c|}{ Reagentes } & \multicolumn{2}{|r|}{ Produtos } & \multirow{2}{*}{$\frac{\gamma}{4.80 \mathrm{e}-10}$} & \multirow{2}{*}{$\begin{array}{l}\alpha \\
0\end{array}$} & \multirow{2}{*}{$\begin{array}{l}\beta \\
0.0\end{array}$} & \multirow{2}{*}{$\frac{\text { Tipo de Reação }}{4}$} \\
\hline $\mathrm{oh}+$ & $\operatorname{ch} 2$ & $\operatorname{ch} 3+$ & o & & & & \\
\hline $\mathrm{oh}+$ & co2 & hco $2+$ & o & $1.40 \mathrm{e}-09$ & 0 & 0.0 & 4 \\
\hline $\mathrm{oh}+$ & h2o & h2o+ & oh & $1.50 \mathrm{e}-09$ & 0 & 0.0 & 4 \\
\hline $\mathrm{oh}+$ & h2o & h3o+ & o & $1.30 \mathrm{e}-09$ & 0 & 0.0 & 4 \\
\hline $\mathrm{oh}+$ & $\operatorname{ch} 4$ & h3o+ & $\operatorname{ch} 2$ & $1.40 \mathrm{e}-09$ & 0 & 0.0 & 4 \\
\hline $\mathrm{oh}+$ & $\operatorname{ch} 4$ & $\operatorname{ch} 5+$ & o & $1.95 \mathrm{e}-10$ & 0 & 0.0 & 4 \\
\hline $\mathrm{h} 2 \mathrm{o}+$ & $\mathrm{h} 2$ & h3o+ & $\mathrm{h}$ & $8.30 \mathrm{e}-10$ & 0 & 0.0 & 4 \\
\hline $\mathrm{h} 2 \mathrm{o}+$ & $\mathrm{c}$ & $\operatorname{ch}+$ & oh & $1.10 \mathrm{e}-09$ & 0 & 0.0 & 4 \\
\hline h2o+ & o & $\mathrm{o} 2+$ & h2 & $4.00 \mathrm{e}-11$ & 0 & 0.0 & 4 \\
\hline $\mathrm{h} 2 \mathrm{o}+$ & $\mathrm{ch}$ & $\operatorname{ch} 2+$ & oh & $3.40 \mathrm{e}-10$ & 0 & 0.0 & 4 \\
\hline $\mathrm{h} 2 \mathrm{o}+$ & $\mathrm{co}$ & hco+ & oh & $5.00 \mathrm{e}-10$ & 0 & 0.0 & 4 \\
\hline $\mathrm{h} 2 \mathrm{o}+$ & o2 & $\mathrm{o} 2+$ & h2o & $4.30 \mathrm{e}-10$ & 0 & 0.0 & 4 \\
\hline $\mathrm{h} 2 \mathrm{o}+$ & oh & h3o+ & o & $6.90 \mathrm{e}-10$ & 0 & 0.0 & 4 \\
\hline $\mathrm{h} 2 \mathrm{o}+$ & h2o & h3o+ & oh & $2.10 \mathrm{e}-09$ & 0 & 0.0 & 4 \\
\hline $\mathrm{h} 2 \mathrm{o}+$ & $\operatorname{ch} 4$ & h3o+ & $\operatorname{ch} 3$ & $1.30 \mathrm{e}-09$ & 0 & 0.0 & 4 \\
\hline h3o+ & $\mathrm{h}$ & $\mathrm{h} 2 \mathrm{o}+$ & $\mathrm{h} 2$ & $6.10 \mathrm{e}-10$ & 0 & 20500.0 & 4 \\
\hline h3o+ & $\mathrm{c}$ & hco+ & $\mathrm{h} 2$ & $1.00 \mathrm{e}-11$ & 0 & 0.0 & 4 \\
\hline h3o+ & $\mathrm{ch}$ & $\operatorname{ch} 2+$ & h2o & $6.80 \mathrm{e}-10$ & 0 & 0.0 & 4 \\
\hline h3o+ & $\operatorname{ch} 2$ & $\operatorname{ch} 3+$ & h2o & $9.40 \mathrm{e}-10$ & 0 & 0.0 & 4 \\
\hline h3o+ & $\mathrm{h} 2 \mathrm{co}$ & h3co+ & h2o & $0.26 \mathrm{D}-08$ & -0.5 & 0.0 & 4 \\
\hline $\mathrm{co}+$ & h2 & hco+ & $\mathrm{h}$ & $1.30 \mathrm{e}-09$ & 0 & 0.0 & 4 \\
\hline $\mathrm{co}+$ & h2 & hoct & $\mathrm{h}$ & $7.50 \mathrm{e}-10$ & 0 & 0.0 & 4 \\
\hline $\mathrm{co}+$ & $\mathrm{h}$ & $\mathrm{h}+$ & $\mathrm{co}$ & $7.50 \mathrm{e}-10$ & 0 & 0.0 & 4 \\
\hline $\mathrm{co}+$ & o & $\mathrm{o}+$ & $\mathrm{co}$ & $1.40 \mathrm{e}-10$ & 0 & 0.0 & 4 \\
\hline $\mathrm{co}+$ & $\mathrm{ch}$ & hco+ & c & $3.20 \mathrm{e}-10$ & 0 & 0.0 & 4 \\
\hline $\mathrm{co}+$ & o2 & $\mathrm{o} 2+$ & $\mathrm{co}$ & $1.20 \mathrm{e}-10$ & 0 & 0.0 & 4 \\
\hline $\mathrm{co}+$ & oh & $\mathrm{oh}+$ & $\mathrm{co}$ & $3.10 \mathrm{e}-10$ & 0 & 0.0 & 4 \\
\hline $\mathrm{co}+$ & oh & hcot & o & $3.10 \mathrm{e}-10$ & 0 & 0.0 & 4 \\
\hline $\mathrm{co}+$ & $\operatorname{ch} 2$ & $\operatorname{ch} 2+$ & $\mathrm{co}$ & $4.30 \mathrm{e}-10$ & 0 & 0.0 & 4 \\
\hline $\mathrm{co}+$ & $\operatorname{ch} 2$ & hco+ & $\mathrm{ch}$ & $4.30 \mathrm{e}-10$ & 0 & 0.0 & 4 \\
\hline $\mathrm{co}+$ & h2o & $\mathrm{h} 2 \mathrm{o}+$ & $\mathrm{co}$ & $1.70 \mathrm{e}-09$ & 0 & 0.0 & 4 \\
\hline $\mathrm{co}+$ & h2o & hco+ & oh & $8.80 \mathrm{e}-10$ & 0 & 0.0 & 4 \\
\hline $\mathrm{co}+$ & $\operatorname{ch} 4$ & hco+ & ch3 & $4.55 \mathrm{e}-10$ & 0 & 0.0 & 4 \\
\hline $\mathrm{co}+$ & $\operatorname{ch} 4$ & $\operatorname{ch} 4+$ & $\mathrm{co}$ & $7.93 \mathrm{e}-10$ & 0 & 0.0 & 4 \\
\hline hco+ & $\mathrm{h}$ & $\mathrm{co}+$ & $\mathrm{h} 2$ & $1.30 \mathrm{e}-09$ & 0 & 24500.0 & 4 \\
\hline hco+ & $\mathrm{c}$ & $\operatorname{ch}+$ & $\mathrm{co}$ & $1.10 \mathrm{e}-09$ & 0 & 0.0 & 4 \\
\hline hco+ & $\mathrm{ch}$ & $\operatorname{ch} 2+$ & $\mathrm{co}$ & $6.30 \mathrm{e}-10$ & 0 & 0.0 & 4 \\
\hline hco+ & $\operatorname{ch} 2$ & $\operatorname{ch} 3+$ & $\mathrm{co}$ & $8.60 \mathrm{e}-10$ & 0 & 0.0 & 4 \\
\hline hco+ & $\operatorname{ch} 3$ & $\operatorname{ch} 4+$ & $\mathrm{co}$ & $1.40 \mathrm{e}-09$ & 0 & 9060.0 & 4 \\
\hline hco+ & $\operatorname{ch} 4$ & $\operatorname{ch} 5+$ & $\mathrm{co}$ & $9.90 \mathrm{e}-10$ & 0 & 4920.0 & 4 \\
\hline hco+ & h2o & h3o+ & $\mathrm{co}$ & $2.50 \mathrm{e}-09$ & 0 & 0.0 & 4 \\
\hline hco+ & $\mathrm{h} 2 \mathrm{co}$ & h3co+ & $\mathrm{co}$ & $2.40 \mathrm{e}-09$ & -0.5 & 0.0 & 4 \\
\hline hco+ & oh & hco $2+$ & $\mathrm{h}$ & $1.00 \mathrm{e}-09$ & 0 & 0.0 & 4 \\
\hline
\end{tabular}

Continua na próxima página... 
Tabela B.2 - Continuação

\begin{tabular}{|c|c|c|c|c|c|c|c|c|}
\hline \multicolumn{2}{|c|}{ Reagentes } & \multicolumn{3}{|c|}{ Produtos } & $\gamma$ & $\alpha$ & $\beta$ & Tipo de Reação \\
\hline hco+ & o2 & hco $2+$ & o & & $1.00 \mathrm{e}-09$ & 0 & 1450.0 & 4 \\
\hline hco+ & $\operatorname{co} 2$ & hco $2+$ & $\mathrm{co}$ & & $1.00 \mathrm{e}-09$ & 0 & 5000.0 & 4 \\
\hline hoc + & $\mathrm{co}$ & hco + & co & & $4.00 \mathrm{e}-10$ & 0 & 0.0 & 4 \\
\hline hoct & h2 & hco+ & h2 & & $1.00 \mathrm{e}-11$ & 0 & 0.0 & 4 \\
\hline hco $2+$ & o & hco+ & o2 & & $1.00 \mathrm{e}-09$ & 0 & 0.0 & 4 \\
\hline hco $2+$ & $\mathrm{h}$ & hco + & oh & & $1.00 \mathrm{e}-09$ & 0 & 7500.0 & 4 \\
\hline hco $2+$ & $\mathrm{co}$ & hco+ & $\operatorname{co} 2$ & & $1.00 \mathrm{e}-09$ & 0 & 0.0 & 4 \\
\hline hco $2+$ & $\operatorname{ch} 4$ & $\operatorname{ch} 5+$ & $\operatorname{co} 2$ & & $7.80 \mathrm{e}-10$ & 0 & 0.0 & 4 \\
\hline h2co+ & h2 & h3co+ & $\mathrm{h}$ & & $1.00 \mathrm{e}-19$ & 0 & 0.0 & 4 \\
\hline h3co+ & $\mathrm{ch}$ & $\operatorname{ch} 2+$ & h2co & & $4.40 \mathrm{e}-09$ & -0.5 & 0.0 & 4 \\
\hline $\mathrm{c} 2+$ & h2 & $\mathrm{c} 2 \mathrm{~h}+$ & $\mathrm{h}$ & & $1.40 \mathrm{e}-09$ & 0 & 0.0 & 4 \\
\hline $\mathrm{c} 2+$ & h2 & $\mathrm{h}+$ & $\mathrm{c} 2 \mathrm{~h}$ & & $1.50 \mathrm{e}-09$ & 0 & 1260.0 & 4 \\
\hline $\mathrm{c} 2 \mathrm{~h}+$ & h2 & $\mathrm{c} 2 \mathrm{~h} 2+$ & $\mathrm{h}$ & & $1.70 \mathrm{e}-09$ & 0 & 0.0 & 4 \\
\hline c2h2+ & h2 & c2h3+ & $\mathrm{h}$ & & $5.00 \mathrm{e}-10$ & 0 & 800.0 & 4 \\
\hline c3+ & h2 & $\mathrm{c} 3 \mathrm{~h}+$ & $\mathrm{h}$ & & $3.00 \mathrm{e}-10$ & 0 & 0.0 & 4 \\
\hline $\mathrm{c} 3 \mathrm{~h}+$ & h2 & c3h $2+$ & $\mathrm{h}$ & & $1.00 \mathrm{e}-09$ & 0 & 500.0 & 4 \\
\hline c3h2+ & h2 & c3h3+ & $\mathrm{h}$ & & $1.00 \mathrm{e}-10$ & 0 & 2000.0 & 4 \\
\hline $\mathrm{h}+$ & $\mathrm{c} 2$ & $\mathrm{c} 2+$ & $\mathrm{h}$ & & $3.10 \mathrm{e}-09$ & 0 & 0.0 & 4 \\
\hline $\mathrm{h}+$ & $\mathrm{c} 2 \mathrm{~h}$ & $\mathrm{c} 2+$ & h2 & & $3.70 \mathrm{e}-09$ & -0.5 & 0.0 & 4 \\
\hline $\mathrm{h}+$ & $\mathrm{c} 2 \mathrm{~h}$ & $\mathrm{c} 2 \mathrm{~h}+$ & $\mathrm{h}$ & & $3.70 \mathrm{e}-09$ & -0.5 & 0.0 & 4 \\
\hline $\mathrm{h}+$ & $\mathrm{c} 2 \mathrm{~h} 2$ & $\mathrm{c} 2 \mathrm{~h}+$ & h2 & & $2.00 \mathrm{e}-09$ & 0 & 0.0 & 4 \\
\hline $\mathrm{h}+$ & $\mathrm{c} 2 \mathrm{~h} 2$ & $\mathrm{c} 2 \mathrm{~h} 2+$ & $\mathrm{h}$ & & $2.00 \mathrm{e}-09$ & 0 & 0.0 & 4 \\
\hline $\mathrm{h}+$ & c3 & c3+ & $\mathrm{h}$ & & $4.00 \mathrm{e}-09$ & 0 & 0.0 & 4 \\
\hline $\mathrm{h}+$ & $\mathrm{c} 3 \mathrm{~h}$ & $\mathrm{c} 3 \mathrm{~h}+$ & $\mathrm{h}$ & & $1.22 \mathrm{e}-08$ & -0.5 & 0.0 & 4 \\
\hline $\mathrm{h}+$ & $\mathrm{c} 3 \mathrm{~h}$ & c3+ & h2 & & $1.22 \mathrm{e}-08$ & -0.5 & 0.0 & 4 \\
\hline $\mathrm{h}+$ & $\mathrm{c} 3 \mathrm{~h} 2$ & $\mathrm{c} 3 \mathrm{~h}+$ & h2 & & $5.89 \mathrm{e}-09$ & -0.5 & 0.0 & 4 \\
\hline $\mathrm{h}+$ & $\mathrm{c} 3 \mathrm{~h} 2$ & c3h $2+$ & $\mathrm{h}$ & & $5.89 \mathrm{e}-09$ & -0.5 & 0.0 & 4 \\
\hline $\mathrm{h} 2+$ & $\mathrm{c} 2 \mathrm{~h}$ & $\mathrm{c} 2 \mathrm{~h}+$ & h2 & & $1.00 \mathrm{e}-09$ & 0 & 0.0 & 4 \\
\hline $\mathrm{h} 2+$ & $\mathrm{c} 2 \mathrm{~h}$ & $\mathrm{c} 2 \mathrm{~h} 2+$ & $\mathrm{h}$ & & $1.00 \mathrm{e}-09$ & 0 & 0.0 & 4 \\
\hline $\mathrm{h} 2+$ & $\mathrm{c} 2 \mathrm{~h} 2$ & $\mathrm{c} 2 \mathrm{~h} 2+$ & h2 & & $4.80 \mathrm{e}-09$ & 0 & 0.0 & 4 \\
\hline $\mathrm{h} 2+$ & $\mathrm{c} 2 \mathrm{~h} 2$ & $\mathrm{c} 2 \mathrm{~h} 3+$ & $\mathrm{h}$ & & $4.80 \mathrm{e}-10$ & 0 & 0.0 & 4 \\
\hline he+ & $\mathrm{c} 2 \mathrm{~h}$ & $\mathrm{c}+$ & ch & he & $5.10 \mathrm{e}-10$ & 0 & 0.0 & 4 \\
\hline he+ & $\mathrm{c} 2 \mathrm{~h}$ & $\operatorname{ch}+$ & $\mathrm{c}$ & he & $5.10 \mathrm{e}-10$ & 0 & 0.0 & 4 \\
\hline he+ & $\mathrm{c} 2 \mathrm{~h}$ & $\mathrm{c} 2+$ & $\mathrm{h}$ & he & $5.10 \mathrm{e}-10$ & 0 & 0.0 & 4 \\
\hline he+ & $\mathrm{c} 2 \mathrm{~h} 2$ & $\operatorname{ch}+$ & $\mathrm{ch}$ & he & $7.70 \mathrm{e}-10$ & 0 & 0.0 & 4 \\
\hline he+ & $\mathrm{c} 2 \mathrm{~h} 2$ & $\mathrm{c} 2+$ & h2 & he & $1.61 \mathrm{e}-09$ & 0 & 0.0 & 4 \\
\hline he+ & $\mathrm{c} 2 \mathrm{~h} 2$ & $\mathrm{c} 2 \mathrm{~h}+$ & $\mathrm{h}$ & he & $8.75 \mathrm{e}-10$ & 0 & 0.0 & 4 \\
\hline he+ & $\mathrm{c} 2 \mathrm{~h} 2$ & $\mathrm{c} 2 \mathrm{~h} 2+$ & he & & $2.45 \mathrm{e}-10$ & 0 & 0.0 & 4 \\
\hline he+ & c3 & $\mathrm{c}+$ & $\mathrm{c} 2$ & he & $1.00 \mathrm{e}-09$ & 0 & 0.0 & 4 \\
\hline he+ & c3 & $\mathrm{c} 2+$ & c & he & $1.00 \mathrm{e}-09$ & 0 & 0.0 & 4 \\
\hline he+ & $\mathrm{c} 3 \mathrm{~h}$ & c3+ & $\mathrm{h}$ & he & $2.00 \mathrm{e}-09$ & 0 & 0.0 & 4 \\
\hline he+ & $\mathrm{c} 3 \mathrm{~h} 2$ & $\mathrm{c} 3 \mathrm{~h}+$ & $\mathrm{h}$ & he & $1.00 \mathrm{e}-09$ & 0 & 0.0 & 4 \\
\hline he+ & $\mathrm{c} 3 \mathrm{~h} 2$ & c3+ & h2 & he & $1.00 \mathrm{e}-09$ & 0 & 0.0 & 4 \\
\hline
\end{tabular}

Continua na próxima página... 
Tabela B.2 - Continuação

\begin{tabular}{|c|c|c|c|c|c|c|c|c|}
\hline \multicolumn{2}{|c|}{ Reagentes } & \multicolumn{3}{|c|}{ Produtos } & \multirow{2}{*}{$\frac{\gamma}{4.50 \mathrm{e}-09}$} & \multirow{2}{*}{$\begin{array}{c}\alpha \\
-0.5\end{array}$} & \multirow{2}{*}{$\begin{array}{l}\beta \\
0.0\end{array}$} & \multirow{2}{*}{$\begin{array}{c}\text { Tipo de Reação } \\
4\end{array}$} \\
\hline h3+ & $\mathrm{c} 2 \mathrm{~h}$ & $\mathrm{c} 2 \mathrm{~h} 2+$ & $\mathrm{h} 2$ & & & & & \\
\hline h3+ & $\mathrm{c} 2 \mathrm{~h} 2$ & $\mathrm{c} 2 \mathrm{~h} 3+$ & h2 & & $2.90 \mathrm{e}-09$ & 0 & 0.0 & 4 \\
\hline h3+ & c3 & $\mathrm{c} 3 \mathrm{~h}+$ & h2 & & $2.00 \mathrm{e}-09$ & 0 & 0.0 & 4 \\
\hline h3+ & $\mathrm{c} 3 \mathrm{~h}$ & $\mathrm{c} 3 \mathrm{~h} 2+$ & h2 & & $1.48 \mathrm{e}-08$ & -0.5 & 0.0 & 4 \\
\hline h3+ & $\mathrm{c} 3 \mathrm{~h} 2$ & c3h3+ & h2 & & $6.98 \mathrm{e}-09$ & -0.5 & 0.0 & 4 \\
\hline $\mathrm{c}+$ & $\mathrm{c} 2 \mathrm{~h}$ & $\mathrm{c} 3+$ & $\mathrm{h}$ & & $2.60 \mathrm{e}-09$ & -0.5 & 0.0 & 4 \\
\hline $\mathrm{c}+$ & $\mathrm{c} 2 \mathrm{~h} 2$ & $\mathrm{c} 3 \mathrm{~h}+$ & $\mathrm{h}$ & & $2.20 \mathrm{e}-09$ & 0 & 0.0 & 4 \\
\hline $\operatorname{ch}+$ & c & $\mathrm{c} 2+$ & $\mathrm{h}$ & & $1.20 \mathrm{e}-09$ & 0 & 0.0 & 4 \\
\hline $\operatorname{ch}+$ & o & $\mathrm{co}+$ & $\mathrm{h}$ & & $3.50 \mathrm{e}-10$ & 0 & 0.0 & 4 \\
\hline $\operatorname{ch}+$ & $\mathrm{ch}$ & $\mathrm{c} 2+$ & $\mathrm{h} 2$ & & $7.40 \mathrm{e}-10$ & 0 & 0.0 & 4 \\
\hline $\operatorname{ch}+$ & $\operatorname{ch} 2$ & $\mathrm{c} 2 \mathrm{~h}+$ & $\mathrm{h} 2$ & & $1.00 \mathrm{e}-09$ & 0 & 0.0 & 4 \\
\hline $\operatorname{ch}+$ & $\operatorname{ch} 4$ & $\mathrm{c} 2 \mathrm{~h} 2+$ & $\mathrm{h} 2$ & $\mathrm{~h}$ & $1.40 \mathrm{e}-10$ & 0 & 0.0 & 4 \\
\hline $\operatorname{ch}+$ & $\operatorname{ch} 4$ & $\mathrm{c} 2 \mathrm{~h} 3+$ & $\mathrm{h} 2$ & & $1.10 \mathrm{e}-09$ & 0 & 0.0 & 4 \\
\hline $\operatorname{ch}+$ & $\operatorname{ch} 4$ & $\mathrm{c} 2 \mathrm{~h} 4+$ & $\mathrm{h}$ & & $6.50 \mathrm{e}-11$ & 0 & 0.0 & 4 \\
\hline $\operatorname{ch}+$ & o2 & $\mathrm{co}+$ & $\mathrm{oh}$ & & $1.00 \mathrm{e}-11$ & 0 & 0.0 & 4 \\
\hline $\operatorname{ch}+$ & o2 & hco+ & o & & $9.70 \mathrm{e}-10$ & 0 & 0.0 & 4 \\
\hline $\operatorname{ch}+$ & oh & $\mathrm{co}+$ & h2 & & $7.50 \mathrm{e}-10$ & 0 & 0.0 & 4 \\
\hline $\mathrm{ch}+$ & h2o & hco+ & $\mathrm{h} 2$ & & $2.90 \mathrm{e}-09$ & 0 & 0.0 & 4 \\
\hline $\operatorname{ch}+$ & h2o & h3o+ & c & & $5.80 \mathrm{e}-10$ & 0 & 0.0 & 4 \\
\hline $\mathrm{ch}+$ & $\operatorname{co} 2$ & hco+ & co & & $1.60 \mathrm{e}-09$ & 0 & 0.0 & 4 \\
\hline $\operatorname{ch}+$ & $\mathrm{c} 2$ & $\mathrm{c} 3+$ & $\mathrm{h}$ & & $1.00 \mathrm{e}-09$ & 0 & 0.0 & 4 \\
\hline $\operatorname{ch}+$ & $\mathrm{c} 2 \mathrm{~h} 2$ & c3h2+ & $\mathrm{h}$ & & $1.20 \mathrm{e}-09$ & 0 & 0.0 & 4 \\
\hline $\operatorname{ch} 2+$ & $\operatorname{ch} 2$ & $\mathrm{c} 2 \mathrm{~h} 3+$ & $\mathrm{h}$ & & $1.00 \mathrm{e}-09$ & 0 & 0.0 & 4 \\
\hline $\operatorname{ch} 2+$ & $\mathrm{c} 2$ & $\mathrm{c} 3 \mathrm{~h}+$ & $\mathrm{h}$ & & $1.00 \mathrm{e}-09$ & 0 & 0.0 & 4 \\
\hline $\operatorname{ch} 2+$ & $\mathrm{c} 2 \mathrm{~h}$ & c3h2+ & $\mathrm{h}$ & & $4.75 \mathrm{e}-10$ & 0 & 0.0 & 4 \\
\hline $\operatorname{ch} 3+$ & $\operatorname{ch} 2$ & $\mathrm{c} 2 \mathrm{~h} 3+$ & h2 & & $8.21 \mathrm{e}-10$ & -0.5 & 0.0 & 4 \\
\hline $\operatorname{ch} 3+$ & $\mathrm{c} 2 \mathrm{~h}$ & $\mathrm{c} 3 \mathrm{~h} 2+$ & $\mathrm{h} 2$ & & $6.00 \mathrm{e}-10$ & -0.5 & 0.0 & 4 \\
\hline $\operatorname{ch} 4+$ & $\mathrm{c} 2 \mathrm{~h} 2$ & $\mathrm{c} 2 \mathrm{~h} 2+$ & $\operatorname{ch} 4$ & & $1.10 \mathrm{e}-09$ & 0 & 0.0 & 4 \\
\hline $\operatorname{ch} 4+$ & $\mathrm{c} 2 \mathrm{~h} 2$ & $\mathrm{c} 2 \mathrm{~h} 3+$ & ch3 & & $1.40 \mathrm{e}-09$ & 0 & 0.0 & 4 \\
\hline $\operatorname{ch} 4+$ & $\mathrm{c} 2 \mathrm{~h} 2$ & c3h3+ & $\mathrm{h} 2$ & $\mathrm{~h}$ & $6.25 \mathrm{e}-11$ & 0 & 0.0 & 4 \\
\hline $\mathrm{c} 2+$ & $\mathrm{c}$ & $c+$ & c2 & & $1.10 \mathrm{e}-10$ & 0 & 0.0 & 4 \\
\hline $\mathrm{c} 2+$ & o & $\mathrm{co}+$ & c & & $3.10 \mathrm{e}-10$ & 0 & 0.0 & 4 \\
\hline $\mathrm{c} 2+$ & $\mathrm{ch}$ & $\operatorname{ch}+$ & $\mathrm{c} 2$ & & $3.20 \mathrm{e}-10$ & 0 & 0.0 & 4 \\
\hline $\mathrm{c} 2+$ & $\mathrm{ch}$ & $\mathrm{c} 3+$ & $\mathrm{h}$ & & $3.20 \mathrm{e}-10$ & 0 & 0.0 & 4 \\
\hline $\mathrm{c} 2+$ & $\operatorname{ch} 2$ & $\operatorname{ch} 2+$ & c2 & & $4.50 \mathrm{e}-10$ & 0 & 0.0 & 4 \\
\hline $\mathrm{c} 2+$ & $\operatorname{ch} 2$ & $\mathrm{c} 3 \mathrm{~h}+$ & $\mathrm{h}$ & & $4.50 \mathrm{e}-10$ & 0 & 0.0 & 4 \\
\hline $\mathrm{c} 2+$ & $\operatorname{ch} 4$ & $\mathrm{c} 2 \mathrm{~h}+$ & $\operatorname{ch} 3$ & & $2.38 \mathrm{e}-10$ & 0 & 0.0 & 4 \\
\hline $\mathrm{c} 2+$ & $\operatorname{ch} 4$ & $\mathrm{c} 2 \mathrm{~h} 2+$ & $\operatorname{ch} 2$ & & $1.82 \mathrm{e}-10$ & 0 & 0.0 & 4 \\
\hline $\mathrm{c} 2+$ & $\operatorname{ch} 4$ & $\mathrm{c} 3 \mathrm{~h}+$ & h2 & $\mathrm{h}$ & $1.96 \mathrm{e}-10$ & 0 & 0.0 & 4 \\
\hline $\mathrm{c} 2+$ & $\operatorname{ch} 4$ & $\mathrm{c} 3 \mathrm{~h} 2+$ & $\mathrm{h} 2$ & & $5.74 \mathrm{e}-10$ & 0 & 0.0 & 4 \\
\hline $\mathrm{c} 2+$ & $\operatorname{ch} 4$ & c3h3+ & $\mathrm{h}$ & & $2.10 \mathrm{e}-10$ & 0 & 0.0 & 4 \\
\hline $\mathrm{c} 2+$ & $\mathrm{c} 2$ & $\mathrm{c} 3+$ & $\mathrm{c}$ & & $8.70 \mathrm{e}-10$ & 0 & 0.0 & 4 \\
\hline $\mathrm{c} 2 \mathrm{~h}+$ & c & c3+ & $\mathrm{h}$ & & $1.10 \mathrm{e}-09$ & 0 & 0.0 & 4 \\
\hline
\end{tabular}

Continua na próxima página... 
Tabela B.2 - Continuação

\begin{tabular}{|c|c|c|c|c|c|c|c|}
\hline \multicolumn{2}{|c|}{ Reagentes } & \multicolumn{2}{|r|}{ Produtos } & $\gamma$ & $\alpha$ & $\beta$ & \multirow[t]{2}{*}{ Tipo de Reação } \\
\hline $\mathrm{c} 2 \mathrm{~h}+$ & $\mathrm{ch}$ & $\operatorname{ch} 2+$ & $\mathrm{c} 2$ & $3.20 \mathrm{e}-10$ & 0 & 0.0 & \\
\hline $\mathrm{c} 2 \mathrm{~h}+$ & $\mathrm{ch}$ & $\mathrm{c} 3 \mathrm{~h}+$ & $\mathrm{h}$ & $3.20 \mathrm{e}-10$ & 0 & 0.0 & 4 \\
\hline $\mathrm{c} 2 \mathrm{~h}+$ & $\operatorname{ch} 2$ & $\operatorname{ch} 3+$ & $\mathrm{c} 2$ & $4.40 \mathrm{e}-10$ & 0 & 0.0 & 4 \\
\hline $\mathrm{c} 2 \mathrm{~h}+$ & $\operatorname{ch} 2$ & c3h2+ & $\mathrm{h}$ & $2.20 \mathrm{e}-10$ & 0 & 0.0 & 4 \\
\hline $\mathrm{c} 2 \mathrm{~h}+$ & $\operatorname{ch} 4$ & $\mathrm{c} 2 \mathrm{~h} 2+$ & $\operatorname{ch} 3$ & $3.74 \mathrm{e}-10$ & 0 & 0.0 & 4 \\
\hline $\mathrm{c} 2 \mathrm{~h}+$ & $\operatorname{ch} 4$ & c3h3+ & h2 & $1.87 \mathrm{e}-10$ & 0 & 0.0 & 4 \\
\hline $\mathrm{c} 2 \mathrm{~h}+$ & $\mathrm{h} 2 \mathrm{co}$ & h3cot & $\mathrm{c} 2$ & $1.10 \mathrm{e}-09$ & 0 & 0.0 & 4 \\
\hline $\mathrm{c} 2 \mathrm{~h} 2+$ & $\mathrm{c}$ & $\mathrm{c} 2 \mathrm{~h} 2$ & $\mathrm{c}+$ & $1.10 \mathrm{e}-09$ & 0 & 0.0 & 4 \\
\hline $\mathrm{c} 2 \mathrm{~h} 2+$ & $\mathrm{c}$ & $\mathrm{c} 3+$ & $\mathrm{h} 2$ & $1.10 \mathrm{e}-09$ & 0 & 0.0 & 4 \\
\hline $\mathrm{c} 2 \mathrm{~h} 2+$ & $\mathrm{c}$ & $\mathrm{c} 3 \mathrm{~h}+$ & $\mathrm{h}$ & $1.10 \mathrm{e}-09$ & 0 & 0.0 & 4 \\
\hline $\mathrm{c} 2 \mathrm{~h} 2+$ & o & hco+ & $\mathrm{ch}$ & $5.00 \mathrm{e}-11$ & 0 & 0.0 & 4 \\
\hline $\mathrm{c} 2 \mathrm{~h} 2+$ & o & hoct & $\mathrm{ch}$ & $5.00 \mathrm{e}-11$ & 0 & 0.0 & 4 \\
\hline $\mathrm{c} 2 \mathrm{~h} 2+$ & $\mathrm{ch}$ & c3h2+ & $\mathrm{h}$ & $2.30 \mathrm{e}-09$ & -0.5 & 0.0 & 4 \\
\hline $\mathrm{c} 2 \mathrm{~h} 2+$ & $\operatorname{ch} 2$ & c3h3+ & $\mathrm{h}$ & $3.66 \mathrm{e}-10$ & -0.5 & 0.0 & 4 \\
\hline $\mathrm{c} 2 \mathrm{~h} 2+$ & $\mathrm{o} 2$ & hco+ & hco & $9.80 \mathrm{e}-13$ & 0 & 0.0 & 4 \\
\hline $\mathrm{c} 2 \mathrm{~h} 2+$ & hco & hco+ & $\mathrm{c} 2 \mathrm{~h} 2$ & $5.70 \mathrm{e}-10$ & -0.5 & 0.0 & 4 \\
\hline $\mathrm{c} 2 \mathrm{~h} 2+$ & hco & $\mathrm{c} 2 \mathrm{~h} 3+$ & $\mathrm{co}$ & $4.30 \mathrm{e}-10$ & -0.5 & 0.0 & 4 \\
\hline $\mathrm{c} 2 \mathrm{~h} 2+$ & h2o & h3o+ & $\mathrm{c} 2 \mathrm{~h}$ & $2.20 \mathrm{e}-10$ & 0 & 0.0 & 4 \\
\hline $\mathrm{c} 2 \mathrm{~h} 2+$ & h2co & h2co+ & $\mathrm{c} 2 \mathrm{~h} 2$ & $1.60 \mathrm{e}-09$ & -0.5 & 0.0 & 4 \\
\hline $\mathrm{c} 2 \mathrm{~h} 3+$ & $\mathrm{h}$ & c2h2+ & $\mathrm{h} 2$ & $6.80 \mathrm{e}-11$ & 0 & 0.0 & 4 \\
\hline $\mathrm{c} 2 \mathrm{~h} 3+$ & $\mathrm{c}$ & $\mathrm{c} 3 \mathrm{~h}+$ & $\mathrm{h} 2$ & $1.00 \mathrm{e}-09$ & 0 & 0.0 & 4 \\
\hline $\mathrm{c} 2 \mathrm{~h} 3+$ & $\mathrm{c}$ & c3h2+ & $\mathrm{h}$ & $5.00 \mathrm{e}-10$ & 0 & 0.0 & 4 \\
\hline $\mathrm{c} 2 \mathrm{~h} 3+$ & $\mathrm{o}$ & $\operatorname{ch} 3+$ & $\mathrm{co}$ & $5.00 \mathrm{e}-12$ & 0 & 0.0 & 4 \\
\hline $\mathrm{c} 2 \mathrm{~h} 3+$ & $\mathrm{c} 2 \mathrm{~h}$ & $\mathrm{c} 2 \mathrm{~h} 2+$ & $\mathrm{c} 2 \mathrm{~h} 2$ & $6.80 \mathrm{e}-10$ & -0.5 & 0.0 & 4 \\
\hline $\mathrm{c} 2 \mathrm{~h} 3+$ & $\mathrm{c} 3 \mathrm{~h}$ & c3h2+ & $\mathrm{c} 2 \mathrm{~h} 2$ & $2.09 \mathrm{e}-09$ & -0.5 & 0.0 & 4 \\
\hline $\mathrm{c} 2 \mathrm{~h} 3+$ & c3h2 & c3h3+ & $\mathrm{c} 2 \mathrm{~h} 2$ & $1.01 \mathrm{e}-09$ & -0.5 & 0.0 & 4 \\
\hline $\mathrm{c} 2 \mathrm{~h} 3+$ & h2o & h3o+ & $\mathrm{c} 2 \mathrm{~h} 2$ & $1.11 \mathrm{e}-09$ & 0 & 0.0 & 4 \\
\hline $\mathrm{c} 2 \mathrm{~h} 4+$ & $\mathrm{h}$ & $\mathrm{c} 2 \mathrm{~h} 3+$ & $\mathrm{h} 2$ & $3.00 \mathrm{e}-10$ & 0 & 0.0 & 4 \\
\hline $\mathrm{c} 2 \mathrm{~h} 4+$ & $\mathrm{c}$ & c3h2+ & h2 & $1.00 \mathrm{e}-09$ & 0 & 0.0 & 4 \\
\hline $\mathrm{c} 2 \mathrm{~h} 4+$ & $\mathrm{c}$ & c3h3+ & $\mathrm{h}$ & $1.00 \mathrm{e}-09$ & 0 & 0.0 & 4 \\
\hline $\mathrm{c} 2 \mathrm{~h} 4+$ & $\mathrm{o}$ & hco+ & $\operatorname{ch} 3$ & $8.40 \mathrm{e}-11$ & 0 & 0.0 & 4 \\
\hline $\mathrm{c} 2 \mathrm{~h} 4+$ & o & $\operatorname{ch} 3+$ & hco & $1.08 \mathrm{e}-10$ & 0 & 0.0 & 4 \\
\hline $\mathrm{c} 2 \mathrm{~h} 4+$ & $\mathrm{c} 2 \mathrm{~h}$ & c3h3+ & $\operatorname{ch} 2$ & $1.00 \mathrm{e}-09$ & -0.5 & 0.0 & 4 \\
\hline $\mathrm{c} 2 \mathrm{~h} 4+$ & $\mathrm{c} 2 \mathrm{~h} 2$ & c3h3+ & $\operatorname{ch} 3$ & $6.30 \mathrm{e}-10$ & 0 & 0.0 & 4 \\
\hline $\mathrm{c} 3 \mathrm{~h}+$ & h2o & hco + & $\mathrm{c} 2 \mathrm{~h} 2$ & $2.48 \mathrm{e}-10$ & 0 & 0.0 & 4 \\
\hline $\mathrm{c} 3 \mathrm{~h}+$ & h2o & $\mathrm{c} 2 \mathrm{~h} 3+$ & $\mathrm{co}$ & $2.02 \mathrm{e}-10$ & 0 & 0.0 & 4 \\
\hline $\mathrm{c} 3 \mathrm{~h}+$ & $\operatorname{ch} 4$ & c2h3+ & $\mathrm{c} 2 \mathrm{~h} 2$ & $6.12 \mathrm{e}-10$ & 0 & 0.0 & 4 \\
\hline c3h $2+$ & $\mathrm{h}$ & $\mathrm{c} 3 \mathrm{~h}+$ & h2 & $6.00 \mathrm{e}-11$ & 0 & 0.0 & 4 \\
\hline $\mathrm{c} 3 \mathrm{~h} 2+$ & $\mathrm{o}$ & hco+ & $\mathrm{c} 2 \mathrm{~h}$ & $2.00 \mathrm{e}-10$ & 0 & 0.0 & 4 \\
\hline c3h3+ & $\mathrm{o}$ & $\mathrm{c} 2 \mathrm{~h} 3+$ & $\mathrm{CO}$ & $4.50 \mathrm{e}-11$ & 0 & 0.0 & 4 \\
\hline $\mathrm{o}+$ & $\mathrm{c} 2$ & $\mathrm{c} 2+$ & o & $4.80 \mathrm{e}-10$ & 0 & 0.0 & 4 \\
\hline $\mathrm{o}+$ & $\mathrm{c} 2$ & $\mathrm{co}+$ & $\mathrm{c}$ & $4.80 \mathrm{e}-10$ & 0 & 0.0 & 4 \\
\hline $\mathrm{o}+$ & $\mathrm{c} 2 \mathrm{~h}$ & $\mathrm{co}+$ & $\mathrm{ch}$ & $4.60 \mathrm{e}-10$ & 0 & 0.0 & 4 \\
\hline
\end{tabular}

Continua na próxima página... 
Tabela B.2 - Continuação

\begin{tabular}{|c|c|c|c|c|c|c|c|c|}
\hline \multicolumn{2}{|c|}{ Reagentes } & \multicolumn{3}{|c|}{ Produtos } & \multirow{2}{*}{$\frac{\gamma}{4.60 \mathrm{e}-10}$} & \multirow{2}{*}{$\begin{array}{l}\alpha \\
0\end{array}$} & \multirow{2}{*}{$\begin{array}{l}\beta \\
0.0\end{array}$} & \multirow{2}{*}{$\frac{\text { Tipo de Reação }}{4}$} \\
\hline $\mathrm{o}+$ & $\mathrm{c} 2 \mathrm{~h}$ & $\mathrm{c} 2 \mathrm{~h}+$ & o & & & & & \\
\hline $\mathrm{co}+$ & $\mathrm{c} 2$ & $\mathrm{c} 2+$ & $\mathrm{co}$ & & $8.40 \mathrm{e}-10$ & 0 & 0.0 & 4 \\
\hline $\mathrm{co}+$ & $\mathrm{c} 2 \mathrm{~h}$ & hco+ & $\mathrm{c} 2$ & & $3.90 \mathrm{e}-10$ & 0 & 0.0 & 4 \\
\hline hco+ & $\mathrm{c} 2 \mathrm{~h}$ & $\mathrm{c} 2 \mathrm{~h} 2+$ & $\mathrm{co}$ & & $7.80 \mathrm{e}-10$ & 0 & 0.0 & 4 \\
\hline hco+ & $\mathrm{c} 2 \mathrm{~h} 2$ & c2h3+ & $\mathrm{co}$ & & $1.36 \mathrm{e}-09$ & 0 & 0.0 & 4 \\
\hline hco+ & $\mathrm{c} 3$ & $\mathrm{c} 3 \mathrm{~h}+$ & $\mathrm{co}$ & & $1.40 \mathrm{e}-09$ & 0 & 0.0 & 4 \\
\hline hco+ & $\mathrm{c} 3 \mathrm{~h}$ & $\mathrm{c} 3 \mathrm{~h} 2+$ & $\mathrm{co}$ & & $1.40 \mathrm{e}-09$ & 0 & 0.0 & 4 \\
\hline hco+ & $\mathrm{c} 3 \mathrm{~h} 2$ & c3h3+ & $\mathrm{co}$ & & $1.40 \mathrm{e}-09$ & 0 & 0.0 & 4 \\
\hline $\mathrm{oh}+$ & $\mathrm{c} 2$ & $\mathrm{c} 2+$ & oh & & $4.80 \mathrm{e}-10$ & 0 & 0.0 & 4 \\
\hline $\mathrm{oh}+$ & $\mathrm{c} 2$ & $\mathrm{c} 2 \mathrm{~h}+$ & o & & $4.80 \mathrm{e}-10$ & 0 & 0.0 & 4 \\
\hline $\mathrm{oh}+$ & $\mathrm{c} 2 \mathrm{~h}$ & $\mathrm{c} 2 \mathrm{~h}+$ & oh & & $4.50 \mathrm{e}-10$ & 0 & 0.0 & 4 \\
\hline $\mathrm{oh}+$ & $\mathrm{c} 2 \mathrm{~h}$ & $\mathrm{c} 2 \mathrm{~h} 2+$ & o & & $4.50 \mathrm{e}-10$ & 0 & 0.0 & 4 \\
\hline h2o+ & $\mathrm{c} 2$ & $\mathrm{c} 2+$ & $\mathrm{h} 2 \mathrm{o}$ & & $4.70 \mathrm{e}-10$ & 0 & 0.0 & 4 \\
\hline h2o+ & $\mathrm{c} 2$ & $\mathrm{c} 2 \mathrm{~h}+$ & oh & & $4.70 \mathrm{e}-10$ & 0 & 0.0 & 4 \\
\hline h2o+ & $\mathrm{c} 2 \mathrm{~h}$ & $\mathrm{c} 2 \mathrm{~h}+$ & $\mathrm{h} 2 \mathrm{o}$ & & $4.40 \mathrm{e}-10$ & 0 & 0.0 & 4 \\
\hline h2o+ & $\mathrm{c} 2 \mathrm{~h}$ & $\mathrm{c} 2 \mathrm{~h} 2+$ & oh & & $4.40 \mathrm{e}-10$ & 0 & 0.0 & 4 \\
\hline h3o+ & $\mathrm{c} 2 \mathrm{~h}$ & $\mathrm{c} 2 \mathrm{~h} 2+$ & h2o & & $2.20 \mathrm{e}-10$ & 0 & 4100.0 & 4 \\
\hline h3o+ & $\mathrm{c} 2 \mathrm{~h} 2$ & $\mathrm{c} 2 \mathrm{~h} 3+$ & h2o & & $1.00 \mathrm{e}-09$ & 0 & 7330.0 & 4 \\
\hline h3o+ & $\mathrm{c} 3 \mathrm{~h}$ & c3h $2+$ & h2o & & $2.00 \mathrm{e}-09$ & 0 & 0.0 & 4 \\
\hline h3o+ & $\mathrm{c} 3 \mathrm{~h} 2$ & c3h3+ & h2o & & $3.00 \mathrm{e}-09$ & 0 & 0.0 & 4 \\
\hline $\mathrm{h}+$ & fe & $\mathrm{fe}+$ & $\mathrm{h}$ & & $7.40 \mathrm{e}-09$ & 0 & 0.0 & 4 \\
\hline h3+ & fe & $\mathrm{fe}+$ & h2 & $\mathrm{h}$ & $4.90 \mathrm{e}-09$ & 0 & 0.0 & 4 \\
\hline$c+$ & fe & fe+ & c & & $2.60 \mathrm{e}-09$ & 0 & 0.0 & 4 \\
\hline $\operatorname{ch}+$ & fe & fe+ & $\mathrm{ch}$ & & $2.60 \mathrm{e}-10$ & 0 & 0.0 & 4 \\
\hline $\operatorname{ch} 3+$ & $\mathrm{fe}$ & $\mathrm{fe}+$ & $\operatorname{ch} 3$ & & $2.40 \mathrm{e}-09$ & 0 & 0.0 & 4 \\
\hline $\mathrm{o}+$ & fe & fe+ & o & & $2.90 \mathrm{e}-09$ & 0 & 0.0 & 4 \\
\hline $\mathrm{o} 2+$ & fe & fe+ & o 2 & & $1.10 \mathrm{e}-09$ & 0 & 0.0 & 4 \\
\hline h2o+ & fe & fe+ & h2o & & $1.50 \mathrm{e}-09$ & 0 & 0.0 & 4 \\
\hline h3o+ & fe & fe+ & h2o & $\mathrm{h}$ & $3.10 \mathrm{e}-09$ & 0 & 0.0 & 4 \\
\hline hco+ & fe & fe+ & $\mathrm{co}$ & $\mathrm{h}$ & $1.90 \mathrm{e}-09$ & 0 & 0.0 & 4 \\
\hline hoc + & fe & fe+ & $\mathrm{co}$ & $\mathrm{h}$ & $1.90 \mathrm{e}-09$ & 0 & 0.0 & 4 \\
\hline $\mathrm{c} 2 \mathrm{~h} 2+$ & fe & fe+ & $\mathrm{c} 2 \mathrm{~h} 2$ & & $2.00 \mathrm{e}-09$ & 0 & 0.0 & 4 \\
\hline c & $\mathrm{h}$ & $\mathrm{ch}$ & photon & & $1.00 \mathrm{e}-17$ & 0 & 0.0 & 3 \\
\hline c & c & $\mathrm{c} 2$ & photon & & $1.00 \mathrm{e}-17$ & 0 & 0.0 & 3 \\
\hline c & o & $\mathrm{co}$ & photon & & $2.10 \mathrm{e}-19$ & 0 & 0.0 & 3 \\
\hline $\mathrm{ch}$ & h2 & ch3 & photon & & $3.25 \mathrm{e}-17$ & -0.6 & 0.0 & 3 \\
\hline $\mathrm{h}+$ & $\mathrm{h}$ & $\mathrm{h} 2+$ & photon & & $2.00 \mathrm{e}-20$ & 1 & 0.0 & 3 \\
\hline $\mathrm{c}+$ & $\mathrm{h}$ & $\operatorname{ch}+$ & photon & & $7.00 \mathrm{e}-17$ & 0 & 0.0 & 3 \\
\hline$c+$ & h2 & $\operatorname{ch} 2+$ & photon & & $1.70 \mathrm{e}-15$ & 0 & 0.0 & 3 \\
\hline$c+$ & o & $\mathrm{co}+$ & photon & & $2.50 \mathrm{e}-18$ & 0 & 0.0 & 3 \\
\hline $\operatorname{ch} 3+$ & $\mathrm{h} 2$ & $\operatorname{ch} 5+$ & photon & & $1.30 \mathrm{e}-14$ & -1 & 0.0 & 3 \\
\hline $\mathrm{c} 2 \mathrm{~h} 2+$ & $\mathrm{h}$ & $\mathrm{c} 2 \mathrm{~h} 3+$ & photon & & $7.00 \mathrm{e}-15$ & -1.5 & 0.0 & 3 \\
\hline $\mathrm{c} 2 \mathrm{~h} 2+$ & $\mathrm{h} 2$ & $\mathrm{c} 2 \mathrm{~h} 4+$ & photon & & $1.50 \mathrm{e}-14$ & -1 & 0.0 & 3 \\
\hline
\end{tabular}

Continua na próxima página... 
Tabela B.2 - Continuação

\begin{tabular}{|c|c|c|c|c|c|c|c|c|}
\hline \multicolumn{2}{|c|}{ Reagentes } & \multicolumn{3}{|c|}{ Produtos } & $\gamma$ & $\alpha$ & $\beta$ & Tipo de Reação \\
\hline $\mathrm{c} 3+$ & $\mathrm{h}$ & $\mathrm{c} 3 \mathrm{~h}+$ & photon & & $7.00 \mathrm{e}-16$ & -1.5 & 0.0 & 3 \\
\hline $\mathrm{c} 3 \mathrm{~h}+$ & $\mathrm{h}$ & $\mathrm{c} 3 \mathrm{~h} 2+$ & photon & & $2.00 \mathrm{e}-14$ & -1.5 & 0.0 & 3 \\
\hline $\mathrm{c} 3 \mathrm{~h}+$ & $\mathrm{h} 2$ & c3h3+ & photon & & $3.00 \mathrm{e}-13$ & -1 & 0.0 & 3 \\
\hline $\mathrm{c} 3 \mathrm{~h} 2+$ & $\mathrm{h}$ & c3h3+ & photon & & $4.00 \mathrm{e}-15$ & -1.5 & 0.0 & 3 \\
\hline nh3 & $\mathrm{c} 2 \mathrm{~h} 4+$ & $\mathrm{c} 2 \mathrm{~h} 4$ & nh3+ & & $1.80 \mathrm{e}-09$ & 0 & 0.0 & 4 \\
\hline $\mathrm{c} 2 \mathrm{~h} 4$ & phosec & $\mathrm{c} 2 \mathrm{~h} 2$ & $\mathrm{~h} 2$ & & $3.00 \mathrm{e}-09$ & 0 & 1.7 & 2 \\
\hline $\operatorname{ch} 3$ & $\operatorname{ch} 3$ & $\mathrm{c} 2 \mathrm{~h} 4$ & $\mathrm{~h} 2$ & & $1.66 \mathrm{e}-08$ & 0 & 16556.0 & 4 \\
\hline o & $\mathrm{c} 2 \mathrm{~h} 4$ & hco & $\operatorname{ch} 3$ & & $1.52 \mathrm{e}-12$ & 1.55 & 215.0 & 4 \\
\hline $\operatorname{ch} 2$ & $\operatorname{ch} 2$ & $\mathrm{c} 2 \mathrm{~h} 3$ & $\mathrm{~h}$ & & $3.32 \mathrm{e}-08$ & 0 & 0.0 & 4 \\
\hline oh & $\mathrm{c} 2 \mathrm{~h} 3$ & $\mathrm{c} 2 \mathrm{~h} 2$ & h2o & & $5.00 \mathrm{e}-11$ & 0 & 0.0 & 4 \\
\hline o & $\mathrm{c} 2 \mathrm{~h} 4$ & c2h3 & oh & & $2.42 \mathrm{e}-13$ & 2.13 & 1338.0 & 4 \\
\hline $\mathrm{c} 2 \mathrm{~h} 3$ & phosec & $\mathrm{c} 2 \mathrm{~h} 2$ & $\mathrm{~h}$ & & $1.00 \mathrm{e}-09$ & 0 & 1.7 & 2 \\
\hline hc3 & phosec & $\mathrm{c} 3$ & $\mathrm{~h}$ & & $8.16 \mathrm{e}+03$ & 0 & 0.0 & 2 \\
\hline h2c3 & phosec & hc3 & $\mathrm{h}$ & & $8.16 \mathrm{e}+03$ & 0 & 0.0 & 2 \\
\hline hc3 & o & $\mathrm{c} 2 \mathrm{~h}$ & $\mathrm{co}$ & & $1.70 \mathrm{e}-11$ & 0 & 0.0 & 4 \\
\hline $\mathrm{o}$ & $\mathrm{c} 4 \mathrm{~h}$ & hc3 & $\mathrm{co}$ & & $8.50 \mathrm{e}-12$ & 0 & 0.0 & 4 \\
\hline $\mathrm{c}$ & $\mathrm{c} 2 \mathrm{~h} 2$ & hc3 & $\mathrm{h}$ & & $1.45 \mathrm{e}-10$ & -0.12 & 0.0 & 4 \\
\hline $\mathrm{c}$ & hc3 & $\mathrm{c} 4$ & $\mathrm{~h}$ & & $1.00 \mathrm{e}-10$ & 0 & 0.0 & 4 \\
\hline h2c3+ & electr & hc3 & $\mathrm{h}$ & & $1.50 \mathrm{e}-07$ & -0.5 & 0.0 & 4 \\
\hline h3c3+ & electr & hc3 & $\mathrm{h} 2$ & & $3.15 \mathrm{e}-07$ & -0.5 & 0.0 & 4 \\
\hline $\mathrm{h}+$ & hc3 & $\mathrm{c} 3 \mathrm{~h}+$ & $\mathrm{h}$ & & $1.58 \mathrm{e}-08$ & -0.5 & 0.0 & 4 \\
\hline $\mathrm{h}+$ & hc3 & $\mathrm{c} 3+$ & $\mathrm{h} 2$ & & $1.58 \mathrm{e}-08$ & -0.5 & 0.0 & 4 \\
\hline he+ & hc3 & $\mathrm{c} 3+$ & $\mathrm{h}$ & he & $2.00 \mathrm{e}-09$ & 0 & 0.0 & 4 \\
\hline h3+ & hc3 & h2c3+ & $\mathrm{h} 2$ & & $1.92 \mathrm{e}-08$ & -0.5 & 0.0 & 4 \\
\hline$c+$ & hc3 & $\mathrm{c} 4+$ & $\mathrm{h}$ & & $1.07 \mathrm{e}-08$ & -0.5 & 0.0 & 4 \\
\hline $\operatorname{ch} 3+$ & hc3 & $\mathrm{c} 3 \mathrm{~h}+$ & $\operatorname{ch} 3$ & & $4.90 \mathrm{e}-09$ & -0.5 & 0.0 & 4 \\
\hline $\operatorname{ch} 3+$ & hc3 & $\mathrm{c} 4 \mathrm{~h} 2+$ & h2 & & $4.35 \mathrm{e}-09$ & -0.5 & 0.0 & 4 \\
\hline hco+ & hc3 & h2c3+ & $\mathrm{co}$ & & $1.40 \mathrm{e}-09$ & 0 & 0.0 & 4 \\
\hline h3o+ & hc3 & h2c3+ & $\mathrm{h} 2 \mathrm{o}$ & & $2.00 \mathrm{e}-09$ & 0 & 0.0 & 4 \\
\hline $\mathrm{c} 2 \mathrm{~h} 3+$ & hc3 & $\mathrm{h} 2 \mathrm{c} 3+$ & $\mathrm{c} 2 \mathrm{~h} 2$ & & $2.71 \mathrm{e}-09$ & -0.5 & 0.0 & 4 \\
\hline $\mathrm{c} 2 \mathrm{~h} 4+$ & hc3 & $\mathrm{c} 4 \mathrm{~h} 2+$ & $\operatorname{ch} 3$ & & $5.34 \mathrm{e}-09$ & -0.5 & 0.0 & 4 \\
\hline $\mathrm{c} 3 \mathrm{~h}+$ & no & not & hc3 & & $8.65 \mathrm{e}-11$ & -0.5 & 0.0 & 4 \\
\hline $\mathrm{c} 3 \mathrm{~h}+$ & nh3 & nh3+ & hc3 & & $2.79 \mathrm{e}-10$ & -0.5 & 0.0 & 4 \\
\hline hc3 & photon & c3 & $\mathrm{h}$ & & $1.00 \mathrm{e}-09$ & 0 & 1.70 & 5 \\
\hline h2c3 & photon & hc3 & $\mathrm{h}$ & & $1.00 \mathrm{e}-09$ & 0 & 1.7 & 5 \\
\hline h2c3 & o & $\mathrm{c} 2 \mathrm{~h} 2$ & $\mathrm{co}$ & & $5.00 \mathrm{e}-11$ & 0.5 & 0.0 & 4 \\
\hline $\mathrm{c}$ & h2c3 & $\mathrm{c} 4 \mathrm{~h}$ & $\mathrm{~h}$ & & $1.00 \mathrm{e}-10$ & 0 & 0.0 & 4 \\
\hline h3c3+ & electr & h2c3 & $\mathrm{h}$ & & $3.15 \mathrm{e}-07$ & -0.5 & 0.0 & 4 \\
\hline $\mathrm{h}+$ & h2c3 & $\mathrm{c} 3 \mathrm{~h}+$ & $\mathrm{h} 2$ & & 7.11e-09 & -0.5 & 0.0 & 4 \\
\hline $\mathrm{h}+$ & h2c3 & h2c3+ & $\mathrm{h}$ & & $7.11 \mathrm{e}-09$ & -0.5 & 0.0 & 4 \\
\hline he+ & h2c3 & $\mathrm{c} 3 \mathrm{~h}+$ & $\mathrm{h}$ & he & $1.00 \mathrm{e}-09$ & 0 & 0.0 & 4 \\
\hline he+ & $\mathrm{h} 2 \mathrm{c} 3$ & $\mathrm{c} 3+$ & $\mathrm{h} 2$ & he & $1.00 \mathrm{e}-09$ & 0 & 0.0 & 4 \\
\hline h3+ & $\mathrm{h} 2 \mathrm{c} 3$ & h3c3+ & $\mathrm{h} 2$ & & $8.42 \mathrm{e}-09$ & -0.5 & 0.0 & 4 \\
\hline
\end{tabular}

Continua na próxima página... 
Tabela B.2 - Continuação

\begin{tabular}{|c|c|c|c|c|c|c|c|c|}
\hline \multicolumn{2}{|c|}{ Reagentes } & \multicolumn{3}{|c|}{ Produtos } & \multirow{2}{*}{$\frac{\gamma}{2.10 \mathrm{e}-09}$} & \multirow{2}{*}{$\begin{array}{c}\alpha \\
-0.5\end{array}$} & \multirow{2}{*}{$\begin{array}{l}\beta \\
0.0\end{array}$} & \multirow{2}{*}{$\begin{array}{c}\text { Tipo de Reação } \\
4\end{array}$} \\
\hline $\mathrm{c}+$ & h2c3 & $\mathrm{c} 4+$ & $\mathrm{h} 2$ & & & & & \\
\hline $\mathrm{c}+$ & h2c3 & $\mathrm{c} 4 \mathrm{~h}+$ & $\mathrm{h}$ & & $2.10 \mathrm{e}-09$ & -0.5 & 0.0 & 4 \\
\hline $\operatorname{ch} 3+$ & h2c3 & c4h3+ & $\mathrm{h} 2$ & & $4.02 \mathrm{e}-09$ & -0.5 & 0.0 & 4 \\
\hline hco+ & h2c3 & h3c3+ & $\mathrm{co}$ & & $1.40 \mathrm{e}-09$ & 0 & 0.0 & 4 \\
\hline h3o+ & h2c3 & h3c $3+$ & h2o & & $3.00 \mathrm{e}-09$ & 0 & 0.0 & 4 \\
\hline $\mathrm{c} 2 \mathrm{~h} 3+$ & $\mathrm{h} 2 \mathrm{c} 3$ & h3c3+ & $\mathrm{c} 2 \mathrm{~h} 2$ & & $1.21 \mathrm{e}-09$ & -0.5 & 0.0 & 4 \\
\hline $\mathrm{c} 2 \mathrm{~h} 4+$ & h2c3 & c4h3+ & $\operatorname{ch} 3$ & & $2.69 \mathrm{e}-09$ & -0.5 & 0.0 & 4 \\
\hline c4h3+ & o & hco+ & $\mathrm{h} 2 \mathrm{c} 3$ & & $2.50 \mathrm{e}-11$ & 0 & 0.0 & 4 \\
\hline $\mathrm{h} 2 \mathrm{c} 3$ & photon & c3 & h2 & & $1.00 \mathrm{e}-09$ & 0 & 1.7 & 5 \\
\hline $\mathrm{c} 4$ & phosec & c3 & c & & $2.00 \mathrm{e}+03$ & 0 & 0.0 & 2 \\
\hline $\mathrm{c} 4 \mathrm{~h}$ & phosec & $\mathrm{c} 4$ & $\mathrm{~h}$ & & $1.00 \mathrm{e}+04$ & 0 & 0.0 & 2 \\
\hline o & $\mathrm{c} 4$ & $\mathrm{co}$ & c3 & & $1.00 \mathrm{e}-10$ & 0 & 0.0 & 4 \\
\hline c & $\mathrm{c} 3 \mathrm{~h}$ & $\mathrm{c} 4$ & $\mathrm{~h}$ & & $1.00 \mathrm{e}-10$ & 0 & 0.0 & 4 \\
\hline $\mathrm{c} 4 \mathrm{~h}+$ & electr & $\mathrm{c} 4$ & $\mathrm{~h}$ & & $1.20 \mathrm{e}-07$ & -0.5 & 0.0 & 4 \\
\hline $\mathrm{c} 4 \mathrm{~h} 2+$ & electr & $\mathrm{c} 4$ & $\mathrm{~h} 2$ & & $1.50 \mathrm{e}-07$ & -0.5 & 0.0 & 4 \\
\hline $\mathrm{h}+$ & $\mathrm{c} 4$ & $\mathrm{c} 4+$ & $\mathrm{h}$ & & $4.00 \mathrm{e}-09$ & 0 & 0.0 & 4 \\
\hline he+ & $\mathrm{c} 4$ & $\mathrm{c}+$ & c3 & he & $6.70 \mathrm{e}-10$ & 0 & 0.0 & 4 \\
\hline he+ & $\mathrm{c} 4$ & $\mathrm{c} 2+$ & $\mathrm{c} 2$ & he & $6.70 \mathrm{e}-10$ & 0 & 0.0 & 4 \\
\hline he+ & $\mathrm{c} 4$ & $\mathrm{c} 3+$ & c & he & $6.70 \mathrm{e}-10$ & 0 & 0.0 & 4 \\
\hline h3+ & $\mathrm{c} 4$ & $\mathrm{c} 4 \mathrm{~h}+$ & $\mathrm{h} 2$ & & $2.00 \mathrm{e}-09$ & 0 & 0.0 & 4 \\
\hline hco+ & $\mathrm{c} 4$ & $\mathrm{c} 4 \mathrm{~h}+$ & $\mathrm{co}$ & & $1.40 \mathrm{e}-09$ & 0 & 0.0 & 4 \\
\hline h3o+ & $\mathrm{c} 4$ & $\mathrm{c} 4 \mathrm{~h}+$ & h2o & & $1.10 \mathrm{e}-09$ & 0 & 0.0 & 4 \\
\hline $\mathrm{c} 4 \mathrm{~h}+$ & $\mathrm{c} 4 \mathrm{~h}$ & $\mathrm{c} 4 \mathrm{~h} 2+$ & $\mathrm{c} 4$ & & $8.35 \mathrm{e}-10$ & -0.5 & 0.0 & 4 \\
\hline c & $\mathrm{c} 3$ & $\mathrm{c} 4$ & photon & & $1.00 \mathrm{e}-10$ & 0 & 0.0 & 3 \\
\hline $\mathrm{c} 4$ & photon & $\mathrm{c} 2$ & $\mathrm{c} 2$ & & $2.00 \mathrm{e}-10$ & 0 & 2.3 & 5 \\
\hline $\mathrm{c} 4$ & photon & c3 & c & & $2.00 \mathrm{e}-10$ & 0 & 2.3 & 5 \\
\hline $\mathrm{c} 4 \mathrm{~h}$ & photon & $\mathrm{c} 4$ & $\mathrm{~h}$ & & $1.00 \mathrm{e}-09$ & 0 & 1.7 & 5 \\
\hline $\mathrm{c} 4 \mathrm{~h} 2$ & phosec & $\mathrm{c} 4 \mathrm{~h}$ & $\mathrm{~h}$ & & $3.46 \mathrm{e}+03$ & 0 & 0.0 & 2 \\
\hline o & $\mathrm{c} 4 \mathrm{~h}$ & $\mathrm{c} 3 \mathrm{~h}$ & $\mathrm{co}$ & & $8.50 \mathrm{e}-12$ & 0 & 0.0 & 4 \\
\hline c & c3h2 & $\mathrm{c} 4 \mathrm{~h}$ & $\mathrm{~h}$ & & $1.00 \mathrm{e}-10$ & 0 & 0.0 & 4 \\
\hline c4h $2+$ & electr & $\mathrm{c} 4 \mathrm{~h}$ & $\mathrm{~h}$ & & $1.50 \mathrm{e}-07$ & -0.5 & 0.0 & 4 \\
\hline c4h3+ & electr & $\mathrm{c} 4 \mathrm{~h}$ & $\mathrm{~h} 2$ & & $1.50 \mathrm{e}-07$ & -0.5 & 0.0 & 4 \\
\hline $\mathrm{h}+$ & $\mathrm{c} 4 \mathrm{~h}$ & $\mathrm{c} 4+$ & h2 & & $4.20 \mathrm{e}-09$ & -0.5 & 0.0 & 4 \\
\hline $\mathrm{h}+$ & $\mathrm{c} 4 \mathrm{~h}$ & $\mathrm{c} 4 \mathrm{~h}+$ & $\mathrm{h}$ & & $4.20 \mathrm{e}-09$ & -0.5 & 0.0 & 4 \\
\hline he+ & $\mathrm{c} 4 \mathrm{~h}$ & $\mathrm{c} 2 \mathrm{~h}+$ & $\mathrm{c} 2$ & he & $2.10 \mathrm{e}-09$ & -0.5 & 0.0 & 4 \\
\hline he+ & $\mathrm{c} 4 \mathrm{~h}$ & $\mathrm{c} 4+$ & $\mathrm{h}$ & he & $2.10 \mathrm{e}-09$ & -0.5 & 0.0 & 4 \\
\hline hcot & $\mathrm{c} 4 \mathrm{~h}$ & $\mathrm{c} 4 \mathrm{~h} 2+$ & $\mathrm{co}$ & & $1.90 \mathrm{e}-09$ & -0.5 & 0.0 & 4 \\
\hline h3o+ & $\mathrm{c} 4 \mathrm{~h}$ & $\mathrm{c} 4 \mathrm{~h} 2+$ & h2o & & $2.23 \mathrm{e}-09$ & -0.5 & 0.0 & 4 \\
\hline c2h3+ & $\mathrm{c} 4 \mathrm{~h}$ & $\mathrm{c} 4 \mathrm{~h} 2+$ & $\mathrm{c} 2 \mathrm{~h} 2$ & & $6.60 \mathrm{e}-10$ & -0.5 & 0.0 & 4 \\
\hline $\mathrm{c} 4 \mathrm{~h}+$ & fe & fe+ & $\mathrm{c} 4 \mathrm{~h}$ & & $1.00 \mathrm{e}-09$ & 0 & 0.0 & 4 \\
\hline $\mathrm{c} 4 \mathrm{~h}$ & photon & $\mathrm{c} 2 \mathrm{~h}$ & $\mathrm{c} 2$ & & $1.00 \mathrm{e}-09$ & 0 & 1.7 & 5 \\
\hline $\mathrm{c} 4 \mathrm{~h}$ & photon & $\mathrm{c} 4$ & $\mathrm{~h}$ & & $1.00 \mathrm{e}-09$ & 0 & 1.7 & 5 \\
\hline $\mathrm{c} 4 \mathrm{~h} 2$ & photon & $\mathrm{c} 4 \mathrm{~h}$ & $\mathrm{~h}$ & & $1.13 \mathrm{e}-09$ & 0 & 1.6 & 5 \\
\hline
\end{tabular}

Continua na próxima página... 
Tabela B.2 - Continuação

\begin{tabular}{|c|c|c|c|c|c|c|c|c|}
\hline \multicolumn{2}{|c|}{ Reagentes } & \multicolumn{3}{|c|}{ Produtos } & \multirow{2}{*}{$\frac{\gamma}{3.46 \mathrm{e}+03}$} & \multirow{2}{*}{$\begin{array}{c}\alpha \\
0\end{array}$} & \multirow{2}{*}{$\begin{array}{l}\beta \\
0.0\end{array}$} & \multirow{2}{*}{$\begin{array}{c}\text { Tipo de Reação } \\
2\end{array}$} \\
\hline $\mathrm{c} 4 \mathrm{~h} 2$ & phosec & $\mathrm{c} 2 \mathrm{~h}$ & $\mathrm{c} 2 \mathrm{~h}$ & & & & & \\
\hline $\mathrm{c} 4 \mathrm{~h} 2$ & phosec & $\mathrm{c} 4 \mathrm{~h} 2+$ & electr & & $2.24 \mathrm{e}+03$ & 0 & 0.0 & 2 \\
\hline c4h3+ & electr & $\mathrm{c} 4 \mathrm{~h} 2$ & $\mathrm{~h}$ & & $1.50 \mathrm{e}-07$ & -0.5 & 0.0 & 4 \\
\hline $\mathrm{h}+$ & c4h2 & $\mathrm{c} 4 \mathrm{~h}+$ & h2 & & $2.00 \mathrm{e}-09$ & 0 & 0.0 & 4 \\
\hline $\mathrm{h}+$ & $\mathrm{c} 4 \mathrm{~h} 2$ & $\mathrm{c} 4 \mathrm{~h} 2+$ & $\mathrm{h}$ & & $2.00 \mathrm{e}-09$ & 0 & 0.0 & 4 \\
\hline he+ & $\mathrm{c} 4 \mathrm{~h} 2$ & $\mathrm{c} 2 \mathrm{~h}+$ & $\mathrm{c} 2 \mathrm{~h}$ & he & $1.00 \mathrm{e}-09$ & 0 & 0.0 & 4 \\
\hline he+ & c4h2 & $\mathrm{c} 4+$ & h2 & he & $1.00 \mathrm{e}-09$ & 0 & 0.0 & 4 \\
\hline he+ & $\mathrm{c} 4 \mathrm{~h} 2$ & $\mathrm{c} 4 \mathrm{~h}+$ & $\mathrm{h}$ & he & $1.00 \mathrm{e}-09$ & 0 & 0.0 & 4 \\
\hline $\mathrm{c}+$ & $\mathrm{c} 4 \mathrm{~h} 2$ & $\mathrm{c} 3 \mathrm{~h}+$ & $\mathrm{c} 2 \mathrm{~h}$ & & $1.45 \mathrm{e}-10$ & 0 & 0.0 & 4 \\
\hline $\mathrm{c}+$ & c4h2 & $\mathrm{c} 4 \mathrm{~h} 2+$ & $\mathrm{c}$ & & $1.40 \mathrm{e}-09$ & 0 & 0.0 & 4 \\
\hline $\operatorname{ch} 3+$ & $\mathrm{c} 4 \mathrm{~h} 2$ & c3h3+ & $\mathrm{c} 2 \mathrm{~h} 2$ & & $1.20 \mathrm{e}-09$ & 0 & 0.0 & 4 \\
\hline $\operatorname{ch} 3+$ & $\mathrm{c} 4 \mathrm{~h} 2$ & h3c3+ & $\mathrm{c} 2 \mathrm{~h} 2$ & & $1.20 \mathrm{e}-09$ & 0 & 0.0 & 4 \\
\hline hco+ & c4h2 & c4h3+ & co & & $1.40 \mathrm{e}-09$ & 0 & 0.0 & 4 \\
\hline h3o+ & $\mathrm{c} 4 \mathrm{~h} 2$ & c4h3+ & h2o & & $1.10 \mathrm{e}-09$ & 0 & 0.0 & 4 \\
\hline c $2 \mathrm{~h} 3+$ & $\mathrm{c} 4 \mathrm{~h} 2$ & c4h3+ & $\mathrm{c} 2 \mathrm{~h} 2$ & & $3.00 \mathrm{e}-10$ & 0 & 0.0 & 4 \\
\hline $\mathrm{s}+$ & $\mathrm{c} 4 \mathrm{~h} 2$ & c3h $2+$ & $\mathrm{cs}$ & & $1.20 \mathrm{e}-10$ & 0 & 0.0 & 4 \\
\hline $\mathrm{s}+$ & $\mathrm{c} 4 \mathrm{~h} 2$ & h2c3+ & $\mathrm{cs}$ & & $1.20 \mathrm{e}-10$ & 0 & 0.0 & 4 \\
\hline $\mathrm{s}+$ & $\mathrm{c} 4 \mathrm{~h} 2$ & $\mathrm{c} 4 \mathrm{~h}+$ & $\mathrm{sh}$ & & $1.60 \mathrm{e}-10$ & 0 & 0.0 & 4 \\
\hline $\mathrm{s}+$ & $\mathrm{c} 4 \mathrm{~h} 2$ & $\mathrm{c} 4 \mathrm{~h} 2+$ & $\mathrm{s}$ & & $7.20 \mathrm{e}-10$ & 0 & 0.0 & 4 \\
\hline $\mathrm{c} 4 \mathrm{~h} 2$ & photon & $\mathrm{c} 2 \mathrm{~h}$ & $\mathrm{c} 2 \mathrm{~h}$ & & $1.13 \mathrm{e}-09$ & 0 & 1.6 & 5 \\
\hline $\mathrm{c} 4 \mathrm{~h} 2$ & photon & $\mathrm{c} 4 \mathrm{~h} 2+$ & electr & & $2.60 \mathrm{e}-10$ & 0 & 2.3 & 5 \\
\hline $\mathrm{nh}+$ & $\mathrm{o} 2$ & $\mathrm{o} 2 \mathrm{~h}+$ & $\mathrm{n}$ & & $1.60 \mathrm{e}-10$ & 0 & 0.0 & 4 \\
\hline h2c3+ & electr & $\mathrm{c} 2$ & $\operatorname{ch} 2$ & & $3.00 \mathrm{e}-08$ & -0.5 & 0.0 & 4 \\
\hline h2c3+ & electr & c3 & $\mathrm{h}$ & $\mathrm{h}$ & $6.00 \mathrm{e}-08$ & -0.5 & 0.0 & 4 \\
\hline h2c3+ & electr & c3 & $\mathrm{h} 2$ & & $1.50 \mathrm{e}-07$ & -0.5 & 0.0 & 4 \\
\hline h2c3+ & electr & $\mathrm{c} 2 \mathrm{~h} 2$ & c & & $3.00 \mathrm{e}-08$ & -0.5 & 0.0 & 4 \\
\hline $\operatorname{ch}+$ & $\mathrm{c} 2 \mathrm{~h} 2$ & h2c3+ & $\mathrm{h}$ & & $1.20 \mathrm{e}-09$ & 0 & 0.0 & 4 \\
\hline $\operatorname{ch} 2+$ & $\mathrm{c} 2 \mathrm{~h}$ & h2c3+ & $\mathrm{h}$ & & $4.75 \mathrm{e}-10$ & 0 & 0.0 & 4 \\
\hline $\operatorname{ch} 3+$ & $\mathrm{c} 2 \mathrm{~h}$ & h2c3+ & $\mathrm{h} 2$ & & $6.00 \mathrm{e}-10$ & -0.5 & 0.0 & 4 \\
\hline $\mathrm{c} 2+$ & $\operatorname{ch} 4$ & h2c3+ & h2 & & $5.74 \mathrm{e}-10$ & 0 & 0.0 & 4 \\
\hline $\mathrm{c} 2 \mathrm{~h}+$ & $\operatorname{ch} 2$ & h2c3+ & $\mathrm{h}$ & & $2.20 \mathrm{e}-10$ & 0 & 0.0 & 4 \\
\hline $\mathrm{c} 2 \mathrm{~h} 2+$ & $\mathrm{ch}$ & h2c3+ & $\mathrm{h}$ & & $2.30 \mathrm{e}-09$ & -0.5 & 0.0 & 4 \\
\hline c2h3+ & $\mathrm{c}$ & h2c3+ & $\mathrm{h}$ & & $5.00 \mathrm{e}-10$ & 0 & 0.0 & 4 \\
\hline $\mathrm{c} 2 \mathrm{~h} 4+$ & $\mathrm{c}$ & h2c3+ & h2 & & $5.00 \mathrm{e}-10$ & 0 & 0.0 & 4 \\
\hline h2c3+ & c & $\mathrm{c} 4 \mathrm{~h}+$ & $\mathrm{h}$ & & $1.00 \mathrm{e}-09$ & 0 & 0.0 & 4 \\
\hline h2c3+ & $\mathrm{h}$ & $\mathrm{c} 3 \mathrm{~h}+$ & h2 & & $6.00 \mathrm{e}-11$ & 0 & 0.0 & 4 \\
\hline h2c3+ & $\mathrm{O}$ & hco+ & $\mathrm{c} 2 \mathrm{~h}$ & & $2.00 \mathrm{e}-10$ & 0 & 0.0 & 4 \\
\hline c4h2+ & o & h2c3+ & $\mathrm{co}$ & & $1.10 \mathrm{e}-10$ & 0 & 0.0 & 4 \\
\hline $\mathrm{c} 3 \mathrm{~h}+$ & $\mathrm{h}$ & h2c3+ & photon & & $2.00 \mathrm{e}-14$ & -1.5 & 0.0 & 3 \\
\hline h2c3+ & $\mathrm{h}$ & h3c3+ & photon & & $4.00 \mathrm{e}-15$ & -1.5 & 0.0 & 3 \\
\hline h2c3+ & photon & c3+ & $\mathrm{h} 2$ & & $1.00 \mathrm{e}-10$ & 0 & 3.0 & 5 \\
\hline $\mathrm{c} 3 \mathrm{~h}+$ & $\mathrm{h} 2$ & h3c3+ & photon & & $3.00 \mathrm{e}-13$ & -1 & 0.0 & 3 \\
\hline $\operatorname{ch} 3+$ & $\mathrm{c} 2 \mathrm{~h}$ & h3c3+ & $\mathrm{h}$ & & $6.00 \mathrm{e}-10$ & -0.5 & 0.0 & 4 \\
\hline
\end{tabular}

Continua na próxima página... 
Tabela B.2 - Continuação

\begin{tabular}{|c|c|c|c|c|c|c|c|c|}
\hline \multicolumn{2}{|c|}{ Reagentes } & \multicolumn{3}{|c|}{ Produtos } & \multirow{2}{*}{$\frac{\gamma}{6.25 \mathrm{e}-11}$} & \multirow{2}{*}{$\begin{array}{c}\alpha \\
0\end{array}$} & \multirow{2}{*}{$\begin{array}{l}\beta \\
0.0\end{array}$} & \multirow{2}{*}{$\begin{array}{c}\text { Tipo de Reação } \\
4\end{array}$} \\
\hline $\operatorname{ch} 4+$ & $\mathrm{c} 2 \mathrm{~h} 2$ & h3c3+ & h2 & $\mathrm{h}$ & & & & \\
\hline $\mathrm{c} 2+$ & $\operatorname{ch} 4$ & h3c3+ & $\mathrm{h}$ & & $2.10 \mathrm{e}-10$ & 0 & 0.0 & 4 \\
\hline $\mathrm{c} 2 \mathrm{~h}+$ & $\operatorname{ch} 4$ & h3c3+ & h2 & & $1.87 \mathrm{e}-10$ & 0 & 0.0 & 4 \\
\hline $\mathrm{c} 2 \mathrm{~h} 2+$ & $\operatorname{ch} 2$ & h3c3+ & $\mathrm{h}$ & & $3.66 \mathrm{e}-10$ & -0.5 & 0.0 & 4 \\
\hline c2h4+ & c & h3c3+ & $\mathrm{h}$ & & $5.00 \mathrm{e}-10$ & 0 & 0.0 & 4 \\
\hline $\mathrm{c} 2 \mathrm{~h} 4+$ & $\mathrm{c} 2 \mathrm{~h}$ & h3c3+ & $\operatorname{ch} 2$ & & $5.00 \mathrm{e}-10$ & -0.5 & 0.0 & 4 \\
\hline $\mathrm{c} 2 \mathrm{~h} 4+$ & $\mathrm{c} 2 \mathrm{~h} 2$ & h3c3+ & $\operatorname{ch} 3$ & & $3.15 \mathrm{e}-10$ & 0 & 0.0 & 4 \\
\hline h3c3+ & $\mathrm{c}$ & $\mathrm{c} 4 \mathrm{~h}+$ & h2 & & $1.00 \mathrm{e}-09$ & 0 & 0.0 & 4 \\
\hline h3c3+ & $\mathrm{c}$ & $\mathrm{c} 4 \mathrm{~h} 2+$ & $\mathrm{h}$ & & $1.00 \mathrm{e}-09$ & 0 & 0.0 & 4 \\
\hline h3c3+ & o & $\mathrm{c} 2 \mathrm{~h} 3+$ & $\mathrm{co}$ & & $4.50 \mathrm{e}-11$ & 0 & 0.0 & 4 \\
\hline h2c3+ & $\mathrm{h}$ & h3c3+ & photon & & $4.00 \mathrm{e}-15$ & -1.5 & 0.0 & 3 \\
\hline h3c3+ & photon & $\mathrm{c} 3 \mathrm{~h}+$ & $\mathrm{h} 2$ & & $1.00 \mathrm{e}-10$ & 0 & 3.0 & 5 \\
\hline $\mathrm{c} 4+$ & h2 & $\mathrm{c} 4 \mathrm{~h}+$ & $\mathrm{h}$ & & $1.30 \mathrm{e}-10$ & 0 & 0.0 & 4 \\
\hline $\mathrm{c} 4+$ & electr & $\mathrm{c} 2$ & $\mathrm{c} 2$ & & $1.75 \mathrm{e}-07$ & -0.5 & 0.0 & 4 \\
\hline $\mathrm{c} 4+$ & electr & c3 & c & & $2.75 \mathrm{e}-07$ & -0.5 & 0.0 & 4 \\
\hline $\mathrm{c}+$ & $\mathrm{c} 3 \mathrm{~h}$ & $\mathrm{c} 4+$ & $\mathrm{h}$ & & $9.50 \mathrm{e}-09$ & -0.5 & 0.0 & 4 \\
\hline $\mathrm{c}+$ & c3h2 & $\mathrm{c} 4+$ & h2 & & $2.10 \mathrm{e}-09$ & -0.5 & 0.0 & 4 \\
\hline $\mathrm{c}+$ & h2c3 & $\mathrm{c} 4+$ & $\mathrm{h} 2$ & & $2.10 \mathrm{e}-09$ & -0.5 & 0.0 & 4 \\
\hline $\mathrm{c}+$ & c3 & $\mathrm{c} 4+$ & photon & & $1.00 \mathrm{e}-13$ & -1 & 0.0 & 3 \\
\hline $\mathrm{c} 4 \mathrm{~h}+$ & electr & $\mathrm{c} 2 \mathrm{~h}$ & $\mathrm{c} 2$ & & $9.00 \mathrm{e}-08$ & -0.5 & 0.0 & 4 \\
\hline $\mathrm{c} 4 \mathrm{~h}+$ & electr & $\mathrm{c} 3 \mathrm{~h}$ & $\mathrm{c}$ & & $4.50 \mathrm{e}-08$ & -0.5 & 0.0 & 4 \\
\hline $\mathrm{c} 4 \mathrm{~h}+$ & electr & c3 & $\mathrm{ch}$ & & $4.50 \mathrm{e}-08$ & -0.5 & 0.0 & 4 \\
\hline $\mathrm{c} 4 \mathrm{~h}+$ & electr & $\mathrm{c} 4$ & $\mathrm{~h}$ & & $1.20 \mathrm{e}-07$ & -0.5 & 0.0 & 4 \\
\hline $\mathrm{c}+$ & c3h2 & $\mathrm{c} 4 \mathrm{~h}+$ & $\mathrm{h}$ & & $2.10 \mathrm{e}-09$ & -0.5 & 0.0 & 4 \\
\hline $\mathrm{c}+$ & h2c3 & $\mathrm{c} 4 \mathrm{~h}+$ & $\mathrm{h}$ & & $2.10 \mathrm{e}-09$ & -0.5 & 0.0 & 4 \\
\hline $\mathrm{c} 2+$ & $\mathrm{c} 2 \mathrm{~h} 2$ & $\mathrm{c} 4 \mathrm{~h}+$ & $\mathrm{h}$ & & $1.70 \mathrm{e}-09$ & 0 & 0.0 & 4 \\
\hline c3h $2+$ & $\mathrm{c}$ & $\mathrm{c} 4 \mathrm{~h}+$ & $\mathrm{h}$ & & $1.00 \mathrm{e}-09$ & 0 & 0.0 & 4 \\
\hline $\mathrm{c} 4 \mathrm{~h}+$ & o & hco+ & c3 & & $2.00 \mathrm{e}-10$ & 0 & 0.0 & 4 \\
\hline $\mathrm{c} 4 \mathrm{~h}+$ & h2 & $\mathrm{c} 4 \mathrm{~h} 2+$ & $\mathrm{h}$ & & $1.65 \mathrm{e}-10$ & 0 & 0.0 & 4 \\
\hline c3h3+ & c & $\mathrm{c} 4 \mathrm{~h}+$ & $\mathrm{h} 2$ & & $1.00 \mathrm{e}-09$ & 0 & 0.0 & 4 \\
\hline $\mathrm{c} 4 \mathrm{~h}+$ & $\mathrm{h}$ & $\mathrm{c} 4 \mathrm{~h} 2+$ & photon & & $6.00 \mathrm{e}-14$ & -1.5 & 0.0 & 3 \\
\hline $\operatorname{ch} 3+$ & $\mathrm{c} 3 \mathrm{~h}$ & c4h2+ & $\mathrm{h} 2$ & & $4.35 \mathrm{e}-09$ & -0.5 & 0.0 & 4 \\
\hline $\mathrm{c} 2 \mathrm{~h}+$ & $\mathrm{c} 2 \mathrm{~h} 2$ & $\mathrm{c} 4 \mathrm{~h} 2+$ & $\mathrm{h}$ & & $1.70 \mathrm{e}-09$ & 0 & 0.0 & 4 \\
\hline $\mathrm{c} 2 \mathrm{~h} 2+$ & $\mathrm{c} 2 \mathrm{~h}$ & $\mathrm{c} 4 \mathrm{~h} 2+$ & $\mathrm{h}$ & & $2.10 \mathrm{e}-09$ & -0.5 & 0.0 & 4 \\
\hline $\mathrm{c} 2 \mathrm{~h} 2+$ & $\mathrm{c} 2 \mathrm{~h} 2$ & $\mathrm{c} 4 \mathrm{~h} 2+$ & $\mathrm{h} 2$ & & $5.20 \mathrm{e}-10$ & 0 & 0.0 & 4 \\
\hline c2h3+ & $\mathrm{c} 2 \mathrm{~h}$ & $\mathrm{c} 4 \mathrm{~h} 2+$ & $\mathrm{h} 2$ & & $6.80 \mathrm{e}-10$ & -0.5 & 0.0 & 4 \\
\hline $\mathrm{c} 2 \mathrm{~h} 4+$ & $\mathrm{c} 3 \mathrm{~h}$ & $\mathrm{c} 4 \mathrm{~h} 2+$ & $\operatorname{ch} 3$ & & $5.34 \mathrm{e}-09$ & -0.5 & 0.0 & 4 \\
\hline c3h3+ & $\mathrm{c}$ & c4h2+ & $\mathrm{h}$ & & $1.00 \mathrm{e}-09$ & 0 & 0.0 & 4 \\
\hline c4h2+ & o & c3h2+ & $\mathrm{co}$ & & $1.10 \mathrm{e}-10$ & 0 & 0.0 & 4 \\
\hline c4h2+ & o & $\mathrm{h} 2 \mathrm{c} 3+$ & $\mathrm{co}$ & & $1.10 \mathrm{e}-10$ & 0 & 0.0 & 4 \\
\hline $\mathrm{c} 4 \mathrm{~h} 2+$ & $\mathrm{h}$ & $\mathrm{c} 4 \mathrm{~h} 3+$ & photon & & $7.00 \mathrm{e}-11$ & -0.1 & 0.0 & 3 \\
\hline $\operatorname{ch} 3+$ & c3h2 & c4h3+ & $\mathrm{h} 2$ & & $4.02 \mathrm{e}-09$ & -0.5 & 0.0 & 4 \\
\hline $\mathrm{c} 2 \mathrm{~h} 2+$ & $\mathrm{c} 2 \mathrm{~h} 2$ & $\mathrm{c} 4 \mathrm{~h} 3+$ & $\mathrm{h}$ & & $8.80 \mathrm{e}-10$ & 0 & 0.0 & 4 \\
\hline
\end{tabular}

Continua na próxima página... 
Tabela B.2 - Continuação

\begin{tabular}{|c|c|c|c|c|c|c|c|c|}
\hline \multicolumn{2}{|c|}{ Reagentes } & \multicolumn{3}{|c|}{ Produtos } & \multirow{2}{*}{$\frac{\gamma}{6.80 \mathrm{e}-10}$} & \multirow{2}{*}{$\begin{array}{c}\alpha \\
-0.5\end{array}$} & \multirow{2}{*}{$\begin{array}{c}\beta \\
0.0\end{array}$} & \multirow{2}{*}{$\begin{array}{c}\text { Tipo de Reação } \\
4\end{array}$} \\
\hline c $2 \mathrm{~h} 3+$ & $\mathrm{c} 2 \mathrm{~h}$ & c4h3+ & $\mathrm{h}$ & & & & & \\
\hline c $2 \mathrm{~h} 3+$ & $\mathrm{c} 2 \mathrm{~h} 2$ & $\mathrm{c} 4 \mathrm{~h} 3+$ & h2 & & $7.20 \mathrm{e}-10$ & 0 & 0.0 & 4 \\
\hline c2h4+ & $\mathrm{c} 2 \mathrm{~h}$ & c4h3+ & h2 & & $1.00 \mathrm{e}-09$ & -0.5 & 0.0 & 4 \\
\hline c2h4+ & $\mathrm{c} 3 \mathrm{~h} 2$ & c4h3+ & $\operatorname{ch} 3$ & & $2.23 \mathrm{e}-09$ & -0.5 & 0.0 & 4 \\
\hline $\mathrm{c} 3 \mathrm{~h}+$ & $\operatorname{ch} 4$ & $\mathrm{c} 4 \mathrm{~h} 3+$ & h2 & & $5.50 \mathrm{e}-11$ & 0 & 0.0 & 4 \\
\hline c4h3+ & $\mathrm{o}$ & hcot & c3h2 & & $2.50 \mathrm{e}-11$ & 0 & 0.0 & 4 \\
\hline $\mathrm{c} 2$ & $\operatorname{ch} 4$ & c3h3 & $\mathrm{h}$ & & $1.50 \mathrm{e}-11$ & 0 & 0.0 & 4 \\
\hline $\mathrm{c}+$ & c3h3 & $\mathrm{c} 4 \mathrm{~h}+$ & h2 & & $1.00 \mathrm{e}-09$ & 0 & 0.0 & 4 \\
\hline $\mathrm{c}$ & $\mathrm{c} 2 \mathrm{~h} 4$ & c3h3 & $\mathrm{h}$ & & $3.00 \mathrm{e}-10$ & -0.11 & 0.0 & 4 \\
\hline $\mathrm{c} 3 \mathrm{~h} 3$ & phosec & $\mathrm{c} 3 \mathrm{~h}$ & h2 & & $1.30 \mathrm{e}-17$ & 0 & 2500.0 & 2 \\
\hline $\mathrm{c} 2 \mathrm{~h} 2$ & $\mathrm{c} 2 \mathrm{~h} 4+$ & c4h $5+$ & $\mathrm{h}$ & & $1.93 \mathrm{e}-10$ & 0 & 0.0 & 4 \\
\hline c4h5+ & electr & $\mathrm{c} 4 \mathrm{~h} 2$ & $\mathrm{~h} 2$ & $\mathrm{~h}$ & $1.50 \mathrm{e}-07$ & -0.5 & 0.0 & 4 \\
\hline $\operatorname{ch} 3+$ & c3h3 & c4h5+ & $\mathrm{h}$ & & $4.00 \mathrm{e}-09$ & 0 & 0.0 & 4 \\
\hline $\mathrm{c} 2 \mathrm{~h} 2+$ & $\mathrm{c} 2 \mathrm{~h} 4$ & c4h5+ & $\mathrm{h}$ & & $3.17 \mathrm{e}-10$ & 0 & 0.0 & 4 \\
\hline $\mathrm{c}$ & c3h3 & $\mathrm{h} 2 \mathrm{c} 4$ & $\mathrm{~h}$ & & $1.00 \mathrm{e}-10$ & 0 & 0.0 & 4 \\
\hline $\mathrm{c} 3 \mathrm{~h} 3$ & phosec & c3h2 & $\mathrm{h}$ & & $1.30 \mathrm{e}-17$ & 0 & 2500.0 & 2 \\
\hline c3h3 & photon & $\mathrm{c} 3 \mathrm{~h}$ & $\mathrm{~h} 2$ & & $1.00 \mathrm{e}-09$ & 0 & 1.7 & 5 \\
\hline c3h3 & photon & c3h2 & $\mathrm{h}$ & & $1.00 \mathrm{e}-09$ & 0 & 1.7 & 5 \\
\hline $\operatorname{ch} 4$ & $\mathrm{c} 2 \mathrm{~h} 3+$ & c3h5+ & h2 & & $2.00 \mathrm{e}-10$ & 0 & 0.0 & 4 \\
\hline $\operatorname{ch} 4$ & $\mathrm{c} 2 \mathrm{~h} 2+$ & c3h5+ & $\mathrm{h}$ & & $6.64 \mathrm{e}-10$ & 0 & 0.0 & 4 \\
\hline c3h5+ & electr & c3h3 & $\mathrm{h} 2$ & & $1.50 \mathrm{e}-07$ & -0.5 & 0.0 & 4 \\
\hline $\mathrm{n}$ & c3h5+ & $\mathrm{c} 2 \mathrm{~h} 4+$ & hen & & $1.10 \mathrm{e}-10$ & 0 & 0.0 & 4 \\
\hline $\mathrm{c} 2 \mathrm{~h} 4+$ & $\mathrm{c} 2 \mathrm{~h} 4$ & c3h5+ & $\operatorname{ch} 3$ & & $7.11 \mathrm{e}-10$ & 0 & 0.0 & 4 \\
\hline $\operatorname{ch} 3+$ & $\mathrm{c} 2 \mathrm{~h} 4$ & c3h5+ & $\mathrm{h} 2$ & & $5.24 \mathrm{e}-10$ & 0 & 0.0 & 4 \\
\hline c3h5+ & electr & c3h4 & $\mathrm{h}$ & & $1.50 \mathrm{e}-07$ & -0.5 & 0.0 & 4 \\
\hline $\mathrm{c}$ & c3h4 & $\mathrm{c} 4 \mathrm{~h} 2$ & $\mathrm{~h} 2$ & & $4.00 \mathrm{e}-20$ & 0 & 0.0 & 4 \\
\hline c4h5+ & electr & $\mathrm{c} 3 \mathrm{~h} 4$ & $\mathrm{ch}$ & & $1.50 \mathrm{e}-07$ & -0.5 & 0.0 & 4 \\
\hline $\mathrm{c}+$ & c3h4 & c4h2+ & h2 & & $5.70 \mathrm{e}-10$ & 0 & 0.0 & 4 \\
\hline$c+$ & c3h4 & $\mathrm{c} 2 \mathrm{~h} 2+$ & $\mathrm{c} 2 \mathrm{~h} 2$ & & $1.90 \mathrm{e}-10$ & 0 & 0.0 & 4 \\
\hline c3h4 & photon & c3h2 & $\mathrm{h} 2$ & & $2.25 \mathrm{e}-10$ & 0 & 1.7 & 5 \\
\hline $\mathrm{c} 2 \mathrm{~h}$ & $\mathrm{c} 3 \mathrm{~h} 2$ & $\mathrm{c} 5 \mathrm{~h} 2$ & $\mathrm{~h}$ & & $1.06 \mathrm{e}-10$ & -0.25 & 0.0 & 4 \\
\hline $\mathrm{c} 5 \mathrm{~h} 2$ & photon & $\mathrm{c} 3 \mathrm{~h}$ & $\mathrm{c} 2 \mathrm{~h}$ & & $1.00 \mathrm{e}-11$ & 0 & 1.7 & 5 \\
\hline he+ & $\mathrm{c} 5 \mathrm{~h} 2$ & $\mathrm{c} 3 \mathrm{~h}+$ & $\mathrm{c} 2 \mathrm{~h}$ & he & $1.00 \mathrm{e}-09$ & 0 & 0.0 & 4 \\
\hline $\mathrm{c} 2$ & $\mathrm{c} 2 \mathrm{~h} 4$ & c4h3 & $\mathrm{h}$ & & $3.50 \mathrm{e}-10$ & 0 & 0.0 & 4 \\
\hline $\mathrm{c} 4 \mathrm{~h} 3$ & c & $\mathrm{c} 5 \mathrm{~h} 2$ & $\mathrm{~h}$ & & $3.10 \mathrm{e}-10$ & 0 & 0.0 & 4 \\
\hline $\mathrm{c}$ & c3h4 & c4h3 & $\mathrm{h}$ & & $2.70 \mathrm{e}-10$ & -0.11 & 0.0 & 4 \\
\hline $\mathrm{h}+$ & c4h3 & c4h2+ & $\mathrm{h} 2$ & & $2.00 \mathrm{e}-09$ & 0 & 0.0 & 4 \\
\hline he+ & c4h3 & c3h2+ & $\mathrm{ch}$ & he & $6.70 \mathrm{e}-10$ & 0 & 0.0 & 4 \\
\hline he+ & c4h3 & c4h2+ & he & $\mathrm{h}$ & $6.70 \mathrm{e}-10$ & 0 & 0.0 & 4 \\
\hline he+ & c4h3 & c3h3+ & c & he & $6.70 \mathrm{e}-10$ & 0 & 0.0 & 4 \\
\hline $\mathrm{c}+$ & c4h3 & $\mathrm{c} 3 \mathrm{~h} 2+$ & $\mathrm{c} 2 \mathrm{~h}$ & & $3.10 \mathrm{e}-10$ & 0 & 0.0 & 4 \\
\hline c & c5h2 & $\mathrm{c} 6 \mathrm{~h}$ & $\mathrm{~h}$ & & $5.30 \mathrm{e}-10$ & 0 & 0.0 & 4 \\
\hline $\mathrm{c} 6 \mathrm{~h}$ & phosec & $\mathrm{c} 3 \mathrm{~h}$ & $\mathrm{c} 3$ & & $1.30 \mathrm{e}-17$ & 0 & 2500.0 & 2 \\
\hline
\end{tabular}

Continua na próxima página... 
Tabela B.2 - Continuação

\begin{tabular}{|c|c|c|c|c|c|c|c|c|}
\hline \multicolumn{2}{|c|}{ Reagentes } & \multicolumn{3}{|c|}{ Produtos } & \multirow{2}{*}{$\frac{\gamma}{1.30 \mathrm{e}-17}$} & \multirow{2}{*}{$\begin{array}{c}\alpha \\
0\end{array}$} & \multirow{2}{*}{$\begin{array}{c}\beta \\
2500.0\end{array}$} & \multirow{2}{*}{$\begin{array}{c}\text { Tipo de Reação } \\
2\end{array}$} \\
\hline $\mathrm{c} 6 \mathrm{~h}$ & phosec & $\mathrm{c} 4$ & $\mathrm{c} 2 \mathrm{~h}$ & & & & & \\
\hline $\mathrm{c} 2 \mathrm{~h}$ & c4h2 & $\mathrm{c} 6 \mathrm{~h} 2$ & $\mathrm{~h}$ & & $1.06 \mathrm{e}-10$ & -0.25 & 0.0 & 4 \\
\hline $\mathrm{c} 2 \mathrm{~h} 2$ & $\mathrm{c} 4 \mathrm{~h}$ & $\mathrm{c} 6 \mathrm{~h} 2$ & $\mathrm{~h}$ & & $1.50 \mathrm{e}-10$ & 0 & 0.0 & 4 \\
\hline he+ & c6h2 & $\mathrm{c} 4 \mathrm{~h}+$ & $\mathrm{c} 2 \mathrm{~h}$ & he & $1.00 \mathrm{e}-09$ & 0 & 0.0 & 4 \\
\hline c & c4h2 & $\mathrm{c} 5 \mathrm{~h}$ & $\mathrm{~h}$ & & $6.50 \mathrm{e}-10$ & 0 & 0.0 & 4 \\
\hline c5h2 & photon & $\mathrm{c} 5 \mathrm{~h}$ & $\mathrm{~h}$ & & $1.00 \mathrm{e}-11$ & 0 & 1.7 & 5 \\
\hline $\mathrm{n}$ & $\mathrm{c} 6 \mathrm{~h}$ & $\mathrm{cn}$ & $\mathrm{c} 5 \mathrm{~h}$ & & $1.00 \mathrm{e}-13$ & 0 & 0.0 & 4 \\
\hline o & $\mathrm{c} 6 \mathrm{~h}$ & $\mathrm{c} 5 \mathrm{~h}$ & $\mathrm{co}$ & & $1.70 \mathrm{e}-13$ & 0 & 0.0 & 4 \\
\hline o & $\mathrm{c} 5 \mathrm{~h}$ & $\mathrm{c} 4 \mathrm{~h}$ & $\mathrm{co}$ & & $1.70 \mathrm{e}-11$ & 0 & 0.0 & 4 \\
\hline $\mathrm{c} 5 \mathrm{~h}$ & photon & c3 & $\mathrm{c} 2 \mathrm{~h}$ & & $1.00 \mathrm{e}-11$ & 0 & 1.7 & 5 \\
\hline $\mathrm{c} 5 \mathrm{~h}$ & photon & $\mathrm{c} 3 \mathrm{~h}$ & $\mathrm{c} 2$ & & $1.00 \mathrm{e}-11$ & 0 & 1.7 & 5 \\
\hline he+ & $\mathrm{c} 5 \mathrm{~h}$ & $\mathrm{c} 3 \mathrm{~h}+$ & $\mathrm{c} 2$ & he & $1.50 \mathrm{e}-09$ & 0 & 0.0 & 4 \\
\hline $\mathrm{c} 5 \mathrm{~h}$ & phosec & $\mathrm{c} 3 \mathrm{~h}$ & $\mathrm{c} 2$ & & $1.30 \mathrm{e}-17$ & 0 & 2500.0 & 2 \\
\hline $\mathrm{c} 5 \mathrm{~h}$ & phosec & c3 & $\mathrm{c} 2 \mathrm{~h}$ & & $1.30 \mathrm{e}-17$ & 0 & 2500.0 & 2 \\
\hline $\mathrm{c} 2 \mathrm{~h} 2$ & c4h2+ & c6h3+ & $\mathrm{h}$ & & $7.00 \mathrm{e}-12$ & 0 & 0.0 & 4 \\
\hline $\mathrm{c} 2 \mathrm{~h} 2+$ & c4h2 & c6h3+ & $\mathrm{h}$ & & $1.40 \mathrm{e}-10$ & 0 & 0.0 & 4 \\
\hline $\mathrm{c} 2 \mathrm{~h} 3$ & $\mathrm{c} 4 \mathrm{~h}+$ & c6h3+ & $\mathrm{h}$ & & $2.00 \mathrm{e}-09$ & 0 & 0.0 & 4 \\
\hline $\mathrm{c} 2 \mathrm{~h} 3$ & $\mathrm{c} 4 \mathrm{~h} 2+$ & c6h3+ & h2 & & $3.00 \mathrm{e}-10$ & 0 & 0.0 & 4 \\
\hline $\mathrm{c} 2 \mathrm{~h} 3+$ & $\mathrm{c} 4 \mathrm{~h}$ & c6h3+ & $\mathrm{h}$ & & $4.00 \mathrm{e}-10$ & 0 & 0.0 & 4 \\
\hline o & c6h3+ & $\mathrm{c} 5 \mathrm{~h} 2$ & hco + & & $2.00 \mathrm{e}-10$ & 0 & 0.0 & 4 \\
\hline c6h3+ & electr & c6h2 & $\mathrm{h}$ & & $1.00 \mathrm{e}-06$ & -0.3 & 0.0 & 4 \\
\hline c6h3+ & electr & $\mathrm{c} 6 \mathrm{~h}$ & $\mathrm{~h} 2$ & & $1.00 \mathrm{e}-06$ & -0.3 & 0.0 & 4 \\
\hline $\mathrm{c} 2 \mathrm{~h} 2$ & c4h2+ & c6h4+ & photon & & $1.00 \mathrm{e}-09$ & 0 & 0.0 & 4 \\
\hline $\mathrm{c} 2 \mathrm{~h} 3$ & $\mathrm{c} 4 \mathrm{~h} 2+$ & c6h4+ & $\mathrm{h}$ & & $1.20 \mathrm{e}-09$ & 0 & 0.0 & 4 \\
\hline $\mathrm{c} 2 \mathrm{~h} 3+$ & $\mathrm{c} 4 \mathrm{~h} 2$ & c6h4+ & $\mathrm{h}$ & & $3.00 \mathrm{e}-10$ & 0 & 0.0 & 4 \\
\hline $\mathrm{c} 2 \mathrm{~h} 4$ & $\mathrm{c} 4 \mathrm{~h}+$ & c6h4+ & $\mathrm{h}$ & & $7.50 \mathrm{e}-10$ & 0 & 0.0 & 4 \\
\hline c3h2 & c3h3+ & c6h4+ & $\mathrm{h}$ & & $1.00 \mathrm{e}-09$ & 0 & 0.0 & 4 \\
\hline c6h4+ & electr & c6h2 & h2 & & $1.00 \mathrm{e}-06$ & -0.3 & 0.0 & 4 \\
\hline c6h4+ & electr & $\mathrm{c} 6 \mathrm{~h}$ & $\mathrm{~h} 2$ & $\mathrm{~h}$ & $1.00 \mathrm{e}-06$ & -0.3 & 0.0 & 4 \\
\hline $\mathrm{c} 2 \mathrm{~h} 3$ & c4h3+ & c6h5+ & $\mathrm{h}$ & & $5.00 \mathrm{e}-10$ & 0 & 0.0 & 4 \\
\hline $\mathrm{c} 2 \mathrm{~h} 4$ & c4h2+ & c6h5+ & $\mathrm{h}$ & & $8.00 \mathrm{e}-10$ & 0 & 0.0 & 4 \\
\hline c3h3+ & c3h3 & c6h5+ & $\mathrm{h}$ & & $1.50 \mathrm{e}-09$ & 0 & 0.0 & 4 \\
\hline c6h5+ & electr & c6h2 & h2 & $\mathrm{h}$ & $1.00 \mathrm{e}-06$ & -0.3 & 0.0 & 4 \\
\hline c6h5+ & electr & $\mathrm{c} 6 \mathrm{~h}$ & h2 & h2 & $1.00 \mathrm{e}-06$ & -0.3 & 0.0 & 4 \\
\hline $\mathrm{c} 2 \mathrm{~h} 3+$ & c3h3 & c5h5+ & $\mathrm{h}$ & & $1.00 \mathrm{e}-09$ & 0 & 0.0 & 4 \\
\hline $\mathrm{c} 2 \mathrm{~h} 4$ & c3h2+ & c5h5+ & $\mathrm{h}$ & & $4.40 \mathrm{e}-10$ & 0 & 0.0 & 4 \\
\hline $\mathrm{c} 2 \mathrm{~h} 4$ & c3h3+ & c5h5+ & $\mathrm{h} 2$ & & $1.10 \mathrm{e}-19$ & 0 & 0.0 & 4 \\
\hline $\mathrm{c} 2 \mathrm{~h} 4+$ & c3h2 & c5h5+ & $\mathrm{h}$ & & $5.00 \mathrm{e}-10$ & 0 & 0.0 & 4 \\
\hline $\mathrm{c} 2 \mathrm{~h} 4+$ & $\mathrm{c} 3 \mathrm{~h} 3$ & c5h5+ & $\mathrm{h} 2$ & & $8.00 \mathrm{e}-10$ & 0 & 0.0 & 4 \\
\hline c5h5+ & electr & c5h2 & h2 & $\mathrm{h}$ & $1.00 \mathrm{e}-06$ & -0.3 & 0.0 & 4 \\
\hline c5h5+ & electr & c5h4 & $\mathrm{h}$ & & $3.00 \mathrm{e}-07$ & -0.5 & 0.0 & 4 \\
\hline c5h4 & photon & $\mathrm{c} 4 \mathrm{~h}$ & ch3 & & $2.00 \mathrm{e}-11$ & 0 & 1.7 & 5 \\
\hline c5h4 & phosec & $\mathrm{c} 4 \mathrm{~h}$ & ch3 & & $1.30 \mathrm{e}-17$ & 0 & 750.0 & 2 \\
\hline
\end{tabular}

Continua na próxima página... 
Tabela B.2 - Continuação

\begin{tabular}{|c|c|c|c|c|c|c|c|c|}
\hline \multicolumn{2}{|c|}{ Reagentes } & \multicolumn{3}{|c|}{ Produtos } & $\gamma$ & $\alpha$ & $\beta$ & Tipo de Reação \\
\hline $\mathrm{c}$ & $\mathrm{c} 5 \mathrm{~h} 4$ & $\mathrm{c} 6 \mathrm{~h} 2$ & h2 & & $6.50 \mathrm{e}-10$ & 0 & 0.0 & 4 \\
\hline h3+ & $\mathrm{c} 5 \mathrm{~h} 4$ & c5h5+ & h2 & & $2.50 \mathrm{e}-09$ & 0 & 0.0 & 4 \\
\hline hco+ & $\mathrm{c} 5 \mathrm{~h} 4$ & c5h5+ & $\mathrm{co}$ & & $2.00 \mathrm{e}-09$ & 0 & 0.0 & 4 \\
\hline $\mathrm{c} 2 \mathrm{~h} 2+$ & $\mathrm{c} 3 \mathrm{~h} 3$ & c5h4+ & $\mathrm{h}$ & & $1.00 \mathrm{e}-09$ & 0 & 0.0 & 4 \\
\hline $\mathrm{c} 2 \mathrm{~h} 3$ & $\mathrm{c} 3 \mathrm{~h} 2+$ & c5h4+ & $\mathrm{h}$ & & $6.00 \mathrm{e}-10$ & 0 & 0.0 & 4 \\
\hline $\mathrm{c} 2 \mathrm{~h} 3$ & $\mathrm{c} 3 \mathrm{~h} 3+$ & c5h4+ & h2 & & $1.50 \mathrm{e}-09$ & 0 & 0.0 & 4 \\
\hline $\mathrm{c} 2 \mathrm{~h} 4+$ & $\mathrm{c} 3 \mathrm{~h}$ & c5h4+ & $\mathrm{h}$ & & $6.30 \mathrm{e}-10$ & 0 & 0.0 & 4 \\
\hline $\operatorname{ch} 4$ & $\mathrm{c} 4 \mathrm{~h} 2+$ & c5h4+ & h2 & & $2.00 \mathrm{e}-10$ & 0 & 0.0 & 4 \\
\hline c5h4+ & electr & $\mathrm{c} 5 \mathrm{~h} 2$ & h2 & & $1.00 \mathrm{e}-06$ & -0.3 & 0.0 & 4 \\
\hline c5h4+ & electr & $\mathrm{c} 5 \mathrm{~h}$ & $\mathrm{~h} 2$ & $\mathrm{~h}$ & $1.00 \mathrm{e}-06$ & -0.3 & 0.0 & 4 \\
\hline $\mathrm{c}$ & $\mathrm{c} 4 \mathrm{~h}$ & c5 & $\mathrm{h}$ & & $1.00 \mathrm{e}-10$ & 0 & 0.0 & 4 \\
\hline $\mathrm{c} 5 \mathrm{~h}$ & phosec & c5 & $\mathrm{h}$ & & $1.30 \mathrm{e}-17$ & 0 & 2500.0 & 2 \\
\hline $\mathrm{c} 5 \mathrm{~h}$ & photon & c5 & $\mathrm{h}$ & & $1.00 \mathrm{e}-11$ & 0 & 1.7 & 5 \\
\hline c5 & phosec & c3 & $\mathrm{c} 2$ & & $1.30 \mathrm{e}-17$ & 0 & 500.0 & 2 \\
\hline c5 & phosec & $\mathrm{c} 4$ & $\mathrm{c}$ & & $1.30 \mathrm{e}-17$ & 0 & 500.0 & 2 \\
\hline he+ & c5 & $\mathrm{c} 3+$ & $\mathrm{c} 2$ & he & $1.00 \mathrm{e}-09$ & 0 & 0.0 & 4 \\
\hline $\mathrm{n}$ & c5 & cn & $\mathrm{c} 4$ & & $1.00 \mathrm{e}-10$ & 0 & 0.0 & 4 \\
\hline $\mathrm{c}$ & $\mathrm{c} 5 \mathrm{~h}$ & c6 & $\mathrm{h}$ & & $1.00 \mathrm{e}-10$ & 0 & 0.0 & 4 \\
\hline $\mathrm{c} 6 \mathrm{~h}$ & phosec & c6 & $\mathrm{h}$ & & $1.30 \mathrm{e}-17$ & 0 & 2500.0 & 2 \\
\hline he+ & c6 & $\mathrm{c} 4+$ & $\mathrm{c} 2$ & he & $1.40 \mathrm{e}-09$ & 0 & 0.0 & 4 \\
\hline o & c6 & c5 & $\mathrm{co}$ & & $1.00 \mathrm{e}-10$ & 0 & 0.0 & 4 \\
\hline $\mathrm{c} 6$ & phosec & c5 & $\mathrm{c}$ & & $1.30 \mathrm{e}-17$ & 0 & 500.0 & 2 \\
\hline $\mathrm{n}$ & c6 & $\mathrm{cn}$ & c5 & & $1.00 \mathrm{e}-10$ & 0 & 0.0 & 4 \\
\hline $\mathrm{c}$ & c6 & $\mathrm{c} 2$ & c5 & & $1.00 \mathrm{e}-13$ & 0 & 0.0 & 4 \\
\hline $\mathrm{c}+$ & $\mathrm{c} 5 \mathrm{~h} 4$ & c6h2+ & h2 & & $7.50 \mathrm{e}-10$ & 0 & 0.0 & 4 \\
\hline $\mathrm{c} 2 \mathrm{~h}$ & $\mathrm{c} 4 \mathrm{~h} 2+$ & c6h2+ & $\mathrm{h}$ & & $1.30 \mathrm{e}-09$ & 0 & 0.0 & 4 \\
\hline $\mathrm{c} 2 \mathrm{~h} 2$ & $\mathrm{c} 4 \mathrm{~h}+$ & c6h2+ & $\mathrm{h}$ & & $1.50 \mathrm{e}-09$ & 0 & 0.0 & 4 \\
\hline $\mathrm{c} 2 \mathrm{~h} 2+$ & $\mathrm{c} 4 \mathrm{~h}$ & c6h2+ & $\mathrm{h}$ & & $1.00 \mathrm{e}-09$ & 0 & 0.0 & 4 \\
\hline $\mathrm{c} 2 \mathrm{~h} 2+$ & $\mathrm{c} 4 \mathrm{~h} 2$ & c6h2+ & h2 & & $1.00 \mathrm{e}-17$ & 0 & 0.0 & 4 \\
\hline $\mathrm{c} 2 \mathrm{~h}$ & $\mathrm{c} 4 \mathrm{~h} 2+$ & c6h2+ & $\mathrm{h}$ & & $1.30 \mathrm{e}-09$ & 0 & 0.0 & 4 \\
\hline c6h2+ & electr & c6 & h2 & & $1.00 \mathrm{e}-06$ & -0.3 & 0.0 & 4 \\
\hline $\mathrm{c} 6 \mathrm{~h} 2+$ & electr & $\mathrm{c} 6 \mathrm{~h}$ & $\mathrm{~h}$ & & $1.00 \mathrm{e}-06$ & -0.3 & 0.0 & 4 \\
\hline $\mathrm{h}$ & $\mathrm{c} 4 \mathrm{~h} 3+$ & c4h4+ & photon & & $6.00 \mathrm{e}-14$ & -0.7 & 0.0 & 4 \\
\hline $\mathrm{h} 3+$ & $\mathrm{c} 4 \mathrm{~h} 3$ & $\mathrm{c} 4 \mathrm{~h} 4+$ & h2 & & $1.00 \mathrm{e}-09$ & 0 & 0.0 & 4 \\
\hline h3o+ & $\mathrm{c} 4 \mathrm{~h} 3$ & $\mathrm{c} 4 \mathrm{~h} 4+$ & h2o & & $1.00 \mathrm{e}-09$ & 0 & 0.0 & 4 \\
\hline hco+ & $\mathrm{c} 4 \mathrm{~h} 3$ & c4h4+ & $\mathrm{co}$ & & $9.00 \mathrm{e}-10$ & 0 & 0.0 & 4 \\
\hline $\mathrm{c} 2 \mathrm{~h} 2$ & $\mathrm{c} 4 \mathrm{~h} 4+$ & c6h5+ & $\mathrm{h}$ & & $9.00 \mathrm{e}-11$ & 0 & 0.0 & 4 \\
\hline $\mathrm{c} 2 \mathrm{~h} 2$ & $\mathrm{c} 4 \mathrm{~h} 4+$ & c6h4+ & h2 & & $1.20 \mathrm{e}-11$ & 0 & 0.0 & 4 \\
\hline $\mathrm{c} 4 \mathrm{~h} 4+$ & electr & $\mathrm{c} 4 \mathrm{~h} 3$ & $\mathrm{~h}$ & & $3.30 \mathrm{e}-07$ & -0.5 & 0.0 & 4 \\
\hline $\mathrm{h} 2 \mathrm{c} 4$ & $\mathrm{c} 4 \mathrm{~h} 4+$ & c6h4+ & $\mathrm{c} 2 \mathrm{~h} 2$ & & $7.00 \mathrm{e}-10$ & 0 & 0.0 & 4 \\
\hline $\mathrm{c} 2 \mathrm{~h}$ & $\mathrm{c} 4 \mathrm{~h}+$ & $\mathrm{c} 6 \mathrm{~h}+$ & $\mathrm{h}$ & & $6.00 \mathrm{e}-10$ & 0 & 0.0 & 4 \\
\hline $\mathrm{c} 2 \mathrm{~h} 2$ & $\mathrm{c} 4+$ & $\mathrm{c} 6 \mathrm{~h}+$ & $\mathrm{h}$ & & $1.41 \mathrm{e}-09$ & 0 & 0.0 & 4 \\
\hline $\mathrm{c} 2 \mathrm{~h} 2+$ & $\mathrm{c} 4 \mathrm{~h}$ & $\mathrm{c} 6 \mathrm{~h}+$ & h2 & & $1.00 \mathrm{e}-09$ & 0 & 0.0 & 4 \\
\hline
\end{tabular}

Continua na próxima página... 
Tabela B.2 - Continuação

\begin{tabular}{|c|c|c|c|c|c|c|c|c|}
\hline \multicolumn{2}{|c|}{ Reagentes } & \multicolumn{3}{|c|}{ Produtos } & \multirow{2}{*}{$\frac{\gamma}{2.00 \mathrm{e}-09}$} & \multirow{2}{*}{$\begin{array}{c}\alpha \\
0\end{array}$} & \multirow{2}{*}{$\begin{array}{l}\beta \\
0.0\end{array}$} & \multirow{2}{*}{$\frac{\text { Tipo de Reação }}{4}$} \\
\hline $\mathrm{h}+$ & $\mathrm{c} 6 \mathrm{~h}$ & $\mathrm{c} 6 \mathrm{~h}+$ & $\mathrm{h}$ & & & & & \\
\hline $\mathrm{h}+$ & $\mathrm{c} 6 \mathrm{~h} 2$ & $\mathrm{c} 6 \mathrm{~h}+$ & $\mathrm{h} 2$ & & $2.00 \mathrm{e}-09$ & 0 & 0.0 & 4 \\
\hline he+ & c6h2 & $\mathrm{c} 6 \mathrm{~h}+$ & $\mathrm{h}$ & he & $1.00 \mathrm{e}-09$ & 0 & 0.0 & 4 \\
\hline $\mathrm{h} 2$ & $\mathrm{c} 6 \mathrm{~h}+$ & c6h $2+$ & $\mathrm{h}$ & & $1.30 \mathrm{e}-12$ & 0 & 0.0 & 4 \\
\hline $\mathrm{c} 6 \mathrm{~h}+$ & electr & c6 & $\mathrm{h}$ & & $1.00 \mathrm{e}-06$ & -0.3 & 0.0 & 4 \\
\hline $\mathrm{c} 6 \mathrm{~h}+$ & electr & $\mathrm{c} 5 \mathrm{~h}$ & c & & $1.00 \mathrm{e}-06$ & -0.3 & 0.0 & 4 \\
\hline $\mathrm{c} 6 \mathrm{~h}$ & phosec & c6 & $\mathrm{h}$ & & $1.30 \mathrm{e}-17$ & 0 & 0.0 & 4 \\
\hline c & $\mathrm{c} 6 \mathrm{~h}$ & $\mathrm{c} 7$ & $\mathrm{~h}$ & & $2.00 \mathrm{e}-10$ & 0 & 0.0 & 4 \\
\hline $\mathrm{c} 7$ & phosec & c6 & $\mathrm{c}$ & & $1.30 \mathrm{e}-17$ & 0 & 500.0 & 2 \\
\hline $\mathrm{c} 7$ & photon & c6 & $\mathrm{c}$ & & $1.00 \mathrm{e}-09$ & 0 & 1.7 & 5 \\
\hline $\mathrm{n}$ & $\mathrm{c} 7$ & $\mathrm{cn}$ & c6 & & $1.00 \mathrm{e}-13$ & 0 & 0.0 & 4 \\
\hline o & $\mathrm{c} 7$ & c6 & $\mathrm{co}$ & & $5.00 \mathrm{e}-12$ & 0 & 900.0 & 4 \\
\hline c & c6h2 & $\mathrm{c} 7 \mathrm{~h}$ & $\mathrm{~h}$ & & $7.40 \mathrm{e}-10$ & 0 & 0.0 & 4 \\
\hline he+ & $\mathrm{c} 7 \mathrm{~h}$ & $\mathrm{c} 5 \mathrm{~h}+$ & $\mathrm{c} 2$ & he & $2.00 \mathrm{e}-09$ & 0 & 0.0 & 4 \\
\hline o & $\mathrm{c} 7 \mathrm{~h}$ & $\mathrm{c} 6 \mathrm{~h}$ & $\mathrm{co}$ & & $1.70 \mathrm{e}-11$ & 0 & 0.0 & 4 \\
\hline $\mathrm{c} 7 \mathrm{~h}$ & phosec & $\mathrm{c} 7$ & $\mathrm{~h}$ & & $1.30 \mathrm{e}-17$ & 0 & 2500.0 & 2 \\
\hline $\mathrm{c} 7 \mathrm{~h}$ & photon & $\mathrm{c} 7$ & $\mathrm{~h}$ & & $1.00 \mathrm{e}-09$ & 0 & 1.7 & 5 \\
\hline $\mathrm{c} 2 \mathrm{~h} 2$ & $\mathrm{c} 6 \mathrm{~h}+$ & $\mathrm{c} 8 \mathrm{~h} 2+$ & $\mathrm{h}$ & & $5.80 \mathrm{e}-10$ & 0 & 0.0 & 4 \\
\hline $\mathrm{c} 2 \mathrm{~h} 2+$ & $\mathrm{c} 6 \mathrm{~h}$ & $\mathrm{c} 8 \mathrm{~h} 2+$ & $\mathrm{h}$ & & $1.20 \mathrm{e}-09$ & 0 & 0.0 & 4 \\
\hline $\mathrm{c} 2 \mathrm{~h} 2+$ & c6h2 & $\mathrm{c} 8 \mathrm{~h} 2+$ & $\mathrm{h} 2$ & & $5.00 \mathrm{e}-10$ & 0 & 0.0 & 4 \\
\hline c2h3+ & $\mathrm{c} 6 \mathrm{~h}$ & $\mathrm{c} 8 \mathrm{~h} 2+$ & $\mathrm{h} 2$ & & $5.00 \mathrm{e}-10$ & 0 & 0.0 & 4 \\
\hline $\mathrm{c} 4 \mathrm{~h}$ & c4h2+ & $\mathrm{c} 8 \mathrm{~h} 2+$ & $\mathrm{h}$ & & $1.30 \mathrm{e}-09$ & 0 & 0.0 & 4 \\
\hline $\mathrm{c} 4 \mathrm{~h}+$ & $\mathrm{c} 4 \mathrm{~h} 2$ & c8h2+ & $\mathrm{h}$ & & $1.50 \mathrm{e}-09$ & 0 & 0.0 & 4 \\
\hline c & $\mathrm{c} 8 \mathrm{~h} 2+$ & $\mathrm{c} 9 \mathrm{~h}+$ & $\mathrm{h}$ & & $5.00 \mathrm{e}-10$ & 0 & 0.0 & 4 \\
\hline c & c8h2+ & c9+ & h2 & & $5.00 \mathrm{e}-10$ & 0 & 0.0 & 4 \\
\hline c8h $2+$ & electr & $\mathrm{c} 8 \mathrm{~h}$ & $\mathrm{~h}$ & & $1.00 \mathrm{e}-06$ & -0.3 & 0.0 & 4 \\
\hline c8h $2+$ & electr & $\mathrm{c} 8$ & $\mathrm{~h} 2$ & & $1.00 \mathrm{e}-06$ & -0.3 & 0.0 & 4 \\
\hline $\mathrm{c} 8 \mathrm{~h}$ & phosec & $\mathrm{c} 8$ & $\mathrm{~h}$ & & $1.30 \mathrm{e}-17$ & 0 & 2500.0 & 2 \\
\hline $\mathrm{c} 8 \mathrm{~h}$ & photon & c8 & $\mathrm{h}$ & & $1.00 \mathrm{e}-09$ & 0 & 1.7 & 5 \\
\hline $\mathrm{c} 9+$ & electr & $\mathrm{c} 8$ & c & & $1.00 \mathrm{e}-06$ & -0.3 & 0.0 & 4 \\
\hline o & c9 & $\mathrm{c} 8$ & $\mathrm{co}$ & & $5.00 \mathrm{e}-12$ & 0 & 900.0 & 4 \\
\hline $\mathrm{n}$ & c9 & $\mathrm{cn}$ & $\mathrm{c} 8$ & & $1.00 \mathrm{e}-13$ & 0 & 0.0 & 4 \\
\hline c9 & photon & c8 & $\mathrm{c}$ & & $1.00 \mathrm{e}-09$ & 0 & 1.7 & 5 \\
\hline c & $\mathrm{c} 8$ & $\mathrm{c} 2$ & c7 & & $1.00 \mathrm{e}-13$ & 0 & 0.0 & 4 \\
\hline $\mathrm{c}+$ & $\mathrm{c} 8$ & c9+ & photon & & $1.00 \mathrm{e}-09$ & 0 & 0.0 & 4 \\
\hline $\mathrm{c} 8$ & phosec & $\mathrm{c} 7$ & $\mathrm{c}$ & & $1.30 \mathrm{e}-17$ & 0 & 500.0 & 4 \\
\hline c8 & photon & $\mathrm{c} 7$ & c & & $1.00 \mathrm{e}-09$ & 0 & 1.7 & 2 \\
\hline $\mathrm{n}$ & $\mathrm{c} 8$ & $\mathrm{cn}$ & $\mathrm{c} 7$ & & $1.00 \mathrm{e}-10$ & 0 & 0.0 & 4 \\
\hline o & $\mathrm{c} 8$ & $\mathrm{c} 7$ & $\mathrm{co}$ & & $1.00 \mathrm{e}-10$ & 0 & 0.0 & 4 \\
\hline $\mathrm{c} 2 \mathrm{~h} 2+$ & $\mathrm{c} 7 \mathrm{~h}$ & $\mathrm{c} 9 \mathrm{~h}+$ & $\mathrm{h} 2$ & & $2.00 \mathrm{e}-09$ & 0 & 0.0 & 4 \\
\hline c3h $2+$ & $\mathrm{c} 6 \mathrm{~h}$ & $\mathrm{c} 9 \mathrm{~h}+$ & $\mathrm{h} 2$ & & $5.00 \mathrm{e}-10$ & 0 & 0.0 & 4 \\
\hline $\mathrm{h} 2$ & c9+ & $\mathrm{c} 9 \mathrm{~h}+$ & $\mathrm{h}$ & & $4.10 \mathrm{e}-11$ & 0 & 0.0 & 4 \\
\hline h3+ & c9 & $\mathrm{c} 9 \mathrm{~h}+$ & $\mathrm{h} 2$ & & $2.00 \mathrm{e}-09$ & 0 & 0.0 & 4 \\
\hline
\end{tabular}

Continua na próxima página... 
Tabela B.2 - Continuação

\begin{tabular}{|c|c|c|c|c|c|c|c|c|}
\hline \multicolumn{2}{|c|}{ Reagentes } & \multicolumn{3}{|c|}{ Produtos } & \multirow{2}{*}{$\frac{\gamma}{1.40 \mathrm{e}-09}$} & \multirow{2}{*}{$\begin{array}{c}\alpha \\
0\end{array}$} & \multirow{2}{*}{$\begin{array}{c}\beta \\
0.0\end{array}$} & \multirow{2}{*}{$\begin{array}{c}\text { Tipo de Reação } \\
4\end{array}$} \\
\hline hco+ & c9 & c9h+ & $\mathrm{co}$ & & & & & \\
\hline $\mathrm{c} 9 \mathrm{~h}+$ & electr & c9 & $\mathrm{h}$ & & $1.00 \mathrm{e}-06$ & -0.3 & 0.0 & 4 \\
\hline $\mathrm{c} 9 \mathrm{~h}+$ & electr & $\mathrm{c} 8 \mathrm{~h}$ & c & & $1.00 \mathrm{e}-06$ & -0.3 & 0.0 & 4 \\
\hline $\mathrm{c} 9 \mathrm{~h}+$ & $\mathrm{O}$ & $\mathrm{c} 8$ & hco+ & & $2.00 \mathrm{e}-10$ & 0 & 0.0 & 4 \\
\hline $\mathrm{c}+$ & $\mathrm{c} 8 \mathrm{~h}$ & c9+ & $\mathrm{h}$ & & $1.40 \mathrm{e}-09$ & 0 & 0.0 & 4 \\
\hline c9 & photon & c9+ & electr & & $2.00 \mathrm{e}-10$ & 0 & 2.5 & 4 \\
\hline $\mathrm{h}+$ & c9 & c9+ & $\mathrm{h}$ & & $4.00 \mathrm{e}-09$ & 0 & 0.0 & 4 \\
\hline $\mathrm{h}+$ & c9h & $\mathrm{c} 9+$ & h2 & & $3.50 \mathrm{e}-09$ & 0 & 0.0 & 4 \\
\hline he+ & $\mathrm{c} 9 \mathrm{~h}$ & c9+ & $\mathrm{h}$ & he & $2.50 \mathrm{e}-09$ & 0 & 0.0 & 4 \\
\hline c9+ & electr & $\mathrm{c} 7$ & $\mathrm{c} 2$ & & $1.00 \mathrm{e}-06$ & -0.3 & 0.0 & 4 \\
\hline $\mathrm{c} 8 \mathrm{~h} 2$ & phosec & $\mathrm{c} 8 \mathrm{~h}$ & $\mathrm{~h}$ & & $1.30 \mathrm{e}-17$ & 0 & 875.0 & 2 \\
\hline $\mathrm{c} 8 \mathrm{~h} 2$ & photon & $\mathrm{c} 8 \mathrm{~h}$ & $\mathrm{~h}$ & & $1.00 \mathrm{e}-09$ & 0 & 1.7 & 5 \\
\hline $\mathrm{c}$ & $\mathrm{c} 8 \mathrm{~h}$ & c9 & $\mathrm{h}$ & & $2.00 \mathrm{e}-10$ & 0 & 0.0 & 4 \\
\hline h3+ & $\mathrm{c} 8 \mathrm{~h}$ & c $8 \mathrm{~h} 2+$ & h2 & & $2.50 \mathrm{e}-09$ & 0 & 0.0 & 4 \\
\hline hco+ & $\mathrm{c} 8 \mathrm{~h}$ & c $8 \mathrm{~h} 2+$ & $\mathrm{co}$ & & $2.00 \mathrm{e}-09$ & 0 & 0.0 & 4 \\
\hline he+ & $\mathrm{c} 8 \mathrm{~h}$ & $\mathrm{c} 6 \mathrm{~h}+$ & $\mathrm{c} 2$ & he & $1.50 \mathrm{e}-09$ & 0 & 0.0 & 4 \\
\hline $\mathrm{n}$ & $\mathrm{c} 8 \mathrm{~h}$ & $\mathrm{cn}$ & $\mathrm{c} 7 \mathrm{~h}$ & & $1.00 \mathrm{e}-10$ & 0 & 0.0 & 4 \\
\hline o & $\mathrm{c} 8 \mathrm{~h}$ & $\mathrm{c} 7 \mathrm{~h}$ & co & & $1.70 \mathrm{e}-11$ & 0 & 0.0 & 4 \\
\hline c9 & phosec & $\mathrm{c} 8$ & c & & $1.30 \mathrm{e}-17$ & 0 & 500.0 & 2 \\
\hline $\mathrm{c} 2 \mathrm{~h}$ & c6h2 & c8h2 & $\mathrm{h}$ & & $1.06 \mathrm{e}-10$ & -0.25 & 0.0 & 4 \\
\hline $\mathrm{c}+$ & c8h2 & $\mathrm{c} 9 \mathrm{~h}+$ & $\mathrm{h}$ & & $1.20 \mathrm{e}-09$ & 0 & 0.0 & 4 \\
\hline $\mathrm{c}+$ & c8h2 & c9+ & h2 & & $1.20 \mathrm{e}-09$ & 0 & 0.0 & 4 \\
\hline $\mathrm{h}+$ & c8h2 & c8h2+ & $\mathrm{h}$ & & $2.00 \mathrm{e}-09$ & 0 & 0.0 & 4 \\
\hline he+ & c8h2 & $\mathrm{c} 6 \mathrm{~h}+$ & $\mathrm{c} 2 \mathrm{~h}$ & he & $1.00 \mathrm{e}-09$ & 0 & 0.0 & 4 \\
\hline c & c3h4+ & $\mathrm{c} 4 \mathrm{~h} 2+$ & h2 & & $1.00 \mathrm{e}-09$ & 0 & 0.0 & 4 \\
\hline c & c3h4+ & c4h3+ & $\mathrm{h}$ & & $1.00 \mathrm{e}-09$ & 0 & 0.0 & 4 \\
\hline $\mathrm{c}+$ & c3h4 & c3h4+ & $\mathrm{c}$ & & $5.70 \mathrm{e}-10$ & 0 & 0.0 & 4 \\
\hline $\mathrm{c} 2 \mathrm{~h} 2$ & c3h4+ & c5h5+ & $\mathrm{h}$ & & $4.90 \mathrm{e}-10$ & 0 & 0.0 & 4 \\
\hline $\mathrm{c} 2 \mathrm{~h} 2+$ & c3h4 & c3h4+ & $\mathrm{c} 2 \mathrm{~h} 2$ & & $5.00 \mathrm{e}-10$ & 0 & 0.0 & 4 \\
\hline c2h3+ & c3h3 & c3h4+ & $\mathrm{c} 2 \mathrm{~h} 2$ & & $1.00 \mathrm{e}-09$ & 0 & 0.0 & 4 \\
\hline $\mathrm{c} 2 \mathrm{~h} 4$ & c3h2+ & c3h4+ & $\mathrm{c} 2 \mathrm{~h} 2$ & & $6.60 \mathrm{e}-10$ & 0 & 0.0 & 4 \\
\hline $\operatorname{ch} 3+$ & $\mathrm{c} 2 \mathrm{~h} 3$ & c3h4+ & h2 & & $6.00 \mathrm{e}-10$ & 0 & 0.0 & 4 \\
\hline c3h4 & phosec & c3h4+ & electr & & $1.30 \mathrm{e}-17$ & 0 & 2652.5 & 2 \\
\hline c3h4 & photon & c3h4+ & electr & & $2.20 \mathrm{e}-09$ & 0 & 2.4 & 5 \\
\hline c3h4+ & c3h4 & c6h5+ & h2 & $\mathrm{h}$ & $8.80 \mathrm{e}-11$ & 0 & 0.0 & 4 \\
\hline c3h4+ & c3h4 & c3h5+ & c3h3 & & $1.98 \mathrm{e}-10$ & 0 & 0.0 & 4 \\
\hline c3h4+ & electr & $\mathrm{c} 2 \mathrm{~h} 3$ & $\mathrm{ch}$ & & $4.40 \mathrm{e}-08$ & -0.67 & 0.0 & 4 \\
\hline c3h4+ & electr & c3h2 & $\mathrm{h}$ & $\mathrm{h}$ & $1.48 \mathrm{e}-07$ & -0.67 & 0.0 & 4 \\
\hline c3h4+ & electr & $\operatorname{ch} 3$ & $\mathrm{c} 2 \mathrm{~h}$ & & $2.60 \mathrm{e}-07$ & -0.67 & 0.0 & 4 \\
\hline c3h4+ & electr & c3h3 & $\mathrm{h}$ & & $2.56 \mathrm{e}-06$ & -0.67 & 0.0 & 4 \\
\hline $\operatorname{ch} 4$ & $\mathrm{c} 2 \mathrm{~h}+$ & c3h4+ & $\mathrm{h}$ & & $1.32 \mathrm{e}-10$ & 0 & 0.0 & 4 \\
\hline $\operatorname{ch} 4$ & $\mathrm{c} 2 \mathrm{~h} 2+$ & c3h4+ & $\mathrm{h} 2$ & & $1.76 \mathrm{e}-10$ & 0 & 0.0 & 4 \\
\hline $\mathrm{h}$ & c3h4+ & c3h3+ & h2 & & $2.40 \mathrm{e}-10$ & 0 & 0.0 & 4 \\
\hline
\end{tabular}

Continua na próxima página... 
Tabela B.2 - Continuação

\begin{tabular}{|c|c|c|c|c|c|c|c|c|c|}
\hline \multicolumn{2}{|c|}{ Reagentes } & \multicolumn{4}{|c|}{ Produtos } & \multirow{2}{*}{$\frac{\gamma}{2.00 \mathrm{e}-09}$} & \multirow{2}{*}{$\begin{array}{c}\alpha \\
0\end{array}$} & \multirow{2}{*}{$\begin{array}{l}\beta \\
0.0\end{array}$} & \multirow{2}{*}{$\frac{\text { Tipo de Reação }}{4}$} \\
\hline $\mathrm{h}+$ & c3h4 & c3h4+ & $\mathrm{h}$ & & & & & & \\
\hline h3+ & c3h3 & c3h4+ & h2 & & & $2.00 \mathrm{e}-09$ & 0 & 0.0 & 4 \\
\hline h3o+ & c3h3 & c3h4+ & h2o & & & $2.00 \mathrm{e}-09$ & 0 & 0.0 & 4 \\
\hline hco+ & c3h3 & c3h4+ & $\mathrm{co}$ & & & $1.40 \mathrm{e}-09$ & 0 & 0.0 & 4 \\
\hline o & c3h4+ & hco+ & $\mathrm{c} 2 \mathrm{~h} 3$ & & & $2.00 \mathrm{e}-10$ & 0 & 0.0 & 4 \\
\hline $\mathrm{c} 2 \mathrm{~h} 4$ & c6h5+ & c6h7+ & $\mathrm{c} 2 \mathrm{~h} 2$ & & & $8.50 \mathrm{e}-11$ & 0 & 0.0 & 4 \\
\hline c6h7+ & electr & c6h2 & $\mathrm{h} 2$ & $\mathrm{~h} 2$ & $\mathrm{~h}$ & $5.00 \mathrm{e}-07$ & -0.5 & 0.0 & 4 \\
\hline $\mathrm{c} 3 \mathrm{~h} 4$ & c3h5+ & c6h7+ & $\mathrm{h} 2$ & & & $3.50 \mathrm{e}-10$ & 0 & 0.0 & 4 \\
\hline c3h4+ & c3h4 & c6h7+ & $\mathrm{h}$ & & & $7.48 \mathrm{e}-10$ & 0 & 0.0 & 4 \\
\hline $\mathrm{h} 2$ & c6h5+ & c6h7+ & photon & & & $6.00 \mathrm{e}-11$ & 0 & 0.0 & 4 \\
\hline c6h7+ & electr & c6h6 & $\mathrm{h}$ & & & $5.00 \mathrm{e}-07$ & -0.5 & 0.0 & 4 \\
\hline $\mathrm{c}+$ & c6h6 & c3h3+ & c4h3 & & & $1.44 \mathrm{e}-10$ & 0 & 0.0 & 4 \\
\hline c2h3+ & c6h6 & c6h7+ & $\mathrm{c} 2 \mathrm{~h} 2$ & & & $1.60 \mathrm{e}-09$ & 0 & 0.0 & 4 \\
\hline c3h5+ & c6h6 & c6h7+ & $\mathrm{c} 3 \mathrm{~h} 4$ & & & $1.15 \mathrm{e}-10$ & 0 & 0.0 & 4 \\
\hline $\operatorname{ch} 5+$ & c6h6 & c6h7+ & $\operatorname{ch} 4$ & & & $2.00 \mathrm{e}-09$ & 0 & 0.0 & 4 \\
\hline h3+ & c6h6 & c6h7+ & $\mathrm{h} 2$ & & & $3.90 \mathrm{e}-09$ & 0 & 0.0 & 4 \\
\hline h3o+ & c6h6 & c6h7+ & h2o & & & $1.30 \mathrm{e}-09$ & 0 & 0.0 & 4 \\
\hline hco+ & c6h6 & c6h7+ & $\mathrm{co}$ & & & $1.60 \mathrm{e}-09$ & 0 & 0.0 & 4 \\
\hline he+ & c6h6 & c6h5+ & he & $\mathrm{h}$ & & $7.00 \mathrm{e}-10$ & 0 & 0.0 & 4 \\
\hline he+ & c6h6 & c5h5+ & $\mathrm{ch}$ & he & & $7.00 \mathrm{e}-10$ & 0 & 0.0 & 4 \\
\hline c & electr & $c-$ & photon & & & $2.25 \mathrm{e}-15$ & 0 & 0.0 & 4 \\
\hline$c+$ & $c-$ & c & c & & & $2.30 \mathrm{e}-07$ & 0 & 0.0 & 4 \\
\hline c- & $\mathrm{c}$ & $\mathrm{c} 2$ & electr & & & $5.00 \mathrm{e}-10$ & 0 & 0.0 & 4 \\
\hline $\mathrm{c}-$ & $\mathrm{ch}$ & $\mathrm{c} 2 \mathrm{~h}$ & electr & & & $5.00 \mathrm{e}-10$ & 0 & 0.0 & 4 \\
\hline c- & $\operatorname{ch} 2$ & $\mathrm{c} 2 \mathrm{~h} 2$ & electr & & & $5.00 \mathrm{e}-10$ & 0 & 0.0 & 4 \\
\hline $\mathrm{c}-$ & $\operatorname{co} 2$ & $\mathrm{co}$ & $\mathrm{co}$ & electr & & $4.70 \mathrm{e}-10$ & 0 & 0.0 & 4 \\
\hline$c-$ & $\mathrm{fe}+$ & fe & $\mathrm{c}$ & & & $2.30 \mathrm{e}-07$ & -0.5 & 0.0 & 4 \\
\hline c- & h2o & $\mathrm{h} 2 \mathrm{co}$ & electr & & & $5.00 \mathrm{e}-10$ & 0 & 0.0 & 4 \\
\hline c- & $\mathrm{n}$ & $\mathrm{cn}$ & electr & & & $5.00 \mathrm{e}-10$ & 0 & 0.0 & 4 \\
\hline c- & $\mathrm{n}+$ & $\mathrm{n}$ & c & & & $2.30 \mathrm{e}-07$ & -0.5 & 0.0 & 4 \\
\hline$c-$ & $\mathrm{nh}$ & hen & electr & & & $5.00 \mathrm{e}-10$ & 0 & 0.0 & 4 \\
\hline c- & o & $\mathrm{co}$ & electr & & & $5.00 \mathrm{e}-10$ & 0 & 0.0 & 4 \\
\hline c- & $\mathrm{o}+$ & o & c & & & $2.30 \mathrm{e}-07$ & -0.5 & 0.0 & 4 \\
\hline c- & o2 & $\operatorname{co} 2$ & electr & & & $5.00 \mathrm{e}-11$ & 0 & 0.0 & 4 \\
\hline $\mathrm{c}-$ & oh & hco & electr & & & $5.00 \mathrm{e}-10$ & 0 & 0.0 & 4 \\
\hline c- & phosec & c & electr & & & $2.40 \mathrm{e}-07$ & 0 & 0.9 & 2 \\
\hline $\mathrm{h}$ & $c-$ & $\mathrm{ch}$ & electr & & & $5.00 \mathrm{e}-10$ & 0 & 0.0 & 4 \\
\hline $\mathrm{h}+$ & c- & c & $\mathrm{h}$ & & & $2.30 \mathrm{e}-07$ & -0.5 & 0.0 & 4 \\
\hline $\mathrm{h} 2$ & $\mathrm{c}-$ & $\operatorname{ch} 2$ & electr & & & $1.00 \mathrm{e}-13$ & 0 & 0.0 & 4 \\
\hline he+ & $c-$ & c & he & & & $2.30 \mathrm{e}-13$ & -0.5 & 0.0 & 4 \\
\hline hco & no & hno & $\mathrm{co}$ & & & $1.20 \mathrm{e}-11$ & 0 & 0.0 & 4 \\
\hline nh & o2 & hno & o & & & $6.88 \mathrm{e}-14$ & 2.07 & 3281.0 & 4 \\
\hline $\mathrm{nh}$ & oh & hno & $\mathrm{h}$ & & & $3.32 \mathrm{e}-11$ & 0 & 0.0 & 4 \\
\hline
\end{tabular}

Continua na próxima página... 
Tabela B.2 - Continuação

\begin{tabular}{|c|c|c|c|c|c|c|c|c|}
\hline \multicolumn{2}{|c|}{ Reagentes } & \multicolumn{3}{|c|}{ Produtos } & \multirow{2}{*}{$\frac{\gamma}{4.56 \mathrm{e}-11}$} & \multirow{2}{*}{$\begin{array}{c}\alpha \\
0\end{array}$} & \multirow{2}{*}{$\begin{array}{c}\beta \\
-10.0\end{array}$} & \multirow{2}{*}{$\begin{array}{c}\text { Tipo de Reação } \\
4\end{array}$} \\
\hline $\mathrm{o}$ & nh2 & hno & $\mathrm{h}$ & & & & & \\
\hline $\mathrm{ch}$ & hno & no & $\operatorname{ch} 2$ & & $1.73 \mathrm{e}-11$ & 0 & 0.0 & 4 \\
\hline $\operatorname{ch} 2$ & hno & no & $\operatorname{ch} 3$ & & $1.70 \mathrm{e}-11$ & 0 & 0.0 & 4 \\
\hline $\operatorname{ch} 3$ & hno & no & $\operatorname{ch} 4$ & & $3.32 \mathrm{e}-12$ & 0 & 0.0 & 4 \\
\hline $\mathrm{cn}$ & hno & no & hen & & $3.00 \mathrm{e}-11$ & 0 & 0.0 & 4 \\
\hline $\mathrm{co}$ & hno & $\operatorname{co} 2$ & $\mathrm{nh}$ & & $3.32 \mathrm{e}-12$ & 0 & 6170.0 & 4 \\
\hline $\mathrm{h}$ & hno & oh & $\mathrm{nh}$ & & $2.40 \mathrm{e}-09$ & -0.5 & 9010.0 & 4 \\
\hline $\mathrm{h}$ & hno & no & h2 & & $4.50 \mathrm{e}-11$ & 0.72 & 329.0 & 4 \\
\hline $\mathrm{h}$ & hno & nh2 & o & & $1.05 \mathrm{e}-09$ & 0.3 & 14730.0 & 4 \\
\hline $\mathrm{h}+$ & hno & not & h2 & & $4.00 \mathrm{e}-09$ & 0 & 0.0 & 4 \\
\hline hco & hno & $\mathrm{h} 2 \mathrm{co}$ & no & & $1.00 \mathrm{e}-12$ & 0 & 1000.0 & 4 \\
\hline he+ & hno & no+ & he & $\mathrm{h}$ & $1.00 \mathrm{e}-09$ & 0 & 0.0 & 4 \\
\hline he+ & hno & no & he & $\mathrm{h}+$ & $1.00 \mathrm{e}-09$ & 0 & 0.0 & 4 \\
\hline hno & phosec & no & $\mathrm{h}$ & & $1.30 \mathrm{e}-17$ & 0 & 500.0 & 2 \\
\hline hno & photon & no & $\mathrm{h}$ & & $1.70 \mathrm{e}-10$ & 0 & 0.5 & 5 \\
\hline $\mathrm{n}$ & hno & no & $\mathrm{nh}$ & & $2.94 \mathrm{e}-12$ & 0.5 & 1000.0 & 4 \\
\hline o & hno & o2 & $\mathrm{nh}$ & & $2.94 \mathrm{e}-12$ & 0.5 & 3500.0 & 4 \\
\hline o & hno & no & oh & & $6.00 \mathrm{e}-11$ & 0 & 0.0 & 4 \\
\hline oh & hno & no & h2o & & $4.44 \mathrm{e}-12$ & 1.37 & -169.0 & 4 \\
\hline $\operatorname{ch} 3$ & $\operatorname{ch} 3$ & $\mathrm{c} 2 \mathrm{~h} 5$ & $\mathrm{~h}$ & & $1.46 \mathrm{e}-11$ & 0.1 & 5335.0 & 4 \\
\hline $\mathrm{c}$ & $\mathrm{c} 2 \mathrm{~h} 5$ & c3h4 & $\mathrm{h}$ & & $2.00 \mathrm{e}-10$ & 0 & 0.0 & 4 \\
\hline $\mathrm{c}+$ & c2h5 & c3h3+ & h2 & & $5.00 \mathrm{e}-10$ & 0 & 0.0 & 4 \\
\hline $\mathrm{c} 2 \mathrm{~h} 5$ & phosec & c2h3 & h2 & & $1.30 \mathrm{e}-17$ & 0 & 1881.0 & 2 \\
\hline $\mathrm{c} 2 \mathrm{~h} 5$ & photon & $\mathrm{c} 2 \mathrm{~h} 3$ & $\mathrm{~h} 2$ & & $1.00 \mathrm{e}-09$ & 0 & 1.7 & 5 \\
\hline $\mathrm{h}+$ & $\mathrm{c} 2 \mathrm{~h} 5$ & c2h3+ & h2 & $\mathrm{h}$ & $3.06 \mathrm{e}-09$ & 0 & 0.0 & 4 \\
\hline $\mathrm{h}+$ & c2h5 & $\mathrm{c} 2 \mathrm{~h} 4+$ & h2 & & $1.65 \mathrm{e}-09$ & 0 & 0.0 & 4 \\
\hline he+ & c2h5 & c2h3+ & he & h2 & $5.00 \mathrm{e}-10$ & 0 & 0.0 & 4 \\
\hline he+ & c2h5 & $\mathrm{c} 2 \mathrm{~h} 4+$ & he & $\mathrm{h}$ & $5.00 \mathrm{e}-10$ & 0 & 0.0 & 4 \\
\hline $\mathrm{n}$ & c2h5 & $\mathrm{c} 2 \mathrm{~h} 4$ & $\mathrm{nh}$ & & $7.15 \mathrm{e}-11$ & 0 & 0.0 & 4 \\
\hline o & $\mathrm{c} 2 \mathrm{~h} 5$ & h2co & $\operatorname{ch} 3$ & & $2.67 \mathrm{e}-11$ & 0 & 0.0 & 4 \\
\hline oh & $\mathrm{c} 2 \mathrm{~h} 5$ & $\mathrm{c} 2 \mathrm{~h} 4$ & h2o & & $4.00 \mathrm{e}-11$ & 0 & 0.0 & 4 \\
\hline $\mathrm{n}$ & $\mathrm{c} 2 \mathrm{~h}$ & $\mathrm{c} 2 \mathrm{n}$ & $\mathrm{h}$ & & $1.70 \mathrm{e}-11$ & 0 & 0.0 & 4 \\
\hline $\mathrm{c}$ & $\mathrm{c} 2 \mathrm{n}$ & $\mathrm{c} 2$ & $\mathrm{cn}$ & & $1.00 \mathrm{e}-10$ & 0 & 0.0 & 4 \\
\hline $\mathrm{c} 2 \mathrm{n}$ & phosec & $\mathrm{c} 2$ & $\mathrm{n}$ & & $1.30 \mathrm{e}-17$ & 0 & 500.0 & 2 \\
\hline $\mathrm{c} 2 \mathrm{n}$ & phosec & $\mathrm{cn}$ & $\mathrm{c}$ & & $1.30 \mathrm{e}-17$ & 0 & 500.0 & 2 \\
\hline $\mathrm{c} 2 \mathrm{n}$ & photon & $\mathrm{cn}$ & $\mathrm{c}$ & & $5.00 \mathrm{e}-10$ & 0 & 1.7 & 5 \\
\hline $\mathrm{c} 2 \mathrm{n}$ & photon & $\mathrm{c} 2$ & $\mathrm{n}$ & & $5.00 \mathrm{e}-10$ & 0 & 1.7 & 5 \\
\hline he+ & $\mathrm{c} 2 \mathrm{n}$ & $\mathrm{cn}$ & $\mathrm{c}+$ & he & $8.00 \mathrm{e}-09$ & 0 & 0.0 & 4 \\
\hline $\mathrm{n}$ & $\mathrm{c} 2 \mathrm{n}$ & $\mathrm{cn}$ & $\mathrm{cn}$ & & $1.00 \mathrm{e}-10$ & 0 & 0.0 & 4 \\
\hline o & $\mathrm{c} 2 \mathrm{n}$ & $\mathrm{co}$ & $\mathrm{cn}$ & & $6.00 \mathrm{e}-12$ & 0 & 0.0 & 4 \\
\hline $\mathrm{n}$ & $\mathrm{c} 2 \mathrm{~h} 5$ & $\mathrm{~h} 2 \mathrm{cn}$ & ch3 & & $3.85 \mathrm{e}-11$ & 0 & 0.0 & 4 \\
\hline $\mathrm{n}$ & $\operatorname{ch} 3$ & $\mathrm{~h} 2 \mathrm{cn}$ & $\mathrm{h}$ & & $7.40 \mathrm{e}-11$ & 0.26 & 8.4 & 4 \\
\hline $\mathrm{c}$ & $\mathrm{h} 2 \mathrm{cn}$ & $\mathrm{c} 2 \mathrm{n}$ & h2 & & $2.00 \mathrm{e}-10$ & 0 & 0.0 & 4 \\
\hline
\end{tabular}

Continua na próxima página... 
Tabela B.2 - Continuação

\begin{tabular}{|c|c|c|c|c|c|c|c|c|}
\hline \multicolumn{2}{|c|}{ Reagentes } & \multicolumn{3}{|c|}{ Produtos } & \multirow{2}{*}{$\frac{\gamma}{1.00 \mathrm{e}-10}$} & \multirow{2}{*}{$\begin{array}{c}\alpha \\
0\end{array}$} & \multirow{2}{*}{$\begin{array}{l}\beta \\
0.0\end{array}$} & \multirow{2}{*}{$\begin{array}{c}\text { Tipo de Reação } \\
4\end{array}$} \\
\hline $\mathrm{h}$ & $\mathrm{h} 2 \mathrm{cn}$ & hen & $\mathrm{h} 2$ & & & & & \\
\hline $\mathrm{n}$ & h2cn & hen & $\mathrm{nh}$ & & $1.00 \mathrm{e}-10$ & 0 & 200.0 & 4 \\
\hline o & $\mathrm{h} 2 \mathrm{cn}$ & ocn & h2 & & $1.00 \mathrm{e}-10$ & 0 & 0.0 & 4 \\
\hline $\mathrm{h}$ & electr & h- & photon & & $3.00 \mathrm{e}-16$ & 0.85 & 0.0 & 4 \\
\hline $\mathrm{h}$ & electr & h- & photon & & $3.70 \mathrm{e}-15$ & 0 & 0.0 & 4 \\
\hline $\mathrm{h}$ & electr & h- & photon & & $4.81 \mathrm{e}-16$ & 0.52 & 0.0 & 4 \\
\hline h2 & phosec & $\mathrm{h}+$ & h- & & $3.90 \mathrm{e}-21$ & 0 & 0.0 & 2 \\
\hline $\mathrm{h}+$ & h- & $\mathrm{h}$ & $\mathrm{h}$ & & $2.30 \mathrm{e}-07$ & -0.5 & 0.0 & 4 \\
\hline h- & $\mathrm{c}$ & $\mathrm{ch}$ & electr & & $1.00 \mathrm{e}-09$ & 0 & 0.0 & 4 \\
\hline h- & $\mathrm{c}+$ & c & $\mathrm{h}$ & & $2.30 \mathrm{e}-07$ & -0.5 & 0.0 & 4 \\
\hline h- & $\mathrm{c} 2$ & $\mathrm{c} 2 \mathrm{~h}$ & electr & & $1.00 \mathrm{e}-09$ & 0 & 0.0 & 4 \\
\hline h- & $\mathrm{c} 2 \mathrm{~h}$ & $\mathrm{c} 2 \mathrm{~h} 2$ & electr & & $1.00 \mathrm{e}-09$ & 0 & 0.0 & 4 \\
\hline h- & $\mathrm{ch}$ & $\operatorname{ch} 2$ & electr & & $1.00 \mathrm{e}-10$ & 0 & 0.0 & 4 \\
\hline h- & $\operatorname{ch} 2$ & $\operatorname{ch} 3$ & electr & & $1.00 \mathrm{e}-09$ & 0 & 0.0 & 4 \\
\hline h- & $\operatorname{ch} 3$ & $\operatorname{ch} 4$ & electr & & $1.00 \mathrm{e}-09$ & 0 & 0.0 & 4 \\
\hline h- & $\mathrm{cn}$ & hen & electr & & $1.00 \mathrm{e}-10$ & 0 & 0.0 & 4 \\
\hline h- & $\mathrm{CO}$ & hco & electr & & $5.00 \mathrm{e}-11$ & 0 & 0.0 & 4 \\
\hline h- & $\mathrm{fe}+$ & fe & $\mathrm{h}$ & & $2.30 \mathrm{e}-07$ & -0.5 & 0.0 & 4 \\
\hline h- & $\mathrm{h}$ & h2 & electr & & $1.30 \mathrm{e}-09$ & 0 & 0.0 & 4 \\
\hline h- & h2+ & h2 & $\mathrm{h}$ & & $2.30 \mathrm{e}-07$ & -0.5 & 0.0 & 4 \\
\hline h- & h3+ & h2 & h2 & & $2.30 \mathrm{e}-07$ & -0.5 & 0.0 & 4 \\
\hline h- & h3o+ & oh & h2 & $\mathrm{h}$ & $2.30 \mathrm{e}-07$ & -0.5 & 0.0 & 4 \\
\hline h- & h3o+ & h2o & $\mathrm{h} 2$ & & $2.30 \mathrm{e}-07$ & -0.5 & 0.0 & 4 \\
\hline h- & hco & $\mathrm{h} 2 \mathrm{co}$ & electr & & $1.00 \mathrm{e}-09$ & 0 & 0.0 & 4 \\
\hline h- & hco + & $\mathrm{co}$ & h2 & & $2.30 \mathrm{e}-07$ & -0.5 & 0.0 & 4 \\
\hline h- & he+ & he & $\mathrm{h}$ & & $2.30 \mathrm{e}-07$ & -0.5 & 0.0 & 4 \\
\hline h- & $\mathrm{n}$ & $\mathrm{nh}$ & electr & & $1.00 \mathrm{e}-09$ & 0 & 0.0 & 4 \\
\hline h- & $\mathrm{n}+$ & $\mathrm{n}$ & $\mathrm{h}$ & & $2.30 \mathrm{e}-07$ & -0.5 & 0.0 & 4 \\
\hline h- & $\mathrm{nh}$ & nh2 & electr & & $1.00 \mathrm{e}-10$ & 0 & 0.0 & 4 \\
\hline h- & nh2 & nh3 & electr & & $1.00 \mathrm{e}-09$ & 0 & 0.0 & 4 \\
\hline h- & nh4+ & nh3 & h2 & & $2.30 \mathrm{e}-07$ & -0.5 & 0.0 & 4 \\
\hline h- & o & oh & electr & & $1.00 \mathrm{e}-09$ & 0 & 0.0 & 4 \\
\hline h- & $\mathrm{o}+$ & o & $\mathrm{h}$ & & $2.30 \mathrm{e}-07$ & -0.5 & 0.0 & 4 \\
\hline h- & oh & h2o & electr & & $1.00 \mathrm{e}-10$ & 0 & 0.0 & 4 \\
\hline h- & phosec & $\mathrm{h}$ & electr & & $2.40 \mathrm{e}-07$ & 0 & 0.5 & 2 \\
\hline c- & o2 & $\mathrm{co}$ & O- & & $4.00 \mathrm{e}-10$ & 0 & 0.0 & 4 \\
\hline o & electr & o- & photon & & $1.50 \mathrm{e}-15$ & 0 & 0.0 & 4 \\
\hline $\mathrm{c}$ & O- & $\mathrm{co}$ & electr & & $5.00 \mathrm{e}-10$ & 0 & 0.0 & 4 \\
\hline $\mathrm{ch}$ & O- & hco & electr & & $5.00 \mathrm{e}-10$ & 0 & 0.0 & 4 \\
\hline $\operatorname{ch} 2$ & O- & $\mathrm{h} 2 \mathrm{co}$ & electr & & $5.00 \mathrm{e}-10$ & 0 & 0.0 & 4 \\
\hline $\mathrm{h}$ & O- & oh & electr & & $5.00 \mathrm{e}-10$ & 0 & 0.0 & 4 \\
\hline $\mathrm{h} 2$ & O- & h2o & electr & & $7.00 \mathrm{e}-10$ & 0 & 0.0 & 4 \\
\hline $\mathrm{n}$ & O- & no & electr & & $2.20 \mathrm{e}-10$ & 0 & 0.0 & 4 \\
\hline
\end{tabular}

Continua na próxima página... 
Tabela B.2 - Continuação

\begin{tabular}{|c|c|c|c|c|c|c|c|c|}
\hline \multicolumn{2}{|c|}{ Reagentes } & \multicolumn{3}{|c|}{ Produtos } & \multirow{2}{*}{$\frac{\gamma}{6.50 \mathrm{e}-10}$} & \multirow{2}{*}{$\begin{array}{l}\alpha \\
0\end{array}$} & \multirow{2}{*}{$\begin{array}{c}\beta \\
0.0\end{array}$} & \multirow{2}{*}{$\begin{array}{c}\text { Tipo de Reação } \\
4\end{array}$} \\
\hline O- & $\mathrm{co}$ & $\operatorname{co} 2$ & electr & & & & & \\
\hline O- & no & no2 & electr & & $3.10 \mathrm{e}-10$ & -0.83 & 0.0 & 4 \\
\hline O- & o & o2 & electr & & $1.90 \mathrm{e}-10$ & 0 & 0.0 & 4 \\
\hline O- & phosec & $\mathrm{O}$ & electr & & $2.40 \mathrm{e}-07$ & 0 & 0.5 & 2 \\
\hline h- & h2o & oh- & h2 & & $3.80 \mathrm{e}-09$ & 0 & 0.0 & 4 \\
\hline h2 & O- & oh- & $\mathrm{h}$ & & $3.00 \mathrm{e}-11$ & 0 & 0.0 & 4 \\
\hline O- & $\operatorname{ch} 4$ & oh- & $\operatorname{ch} 3$ & & $1.00 \mathrm{e}-10$ & 0 & 0.0 & 4 \\
\hline $\mathrm{c}$ & oh- & hco & electr & & $5.00 \mathrm{e}-10$ & 0 & 0.0 & 4 \\
\hline $\mathrm{ch}$ & oh- & $\mathrm{h} 2 \mathrm{co}$ & electr & & $5.00 \mathrm{e}-10$ & 0 & 0.0 & 4 \\
\hline $\mathrm{h}$ & oh- & h2o & electr & & $1.40 \mathrm{e}-09$ & 0 & 0.0 & 4 \\
\hline oh- & phosec & oh & electr & & $2.40 \mathrm{e}-07$ & 0 & 0.9 & 2 \\
\hline c- & no & cn- & o & & $1.00 \mathrm{e}-09$ & 0 & 0.0 & 4 \\
\hline cn- & phosec & $\mathrm{cn}$ & electr & & $2.40 \mathrm{e}-07$ & 0 & 0.9 & 2 \\
\hline $\mathrm{h}$ & $\mathrm{cn}-$ & hen & electr & & $1.30 \mathrm{e}-09$ & 0 & 0.0 & 4 \\
\hline h- & hen & cn- & h2 & & $3.80 \mathrm{e}-09$ & 0 & 0.0 & 4 \\
\hline O- & $\mathrm{cn}$ & cn- & o & & $1.00 \mathrm{e}-09$ & 0 & 0.0 & 4 \\
\hline O- & hcn & cn- & oh & & $1.20 \mathrm{e}-09$ & 0 & 0.0 & 4 \\
\hline oh- & $\mathrm{cn}$ & cn- & oh & & $1.00 \mathrm{e}-09$ & 0 & 0.0 & 4 \\
\hline oh- & hen & cn- & h2o & & $1.20 \mathrm{e}-09$ & 0 & 0.0 & 4 \\
\hline $\mathrm{c} 4 \mathrm{~h}$ & electr & $\mathrm{c} 4 \mathrm{~h}-$ & photon & & $2.00 \mathrm{e}-09$ & -0.5 & 0.0 & 4 \\
\hline $\mathrm{c} 4 \mathrm{~h}-$ & photon & c4h & electr & & $1.80 \mathrm{e}-09$ & 0 & 2.0 & 5 \\
\hline $\mathrm{c} 6 \mathrm{~h}$ & electr & c6h- & photon & & $6.00 \mathrm{e}-08$ & -0.5 & 0.0 & 4 \\
\hline c6h- & photon & $\mathrm{c} 6 \mathrm{~h}$ & electr & & $1.50 \mathrm{e}-09$ & 0 & 2.0 & 5 \\
\hline c5 & electr & c5- & photon & & $3.30 \mathrm{e}-08$ & -0.5 & 0.0 & 4 \\
\hline c5- & photon & c5 & electr & & $3.00 \mathrm{e}-09$ & 0 & 1.5 & 5 \\
\hline c6 & electr & c6- & photon & & $1.70 \mathrm{e}-07$ & -0.5 & 0.0 & 4 \\
\hline $\mathrm{c} 7$ & electr & c7- & photon & & $5.00 \mathrm{e}-07$ & -0.5 & 0.0 & 4 \\
\hline c6- & photon & c6 & electr & & $1.30 \mathrm{e}-09$ & 0 & 2.0 & 5 \\
\hline c7- & photon & $\mathrm{c} 7$ & electr & & $2.40 \mathrm{e}-09$ & 0 & 1.5 & 5 \\
\hline $\mathrm{n}$ & $\mathrm{c} 3 \mathrm{~h}$ & c3n & $\mathrm{h}$ & & $1.70 \mathrm{e}-11$ & 0 & 0.0 & 4 \\
\hline c & c3n & c3 & $\mathrm{cn}$ & & $1.00 \mathrm{e}-13$ & 0 & 0.0 & 4 \\
\hline c3n & phosec & $\mathrm{cn}$ & $\mathrm{c} 2$ & & $1.30 \mathrm{e}-17$ & 0 & 875.0 & 2 \\
\hline c3n & photon & $\mathrm{cn}$ & $\mathrm{c} 2$ & & $5.00 \mathrm{e}-10$ & 0 & 1.8 & 5 \\
\hline he+ & c3n & $\mathrm{cn}$ & $\mathrm{c} 2+$ & he & $8.00 \mathrm{e}-09$ & 0 & 0.0 & 4 \\
\hline hen & c3+ & $\mathrm{c} 4 \mathrm{n}+$ & $\mathrm{h}$ & & $1.04 \mathrm{e}-09$ & 0 & 0.0 & 4 \\
\hline $\mathrm{c}+$ & hc3n & $\mathrm{c} 4 \mathrm{n}+$ & $\mathrm{h}$ & & $1.40 \mathrm{e}-09$ & 0 & 0.0 & 4 \\
\hline $\mathrm{c} 4 \mathrm{n}+$ & electr & c3n & $\mathrm{c}$ & & $1.50 \mathrm{e}-07$ & -0.5 & 0.0 & 4 \\
\hline $\mathrm{c} 4 \mathrm{n}+$ & electr & $\mathrm{c} 2 \mathrm{n}$ & $\mathrm{c} 2$ & & $1.50 \mathrm{e}-07$ & -0.5 & 0.0 & 4 \\
\hline $\operatorname{ch} 4$ & $\mathrm{c} 4 \mathrm{n}+$ & c $2 \mathrm{~h} 3+$ & $\operatorname{ch} 3 n$ & & $1.43 \mathrm{e}-10$ & 0 & 0.0 & 4 \\
\hline $\operatorname{ch} 4$ & $\mathrm{c} 4 \mathrm{n}+$ & $\mathrm{c} 4 \mathrm{~h} 3+$ & hen & & $1.71 \mathrm{e}-10$ & 0 & 0.0 & 4 \\
\hline h2 & $\mathrm{c} 4 \mathrm{n}+$ & $\mathrm{c} 3 \mathrm{~h}+$ & hen & & $2.20 \mathrm{e}-11$ & 0 & 0.0 & 4 \\
\hline h2o & $\mathrm{c} 4 \mathrm{n}+$ & hc3n & hco + & & $7.50 \mathrm{e}-10$ & 0 & 0.0 & 4 \\
\hline ch3 & $\mathrm{cn}$ & h3c2n & photon & & $1.00 \mathrm{e}-16$ & 0 & 0.0 & 4 \\
\hline
\end{tabular}

Continua na próxima página... 
Tabela B.2 - Continuação

\begin{tabular}{|c|c|c|c|c|c|c|c|c|}
\hline \multicolumn{2}{|c|}{ Reagentes } & \multicolumn{3}{|c|}{ Produtos } & \multirow{2}{*}{$\frac{\gamma}{1.00 \mathrm{e}-09}$} & \multirow{2}{*}{$\frac{\alpha}{0}$} & \multirow{2}{*}{$\begin{array}{l}\beta \\
0.0\end{array}$} & \multirow{2}{*}{$\frac{\text { Tipo de Reação }}{4}$} \\
\hline $\operatorname{ch} 3$ & cn- & $\mathrm{h} 3 \mathrm{c} 2 \mathrm{n}$ & electr & & & & & \\
\hline $\mathrm{c}+$ & $\mathrm{h} 3 \mathrm{c} 2 \mathrm{n}$ & $\mathrm{c} 2 \mathrm{~h} 3+$ & $\mathrm{cn}$ & & $1.06 \mathrm{e}-09$ & 0 & 0.0 & 4 \\
\hline $\mathrm{c} 2 \mathrm{~h} 2+$ & $\mathrm{h} 3 \mathrm{c} 2 \mathrm{n}$ & c3h5+ & $\mathrm{cn}$ & & $1.06 \mathrm{e}-09$ & 0 & 0.0 & 4 \\
\hline $\mathrm{h} 3 \mathrm{c} 2 \mathrm{n}$ & phosec & $\mathrm{cn}$ & $\operatorname{ch} 3$ & & $1.30 \mathrm{e}-17$ & 0 & 2388.0 & 2 \\
\hline h3c $2 n$ & photon & $\mathrm{cn}$ & $\operatorname{ch} 3$ & & $3.40 \mathrm{e}-09$ & 0 & 2.0 & 5 \\
\hline $\mathrm{h}+$ & $\mathrm{h} 3 \mathrm{c} 2 \mathrm{n}$ & $\operatorname{ch} 3+$ & hen & & $3.00 \mathrm{e}-09$ & 0 & 0.0 & 4 \\
\hline he+ & h3c $2 n$ & $\mathrm{cn}$ & $\operatorname{ch} 3+$ & he & $1.20 \mathrm{e}-09$ & 0 & 0.0 & 4 \\
\hline he+ & $\mathrm{h} 3 \mathrm{c} 2 \mathrm{n}$ & $\mathrm{cn}+$ & $\operatorname{ch} 3$ & he & $1.20 \mathrm{e}-09$ & 0 & 0.0 & 4 \\
\hline $\mathrm{o}+$ & $\mathrm{h} 3 \mathrm{c} 2 \mathrm{n}$ & no & $\mathrm{c} 2 \mathrm{~h} 3+$ & & $1.26 \mathrm{e}-09$ & 0 & 0.0 & 4 \\
\hline $\mathrm{n}$ & $\mathrm{c} 4 \mathrm{~h}$ & $\mathrm{c} 4 \mathrm{n}$ & $\mathrm{h}$ & & $1.70 \mathrm{e}-11$ & 0 & 0.0 & 4 \\
\hline $\mathrm{c} 4 \mathrm{n}$ & phosec & c3 & $\mathrm{cn}$ & & $1.30 \mathrm{e}-17$ & 0 & 750.0 & 2 \\
\hline $\mathrm{c} 4 \mathrm{n}$ & photon & c3 & $\mathrm{cn}$ & & $5.00 \mathrm{e}-10$ & 0 & 1.7 & 5 \\
\hline $\mathrm{c} 4 \mathrm{n}$ & photon & $\mathrm{c} 4$ & $\mathrm{n}$ & & $1.00 \mathrm{e}-09$ & 0 & 1.7 & 5 \\
\hline $\mathrm{n}$ & $\mathrm{c} 4 \mathrm{n}$ & $\mathrm{cn}$ & $c 3 n$ & & $1.00 \mathrm{e}-10$ & 0 & 0.0 & 4 \\
\hline o & $\mathrm{c} 4 \mathrm{n}$ & c3n & $\mathrm{co}$ & & $6.00 \mathrm{e}-12$ & 0 & 0.0 & 4 \\
\hline o & $\mathrm{c} 2 \mathrm{~h} 5$ & $\mathrm{c} 2 \mathrm{~h} 4 \mathrm{o}$ & $\mathrm{h}$ & & $1.33 \mathrm{e}-10$ & 0 & 0.0 & 4 \\
\hline oh & $\mathrm{c} 2 \mathrm{~h} 3$ & c2h4o & photon & & $5.00 \mathrm{e}-21$ & 0 & 10.0 & 4 \\
\hline $\operatorname{ch} 3+$ & $\mathrm{c} 2 \mathrm{~h} 4 \mathrm{o}$ & h3cot & $\mathrm{c} 2 \mathrm{~h} 4$ & & $1.98 \mathrm{e}-09$ & 0 & 0.0 & 4 \\
\hline c2h4o & phosec & hco & $\operatorname{ch} 3$ & & $1.30 \mathrm{e}-17$ & 0 & 263.5 & 2 \\
\hline $\mathrm{c} 2 \mathrm{~h} 4 \mathrm{o}$ & phosec & $\mathrm{co}$ & $\operatorname{ch} 4$ & & $1.30 \mathrm{e}-17$ & 0 & 263.5 & 2 \\
\hline c2h4o & photon & hco & $\operatorname{ch} 3$ & & $1.10 \mathrm{e}-09$ & 0 & 1.5 & 5 \\
\hline c2h4o & photon & $\mathrm{co}$ & $\operatorname{ch} 4$ & & $1.10 \mathrm{e}-09$ & 0 & 1.5 & 5 \\
\hline $\mathrm{c} 2 \mathrm{~h} 4 \mathrm{o}$ & h3+ & $\mathrm{c} 2 \mathrm{~h} 3+$ & $\mathrm{h} 2$ & h2o & $8.97 \mathrm{e}-10$ & 0 & 0.0 & 4 \\
\hline $\mathrm{c} 2 \mathrm{~h} 4 \mathrm{o}$ & h3+ & h3o+ & $\mathrm{c} 2 \mathrm{~h} 4$ & & $1.04 \mathrm{e}-09$ & 0 & 0.0 & 4 \\
\hline h3+ & $\mathrm{c} 2 \mathrm{~h} 4 \mathrm{o}$ & $\operatorname{ch} 5+$ & h2co & & $8.28 \mathrm{e}-10$ & 0 & 0.0 & 4 \\
\hline he+ & c $2 \mathrm{~h} 4 \mathrm{o}$ & hco & $\operatorname{ch} 3+$ & he & $3.00 \mathrm{e}-09$ & 0 & 0.0 & 4 \\
\hline $\operatorname{ch} 3$ & oh- & $\operatorname{ch} 40$ & electr & & $1.00 \mathrm{e}-09$ & 0 & 0.0 & 4 \\
\hline $\mathrm{c} 2 \mathrm{~h} 4 \mathrm{o}$ & h3+ & ch4o & $\operatorname{ch} 3+$ & & $1.45 \mathrm{e}-09$ & 0 & 0.0 & 4 \\
\hline $\mathrm{c}+$ & $\operatorname{ch} 40$ & hco & $\operatorname{ch} 3+$ & & $2.08 \mathrm{e}-09$ & 0 & 0.0 & 4 \\
\hline $\mathrm{c}+$ & $\operatorname{ch} 40$ & h3co+ & $\mathrm{ch}$ & & $5.20 \mathrm{e}-10$ & 0 & 0.0 & 4 \\
\hline $\mathrm{ch}$ & ch4o & ch3 & $\mathrm{h} 2 \mathrm{co}$ & & $2.49 \mathrm{e}-10$ & -1.93 & 0.0 & 4 \\
\hline $\mathrm{ch}+$ & $\operatorname{ch} 40$ & h3cot & $\operatorname{ch} 2$ & & $2.90 \mathrm{e}-10$ & 0 & 0.0 & 4 \\
\hline $\operatorname{ch}+$ & $\operatorname{ch} 40$ & $\mathrm{~h} 2 \mathrm{co}$ & $\operatorname{ch} 3+$ & & $1.45 \mathrm{e}-09$ & 0 & 0.0 & 4 \\
\hline $\operatorname{ch} 3+$ & $\operatorname{ch} 40$ & h3cot & $\operatorname{ch} 4$ & & $2.30 \mathrm{e}-09$ & 0 & 0.0 & 4 \\
\hline $\operatorname{ch} 40$ & $\mathrm{c} 3 \mathrm{~h}+$ & h3cot & $\mathrm{c} 3 \mathrm{~h} 2$ & & $2.20 \mathrm{e}-10$ & 0 & 0.0 & 4 \\
\hline $\operatorname{ch} 40$ & phosec & oh & $\operatorname{ch} 3$ & & $1.30 \mathrm{e}-17$ & 0 & 752.0 & 2 \\
\hline $\operatorname{ch} 40$ & phosec & h2co & h2 & & $1.30 \mathrm{e}-17$ & 0 & 1584.0 & 2 \\
\hline $\operatorname{ch} 4 o$ & photon & $\mathrm{h} 2 \mathrm{co}$ & $\mathrm{h} 2$ & & $6.00 \mathrm{e}-10$ & 0 & 1.8 & 5 \\
\hline $\operatorname{ch} 40$ & photon & oh & $\operatorname{ch} 3$ & & $6.00 \mathrm{e}-10$ & 0 & 1.8 & 5 \\
\hline $\operatorname{ch} 40$ & photon & h3co+ & $\mathrm{h}$ & electr & $1.30 \mathrm{e}-10$ & 0 & 2.6 & 5 \\
\hline $\mathrm{h}+$ & $\operatorname{ch} 40$ & $\mathrm{~h} 3 \mathrm{co}+$ & $\mathrm{h} 2$ & & $3.84 \mathrm{e}-09$ & 0 & 0.0 & 4 \\
\hline $\mathrm{h}+$ & $\operatorname{ch} 40$ & hco+ & $\mathrm{h} 2$ & $\mathrm{~h} 2$ & $8.85 \mathrm{e}-10$ & 0 & 0.0 & 4 \\
\hline $\mathrm{h}+$ & ch4o & $\operatorname{ch} 3+$ & h2o & & $5.90 \mathrm{e}-10$ & 0 & 0.0 & 4 \\
\hline
\end{tabular}

Continua na próxima página... 
Tabela B.2 - Continuação

\begin{tabular}{|c|c|c|c|c|c|c|c|c|}
\hline \multicolumn{2}{|c|}{ Reagentes } & \multicolumn{3}{|c|}{ Produtos } & \multirow{2}{*}{$\frac{\gamma}{3.71 \mathrm{e}-09}$} & \multirow{2}{*}{$\alpha$} & \multirow{2}{*}{$\begin{array}{l}\beta \\
0.0\end{array}$} & \multirow{2}{*}{$\begin{array}{c}\text { Tipo de Reação } \\
4\end{array}$} \\
\hline h3+ & $\operatorname{ch} 40$ & $\operatorname{ch} 3+$ & $\mathrm{h} 2 \mathrm{o}$ & h2 & & & & \\
\hline he+ & $\operatorname{ch} 40$ & $\mathrm{oh}+$ & $\operatorname{ch} 3$ & he & $1.10 \mathrm{e}-09$ & 0 & 0.0 & 4 \\
\hline he+ & $\operatorname{ch} 40$ & oh & $\operatorname{ch} 3+$ & he & $1.10 \mathrm{e}-09$ & 0 & 0.0 & 4 \\
\hline $\mathrm{n}+$ & $\operatorname{ch} 40$ & no & $\operatorname{ch} 3+$ & $\mathrm{h}$ & $1.24 \mathrm{e}-10$ & 0 & 0.0 & 4 \\
\hline $\mathrm{n}+$ & $\operatorname{ch} 40$ & h3co+ & $\mathrm{nh}$ & & $4.96 \mathrm{e}-10$ & 0 & 0.0 & 4 \\
\hline $\mathrm{n}+$ & $\operatorname{ch} 40$ & not & $\operatorname{ch} 3$ & $\mathrm{~h}$ & $3.10 \mathrm{e}-10$ & 0 & 0.0 & 4 \\
\hline $\mathrm{n}+$ & $\operatorname{ch} 40$ & $\mathrm{~h} 2 \mathrm{co}+$ & $\mathrm{nh}$ & $\mathrm{h}$ & $9.30 \mathrm{e}-10$ & 0 & 0.0 & 4 \\
\hline $\mathrm{o}+$ & $\operatorname{ch} 40$ & h3co+ & oh & & $1.33 \mathrm{e}-09$ & 0 & 0.0 & 4 \\
\hline $\mathrm{o}+$ & $\operatorname{ch} 40$ & h2co+ & h2o & & $9.50 \mathrm{e}-11$ & 0 & 0.0 & 4 \\
\hline $\mathrm{o} 2+$ & $\operatorname{ch} 40$ & h3co+ & $\mathrm{h}$ & $\mathrm{o} 2$ & $5.00 \mathrm{e}-10$ & 0 & 0.0 & 4 \\
\hline $\operatorname{ch} 3+$ & $\mathrm{h} 2 \mathrm{o}$ & $\operatorname{ch} 50+$ & photon & & $2.00 \mathrm{e}-12$ & 0 & 0.0 & 4 \\
\hline $\mathrm{ch}+$ & $\operatorname{ch} 40$ & $\operatorname{ch} 50+$ & c & & $1.16 \mathrm{e}-09$ & 0 & 0.0 & 4 \\
\hline $\operatorname{ch} 40$ & c4h3+ & $\operatorname{ch} 50+$ & $\mathrm{c} 4 \mathrm{~h} 2$ & & $3.00 \mathrm{e}-10$ & 0 & 0.0 & 4 \\
\hline $\operatorname{ch} 4+$ & $\operatorname{ch} 40$ & ch5o+ & $\operatorname{ch} 3$ & & $1.20 \mathrm{e}-09$ & 0 & 0.0 & 4 \\
\hline h2co+ & $\operatorname{ch} 40$ & $\operatorname{ch} 50+$ & hco & & $2.16 \mathrm{e}-09$ & 0 & 0.0 & 4 \\
\hline h3+ & $\operatorname{ch} 40$ & $\operatorname{ch} 50+$ & h2 & & $8.40 \mathrm{e}-10$ & 0 & 0.0 & 4 \\
\hline h3co+ & $\operatorname{ch} 40$ & $\operatorname{ch} 50+$ & $\mathrm{h} 2 \mathrm{co}$ & & $1.90 \mathrm{e}-09$ & 0 & 0.0 & 4 \\
\hline h3o+ & $\operatorname{ch} 40$ & $\operatorname{ch} 50+$ & $\mathrm{h} 2 \mathrm{o}$ & & $2.50 \mathrm{e}-09$ & 0 & 0.0 & 4 \\
\hline hco+ & $\operatorname{ch} 40$ & ch5o+ & $\mathrm{co}$ & & $2.70 \mathrm{e}-09$ & 0 & 0.0 & 4 \\
\hline $\operatorname{ch} 50+$ & electr & $\operatorname{ch} 2$ & h2o & $\mathrm{h}$ & $1.87 \mathrm{e}-07$ & -0.59 & 0.0 & 4 \\
\hline $\operatorname{ch} 5 o+$ & electr & $\operatorname{ch} 40$ & $\mathrm{~h}$ & & $2.67 \mathrm{e}-08$ & -0.59 & 0.0 & 4 \\
\hline $\operatorname{ch} 5 o+$ & electr & $\operatorname{ch} 3$ & oh & $\mathrm{h}$ & $4.45 \mathrm{e}-07$ & -0.59 & 0.0 & 4 \\
\hline $\operatorname{ch} 50+$ & electr & $\mathrm{h} 2 \mathrm{co}$ & $\mathrm{h} 2$ & $\mathrm{~h}$ & $8.90 \mathrm{e}-08$ & -0.59 & 0.0 & 4 \\
\hline $\operatorname{ch} 50+$ & electr & $\operatorname{ch} 3$ & h2o & & $8.01 \mathrm{e}-08$ & -0.59 & 0.0 & 4 \\
\hline $\mathrm{h} 2 \mathrm{co}$ & $\operatorname{ch} 50+$ & $\mathrm{c} 2 \mathrm{~h} 5 \mathrm{o} 2+$ & h2 & & $2.10 \mathrm{e}-11$ & 0 & 0.0 & 4 \\
\hline c2h5o & $2+$ electr & $\operatorname{ch} 40$ & hco & & $1.50 \mathrm{e}-07$ & 0 & 0.0 & 4 \\
\hline $\mathrm{c}$ & $\mathrm{c} 7 \mathrm{n}$ & $\mathrm{c} 7$ & $\mathrm{cn}$ & & $1.00 \mathrm{e}-13$ & 0 & 0.0 & 4 \\
\hline $\mathrm{c} 2 \mathrm{~h} 4 \mathrm{o} 2$ & $\mathrm{c} 2 \mathrm{~h} 2$ & c4h6o2 & photon & & $5.00 \mathrm{e}-07$ & -0.50 & 0.0 & \\
\hline c4h6o 2 & phosec & $\mathrm{c} 4 \mathrm{~h} 2$ & $\mathrm{~h} 2 \mathrm{o}$ & $\mathrm{h} 2 \mathrm{o}$ & $3.30 \mathrm{e}-18$ & 0.00 & 1000.0 & \\
\hline c4h6o 2 & photon & $\mathrm{c} 4 \mathrm{~h} 2$ & h2o & $\mathrm{h} 2 \mathrm{o}$ & $3.30 \mathrm{e}-12$ & 0.00 & 1.7 & \\
\hline c4h6o2 & phosec & $\mathrm{c} 2 \mathrm{~h} 4$ & hco & hco & $3.30 \mathrm{e}-18$ & 0.00 & 1000.0 & \\
\hline c4h6o2 & phosec & c3h3 & $\operatorname{ch} 3$ & o2 & $3.30 \mathrm{e}-18$ & 0.00 & 1000.0 & \\
\hline c4h6o 2 & photon & $\mathrm{c} 2 \mathrm{~h} 4$ & hco & hco & $3.30 \mathrm{e}-12$ & 0.00 & 1.8 & \\
\hline c4h6o 2 & photon & c3h3 & $\operatorname{ch} 3$ & o2 & $3.30 \mathrm{e}-12$ & 0.00 & 1.8 & \\
\hline c4h6o 2 & nh3 & c4h5n & h2o & $\mathrm{h} 2 \mathrm{o}$ & $5.00 \mathrm{e}-07$ & -0.50 & 0.0 & \\
\hline c4h5n & phosec & $\mathrm{c} 2 \mathrm{~h} 5$ & $\mathrm{c} 2 \mathrm{n}$ & & $2.00 \mathrm{e}-18$ & 0.00 & 1000.0 & \\
\hline c4h5n & phosec & $\mathrm{h} 2 \mathrm{cn}$ & c3h3 & & $2.00 \mathrm{e}-18$ & 0.00 & 1000.0 & \\
\hline c4h5n & phosec & hc3n & $\operatorname{ch} 4$ & & $2.00 \mathrm{e}-18$ & 0.00 & 1000.0 & \\
\hline c4h5n & phosec & h3c $2 n$ & $\mathrm{c} 2 \mathrm{~h} 2$ & & $2.00 \mathrm{e}-18$ & 0.00 & 1000.0 & \\
\hline c4h5n & phosec & c3h4 & hen & & $2.00 \mathrm{e}-18$ & 0.00 & 1000.0 & \\
\hline c4h5n & photon & c2h5 & $\mathrm{c} 2 \mathrm{n}$ & & $2.00 \mathrm{e}-12$ & 0.00 & 1.8 & \\
\hline $\mathrm{c} 4 \mathrm{~h} 5 \mathrm{n}$ & photon & $\mathrm{h} 2 \mathrm{cn}$ & c3h3 & & $2.00 \mathrm{e}-12$ & 0.00 & 1.8 & \\
\hline c4h5n & photon & hc3n & $\operatorname{ch} 4$ & & $2.00 \mathrm{e}-12$ & 0.00 & 1.8 & \\
\hline
\end{tabular}

Continua na próxima página... 
Tabela B.2 - Continuação

\begin{tabular}{|c|c|c|c|c|c|c|c|c|}
\hline \multicolumn{2}{|c|}{ Reagentes } & \multicolumn{3}{|c|}{ Produtos } & \multirow{2}{*}{$\frac{\gamma}{2.00 \mathrm{e}-12}$} & \multirow{2}{*}{$\begin{array}{c}\alpha \\
0.00\end{array}$} & \multirow{2}{*}{$\frac{\beta}{1.8}$} & \multirow{2}{*}{ Tipo de Reação } \\
\hline c4h5n & photon & $\mathrm{h} 3 \mathrm{c} 2 \mathrm{n}$ & $\mathrm{c} 2 \mathrm{~h} 2$ & & & & & \\
\hline c4h5n & photon & c3h4 & hen & & $2.00 \mathrm{e}-12$ & 0.00 & 1.8 & \\
\hline $\mathrm{c} 2 \mathrm{~h} 4 \mathrm{o} 2$ & $\mathrm{c} 3 \mathrm{~h} 2$ & c4h6o2 & $\mathrm{c}$ & & $1.00 \mathrm{e}-08$ & 0.00 & 0.0 & \\
\hline $\mathrm{c} 2 \mathrm{~h} 4 \mathrm{o} 2$ & $\mathrm{c} 2 \mathrm{~h} 3$ & c4h6o2 & $\mathrm{h}$ & & $1.00 \mathrm{e}-08$ & 0.00 & 0.0 & \\
\hline c4h6o 2 & $\mathrm{~h}$ & c4h3 & h2o & h2o & $1.00 \mathrm{e}-10$ & 0.00 & 0.0 & \\
\hline c4h5n & $\mathrm{h}$ & h3c2n & $\mathrm{c} 2 \mathrm{~h} 3$ & & $1.00 \mathrm{e}-10$ & 0.00 & 0.0 & \\
\hline c3h3 & $\mathrm{h} 3 \mathrm{c} 2 \mathrm{n}$ & c4h5n & $\mathrm{ch}$ & & $1.00 \mathrm{e}-08$ & 0.00 & 0.0 & \\
\hline c3h2 & $\mathrm{h} 3 \mathrm{c} 2 \mathrm{n}$ & c4h5n & $\mathrm{c}$ & & $1.00 \mathrm{e}-08$ & 0.00 & 0.0 & \\
\hline $\mathrm{c} 7 \mathrm{n}$ & photon & c6 & $\mathrm{cn}$ & & $5.00 \mathrm{e}-10$ & 0 & 1.7 & 5 \\
\hline $\mathrm{n}$ & $\mathrm{c} 7 \mathrm{~h}$ & $\mathrm{c} 7 \mathrm{n}$ & $\mathrm{h}$ & & $1.70 \mathrm{e}-11$ & 0 & 0.0 & 4 \\
\hline $\mathrm{n}$ & $\mathrm{c} 7 \mathrm{n}$ & $\mathrm{c} 2 \mathrm{n}$ & c5n & & $1.00 \mathrm{e}-10$ & 0 & 0.0 & 4 \\
\hline o & $\mathrm{c} 7 \mathrm{n}$ & c6 & ocn & & $4.00 \mathrm{e}-11$ & 0 & 0.0 & 4 \\
\hline$c 5 n+$ & electr & c3n & $\mathrm{c} 2$ & & $3.00 \mathrm{e}-07$ & 0 & 0.0 & 4 \\
\hline $\mathrm{n}$ & $\mathrm{c} 5 \mathrm{~h}+$ & $\mathrm{c} 5 \mathrm{n}+$ & $\mathrm{h}$ & & $2.00 \mathrm{e}-10$ & 0 & 0.0 & 4 \\
\hline c & $\mathrm{c} 5 \mathrm{n}$ & c5 & $\mathrm{cn}$ & & $1.00 \mathrm{e}-13$ & 0 & 0.0 & 4 \\
\hline c5n & phosec & $\mathrm{c} 4$ & $\mathrm{cn}$ & & $1.30 \mathrm{e}-17$ & 0 & 875.0 & 2 \\
\hline c5n & photon & $\mathrm{c} 4$ & $\mathrm{cn}$ & & $5.00 \mathrm{e}-10$ & 0 & 1.7 & 5 \\
\hline he+ & $\mathrm{c} 5 \mathrm{n}$ & $\mathrm{c} 4+$ & $\mathrm{cn}$ & he & $3.00 \mathrm{e}-09$ & 0 & 0.0 & 4 \\
\hline $\mathrm{n}$ & $\mathrm{c} 5 \mathrm{~h}$ & $\mathrm{c} 5 \mathrm{n}$ & $\mathrm{h}$ & & $1.70 \mathrm{e}-11$ & 0 & 0.0 & 4 \\
\hline $\mathrm{n}$ & c5n & $\mathrm{cn}$ & $\mathrm{c} 4 \mathrm{n}$ & & $1.00 \mathrm{e}-10$ & 0 & 0.0 & 4 \\
\hline $\mathrm{n}$ & $\mathrm{c} 7 \mathrm{n}$ & $\mathrm{c} 2 \mathrm{n}$ & c5n & & $1.00 \mathrm{e}-10$ & 0 & 0.0 & 4 \\
\hline o & c5n & $\mathrm{c} 4 \mathrm{n}$ & $\mathrm{co}$ & & $4.00 \mathrm{e}-11$ & 0 & 0.0 & 4 \\
\hline $\mathrm{c} 7 \mathrm{n}$ & photon & $\mathrm{c} 7 \mathrm{n}+$ & electr & & $2.00 \mathrm{e}-10$ & 0 & 2.5 & 5 \\
\hline $\mathrm{c} 7 \mathrm{n}+$ & electr & c5n & $\mathrm{c} 2$ & & $3.00 \mathrm{e}-07$ & -0.5 & 0.0 & 4 \\
\hline $\mathrm{cn}$ & hen & $\mathrm{c} 2 \mathrm{n} 2$ & $\mathrm{~h}$ & & $2.50 \mathrm{e}-17$ & 1.71 & 770.0 & 4 \\
\hline $\mathrm{cn}$ & hen & $\mathrm{c} 2 \mathrm{n} 2$ & $\mathrm{~h}$ & & $2.00 \mathrm{e}-10$ & 0 & 0.0 & 4 \\
\hline c & $\mathrm{c} 2 \mathrm{n} 2$ & $\mathrm{cn}$ & $\mathrm{c} 2 \mathrm{n}$ & & $3.00 \mathrm{e}-11$ & 0 & 0.0 & 4 \\
\hline $\mathrm{h}$ & $\mathrm{c} 2 \mathrm{n} 2$ & hen & $\mathrm{cn}$ & & $1.48 \mathrm{e}-10$ & 0 & 3588.0 & 4 \\
\hline he+ & $\mathrm{c} 2 \mathrm{n} 2$ & $\mathrm{cn}+$ & $\mathrm{cn}$ & he & $2.70 \mathrm{e}-09$ & 0 & 0.0 & 4 \\
\hline $\mathrm{n}$ & $\mathrm{c} 2 \mathrm{n} 2$ & $\mathrm{n} 2$ & $\mathrm{c} 2 \mathrm{n}$ & & $1.00 \mathrm{e}-11$ & 0 & 0.0 & 4 \\
\hline $\mathrm{c} 2 \mathrm{n} 2$ & phosec & $\mathrm{cn}$ & $\mathrm{cn}$ & & $1.30 \mathrm{e}-17$ & 0 & 474.0 & 2 \\
\hline $\mathrm{c} 2 \mathrm{n} 2$ & photon & $\mathrm{cn}$ & $\mathrm{cn}$ & & $4.70 \mathrm{e}-11$ & 0 & 2.6 & 5 \\
\hline oh & $\mathrm{c} 2 \mathrm{n} 2$ & hen & ocn & & $3.11 \mathrm{e}-13$ & 0 & 1450.0 & 4 \\
\hline $\mathrm{c} 2 \mathrm{nh}+$ & electr & $\mathrm{c} 2 \mathrm{n}$ & $\mathrm{h}$ & & $3.00 \mathrm{e}-07$ & -0.5 & 0.0 & 4 \\
\hline $\mathrm{ch}+$ & hen & $\mathrm{c} 2 \mathrm{nh}+$ & $\mathrm{h}$ & & $2.40 \mathrm{e}-10$ & 0 & 0.0 & 4 \\
\hline h3+ & $\mathrm{c} 2 \mathrm{n}$ & $\mathrm{c} 2 \mathrm{nh}+$ & $\mathrm{h} 2$ & & $9.00 \mathrm{e}-09$ & 0 & 0.0 & 4 \\
\hline $\mathrm{n}$ & $\mathrm{c} 2 \mathrm{~h} 2+$ & $\mathrm{c} 2 \mathrm{nh}+$ & $\mathrm{h}$ & & $1.50 \mathrm{e}-10$ & 0 & 0.0 & 4 \\
\hline $\mathrm{n}$ & c2h3+ & $\mathrm{c} 2 \mathrm{nh}+$ & $\mathrm{h} 2$ & & $2.20 \mathrm{e}-10$ & 0 & 0.0 & 4 \\
\hline nh2 & $\mathrm{c} 2+$ & $\mathrm{c} 2 \mathrm{nh}+$ & $\mathrm{h}$ & & $4.60 \mathrm{e}-10$ & 0 & 0.0 & 4 \\
\hline no & $\mathrm{c} 3 \mathrm{~h}+$ & $\mathrm{c} 2 \mathrm{nh}+$ & $\mathrm{co}$ & & $4.20 \mathrm{e}-10$ & 0 & 0.0 & 4 \\
\hline $\mathrm{c} 2 \mathrm{~h}$ & $\mathrm{cn}$ & hc3n & photon & & $1.00 \mathrm{e}-16$ & 0 & 0.0 & 4 \\
\hline $\mathrm{c} 2 \mathrm{~h}$ & hen & hc3n & $\mathrm{h}$ & & $5.30 \mathrm{e}-12$ & 0 & 770.0 & 4 \\
\hline $\mathrm{c} 2 \mathrm{~h}$ & hnc & hc3n & $\mathrm{h}$ & & $5.30 \mathrm{e}-12$ & 0 & 770.0 & 4 \\
\hline
\end{tabular}

Continua na próxima página... 
Tabela B.2 - Continuação

\begin{tabular}{|c|c|c|c|c|c|c|c|c|}
\hline \multicolumn{2}{|c|}{ Reagentes } & \multicolumn{3}{|c|}{ Produtos } & $\gamma$ & $\alpha$ & $\beta$ & Tipo de Reação \\
\hline $\mathrm{c} 2 \mathrm{~h}$ & $\mathrm{c} 2 \mathrm{n} 2$ & hc3n & $\mathrm{cn}$ & & $2.00 \mathrm{e}-13$ & 0 & 0.0 & 4 \\
\hline $\operatorname{ch} 4$ & $\mathrm{c} 4 \mathrm{n}+$ & $\mathrm{c} 2 \mathrm{~h} 3+$ & hc3n & & $1.43 \mathrm{e}-10$ & 0 & 0.0 & 4 \\
\hline $\mathrm{cn}$ & $\mathrm{c} 2 \mathrm{~h} 2$ & hc3n & $\mathrm{h}$ & & $2.72 \mathrm{e}-10$ & -0.52 & 19.0 & 4 \\
\hline h2o & $\mathrm{c} 4 \mathrm{n}+$ & hc3n & hco+ & & $7.50 \mathrm{e}-10$ & 0 & 0.0 & 4 \\
\hline $\mathrm{n}$ & c3h3 & hc3n & h2 & & $8.00 \mathrm{e}-11$ & 0 & 0.0 & 4 \\
\hline $\mathrm{c}+$ & hc3n & $\mathrm{c} 3 \mathrm{~h}+$ & $\mathrm{cn}$ & & $3.25 \mathrm{e}-09$ & 0 & 0.0 & 4 \\
\hline $\mathrm{c}+$ & hc3n & $\mathrm{c} 4 \mathrm{n}+$ & $\mathrm{h}$ & & $1.40 \mathrm{e}-09$ & 0 & 0.0 & 4 \\
\hline $\mathrm{c}+$ & hc3n & $\mathrm{c} 3+$ & hen & & $2.50 \mathrm{e}-10$ & 0 & 0.0 & 4 \\
\hline $\mathrm{c} 2 \mathrm{~h}+$ & hc3n & $\mathrm{c} 4 \mathrm{~h}+$ & hen & & $7.60 \mathrm{e}-10$ & 0 & 0.0 & 4 \\
\hline $\mathrm{c} 2 \mathrm{~h}+$ & hc3n & $\mathrm{c} 4 \mathrm{~h} 2+$ & $\mathrm{cn}$ & & $4.56 \mathrm{e}-10$ & 0 & 0.0 & 4 \\
\hline $\operatorname{ch} 3+$ & hc3n & c3h3+ & hen & & $1.00 \mathrm{e}-09$ & 0 & 0.0 & 4 \\
\hline hc3n & phosec & $\mathrm{cn}$ & $\mathrm{c} 2 \mathrm{~h}$ & & $1.30 \mathrm{e}-17$ & 0 & 863.5 & 2 \\
\hline hc3n & photon & $\mathrm{cn}$ & $\mathrm{c} 2 \mathrm{~h}$ & & $7.40 \mathrm{e}-09$ & 0 & 1.8 & 5 \\
\hline he+ & hc3n & $\mathrm{cn}$ & $\mathrm{c} 2 \mathrm{~h}+$ & he & $2.20 \mathrm{e}-09$ & 0 & 0.0 & 4 \\
\hline he+ & hc3n & $\mathrm{c} 3 \mathrm{~h}+$ & $\mathrm{n}$ & he & $4.00 \mathrm{e}-10$ & 0 & 0.0 & 4 \\
\hline $\mathrm{c} 2 \mathrm{~h}+$ & hen & hc3n+ & $\mathrm{h}$ & & $1.35 \mathrm{e}-09$ & 0 & 0.0 & 4 \\
\hline $\mathrm{cn}$ & $\mathrm{c} 2 \mathrm{~h} 2+$ & hc3n+ & $\mathrm{h}$ & & $9.00 \mathrm{e}-10$ & 0 & 0.0 & 4 \\
\hline $\mathrm{h}+$ & hc3n & hc3n+ & $\mathrm{h}$ & & $4.00 \mathrm{e}-09$ & 0 & 0.0 & 4 \\
\hline h3+ & c3n & hc3n+ & h2 & & $9.00 \mathrm{e}-09$ & 0 & 0.0 & 4 \\
\hline h3o+ & c3n & hc3n+ & h2o & & $2.00 \mathrm{e}-09$ & 0 & 0.0 & 4 \\
\hline hco+ & c3n & hc3n+ & $\mathrm{CO}$ & & $3.70 \mathrm{e}-09$ & 0 & 0.0 & 4 \\
\hline $\mathrm{c} 2 \mathrm{~h} 2$ & hc3n+ & $\mathrm{c} 2 \mathrm{~h} 2+$ & hc3n & & $1.28 \mathrm{e}-10$ & 0 & 0.0 & 4 \\
\hline $\mathrm{c} 2 \mathrm{~h} 2$ & hc3n+ & c4h $2+$ & hen & & $5.12 \mathrm{e}-10$ & 0 & 0.0 & 4 \\
\hline $\mathrm{c} 2 \mathrm{~h} 4$ & hc3n+ & $\mathrm{c} 2 \mathrm{~h} 4+$ & hc3n & & $5.36 \mathrm{e}-10$ & 0 & 0.0 & 4 \\
\hline $\operatorname{ch} 4$ & hc3n+ & c3h5+ & $\mathrm{cn}$ & & $4.57 \mathrm{e}-10$ & 0 & 0.0 & 4 \\
\hline h2 & hc3n+ & hcn & $\mathrm{c} 2 \mathrm{~h} 2+$ & & $2.00 \mathrm{e}-12$ & 0 & 0.0 & 4 \\
\hline hc3n+ & electr & c3n & $\mathrm{h}$ & & $6.60 \mathrm{e}-07$ & -0.6 & 0.0 & 4 \\
\hline hc3n+ & electr & hen & $\mathrm{c} 2$ & & $3.60 \mathrm{e}-07$ & -0.6 & 0.0 & 4 \\
\hline hc3n+ & electr & $\mathrm{cn}$ & $\mathrm{c} 2 \mathrm{~h}$ & & $3.60 \mathrm{e}-07$ & -0.6 & 0.0 & 4 \\
\hline $\mathrm{n}$ & hc3n+ & $\mathrm{c} 3 \mathrm{~h}+$ & $\mathrm{n} 2$ & & $9.60 \mathrm{e}-11$ & 0 & 0.0 & 4 \\
\hline nh3 & hc3n+ & hc3n & nh3+ & & $1.70 \mathrm{e}-09$ & 0 & 0.0 & 4 \\
\hline $\mathrm{cn}+$ & hen & $\mathrm{c} 2 \mathrm{n} 2+$ & $\mathrm{h}$ & & $3.15 \mathrm{e}-10$ & 0 & 0.0 & 4 \\
\hline $\mathrm{n}+$ & $\mathrm{c} 2 \mathrm{n} 2$ & $\mathrm{c} 2 \mathrm{n} 2+$ & $\mathrm{n}$ & & $1.40 \mathrm{e}-09$ & 0 & 0.0 & 4 \\
\hline $\mathrm{c} 2 \mathrm{~h} 2$ & $\mathrm{c} 2 \mathrm{n} 2+$ & $\mathrm{c} 2 \mathrm{~h} 2+$ & $\mathrm{c} 2 \mathrm{n} 2$ & & $5.80 \mathrm{e}-10$ & 0 & 0.0 & 4 \\
\hline $\mathrm{c} 2 \mathrm{~h} 4$ & $\mathrm{c} 2 \mathrm{n} 2+$ & $\mathrm{c} 2 \mathrm{~h} 4+$ & $\mathrm{c} 2 \mathrm{n} 2$ & & $1.30 \mathrm{e}-09$ & 0 & 0.0 & 4 \\
\hline $\mathrm{c} 2 \mathrm{n} 2+$ & electr & $\mathrm{cn}$ & $\mathrm{cn}$ & & $1.50 \mathrm{e}-07$ & -0.5 & 0.0 & 4 \\
\hline $\mathrm{c} 2 \mathrm{n} 2+$ & electr & $\mathrm{c} 2 \mathrm{n}$ & $\mathrm{n}$ & & $1.50 \mathrm{e}-07$ & -0.5 & 0.0 & 4 \\
\hline $\mathrm{h}$ & $\mathrm{c} 2 \mathrm{n} 2+$ & hen+ & $\mathrm{cn}$ & & $6.20 \mathrm{e}-10$ & 0 & 0.0 & 4 \\
\hline hen & $\mathrm{c} 2 \mathrm{n} 2+$ & hen+ & $\mathrm{c} 2 \mathrm{n} 2$ & & $5.40 \mathrm{e}-10$ & 0 & 0.0 & 4 \\
\hline $\mathrm{n}$ & c2h3 & $\mathrm{c} 2 \mathrm{~h} 2 \mathrm{n}$ & $\mathrm{h}$ & & $6.20 \mathrm{e}-11$ & 0 & 0.0 & 4 \\
\hline $\mathrm{c}$ & $\mathrm{c} 2 \mathrm{~h} 2 \mathrm{n}$ & hc3n & $\mathrm{h}$ & & $1.00 \mathrm{e}-10$ & 0 & 0.0 & 4 \\
\hline he+ & $\mathrm{c} 2 \mathrm{~h} 2 \mathrm{n}$ & $\mathrm{cn}$ & $\operatorname{ch} 2+$ & he & $3.30 \mathrm{e}-09$ & 0 & 0.0 & 4 \\
\hline $\mathrm{c} 2 \mathrm{~h} 2 \mathrm{n}$ & + electr & hen & $\mathrm{ch}$ & & $1.50 \mathrm{e}-07$ & -0.5 & 0.0 & 4 \\
\hline
\end{tabular}

Continua na próxima página... 
Tabela B.2 - Continuação

\begin{tabular}{|c|c|c|c|c|c|c|c|c|}
\hline \multicolumn{2}{|c|}{ Reagentes } & \multicolumn{3}{|c|}{ Produtos } & \multirow{2}{*}{$\frac{\gamma}{1.50 \mathrm{e}-07}$} & \multirow{2}{*}{$\begin{array}{c}\alpha \\
-0.5\end{array}$} & \multirow{2}{*}{$\begin{array}{l}\beta \\
0.0\end{array}$} & \multirow{2}{*}{$\begin{array}{c}\text { Tipo de Reação } \\
4\end{array}$} \\
\hline $\mathrm{c} 2 \mathrm{~h} 2 \mathrm{n}$ & + electr & $\mathrm{cn}$ & $\operatorname{ch} 2$ & & & & & \\
\hline $\mathrm{c}+$ & $\mathrm{c} 2 \mathrm{~h} 2 \mathrm{n}$ & $\mathrm{c} 2 \mathrm{~h} 2 \mathrm{n}+$ & $\mathrm{c}$ & & $2.00 \mathrm{e}-09$ & 0 & 0.0 & 4 \\
\hline $\operatorname{ch} 2+$ & hen & $\mathrm{c} 2 \mathrm{~h} 2 \mathrm{n}+$ & $\mathrm{h}$ & & $1.80 \mathrm{e}-09$ & 0 & 0.0 & 4 \\
\hline $\operatorname{ch} 3+$ & $\mathrm{cn}$ & $\mathrm{c} 2 \mathrm{~h} 2 \mathrm{n}+$ & $\mathrm{h}$ & & $1.10 \mathrm{e}-09$ & 0 & 0.0 & 4 \\
\hline $\mathrm{h}+$ & $\mathrm{c} 2 \mathrm{~h} 2 \mathrm{n}$ & $\mathrm{c} 2 \mathrm{~h} 2 \mathrm{n}+$ & $\mathrm{h}$ & & $6.30 \mathrm{e}-09$ & 0 & 0.0 & 4 \\
\hline $\mathrm{nh}$ & $\mathrm{c} 2 \mathrm{~h} 2+$ & $\mathrm{c} 2 \mathrm{~h} 2 \mathrm{n}+$ & $\mathrm{h}$ & & $6.50 \mathrm{e}-10$ & 0 & 0.0 & 4 \\
\hline nh2 & $\mathrm{c} 2 \mathrm{~h}+$ & $\mathrm{c} 2 \mathrm{~h} 2 \mathrm{n}+$ & $\mathrm{h}$ & & $4.60 \mathrm{e}-10$ & 0 & 0.0 & 4 \\
\hline nh3 & $\mathrm{c} 2 \mathrm{~h}+$ & $\mathrm{c} 2 \mathrm{~h} 2 \mathrm{n}+$ & $\mathrm{h} 2$ & & $5.50 \mathrm{e}-10$ & 0 & 0.0 & 4 \\
\hline $\mathrm{c} 4 \mathrm{~h}$ & $\mathrm{c} 2 \mathrm{n} 2$ & hc5n & $\mathrm{cn}$ & & $2.00 \mathrm{e}-13$ & 0 & 0.0 & 4 \\
\hline $\mathrm{cn}$ & $\mathrm{c} 4 \mathrm{~h} 2$ & hc5n & $\mathrm{h}$ & & $2.72 \mathrm{e}-10$ & -0.52 & 0.0 & 4 \\
\hline $\mathrm{n}$ & $\mathrm{c} 5 \mathrm{~h} 2$ & hc5n & $\mathrm{h}$ & & $1.00 \mathrm{e}-13$ & 0 & 0.0 & 4 \\
\hline hc5n & phosec & c5n & $\mathrm{h}$ & & $1.30 \mathrm{e}-17$ & 0 & 875.0 & 2 \\
\hline hc5n & phosec & $\mathrm{c} 4 \mathrm{~h}$ & $\mathrm{cn}$ & & $1.30 \mathrm{e}-17$ & 0 & 875.0 & 2 \\
\hline hc5n & photon & c5n & $\mathrm{h}$ & & $5.00 \mathrm{e}-10$ & 0 & 1.8 & 5 \\
\hline hc5n & photon & $\mathrm{c} 4 \mathrm{~h}$ & $\mathrm{cn}$ & & $5.00 \mathrm{e}-10$ & 0 & 1.8 & 5 \\
\hline he+ & hc5n & c3n & $\mathrm{c} 2 \mathrm{~h}+$ & he & $1.00 \mathrm{e}-09$ & 0 & 0.0 & 4 \\
\hline he+ & hc5n & $\mathrm{c} 4 \mathrm{~h}+$ & $\mathrm{cn}$ & he & $1.00 \mathrm{e}-13$ & 0 & 0.0 & 4 \\
\hline hc5n+ & electr & c5n & $\mathrm{h}$ & & $1.50 \mathrm{e}-07$ & -0.5 & 0.0 & 4 \\
\hline $\mathrm{c} 2 \mathrm{~h}+$ & hc3n & hc5n+ & $\mathrm{h}$ & & $1.18 \mathrm{e}-09$ & 0 & 0.0 & 4 \\
\hline $\mathrm{h}+$ & hc5n & hc5n+ & $\mathrm{h}$ & & $4.00 \mathrm{e}-09$ & 0 & 0.0 & 4 \\
\hline h2 & $\mathrm{c} 5 \mathrm{n}+$ & hc5n+ & $\mathrm{h}$ & & $1.50 \mathrm{e}-09$ & 0 & 0.0 & 4 \\
\hline h3+ & $\mathrm{c} 5 \mathrm{n}$ & hc5n+ & h2 & & $8.00 \mathrm{e}-09$ & 0 & 0.0 & 4 \\
\hline hen & $\mathrm{c} 4 \mathrm{~h}+$ & hc5n+ & $\mathrm{h}$ & & $1.23 \mathrm{e}-09$ & 0 & 0.0 & 4 \\
\hline hco+ & $c 5 n$ & hc5n+ & $\mathrm{co}$ & & $3.00 \mathrm{e}-09$ & 0 & 0.0 & 4 \\
\hline $\mathrm{c} 5 \mathrm{~h}+$ & electr & $\mathrm{c} 4 \mathrm{~h}$ & $\mathrm{c}$ & & $1.00 \mathrm{e}-06$ & -0.3 & 0.0 & 4 \\
\hline $\mathrm{c} 5 \mathrm{~h}+$ & electr & c5 & $\mathrm{h}$ & & $3.00 \mathrm{e}-07$ & -0.5 & 0.0 & 4 \\
\hline o & $\mathrm{c} 5 \mathrm{~h}+$ & $\mathrm{c} 4$ & hco+ & & $2.00 \mathrm{e}-10$ & 0 & 0.0 & 4 \\
\hline c & $\mathrm{c} 4 \mathrm{~h} 2+$ & $\mathrm{c} 5 \mathrm{~h}+$ & $\mathrm{h}$ & & $5.00 \mathrm{e}-10$ & 0 & 0.0 & 4 \\
\hline c & $\mathrm{c} 4 \mathrm{~h} 3+$ & $\mathrm{c} 5 \mathrm{~h}+$ & $\mathrm{h} 2$ & & $5.00 \mathrm{e}-10$ & 0 & 0.0 & 4 \\
\hline $\mathrm{c}+$ & c4h3 & $\mathrm{c} 5 \mathrm{~h}+$ & $\mathrm{h} 2$ & & $3.10 \mathrm{e}-10$ & 0 & 0.0 & 4 \\
\hline $\mathrm{c}+$ & $\mathrm{c} 4 \mathrm{~h} 2$ & $\mathrm{c} 5 \mathrm{~h}+$ & $\mathrm{h}$ & & $1.45 \mathrm{e}-09$ & 0 & 0.0 & 4 \\
\hline $\mathrm{c}+$ & hc5n & $\mathrm{c} 5 \mathrm{~h}+$ & $\mathrm{cn}$ & & $6.00 \mathrm{e}-09$ & 0 & 0.0 & 4 \\
\hline $\mathrm{c} 2 \mathrm{~h} 2$ & $\mathrm{c} 3+$ & $\mathrm{c} 5 \mathrm{~h}+$ & $\mathrm{h}$ & & $1.70 \mathrm{e}-09$ & 0 & 0.0 & 4 \\
\hline $\mathrm{c} 2 \mathrm{~h} 2$ & $\mathrm{c} 4 \mathrm{n}+$ & $\mathrm{c} 5 \mathrm{~h}+$ & hen & & $8.00 \mathrm{e}-10$ & 0 & 0.0 & 4 \\
\hline $\mathrm{c} 2 \mathrm{~h} 2+$ & $\mathrm{c} 3 \mathrm{~h}$ & $\mathrm{c} 5 \mathrm{~h}+$ & $\mathrm{h} 2$ & & $1.75 \mathrm{e}-09$ & 0 & 0.0 & 4 \\
\hline $\mathrm{c} 3+$ & hc3n & $\mathrm{c} 5 \mathrm{~h}+$ & $\mathrm{cn}$ & & $3.20 \mathrm{e}-09$ & 0 & 0.0 & 4 \\
\hline $\mathrm{c} 3 \mathrm{~h}+$ & $\mathrm{c} 4 \mathrm{~h} 2$ & $\mathrm{c} 5 \mathrm{~h}+$ & $\mathrm{c} 2 \mathrm{~h} 2$ & & $1.20 \mathrm{e}-10$ & 0 & 0.0 & 4 \\
\hline $\mathrm{h}+$ & $\mathrm{c} 5 \mathrm{~h}$ & $\mathrm{c} 5 \mathrm{~h}+$ & $\mathrm{h}$ & & $3.00 \mathrm{e}-09$ & 0 & 0.0 & 4 \\
\hline $\mathrm{h}+$ & $\mathrm{c} 5 \mathrm{~h} 2$ & $\mathrm{c} 5 \mathrm{~h}+$ & h2 & & $2.50 \mathrm{e}-09$ & 0 & 0.0 & 4 \\
\hline h3+ & c5 & $\mathrm{c} 5 \mathrm{~h}+$ & $\mathrm{h} 2$ & & $2.00 \mathrm{e}-09$ & 0 & 0.0 & 4 \\
\hline hco+ & $\mathrm{c} 5$ & $\mathrm{c} 5 \mathrm{~h}+$ & $\mathrm{co}$ & & $2.00 \mathrm{e}-09$ & 0 & 0.0 & 4 \\
\hline he+ & c5h2 & $\mathrm{c} 5 \mathrm{~h}+$ & he & $\mathrm{h}$ & $1.00 \mathrm{e}-09$ & 0 & 0.0 & 4 \\
\hline he+ & $\mathrm{c} 7 \mathrm{~h}$ & $\mathrm{c} 5 \mathrm{~h}+$ & $\mathrm{c} 2$ & he & $2.00 \mathrm{e}-09$ & 0 & 0.0 & 4 \\
\hline
\end{tabular}

Continua na próxima página... 
Tabela B.2 - Continuação

\begin{tabular}{|c|c|c|c|c|c|c|c|c|}
\hline \multicolumn{2}{|c|}{ Reagentes } & \multicolumn{3}{|c|}{ Produtos } & \multirow{2}{*}{$\frac{\gamma}{1.90 \mathrm{e}-10}$} & \multirow{2}{*}{$\begin{array}{c}\alpha \\
0\end{array}$} & \multirow{2}{*}{$\begin{array}{l}\beta \\
0.0\end{array}$} & \multirow{2}{*}{$\begin{array}{c}\text { Tipo de Reação } \\
4\end{array}$} \\
\hline $\mathrm{n}$ & c6h2+ & $\mathrm{c} 5 \mathrm{~h}+$ & hen & & & & & \\
\hline $\mathrm{c} 7 \mathrm{~h}+$ & electr & $\mathrm{c} 6 \mathrm{~h}$ & $\mathrm{c}$ & & $1.00 \mathrm{e}-06$ & -0.3 & 0.0 & 4 \\
\hline $\mathrm{c} 7 \mathrm{~h}+$ & electr & $\mathrm{c} 7$ & $\mathrm{~h}$ & & $1.00 \mathrm{e}-06$ & -0.3 & 0.0 & 4 \\
\hline $\mathrm{n}$ & $\mathrm{c} 7 \mathrm{~h}+$ & $\mathrm{c} 7 \mathrm{n}+$ & $\mathrm{h}$ & & $2.00 \mathrm{e}-10$ & 0 & 0.0 & 4 \\
\hline o & $\mathrm{c} 7 \mathrm{~h}+$ & c6 & hcot & & $2.00 \mathrm{e}-10$ & 0 & 0.0 & 4 \\
\hline $\mathrm{c}$ & c6h2+ & $\mathrm{c} 7 \mathrm{~h}+$ & $\mathrm{h}$ & & $5.00 \mathrm{e}-10$ & 0 & 0.0 & 4 \\
\hline $\mathrm{c}$ & c6h3+ & $\mathrm{c} 7 \mathrm{~h}+$ & h2 & & $5.00 \mathrm{e}-10$ & 0 & 0.0 & 4 \\
\hline $\mathrm{c}+$ & $\mathrm{c} 6 \mathrm{~h} 2$ & $\mathrm{c} 7 \mathrm{~h}+$ & $\mathrm{h}$ & & $1.20 \mathrm{e}-09$ & 0 & 0.0 & 4 \\
\hline $\mathrm{c} 2 \mathrm{~h} 2+$ & $\mathrm{c} 5 \mathrm{~h}$ & $\mathrm{c} 7 \mathrm{~h}+$ & h2 & & $1.75 \mathrm{e}-09$ & 0 & 0.0 & 4 \\
\hline $\mathrm{c} 3 \mathrm{~h}$ & $\mathrm{c} 4 \mathrm{~h}+$ & $\mathrm{c} 7 \mathrm{~h}+$ & $\mathrm{h}$ & & $1.50 \mathrm{e}-09$ & 0 & 0.0 & 4 \\
\hline c3h2+ & $\mathrm{c} 4 \mathrm{~h}$ & $\mathrm{c} 7 \mathrm{~h}+$ & $\mathrm{h} 2$ & & $5.00 \mathrm{e}-10$ & 0 & 0.0 & 4 \\
\hline $\mathrm{c} 7 \mathrm{~h}$ & photon & $\mathrm{c} 7 \mathrm{~h}+$ & electr & & $2.00 \mathrm{e}-10$ & 0 & 2.5 & 4 \\
\hline $\mathrm{h}+$ & $\mathrm{c} 7 \mathrm{~h}$ & $\mathrm{c} 7 \mathrm{~h}+$ & $\mathrm{h}$ & & $3.00 \mathrm{e}-09$ & 0 & 0.0 & 4 \\
\hline h3+ & $\mathrm{c} 7$ & $\mathrm{c} 7 \mathrm{~h}+$ & $\mathrm{h} 2$ & & $2.00 \mathrm{e}-09$ & 0 & 0.0 & 4 \\
\hline hco+ & c7 & $\mathrm{c} 7 \mathrm{~h}+$ & $\mathrm{co}$ & & $1.40 \mathrm{e}-09$ & 0 & 0.0 & 4 \\
\hline $\mathrm{cn}$ & c6h2 & hc7n & $\mathrm{h}$ & & $2.72 \mathrm{e}-10$ & -0.52 & 19.0 & 4 \\
\hline hc7n & phosec & $\mathrm{c} 6 \mathrm{~h}$ & $\mathrm{cn}$ & & $1.30 \mathrm{e}-17$ & 0 & 875.0 & 2 \\
\hline hc7n & photon & $\mathrm{c} 6 \mathrm{~h}$ & $\mathrm{cn}$ & & $1.00 \mathrm{e}-09$ & 0 & 1.7 & 5 \\
\hline he+ & hc7n & $\mathrm{c} 6 \mathrm{~h}+$ & $\mathrm{cn}$ & he & $7.00 \mathrm{e}-09$ & 0 & 0.0 & 4 \\
\hline hc7n+ & electr & $\mathrm{c} 7 \mathrm{n}$ & $\mathrm{h}$ & & $1.00 \mathrm{e}-06$ & -0.3 & 0.0 & 4 \\
\hline hc7n+ & electr & $\mathrm{c} 6 \mathrm{~h}$ & $\mathrm{cn}$ & & $1.00 \mathrm{e}-06$ & -0.3 & 0.0 & 4 \\
\hline $\mathrm{h}+$ & hc7n & hc7n+ & $\mathrm{h}$ & & $1.00 \mathrm{e}-08$ & 0 & 0.0 & 4 \\
\hline $\mathrm{h} 2$ & $\mathrm{c} 7 \mathrm{n}+$ & hc7n+ & $\mathrm{h}$ & & $1.50 \mathrm{e}-09$ & 0 & 0.0 & 4 \\
\hline h3+ & $\mathrm{c} 7 \mathrm{n}$ & hc7n+ & h2 & & $4.00 \mathrm{e}-09$ & 0 & 0.0 & 4 \\
\hline hc7n & photon & hc7n+ & electr & & $2.00 \mathrm{e}-10$ & 0 & 2.5 & 5 \\
\hline hco+ & $\mathrm{c} 7 \mathrm{n}$ & hc7n+ & $\mathrm{CO}$ & & $3.00 \mathrm{e}-09$ & 0 & 0.0 & 4 \\
\hline $\mathrm{c} 2+$ & hen & $\mathrm{c} 3 \mathrm{n}+$ & $\mathrm{h}$ & & $2.60 \mathrm{e}-09$ & 0 & 0.0 & 4 \\
\hline $\mathrm{c} 2 \mathrm{~h}+$ & $\mathrm{cn}$ & $\mathrm{c} 3 \mathrm{n}+$ & $\mathrm{h}$ & & $9.10 \mathrm{e}-10$ & 0 & 0.0 & 4 \\
\hline $\mathrm{c} 3 \mathrm{n}+$ & electr & $\mathrm{cn}$ & $\mathrm{c} 2$ & & $3.00 \mathrm{e}-07$ & -0.5 & 0.0 & 4 \\
\hline he+ & c3n & $\mathrm{c} 3 \mathrm{n}+$ & he & & $8.20 \mathrm{e}-09$ & 0 & 0.0 & 4 \\
\hline $\mathrm{n}$ & $\mathrm{c} 3 \mathrm{~h}+$ & $\mathrm{c} 3 \mathrm{n}+$ & $\mathrm{h}$ & & $2.70 \mathrm{e}-10$ & 0 & 0.0 & 4 \\
\hline he+ & hc3n & $\mathrm{c} 3 \mathrm{n}+$ & he & $\mathrm{h}$ & $2.45 \mathrm{e}-09$ & 0 & 0.0 & 4 \\
\hline h3+ & $\operatorname{ch} 2 \mathrm{o} 2$ & h3o+ & $\mathrm{co}$ & $\mathrm{h} 2$ & $1.80 \mathrm{e}-09$ & 0.00 & 0.0 & 4 \\
\hline h3+ & $\operatorname{ch} 2 \mathrm{o} 2$ & hco+ & h2o & $\mathrm{h} 2$ & $4.30 \mathrm{e}-09$ & 0.00 & 0.0 & 4 \\
\hline $\operatorname{ch} 2 \mathrm{o} 2$ & phosec & hco & oh & & $1.30 \mathrm{e}-17$ & 0.00 & 0.0 & 2 \\
\hline $\operatorname{ch} 2 \mathrm{o} 2$ & photon & hco & oh & & $4.10 \mathrm{e}-10$ & 0.00 & 1.8 & 5 \\
\hline oh & h2co & $\operatorname{ch} 2 \mathrm{o} 2$ & $\mathrm{~h}$ & & $2.00 \mathrm{e}-13$ & 0.00 & 0.0 & 4 \\
\hline $\mathrm{nh}$ & $\operatorname{ch} 2 \mathrm{o} 2$ & ch3no & o & & $5.00 \mathrm{e}-07$ & 0.5 & 0 & \\
\hline ch3no & phosec & $\operatorname{ch} 3$ & no & & $2.00 \mathrm{e}-18$ & 0 & 1000 & \\
\hline ch3no & phosec & $\operatorname{ch} 2$ & hno & & $2.00 \mathrm{e}-18$ & 0 & 1000 & \\
\hline ch3no & phosec & $\operatorname{ch} 2$ & no & $\mathrm{h}$ & $2.00 \mathrm{e}-18$ & 0 & 1000 & \\
\hline ch3no & phosec & $\mathrm{ch}$ & no & $\mathrm{h} 2$ & $2.00 \mathrm{e}-18$ & 0 & 1000 & \\
\hline ch3no & phosec & $\mathrm{ch}$ & hno & $\mathrm{h}$ & $2.00 \mathrm{e}-18$ & 0 & 1000 & \\
\hline
\end{tabular}

Continua na próxima página... 
Tabela B.2 - Continuação

\begin{tabular}{|c|c|c|c|c|c|c|c|c|}
\hline \multicolumn{2}{|c|}{ Reagentes } & \multicolumn{3}{|c|}{ Produtos } & \multirow{2}{*}{$\frac{\gamma}{2.00 \mathrm{e}-12}$} & \multirow{2}{*}{$\begin{array}{l}\alpha \\
0 \\
0\end{array}$} & \multirow{2}{*}{$\begin{array}{c}\beta \\
1.8\end{array}$} & \multirow{2}{*}{ Tipo de Reação } \\
\hline ch3no & photon & $\operatorname{ch} 3$ & no & & & & & \\
\hline ch3no & photon & $\operatorname{ch} 2$ & hno & & $2.00 \mathrm{e}-12$ & 0 & 1.8 & \\
\hline ch3no & photon & $\operatorname{ch} 2$ & no & $\mathrm{h}$ & $2.00 \mathrm{e}-12$ & 0 & 1.8 & \\
\hline ch3no & photon & $\mathrm{ch}$ & no & h2 & $2.00 \mathrm{e}-12$ & 0 & 1.8 & \\
\hline ch3no & photon & $\mathrm{ch}$ & hno & $\mathrm{h}$ & $2.00 \mathrm{e}-12$ & 0 & 1.8 & \\
\hline ch3no & $\mathrm{s}$ & $\operatorname{ch} 3 n s$ & o & & $5.00 \mathrm{e}-07$ & 0.5 & 0 & \\
\hline ch3ns & phosec & $\operatorname{ch} 3$ & $\mathrm{n}$ & $\mathrm{s}$ & $2.00 \mathrm{e}-18$ & 0 & 1000 & \\
\hline ch3ns & phosec & $\mathrm{h} 2 \mathrm{cs}$ & $\mathrm{nh}$ & & $2.00 \mathrm{e}-18$ & 0 & 1000 & \\
\hline ch3ns & phosec & $\mathrm{h} 2 \mathrm{~s}$ & hnc & & $2.00 \mathrm{e}-18$ & 0 & 1000 & \\
\hline ch3ns & phosec & sh & $\mathrm{h} 2 \mathrm{cn}$ & & $2.00 \mathrm{e}-18$ & 0 & 1000 & \\
\hline ch3ns & phosec & h2s & hnc & & $2.00 \mathrm{e}-18$ & 0 & 1000 & \\
\hline ch3ns & photon & $\operatorname{ch} 3$ & $\mathrm{n}$ & $\mathrm{s}$ & $2.00 \mathrm{e}-12$ & 0 & 1.8 & \\
\hline ch3ns & photon & $\mathrm{h} 2 \mathrm{cs}$ & $\mathrm{nh}$ & & $2.00 \mathrm{e}-12$ & 0 & 1.8 & \\
\hline ch3ns & photon & h2s & hnc & & $2.00 \mathrm{e}-12$ & 0 & 1.8 & \\
\hline ch3ns & photon & sh & $\mathrm{h} 2 \mathrm{cn}$ & & $2.00 \mathrm{e}-12$ & 0 & 1.8 & \\
\hline ch3ns & photon & h2s & hnc & & $2.00 \mathrm{e}-12$ & 0 & 1.8 & \\
\hline $\mathrm{c} 2$ & $\operatorname{ch} 3 n s$ & c3h3ns & "photon" & & $5.00 \mathrm{e}-07$ & 0.5 & 0 & \\
\hline c3h3ns & phosec & $\mathrm{h} 2 \mathrm{cs}$ & $\mathrm{ch}$ & $\mathrm{cn}$ & $1.50 \mathrm{e}-18$ & 0 & 1000 & \\
\hline c3h3ns & phosec & h2cs & $\mathrm{c} 2 \mathrm{~h}$ & $\mathrm{n}$ & $1.50 \mathrm{e}-18$ & 0 & 1000 & \\
\hline c3h3ns & phosec & $\mathrm{h} 2 \mathrm{cs}$ & $\mathrm{c} 2 \mathrm{n}$ & $\mathrm{h}$ & $1.50 \mathrm{e}-18$ & 0 & 1000 & \\
\hline c3h3ns & phosec & h2s & c3h & $\mathrm{n}$ & $1.50 \mathrm{e}-18$ & 0 & 1000 & \\
\hline c3h3ns & phosec & h2s & $\mathrm{c} 3 \mathrm{n}$ & $\mathrm{h}$ & $1.50 \mathrm{e}-18$ & 0 & 1000 & \\
\hline c3h3ns & phosec & $\mathrm{sh}$ & c $3 \mathrm{~h} 2$ & $\mathrm{n}$ & $1.50 \mathrm{e}-18$ & 0 & 1000 & \\
\hline c3h3ns & phosec & sh & c3n & h2 & $1.50 \mathrm{e}-18$ & 0 & 1000 & \\
\hline c3h3ns & photon & h2cs & $\mathrm{ch}$ & $\mathrm{cn}$ & $1.50 \mathrm{e}-12$ & 0 & 1.8 & \\
\hline c3h3ns & photon & $\mathrm{h} 2 \mathrm{cs}$ & $\mathrm{c} 2 \mathrm{~h}$ & $\mathrm{n}$ & $1.50 \mathrm{e}-12$ & 0 & 1.8 & \\
\hline c3h3ns & photon & h2cs & $\mathrm{c} 2 \mathrm{n}$ & $\mathrm{h}$ & $1.50 \mathrm{e}-12$ & 0 & 1.8 & \\
\hline c3h3ns & photon & $\mathrm{h} 2 \mathrm{~s}$ & $\mathrm{c} 3 \mathrm{~h}$ & $\mathrm{n}$ & $1.50 \mathrm{e}-12$ & 0 & 1.8 & \\
\hline c3h3ns & photon & h2s & $c 3 n$ & $\mathrm{~h}$ & $1.50 \mathrm{e}-12$ & 0 & 1.8 & \\
\hline c3h3ns & photon & sh & c3h2 & $\mathrm{n}$ & $1.50 \mathrm{e}-12$ & 0 & 1.8 & \\
\hline c3h3ns & photon & $\mathrm{sh}$ & $\mathrm{c} 3 \mathrm{n}$ & h2 & $1.50 \mathrm{e}-12$ & 0 & 1.8 & \\
\hline c3h3ns & $\mathrm{h}$ & h2cs & $\mathrm{c} 2 \mathrm{~h} 2$ & $\mathrm{n}$ & $1.00 \mathrm{e}-10$ & 0 & 0 & \\
\hline $\mathrm{ch}$ & nh3 & $\operatorname{ch} 3 n$ & $\mathrm{~h}$ & & $1.69 \mathrm{e}-10$ & -0.41 & 19 & \\
\hline $\operatorname{ch} 3 n$ & phosec & $\mathrm{nh}$ & $\operatorname{ch} 2$ & & $1.30 \mathrm{e}-17$ & 0 & 500 & \\
\hline $\operatorname{ch} 3 n$ & photon & hnc & h2 & & $3.50 \mathrm{e}-09$ & 0 & 1.6 & \\
\hline $\mathrm{h}+$ & $\operatorname{ch} 3 n$ & $\mathrm{nh} 2+$ & $\operatorname{ch} 2$ & & $1.00 \mathrm{e}-09$ & 0 & 0 & \\
\hline $\mathrm{h}+$ & ch3n & nh2 & $\operatorname{ch} 2+$ & & $1.00 \mathrm{e}-09$ & 0 & 0 & \\
\hline he+ & $\operatorname{ch} 3 n$ & $\mathrm{nh}$ & $\operatorname{ch} 2+$ & he & $1.00 \mathrm{e}-09$ & 0 & 0 & \\
\hline $\mathrm{c} 2 \mathrm{n} 2$ & $\operatorname{ch} 3 n$ & c3h3n3 & photon & & $5.00 \mathrm{e}-07$ & 0.5 & 0 & \\
\hline c3h3n3 & phosec & hen & hen & hen & $1.00 \mathrm{e}-17$ & 0 & 0 & \\
\hline c3h3n3 & photon & hen & hen & hen & $9.00 \mathrm{e}-11$ & 0 & 1.8 & \\
\hline $\mathrm{ch}$ & c3h3n3 & $\mathrm{c} 4 \mathrm{~h} 4 \mathrm{n}$ & $\mathrm{n} 2$ & & $5.00 \mathrm{e}-07$ & 0.50 & 0.0 & \\
\hline $\mathrm{c} 4 \mathrm{~h} 4 \mathrm{n}$ & phosec & $\mathrm{c} 2 \mathrm{~h} 2$ & $\mathrm{c} 2 \mathrm{~h} 2$ & $\mathrm{n}$ & $3.30 \mathrm{e}-18$ & 0 & 1000 & \\
\hline
\end{tabular}

Continua na próxima página... 
Tabela B.2 - Continuação

\begin{tabular}{|c|c|c|c|c|c|c|c|c|}
\hline \multicolumn{2}{|c|}{ Reagentes } & \multicolumn{3}{|c|}{ Produtos } & \multirow{2}{*}{$\frac{\gamma}{3.30 \mathrm{e}-18}$} & \multirow{2}{*}{$\begin{array}{c}\alpha \\
0\end{array}$} & \multirow{2}{*}{$\begin{array}{c}\beta \\
1000\end{array}$} & \multirow{2}{*}{ Tipo de Reação } \\
\hline $\mathrm{c} 4 \mathrm{~h} 4 \mathrm{n}$ & phosec & $\mathrm{c} 3 \mathrm{~h} 3$ & hen & & & & & \\
\hline $\mathrm{c} 4 \mathrm{~h} 4 \mathrm{n}$ & phosec & c3h3 & hnc & & $3.30 \mathrm{e}-18$ & 0 & 1000 & \\
\hline $\mathrm{c} 4 \mathrm{~h} 4 \mathrm{n}$ & photon & $\mathrm{c} 2 \mathrm{~h} 2$ & $\mathrm{c} 2 \mathrm{~h} 2$ & $\mathrm{n}$ & $3.30 \mathrm{e}-12$ & 0 & 1.8 & \\
\hline $\mathrm{c} 4 \mathrm{~h} 4 \mathrm{n}$ & photon & c3h3 & hen & & $3.30 \mathrm{e}-12$ & 0 & 1.8 & \\
\hline $\mathrm{c} 4 \mathrm{~h} 4 \mathrm{n}$ & photon & c3h3 & hnc & & $3.30 \mathrm{e}-12$ & 0 & 1.8 & \\
\hline $\mathrm{ch}$ & $\mathrm{c} 4 \mathrm{~h} 4 \mathrm{n}$ & c4h5n & c & & $5.00 \mathrm{e}-07$ & 0.5 & 0 & \\
\hline $\mathrm{ch}$ & c4h5n & c5h5n & $\mathrm{h}$ & & $4.00 \mathrm{e}-10$ & 0 & 0 & \\
\hline c5h5n & photon & c3h3 & $\mathrm{c} 2 \mathrm{~h} 2 \mathrm{n}$ & & $4.00 \mathrm{e}-12$ & 0 & 1.8 & \\
\hline c5h5n & photon & $\mathrm{c} 2 \mathrm{~h} 4$ & hc3n & & $4.00 \mathrm{e}-12$ & 0 & 1.8 & \\
\hline c $5 \mathrm{~h} 5 \mathrm{n}$ & photon & $\mathrm{c} 2 \mathrm{~h} 2$ & c3h3n & & $4.00 \mathrm{e}-12$ & 0 & 1.8 & \\
\hline $\mathrm{c}+$ & c3h3n & $\mathrm{c} 3 \mathrm{~h} 2+$ & hen & & $9.84 \mathrm{e}-10$ & 0 & 0 & \\
\hline $\mathrm{c}+$ & c3h3n & c3h3+ & $\mathrm{cn}$ & & $1.80 \mathrm{e}-09$ & 0 & 0 & \\
\hline c3h3n & phosec & $\mathrm{c} 2 \mathrm{~h} 3$ & $\mathrm{cn}$ & & $1.30 \mathrm{e}-17$ & 0 & 375 & \\
\hline c3h3n & photon & $\mathrm{c} 2 \mathrm{~h} 3$ & $\mathrm{cn}$ & & $1.00 \mathrm{e}-10$ & 0 & 1.7 & \\
\hline $\mathrm{cn}$ & $\mathrm{c} 2 \mathrm{~h} 4$ & c3h3n & $\mathrm{h}$ & & $1.25 \mathrm{e}-10$ & 0.7 & 30 & \\
\hline $\mathrm{c} 2 \mathrm{~h} 4$ & $\mathrm{c} 2 \mathrm{~h} 6+$ & $\mathrm{c} 2 \mathrm{~h} 6$ & $\mathrm{c} 2 \mathrm{~h} 4+$ & & $1.15 \mathrm{e}-09$ & 0 & 0 & \\
\hline $\operatorname{ch} 3$ & $\operatorname{ch} 3$ & $\mathrm{c} 2 \mathrm{~h} 6$ & photon & & $1.68 \mathrm{e}-24$ & -7 & 1390 & \\
\hline $\mathrm{c} 2 \mathrm{~h} 6+$ & $\mathrm{h} 2 \mathrm{~s}$ & $\mathrm{~h} 2 \mathrm{~s}+$ & $\mathrm{c} 2 \mathrm{~h} 6$ & & $1.98 \mathrm{e}-09$ & 0 & 0 & \\
\hline nh3 & $\mathrm{c} 2 \mathrm{~h} 6+$ & $\mathrm{c} 2 \mathrm{~h} 6$ & nh3+ & & $6.24 \mathrm{e}-10$ & 0 & 0 & \\
\hline oh & $\mathrm{c} 2 \mathrm{~h} 5$ & c $2 \mathrm{~h} 6$ & o & & $1.04 \mathrm{e}-18$ & 8.8 & 250 & \\
\hline $\mathrm{oh}+$ & $\mathrm{c} 2 \mathrm{~h} 6$ & $\mathrm{c} 2 \mathrm{~h} 4$ & h3o+ & & $1.60 \mathrm{e}-10$ & 0 & 0 & \\
\hline $\mathrm{oh}+$ & c $2 \mathrm{~h} 6$ & $\mathrm{c} 2 \mathrm{~h} 6+$ & oh & & $4.80 \mathrm{e}-11$ & 0 & 0 & \\
\hline $\mathrm{oh}+$ & $\mathrm{c} 2 \mathrm{~h} 6$ & $\mathrm{c} 2 \mathrm{~h} 4+$ & oh & $\mathrm{h} 2$ & $1.04 \mathrm{e}-09$ & 0 & 0 & \\
\hline $\mathrm{c}+$ & $\mathrm{c} 2 \mathrm{~h} 6$ & c3h3+ & h2 & $\mathrm{h}$ & $7.10 \mathrm{e}-10$ & 0 & 0 & \\
\hline$c+$ & $\mathrm{c} 2 \mathrm{~h} 6$ & $\mathrm{c} 2 \mathrm{~h} 4+$ & $\operatorname{ch} 2$ & & $1.16 \mathrm{e}-10$ & 0 & 0 & \\
\hline$c+$ & $\mathrm{c} 2 \mathrm{~h} 6$ & c3h2+ & h2 & $\mathrm{h} 2$ & $1.65 \mathrm{e}-11$ & 0 & 0 & \\
\hline $\mathrm{c}+$ & $\mathrm{c} 2 \mathrm{~h} 6$ & $\mathrm{c} 2 \mathrm{~h} 3+$ & ch3 & & $4.95 \mathrm{e}-10$ & 0 & 0 & \\
\hline$c+$ & $\mathrm{c} 2 \mathrm{~h} 6$ & $\mathrm{c} 2 \mathrm{~h} 2+$ & $\operatorname{ch} 4$ & & $8.25 \mathrm{e}-11$ & 0 & 0 & \\
\hline $\mathrm{c} 2 \mathrm{~h} 2+$ & $\mathrm{c} 2 \mathrm{~h} 6$ & $\mathrm{c} 2 \mathrm{~h} 4+$ & c2h4 & & $2.48 \mathrm{e}-10$ & 0 & 0 & \\
\hline $\mathrm{c} 2 \mathrm{~h} 2+$ & $\mathrm{c} 2 \mathrm{~h} 6$ & c3h5+ & $\operatorname{ch} 3$ & & $7.45 \mathrm{e}-10$ & 0 & 0 & \\
\hline c $2 \mathrm{~h} 3+$ & $\mathrm{c} 2 \mathrm{~h} 6$ & c3h5+ & $\operatorname{ch} 4$ & & $2.48 \mathrm{e}-10$ & 0 & 0 & \\
\hline $\mathrm{ch}$ & $\mathrm{c} 2 \mathrm{~h} 6$ & $\mathrm{c} 2 \mathrm{~h} 4$ & $\operatorname{ch} 3$ & & $1.63 \mathrm{e}-10$ & 0 & 0 & \\
\hline $\operatorname{ch} 3+$ & $\mathrm{c} 2 \mathrm{~h} 6$ & c3h5+ & $\mathrm{h} 2$ & $\mathrm{~h} 2$ & $1.57 \mathrm{e}-10$ & 0 & 0 & \\
\hline $\mathrm{c} 2 \mathrm{~h} 6$ & phosec & $\mathrm{c} 2 \mathrm{~h} 4$ & h2 & & $1.30 \mathrm{e}-17$ & 0 & 1881 & \\
\hline $\mathrm{c} 2 \mathrm{~h} 6$ & phosec & $\mathrm{c} 2 \mathrm{~h} 6+$ & electr & & $1.30 \mathrm{e}-17$ & 0 & 389 & \\
\hline $\mathrm{cn}$ & $\mathrm{c} 2 \mathrm{~h} 6$ & $\mathrm{c} 2 \mathrm{~h} 5$ & hen & & $4.80 \mathrm{e}-12$ & 2.08 & -484 & \\
\hline $\mathrm{h}+$ & $\mathrm{c} 2 \mathrm{~h} 6$ & $\mathrm{c} 2 \mathrm{~h} 4+$ & h2 & $\mathrm{h}$ & $1.40 \mathrm{e}-09$ & 0 & 0 & \\
\hline $\mathrm{h}+$ & $\mathrm{c} 2 \mathrm{~h} 6$ & $\mathrm{c} 2 \mathrm{~h} 3+$ & h2 & $\mathrm{h} 2$ & $2.80 \mathrm{e}-09$ & 0 & 0 & \\
\hline $\mathrm{h} 2+$ & $\mathrm{c} 2 \mathrm{~h} 6$ & $\mathrm{c} 2 \mathrm{~h} 6+$ & h2 & & $2.94 \mathrm{e}-10$ & 0 & 0 & \\
\hline $\mathrm{h} 2+$ & $\mathrm{c} 2 \mathrm{~h} 6$ & $\mathrm{c} 2 \mathrm{~h} 4+$ & h2 & $\mathrm{h} 2$ & $2.35 \mathrm{e}-09$ & 0 & 0 & \\
\hline $\mathrm{h} 2 \mathrm{o}+$ & $\mathrm{c} 2 \mathrm{~h} 6$ & $\mathrm{c} 2 \mathrm{~h} 4+$ & h2o & h2 & $1.92 \mathrm{e}-10$ & 0 & 0 & \\
\hline $\mathrm{h} 2 \mathrm{o}+$ & $\mathrm{c} 2 \mathrm{~h} 6$ & $\mathrm{c} 2 \mathrm{~h} 6+$ & h2o & & $6.40 \mathrm{e}-11$ & 0 & 0 & \\
\hline $\mathrm{h} 2 \mathrm{o}+$ & $\mathrm{c} 2 \mathrm{~h} 6$ & $\mathrm{c} 2 \mathrm{~h} 5$ & h3o+ & & $1.33 \mathrm{e}-09$ & 0 & 0 & \\
\hline
\end{tabular}

Continua na próxima página... 
Tabela B.2 - Continuação

\begin{tabular}{|c|c|c|c|c|c|c|c|c|c|}
\hline \multicolumn{2}{|c|}{ Reagentes } & \multicolumn{4}{|c|}{ Produtos } & \multirow{2}{*}{$\frac{\gamma}{8.40 \mathrm{e}-10}$} & \multirow{2}{*}{$\begin{array}{c}\alpha \\
0\end{array}$} & \multirow{2}{*}{$\begin{array}{l}\beta \\
0\end{array}$} & \multirow{2}{*}{ Tipo de Reação } \\
\hline he+ & $\mathrm{c} 2 \mathrm{~h} 6$ & $\mathrm{c} 2 \mathrm{~h} 2+$ & he & $\mathrm{h} 2$ & h2 & & & & \\
\hline he+ & $\mathrm{c} 2 \mathrm{~h} 6$ & $\mathrm{c} 2 \mathrm{~h} 4+$ & he & h2 & & $4.20 \mathrm{e}-10$ & 0 & 0 & \\
\hline he+ & c $2 \mathrm{~h} 6$ & $\mathrm{c} 2 \mathrm{~h} 3+$ & he & h2 & $\mathrm{h}$ & $1.80 \mathrm{e}-09$ & 0 & 0 & \\
\hline $\mathrm{c} 2 \mathrm{~h} 2$ & $\mathrm{c} 2 \mathrm{~h} 6+$ & c3h5+ & $\operatorname{ch} 3$ & & & $9.10 \mathrm{e}-10$ & 0 & 0 & \\
\hline $\mathrm{c} 2 \mathrm{~h} 6+$ & electr & $\mathrm{c} 2 \mathrm{~h} 4$ & h2 & & & $1.50 \mathrm{e}-07$ & -0.5 & 0 & \\
\hline $\mathrm{c} 2 \mathrm{~h} 6+$ & electr & $\mathrm{c} 2 \mathrm{~h} 5$ & $\mathrm{~h}$ & & & $1.50 \mathrm{e}-07$ & -0.5 & 0 & \\
\hline $\mathrm{c} 2 \mathrm{~h} 6+$ & $\mathrm{h} 2 \mathrm{~s}$ & h3s+ & $\mathrm{c} 2 \mathrm{~h} 5$ & & & $8.90 \mathrm{e}-10$ & 0 & 0 & \\
\hline $\mathrm{h} 2 \mathrm{o}$ & $\mathrm{c} 2 \mathrm{~h} 6+$ & c $2 \mathrm{~h} 5$ & h3o+ & & & $2.95 \mathrm{e}-09$ & 0 & 0 & \\
\hline h3+ & $\mathrm{c} 2 \mathrm{~h} 5$ & $\mathrm{c} 2 \mathrm{~h} 6+$ & h2 & & & $1.40 \mathrm{e}-09$ & 0 & 0 & \\
\hline hco+ & $\mathrm{c} 2 \mathrm{~h} 5$ & $\mathrm{c} 2 \mathrm{~h} 6+$ & $\mathrm{co}$ & & & $1.40 \mathrm{e}-09$ & 0 & 0 & \\
\hline nh3 & $\mathrm{c} 2 \mathrm{~h} 6+$ & c $2 \mathrm{~h} 5$ & nh4+ & & & $1.40 \mathrm{e}-09$ & 0 & 0 & \\
\hline c3n & $\mathrm{c} 2 \mathrm{~h} 6$ & c5h5n & $\mathrm{h}$ & & & $4.00 \mathrm{e}-10$ & 0 & 0 & \\
\hline h3+ & o2 & $\mathrm{o} 2 \mathrm{~h}+$ & $\mathrm{h} 2$ & & & $5.00 \mathrm{e}-09$ & 0 & 150.0 & 4 \\
\hline $\mathrm{h} 2+$ & o2 & $\mathrm{o} 2 \mathrm{~h}+$ & $\mathrm{h}$ & & & $1.90 \mathrm{e}-09$ & 0 & 0.0 & 4 \\
\hline $\mathrm{o} 2 \mathrm{~h}+$ & $\mathrm{h} 2$ & h3+ & o 2 & & & $6.40 \mathrm{e}-10$ & 0 & 0.0 & 4 \\
\hline $\mathrm{o} 2 \mathrm{~h}+$ & electr & o2 & $\mathrm{h}$ & & & $3.00 \mathrm{e}-07$ & -0.5 & 0.0 & 4 \\
\hline $\mathrm{o} 2 \mathrm{~h}+$ & $\operatorname{ch} 4$ & $\operatorname{ch} 5+$ & o 2 & & & $1.00 \mathrm{e}-09$ & 0 & 0.0 & 4 \\
\hline $\mathrm{o} 2 \mathrm{~h}+$ & nh3 & nh4+ & $\mathrm{o} 2$ & & & $1.80 \mathrm{e}-09$ & 0 & 0.0 & 4 \\
\hline $\mathrm{o} 2 \mathrm{~h}+$ & $\mathrm{n} 2$ & $\mathrm{n} 2 \mathrm{~h}+$ & o 2 & & & $8.00 \mathrm{e}-10$ & 0 & 0.0 & 4 \\
\hline $\mathrm{o} 2 \mathrm{~h}+$ & no & hno+ & o2 & & & $7.00 \mathrm{e}-10$ & 0 & 0.0 & 4 \\
\hline $\mathrm{o} 2 \mathrm{~h}+$ & $\mathrm{c}$ & $\operatorname{ch}+$ & o 2 & & & $1.00 \mathrm{e}-09$ & 0 & 0.0 & 4 \\
\hline $\mathrm{o} 2 \mathrm{~h}+$ & o & $\mathrm{oh}+$ & $\mathrm{o} 2$ & & & $6.20 \mathrm{e}-10$ & 0 & 0.0 & 4 \\
\hline $\mathrm{o} 2 \mathrm{~h}+$ & $\mathrm{n}$ & $\mathrm{nh}+$ & o2 & & & $6.40 \mathrm{e}-12$ & 0 & 0.0 & 4 \\
\hline $\mathrm{o} 2 \mathrm{~h}+$ & $\mathrm{s}$ & $\operatorname{sh}+$ & o 2 & & & $1.10 \mathrm{e}-09$ & 0 & 0.0 & 4 \\
\hline $\mathrm{o} 2 \mathrm{~h}+$ & $\mathrm{ch}$ & $\operatorname{ch} 2+$ & o2 & & & $6.20 \mathrm{e}-10$ & 0 & 0.0 & 4 \\
\hline $\mathrm{o} 2 \mathrm{~h}+$ & $\operatorname{ch} 2$ & $\operatorname{ch} 3+$ & o2 & & & $8.50 \mathrm{e}-10$ & 0 & 0.0 & 4 \\
\hline $\mathrm{o} 2 \mathrm{~h}+$ & $\mathrm{nh}$ & nh2 $2+$ & o 2 & & & $6.30 \mathrm{e}-10$ & 0 & 0.0 & 4 \\
\hline $\mathrm{o} 2 \mathrm{~h}+$ & nh2 & nh3+ & o2 & & & $8.70 \mathrm{e}-10$ & 0 & 0.0 & 4 \\
\hline $\mathrm{o} 2 \mathrm{~h}+$ & oh & $\mathrm{h} 2 \mathrm{o}+$ & $\mathrm{o} 2$ & & & $6.10 \mathrm{e}-10$ & 0 & 0.0 & 4 \\
\hline $\mathrm{o} 2 \mathrm{~h}+$ & h2o & h3o+ & $\mathrm{o} 2$ & & & $8.20 \mathrm{e}-10$ & 0 & 0.0 & 4 \\
\hline $\mathrm{o} 2 \mathrm{~h}+$ & $\mathrm{c} 2$ & $\mathrm{c} 2 \mathrm{~h}+$ & $\mathrm{o} 2$ & & & $8.10 \mathrm{e}-10$ & 0 & 0.0 & 4 \\
\hline $\mathrm{o} 2 \mathrm{~h}+$ & $\mathrm{c} 2 \mathrm{~h}$ & $\mathrm{c} 2 \mathrm{~h} 2+$ & o 2 & & & $7.60 \mathrm{e}-10$ & 0 & 0.0 & 4 \\
\hline $\mathrm{o} 2 \mathrm{~h}+$ & $\mathrm{cn}$ & hen+ & o2 & & & $8.60 \mathrm{e}-10$ & 0 & 0.0 & 4 \\
\hline $\mathrm{o} 2 \mathrm{~h}+$ & hen & hcnh+ & o2 & & & $9.70 \mathrm{e}-10$ & 0 & 0.0 & 4 \\
\hline $\mathrm{o} 2 \mathrm{~h}+$ & hnc & $\mathrm{hcnh}+$ & o 2 & & & $9.70 \mathrm{e}-10$ & 0 & 0.0 & 4 \\
\hline $\mathrm{o} 2 \mathrm{~h}+$ & $\mathrm{co}$ & hco+ & o2 & & & $8.40 \mathrm{e}-10$ & 0 & 0.0 & 4 \\
\hline $\mathrm{o} 2 \mathrm{~h}+$ & $\operatorname{co} 2$ & hco $2+$ & o2 & & & $1.10 \mathrm{e}-09$ & 0 & 0.0 & 4 \\
\hline $\mathrm{n}$ & crp & $\mathrm{n}+$ & electr & & & $2.10 \mathrm{e}+00$ & 0 & 0.0 & 1 \\
\hline $\mathrm{n} 2$ & phosec & $\mathrm{n}$ & $\mathrm{n}$ & & & $5.00 \mathrm{e}+00$ & 0 & 0.0 & 2 \\
\hline $\mathrm{cn}$ & phosec & c & $\mathrm{n}$ & & & $1.06 \mathrm{e}+04$ & 0 & 0.0 & 2 \\
\hline $\mathrm{nh}$ & phosec & $\mathrm{n}$ & $\mathrm{h}$ & & & $5.00 \mathrm{e}+02$ & 0 & 0.0 & 2 \\
\hline nh2 & phosec & $\mathrm{nh}$ & $\mathrm{h}$ & & & $8.00 \mathrm{e}+01$ & 0 & 0.0 & 2 \\
\hline nh2 & phosec & nh2+ & electr & & & $6.50 \mathrm{e}+02$ & 0 & 0.0 & 2 \\
\hline
\end{tabular}

Continua na próxima página... 
Tabela B.2 - Continuação

\begin{tabular}{|c|c|c|c|c|c|c|c|}
\hline \multicolumn{2}{|c|}{ Reagentes } & & Produtos & $\gamma$ & $\alpha$ & $\beta$ & Tipo de Reação \\
\hline nh3 & phosec & $\mathrm{nh}$ & h2 & $5.40 \mathrm{e}+02$ & 0 & 0.0 & 2 \\
\hline nh3 & phosec & nh2 & $\mathrm{h}$ & $1.32 \mathrm{e}+03$ & 0 & 0.0 & 2 \\
\hline nh3 & phosec & nh3+ & electr & $5.75 \mathrm{e}+02$ & 0 & 0.0 & 2 \\
\hline no & phosec & $\mathrm{n}$ & $\mathrm{o}$ & $4.82 \mathrm{e}+02$ & 0 & 0.0 & 2 \\
\hline no & phosec & not & electr & $4.94 \mathrm{e}+02$ & 0 & 0.0 & 2 \\
\hline hen & phosec & $\mathrm{cn}$ & $\mathrm{h}$ & $3.12 \mathrm{e}+03$ & 0 & 0.0 & 2 \\
\hline hnc & phosec & $\mathrm{cn}$ & $\mathrm{h}$ & $3.00 \mathrm{e}+03$ & 0 & 0.0 & 2 \\
\hline $\mathrm{n}$ & h2 & $\mathrm{nh}$ & $\mathrm{h}$ & $8.66 \mathrm{e}-10$ & 0.5 & 14600.0 & 4 \\
\hline $\mathrm{nh}$ & $\mathrm{h} 2$ & nh2 & $\mathrm{h}$ & $5.25 \mathrm{e}-12$ & 0.79 & 6700.0 & 4 \\
\hline $\mathrm{nh}$ & $\mathrm{h}$ & $\mathrm{n}$ & h2 & $8.66 \mathrm{e}-10$ & 0.5 & 2400.0 & 4 \\
\hline $\mathrm{nh}$ & $\mathrm{c}$ & cn & $\mathrm{h}$ & $1.10 \mathrm{e}-10$ & 0.5 & 0.0 & 4 \\
\hline $\mathrm{nh}$ & $\mathrm{o}$ & oh & $\mathrm{n}$ & $2.90 \mathrm{e}-11$ & 0.5 & 0.0 & 4 \\
\hline $\mathrm{nh}$ & $\mathrm{n}$ & n2 & $\mathrm{h}$ & $9.20 \mathrm{e}-11$ & 0 & 0.0 & 4 \\
\hline nh2 & $\mathrm{h}$ & $\mathrm{nh}$ & h2 & $5.25 \mathrm{e}-12$ & 0.79 & 2200.0 & 4 \\
\hline nh2 & $\mathrm{h} 2$ & nh3 & $\mathrm{h}$ & $6.22 \mathrm{e}-11$ & 0.5 & 6300.0 & 4 \\
\hline nh2 & o & $\mathrm{nh}$ & oh & $3.50 \mathrm{e}-12$ & 0.5 & 0.0 & 4 \\
\hline nh3 & $\mathrm{h}$ & nh2 & h2 & $6.22 \mathrm{e}-11$ & 0.5 & 5700.0 & 4 \\
\hline nh3 & o & nh2 & oh & $2.50 \mathrm{e}-12$ & 0 & 3020.0 & 4 \\
\hline nh3 & oh & nh2 & h2o & $2.30 \mathrm{e}-12$ & 0 & 800.0 & 4 \\
\hline $\mathrm{cn}$ & h2 & hen & $\mathrm{h}$ & $3.53 \mathrm{e}-13$ & 3.31 & 756.0 & 4 \\
\hline $\mathrm{cn}$ & o & $\mathrm{co}$ & $\mathrm{n}$ & $1.80 \mathrm{e}-11$ & 0.5 & 50.0 & 4 \\
\hline $\mathrm{cn}$ & o2 & no & $\mathrm{co}$ & $2.49 \mathrm{e}-11$ & -0.63 & 0.0 & 4 \\
\hline $\mathrm{cn}$ & $\mathrm{n}$ & $\mathrm{n} 2$ & $\mathrm{c}$ & $7.30 \mathrm{e}-10$ & 0 & 4500.0 & 4 \\
\hline $\mathrm{cn}$ & nh3 & nh2 & hen & $2.77 \mathrm{e}-11$ & -1.1 & 0.0 & 4 \\
\hline $\mathrm{ch}$ & $\mathrm{n}$ & $\mathrm{cn}$ & $\mathrm{h}$ & $2.10 \mathrm{e}-11$ & 0 & 0.0 & 4 \\
\hline oh & $\mathrm{n}$ & no & $\mathrm{h}$ & $5.30 \mathrm{e}-11$ & 0 & 50.0 & 4 \\
\hline o2 & $\mathrm{n}$ & no & o & $3.30 \mathrm{e}-12$ & 1 & 3150.0 & 4 \\
\hline no & $\mathrm{c}$ & cn & o & $1.10 \mathrm{e}-10$ & 0.5 & 0.0 & 4 \\
\hline no & $\mathrm{n}$ & $\mathrm{n} 2$ & o & $3.40 \mathrm{e}-11$ & 0 & 50.0 & 4 \\
\hline no & o & o2 & $\mathrm{n}$ & $7.50 \mathrm{e}-13$ & 1 & 16000.0 & 4 \\
\hline hnc & $\mathrm{h}$ & hen & $\mathrm{h}$ & $1.00 \mathrm{e}-10$ & 0.5 & 200.0 & 4 \\
\hline hnc & o & $\mathrm{co}$ & $\mathrm{nh}$ & $2.00 \mathrm{e}-10$ & 0.5 & 200.0 & 4 \\
\hline hnc & oh & h2o & $\mathrm{cn}$ & $2.00 \mathrm{e}-10$ & 0.5 & 200.0 & 4 \\
\hline hnc & o2 & $\operatorname{co} 2$ & $\mathrm{nh}$ & $2.00 \mathrm{e}-11$ & 0.5 & 2000.0 & 4 \\
\hline nh2 & $\mathrm{c}$ & hnc & $\mathrm{h}$ & $2.00 \mathrm{e}-11$ & 0.5 & 0.0 & 4 \\
\hline $\operatorname{ch} 2$ & $\mathrm{n}$ & hen & $\mathrm{h}$ & $2.00 \mathrm{e}-11$ & 0.5 & 0.0 & 4 \\
\hline $\operatorname{ch} 3$ & $\mathrm{n}$ & hen & $\mathrm{h} 2$ & $2.00 \mathrm{e}-11$ & 0.5 & 0.0 & 4 \\
\hline $\operatorname{ch} 5+$ & hnc & c2h3+ & nh3 & $1.00 \mathrm{e}-09$ & 0 & 0.0 & 4 \\
\hline $\operatorname{ch} 5+$ & hen & c $2 \mathrm{~h} 3+$ & nh3 & $1.00 \mathrm{e}-09$ & 0 & 5120.0 & 4 \\
\hline $\mathrm{n}+$ & $\mathrm{h} 2$ & $\mathrm{nh}+$ & $\mathrm{h}$ & $8.40 \mathrm{e}-10$ & 0 & 168.5 & 101 \\
\hline $\mathrm{nh}+$ & $\mathrm{h} 2$ & nh2+ & $\mathrm{h}$ & $1.27 \mathrm{e}-09$ & 0 & 0.0 & 4 \\
\hline $\mathrm{nh}+$ & $\mathrm{h} 2$ & h3+ & $\mathrm{n}$ & $2.25 \mathrm{e}-10$ & 0 & 0.0 & 4 \\
\hline
\end{tabular}

Continua na próxima página... 
Tabela B.2 - Continuação

\begin{tabular}{|c|c|c|c|c|c|c|c|}
\hline \multicolumn{2}{|c|}{ Reagentes } & & \multirow{2}{*}{$\begin{array}{c}\text { Produtos } \\
\mathrm{h}\end{array}$} & \multirow{2}{*}{$\frac{\gamma}{2.70 \mathrm{e}-10}$} & \multirow{2}{*}{$\begin{array}{l}\alpha \\
0\end{array}$} & \multirow{2}{*}{$\begin{array}{l}\beta \\
0.0\end{array}$} & \multirow{2}{*}{$\frac{\text { Tipo de Reação }}{4}$} \\
\hline nh2+ & h2 & nh3+ & & & & & \\
\hline nh3+ & $\mathrm{h} 2$ & nh4+ & $\mathrm{h}$ & $2.40 \mathrm{e}-12$ & 0 & 0.0 & 4 \\
\hline $\mathrm{nh}+$ & $\mathrm{h}$ & $\mathrm{n}+$ & $\mathrm{h} 2$ & $6.52 \mathrm{e}-10$ & 0 & 0.0 & 4 \\
\hline $\operatorname{nh} 2+$ & $\mathrm{h}$ & $\mathrm{nh}+$ & $\mathrm{h} 2$ & $1.27 \mathrm{e}-09$ & 0 & 24000.0 & 4 \\
\hline nh3+ & $\mathrm{h}$ & $\operatorname{nh} 2+$ & $\mathrm{h} 2$ & $2.25 \mathrm{e}-10$ & 0 & 12800.0 & 4 \\
\hline nh4+ & $\mathrm{h}$ & nh3+ & $\mathrm{h} 2$ & $1.00 \mathrm{e}-09$ & 0 & 11000.0 & 4 \\
\hline $\mathrm{cn}+$ & $\mathrm{h} 2$ & hen + & $\mathrm{h}$ & $5.00 \mathrm{e}-10$ & 0 & 0.0 & 4 \\
\hline $\mathrm{cn}+$ & $\mathrm{h} 2$ & hnct & $\mathrm{h}$ & $5.00 \mathrm{e}-10$ & 0 & 0.0 & 4 \\
\hline $\mathrm{cn}+$ & $\mathrm{n}$ & $\mathrm{n} 2+$ & c & $0.61 \mathrm{e}-09$ & 0 & 0.0 & 4 \\
\hline hen+ & $\mathrm{h}$ & $\mathrm{cn}+$ & $\mathrm{h} 2$ & $1.00 \mathrm{e}-09$ & 0 & 15800.0 & 4 \\
\hline hnc+ & $\mathrm{h}$ & $\mathrm{cn}+$ & $\mathrm{h} 2$ & $1.00 \mathrm{e}-09$ & 0 & 15800.0 & 4 \\
\hline hen + & $\mathrm{h} 2$ & henh+ & $\mathrm{h}$ & $9.80 \mathrm{e}-10$ & 0 & 0.0 & 4 \\
\hline hen + & $\mathrm{n}$ & $\operatorname{ch}+$ & $\mathrm{n} 2$ & $0.22 \mathrm{e}-09$ & 0 & 0.0 & 4 \\
\hline hnct & $\mathrm{h} 2$ & henh+ & $\mathrm{h}$ & $4.90 \mathrm{e}-10$ & 0 & 0.0 & 4 \\
\hline hnct & h2 & $\mathrm{h} 2 \mathrm{nc}+$ & $\mathrm{h}$ & $4.90 \mathrm{e}-10$ & 0 & 0.0 & 4 \\
\hline honh+ & $\mathrm{h}$ & hen+ & $\mathrm{h} 2$ & $9.80 \mathrm{e}-10$ & 0 & 34400.0 & 4 \\
\hline henh+ & $\mathrm{h}$ & hnct & $\mathrm{h} 2$ & $4.90 \mathrm{e}-10$ & 0 & 29400.0 & 4 \\
\hline $\mathrm{h} 2 \mathrm{nc}+$ & $\mathrm{h}$ & hnct & $\mathrm{h} 2$ & $4.90 \mathrm{e}-10$ & 0 & 29400.0 & 4 \\
\hline $\mathrm{c} 2 \mathrm{n}+$ & $\mathrm{h} 2$ & henh+ & c & $8.10 \mathrm{e}-10$ & 0 & 0.0 & 4 \\
\hline $\mathrm{n} 2+$ & $\mathrm{h} 2$ & $\mathrm{n} 2 \mathrm{~h}+$ & $\mathrm{h}$ & $2.00 \mathrm{e}-09$ & 0.24 & 0.0 & 4 \\
\hline $\mathrm{n} 2 \mathrm{~h}+$ & $\mathrm{h}$ & $\mathrm{n} 2+$ & $\mathrm{h} 2$ & $2.10 \mathrm{e}-09$ & 0 & 30300.0 & 4 \\
\hline $\mathrm{n} 2 \mathrm{~h}+$ & h2 & h3+ & $\mathrm{n} 2$ & $1.80 \mathrm{e}-09$ & 0 & 8300.0 & 4 \\
\hline $\mathrm{h}+$ & hnc & $\mathrm{h}+$ & hen & $2.51 \mathrm{e}-08$ & -0.5 & 0.0 & 4 \\
\hline $\mathrm{h}+$ & hen & $\mathrm{h}+$ & hnc & $1.00 \mathrm{e}-09$ & 0 & 7850.0 & 4 \\
\hline $\mathrm{h}+$ & $\mathrm{nh}$ & $\mathrm{nh}+$ & $\mathrm{h}$ & $1.20 \mathrm{e}-08$ & -0.5 & 0.0 & 4 \\
\hline $\mathrm{h}+$ & nh2 & $\operatorname{nh} 2+$ & $\mathrm{h}$ & $7.30 \mathrm{e}-09$ & -0.5 & 0.0 & 4 \\
\hline $\mathrm{h}+$ & nh3 & nh3+ & $\mathrm{h}$ & $5.80 \mathrm{e}-09$ & -0.5 & 0.0 & 4 \\
\hline $\mathrm{h}+$ & $\mathrm{cn}$ & $\mathrm{cn}+$ & $\mathrm{h}$ & $2.10 \mathrm{e}-09$ & 0 & 6150.0 & 4 \\
\hline $\mathrm{h}+$ & hen & hen + & $\mathrm{h}$ & $2.78 \mathrm{e}-08$ & -0.5 & 0.0 & 4 \\
\hline $\mathrm{h}+$ & hen & hnct & $\mathrm{h}$ & $0.55 \mathrm{D}-08$ & 0 & 0.0 & 4 \\
\hline $\mathrm{h}+$ & hnc & hnc+ & $\mathrm{h}$ & $0.11 \mathrm{D}-07$ & 0 & 22.0 & 4 \\
\hline $\mathrm{h}+$ & no & no+ & h & $1.40 \mathrm{e}-09$ & -0.5 & 0.0 & 4 \\
\hline $\mathrm{h} 2+$ & $\mathrm{n}$ & $\mathrm{nh}+$ & $\mathrm{h}$ & $1.90 \mathrm{e}-09$ & 0 & 0.0 & 4 \\
\hline $\mathrm{h} 2+$ & $\mathrm{n} 2$ & $\mathrm{n} 2 \mathrm{~h}+$ & $\mathrm{h}$ & $2.00 \mathrm{e}-09$ & 0 & 0.0 & 4 \\
\hline $\mathrm{h} 2+$ & $\mathrm{nh}$ & $\mathrm{nh}+$ & $\mathrm{h} 2$ & $7.60 \mathrm{e}-10$ & 0 & 0.0 & 4 \\
\hline $\mathrm{h} 2+$ & $\mathrm{nh}$ & $\operatorname{nh} 2+$ & $\mathrm{h}$ & $7.60 \mathrm{e}-10$ & 0 & 0.0 & 4 \\
\hline $\mathrm{h} 2+$ & nh2 & $\mathrm{nh} 2+$ & $\mathrm{h} 2$ & $2.10 \mathrm{e}-09$ & 0 & 0.0 & 4 \\
\hline $\mathrm{h} 2+$ & nh3 & $\operatorname{nh} 3+$ & $\mathrm{h} 2$ & $5.70 \mathrm{e}-09$ & 0 & 0.0 & 4 \\
\hline $\mathrm{h} 2+$ & $\mathrm{cn}$ & $\mathrm{cn}+$ & $\mathrm{h} 2$ & $1.20 \mathrm{e}-09$ & 0 & 0.0 & 4 \\
\hline $\mathrm{h} 2+$ & $\mathrm{cn}$ & hen + & $\mathrm{h}$ & $1.20 \mathrm{e}-09$ & 0 & 0.0 & 4 \\
\hline $\mathrm{h} 2+$ & $\mathrm{cn}$ & hnct & $\mathrm{h}$ & $1.20 \mathrm{e}-09$ & 0 & 0.0 & 4 \\
\hline $\mathrm{h} 2+$ & hen & hen+ & $\mathrm{h} 2$ & $2.70 \mathrm{e}-09$ & 0 & 0.0 & 4 \\
\hline $\mathrm{h} 2+$ & hnc & hnc+ & $\mathrm{h} 2$ & $2.70 \mathrm{e}-09$ & 0 & 0.0 & 4 \\
\hline
\end{tabular}

Continua na próxima página... 
Tabela B.2 - Continuação

\begin{tabular}{|c|c|c|c|c|c|c|c|c|}
\hline \multicolumn{2}{|c|}{ Reagentes } & \multicolumn{3}{|c|}{ Produtos } & \multirow{2}{*}{$\frac{\gamma}{1.10 \mathrm{e}-09}$} & \multirow{2}{*}{$\begin{array}{c}\alpha \\
0\end{array}$} & \multirow{2}{*}{$\begin{array}{c}\beta \\
0.0\end{array}$} & \multirow{2}{*}{$\begin{array}{c}\text { Tipo de Reação } \\
4\end{array}$} \\
\hline h2+ & no & not & h2 & & & & & \\
\hline h2+ & no & hnot & $\mathrm{h}$ & & $1.10 \mathrm{e}-09$ & 0 & 0.0 & 4 \\
\hline he+ & $\mathrm{nh}$ & $\mathrm{n}+$ & $\mathrm{h}$ & he & $1.10 \mathrm{e}-09$ & 0 & 0.0 & 4 \\
\hline he+ & nh2 & $\mathrm{nh}+$ & $\mathrm{h}$ & he & $8.00 \mathrm{e}-10$ & 0 & 0.0 & 4 \\
\hline he+ & nh2 & $\mathrm{n}+$ & h2 & he & $8.00 \mathrm{e}-10$ & 0 & 0.0 & 4 \\
\hline he+ & nh3 & nh3+ & he & & $2.64 \mathrm{e}-10$ & 0 & 0.0 & 4 \\
\hline he+ & nh3 & nh2+ & $\mathrm{h}$ & he & $1.76 \mathrm{e}-09$ & 0 & 0.0 & 4 \\
\hline he+ & nh3 & $\mathrm{nh}+$ & h2 & he & $1.76 \mathrm{e}-10$ & 0 & 0.0 & 4 \\
\hline he+ & $\mathrm{cn}$ & $\mathrm{c}+$ & $\mathrm{n}$ & he & $8.80 \mathrm{e}-10$ & 0 & 0.0 & 4 \\
\hline he+ & $\mathrm{cn}$ & $\mathrm{n}+$ & $\mathrm{c}$ & he & $8.80 \mathrm{e}-10$ & 0 & 0.0 & 4 \\
\hline he+ & hen & $\mathrm{cn}+$ & $\mathrm{h}$ & he & $1.46 \mathrm{e}-09$ & 0 & 0.0 & 4 \\
\hline he+ & hen & $\mathrm{ch}+$ & $\mathrm{n}$ & he & $6.20 \mathrm{e}-10$ & 0 & 0.0 & 4 \\
\hline he+ & hen & $\mathrm{c}+$ & $\mathrm{nh}$ & he & $7.75 \mathrm{e}-10$ & 0 & 0.0 & 4 \\
\hline he+ & hen & $\mathrm{n}+$ & $\mathrm{ch}$ & he & $2.48 \mathrm{e}-10$ & 0 & 0.0 & 4 \\
\hline he+ & hnc & $\mathrm{cn}+$ & $\mathrm{h}$ & he & $1.55 \mathrm{e}-09$ & 0 & 0.0 & 4 \\
\hline he+ & hnc & $\mathrm{c}+$ & nh & he & $1.55 \mathrm{e}-09$ & 0 & 0.0 & 4 \\
\hline he+ & $\mathrm{n} 2$ & $\mathrm{n}+$ & $\mathrm{n}$ & he & $7.92 \mathrm{e}-10$ & 0 & 0.0 & 4 \\
\hline he+ & $\mathrm{n} 2$ & $\mathrm{n} 2+$ & he & & $4.08 \mathrm{e}-10$ & 0 & 0.0 & 4 \\
\hline he+ & no & $\mathrm{n}+$ & o & he & $1.38 \mathrm{e}-09$ & 0 & 0.0 & 4 \\
\hline he+ & no & $\mathrm{o}+$ & $\mathrm{n}$ & he & $2.24 \mathrm{e}-10$ & 0 & 0.0 & 4 \\
\hline h3+ & $\mathrm{n}$ & nh2+ & $\mathrm{h}$ & & $4.50 \mathrm{e}-20$ & 0 & 0.0 & 4 \\
\hline h3+ & $\mathrm{nh}$ & nh2+ & h2 & & $7.50 \mathrm{e}-09$ & -0.5 & 0.0 & 4 \\
\hline h3+ & nh2 & nh3+ & h2 & & $4.50 \mathrm{e}-09$ & -0.5 & 0.0 & 4 \\
\hline h3+ & nh3 & nh4+ & $\mathrm{h} 2$ & & $3.60 \mathrm{e}-09$ & -0.5 & 0.0 & 4 \\
\hline h3+ & $\mathrm{cn}$ & hen+ & h2 & & $8.10 \mathrm{e}-09$ & -0.5 & 0.0 & 4 \\
\hline h3+ & $\mathrm{cn}$ & hnc+ & $\mathrm{h} 2$ & & $8.10 \mathrm{e}-09$ & -0.5 & 0.0 & 4 \\
\hline h3+ & $\mathrm{cn}$ & hcnh + & $\mathrm{h}$ & & $1.00 \mathrm{e}-09$ & 0 & 0.0 & 4 \\
\hline h3+ & hen & hcnh+ & $\mathrm{h} 2$ & & $1.70 \mathrm{e}-08$ & -0.5 & 0.0 & 4 \\
\hline h3+ & hnc & hcnh+ & $\mathrm{h} 2$ & & $1.50 \mathrm{e}-08$ & -0.5 & 0.0 & 4 \\
\hline h3+ & $\mathrm{cn}$ & $\mathrm{h} 2 \mathrm{nc}+$ & $\mathrm{h}$ & & $0.10 \mathrm{D}-08$ & 0 & 0.0 & 4 \\
\hline h3+ & hnc & h2nc+ & h2 & & $0.47 \mathrm{D}-08$ & 0 & 0.0 & 4 \\
\hline h3+ & $\mathrm{n} 2$ & $\mathrm{n} 2 \mathrm{~h}+$ & h2 & & $1.63 \mathrm{e}-09$ & 0 & 0.0 & 4 \\
\hline h3+ & no & hnot & h2 & & $8.50 \mathrm{e}-10$ & -0.5 & 0.0 & 4 \\
\hline $\mathrm{o}+$ & $\mathrm{cn}$ & no+ & $\mathrm{c}$ & & $1.00 \mathrm{e}-09$ & 0 & 0.0 & 4 \\
\hline $\mathrm{o}+$ & $\mathrm{n} 2$ & not & $\mathrm{n}$ & & $1.20 \mathrm{e}-12$ & 0 & 0.0 & 4 \\
\hline $\mathrm{o}+$ & $\mathrm{nh}$ & $\mathrm{nh}+$ & o & & $3.60 \mathrm{e}-10$ & 0 & 0.0 & 4 \\
\hline $\mathrm{o}+$ & $\mathrm{nh}$ & not & $\mathrm{h}$ & & $3.60 \mathrm{e}-10$ & 0 & 0.0 & 4 \\
\hline $\mathrm{o}+$ & nh2 & nh2+ & o & & $1.00 \mathrm{e}-09$ & 0 & 0.0 & 4 \\
\hline$o+$ & hen & $\mathrm{co}+$ & nh & & $1.20 \mathrm{e}-09$ & 0 & 0.0 & 4 \\
\hline $\mathrm{o}+$ & hen & no+ & $\mathrm{ch}$ & & $1.20 \mathrm{e}-09$ & 0 & 0.0 & 4 \\
\hline $\mathrm{o}+$ & hen & hco+ & $\mathrm{n}$ & & $1.20 \mathrm{e}-09$ & 0 & 0.0 & 4 \\
\hline $\mathrm{o}+$ & hnc & $\mathrm{co}+$ & $\mathrm{nh}$ & & $1.20 \mathrm{e}-09$ & 0 & 0.0 & 4 \\
\hline $\mathrm{o}+$ & hnc & no+ & $\mathrm{ch}$ & & $1.20 \mathrm{e}-09$ & 0 & 0.0 & 4 \\
\hline
\end{tabular}

Continua na próxima página... 
Tabela B.2 - Continuação

\begin{tabular}{|c|c|c|c|c|c|c|c|}
\hline \multicolumn{2}{|c|}{ Reagentes } & \multicolumn{2}{|r|}{ Produtos } & \multirow{2}{*}{$\frac{\gamma}{1.20 \mathrm{e}-09}$} & \multirow{2}{*}{$\begin{array}{c}\alpha \\
0 \\
0\end{array}$} & \multirow{2}{*}{$\begin{array}{l}\beta \\
0.0\end{array}$} & \multirow{2}{*}{$\begin{array}{c}\text { Tipo de Reação } \\
4\end{array}$} \\
\hline $\mathrm{o}+$ & hnc & hoct & $\mathrm{n}$ & & & & \\
\hline $\mathrm{o}+$ & nh3 & nh3+ & o & $1.20 \mathrm{e}-09$ & 0 & 0.0 & 4 \\
\hline $\mathrm{oh}+$ & $\mathrm{n}$ & no+ & $\mathrm{h}$ & $8.90 \mathrm{e}-10$ & 0 & 0.0 & 4 \\
\hline $\mathrm{oh}+$ & $\mathrm{cn}$ & hen+ & $\mathrm{O}$ & $1.00 \mathrm{e}-09$ & 0 & 0.0 & 4 \\
\hline $\mathrm{oh}+$ & $\mathrm{nh}$ & nh2+ & o & $3.60 \mathrm{e}-10$ & 0 & 0.0 & 4 \\
\hline $\mathrm{oh}+$ & no & not & oh & $3.60 \mathrm{e}-10$ & 0 & 0.0 & 4 \\
\hline $\mathrm{oh}+$ & no & hno+ & o & $6.10 \mathrm{e}-10$ & 0 & 0.0 & 4 \\
\hline $\mathrm{oh}+$ & hen & hcnh+ & o & $1.20 \mathrm{e}-09$ & 0 & 0.0 & 4 \\
\hline $\mathrm{oh}+$ & hnc & henh+ & o & $1.20 \mathrm{e}-09$ & 0 & 0.0 & 4 \\
\hline $\mathrm{oh}+$ & nh2 & nh2+ & oh & $5.00 \mathrm{e}-10$ & 0 & 0.0 & 4 \\
\hline $\mathrm{oh}+$ & nh2 & nh3+ & o & $5.00 \mathrm{e}-10$ & 0 & 0.0 & 4 \\
\hline $\mathrm{oh}+$ & nh3 & nh3+ & $\mathrm{oh}$ & $1.20 \mathrm{e}-09$ & 0 & 0.0 & 4 \\
\hline $\mathrm{oh}+$ & nh3 & nh4+ & o & $1.20 \mathrm{e}-09$ & 0 & 0.0 & 4 \\
\hline $\mathrm{h} 2 \mathrm{o}+$ & $\mathrm{n}$ & hno+ & $\mathrm{h}$ & $1.90 \mathrm{e}-10$ & 0 & 0.0 & 4 \\
\hline h2o+ & $\mathrm{nh}$ & h3o+ & $\mathrm{n}$ & $7.10 \mathrm{e}-10$ & 0 & 0.0 & 4 \\
\hline $\mathrm{h} 2 \mathrm{o}+$ & no & not & h2o & $1.20 \mathrm{e}-09$ & 0 & 0.0 & 4 \\
\hline $\mathrm{h} 2 \mathrm{o}+$ & hen & hcnh+ & oh & $2.10 \mathrm{e}-09$ & 0 & 0.0 & 4 \\
\hline h2o+ & hnc & hcnh+ & oh & $1.10 \mathrm{e}-09$ & 0 & 0.0 & 4 \\
\hline $\mathrm{h} 2 \mathrm{o}+$ & nh2 & nh2+ & h2o & $4.90 \mathrm{e}-10$ & 0 & 0.0 & 4 \\
\hline $\mathrm{h} 2 \mathrm{o}+$ & nh2 & nh3+ & oh & $4.90 \mathrm{e}-10$ & 0 & 0.0 & 4 \\
\hline h2o+ & nh3 & nh3+ & h2o & $2.20 \mathrm{e}-09$ & 0 & 0.0 & 4 \\
\hline h2o+ & nh3 & nh4+ & $\mathrm{oh}$ & $9.00 \mathrm{e}-10$ & 0 & 0.0 & 4 \\
\hline h3o+ & nh3 & nh4+ & h2o & $2.20 \mathrm{e}-09$ & 0 & 0.0 & 4 \\
\hline h3o+ & $\mathrm{cn}$ & hcnh+ & oh & $4.50 \mathrm{e}-09$ & 0 & 0.0 & 4 \\
\hline h3o+ & hen & henh+ & h2o & $4.50 \mathrm{e}-09$ & 0 & 0.0 & 4 \\
\hline h3o+ & hnc & henh+ & h2o & $2.25 \mathrm{e}-09$ & 0 & 0.0 & 4 \\
\hline h3o+ & hnc & h2nc+ & h2o & $2.25 \mathrm{e}-09$ & 0 & 0.0 & 4 \\
\hline $\mathrm{c}+$ & $\mathrm{nh}$ & $\mathrm{cn}+$ & $\mathrm{h}$ & $4.60 \mathrm{e}-09$ & -0.5 & 0.0 & 4 \\
\hline $\mathrm{c}+$ & nh2 & hen+ & $\mathrm{h}$ & $2.70 \mathrm{e}-09$ & -0.5 & 0.0 & 4 \\
\hline $\mathrm{c}+$ & nh2 & hnc+ & $\mathrm{h}$ & $2.70 \mathrm{e}-09$ & -0.5 & 0.0 & 4 \\
\hline $\mathrm{c}+$ & nh3 & nh3+ & c & $5.29 \mathrm{e}-10$ & 0 & 0.0 & 4 \\
\hline $\mathrm{c}+$ & nh3 & h2nc+ & $\mathrm{h}$ & $7.80 \mathrm{e}-10$ & 0 & 0.0 & 4 \\
\hline $\mathrm{c}+$ & nh3 & henh+ & $\mathrm{h}$ & $7.80 \mathrm{e}-10$ & 0 & 0.0 & 4 \\
\hline $\mathrm{c}+$ & nh3 & hen+ & $\mathrm{h} 2$ & $1.04 \mathrm{e}-10$ & 0 & 0.0 & 4 \\
\hline $\mathrm{c}+$ & nh3 & hnc+ & h2 & $1.04 \mathrm{e}-10$ & 0 & 0.0 & 4 \\
\hline $\mathrm{c}+$ & hen & $\mathrm{c} 2 \mathrm{n}+$ & $\mathrm{h}$ & $4.75 \mathrm{e}-09$ & -0.5 & 0.0 & 4 \\
\hline$c+$ & hnc & $\mathrm{c} 2 \mathrm{n}+$ & $\mathrm{h}$ & $4.75 \mathrm{e}-09$ & -0.5 & 0.0 & 4 \\
\hline $\mathrm{c}+$ & no & not & c & $4.80 \mathrm{e}-10$ & -0.5 & 0.0 & 4 \\
\hline$c+$ & no & $\mathrm{n}+$ & $\mathrm{co}$ & 0.90D-09 & 0 & 0.0 & 4 \\
\hline $\mathrm{o} 2+$ & $\mathrm{n}$ & no+ & o & $7.84 \mathrm{e}-11$ & 0 & 0.0 & 4 \\
\hline $\mathrm{o} 2+$ & nh2 & $\operatorname{nh} 2+$ & o 2 & $8.70 \mathrm{e}-10$ & 0 & 0.0 & 4 \\
\hline $\mathrm{o} 2+$ & nh3 & nh3+ & o2 & $2.00 \mathrm{e}-09$ & 0 & 0.0 & 4 \\
\hline $\mathrm{o} 2+$ & no & not & o2 & $4.40 \mathrm{e}-10$ & 0 & 0.0 & 4 \\
\hline
\end{tabular}

Continua na próxima página... 
Tabela B.2 - Continuação

\begin{tabular}{|c|c|c|c|c|c|c|c|}
\hline \multicolumn{2}{|c|}{ Reagentes } & \multicolumn{2}{|r|}{ Produtos } & \multirow{2}{*}{$\frac{\gamma}{8.10 \mathrm{e}-11}$} & \multirow{2}{*}{$\begin{array}{c}\alpha \\
0\end{array}$} & \multirow{2}{*}{$\begin{array}{c}\beta \\
0.0\end{array}$} & \multirow{2}{*}{$\begin{array}{c}\text { Tipo de Reação } \\
4\end{array}$} \\
\hline $\mathrm{co}+$ & $\mathrm{n}$ & not & c & & & & \\
\hline $\mathrm{co}+$ & $\mathrm{nh}$ & $\mathrm{nh}+$ & $\mathrm{co}$ & $3.20 \mathrm{e}-10$ & 0 & 0.0 & 4 \\
\hline $\mathrm{co}+$ & $\mathrm{nh}$ & hco + & $\mathrm{n}$ & $3.20 \mathrm{e}-10$ & 0 & 0.0 & 4 \\
\hline $\mathrm{co}+$ & no & no+ & $\mathrm{co}$ & $3.30 \mathrm{e}-10$ & 0 & 0.0 & 4 \\
\hline $\mathrm{co}+$ & hen & hen + & $\mathrm{co}$ & $3.40 \mathrm{e}-10$ & 0 & 0.0 & 4 \\
\hline $\mathrm{co}+$ & nh2 & hco+ & $\mathrm{nh}$ & $4.50 \mathrm{e}-10$ & 0 & 0.0 & 4 \\
\hline $\mathrm{co}+$ & nh2 & $\operatorname{nh} 2+$ & $\mathrm{co}$ & $4.50 \mathrm{e}-10$ & 0 & 0.0 & 4 \\
\hline $\mathrm{co}+$ & nh3 & hco+ & nh2 & $4.12 \mathrm{e}-11$ & 0 & 0.0 & 4 \\
\hline $\mathrm{co}+$ & nh3 & nh3+ & $\mathrm{co}$ & $2.02 \mathrm{e}-09$ & 0 & 0.0 & 4 \\
\hline hco+ & $\mathrm{n} 2$ & $\mathrm{n} 2 \mathrm{~h}+$ & $\mathrm{co}$ & $8.80 \mathrm{e}-10$ & 0 & 11200.0 & 4 \\
\hline hco+ & $\mathrm{nh}$ & nh2+ & $\mathrm{co}$ & $6.40 \mathrm{e}-10$ & 0 & 0.0 & 4 \\
\hline hco+ & nh2 & nh3+ & $\mathrm{CO}$ & $8.90 \mathrm{e}-10$ & 0 & 0.0 & 4 \\
\hline hco+ & nh3 & nh4+ & co & $1.90 \mathrm{e}-09$ & 0 & 0.0 & 4 \\
\hline hco+ & hen & henh+ & $\mathrm{co}$ & $3.70 \mathrm{e}-09$ & 0 & 0.0 & 4 \\
\hline hco+ & hnc & henh+ & $\mathrm{co}$ & $3.70 \mathrm{e}-09$ & 0 & 0.0 & 4 \\
\hline hco+ & hnc & h2nc+ & $\mathrm{co}$ & $0.19 \mathrm{D}-08$ & 0 & 0.0 & 4 \\
\hline hoc+ & $\mathrm{n} 2$ & $\mathrm{n} 2 \mathrm{~h}+$ & $\mathrm{co}$ & $2.00 \mathrm{e}-09$ & 0 & 0.0 & 4 \\
\hline hco $2+$ & no & hno+ & $\operatorname{co} 2$ & $1.00 \mathrm{e}-10$ & 0 & 0.0 & 4 \\
\hline hco $2+$ & $\mathrm{n} 2$ & $\mathrm{n} 2 \mathrm{~h}+$ & $\operatorname{co} 2$ & $1.40 \mathrm{e}-09$ & 0 & 6400.0 & 4 \\
\hline h3co+ & hnc & hcnh+ & h2co & $6.52 \mathrm{e}-09$ & -0.5 & 0.0 & 4 \\
\hline h3co+ & hnc & h2nc+ & h2co & $6.52 \mathrm{e}-09$ & -0.5 & 0.0 & 4 \\
\hline h3co+ & nh2 & nh3+ & $\mathrm{h} 2 \mathrm{co}$ & $2.20 \mathrm{e}-09$ & -0.5 & 0.0 & 4 \\
\hline h3co+ & nh3 & nh4+ & $\mathrm{h} 2 \mathrm{co}$ & $1.70 \mathrm{e}-09$ & -0.5 & 0.0 & 4 \\
\hline $\operatorname{ch}+$ & $\mathrm{n}$ & $\mathrm{cn}+$ & $\mathrm{h}$ & $1.90 \mathrm{e}-10$ & 0 & 0.0 & 4 \\
\hline $\mathrm{ch}+$ & $\mathrm{cn}$ & $\mathrm{c} 2 \mathrm{n}+$ & $\mathrm{h}$ & $1.10 \mathrm{e}-09$ & 0 & 0.0 & 4 \\
\hline $\mathrm{ch}+$ & $\mathrm{nh}$ & $\mathrm{cn}+$ & $\mathrm{h} 2$ & $7.60 \mathrm{e}-10$ & 0 & 0.0 & 4 \\
\hline $\operatorname{ch}+$ & no & no+ & $\mathrm{ch}$ & $7.60 \mathrm{e}-10$ & 0 & 0.0 & 4 \\
\hline $\mathrm{ch}+$ & hen & hcnh+ & c & $2.40 \mathrm{e}-09$ & 0 & 0.0 & 4 \\
\hline $\mathrm{ch}+$ & hnc & hcnh + & $\mathrm{c}$ & $1.80 \mathrm{e}-09$ & 0 & 0.0 & 4 \\
\hline $\mathrm{ch}+$ & nh2 & hen+ & $\mathrm{h} 2$ & $1.10 \mathrm{e}-09$ & 0 & 0.0 & 4 \\
\hline $\operatorname{ch}+$ & nh3 & nh3+ & $\mathrm{ch}$ & $4.59 \mathrm{e}-10$ & 0 & 0.0 & 4 \\
\hline $\mathrm{ch}+$ & nh3 & nh4+ & $\mathrm{c}$ & $4.05 \mathrm{e}-10$ & 0 & 0.0 & 4 \\
\hline $\operatorname{ch} 2+$ & $\mathrm{n}$ & hen+ & $\mathrm{h}$ & $4.70 \mathrm{e}-10$ & 0 & 0.0 & 4 \\
\hline $\operatorname{ch} 2+$ & $\mathrm{n}$ & hnc+ & $\mathrm{h}$ & $4.70 \mathrm{e}-10$ & 0 & 0.0 & 4 \\
\hline $\operatorname{ch} 2+$ & $\mathrm{nh}$ & hcnh+ & $\mathrm{h}$ & $7.50 \mathrm{e}-10$ & 0 & 0.0 & 4 \\
\hline $\operatorname{ch} 2+$ & no & not & $\operatorname{ch} 2$ & $4.20 \mathrm{e}-10$ & 0 & 0.0 & 4 \\
\hline $\operatorname{ch} 2+$ & nh2 & henh+ & $\mathrm{h} 2$ & $1.00 \mathrm{e}-09$ & 0 & 0.0 & 4 \\
\hline $\operatorname{ch} 2+$ & nh3 & nh4+ & $\mathrm{ch}$ & $1.30 \mathrm{e}-09$ & 0 & 0.0 & 4 \\
\hline $\operatorname{ch} 3+$ & $\mathrm{n}$ & hen+ & $\mathrm{h} 2$ & $3.35 \mathrm{e}-11$ & 0 & 0.0 & 4 \\
\hline $\operatorname{ch} 3+$ & $\mathrm{n}$ & hnc+ & $\mathrm{h} 2$ & $3.35 \mathrm{e}-11$ & 0 & 0.0 & 4 \\
\hline $\operatorname{ch} 3+$ & $\mathrm{n}$ & hcnh+ & $\mathrm{h}$ & $6.70 \mathrm{e}-11$ & 0 & 0.0 & 4 \\
\hline $\operatorname{ch} 3+$ & $\mathrm{n}$ & h2nc+ & $\mathrm{h}$ & $0.22 \mathrm{D}-10$ & 0 & 0.0 & 4 \\
\hline $\operatorname{ch} 4+$ & nh3 & nh3+ & $\operatorname{ch} 4$ & $6.90 \mathrm{e}-10$ & 0 & 0.0 & 4 \\
\hline
\end{tabular}

Continua na próxima página... 
Tabela B.2 - Continuação

\begin{tabular}{|c|c|c|c|c|c|c|c|c|}
\hline \multicolumn{2}{|c|}{ Reagentes } & \multicolumn{3}{|c|}{ Produtos } & \multirow{2}{*}{$\frac{\gamma}{6.60 \mathrm{e}-10}$} & \multirow{2}{*}{$\begin{array}{l}\alpha \\
0\end{array}$} & \multirow{2}{*}{$\begin{array}{l}\beta \\
0.0\end{array}$} & \multirow{2}{*}{$\frac{\text { Tipo de Reação }}{4}$} \\
\hline $\operatorname{ch} 4+$ & nh3 & nh4+ & $\operatorname{ch} 3$ & & & & & \\
\hline $\operatorname{ch} 4+$ & nh3 & $\operatorname{ch} 5+$ & $\mathrm{nh} 2$ & & $3.00 \mathrm{e}-11$ & 0 & 0.0 & 4 \\
\hline $\mathrm{c} 2+$ & $\mathrm{nh}$ & $\mathrm{c} 2 \mathrm{~h}+$ & $\mathrm{n}$ & & $3.30 \mathrm{e}-10$ & 0 & 0.0 & 4 \\
\hline $\mathrm{c} 2+$ & nh2 & nh2+ & $\mathrm{c} 2$ & & $4.60 \mathrm{e}-10$ & 0 & 0.0 & 4 \\
\hline $\mathrm{c} 2+$ & no & not & $\mathrm{c} 2$ & & $3.40 \mathrm{e}-10$ & 0 & 0.0 & 4 \\
\hline $\mathrm{c} 2+$ & hen & $\mathrm{c} 3 \mathrm{~h}+$ & $\mathrm{n}$ & & $7.80 \mathrm{e}-10$ & 0 & 0.0 & 4 \\
\hline $\mathrm{c} 2 \mathrm{~h}+$ & $\mathrm{n}$ & $\operatorname{ch}+$ & $\mathrm{cn}$ & & $9.00 \mathrm{e}-11$ & 0 & 0.0 & 4 \\
\hline $\mathrm{c} 2 \mathrm{~h}+$ & $\mathrm{n}$ & $\mathrm{c} 2 \mathrm{n}+$ & $\mathrm{h}$ & & $8.30 \mathrm{e}-10$ & 0 & 0.0 & 4 \\
\hline $\mathrm{c} 2 \mathrm{~h}+$ & no & no+ & $\mathrm{c} 2 \mathrm{~h}$ & & $1.20 \mathrm{e}-10$ & 0 & 0.0 & 4 \\
\hline $\mathrm{c} 2 \mathrm{~h}+$ & hcn & $\mathrm{c} 2 \mathrm{~h} 2+$ & $\mathrm{cn}$ & & $1.40 \mathrm{e}-09$ & 0 & 0.0 & 4 \\
\hline $\mathrm{c} 2 \mathrm{~h}+$ & hcn & hcnh+ & $\mathrm{c} 2$ & & $9.50 \mathrm{e}-10$ & 0 & 0.0 & 4 \\
\hline $\mathrm{c} 2 \mathrm{~h}+$ & hnc & hcnh+ & $\mathrm{c} 2$ & & $1.40 \mathrm{e}-09$ & 0 & 0.0 & 4 \\
\hline $\mathrm{c} 2 \mathrm{~h}+$ & nh2 & nh3+ & $\mathrm{c} 2$ & & $4.60 \mathrm{e}-10$ & 0 & 0.0 & 4 \\
\hline $\mathrm{c} 2 \mathrm{~h}+$ & nh3 & nh4+ & $\mathrm{c} 2$ & & $5.50 \mathrm{e}-10$ & 0 & 0.0 & 4 \\
\hline $\mathrm{c} 2 \mathrm{~h} 2+$ & $\mathrm{n}$ & $\operatorname{ch}+$ & hnc & & $2.50 \mathrm{e}-11$ & 0 & 2600.0 & 4 \\
\hline $\mathrm{c} 2 \mathrm{~h} 2+$ & $\mathrm{n}$ & $\operatorname{ch}+$ & hen & & $2.50 \mathrm{e}-11$ & 0 & 0.0 & 4 \\
\hline $\mathrm{c} 2 \mathrm{~h} 2+$ & $\mathrm{n}$ & $\mathrm{c} 2 \mathrm{n}+$ & h2 & & $7.50 \mathrm{e}-11$ & 0 & 0.0 & 4 \\
\hline $\mathrm{c} 2 \mathrm{~h} 2+$ & no & no+ & $\mathrm{c} 2 \mathrm{~h} 2$ & & $3.80 \mathrm{e}-10$ & -0.5 & 0.0 & 4 \\
\hline $\mathrm{c} 2 \mathrm{~h} 2+$ & nh2 & nh3+ & $\mathrm{c} 2 \mathrm{~h}$ & & $1.10 \mathrm{e}-09$ & -0.5 & 0.0 & 4 \\
\hline $\mathrm{c} 2 \mathrm{~h} 2+$ & nh3 & nh3+ & $\mathrm{c} 2 \mathrm{~h} 2$ & & $1.20 \mathrm{e}-09$ & -0.5 & 0.0 & 4 \\
\hline $\mathrm{c} 2 \mathrm{~h} 2+$ & nh3 & nh4+ & $\mathrm{c} 2 \mathrm{~h}$ & & $5.50 \mathrm{e}-10$ & -0.5 & 0.0 & 4 \\
\hline $\mathrm{c} 3 \mathrm{~h}+$ & no & no+ & $\mathrm{c} 3 \mathrm{~h}$ & & $1.73 \mathrm{e}-10$ & -0.5 & 0.0 & 4 \\
\hline $\mathrm{c} 3 \mathrm{~h}+$ & nh3 & nh3+ & $\mathrm{c} 3 \mathrm{~h}$ & & $5.78 \mathrm{e}-10$ & -0.5 & 0.0 & 4 \\
\hline $\mathrm{c} 3 \mathrm{~h}+$ & nh3 & nh4+ & c3 & & $5.57 \mathrm{e}-10$ & -0.5 & 0.0 & 4 \\
\hline $\mathrm{n}+$ & $\mathrm{ch}$ & $\operatorname{ch}+$ & $\mathrm{n}$ & & $3.60 \mathrm{e}-10$ & 0 & 0.0 & 4 \\
\hline $\mathrm{n}+$ & $\mathrm{ch}$ & $\mathrm{cn}+$ & $\mathrm{h}$ & & $3.60 \mathrm{e}-10$ & 0 & 0.0 & 4 \\
\hline $\mathrm{n}+$ & $\operatorname{ch} 4$ & hen+ & $\mathrm{h} 2$ & $\mathrm{~h}$ & $5.60 \mathrm{e}-11$ & 0 & 0.0 & 4 \\
\hline $\mathrm{n}+$ & $\operatorname{ch} 4$ & hnc+ & $\mathrm{h} 2$ & $\mathrm{~h}$ & $0.57 \mathrm{D}-10$ & 0 & 0.0 & 4 \\
\hline $\mathrm{n}+$ & $\operatorname{ch} 4$ & $\operatorname{ch} 3+$ & $\mathrm{n}$ & $\mathrm{h}$ & $4.70 \mathrm{e}-10$ & 0 & 0.0 & 4 \\
\hline $\mathrm{n}+$ & $\operatorname{ch} 4$ & $\operatorname{ch} 3+$ & $\mathrm{nh}$ & & $4.70 \mathrm{e}-10$ & 0 & 0.0 & 4 \\
\hline $\mathrm{n}+$ & $\operatorname{ch} 4$ & hcnh+ & $\mathrm{h}$ & $\mathrm{h}$ & $3.80 \mathrm{e}-10$ & 0 & 0.0 & 4 \\
\hline $\mathrm{n}+$ & $\operatorname{ch} 4$ & hcnh+ & $\mathrm{h} 2$ & & $3.80 \mathrm{e}-10$ & 0 & 0.0 & 4 \\
\hline $\mathrm{n}+$ & $\operatorname{ch} 4$ & $\operatorname{ch} 4+$ & $\mathrm{n}$ & & $2.80 \mathrm{e}-11$ & 0 & 0.0 & 4 \\
\hline $\mathrm{n}+$ & o2 & $\mathrm{o} 2+$ & $\mathrm{n}$ & & $2.81 \mathrm{e}-10$ & 0 & 0.0 & 4 \\
\hline $\mathrm{n}+$ & o2 & not & o & & $2.37 \mathrm{e}-10$ & 0 & 0.0 & 4 \\
\hline $\mathrm{n}+$ & $\mathrm{o} 2$ & $\mathrm{o}+$ & no & & $3.30 \mathrm{e}-11$ & 0 & 0.0 & 4 \\
\hline $\mathrm{n}+$ & $\mathrm{co}$ & $c+$ & no & & $9.02 \mathrm{e}-10$ & 0 & 15400.0 & 4 \\
\hline $\mathrm{n}+$ & $\mathrm{co}$ & $\mathrm{co}+$ & $\mathrm{n}$ & & $8.25 \mathrm{e}-10$ & 0 & 0.0 & 4 \\
\hline $\mathrm{n}+$ & $\mathrm{co}$ & no+ & c & & $1.46 \mathrm{e}-10$ & 0 & 0.0 & 4 \\
\hline $\mathrm{n}+$ & h2co & no+ & $\operatorname{ch} 2$ & & $2.90 \mathrm{e}-10$ & 0 & 0.0 & 4 \\
\hline $\mathrm{n}+$ & h2co & hco+ & $\mathrm{nh}$ & & $7.30 \mathrm{e}-10$ & 0 & 0.0 & 4 \\
\hline $\mathrm{n}+$ & $\mathrm{h} 2 \mathrm{co}$ & h2co+ & $\mathrm{n}$ & & $1.90 \mathrm{e}-09$ & 0 & 0.0 & 4 \\
\hline $\mathrm{n}+$ & no & no+ & $\mathrm{n}$ & & $4.51 \mathrm{e}-10$ & 0 & 0.0 & 4 \\
\hline
\end{tabular}

Continua na próxima página... 
Tabela B.2 - Continuação

\begin{tabular}{|c|c|c|c|c|c|c|c|}
\hline \multicolumn{2}{|c|}{ Reagentes } & \multicolumn{2}{|r|}{ Produtos } & $\gamma$ & $\alpha$ & $\beta$ & \multirow[t]{2}{*}{ Tipo de Reação } \\
\hline $\mathrm{n}+$ & no & $\mathrm{n} 2+$ & o & $7.95 \mathrm{e}-11$ & 0 & 0.0 & \\
\hline $\mathrm{n}+$ & $\mathrm{cn}$ & $\mathrm{cn}+$ & $\mathrm{n}$ & $1.10 \mathrm{e}-09$ & 0 & 0.0 & 4 \\
\hline $\mathrm{n}+$ & hen & hen + & $\mathrm{n}$ & $1.20 \mathrm{e}-09$ & 0 & 0.0 & 4 \\
\hline $\mathrm{n}+$ & hcn & $\operatorname{ch}+$ & $\mathrm{n} 2$ & $0.13 \mathrm{D}-08$ & 0 & 0.0 & 4 \\
\hline $\mathrm{n}+$ & $\mathrm{nh}$ & $\mathrm{n} 2+$ & $\mathrm{h}$ & $3.70 \mathrm{e}-10$ & 0 & 0.0 & 4 \\
\hline $\mathrm{n}+$ & $\mathrm{nh}$ & $\mathrm{nh}+$ & $\mathrm{n}$ & $3.70 \mathrm{e}-10$ & 0 & 0.0 & 4 \\
\hline $\mathrm{n}+$ & nh2 & nh2+ & $\mathrm{n}$ & $1.00 \mathrm{e}-09$ & 0 & 0.0 & 4 \\
\hline $\mathrm{n}+$ & nh3 & $\mathrm{n} 2 \mathrm{~h}+$ & h2 & $2.20 \mathrm{e}-10$ & 0 & 0.0 & 4 \\
\hline $\mathrm{n}+$ & nh3 & nh2+ & $\mathrm{nh}$ & $2.20 \mathrm{e}-10$ & 0 & 0.0 & 4 \\
\hline $\mathrm{n}+$ & nh3 & nh3+ & $\mathrm{n}$ & $2.00 \mathrm{e}-09$ & 0 & 0.0 & 4 \\
\hline $\mathrm{n}+$ & oh & $\mathrm{oh}+$ & $\mathrm{n}$ & $3.70 \mathrm{e}-10$ & 0 & 0.0 & 4 \\
\hline $\mathrm{n}+$ & $\mathrm{c} 2 \mathrm{~h}$ & $\mathrm{c} 2 \mathrm{~h}+$ & $\mathrm{n}$ & $9.50 \mathrm{e}-10$ & 0 & 0.0 & 4 \\
\hline $\mathrm{n}+$ & $\operatorname{ch} 2$ & $\operatorname{ch} 2+$ & $\mathrm{n}$ & $1.00 \mathrm{e}-09$ & 0 & 0.0 & 4 \\
\hline $\mathrm{n}+$ & co2 & $\mathrm{co}+$ & no & $2.50 \mathrm{e}-10$ & 0 & 0.0 & 4 \\
\hline $\mathrm{n}+$ & h2o & $\mathrm{h} 2 \mathrm{o}+$ & $\mathrm{n}$ & $2.60 \mathrm{e}-09$ & 0 & 0.0 & 4 \\
\hline $\mathrm{nh}+$ & $\mathrm{c}$ & $\operatorname{ch}+$ & $\mathrm{n}$ & $1.60 \mathrm{e}-09$ & 0 & 0.0 & 4 \\
\hline $\mathrm{nh}+$ & $\mathrm{n}$ & $\mathrm{n} 2+$ & $\mathrm{h}$ & $1.30 \mathrm{e}-09$ & 0 & 0.0 & 4 \\
\hline $\mathrm{nh}+$ & o & $\mathrm{oh}+$ & $\mathrm{n}$ & $1.00 \mathrm{e}-09$ & 0 & 0.0 & 4 \\
\hline $\mathrm{nh}+$ & $\mathrm{c} 2$ & $\mathrm{c} 2 \mathrm{~h}+$ & $\mathrm{n}$ & $4.90 \mathrm{e}-10$ & 0 & 0.0 & 4 \\
\hline $\mathrm{nh}+$ & $\mathrm{c} 2$ & $\mathrm{c} 2 \mathrm{n}+$ & $\mathrm{h}$ & $4.90 \mathrm{e}-10$ & 0 & 0.0 & 4 \\
\hline $\mathrm{nh}+$ & $\mathrm{c} 2$ & hen + & $\mathrm{c}$ & $4.90 \mathrm{e}-10$ & 0 & 0.0 & 4 \\
\hline $\mathrm{nh}+$ & $\mathrm{ch}$ & $\operatorname{ch} 2+$ & $\mathrm{n}$ & $9.90 \mathrm{e}-10$ & 0 & 0.0 & 4 \\
\hline $\mathrm{nh}+$ & $\mathrm{cn}$ & hen+ & $\mathrm{n}$ & $1.60 \mathrm{e}-09$ & 0 & 0.0 & 4 \\
\hline $\mathrm{nh}+$ & $\mathrm{co}$ & hco+ & $\mathrm{n}$ & $1.60 \mathrm{e}-09$ & 0 & 0.0 & 4 \\
\hline $\mathrm{nh}+$ & $\mathrm{n} 2$ & $\mathrm{n} 2 \mathrm{~h}+$ & $\mathrm{n}$ & $1.50 \mathrm{e}-09$ & 0 & 0.0 & 4 \\
\hline $\mathrm{nh}+$ & nh & nh2+ & $\mathrm{n}$ & $1.00 \mathrm{e}-09$ & 0 & 0.0 & 4 \\
\hline $\mathrm{nh}+$ & no & not & $\mathrm{nh}$ & $7.10 \mathrm{e}-10$ & 0 & 0.0 & 4 \\
\hline $\mathrm{nh}+$ & no & $\mathrm{n} 2 \mathrm{~h}+$ & $\mathrm{o}$ & $1.78 \mathrm{e}-10$ & 0 & 0.0 & 4 \\
\hline $\mathrm{nh}+$ & $\mathrm{o} 2$ & not & oh & $2.00 \mathrm{e}-10$ & 0 & 0.0 & 4 \\
\hline $\mathrm{nh}+$ & $\mathrm{o} 2$ & $\mathrm{o} 2+$ & $\mathrm{nh}$ & $4.50 \mathrm{e}-10$ & 0 & 0.0 & 4 \\
\hline $\mathrm{nh}+$ & oh & $\mathrm{h} 2 \mathrm{o}+$ & $\mathrm{n}$ & $1.00 \mathrm{e}-09$ & 0 & 0.0 & 4 \\
\hline $\mathrm{nh}+$ & $\mathrm{c} 2 \mathrm{~h}$ & $\mathrm{c} 2 \mathrm{~h} 2+$ & $\mathrm{n}$ & $1.40 \mathrm{e}-09$ & 0 & 0.0 & 4 \\
\hline $\mathrm{nh}+$ & $\operatorname{ch} 2$ & $\operatorname{ch} 3+$ & $\mathrm{n}$ & $1.40 \mathrm{e}-09$ & 0 & 0.0 & 4 \\
\hline $\mathrm{nh}+$ & $\operatorname{co} 2$ & hno+ & $\mathrm{co}$ & $3.85 \mathrm{e}-10$ & 0 & 0.0 & 4 \\
\hline $\mathrm{nh}+$ & $\operatorname{co} 2$ & hco $2+$ & $\mathrm{n}$ & $3.90 \mathrm{e}-10$ & 0 & 0.0 & 4 \\
\hline $\mathrm{nh}+$ & h2o & $\mathrm{h} 2 \mathrm{o}+$ & $\mathrm{nh}$ & $1.05 \mathrm{e}-09$ & 0 & 0.0 & 4 \\
\hline $\mathrm{nh}+$ & h2o & hno+ & $\mathrm{h} 2$ & $3.50 \mathrm{e}-10$ & 0 & 0.0 & 4 \\
\hline $\mathrm{nh}+$ & h2o & nh2+ & oh & $8.75 \mathrm{e}-10$ & 0 & 0.0 & 4 \\
\hline $\mathrm{nh}+$ & h2o & $\mathrm{h} 3 \mathrm{o}+$ & $\mathrm{n}$ & $2.10 \mathrm{e}-09$ & 0 & 0.0 & 4 \\
\hline $\mathrm{nh}+$ & h2o & nh3+ & o & $1.75 \mathrm{e}-10$ & 0 & 0.0 & 4 \\
\hline $\mathrm{nh}+$ & hcn & hcnh+ & $\mathrm{n}$ & $1.80 \mathrm{e}-09$ & 0 & 0.0 & 4 \\
\hline $\mathrm{nh}+$ & hnc & hcnh+ & $\mathrm{n}$ & $1.80 \mathrm{e}-09$ & 0 & 0.0 & 4 \\
\hline $\mathrm{nh}+$ & nh2 & nh3+ & $\mathrm{n}$ & $1.50 \mathrm{e}-09$ & 0 & 0.0 & 4 \\
\hline
\end{tabular}

Continua na próxima página... 
Tabela B.2 - Continuação

\begin{tabular}{|c|c|c|c|c|c|c|c|}
\hline \multicolumn{2}{|c|}{ Reagentes } & \multicolumn{2}{|r|}{ Produtos } & \multirow{2}{*}{$\frac{\gamma}{1.80 \mathrm{e}-09}$} & \multirow{2}{*}{$\begin{array}{c}\alpha \\
0\end{array}$} & \multirow{2}{*}{$\begin{array}{l}\beta \\
0.0\end{array}$} & \multirow{2}{*}{$\frac{\text { Tipo de Reação }}{4}$} \\
\hline $\mathrm{nh}+$ & nh3 & nh3+ & $\mathrm{nh}$ & & & & \\
\hline $\mathrm{nh}+$ & nh3 & nh4+ & $\mathrm{n}$ & $6.00 \mathrm{e}-10$ & 0 & 0.0 & 4 \\
\hline nh2+ & $\mathrm{CO}$ & hco+ & $\mathrm{nh}$ & $6.40 \mathrm{e}-10$ & 0 & 6100.0 & 4 \\
\hline $\operatorname{nh} 2+$ & $\mathrm{n}$ & $\mathrm{n} 2 \mathrm{~h}+$ & $\mathrm{h}$ & $9.10 \mathrm{e}-11$ & 0 & 0.0 & 4 \\
\hline $\mathrm{nh} 2+$ & $\mathrm{c} 2$ & $\mathrm{c} 2 \mathrm{~h}+$ & $\mathrm{nh}$ & $9.70 \mathrm{e}-10$ & 0 & 0.0 & 4 \\
\hline $\mathrm{nh} 2+$ & $\mathrm{ch}$ & $\operatorname{ch}+$ & $\mathrm{nh} 2$ & $3.50 \mathrm{e}-10$ & 0 & 0.0 & 4 \\
\hline $\mathrm{nh} 2+$ & $\mathrm{ch}$ & $\operatorname{ch} 2+$ & $\mathrm{nh}$ & $3.50 \mathrm{e}-10$ & 0 & 0.0 & 4 \\
\hline $\mathrm{nh} 2+$ & $\mathrm{cn}$ & hcnh+ & $\mathrm{n}$ & $1.00 \mathrm{e}-10$ & 0 & 0.0 & 4 \\
\hline $\operatorname{nh} 2+$ & $\mathrm{cn}$ & $\mathrm{h} 2 \mathrm{nc}+$ & $\mathrm{n}$ & $1.00 \mathrm{e}-10$ & 0 & 0.0 & 4 \\
\hline $\mathrm{nh} 2+$ & $\mathrm{nh}$ & nh3+ & $\mathrm{n}$ & $7.30 \mathrm{e}-10$ & 0 & 0.0 & 4 \\
\hline $\mathrm{nh} 2+$ & no & no+ & $\mathrm{nh} 2$ & $9.40 \mathrm{e}-10$ & 0 & 0.0 & 4 \\
\hline $\operatorname{nh} 2+$ & $\mathrm{c} 2 \mathrm{~h}$ & $\mathrm{c} 2 \mathrm{~h} 2+$ & $\mathrm{nh}$ & $9.10 \mathrm{e}-10$ & 0 & 0.0 & 4 \\
\hline $\operatorname{nh} 2+$ & $\operatorname{ch} 2$ & $\operatorname{ch} 2+$ & nh2 & $4.90 \mathrm{e}-10$ & 0 & 0.0 & 4 \\
\hline nh2+ & $\operatorname{ch} 2$ & $\operatorname{ch} 3+$ & $\mathrm{nh}$ & $4.90 \mathrm{e}-10$ & 0 & 0.0 & 4 \\
\hline nh2+ & h2o & h3o+ & $\mathrm{nh}$ & $1.60 \mathrm{e}-09$ & 0 & 0.0 & 4 \\
\hline $\mathrm{nh} 2+$ & h2o & nh3+ & oh & $1.00 \mathrm{e}-10$ & 0 & 0.0 & 4 \\
\hline $\mathrm{nh} 2+$ & h2o & nh4+ & o & $3.00 \mathrm{e}-11$ & 0 & 0.0 & 4 \\
\hline $\mathrm{nh} 2+$ & hcn & hcnh+ & $\mathrm{nh}$ & $1.20 \mathrm{e}-09$ & 0 & 0.0 & 4 \\
\hline $\mathrm{nh} 2+$ & hnc & hcnh+ & $\mathrm{nh}$ & $1.20 \mathrm{e}-09$ & 0 & 0.0 & 4 \\
\hline $\mathrm{nh} 2+$ & nh2 & nh3+ & $\mathrm{nh}$ & $1.00 \mathrm{e}-09$ & 0 & 0.0 & 4 \\
\hline nh2+ & nh3 & nh3+ & nh2 & $1.50 \mathrm{e}-09$ & 0 & 0.0 & 4 \\
\hline nh2+ & nh3 & nh4+ & $\mathrm{nh}$ & $1.00 \mathrm{e}-09$ & 0 & 0.0 & 4 \\
\hline nh3+ & h2o & nh4+ & oh & $2.50 \mathrm{e}-10$ & 0 & 0.0 & 4 \\
\hline nh3+ & nh3 & nh4+ & $\mathrm{nh} 2$ & $0.21 \mathrm{D}-08$ & -0.5 & 0.0 & 4 \\
\hline $\mathrm{nh} 4+$ & oh & nh3+ & h2o & $2.50 \mathrm{e}-10$ & 0 & 3400.0 & 4 \\
\hline nh4+ & $\mathrm{n} 2$ & $\mathrm{n} 2 \mathrm{~h}+$ & nh3 & $2.30 \mathrm{e}-09$ & 0 & 44000.0 & 4 \\
\hline $\mathrm{n} 2+$ & $\mathrm{n}$ & $\mathrm{n}+$ & $\mathrm{n} 2$ & $1.00 \mathrm{e}-11$ & 0 & 0.0 & 4 \\
\hline $\mathrm{n} 2+$ & o & $\mathrm{o}+$ & $\mathrm{n} 2$ & $1.00 \mathrm{e}-11$ & 0 & 0.0 & 4 \\
\hline $\mathrm{n} 2+$ & o & not & $\mathrm{n}$ & $1.40 \mathrm{e}-10$ & 0 & 0.0 & 4 \\
\hline $\mathrm{n} 2+$ & $\mathrm{c} 2$ & $\mathrm{c} 2+$ & $\mathrm{n} 2$ & $8.40 \mathrm{e}-10$ & 0 & 0.0 & 4 \\
\hline $\mathrm{n} 2+$ & $\mathrm{ch}$ & $\operatorname{ch}+$ & $\mathrm{n} 2$ & $6.30 \mathrm{e}-10$ & 0 & 0.0 & 4 \\
\hline $\mathrm{n} 2+$ & $\mathrm{cn}$ & $\mathrm{cn}+$ & $\mathrm{n} 2$ & $1.00 \mathrm{e}-10$ & 0 & 0.0 & 4 \\
\hline $\mathrm{n} 2+$ & $\mathrm{CO}$ & $\mathrm{co}+$ & $\mathrm{n} 2$ & $7.00 \mathrm{e}-11$ & 0 & 0.0 & 4 \\
\hline $\mathrm{n} 2+$ & $\mathrm{nh}$ & $\mathrm{nh}+$ & $\mathrm{n} 2$ & $6.50 \mathrm{e}-10$ & 0 & 0.0 & 4 \\
\hline $\mathrm{n} 2+$ & no & not & $\mathrm{n} 2$ & $4.40 \mathrm{e}-10$ & 0 & 0.0 & 4 \\
\hline $\mathrm{n} 2+$ & $\mathrm{o} 2$ & $\mathrm{o} 2+$ & $\mathrm{n} 2$ & $5.00 \mathrm{e}-11$ & 0 & 0.0 & 4 \\
\hline $\mathrm{n} 2+$ & oh & $\mathrm{oh}+$ & $\mathrm{n} 2$ & $6.30 \mathrm{e}-10$ & 0 & 0.0 & 4 \\
\hline $\mathrm{n} 2+$ & $\mathrm{c} 2 \mathrm{~h}$ & $\mathrm{c} 2 \mathrm{~h}+$ & $\mathrm{n} 2$ & $7.90 \mathrm{e}-10$ & 0 & 0.0 & 4 \\
\hline $\mathrm{n} 2+$ & $\operatorname{ch} 2$ & $\operatorname{ch} 2+$ & $\mathrm{n} 2$ & $8.70 \mathrm{e}-10$ & 0 & 0.0 & 4 \\
\hline $\mathrm{n} 2+$ & h2o & $\mathrm{h} 2 \mathrm{o}+$ & $\mathrm{n} 2$ & $2.20 \mathrm{e}-09$ & 0 & 0.0 & 4 \\
\hline $\mathrm{n} 2+$ & h2o & $\mathrm{n} 2 \mathrm{~h}+$ & oh & $2.00 \mathrm{e}-09$ & 0 & 0.0 & 4 \\
\hline $\mathrm{n} 2+$ & hcn & hen+ & $\mathrm{n} 2$ & $1.00 \mathrm{e}-09$ & 0 & 0.0 & 4 \\
\hline $\mathrm{n} 2+$ & nh2 & $\operatorname{nh} 2+$ & $\mathrm{n} 2$ & $8.90 \mathrm{e}-10$ & 0 & 0.0 & 4 \\
\hline
\end{tabular}

Continua na próxima página... 
Tabela B.2 - Continuação

\begin{tabular}{|c|c|c|c|c|c|c|c|c|}
\hline \multicolumn{2}{|c|}{ Reagentes } & \multicolumn{3}{|c|}{ Produtos } & \multirow{2}{*}{$\frac{\gamma}{1.90 \mathrm{e}-09}$} & \multirow{2}{*}{$\begin{array}{c}\alpha \\
0\end{array}$} & \multirow{2}{*}{$\begin{array}{c}\beta \\
0.0\end{array}$} & \multirow{2}{*}{$\begin{array}{c}\text { Tipo de Reação } \\
4\end{array}$} \\
\hline $\mathrm{n} 2+$ & nh3 & nh3+ & $\mathrm{n} 2$ & & & & & \\
\hline $\mathrm{n} 2+$ & $\operatorname{ch} 4$ & $\operatorname{ch} 2+$ & h2 & $\mathrm{n} 2$ & $7.00 \mathrm{e}-11$ & 0 & 0.0 & 4 \\
\hline $\mathrm{n} 2+$ & $\operatorname{ch} 4$ & $\operatorname{ch} 3+$ & $\mathrm{n} 2$ & $\mathrm{~h}$ & $9.30 \mathrm{e}-10$ & 0 & 0.0 & 4 \\
\hline $\mathrm{n} 2 \mathrm{~h}+$ & c & $\mathrm{ch}+$ & $\mathrm{n} 2$ & & $1.10 \mathrm{e}-09$ & 0 & 0.0 & 4 \\
\hline $\mathrm{n} 2 \mathrm{~h}+$ & $\mathrm{ch}$ & $\operatorname{ch} 2+$ & $\mathrm{n} 2$ & & $4.50 \mathrm{e}-09$ & -0.5 & 0.0 & 4 \\
\hline $\mathrm{n} 2 \mathrm{~h}+$ & $\operatorname{ch} 2$ & $\operatorname{ch} 3+$ & $\mathrm{n} 2$ & & 0.72D-09 & -0.5 & 0.0 & 4 \\
\hline $\mathrm{n} 2 \mathrm{~h}+$ & $\operatorname{ch} 4$ & $\operatorname{ch} 5+$ & $\mathrm{n} 2$ & & $9.00 \mathrm{e}-10$ & 0 & 0.0 & 4 \\
\hline $\mathrm{n} 2 \mathrm{~h}+$ & $\mathrm{c} 2$ & $\mathrm{c} 2 \mathrm{~h}+$ & n2 & & $8.30 \mathrm{e}-10$ & 0 & 0.0 & 4 \\
\hline $\mathrm{n} 2 \mathrm{~h}+$ & $\mathrm{c} 2 \mathrm{~h}$ & $\mathrm{c} 2 \mathrm{~h} 2+$ & n2 & & $0.20 \mathrm{D}-08$ & -0.5 & 0.0 & 4 \\
\hline $\mathrm{n} 2 \mathrm{~h}+$ & $\mathrm{c} 2 \mathrm{~h} 2$ & $\mathrm{c} 2 \mathrm{~h} 3+$ & $\mathrm{n} 2$ & & $1.40 \mathrm{e}-09$ & 0 & 0.0 & 4 \\
\hline $\mathrm{n} 2 \mathrm{~h}+$ & $\mathrm{nh}$ & nh2+ & $\mathrm{n} 2$ & & $3.80 \mathrm{e}-09$ & -0.5 & 0.0 & 4 \\
\hline $\mathrm{n} 2 \mathrm{~h}+$ & hen & henh+ & $\mathrm{n} 2$ & & $7.30 \mathrm{e}-09$ & -0.5 & 0.0 & 4 \\
\hline $\mathrm{n} 2 \mathrm{~h}+$ & hnc & henh+ & $\mathrm{n} 2$ & & $6.63 \mathrm{e}-09$ & -0.5 & 0.0 & 4 \\
\hline $\mathrm{n} 2 \mathrm{~h}+$ & hnc & h2nc+ & $\mathrm{n} 2$ & & $0.66 \mathrm{D}-08$ & -0.5 & 0.0 & 4 \\
\hline $\mathrm{n} 2 \mathrm{~h}+$ & nh2 & nh3+ & $\mathrm{n} 2$ & & $2.20 \mathrm{e}-09$ & -0.5 & 0.0 & 4 \\
\hline $\mathrm{n} 2 \mathrm{~h}+$ & o & $\mathrm{oh}+$ & $\mathrm{n} 2$ & & $1.40 \mathrm{e}-10$ & 0 & 3400.0 & 4 \\
\hline $\mathrm{n} 2 \mathrm{~h}+$ & oh & $\mathrm{h} 2 \mathrm{o}+$ & $\mathrm{n} 2$ & & $0.47 \mathrm{D}-08$ & -0.5 & 0.0 & 4 \\
\hline $\mathrm{n} 2 \mathrm{~h}+$ & h2o & h3o+ & $\mathrm{n} 2$ & & $2.60 \mathrm{e}-09$ & 0 & 0.0 & 4 \\
\hline $\mathrm{n} 2 \mathrm{~h}+$ & $\mathrm{co}$ & hco+ & $\mathrm{n} 2$ & & $8.80 \mathrm{e}-10$ & 0 & 0.0 & 4 \\
\hline $\mathrm{n} 2 \mathrm{~h}+$ & h2co & h3co+ & $\mathrm{n} 2$ & & $2.40 \mathrm{e}-09$ & -0.5 & 0.0 & 4 \\
\hline $\mathrm{n} 2 \mathrm{~h}+$ & $\operatorname{co} 2$ & hco $2+$ & $\mathrm{n} 2$ & & $1.40 \mathrm{e}-09$ & 0 & 0.0 & 4 \\
\hline $\mathrm{n} 2 \mathrm{~h}+$ & nh3 & nh4+ & $\mathrm{n} 2$ & & $2.30 \mathrm{e}-09$ & 0 & 0.0 & 4 \\
\hline $\mathrm{n} 2 \mathrm{~h}+$ & no & hnot & $\mathrm{n} 2$ & & $3.40 \mathrm{e}-10$ & 0 & 0.0 & 4 \\
\hline $\mathrm{cn}+$ & c & $\mathrm{c}+$ & $\mathrm{cn}$ & & $1.10 \mathrm{e}-10$ & 0 & 0.0 & 4 \\
\hline $\mathrm{cn}+$ & $\mathrm{h}$ & $\mathrm{h}+$ & $\mathrm{cn}$ & & $6.40 \mathrm{e}-10$ & 0 & 0.0 & 4 \\
\hline $\mathrm{cn}+$ & $\mathrm{O}$ & $\mathrm{o}+$ & $\mathrm{cn}$ & & $6.50 \mathrm{e}-11$ & 0 & 0.0 & 4 \\
\hline $\mathrm{cn}+$ & $\mathrm{c} 2$ & $\mathrm{c} 2+$ & $\mathrm{cn}$ & & $8.50 \mathrm{e}-10$ & 0 & 0.0 & 4 \\
\hline $\mathrm{cn}+$ & $\mathrm{ch}$ & $\mathrm{ch}+$ & $\mathrm{cn}$ & & $6.40 \mathrm{e}-10$ & 0 & 0.0 & 4 \\
\hline $\mathrm{cn}+$ & $\mathrm{co}$ & $\mathrm{co}+$ & $\mathrm{cn}$ & & $6.30 \mathrm{e}-10$ & 0 & 0.0 & 4 \\
\hline $\mathrm{cn}+$ & $\mathrm{nh}$ & $\mathrm{nh}+$ & $\mathrm{cn}$ & & $6.50 \mathrm{e}-10$ & 0 & 0.0 & 4 \\
\hline $\mathrm{cn}+$ & no & not & $\mathrm{cn}$ & & $8.10 \mathrm{e}-10$ & 0 & 0.0 & 4 \\
\hline $\mathrm{cn}+$ & $\mathrm{o} 2$ & not & $\mathrm{co}$ & & $8.60 \mathrm{e}-11$ & 0 & 0.0 & 4 \\
\hline $\mathrm{cn}+$ & $\mathrm{o} 2$ & $\mathrm{o} 2+$ & $\mathrm{cn}$ & & $7.80 \mathrm{e}-10$ & 0 & 0.0 & 4 \\
\hline $\mathrm{cn}+$ & h2o & hen+ & oh & & $1.60 \mathrm{e}-09$ & 0 & 0.0 & 4 \\
\hline $\mathrm{cn}+$ & h2o & hco+ & $\mathrm{nh}$ & & $1.60 \mathrm{e}-10$ & 0 & 0.0 & 4 \\
\hline $\mathrm{cn}+$ & h2o & h2nc+ & o & & $4.80 \mathrm{e}-10$ & 0 & 0.0 & 4 \\
\hline $\mathrm{cn}+$ & hen & hcn+ & $\mathrm{cn}$ & & $2.40 \mathrm{e}-09$ & 0 & 0.0 & 4 \\
\hline $\mathrm{cn}+$ & nh2 & nh2+ & $\mathrm{cn}$ & & $9.10 \mathrm{e}-10$ & 0 & 0.0 & 4 \\
\hline hen+ & c & $\mathrm{ch}+$ & $\mathrm{cn}$ & & $1.10 \mathrm{e}-09$ & 0 & 0.0 & 4 \\
\hline hen+ & $\mathrm{h}$ & $\mathrm{h}+$ & hen & & $3.70 \mathrm{e}-11$ & 0 & 0.0 & 4 \\
\hline hen+ & o & $\mathrm{o}+$ & hen & & $6.50 \mathrm{e}-11$ & 0 & 0.0 & 4 \\
\hline hen+ & $\mathrm{c} 2$ & $\mathrm{c} 2 \mathrm{~h}+$ & $\mathrm{cn}$ & & $8.40 \mathrm{e}-10$ & 0 & 0.0 & 4 \\
\hline hen+ & $\mathrm{ch}$ & $\operatorname{ch} 2+$ & $\mathrm{cn}$ & & $6.30 \mathrm{e}-10$ & 0 & 0.0 & 4 \\
\hline
\end{tabular}

Continua na próxima página... 
Tabela B.2 - Continuação

\begin{tabular}{|c|c|c|c|c|c|c|c|}
\hline \multicolumn{2}{|c|}{ Reagentes } & \multicolumn{2}{|r|}{ Produtos } & \multirow{2}{*}{$\frac{\gamma}{1.40 \mathrm{e}-10}$} & \multirow{2}{*}{$\begin{array}{l}\alpha \\
0\end{array}$} & \multirow{2}{*}{$\begin{array}{l}\beta \\
0.0\end{array}$} & \multirow{2}{*}{$\frac{\text { Tipo de Reação }}{4}$} \\
\hline hen+ & $\mathrm{co}$ & hco+ & $\mathrm{cn}$ & & & & \\
\hline hen+ & nh & nh2+ & $\mathrm{cn}$ & $6.50 \mathrm{e}-10$ & 0 & 0.0 & 4 \\
\hline hen+ & no & no+ & hen & $8.10 \mathrm{e}-10$ & 0 & 0.0 & 4 \\
\hline hen+ & $\mathrm{o} 2$ & $\mathrm{o} 2+$ & hen & $3.20 \mathrm{e}-10$ & 0 & 0.0 & 4 \\
\hline hen+ & oh & $\mathrm{h} 2 \mathrm{o}+$ & $\mathrm{cn}$ & $6.30 \mathrm{e}-10$ & 0 & 0.0 & 4 \\
\hline hen+ & $\mathrm{c} 2 \mathrm{~h}$ & $\mathrm{c} 2 \mathrm{~h} 2+$ & $\mathrm{cn}$ & $7.90 \mathrm{e}-10$ & 0 & 0.0 & 4 \\
\hline hen+ & $\operatorname{ch} 2$ & $\operatorname{ch} 3+$ & $\mathrm{cn}$ & $8.70 \mathrm{e}-10$ & 0 & 0.0 & 4 \\
\hline hen + & $\operatorname{co} 2$ & hco $2+$ & $\mathrm{cn}$ & $2.10 \mathrm{e}-10$ & 0 & 0.0 & 4 \\
\hline hen+ & h2o & h2o+ & hen & $1.80 \mathrm{e}-09$ & 0 & 0.0 & 4 \\
\hline hen + & h2o & h3o+ & $\mathrm{cn}$ & $8.50 \mathrm{e}-10$ & 0 & 0.0 & 4 \\
\hline hen+ & hcn & hcnh+ & $\mathrm{cn}$ & $1.60 \mathrm{e}-09$ & 0 & 0.0 & 4 \\
\hline hen+ & hnc & hcnh+ & $\mathrm{cn}$ & $1.00 \mathrm{e}-09$ & 0 & 0.0 & 4 \\
\hline hen+ & nh2 & nh3+ & $\mathrm{cn}$ & $9.00 \mathrm{e}-10$ & 0 & 0.0 & 4 \\
\hline hcn+ & nh3 & hcnh+ & $\mathrm{nh} 2$ & $8.40 \mathrm{e}-10$ & 0 & 0.0 & 4 \\
\hline hcn + & nh3 & nh3+ & hen & $1.70 \mathrm{e}-09$ & 0 & 0.0 & 4 \\
\hline hen+ & $\operatorname{ch} 4$ & hcnh+ & $\operatorname{ch} 3$ & $1.04 \mathrm{e}-09$ & 0 & 0.0 & 4 \\
\hline hen+ & $\operatorname{ch} 4$ & $\mathrm{c} 2 \mathrm{~h} 3+$ & $\mathrm{nh} 2$ & $2.60 \mathrm{e}-10$ & 0 & 0.0 & 4 \\
\hline hnc+ & $\mathrm{c}$ & $\operatorname{ch}+$ & $\mathrm{cn}$ & $1.10 \mathrm{e}-09$ & 0 & 0.0 & 4 \\
\hline hnc+ & $\mathrm{c} 2$ & $\mathrm{c} 2 \mathrm{~h}+$ & $\mathrm{cn}$ & $8.40 \mathrm{e}-10$ & 0 & 0.0 & 4 \\
\hline hnct & $\mathrm{ch}$ & $\operatorname{ch} 2+$ & $\mathrm{cn}$ & $6.30 \mathrm{e}-10$ & 0 & 0.0 & 4 \\
\hline hnc+ & $\mathrm{nh}$ & $\operatorname{nh} 2+$ & $\mathrm{cn}$ & $6.50 \mathrm{e}-10$ & 0 & 0.0 & 4 \\
\hline hnc+ & no & no+ & hnc & $8.10 \mathrm{e}-10$ & 0 & 0.0 & 4 \\
\hline hnc+ & oh & h2o+ & $\mathrm{cn}$ & $6.30 \mathrm{e}-10$ & 0 & 0.0 & 4 \\
\hline hnct & $\mathrm{c} 2 \mathrm{~h}$ & $\mathrm{c} 2 \mathrm{~h} 2+$ & $\mathrm{cn}$ & $7.90 \mathrm{e}-10$ & 0 & 0.0 & 4 \\
\hline hnc+ & $\operatorname{ch} 2$ & $\operatorname{ch} 3+$ & $\mathrm{cn}$ & $8.70 \mathrm{e}-10$ & 0 & 0.0 & 4 \\
\hline hnc+ & h2o & h3o+ & $\mathrm{cn}$ & $8.50 \mathrm{e}-10$ & 0 & 0.0 & 4 \\
\hline hnc+ & hen & hcnh+ & $\mathrm{cn}$ & $1.60 \mathrm{e}-09$ & 0 & 0.0 & 4 \\
\hline hnc+ & nh2 & nh3+ & $\mathrm{cn}$ & $9.00 \mathrm{e}-10$ & 0 & 0.0 & 4 \\
\hline hnc+ & nh3 & nh3+ & hnc & $1.70 \mathrm{e}-09$ & 0 & 0.0 & 4 \\
\hline hcnh+ & h2o & h3o+ & hen & $4.50 \mathrm{e}-09$ & 0 & 2460.0 & 4 \\
\hline hcnh+ & h2o & h3o+ & hnc & $4.50 \mathrm{e}-09$ & 0 & 10300.0 & 4 \\
\hline hcnh+ & h2co & h3cot & hen & $2.37 \mathrm{e}-09$ & -0.5 & 0.0 & 4 \\
\hline hcnh+ & nh3 & $\operatorname{nh} 4+$ & hen & 0.88D-09 & -0.5 & 0.0 & 4 \\
\hline hcnh+ & nh3 & $\operatorname{nh} 4+$ & hnc & $0.88 \mathrm{D}-09$ & -0.5 & 0.0 & 4 \\
\hline $\mathrm{c} 2 \mathrm{n}+$ & $\operatorname{ch} 4$ & $\mathrm{c} 2 \mathrm{~h} 3+$ & hen & $4.20 \mathrm{e}-10$ & 0 & 0.0 & 4 \\
\hline $\mathrm{c} 2 \mathrm{n}+$ & h2o & hco+ & hen & $1.50 \mathrm{e}-09$ & 0 & 0.0 & 4 \\
\hline $\mathrm{c} 2 \mathrm{n}+$ & h2o & hcnh+ & $\mathrm{co}$ & $1.30 \mathrm{e}-10$ & 0 & 0.0 & 4 \\
\hline $\mathrm{c} 2 \mathrm{n}+$ & $\mathrm{c} 2 \mathrm{~h} 2$ & $\mathrm{c} 3 \mathrm{~h}+$ & hen & $1.50 \mathrm{e}-09$ & 0 & 0.0 & 4 \\
\hline $\mathrm{c} 2 \mathrm{n}+$ & $\mathrm{c} 2 \mathrm{~h} 2$ & hcnh+ & c3 & $1.30 \mathrm{e}-10$ & 0 & 0.0 & 4 \\
\hline $\mathrm{c} 2 \mathrm{n}+$ & nh3 & $\mathrm{n} 2 \mathrm{~h}+$ & $\mathrm{c} 2 \mathrm{~h} 2$ & $1.90 \mathrm{e}-10$ & 0 & 0.0 & 4 \\
\hline $\mathrm{c} 2 \mathrm{n}+$ & nh3 & $\mathrm{h} 2 \mathrm{nc}+$ & hen & $0.43 \mathrm{D}-09$ & 0 & 0.0 & 4 \\
\hline $\mathrm{c} 2 \mathrm{n}+$ & nh3 & hcnh+ & hen & $1.70 \mathrm{e}-09$ & 0 & 0.0 & 4 \\
\hline $\mathrm{c} 2 \mathrm{n}+$ & nh3 & hcnh+ & hnc & $0.43 \mathrm{D}-09$ & 0 & 0.0 & 4 \\
\hline
\end{tabular}

Continua na próxima página... 
Tabela B.2 - Continuação

\begin{tabular}{|c|c|c|c|c|c|c|c|}
\hline \multicolumn{2}{|c|}{ Reagentes } & \multicolumn{2}{|r|}{ Produtos } & \multirow{2}{*}{$\frac{\gamma}{0.43 \mathrm{D}-09}$} & \multirow{2}{*}{$\begin{array}{l}\alpha \\
0\end{array}$} & \multirow{2}{*}{$\begin{array}{c}\beta \\
0.0\end{array}$} & \multirow{2}{*}{$\begin{array}{c}\text { Tipo de Reação } \\
4\end{array}$} \\
\hline $\mathrm{c} 2 \mathrm{n}+$ & nh3 & h2nc+ & hnc & & & & \\
\hline hnot & $\mathrm{c}$ & $\operatorname{ch}+$ & no & $1.00 \mathrm{e}-09$ & 0 & 0.0 & 4 \\
\hline hnot & $\mathrm{co}$ & hco+ & no & $1.00 \mathrm{e}-10$ & 0 & 0.0 & 4 \\
\hline hno+ & $\mathrm{co} 2$ & hco $2+$ & no & $1.00 \mathrm{e}-10$ & 0 & 0.0 & 4 \\
\hline hno+ & oh & h2o+ & no & $6.20 \mathrm{e}-10$ & 0 & 0.0 & 4 \\
\hline hnot & h2o & h3o+ & no & $2.30 \mathrm{e}-09$ & 0 & 0.0 & 4 \\
\hline hnot & h2co & h3cot & no & $2.30 \mathrm{e}-09$ & -0.5 & 0.0 & 4 \\
\hline $\mathrm{n}+$ & fe & $\mathrm{fe}+$ & $\mathrm{n}$ & $1.50 \mathrm{e}-09$ & 0 & 0.0 & 4 \\
\hline nh3+ & $\mathrm{fe}$ & $\mathrm{fe}+$ & nh3 & $2.30 \mathrm{e}-09$ & 0 & 0.0 & 4 \\
\hline $\mathrm{n} 2+$ & fe & $\mathrm{fe}+$ & $\mathrm{n} 2$ & $4.30 \mathrm{e}-10$ & 0 & 0.0 & 4 \\
\hline no+ & fe & $\mathrm{fe}+$ & no & $1.00 \mathrm{e}-09$ & 0 & 0.0 & 4 \\
\hline $\mathrm{c}$ & $\mathrm{n}$ & $\mathrm{cn}$ & photon & $1.00 \mathrm{e}-17$ & 0 & 0.0 & 3 \\
\hline $\mathrm{s}$ & phosec & $\mathrm{s}+$ & electr & $1.00 \mathrm{e}+03$ & 0 & 0.0 & 2 \\
\hline sh & phosec & $\mathrm{h}$ & $\mathrm{s}$ & $5.00 \mathrm{e}+02$ & 0 & 0.0 & 2 \\
\hline cs & phosec & $\mathrm{c}$ & $\mathrm{s}$ & $5.00 \mathrm{e}+02$ & 0 & 0.0 & 2 \\
\hline so & phosec & $\mathrm{s}$ & o & $5.00 \mathrm{e}+02$ & 0 & 0.0 & 2 \\
\hline ocs & phosec & $\mathrm{co}$ & $\mathrm{s}$ & $5.37 \mathrm{e}+03$ & 0 & 0.0 & 2 \\
\hline $\mathrm{h} 2 \mathrm{~s}$ & phosec & $\mathrm{sh}$ & $\mathrm{h}$ & $5.07 \mathrm{e}+03$ & 0 & 0.0 & 2 \\
\hline $\mathrm{h} 2 \mathrm{~s}$ & phosec & h2s+ & electr & $1.55 \mathrm{e}+03$ & 0 & 0.0 & 2 \\
\hline so2 & phosec & so & o & $2.00 \mathrm{e}+03$ & 0 & 0.0 & 2 \\
\hline h2cs & phosec & $\mathrm{h} 2$ & $\mathrm{cs}$ & $1.50 \mathrm{e}+03$ & 0 & 0.0 & 2 \\
\hline $\mathrm{s}$ & h2 & $\mathrm{sh}$ & $\mathrm{h}$ & $1.04 \mathrm{e}-10$ & 0.132 & 9620.0 & 4 \\
\hline sh & h2 & $\mathrm{h} 2 \mathrm{~s}$ & $\mathrm{~h}$ & $6.41 \mathrm{e}-12$ & 0.087 & 8050.0 & 4 \\
\hline $\mathrm{sh}$ & $\mathrm{h}$ & $\mathrm{s}$ & $\mathrm{h} 2$ & $2.50 \mathrm{e}-11$ & 0 & 0.0 & 4 \\
\hline $\mathrm{h} 2 \mathrm{~s}$ & $\mathrm{~h}$ & sh & h2 & $1.29 \mathrm{e}-11$ & 0 & 860.0 & 4 \\
\hline so & $\mathrm{h}$ & oh & $\mathrm{s}$ & $5.90 \mathrm{e}-10$ & -0.31 & 11100.0 & 4 \\
\hline so2 & $\mathrm{h}$ & so & oh & $9.25 \mathrm{e}-09$ & -0.74 & 14700.0 & 4 \\
\hline ocs & $\mathrm{h}$ & $\mathrm{sh}$ & $\mathrm{co}$ & $1.70 \mathrm{e}-11$ & 0 & 2000.0 & 4 \\
\hline $\mathrm{sh}$ & $\mathrm{O}$ & so & $\mathrm{h}$ & $1.60 \mathrm{e}-10$ & 0 & 100.0 & 4 \\
\hline sh & o & oh & $\mathrm{s}$ & $1.70 \mathrm{e}-11$ & 0.67 & 950.0 & 4 \\
\hline $\mathrm{h} 2 \mathrm{~s}$ & $\mathrm{O}$ & $\mathrm{sh}$ & oh & $1.40 \mathrm{e}-11$ & 0 & 1920.0 & 4 \\
\hline $\mathrm{h} 2 \mathrm{~s}$ & oh & sh & h2o & $6.30 \mathrm{e}-12$ & 0 & 80.0 & 4 \\
\hline cs & o & $\mathrm{CO}$ & $\mathrm{s}$ & $2.70 \mathrm{e}-10$ & 0 & 760.0 & 4 \\
\hline cs & oh & ocs & $\mathrm{h}$ & $1.55 \mathrm{e}-13$ & 1.12 & 800.0 & 4 \\
\hline $\mathrm{s}$ & $\mathrm{o} 2$ & so & o & $5.19 \mathrm{e}-12$ & 0 & 265.0 & 4 \\
\hline s & $\operatorname{ch} 3$ & $\mathrm{~h} 2 \mathrm{cs}$ & $\mathrm{h}$ & $1.40 \mathrm{e}-10$ & 0 & 0.0 & 4 \\
\hline so & o & $\mathrm{s}$ & o2 & $6.60 \mathrm{e}-13$ & 0 & 2760.0 & 4 \\
\hline so & o2 & so 2 & o & $1.40 \mathrm{e}-12$ & 0 & 2820.0 & 4 \\
\hline so & oh & so 2 & $\mathrm{~h}$ & $1.96 \mathrm{e}-10$ & -0.17 & 0.0 & 4 \\
\hline so & $\mathrm{n}$ & no & $\mathrm{s}$ & $1.73 \mathrm{e}-11$ & 0.5 & 750.0 & 4 \\
\hline so & c & $\mathrm{co}$ & $\mathrm{s}$ & $7.20 \mathrm{e}-11$ & 0 & 0.0 & 4 \\
\hline so & c & cs & o & $1.70 \mathrm{e}-10$ & 0 & 0.0 & 4 \\
\hline so2 & o & so & o2 & $9.27 \mathrm{e}-11$ & -0.46 & 9140.0 & 4 \\
\hline
\end{tabular}

Continua na próxima página... 
Tabela B.2 - Continuação

\begin{tabular}{|c|c|c|c|c|c|c|c|c|}
\hline \multicolumn{2}{|c|}{ Reagentes } & \multicolumn{3}{|c|}{ Produtos } & \multirow{2}{*}{$\frac{\gamma}{2.60 \mathrm{e}-11}$} & \multirow{2}{*}{$\begin{array}{c}\alpha \\
0 \\
0\end{array}$} & \multirow{2}{*}{$\begin{array}{c}\beta \\
2250.0\end{array}$} & \multirow{2}{*}{$\begin{array}{c}\text { Tipo de Reação } \\
4\end{array}$} \\
\hline ocs & o & so & $\mathrm{co}$ & & & & & \\
\hline $\mathrm{ch}$ & $\mathrm{s}$ & $\mathrm{cs}$ & $\mathrm{h}$ & & $1.10 \mathrm{e}-12$ & 0 & 0.0 & 4 \\
\hline $\mathrm{ch}$ & $\mathrm{s}$ & $\mathrm{sh}$ & c & & $1.73 \mathrm{e}-11$ & 0.5 & 4000.0 & 4 \\
\hline oh & $\mathrm{s}$ & so & $\mathrm{h}$ & & $1.00 \mathrm{e}-10$ & 0 & 100.0 & 4 \\
\hline $\mathrm{sh}$ & $\mathrm{c}$ & cs & $\mathrm{h}$ & & $2.00 \mathrm{e}-11$ & 0 & 0.0 & 4 \\
\hline $\mathrm{sh}$ & $\mathrm{c}$ & $\mathrm{ch}$ & $\mathrm{s}$ & & $1.20 \mathrm{e}-11$ & 0.58 & 5880.0 & 4 \\
\hline $\mathrm{sh}$ & $\mathrm{CO}$ & ocs & $\mathrm{h}$ & & $5.95 \mathrm{e}-14$ & 1.12 & 8330.0 & 4 \\
\hline $\mathrm{s}+$ & h2 & $\operatorname{sh}+$ & $\mathrm{h}$ & & $2.20 \mathrm{e}-10$ & 0 & 9860.0 & 4 \\
\hline $\operatorname{sh}+$ & h2 & $\mathrm{h} 2 \mathrm{~s}+$ & $\mathrm{h}$ & & $1.90 \mathrm{e}-10$ & 0 & 8500.0 & 4 \\
\hline $\operatorname{sh}+$ & h2 & h3s+ & photon & & $1.00 \mathrm{e}-15$ & 0 & 0.0 & 3 \\
\hline $\mathrm{h} 2 \mathrm{~s}+$ & $\mathrm{h} 2$ & h3s+ & $\mathrm{h}$ & & $1.40 \mathrm{e}-11$ & 0 & 2300.0 & 4 \\
\hline $\operatorname{cs}+$ & h2 & hcs + & $\mathrm{h}$ & & $4.80 \mathrm{e}-10$ & 0 & 0.0 & 4 \\
\hline $\operatorname{sh}+$ & $\mathrm{h}$ & $\mathrm{s}+$ & h2 & & $1.10 \mathrm{e}-10$ & 0 & 0.0 & 4 \\
\hline $\mathrm{h} 2 \mathrm{~s}+$ & $\mathrm{h}$ & $\operatorname{sh}+$ & $\mathrm{h} 2$ & & $2.00 \mathrm{e}-10$ & 0 & 0.0 & 4 \\
\hline h3s+ & $\mathrm{h}$ & $\mathrm{h} 2 \mathrm{~s}+$ & h2 & & $6.00 \mathrm{e}-11$ & 0 & 0.0 & 4 \\
\hline so+ & $\mathrm{h}$ & $\mathrm{s}+$ & $\mathrm{oh}$ & & $6.10 \mathrm{e}-10$ & 0 & 11385.0 & 4 \\
\hline $\mathrm{h}+$ & $\mathrm{s}$ & $\mathrm{s}+$ & $\mathrm{h}$ & & $1.00 \mathrm{e}-15$ & 0 & 0.0 & 4 \\
\hline $\mathrm{h}+$ & $\mathrm{sh}$ & $\mathrm{s}+$ & $\mathrm{h} 2$ & & $3.50 \mathrm{e}-09$ & -0.5 & 0.0 & 4 \\
\hline $\mathrm{h}+$ & $\mathrm{sh}$ & $\operatorname{sh}+$ & $\mathrm{h}$ & & $3.50 \mathrm{e}-09$ & -0.5 & 0.0 & 4 \\
\hline $\mathrm{h}+$ & $\mathrm{h} 2 \mathrm{~s}$ & h2s+ & $\mathrm{h}$ & & $3.80 \mathrm{e}-09$ & -0.5 & 0.0 & 4 \\
\hline $\mathrm{h}+$ & $\mathrm{h} 2 \mathrm{cs}$ & $\mathrm{h} 2 \mathrm{cs}+$ & $\mathrm{h}$ & & $6.40 \mathrm{e}-09$ & -0.5 & 0.0 & 4 \\
\hline $\mathrm{h}+$ & $\mathrm{cs}$ & $\operatorname{cs}+$ & $\mathrm{h}$ & & $1.80 \mathrm{e}-08$ & -0.5 & 0.0 & 4 \\
\hline $\mathrm{h}+$ & so & so+ & $\mathrm{h}$ & & $1.40 \mathrm{e}-08$ & -0.5 & 0.0 & 4 \\
\hline $\mathrm{h}+$ & ocs & $\operatorname{sh}+$ & $\mathrm{CO}$ & & $6.50 \mathrm{e}-09$ & -0.5 & 0.0 & 4 \\
\hline $\mathrm{h} 2+$ & $\mathrm{h} 2 \mathrm{~s}$ & $\mathrm{~s}+$ & h2 & h2 & $7.70 \mathrm{e}-10$ & 0 & 0.0 & 4 \\
\hline $\mathrm{h} 2+$ & $\mathrm{h} 2 \mathrm{~s}$ & $\operatorname{sh}+$ & $\mathrm{h}$ & $\mathrm{h} 2$ & $8.60 \mathrm{e}-10$ & 0 & 0.0 & 4 \\
\hline h2+ & $\mathrm{h} 2 \mathrm{~s}$ & h2s+ & h2 & & $2.70 \mathrm{e}-09$ & 0 & 0.0 & 4 \\
\hline h3+ & $\mathrm{s}$ & $\operatorname{sh}+$ & h2 & & $2.60 \mathrm{e}-09$ & 0 & 0.0 & 4 \\
\hline h3+ & sh & $\mathrm{h} 2 \mathrm{~s}+$ & h2 & & $4.20 \mathrm{e}-09$ & -0.5 & 0.0 & 4 \\
\hline h3+ & $\mathrm{h} 2 \mathrm{~s}$ & h3s+ & $\mathrm{h} 2$ & & $2.30 \mathrm{e}-09$ & -0.5 & 0.0 & 4 \\
\hline h3+ & $\mathrm{cs}$ & hcs + & $\mathrm{h} 2$ & & $1.10 \mathrm{e}-08$ & -0.5 & 0.0 & 4 \\
\hline h3+ & so & hso+ & h2 & & $8.40 \mathrm{e}-09$ & -0.5 & 0.0 & 4 \\
\hline h3+ & so2 & hso2+ & h2 & & $3.72 \mathrm{e}-09$ & -0.5 & 0.0 & 4 \\
\hline h3+ & ocs & hocs + & h2 & & $3.80 \mathrm{e}-09$ & -0.5 & 0.0 & 4 \\
\hline h3+ & $\mathrm{h} 2 \mathrm{cs}$ & $\mathrm{h} 3 \mathrm{cs}+$ & h2 & & $3.80 \mathrm{e}-09$ & -0.5 & 0.0 & 4 \\
\hline he+ & $\mathrm{sh}$ & $\mathrm{s}+$ & $\mathrm{h}$ & he & $3.70 \mathrm{e}-09$ & -0.5 & 0.0 & 4 \\
\hline he+ & $\mathrm{h} 2 \mathrm{~s}$ & $\mathrm{~s}+$ & $\mathrm{h} 2$ & he & $1.60 \mathrm{e}-09$ & -0.5 & 0.0 & 4 \\
\hline he+ & $\mathrm{h} 2 \mathrm{~s}$ & $\operatorname{sh}+$ & $\mathrm{h}$ & he & $2.20 \mathrm{e}-10$ & -0.5 & 0.0 & 4 \\
\hline he+ & $\mathrm{h} 2 \mathrm{~s}$ & $\mathrm{~h} 2 \mathrm{~s}+$ & he & & $1.40 \mathrm{e}-10$ & -0.5 & 0.0 & 4 \\
\hline he+ & $\mathrm{h} 2 \mathrm{cs}$ & $\mathrm{s}+$ & $\operatorname{ch} 2$ & he & $1.11 \mathrm{e}-09$ & -0.5 & 0.0 & 4 \\
\hline he+ & $\mathrm{h} 2 \mathrm{cs}$ & $\mathrm{cs}+$ & h2 & he & $1.11 \mathrm{e}-09$ & -0.5 & 0.0 & 4 \\
\hline he+ & $\mathrm{h} 2 \mathrm{cs}$ & $\operatorname{ch} 2+$ & $\mathrm{s}$ & he & $1.11 \mathrm{e}-09$ & -0.5 & 0.0 & 4 \\
\hline he+ & $\mathrm{cs}$ & $\mathrm{c}+$ & $\mathrm{s}$ & he & $1.30 \mathrm{e}-09$ & 0 & 0.0 & 4 \\
\hline
\end{tabular}

Continua na próxima página... 
Tabela B.2 - Continuação

\begin{tabular}{|c|c|c|c|c|c|c|c|c|}
\hline \multicolumn{2}{|c|}{ Reagentes } & \multicolumn{3}{|c|}{ Produtos } & \multirow{2}{*}{$\frac{\gamma}{1.30 \mathrm{e}-09}$} & \multirow{2}{*}{$\begin{array}{c}\alpha \\
0\end{array}$} & \multirow{2}{*}{$\begin{array}{l}\beta \\
0.0\end{array}$} & \multirow{2}{*}{$\begin{array}{c}\text { Tipo de Reação } \\
4\end{array}$} \\
\hline he+ & cs & $\mathrm{s}+$ & $\mathrm{c}$ & he & & & & \\
\hline he+ & so & $\mathrm{o}+$ & $\mathrm{s}$ & he & $8.30 \mathrm{e}-10$ & 0 & 0.0 & 4 \\
\hline he+ & so & $\mathrm{s}+$ & o & he & $8.30 \mathrm{e}-10$ & 0 & 0.0 & 4 \\
\hline he+ & ocs & $\operatorname{cs}+$ & $\mathrm{o}$ & he & $7.60 \mathrm{e}-10$ & 0 & 0.0 & 4 \\
\hline he+ & ocs & $\mathrm{s}+$ & $\mathrm{co}$ & he & $7.60 \mathrm{e}-10$ & 0 & 0.0 & 4 \\
\hline he+ & ocs & $\mathrm{co}+$ & $\mathrm{s}$ & he & $7.60 \mathrm{e}-10$ & 0 & 0.0 & 4 \\
\hline he+ & ocs & $\mathrm{o}+$ & $\mathrm{cs}$ & he & $7.60 \mathrm{e}-11$ & 0 & 0.0 & 4 \\
\hline he+ & so2 & $\mathrm{s}+$ & o2 & he & $8.60 \mathrm{e}-10$ & 0 & 0.0 & 4 \\
\hline he+ & so2 & so+ & $\mathrm{o}$ & he & $3.44 \mathrm{e}-09$ & 0 & 0.0 & 4 \\
\hline $\mathrm{c}+$ & $\mathrm{s}$ & $\mathrm{s}+$ & $\mathrm{c}$ & & $1.50 \mathrm{e}-09$ & 0 & 0.0 & 4 \\
\hline $\mathrm{c}+$ & sh & $\mathrm{cs}+$ & $\mathrm{h}$ & & $2.40 \mathrm{e}-09$ & -0.5 & 0.0 & 4 \\
\hline $\mathrm{c}+$ & $\mathrm{h} 2 \mathrm{~s}$ & $\mathrm{~h} 2 \mathrm{~s}+$ & $\mathrm{c}$ & & $3.20 \mathrm{e}-10$ & -0.5 & 0.0 & 4 \\
\hline $\mathrm{c}+$ & $\mathrm{h} 2 \mathrm{~s}$ & hcs + & $\mathrm{h}$ & & $9.50 \mathrm{e}-10$ & -0.5 & 0.0 & 4 \\
\hline $\mathrm{c}+$ & $\mathrm{cs}$ & $\operatorname{cs}+$ & $\mathrm{c}$ & & $1.60 \mathrm{e}-09$ & 0 & 700.0 & 4 \\
\hline $\mathrm{c}+$ & $\mathrm{h} 2 \mathrm{cs}$ & $\operatorname{ch} 2+$ & $\mathrm{cs}$ & & $2.10 \mathrm{e}-19$ & -0.5 & 0.0 & 4 \\
\hline $\mathrm{c}+$ & so & $\mathrm{s}+$ & $\mathrm{co}$ & & $1.10 \mathrm{e}-09$ & -0.5 & 0.0 & 4 \\
\hline $\mathrm{c}+$ & so & $\mathrm{co}+$ & $\mathrm{s}$ & & $1.10 \mathrm{e}-09$ & -0.5 & 0.0 & 4 \\
\hline$c+$ & so & $\operatorname{cs}+$ & o & & $1.10 \mathrm{e}-09$ & -0.5 & 0.0 & 4 \\
\hline $\mathrm{c}+$ & so & so+ & $\mathrm{c}$ & & $1.10 \mathrm{e}-09$ & -0.5 & 0.0 & 4 \\
\hline$c+$ & so2 & so+ & $\mathrm{co}$ & & $2.00 \mathrm{e}-09$ & -0.5 & 0.0 & 4 \\
\hline $\mathrm{c}+$ & ocs & $\mathrm{cs}+$ & $\mathrm{co}$ & & $0.16 \mathrm{D}-08$ & 0 & 0.0 & 4 \\
\hline $\operatorname{ch}+$ & $\mathrm{s}$ & $\mathrm{s}+$ & $\mathrm{ch}$ & & $4.70 \mathrm{e}-10$ & 0 & 0.0 & 4 \\
\hline $\mathrm{ch}+$ & $\mathrm{s}$ & $\operatorname{sh}+$ & $\mathrm{c}$ & & $4.70 \mathrm{e}-10$ & 0 & 0.0 & 4 \\
\hline $\operatorname{ch}+$ & $\mathrm{s}$ & $\operatorname{cs}+$ & $\mathrm{h}$ & & $4.70 \mathrm{e}-10$ & 0 & 0.0 & 4 \\
\hline $\mathrm{ch}+$ & so & $\mathrm{oh}+$ & $\mathrm{cs}$ & & $1.00 \mathrm{e}-09$ & 0 & 0.0 & 4 \\
\hline $\operatorname{ch}+$ & so & $\operatorname{sh}+$ & $\mathrm{co}$ & & $1.00 \mathrm{e}-09$ & 0 & 0.0 & 4 \\
\hline $\operatorname{ch}+$ & $\mathrm{h} 2 \mathrm{~s}$ & hes + & h2 & & $6.60 \mathrm{e}-10$ & 0 & 0.0 & 4 \\
\hline $\mathrm{ch}+$ & $\mathrm{h} 2 \mathrm{~s}$ & h3s+ & $\mathrm{c}$ & & $6.30 \mathrm{e}-10$ & 0 & 0.0 & 4 \\
\hline $\operatorname{ch}+$ & ocs & hcs + & co & & $1.05 \mathrm{e}-09$ & 0 & 0.0 & 4 \\
\hline $\operatorname{ch}+$ & ocs & hocs + & $\mathrm{c}$ & & $8.55 \mathrm{e}-10$ & 0 & 0.0 & 4 \\
\hline $\operatorname{ch} 2+$ & $\mathrm{s}$ & hcs + & $\mathrm{h}$ & & $1.40 \mathrm{e}-09$ & 0 & 0.0 & 4 \\
\hline $\operatorname{ch} 2+$ & $\mathrm{h} 2 \mathrm{~s}$ & hes+ & h2 & $\mathrm{h}$ & $1.10 \mathrm{e}-09$ & 0 & 0.0 & 4 \\
\hline $\operatorname{ch} 3+$ & $\mathrm{s}$ & hcs+ & h2 & & $1.40 \mathrm{e}-09$ & 0 & 0.0 & 4 \\
\hline $\operatorname{ch} 3+$ & sh & $\mathrm{h} 2 \mathrm{cs}+$ & h2 & & $2.20 \mathrm{e}-09$ & -0.5 & 0.0 & 4 \\
\hline $\operatorname{ch} 3+$ & $\mathrm{h} 2 \mathrm{~s}$ & h3cs+ & h2 & & $1.00 \mathrm{e}-09$ & -0.5 & 0.0 & 4 \\
\hline $\operatorname{ch} 3+$ & so & hocs + & h2 & & $9.50 \mathrm{e}-10$ & 0 & 0.0 & 4 \\
\hline $\operatorname{ch} 4+$ & $\mathrm{h} 2 \mathrm{~s}$ & $\mathrm{~h} 2 \mathrm{~s}+$ & $\operatorname{ch} 4$ & & $1.60 \mathrm{e}-09$ & 0 & 0.0 & 4 \\
\hline $\operatorname{ch} 4+$ & $\mathrm{h} 2 \mathrm{~s}$ & h3s+ & $\operatorname{ch} 3$ & & $9.50 \mathrm{e}-10$ & 0 & 0.0 & 4 \\
\hline $\operatorname{ch} 4+$ & ocs & hocs+ & $\operatorname{ch} 3$ & & $9.80 \mathrm{e}-10$ & 0 & 0.0 & 4 \\
\hline $\operatorname{ch} 5+$ & $\mathrm{s}$ & $\operatorname{sh}+$ & $\operatorname{ch} 4$ & & $1.30 \mathrm{e}-09$ & 0 & 0.0 & 4 \\
\hline $\mathrm{c} 2+$ & $\mathrm{s}$ & $\mathrm{s}+$ & $\mathrm{c} 2$ & & $5.80 \mathrm{e}-10$ & 0 & 0.0 & 4 \\
\hline $\mathrm{c} 2+$ & $\mathrm{s}$ & $\mathrm{cs}+$ & $\mathrm{c}$ & & $5.80 \mathrm{e}-10$ & 0 & 0.0 & 4 \\
\hline $\mathrm{c} 2 \mathrm{~h}+$ & $\mathrm{s}$ & $\mathrm{s}+$ & $\mathrm{c} 2 \mathrm{~h}$ & & $1.20 \mathrm{e}-09$ & 0 & 0.0 & 4 \\
\hline
\end{tabular}

Continua na próxima página... 
Tabela B.2 - Continuação

\begin{tabular}{|c|c|c|c|c|c|c|c|}
\hline \multicolumn{2}{|c|}{ Reagentes } & \multicolumn{2}{|r|}{ Produtos } & \multirow{2}{*}{$\frac{\gamma}{9.80 \mathrm{e}-10}$} & \multirow{2}{*}{$\begin{array}{c}\alpha \\
-0.5\end{array}$} & \multirow{2}{*}{$\frac{\beta}{0.0}$} & \multirow{2}{*}{$\frac{\text { Tipo de Reação }}{4}$} \\
\hline $\mathrm{c} 2 \mathrm{~h} 2+$ & $\mathrm{h} 2 \mathrm{~s}$ & $\mathrm{~h} 2 \mathrm{~s}+$ & $\mathrm{c} 2 \mathrm{~h} 2$ & & & & \\
\hline $\mathrm{c} 2 \mathrm{~h} 2+$ & $\mathrm{h} 2 \mathrm{~s}$ & $\mathrm{c} 2 \mathrm{~h} 3+$ & $\mathrm{sh}$ & $2.00 \mathrm{e}-11$ & -0.5 & 0.0 & 4 \\
\hline $\mathrm{c} 3 \mathrm{~h}+$ & $\mathrm{h} 2 \mathrm{~s}$ & $\mathrm{c} 2 \mathrm{~h} 3+$ & $\mathrm{cs}$ & $2.98 \mathrm{e}-10$ & -0.5 & 0.0 & 4 \\
\hline $\mathrm{c} 3 \mathrm{~h}+$ & $\mathrm{h} 2 \mathrm{~s}$ & hcs + & $\mathrm{c} 2 \mathrm{~h} 2$ & $2.98 \mathrm{e}-10$ & -0.5 & 0.0 & 4 \\
\hline $\mathrm{o}+$ & $\mathrm{h} 2 \mathrm{~s}$ & h2o & $\mathrm{s}+$ & $2.20 \mathrm{e}-10$ & 0 & 0.0 & 4 \\
\hline $\mathrm{o}+$ & $\mathrm{h} 2 \mathrm{~s}$ & $\operatorname{sh}+$ & oh & $4.20 \mathrm{e}-10$ & 0 & 0.0 & 4 \\
\hline $\mathrm{o}+$ & $\mathrm{h} 2 \mathrm{~s}$ & $\mathrm{~h} 2 \mathrm{~s}+$ & o & $1.80 \mathrm{e}-09$ & 0 & 0.0 & 4 \\
\hline $\mathrm{o}+$ & ocs & $\mathrm{s}+$ & $\operatorname{co} 2$ & $2.00 \mathrm{e}-11$ & 0 & 0.0 & 4 \\
\hline $\mathrm{o}+$ & so2 & $\mathrm{o} 2+$ & so & $8.00 \mathrm{e}-10$ & 0 & 0.0 & 4 \\
\hline $\mathrm{oh}+$ & $\mathrm{s}$ & $\mathrm{s}+$ & oh & $4.30 \mathrm{e}-10$ & 0 & 0.0 & 4 \\
\hline $\mathrm{oh}+$ & $\mathrm{s}$ & $\operatorname{sh}+$ & o & $4.30 \mathrm{e}-10$ & 0 & 0.0 & 4 \\
\hline $\mathrm{oh}+$ & $\mathrm{s}$ & so+ & $\mathrm{h}$ & $4.30 \mathrm{e}-10$ & 0 & 0.0 & 4 \\
\hline $\mathrm{oh}+$ & $\mathrm{h} 2 \mathrm{~s}$ & $\mathrm{~h} 2 \mathrm{~s}+$ & oh & $1.20 \mathrm{e}-09$ & 0 & 0.0 & 4 \\
\hline $\mathrm{oh}+$ & $\mathrm{h} 2 \mathrm{~s}$ & h3s+ & o & $8.20 \mathrm{e}-10$ & 0 & 0.0 & 4 \\
\hline h2o+ & $\mathrm{s}$ & $\mathrm{s}+$ & h2o & $4.30 \mathrm{e}-10$ & 0 & 0.0 & 4 \\
\hline h2o+ & $\mathrm{s}$ & $\operatorname{sh}+$ & oh & $4.30 \mathrm{e}-10$ & 0 & 0.0 & 4 \\
\hline h2o+ & $\mathrm{s}$ & hso+ & $\mathrm{h}$ & $4.30 \mathrm{e}-10$ & 0 & 0.0 & 4 \\
\hline $\mathrm{h} 2 \mathrm{o}+$ & $\mathrm{h} 2 \mathrm{~s}$ & $\mathrm{~h} 2 \mathrm{~s}+$ & h2o & $8.90 \mathrm{e}-10$ & 0 & 0.0 & 4 \\
\hline h2o+ & $\mathrm{h} 2 \mathrm{~s}$ & h3o+ & $\mathrm{sh}$ & $5.90 \mathrm{e}-10$ & 0 & 0.0 & 4 \\
\hline h3o+ & $\mathrm{s}$ & $\operatorname{sh}+$ & h2o & $3.20 \mathrm{e}-10$ & 0 & 4930.0 & 4 \\
\hline h3o+ & $\mathrm{h} 2 \mathrm{~s}$ & h3s+ & h2o & $1.90 \mathrm{e}-09$ & 0 & 0.0 & 4 \\
\hline $\mathrm{co}+$ & s & $\mathrm{s}+$ & $\mathrm{co}$ & $1.10 \mathrm{e}-09$ & 0 & 0.0 & 4 \\
\hline $\mathrm{co}+$ & $\mathrm{h} 2 \mathrm{~s}$ & $\mathrm{~h} 2 \mathrm{~s}+$ & $\mathrm{co}$ & $2.44 \mathrm{e}-09$ & 0 & 0.0 & 4 \\
\hline $\mathrm{co}+$ & $\mathrm{h} 2 \mathrm{~s}$ & hco+ & $\mathrm{sh}$ & $1.56 \mathrm{e}-10$ & 0 & 0.0 & 4 \\
\hline $\mathrm{co}+$ & so2 & so+ & $\mathrm{co} 2$ & $1.70 \mathrm{e}-09$ & 0 & 0.0 & 4 \\
\hline hco+ & $\mathrm{s}$ & $\operatorname{sh}+$ & $\mathrm{co}$ & $3.30 \mathrm{e}-10$ & 0 & 0.0 & 4 \\
\hline hco+ & $\mathrm{sh}$ & $\mathrm{h} 2 \mathrm{~s}+$ & $\mathrm{co}$ & $8.20 \mathrm{e}-10$ & 0 & 0.0 & 4 \\
\hline hco+ & $\mathrm{cs}$ & hcs+ & $\mathrm{co}$ & $1.20 \mathrm{e}-09$ & 0 & 0.0 & 4 \\
\hline hco+ & so & hso+ & $\mathrm{co}$ & $7.50 \mathrm{e}-10$ & 0 & 0.0 & 4 \\
\hline hco+ & $\mathrm{h} 2 \mathrm{~s}$ & h3s+ & $\mathrm{co}$ & $1.60 \mathrm{e}-09$ & 0 & 0.0 & 4 \\
\hline hco+ & ocs & hocs + & $\mathrm{co}$ & $1.10 \mathrm{e}-09$ & 0 & 0.0 & 4 \\
\hline hco+ & $\mathrm{h} 2 \mathrm{cs}$ & h3cs+ & $\mathrm{co}$ & $1.50 \mathrm{e}-09$ & -0.5 & 0.0 & 4 \\
\hline $\mathrm{o} 2+$ & $\mathrm{s}$ & so+ & o & $5.40 \mathrm{e}-10$ & 0 & 0.0 & 4 \\
\hline $\mathrm{o} 2+$ & $\mathrm{s}$ & $\mathrm{s}+$ & o2 & $5.40 \mathrm{e}-10$ & 0 & 0.0 & 4 \\
\hline $\mathrm{o} 2+$ & $\mathrm{h} 2 \mathrm{~s}$ & $\mathrm{~h} 2 \mathrm{~s}+$ & o2 & $1.40 \mathrm{e}-09$ & 0 & 0.0 & 4 \\
\hline $\mathrm{s}+$ & $\mathrm{ch}$ & $\mathrm{cs}+$ & $\mathrm{h}$ & $6.20 \mathrm{e}-10$ & 0 & 0.0 & 4 \\
\hline $\mathrm{s}+$ & $\operatorname{ch} 2$ & hcs+ & $\mathrm{h}$ & $7.08 \mathrm{e}-10$ & -0.5 & 0.0 & 4 \\
\hline $\mathrm{s}+$ & $\mathrm{c} 2$ & $\operatorname{cs}+$ & c & $8.10 \mathrm{e}-10$ & 0 & 0.0 & 4 \\
\hline $\mathrm{s}+$ & oh & so+ & $\mathrm{h}$ & $6.10 \mathrm{e}-10$ & 0 & 0.0 & 4 \\
\hline $\mathrm{s}+$ & oh & $\operatorname{sh}+$ & o & $2.90 \mathrm{e}-10$ & 0 & 8820.0 & 4 \\
\hline $\mathrm{s}+$ & $\mathrm{sh}$ & $\operatorname{sh}+$ & $\mathrm{s}$ & $9.70 \mathrm{e}-10$ & 0 & 350.0 & 4 \\
\hline $\mathrm{s}+$ & o2 & so+ & o & $2.30 \mathrm{e}-11$ & 0 & 0.0 & 4 \\
\hline $\mathrm{s}+$ & $\operatorname{ch} 3$ & $\mathrm{~h} 2 \mathrm{cs}+$ & $\mathrm{h}$ & $1.00 \mathrm{e}-11$ & 0 & 0.0 & 4 \\
\hline
\end{tabular}

Continua na próxima página... 
Tabela B.2 - Continuação

\begin{tabular}{|c|c|c|c|c|c|c|c|}
\hline \multicolumn{2}{|c|}{ Reagentes } & & \multirow{2}{*}{$\begin{array}{c}\text { Produtos } \\
\mathrm{h}\end{array}$} & \multirow{2}{*}{$\frac{\gamma}{1.40 \mathrm{e}-10}$} & \multirow{2}{*}{$\begin{array}{l}\alpha \\
0\end{array}$} & \multirow{2}{*}{$\begin{array}{l}\beta \\
0.0\end{array}$} & \multirow{2}{*}{$\begin{array}{c}\text { Tipo de Reação } \\
4\end{array}$} \\
\hline $\mathrm{s}+$ & $\operatorname{ch} 4$ & h3cs+ & & & & & \\
\hline $\mathrm{s}+$ & $\mathrm{h} 2 \mathrm{co}$ & $\mathrm{h} 2 \mathrm{~s}+$ & $\mathrm{co}$ & $1.10 \mathrm{e}-09$ & -0.5 & 0.0 & 4 \\
\hline $\mathrm{s}+$ & $\mathrm{h} 2 \mathrm{co}$ & hco+ & $\mathrm{sh}$ & $1.10 \mathrm{e}-09$ & -0.5 & 0.0 & 4 \\
\hline $\mathrm{s}+$ & hco & $\operatorname{sh}+$ & $\mathrm{co}$ & $5.00 \mathrm{e}-10$ & -0.5 & 0.0 & 4 \\
\hline $\mathrm{s}+$ & hco & hco+ & $\mathrm{s}$ & $5.00 \mathrm{e}-10$ & -0.5 & 0.0 & 4 \\
\hline $\mathrm{s}+$ & h2s & $\mathrm{h} 2 \mathrm{~s}+$ & $\mathrm{s}$ & $4.40 \mathrm{e}-11$ & -0.5 & 0.0 & 4 \\
\hline $\operatorname{sh}+$ & o & so+ & $\mathrm{h}$ & $2.90 \mathrm{e}-10$ & 0 & 0.0 & 4 \\
\hline $\operatorname{sh}+$ & o & $\mathrm{s}+$ & oh & $2.90 \mathrm{e}-10$ & 0 & 0.0 & 4 \\
\hline $\operatorname{sh}+$ & $\mathrm{s}$ & $\mathrm{s}+$ & $\mathrm{sh}$ & $9.70 \mathrm{e}-10$ & 0 & 0.0 & 4 \\
\hline $\operatorname{sh}+$ & c & cs+ & $\mathrm{h}$ & $9.90 \mathrm{e}-10$ & 0 & 0.0 & 4 \\
\hline $\operatorname{sh}+$ & $\mathrm{ch}$ & $\operatorname{ch} 2+$ & $\mathrm{s}$ & $5.80 \mathrm{e}-10$ & 0 & 0.0 & 4 \\
\hline $\operatorname{sh}+$ & oh & $\mathrm{h} 2 \mathrm{~s}+$ & o & $3.10 \mathrm{e}-10$ & 0 & 7500.0 & 4 \\
\hline $\operatorname{sh}+$ & oh & h2o+ & $\mathrm{s}$ & $4.30 \mathrm{e}-10$ & 0 & 9200.0 & 4 \\
\hline $\operatorname{sh}+$ & h2o & h3o+ & $\mathrm{s}$ & $6.30 \mathrm{e}-10$ & 0 & 0.0 & 4 \\
\hline $\operatorname{sh}+$ & $\mathrm{h} 2 \mathrm{~s}$ & $\mathrm{~h} 2 \mathrm{~s}+$ & $\mathrm{sh}$ & $5.00 \mathrm{e}-10$ & 0 & 1000.0 & 4 \\
\hline $\operatorname{sh}+$ & $\mathrm{h} 2 \mathrm{~s}$ & h3s+ & $\mathrm{s}$ & $5.00 \mathrm{e}-10$ & 0 & 0.0 & 4 \\
\hline $\operatorname{sh}+$ & $\operatorname{ch} 4$ & $\mathrm{~h} 3 \mathrm{cs}+$ & h2 & $5.40 \mathrm{e}-10$ & 0 & 0.0 & 4 \\
\hline $\mathrm{h} 2 \mathrm{~s}+$ & o & $\operatorname{sh}+$ & oh & $3.10 \mathrm{e}-10$ & 0 & 0.0 & 4 \\
\hline $\mathrm{h} 2 \mathrm{~s}+$ & o & so + & h2 & $3.10 \mathrm{e}-10$ & 0 & 0.0 & 4 \\
\hline $\mathrm{h} 2 \mathrm{~s}+$ & c & hcs + & $\mathrm{h}$ & $1.00 \mathrm{e}-09$ & 0 & 0.0 & 4 \\
\hline $\mathrm{h} 2 \mathrm{~s}+$ & $\mathrm{s}$ & $\mathrm{s}+$ & $\mathrm{h} 2 \mathrm{~s}$ & $1.10 \mathrm{e}-09$ & 0 & 0.0 & 4 \\
\hline $\mathrm{h} 2 \mathrm{~s}+$ & $\mathrm{sh}$ & $\operatorname{sh}+$ & $\mathrm{h} 2 \mathrm{~s}$ & $5.00 \mathrm{e}-10$ & 0 & 0.0 & 4 \\
\hline $\mathrm{h} 2 \mathrm{~s}+$ & h2o & h3o+ & $\mathrm{sh}$ & $8.10 \mathrm{e}-10$ & 0 & 0.0 & 4 \\
\hline h3s+ & $\mathrm{h} 2 \mathrm{co}$ & h3co+ & $\mathrm{h} 2 \mathrm{~s}$ & $2.20 \mathrm{e}-09$ & 0 & 0.0 & 4 \\
\hline $\mathrm{cs}+$ & c & $\mathrm{c}+$ & $\mathrm{cs}$ & $1.60 \mathrm{e}-09$ & 0 & 0.0 & 4 \\
\hline $\mathrm{cs}+$ & o & $\mathrm{co}+$ & $\mathrm{s}$ & $6.00 \mathrm{e}-11$ & 0 & 0.0 & 4 \\
\hline $\mathrm{cs}+$ & $\operatorname{ch} 4$ & hcs + & $\operatorname{ch} 3$ & $5.00 \mathrm{e}-10$ & 0 & 0.0 & 4 \\
\hline hcs + & o & hco+ & $\mathrm{s}$ & $1.00 \mathrm{e}-09$ & 0 & 0.0 & 4 \\
\hline $\mathrm{s}+$ & fe & $\mathrm{fe}+$ & $\mathrm{s}$ & $1.80 \mathrm{e}-10$ & 0 & 0.0 & 4 \\
\hline $\operatorname{sh}+$ & fe & $\mathrm{fe}+$ & $\mathrm{sh}$ & $1.60 \mathrm{e}-09$ & 0 & 0.0 & 4 \\
\hline $\mathrm{so}+$ & fe & $\mathrm{fe}+$ & so & $1.60 \mathrm{e}-09$ & 0 & 0.0 & 4 \\
\hline $\mathrm{h} 2 \mathrm{~s}+$ & fe & $\mathrm{fe}+$ & $\mathrm{h} 2 \mathrm{~s}$ & $1.80 \mathrm{e}-09$ & 0 & 0.0 & 4 \\
\hline $\mathrm{cs}+$ & fe & fe+ & cs & $1.70 \mathrm{e}-10$ & 0 & 0.0 & 4 \\
\hline $\mathrm{s}+$ & nh3 & nh3+ & $\mathrm{s}$ & $1.60 \mathrm{e}-09$ & 0 & 0.0 & 4 \\
\hline $\mathrm{s}+$ & no & not & $\mathrm{s}$ & $3.20 \mathrm{e}-10$ & 0 & 0.0 & 4 \\
\hline $\operatorname{sh}+$ & hen & hcnh+ & $\mathrm{s}$ & $8.90 \mathrm{e}-10$ & 0 & 0.0 & 4 \\
\hline $\operatorname{sh}+$ & hnc & hcnh+ & $\mathrm{s}$ & $8.60 \mathrm{e}-10$ & 0 & 0.0 & 4 \\
\hline $\operatorname{sh}+$ & no & not & $\mathrm{sh}$ & $3.30 \mathrm{e}-10$ & 0 & 0.0 & 4 \\
\hline $\operatorname{sh}+$ & nh3 & nh3+ & $\mathrm{sh}$ & $5.25 \mathrm{e}-10$ & 0 & 0.0 & 4 \\
\hline $\operatorname{sh}+$ & nh3 & nh4+ & $\mathrm{s}$ & $9.75 \mathrm{e}-10$ & 0 & 0.0 & 4 \\
\hline $\mathrm{h} 2 \mathrm{~s}+$ & no & not & $\mathrm{h} 2 \mathrm{~s}$ & $3.70 \mathrm{e}-10$ & 0 & 0.0 & 4 \\
\hline $\mathrm{h} 2 \mathrm{~s}+$ & nh3 & nh4+ & $\mathrm{sh}$ & $1.36 \mathrm{e}-09$ & 0 & 0.0 & 4 \\
\hline $\mathrm{h} 2 \mathrm{~s}+$ & nh3 & nh3+ & $\mathrm{h} 2 \mathrm{~s}$ & $3.40 \mathrm{e}-10$ & 0 & 0.0 & 4 \\
\hline
\end{tabular}

Continua na próxima página... 
Tabela B.2 - Continuação

\begin{tabular}{|c|c|c|c|c|c|c|c|c|}
\hline \multicolumn{2}{|c|}{ Reagentes } & \multicolumn{3}{|c|}{ Produtos } & \multirow{2}{*}{$\frac{\gamma}{1.90 \mathrm{e}-09}$} & \multirow{2}{*}{$\begin{array}{c}\alpha \\
0\end{array}$} & \multirow{2}{*}{$\begin{array}{l}\beta \\
0.0\end{array}$} & \multirow{2}{*}{$\begin{array}{c}\text { Tipo de Reação } \\
4\end{array}$} \\
\hline h3s+ & nh3 & nh4+ & $\mathrm{h} 2 \mathrm{~s}$ & & & & & \\
\hline h3s+ & hen & hcnh+ & $\mathrm{h} 2 \mathrm{~s}$ & & $1.50 \mathrm{e}-09$ & 0 & 0.0 & 4 \\
\hline h3s+ & hnc & hcnh+ & $\mathrm{h} 2 \mathrm{~s}$ & & $1.50 \mathrm{e}-09$ & 0 & 0.0 & 4 \\
\hline so+ & nh3 & nh3+ & so & & $1.30 \mathrm{e}-09$ & 0 & 0.0 & 4 \\
\hline $\mathrm{n}+$ & $\mathrm{h} 2 \mathrm{~s}$ & $\operatorname{sh}+$ & $\mathrm{nh}$ & & $5.51 \mathrm{e}-10$ & 0 & 0.0 & 4 \\
\hline $\mathrm{n}+$ & $\mathrm{h} 2 \mathrm{~s}$ & $\mathrm{~h} 2 \mathrm{~s}+$ & $\mathrm{n}$ & & $1.06 \mathrm{e}-09$ & 0 & 0.0 & 4 \\
\hline $\mathrm{n}+$ & $\mathrm{h} 2 \mathrm{~s}$ & $\mathrm{~s}+$ & nh2 & & $0.23 \mathrm{D}-09$ & 0 & 0.0 & 4 \\
\hline $\mathrm{n}+$ & $\mathrm{h} 2 \mathrm{~s}$ & $\mathrm{nh}+$ & $\mathrm{sh}$ & & $0.57 \mathrm{D}-10$ & 0 & 0.0 & 4 \\
\hline $\mathrm{n}+$ & ocs & $\mathrm{s}+$ & $\mathrm{co}$ & $\mathrm{n}$ & $3.08 \mathrm{e}-10$ & 0 & 0.0 & 4 \\
\hline $\mathrm{n}+$ & ocs & $\operatorname{cs}+$ & no & & $7.00 \mathrm{e}-11$ & 0 & 0.0 & 4 \\
\hline $\mathrm{cn}+$ & $\mathrm{s}$ & $\mathrm{s}+$ & $\mathrm{cn}$ & & $1.10 \mathrm{e}-09$ & 0 & 0.0 & 4 \\
\hline hen+ & $\mathrm{s}$ & $\mathrm{s}+$ & hen & & $5.70 \mathrm{e}-10$ & 0 & 0.0 & 4 \\
\hline hen+ & $\mathrm{s}$ & $\operatorname{sh}+$ & $\mathrm{cn}$ & & $5.70 \mathrm{e}-10$ & 0 & 0.0 & 4 \\
\hline hnct & $\mathrm{s}$ & $\mathrm{s}+$ & hnc & & $5.70 \mathrm{e}-10$ & 0 & 0.0 & 4 \\
\hline hnct & $\mathrm{s}$ & $\operatorname{sh}+$ & $\mathrm{cn}$ & & $5.70 \mathrm{e}-10$ & 0 & 0.0 & 4 \\
\hline $\mathrm{nh}+$ & $\mathrm{s}$ & $\mathrm{s}+$ & $\mathrm{nh}$ & & $6.90 \mathrm{e}-10$ & 0 & 0.0 & 4 \\
\hline $\mathrm{nh}+$ & $\mathrm{s}$ & $\operatorname{sh}+$ & $\mathrm{n}$ & & $6.90 \mathrm{e}-10$ & 0 & 0.0 & 4 \\
\hline $\mathrm{nh} 2+$ & $\mathrm{s}$ & $\mathrm{s}+$ & nh2 & & $4.40 \mathrm{e}-10$ & 0 & 0.0 & 4 \\
\hline $\mathrm{nh} 2+$ & $\mathrm{s}$ & $\operatorname{sh}+$ & $\mathrm{nh}$ & & $4.40 \mathrm{e}-10$ & 0 & 0.0 & 4 \\
\hline nh2+ & $\mathrm{h} 2 \mathrm{~s}$ & $\operatorname{sh}+$ & nh3 & & $1.80 \mathrm{e}-10$ & 0 & 0.0 & 4 \\
\hline nh2 $2+$ & $\mathrm{h} 2 \mathrm{~s}$ & $\mathrm{~h} 2 \mathrm{~s}+$ & nh2 & & $3.40 \mathrm{e}-10$ & 0 & 0.0 & 4 \\
\hline nh2+ & $\mathrm{h} 2 \mathrm{~s}$ & h3s+ & $\mathrm{nh}$ & & $2.40 \mathrm{e}-10$ & 0 & 0.0 & 4 \\
\hline nh2+ & $\mathrm{h} 2 \mathrm{~s}$ & nh3+ & $\operatorname{sh}$ & & $4.50 \mathrm{e}-10$ & 0 & 0.0 & 4 \\
\hline $\mathrm{nh} 2+$ & $\mathrm{h} 2 \mathrm{~s}$ & nh4+ & $\mathrm{s}$ & & $1.80 \mathrm{e}-10$ & 0 & 0.0 & 4 \\
\hline nh3+ & $\mathrm{h} 2 \mathrm{~s}$ & nh4+ & $\mathrm{sh}$ & & $6.00 \mathrm{e}-10$ & 0 & 0.0 & 4 \\
\hline $\mathrm{n} 2+$ & $\mathrm{s}$ & $\mathrm{s}+$ & $\mathrm{n} 2$ & & $1.10 \mathrm{e}-09$ & 0 & 0.0 & 4 \\
\hline $\mathrm{n} 2+$ & $\mathrm{h} 2 \mathrm{~s}$ & $\mathrm{~s}+$ & $\mathrm{n} 2$ & $\mathrm{~h} 2$ & $2.25 \mathrm{e}-10$ & 0 & 0.0 & 4 \\
\hline $\mathrm{n} 2+$ & $\mathrm{h} 2 \mathrm{~s}$ & $\operatorname{sh}+$ & $\mathrm{n} 2$ & $\mathrm{~h}$ & $1.13 \mathrm{e}-09$ & 0 & 0.0 & 4 \\
\hline $\mathrm{n} 2+$ & $\mathrm{h} 2 \mathrm{~s}$ & $\mathrm{~h} 2 \mathrm{~s}+$ & $\mathrm{n} 2$ & & $1.50 \mathrm{e}-10$ & 0 & 0.0 & 4 \\
\hline $\mathrm{n} 2+$ & ocs & $\mathrm{s}+$ & $\mathrm{n} 2$ & $\mathrm{co}$ & $1.04 \mathrm{e}-09$ & 0 & 0.0 & 4 \\
\hline hno+ & $\mathrm{s}$ & $\operatorname{sh}+$ & no & & $1.10 \mathrm{e}-09$ & 0 & 0.0 & 4 \\
\hline $\mathrm{n} 2 \mathrm{~h}+$ & $\mathrm{s}$ & $\operatorname{sh}+$ & $\mathrm{n} 2$ & & $1.10 \mathrm{e}-09$ & 0 & 0.0 & 4 \\
\hline $\mathrm{c} 2 \mathrm{n}+$ & $\mathrm{h} 2 \mathrm{~s}$ & hcs+ & hen & & $1.20 \mathrm{e}-09$ & 0 & 0.0 & 4 \\
\hline $\mathrm{o} 2$ & photon & o & o & & $7.90 \mathrm{e}-10$ & 0 & 1.80 & 5 \\
\hline o 2 & photon & $\mathrm{o} 2+$ & electr & & $7.70 \mathrm{e}-11$ & 0 & 3.73 & 5 \\
\hline oh & photon & o & $\mathrm{h}$ & & $4.20 \mathrm{e}-10$ & 0 & 1.72 & 5 \\
\hline oh & photon & $\mathrm{oh}+$ & electr & & $1.60 \mathrm{e}-12$ & 0 & 3.10 & 5 \\
\hline h2o & photon & oh & $\mathrm{h}$ & & $8.00 \mathrm{e}-10$ & 0 & 1.70 & 5 \\
\hline h2o & photon & $\mathrm{h} 2 \mathrm{o}+$ & electr & & $3.30 \mathrm{e}-11$ & 0 & 3.85 & 5 \\
\hline $\mathrm{ch}$ & photon & $\mathrm{c}$ & $\mathrm{h}$ & & $1.40 \mathrm{e}-10$ & 0 & 1.5 & 5 \\
\hline $\mathrm{ch}$ & photon & $\operatorname{ch}+$ & electr & & $2.90 \mathrm{e}-10$ & 0 & 2.8 & 5 \\
\hline $\operatorname{ch} 2$ & photon & $\mathrm{ch}$ & $\mathrm{h}$ & & $7.20 \mathrm{e}-10$ & 0 & 1.67 & 5 \\
\hline $\operatorname{ch} 2$ & photon & $\operatorname{ch} 2+$ & electr & & $3.00 \mathrm{e}-10$ & 0 & 2.3 & 5 \\
\hline
\end{tabular}

Continua na próxima página... 
Tabela B.2 - Continuação

\begin{tabular}{|c|c|c|c|c|c|c|c|}
\hline \multicolumn{2}{|c|}{ Reagentes } & & Produtos & $\gamma$ & $\alpha$ & $\beta$ & Tipo de Reação \\
\hline $\operatorname{ch} 3$ & photon & $\operatorname{ch} 2$ & $\mathrm{~h}$ & $5.00 \mathrm{e}-10$ & 0 & 1.88 & 5 \\
\hline $\operatorname{ch} 3$ & photon & $\operatorname{ch} 3+$ & electr & $1.00 \mathrm{e}-10$ & 0 & 2.1 & 5 \\
\hline $\operatorname{ch} 4$ & photon & $\operatorname{ch} 2$ & h2 & $1.20 \mathrm{e}-09$ & 0 & 2.15 & 5 \\
\hline $\operatorname{ch} 4$ & photon & $\operatorname{ch} 4+$ & electr & $6.80 \mathrm{e}-12$ & 0 & 4.04 & 5 \\
\hline $\mathrm{c} 2$ & photon & c & c & $2.30 \mathrm{e}-10$ & 0 & 2.09 & 5 \\
\hline $\mathrm{c} 2$ & photon & $\mathrm{c} 2+$ & electr & $4.10 \mathrm{e}-10$ & 0 & 3.54 & 5 \\
\hline $\mathrm{c} 2 \mathrm{~h}$ & photon & $\mathrm{c} 2$ & $\mathrm{~h}$ & $5.10 \mathrm{e}-10$ & 0 & 1.89 & 5 \\
\hline $\mathrm{c} 2 \mathrm{~h}$ & photon & $\mathrm{c} 2 \mathrm{~h}+$ & electr & $1.00 \mathrm{e}-11$ & 0 & 2.00 & 5 \\
\hline $\mathrm{c} 2 \mathrm{~h} 2$ & photon & $\mathrm{c} 2 \mathrm{~h}$ & $\mathrm{~h}$ & $3.20 \mathrm{e}-09$ & 0 & 1.84 & 5 \\
\hline $\mathrm{c} 2 \mathrm{~h} 2$ & photon & $\mathrm{c} 2 \mathrm{~h} 2+$ & electr & $3.30 \mathrm{e}-10$ & 0 & 3.12 & 5 \\
\hline c3 & photon & $\mathrm{c} 2$ & c & $2.60 \mathrm{e}-10$ & 0 & 2.3 & 5 \\
\hline $\mathrm{c} 3 \mathrm{~h}$ & photon & c3 & $\mathrm{h}$ & $1.00 \mathrm{e}-09$ & 0 & 1.70 & 5 \\
\hline c3h2 & photon & $\mathrm{c} 3 \mathrm{~h}$ & $\mathrm{~h}$ & $1.90 \mathrm{e}-09$ & 0 & 1.79 & 5 \\
\hline $\mathrm{c} 3 \mathrm{~h} 2$ & photon & c3 & h2 & $1.00 \mathrm{e}-09$ & 0 & 1.7 & 5 \\
\hline $\mathrm{h} 2 \mathrm{co}$ & photon & $\mathrm{co}$ & h2 & $1.00 \mathrm{e}-09$ & 0 & 1.74 & 5 \\
\hline hco & photon & $\mathrm{co}$ & $\mathrm{h}$ & $1.10 \mathrm{e}-09$ & 0 & 0.80 & 5 \\
\hline $\mathrm{co} 2$ & photon & $\mathrm{co}$ & o & $8.70 \mathrm{e}-10$ & 0 & 2.50 & 5 \\
\hline fe & photon & $\mathrm{fe}+$ & electr & $2.80 \mathrm{e}-10$ & 0 & 1.86 & 5 \\
\hline $\mathrm{h} 2+$ & photon & $\mathrm{h}+$ & $\mathrm{h}$ & $5.70 \mathrm{e}-10$ & 0 & 1.85 & 5 \\
\hline h3+ & photon & $\mathrm{h} 2+$ & $\mathrm{h}$ & $5.00 \mathrm{e}-13$ & 0 & 2.3 & 5 \\
\hline h3+ & photon & $\mathrm{h}+$ & h2 & $5.00 \mathrm{e}-13$ & 0 & 1.8 & 5 \\
\hline $\mathrm{ch}+$ & photon & $\mathrm{h}+$ & c & $3.20 \mathrm{e}-10$ & 0 & 2.50 & 5 \\
\hline $\operatorname{ch}+$ & photon & $\mathrm{c}+$ & $\mathrm{h}$ & $2.00 \mathrm{e}-12$ & 0 & 3.0 & 5 \\
\hline $\operatorname{ch} 2+$ & photon & $\operatorname{ch}+$ & $\mathrm{h}$ & $1.70 \mathrm{e}-09$ & 0 & 1.7 & 5 \\
\hline $\operatorname{ch} 3+$ & photon & $\operatorname{ch} 2+$ & $\mathrm{h}$ & $1.00 \mathrm{e}-09$ & 0 & 1.7 & 5 \\
\hline $\operatorname{ch} 3+$ & photon & $\operatorname{ch}+$ & h2 & $1.00 \mathrm{e}-09$ & 0 & 1.7 & 5 \\
\hline $\operatorname{ch} 4+$ & photon & $\operatorname{ch} 3+$ & $\mathrm{h}$ & $1.00 \mathrm{e}-09$ & 0 & 1.7 & 5 \\
\hline $\operatorname{ch} 4+$ & photon & $\operatorname{ch} 2+$ & h2 & $1.00 \mathrm{e}-09$ & 0 & 1.7 & 5 \\
\hline $\operatorname{ch} 5+$ & photon & $\operatorname{ch} 4+$ & $\mathrm{h}$ & $1.00 \mathrm{e}-09$ & 0 & 1.7 & 5 \\
\hline $\operatorname{ch} 5+$ & photon & $\operatorname{ch} 3+$ & h2 & $1.00 \mathrm{e}-09$ & 0 & 1.7 & 5 \\
\hline $\mathrm{c} 2+$ & photon & $\mathrm{c}$ & $\mathrm{c}+$ & $1.00 \mathrm{e}-11$ & 0 & 1.7 & 5 \\
\hline $\mathrm{o} 2+$ & photon & o & $\mathrm{o}+$ & $1.00 \mathrm{e}-11$ & 0 & 1.7 & 5 \\
\hline $\mathrm{oh}+$ & photon & $\mathrm{o}+$ & $\mathrm{h}$ & $1.10 \mathrm{e}-11$ & 0 & 2.80 & 5 \\
\hline $\mathrm{h} 2 \mathrm{o}+$ & photon & $\mathrm{oh}+$ & $\mathrm{h}$ & $3.00 \mathrm{e}-10$ & 0 & 2.00 & 5 \\
\hline $\mathrm{h} 2 \mathrm{o}+$ & photon & $\mathrm{h}+$ & oh & $1.00 \mathrm{e}-10$ & 0 & 2.00 & 5 \\
\hline $\mathrm{h} 2 \mathrm{o}+$ & photon & $\mathrm{h} 2+$ & o & $1.00 \mathrm{e}-10$ & 0 & 2.00 & 5 \\
\hline h3o+ & photon & h2o+ & $\mathrm{h}$ & $1.50 \mathrm{e}-11$ & 0 & 2.00 & 5 \\
\hline h3o+ & photon & $\mathrm{h} 2+$ & oh & $5.00 \mathrm{e}-11$ & 0 & 2.00 & 5 \\
\hline $\mathrm{h} 3 \mathrm{o}+$ & photon & $\mathrm{h} 2 \mathrm{o}$ & $\mathrm{h}+$ & $5.00 \mathrm{e}-11$ & 0 & 2.00 & 5 \\
\hline $\mathrm{co}+$ & photon & $c+$ & o & $3.00 \mathrm{e}-11$ & 0 & 3.0 & 5 \\
\hline hco+ & photon & $\mathrm{co}+$ & $\mathrm{h}$ & $7.80 \mathrm{e}-12$ & 0 & 3.0 & 5 \\
\hline hco $2+$ & photon & $\mathrm{h}+$ & $\operatorname{co} 2$ & $3.00 \mathrm{e}-10$ & 0 & 3.0 & 5 \\
\hline $\mathrm{c} 2 \mathrm{~h}+$ & photon & $\mathrm{c} 2+$ & $\mathrm{h}$ & $1.00 \mathrm{e}-10$ & 0 & 2.0 & 5 \\
\hline
\end{tabular}

Continua na próxima página... 
Tabela B.2 - Continuação

\begin{tabular}{|c|c|c|c|c|c|c|c|}
\hline \multicolumn{2}{|c|}{ Reagentes } & & Produtos & $\gamma$ & $\alpha$ & $\beta$ & Tipo de Reação \\
\hline $\mathrm{c} 2 \mathrm{~h} 2+$ & photon & $\mathrm{c} 2+$ & $\mathrm{h} 2$ & $1.00 \mathrm{e}-10$ & 0 & 2.0 & 5 \\
\hline $\mathrm{c} 2 \mathrm{~h} 3+$ & photon & $\mathrm{c} 2 \mathrm{~h}+$ & h2 & $1.00 \mathrm{e}-10$ & 0 & 3.0 & 5 \\
\hline $\mathrm{c} 3+$ & photon & $\mathrm{c} 2+$ & c & $1.00 \mathrm{e}-10$ & 0 & 3.0 & 5 \\
\hline $\mathrm{c} 3 \mathrm{~h}+$ & photon & c3+ & $\mathrm{h}$ & $1.00 \mathrm{e}-10$ & 0 & 3.0 & 5 \\
\hline c3h2+ & photon & $\mathrm{c} 3+$ & h2 & $1.00 \mathrm{e}-10$ & 0 & 3.0 & 5 \\
\hline c3h3+ & photon & $\mathrm{c} 3 \mathrm{~h}+$ & $\mathrm{h} 2$ & $1.00 \mathrm{e}-10$ & 0 & 3.0 & 5 \\
\hline $\mathrm{n} 2$ & photon & $\mathrm{n}$ & $\mathrm{n}$ & $2.30 \mathrm{e}-10$ & 0 & 3.82 & 5 \\
\hline $\mathrm{nh}$ & photon & $\mathrm{n}$ & $\mathrm{h}$ & $5.00 \mathrm{e}-10$ & 0 & 1.97 & 5 \\
\hline $\mathrm{nh}$ & photon & $\mathrm{nh}+$ & electr & $1.00 \mathrm{e}-11$ & 0 & 2.00 & 5 \\
\hline nh2 & photon & $\mathrm{nh}$ & $\mathrm{h}$ & $7.40 \mathrm{e}-10$ & 0 & 1.63 & 5 \\
\hline nh2 & photon & $\operatorname{nh} 2+$ & electr & $1.73 \mathrm{e}-10$ & 0 & 2.60 & 5 \\
\hline nh3 & photon & nh2 & $\mathrm{h}$ & $1.10 \mathrm{e}-09$ & 0 & 1.79 & 5 \\
\hline nh3 & photon & $\operatorname{nh} 3+$ & electr & $2.80 \mathrm{e}-10$ & 0 & 2.70 & 5 \\
\hline $\mathrm{cn}$ & photon & c & $\mathrm{n}$ & $3.00 \mathrm{e}-10$ & 0 & 3.07 & 5 \\
\hline hcn & photon & $\mathrm{cn}$ & $\mathrm{h}$ & $1.50 \mathrm{e}-09$ & 0 & 2.08 & 5 \\
\hline hnc & photon & $\mathrm{cn}$ & $\mathrm{h}$ & $1.50 \mathrm{e}-09$ & 0 & 2.08 & 5 \\
\hline hnc & photon & hnc+ & electr & $1.00 \mathrm{e}-11$ & 0 & 2.00 & 5 \\
\hline no & photon & $\mathrm{n}$ & o & $4.70 \mathrm{e}-10$ & 0 & 1.71 & 5 \\
\hline no & photon & no+ & electr & $2.60 \mathrm{e}-10$ & 0 & 2.32 & 5 \\
\hline $\mathrm{nh}+$ & photon & $\mathrm{n}+$ & $\mathrm{h}$ & $5.40 \mathrm{e}-11$ & 0 & 1.39 & 5 \\
\hline $\operatorname{nh} 2+$ & photon & $\mathrm{n}+$ & $\mathrm{h} 2$ & $1.00 \mathrm{e}-10$ & 0 & 2.00 & 5 \\
\hline nh3+ & photon & $\mathrm{nh}+$ & $\mathrm{h} 2$ & $1.00 \mathrm{e}-10$ & 0 & 2.00 & 5 \\
\hline nh4+ & photon & nh3+ & $\mathrm{h}$ & $1.00 \mathrm{e}-10$ & 0 & 2.00 & 5 \\
\hline $\mathrm{cn}+$ & photon & $\mathrm{c}+$ & $\mathrm{n}$ & $1.00 \mathrm{e}-10$ & 0 & 2.00 & 5 \\
\hline $\mathrm{c} 2 \mathrm{n}+$ & photon & $c+$ & $\mathrm{cn}$ & $1.00 \mathrm{e}-10$ & 0 & 2.00 & 5 \\
\hline hen+ & photon & $\mathrm{cn}+$ & $\mathrm{h}$ & $1.00 \mathrm{e}-10$ & 0 & 2.00 & 5 \\
\hline hnc+ & photon & $\mathrm{cn}+$ & $\mathrm{h}$ & $1.00 \mathrm{e}-10$ & 0 & 2.00 & 5 \\
\hline hcnh+ & photon & hen+ & $\mathrm{h}$ & $1.00 \mathrm{e}-10$ & 0 & 2.00 & 5 \\
\hline hcnh+ & photon & $\mathrm{hnc}+$ & $\mathrm{h}$ & $1.00 \mathrm{e}-10$ & 0 & 2.00 & 5 \\
\hline $\mathrm{h} 2 \mathrm{nc}+$ & photon & hnc+ & $\mathrm{h}$ & $1.00 \mathrm{e}-10$ & 0 & 2.00 & 5 \\
\hline $\mathrm{n} 2+$ & photon & $\mathrm{n}+$ & $\mathrm{n}$ & $1.00 \mathrm{e}-10$ & 0 & 2.00 & 5 \\
\hline $\mathrm{n} 2 \mathrm{~h}+$ & photon & $\mathrm{h}+$ & $\mathrm{n} 2$ & $1.00 \mathrm{e}-10$ & 0 & 2.00 & 5 \\
\hline not & photon & $\mathrm{n}+$ & o & $1.00 \mathrm{e}-10$ & 0 & 2.00 & 5 \\
\hline hno+ & photon & not & $\mathrm{h}$ & $1.00 \mathrm{e}-10$ & 0 & 2.00 & 5 \\
\hline $\mathrm{s}$ & photon & $\mathrm{s}+$ & electr & $5.90 \mathrm{e}-10$ & 0 & 2.58 & 5 \\
\hline $\mathrm{sh}$ & photon & $\mathrm{s}$ & $\mathrm{h}$ & $9.70 \mathrm{e}-10$ & 0 & 1.42 & 5 \\
\hline $\mathrm{h} 2 \mathrm{~s}$ & photon & $\mathrm{h} 2 \mathrm{~s}+$ & electr & $7.10 \mathrm{e}-10$ & 0 & 2.69 & 5 \\
\hline $\mathrm{h} 2 \mathrm{~s}$ & photon & $\mathrm{sh}$ & $\mathrm{h}$ & $3.10 \mathrm{e}-09$ & 0 & 1.87 & 5 \\
\hline $\mathrm{cs}$ & photon & c & $\mathrm{s}$ & $9.70 \mathrm{e}-10$ & 0 & 2.03 & 5 \\
\hline $\mathrm{h} 2 \mathrm{cs}$ & photon & cs & $\mathrm{h} 2$ & $1.00 \mathrm{e}-09$ & 0 & 1.70 & 5 \\
\hline so & photon & $\mathrm{s}$ & o & $3.70 \mathrm{e}-09$ & 0 & 1.95 & 5 \\
\hline so2 & photon & so & o & $1.90 \mathrm{e}-09$ & 0 & 1.88 & 5 \\
\hline ocs & photon & $\mathrm{s}$ & $\mathrm{co}$ & $3.70 \mathrm{e}-09$ & 0 & 1.69 & 5 \\
\hline
\end{tabular}

Continua na próxima página... 
Tabela B.2 - Continuação

\begin{tabular}{|c|c|c|c|c|c|c|c|c|}
\hline \multicolumn{2}{|c|}{ Reagentes } & \multicolumn{3}{|c|}{ Produtos } & \multirow{2}{*}{$\frac{\gamma}{2.50 \mathrm{e}-10}$} & \multirow{2}{*}{$\begin{array}{c}\alpha \\
0\end{array}$} & \multirow{2}{*}{$\frac{\beta}{1.80}$} & \multirow{2}{*}{$\begin{array}{c}\text { Tipo de Reação } \\
5\end{array}$} \\
\hline $\operatorname{sh}+$ & photon & $\mathrm{s}+$ & $\mathrm{h}$ & & & & & \\
\hline $\mathrm{cs}+$ & photon & $\mathrm{c}+$ & $\mathrm{s}$ & & $1.00 \mathrm{e}-10$ & 0 & 2.00 & 5 \\
\hline hcs + & photon & $\operatorname{cs}+$ & $\mathrm{h}$ & & $1.00 \mathrm{e}-10$ & 0 & 2.00 & 5 \\
\hline $\mathrm{h} 2 \mathrm{~s}+$ & photon & $\operatorname{sh}+$ & $\mathrm{h}$ & & $1.00 \mathrm{e}-10$ & 0 & 2.00 & 5 \\
\hline $\mathrm{h} 3 \mathrm{~s}+$ & photon & $\mathrm{h} 2 \mathrm{~s}+$ & $\mathrm{h}$ & & $1.00 \mathrm{e}-10$ & 0 & 2.00 & 5 \\
\hline $\mathrm{so}+$ & photon & $\mathrm{s}+$ & o & & $1.00 \mathrm{e}-10$ & 0 & 2.00 & 5 \\
\hline hso+ & photon & so+ & $\mathrm{h}$ & & $1.00 \mathrm{e}-10$ & 0 & 2.00 & 5 \\
\hline hso $2+$ & photon & hso+ & o & & $1.00 \mathrm{e}-10$ & 0 & 2.00 & 5 \\
\hline hocs + & photon & $\mathrm{cs}+$ & oh & & $1.00 \mathrm{e}-10$ & 0 & 2.00 & 5 \\
\hline $\mathrm{h}+$ & electr & $\mathrm{h}$ & photon & & $3.61 \mathrm{e}-12$ & -0.75 & 0.0 & 3 \\
\hline $\mathrm{h} 2+$ & electr & $\mathrm{h}$ & $\mathrm{h}$ & & $1.60 \mathrm{e}-08$ & -0.43 & 0.0 & 4 \\
\hline h3+ & electr & $\mathrm{h}$ & $\mathrm{h}$ & $\mathrm{h}$ & $5.44 \mathrm{e}-08$ & -0.5 & 0.0 & 4 \\
\hline h3+ & electr & h2 & $\mathrm{h}$ & & $1.36 \mathrm{e}-08$ & -0.5 & 0.0 & 4 \\
\hline he+ & electr & he & photon & & $4.50 \mathrm{e}-12$ & -0.67 & 0.0 & 3 \\
\hline$c+$ & electr & $\mathrm{c}$ & photon & & $4.40 \mathrm{e}-12$ & -0.61 & 0.0 & 3 \\
\hline $\operatorname{ch}+$ & electr & $\mathrm{c}$ & $\mathrm{h}$ & & $1.50 \mathrm{e}-07$ & -0.42 & 0.0 & 4 \\
\hline $\operatorname{ch} 2+$ & electr & c & $\mathrm{h} 2$ & & $7.68 \mathrm{e}-08$ & -0.6 & 0.0 & 4 \\
\hline $\operatorname{ch} 2+$ & electr & $\mathrm{ch}$ & $\mathrm{h}$ & & $1.60 \mathrm{e}-07$ & -0.6 & 0.0 & 4 \\
\hline $\operatorname{ch} 2+$ & electr & $\mathrm{c}$ & $\mathrm{h}$ & $\mathrm{h}$ & $4.03 \mathrm{e}-07$ & -0.6 & 0.0 & 4 \\
\hline $\operatorname{ch} 3+$ & electr & $\mathrm{c}$ & $\mathrm{h} 2$ & $\mathrm{~h}$ & $1.25 \mathrm{e}-07$ & -0.65 & 0.0 & 4 \\
\hline $\operatorname{ch} 3+$ & electr & $\mathrm{ch}$ & $\mathrm{h}$ & $\mathrm{h}$ & $6.60 \mathrm{e}-08$ & -0.65 & 0.0 & 4 \\
\hline $\operatorname{ch} 3+$ & electr & $\mathrm{ch}$ & h2 & & $5.80 \mathrm{e}-08$ & -0.65 & 0.0 & 4 \\
\hline $\operatorname{ch} 3+$ & electr & $\operatorname{ch} 2$ & $\mathrm{~h}$ & & $1.66 \mathrm{e}-07$ & -0.65 & 0.0 & 4 \\
\hline $\operatorname{ch} 4+$ & electr & ch3 & $\mathrm{h}$ & & $3.00 \mathrm{e}-07$ & -0.5 & 0.0 & 4 \\
\hline $\operatorname{ch} 4+$ & electr & $\operatorname{ch} 2$ & $\mathrm{~h}$ & $\mathrm{~h}$ & $3.00 \mathrm{e}-07$ & -0.5 & 0.0 & 4 \\
\hline $\operatorname{ch} 5+$ & electr & $\mathrm{ch}$ & $\mathrm{h} 2$ & $\mathrm{~h} 2$ & $8.40 \mathrm{e}-09$ & -0.52 & 0.0 & 4 \\
\hline $\operatorname{ch} 5+$ & electr & $\operatorname{ch} 2$ & $\mathrm{~h} 2$ & $\mathrm{~h}$ & $4.76 \mathrm{e}-08$ & -0.52 & 0.0 & 4 \\
\hline $\operatorname{ch} 5+$ & electr & ch3 & $\mathrm{h}$ & $\mathrm{h}$ & $1.96 \mathrm{e}-07$ & -0.52 & 0.0 & 4 \\
\hline $\operatorname{ch} 5+$ & electr & $\operatorname{ch} 3$ & h2 & & $1.40 \mathrm{e}-08$ & -0.52 & 0.0 & 4 \\
\hline $\operatorname{ch} 5+$ & electr & $\operatorname{ch} 4$ & $\mathrm{~h}$ & & $1.40 \mathrm{e}-08$ & -0.52 & 0.0 & 4 \\
\hline $\mathrm{o}+$ & electr & o & photon & & $3.40 \mathrm{e}-12$ & -0.64 & 0.0 & 3 \\
\hline $\mathrm{o} 2+$ & electr & o & o & & $2.40 \mathrm{e}-07$ & -0.7 & 0.0 & 4 \\
\hline $\mathrm{oh}+$ & electr & o & $\mathrm{h}$ & & $3.75 \mathrm{e}-08$ & -0.5 & 0.0 & 4 \\
\hline h2o+ & electr & oh & $\mathrm{h}$ & & $7.80 \mathrm{e}-08$ & -0.5 & 0.0 & 4 \\
\hline h2o+ & electr & o & $\mathrm{h} 2$ & & $3.38 \mathrm{e}-08$ & -0.5 & 0.0 & 4 \\
\hline h2o+ & electr & o & $\mathrm{h}$ & $\mathrm{h}$ & $1.48 \mathrm{e}-07$ & -0.5 & 0.0 & 4 \\
\hline h3o+ & electr & h2o & $\mathrm{h}$ & & $1.07 \mathrm{e}-07$ & -0.65 & 0.0 & 4 \\
\hline h3o+ & electr & oh & $\mathrm{h} 2$ & & $6.02 \mathrm{e}-08$ & -0.65 & 0.0 & 4 \\
\hline h3o+ & electr & oh & $\mathrm{h}$ & $\mathrm{h}$ & $2.58 \mathrm{e}-07$ & -0.65 & 0.0 & 4 \\
\hline h3o+ & electr & o & h2 & $\mathrm{h}$ & $5.59 \mathrm{e}-09$ & -0.65 & 0.0 & 4 \\
\hline $\mathrm{co}+$ & electr & c & o & & $2.25 \mathrm{e}-07$ & -0.46 & 0.0 & 4 \\
\hline hco+ & electr & $\mathrm{co}$ & $\mathrm{h}$ & & $1.00 \mathrm{e}-07$ & -0.69 & 0.0 & 4 \\
\hline hco+ & electr & oh & c & & $1.00 \mathrm{e}-07$ & -0.69 & 0.0 & 4 \\
\hline
\end{tabular}

Continua na próxima página... 
Tabela B.2 - Continuação

\begin{tabular}{|c|c|c|c|c|c|c|c|c|}
\hline \multicolumn{2}{|c|}{ Reagentes } & \multicolumn{3}{|c|}{ Produtos } & \multirow{2}{*}{$\frac{\gamma}{2.00 \mathrm{e}-07}$} & \multirow{2}{*}{$\begin{array}{c}\alpha \\
-0.75\end{array}$} & \multirow{2}{*}{$\begin{array}{c}\beta \\
0.0\end{array}$} & \multirow{2}{*}{$\begin{array}{c}\text { Tipo de Reação } \\
4\end{array}$} \\
\hline hoct & electr & $\mathrm{co}$ & $\mathrm{h}$ & & & & & \\
\hline $\mathrm{h} 2 \mathrm{co}+$ & electr & $\mathrm{co}$ & $\mathrm{h}$ & $\mathrm{h}$ & $5.00 \mathrm{e}-07$ & -0.5 & 0.0 & 4 \\
\hline $\mathrm{h} 2 \mathrm{co}+$ & electr & hco & $\mathrm{h}$ & & $1.00 \mathrm{e}-07$ & -0.5 & 0.0 & 4 \\
\hline h3cot & electr & $\mathrm{co}$ & $\mathrm{h}$ & $\mathrm{h} 2$ & $2.00 \mathrm{e}-07$ & -0.5 & 0.0 & 4 \\
\hline h3cot & electr & hco & $\mathrm{h}$ & $\mathrm{h}$ & $2.00 \mathrm{e}-07$ & -0.5 & 0.0 & 4 \\
\hline h3cot & electr & $\mathrm{h} 2 \mathrm{co}$ & $\mathrm{h}$ & & $2.00 \mathrm{e}-07$ & -0.5 & 0.0 & 4 \\
\hline hco $2+$ & electr & $\operatorname{co} 2$ & $\mathrm{~h}$ & & $2.24 \mathrm{e}-07$ & -0.5 & 0.0 & 4 \\
\hline hco $2+$ & electr & $\mathrm{co}$ & oh & & $1.16 \mathrm{e}-07$ & -0.5 & 0.0 & 4 \\
\hline $\mathrm{c} 2+$ & electr & $\mathrm{c}$ & c & & $2.00 \mathrm{e}-07$ & -0.5 & 0.0 & 4 \\
\hline $\mathrm{c} 2 \mathrm{~h}+$ & electr & $\mathrm{ch}$ & c & & $1.35 \mathrm{e}-07$ & -0.5 & 0.0 & 4 \\
\hline $\mathrm{c} 2 \mathrm{~h} 2+$ & electr & $\mathrm{c} 2 \mathrm{~h}$ & $\mathrm{~h}$ & & $1.50 \mathrm{e}-07$ & -0.5 & 0.0 & 4 \\
\hline $\mathrm{c} 2 \mathrm{~h} 2+$ & electr & $\mathrm{ch}$ & $\mathrm{ch}$ & & $3.90 \mathrm{e}-08$ & -0.5 & 0.0 & 4 \\
\hline $\mathrm{c} 2 \mathrm{~h} 2+$ & electr & $\mathrm{c} 2$ & $\mathrm{~h}$ & $\mathrm{~h}$ & $9.00 \mathrm{e}-08$ & -0.5 & 0.0 & 4 \\
\hline $\mathrm{c} 2 \mathrm{~h} 2+$ & electr & $\operatorname{ch} 2$ & c & & $1.50 \mathrm{e}-08$ & -0.5 & 0.0 & 4 \\
\hline $\mathrm{c} 2 \mathrm{~h} 2+$ & electr & $\mathrm{c} 2$ & h2 & & $6.00 \mathrm{e}-09$ & -0.5 & 0.0 & 4 \\
\hline $\mathrm{c} 2 \mathrm{~h} 3+$ & electr & $\mathrm{c} 2 \mathrm{~h}$ & $\mathrm{~h}$ & $\mathrm{~h}$ & $2.95 \mathrm{e}-07$ & -0.84 & 0.0 & 4 \\
\hline $\mathrm{c} 2 \mathrm{~h} 3+$ & electr & $\mathrm{c} 2 \mathrm{~h}$ & h2 & & $3.00 \mathrm{e}-08$ & -0.84 & 0.0 & 4 \\
\hline $\mathrm{c} 2 \mathrm{~h} 3+$ & electr & $\mathrm{c} 2 \mathrm{~h} 2$ & $\mathrm{~h}$ & & $1.45 \mathrm{e}-07$ & -0.84 & 0.0 & 4 \\
\hline $\mathrm{c} 2 \mathrm{~h} 3+$ & electr & $\mathrm{c} 2$ & $\mathrm{~h}$ & $\mathrm{~h} 2$ & $1.50 \mathrm{e}-08$ & -0.84 & 0.0 & 4 \\
\hline $\mathrm{c} 2 \mathrm{~h} 3+$ & electr & $\operatorname{ch} 3$ & c & & $3.00 \mathrm{e}-09$ & -0.84 & 0.0 & 4 \\
\hline c2h3+ & electr & $\operatorname{ch} 2$ & $\mathrm{ch}$ & & $1.50 \mathrm{e}-08$ & -0.84 & 0.0 & 4 \\
\hline $\mathrm{c} 2 \mathrm{~h} 4+$ & electr & $\mathrm{c} 2 \mathrm{~h} 2$ & $\mathrm{~h}$ & $\mathrm{~h}$ & $4.30 \mathrm{e}-07$ & -0.76 & 0.0 & 4 \\
\hline $\mathrm{c} 2 \mathrm{~h} 4+$ & electr & $\mathrm{c} 2 \mathrm{~h} 2$ & h2 & & $3.36 \mathrm{e}-08$ & -0.76 & 0.0 & 4 \\
\hline $\mathrm{c} 2 \mathrm{~h} 4+$ & electr & $\mathrm{c} 2 \mathrm{~h}$ & $\mathrm{~h} 2$ & $\mathrm{~h}$ & $5.60 \mathrm{e}-08$ & -0.76 & 0.0 & 4 \\
\hline $\mathrm{c} 2 \mathrm{~h} 4+$ & electr & $\operatorname{ch} 4$ & c & & $5.60 \mathrm{e}-09$ & -0.76 & 0.0 & 4 \\
\hline $\mathrm{c} 2 \mathrm{~h} 4+$ & electr & $\operatorname{ch} 3$ & $\mathrm{ch}$ & & $1.12 \mathrm{e}-08$ & -0.76 & 0.0 & 4 \\
\hline $\mathrm{c} 2 \mathrm{~h} 4+$ & electr & $\operatorname{ch} 2$ & $\operatorname{ch} 2$ & & $2.24 \mathrm{e}-08$ & -0.76 & 0.0 & 4 \\
\hline $\mathrm{c} 3+$ & electr & $\mathrm{c} 2$ & $\mathrm{c}$ & & $3.00 \mathrm{e}-07$ & -0.5 & 0.0 & 4 \\
\hline $\mathrm{c} 3 \mathrm{~h}+$ & electr & $\mathrm{c} 2 \mathrm{~h}$ & c & & $1.00 \mathrm{e}-07$ & -0.5 & 0.0 & 4 \\
\hline $\mathrm{c} 3 \mathrm{~h}+$ & electr & c3 & $\mathrm{h}$ & & $2.00 \mathrm{e}-07$ & -0.5 & 0.0 & 4 \\
\hline c3h2+ & electr & c3 & $\mathrm{h}$ & $\mathrm{h}$ & $6.00 \mathrm{e}-08$ & -0.5 & 0.0 & 4 \\
\hline c3h $2+$ & electr & $\mathrm{c} 3 \mathrm{~h}$ & $\mathrm{~h}$ & & $2.63 \mathrm{e}-07$ & -0.5 & 0.0 & 4 \\
\hline c3h $2+$ & electr & c3 & $\mathrm{h} 2$ & & $1.50 \mathrm{e}-07$ & -0.5 & 0.0 & 4 \\
\hline c3h $2+$ & electr & $\mathrm{c} 2 \mathrm{~h}$ & $\mathrm{ch}$ & & $3.75 \mathrm{e}-08$ & -0.5 & 0.0 & 4 \\
\hline c3h3+ & electr & $\mathrm{c} 3 \mathrm{~h}$ & $\mathrm{~h} 2$ & & $3.15 \mathrm{e}-07$ & -0.5 & 0.0 & 4 \\
\hline c3h3+ & electr & $\mathrm{c} 3 \mathrm{~h} 2$ & $\mathrm{~h}$ & & $2.70 \mathrm{e}-07$ & -0.5 & 0.0 & 4 \\
\hline c3h3+ & electr & $\mathrm{c} 2 \mathrm{~h}$ & $\operatorname{ch} 2$ & & $0.30 \mathrm{e}-07$ & -0.5 & 0.0 & 4 \\
\hline $\mathrm{fe}+$ & electr & fe & photon & & $3.70 \mathrm{e}-12$ & -0.65 & 0.0 & 3 \\
\hline $\mathrm{n}+$ & electr & $\mathrm{n}$ & photon & & $3.80 \mathrm{e}-12$ & -0.62 & 0.0 & 3 \\
\hline $\mathrm{nh}+$ & electr & $\mathrm{n}$ & $\mathrm{h}$ & & $2.00 \mathrm{e}-07$ & -0.5 & 0.0 & 4 \\
\hline $\operatorname{nh} 2+$ & electr & $\mathrm{nh}$ & $\mathrm{h}$ & & $1.00 \mathrm{e}-07$ & -0.5 & 0.0 & 4 \\
\hline $\operatorname{nh} 2+$ & electr & $\mathrm{n}$ & $\mathrm{h}$ & $\mathrm{h}$ & $2.00 \mathrm{e}-07$ & -0.5 & 0.0 & 4 \\
\hline nh3+ & electr & nh2 & $\mathrm{h}$ & & $3.00 \mathrm{e}-07$ & -0.5 & 0.0 & 4 \\
\hline
\end{tabular}

Continua na próxima página... 
Tabela B.2 - Continuação

\begin{tabular}{|c|c|c|c|c|c|c|c|c|}
\hline \multicolumn{2}{|c|}{ Reagentes } & \multicolumn{3}{|c|}{ Produtos } & \multirow{2}{*}{$\frac{\gamma}{1.89 \mathrm{e}-08}$} & \multirow{2}{*}{$\begin{array}{c}\alpha \\
-0.605\end{array}$} & \multirow{2}{*}{$\begin{array}{c}\beta \\
0.0\end{array}$} & \multirow{2}{*}{$\begin{array}{c}\text { Tipo de Reação } \\
4\end{array}$} \\
\hline nh4+ & electr & nh2 & $\mathrm{h} 2$ & & & & & \\
\hline nh4+ & electr & nh2 & $\mathrm{h}$ & $\mathrm{h}$ & $1.23 \mathrm{e}-07$ & -0.605 & 0.0 & 4 \\
\hline $\operatorname{nh} 4+$ & electr & nh3 & $\mathrm{h}$ & & $8.01 \mathrm{e}-07$ & -0.605 & 0.0 & 4 \\
\hline $\mathrm{n} 2+$ & electr & $\mathrm{n}$ & $\mathrm{n}$ & & $1.75 \mathrm{e}-07$ & -0.3 & 0.0 & 4 \\
\hline $\mathrm{n} 2 \mathrm{~h}+$ & electr & $\mathrm{n} 2$ & $\mathrm{~h}$ & & $0.95 \mathrm{e}-07$ & -0.51 & 0.0 & 4 \\
\hline $\mathrm{n} 2 \mathrm{~h}+$ & electr & $\mathrm{nh}$ & $\mathrm{n}$ & & $0.05 \mathrm{e}-07$ & -0.51 & 0.0 & 4 \\
\hline $\mathrm{cn}+$ & electr & $\mathrm{c}$ & $\mathrm{n}$ & & $1.80 \mathrm{e}-07$ & -0.5 & 0.0 & 4 \\
\hline hen+ & electr & $\mathrm{cn}$ & $\mathrm{h}$ & & $1.50 \mathrm{e}-07$ & -0.5 & 0.0 & 4 \\
\hline hen+ & electr & $\mathrm{ch}$ & $\mathrm{n}$ & & $1.50 \mathrm{e}-07$ & -0.5 & 0.0 & 4 \\
\hline hnc + & electr & cn & $\mathrm{h}$ & & $1.50 \mathrm{e}-07$ & -0.5 & 0.0 & 4 \\
\hline hnc + & electr & $\mathrm{nh}$ & $\mathrm{c}$ & & $1.50 \mathrm{e}-07$ & -0.5 & 0.0 & 4 \\
\hline hcnh+ & electr & hen & $\mathrm{h}$ & & $0.93 \mathrm{e}-07$ & -0.65 & 0.0 & 4 \\
\hline henh+ & electr & hnc & $\mathrm{h}$ & & $0.93 \mathrm{e}-07$ & -0.65 & 0.0 & 4 \\
\hline henh+ & electr & $\mathrm{cn}$ & $\mathrm{h}$ & $\mathrm{h}$ & $0.93 \mathrm{e}-07$ & -0.65 & 0.0 & 4 \\
\hline h2nc+ & electr & hnc & $\mathrm{h}$ & & $1.75 \mathrm{e}-07$ & -0.5 & 0.0 & 4 \\
\hline h2nc+ & electr & nh2 & $\mathrm{c}$ & & $1.75 \mathrm{e}-07$ & -0.5 & 0.0 & 4 \\
\hline $\mathrm{c} 2 \mathrm{n}+$ & electr & $\mathrm{c} 2$ & $\mathrm{n}$ & & $1.00 \mathrm{e}-07$ & -0.5 & 0.0 & 4 \\
\hline $\mathrm{c} 2 \mathrm{n}+$ & electr & $\mathrm{cn}$ & $\mathrm{c}$ & & $2.00 \mathrm{e}-07$ & -0.5 & 0.0 & 4 \\
\hline no+ & electr & $\mathrm{n}$ & o & & $4.30 \mathrm{e}-07$ & -0.37 & 0.0 & 4 \\
\hline hno+ & electr & no & $\mathrm{h}$ & & $3.00 \mathrm{e}-07$ & -0.5 & 0.0 & 4 \\
\hline $\mathrm{s}+$ & electr & $\mathrm{s}$ & photon & & $3.90 \mathrm{e}-12$ & -0.63 & 0.0 & 3 \\
\hline $\operatorname{sh}+$ & electr & $\mathrm{s}$ & $\mathrm{h}$ & & $2.00 \mathrm{e}-07$ & -0.5 & 0.0 & 4 \\
\hline $\mathrm{h} 2 \mathrm{~s}+$ & electr & $\mathrm{sh}$ & $\mathrm{h}$ & & $1.50 \mathrm{e}-07$ & -0.5 & 0.0 & 4 \\
\hline $\mathrm{h} 2 \mathrm{~s}+$ & electr & $\mathrm{s}$ & $\mathrm{h}$ & $\mathrm{h}$ & $1.50 \mathrm{e}-07$ & -0.5 & 0.0 & 4 \\
\hline $\mathrm{h} 2 \mathrm{~s}+$ & electr & $\mathrm{h} 2 \mathrm{~s}$ & photon & & $1.10 \mathrm{e}-10$ & -0.7 & 0.0 & 3 \\
\hline h3s+ & electr & $\mathrm{h} 2 \mathrm{~s}$ & $\mathrm{~h}$ & & $3.00 \mathrm{e}-07$ & -0.5 & 0.0 & 4 \\
\hline h3s+ & electr & sh & h2 & & $1.00 \mathrm{e}-07$ & -0.5 & 0.0 & 4 \\
\hline $\operatorname{cs}+$ & electr & $\mathrm{c}$ & $\mathrm{s}$ & & $2.00 \mathrm{e}-07$ & -0.5 & 0.0 & 4 \\
\hline hes + & electr & $\mathrm{cs}$ & $\mathrm{h}$ & & $7.00 \mathrm{e}-07$ & -0.5 & 0.0 & 4 \\
\hline so+ & electr & $\mathrm{s}$ & o & & $2.00 \mathrm{e}-07$ & -0.5 & 0.0 & 4 \\
\hline hso+ & electr & so & $\mathrm{h}$ & & $2.00 \mathrm{e}-07$ & -0.5 & 0.0 & 4 \\
\hline hso2+ & electr & so & $\mathrm{h}$ & o & $1.00 \mathrm{e}-07$ & -0.5 & 0.0 & 4 \\
\hline hso2+ & electr & so & oh & & $1.00 \mathrm{e}-07$ & -0.5 & 0.0 & 4 \\
\hline hocs+ & electr & oh & $\mathrm{cs}$ & & $2.00 \mathrm{e}-07$ & -0.5 & 0.0 & 4 \\
\hline hocs+ & electr & ocs & $\mathrm{h}$ & & $2.00 \mathrm{e}-07$ & -0.5 & 0.0 & 4 \\
\hline $\mathrm{h} 2 \mathrm{cs}+$ & electr & $\mathrm{cs}$ & $\mathrm{h}$ & $\mathrm{h}$ & $3.00 \mathrm{e}-07$ & -0.5 & 0.0 & 4 \\
\hline $\mathrm{h} 3 \mathrm{cs}+$ & electr & $\mathrm{Cs}$ & $\mathrm{h}$ & h2 & $3.00 \mathrm{e}-07$ & -0.5 & 0.0 & 4 \\
\hline h3cs+ & electr & $\mathrm{h} 2 \mathrm{cs}$ & $\mathrm{h}$ & & $3.00 \mathrm{e}-07$ & -0.5 & 0.0 & 4 \\
\hline
\end{tabular}

